Monitoring Completed Navigation Projects Program

\title{
Monitoring of Entrance Channel Navigation Improvements at Pentwater, Michigan, and Design Guidance for Pocket Wave Absorbers
}

Edward F. Thompson, Glenn B. Myrick, Nicholas J. Zager,

Robert R. Bottin, Jr., Margaret A. Sabol, James P. Selegean, James P. McKinney, Zeki Demirbilek, and Hugh F. Acuff, Jr.

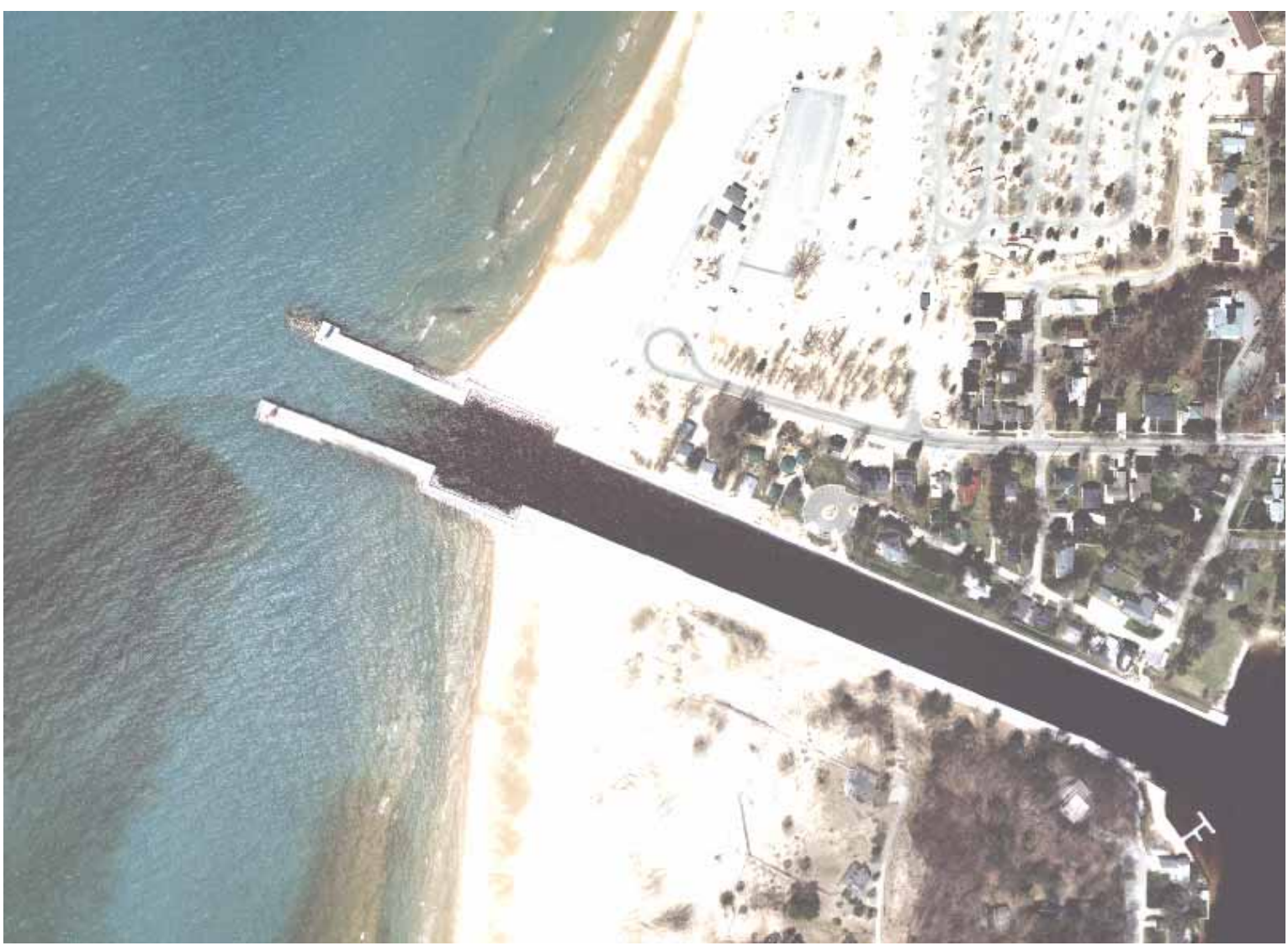




\section{Monitoring of Entrance Channel Navigation Improvements at Pentwater, Michigan, and Design Guidance for Pocket Wave Absorbers}

Edward F. Thompson, Glenn B. Myrick, Robert R. Bottin, Jr., Margaret A. Sabol, James P. McKinney, Zeki Demirbilek, and Hugh F. Acuff, Jr.

Coastal and Hydraulics Laboratory

U.S. Army Engineer Research and Development Center 3909 Halls Ferry Road

Vicksburg, MS 39180-6199

James P. Selegean, Nicholas J. Zager

U.S. Army Engineer District, Detroit

477 Michigan Avenue

Detroit, MI 48226

Final report

Approved for public release; distribution is unlimited. 


\begin{abstract}
In 2002, Pentwater, MI, was accepted for inclusion in the Monitoring Completed Navigation Projects Program. The objectives of the monitoring effort at Pentwater Harbor were to evaluate the design of existing pocket wave absorbers and to develop better design guidance for future pocket wave absorber projects. The study included collection of field wave data at Pentwater, physical modeling, and numerical modeling. Monitoring of the prototype harbor entrance was conducted during spring of 2003 and 2004. The field data provided a basis for validating the physical model. The physical model provided extensive data for the Pentwater configuration and eight other plans, as well as data for calibrating and validating the CGWAVE numerical model. It was concluded that the wave absorber design at Pentwater is very effective, maximizing energy dissipation per unit length of constructed absorber. In addition, guidelines are provided to aid in evaluation of other pocket wave absorber designs and to assist in future projects. Numerical modeling is an effective tool to aid in future evaluations and design.
\end{abstract}

DISCLAIMER: The contents of this report are not to be used for advertising, publication, or promotional purposes. Citation of trade names does not constitute an official endorsement or approval of the use of such commercial products. All product names and trademarks cited are the property of their respective owners. The findings of this report are not to be construed as an official Department of the Army position unless so designated by other authorized documents. 


\section{Contents}

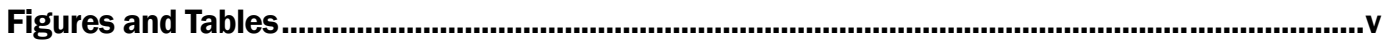

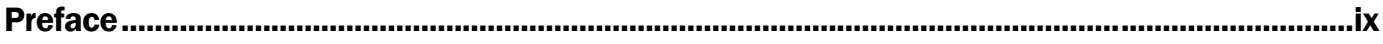

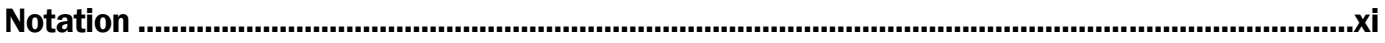

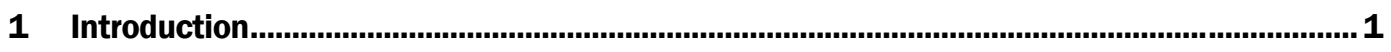

Monitoring Completed Navigation Projects Program ....................................................... 1

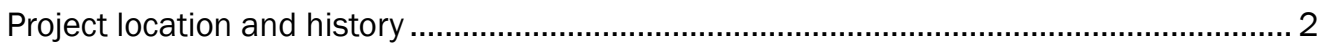

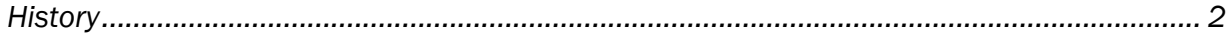

Great Lakes Harbors with pocket absorbers ................................................................... 5

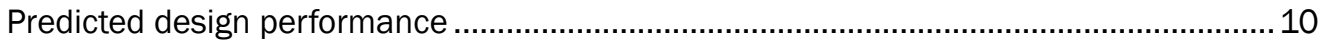

Previous physical model ............................................................................................. 11

Summary of predicted design performance ..................................................................... 16

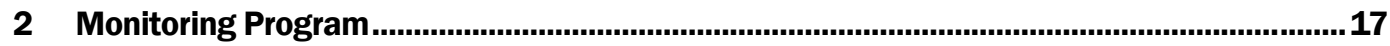

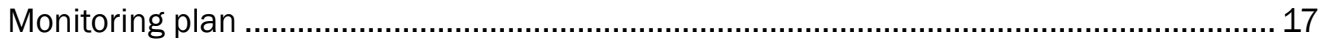

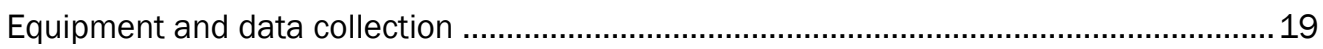

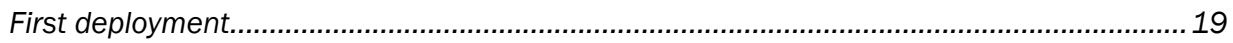

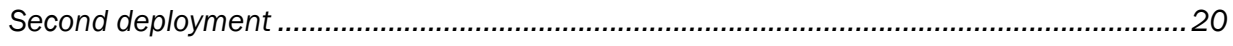

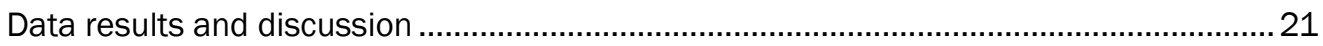

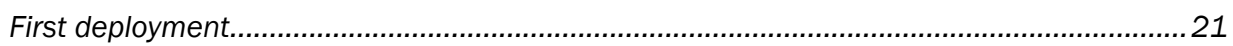

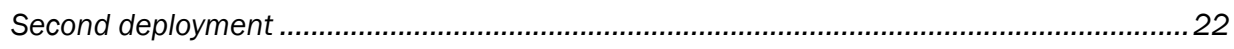

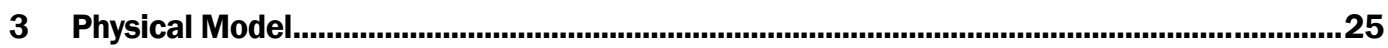

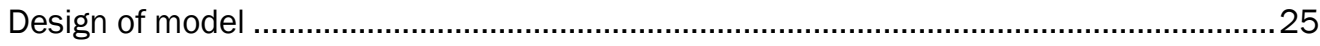

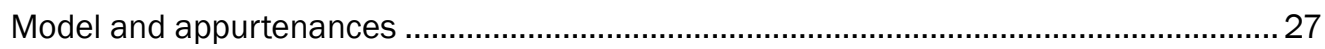

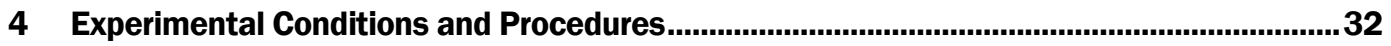

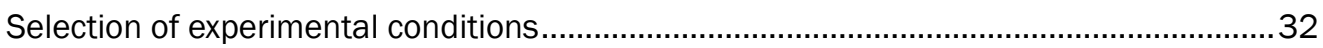

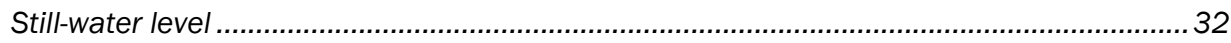

Factors influencing selection of experimental wave characteristics .................................... 34

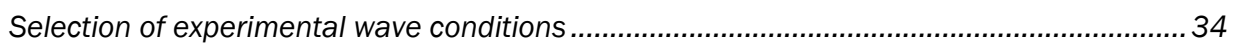

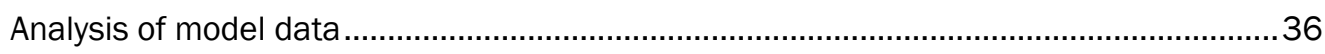

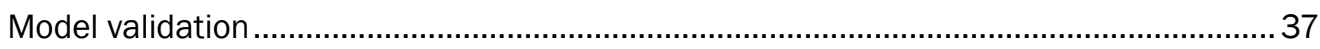

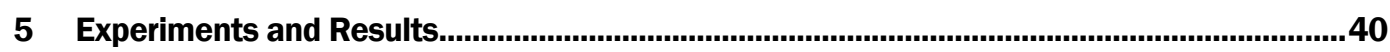

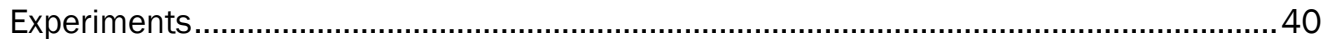

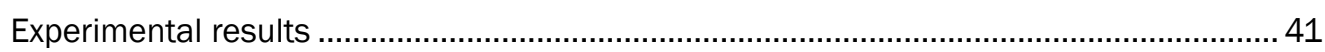

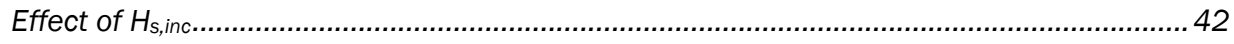

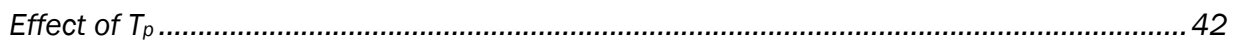

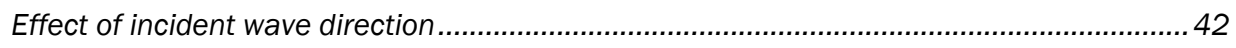

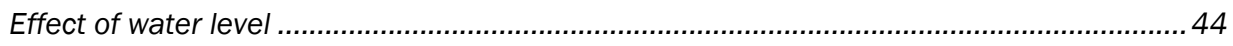


Effect of pocket absorber configuration .................................................................... 45

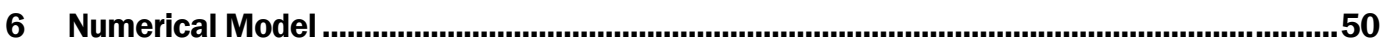

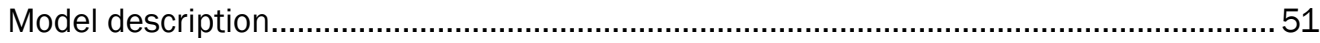

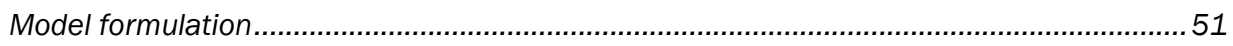

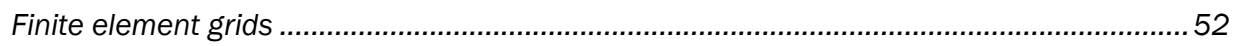

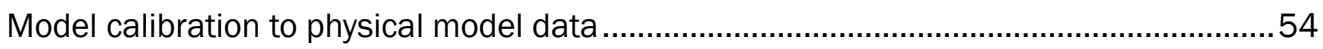

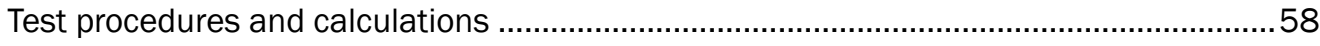

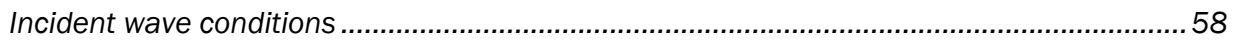

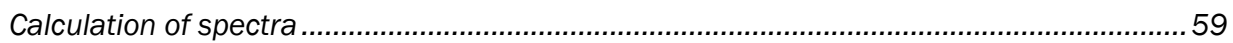

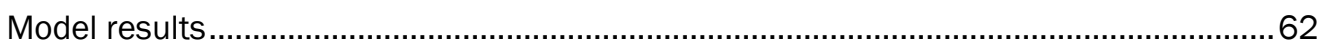

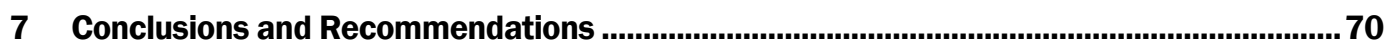

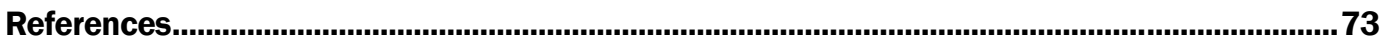

\section{Photographs 1-54}

Plates 1-9

Appendix A: Pocket Wave Absorber Cross Sections......................................................... 138

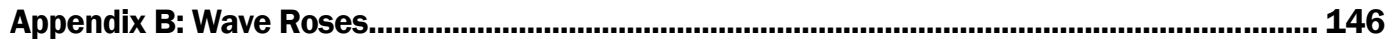

Appendix C: Aerial Photographs ................................................................................... 154

Appendix D: Significant Wave Heights from Physical Model Experiments............................... 158

Appendix E: Cross-Channel Root-Mean-Square $H_{s}$ from Physical Model Experiments ............ 206

Appendix F: Numerical Model Configurations............................................................................. 230

Appendix G: Cross-Channel Average $H_{s}$ from Numerical Model............................................... 235

\section{Report Documentation Page}




\section{Figures and Tables}

\section{Figures}

Figure 1. View of south jetty pocket wave absorber at Pentwater, MI, looking south from north jetty.

Figure 2. View of north jetty pocket wave absorber at Pentwater, MI, looking west.

Figure 3. Waves along south jetty and entrance channel, Pentwater, MI, June 1999, looking south from north jetty: a) waves lakeward of pocket; b) waves attenuated landward of pocket.

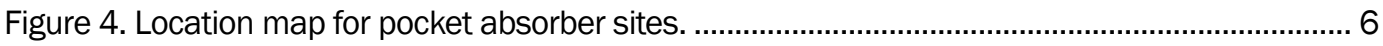

Figure 5. Aerial view of Pentwater Harbor entrance. ........................................................................ 9

Figure 6. Pocket configurations evaluated in previous physical model studies................................ 12

Figure 7. Wave energy fraction passing single pocket for various pocket lengths; wave direction aligned with channel; from physical model..

Figure 8. Wave energy fraction passing pocket for various pocket configurations and incident wave directions; from physical model.

Figure 9. Wave energy fraction passing pocket for various pocket configurations; average from three incident wave directions studied in physical model.

Figure 10. Wave energy fraction passing pocket for three field sites; relative direction is wave approach direction minus direction aligned with entrance channel.

Figure 11. Location of MCNP wave gauges, Pentwater, MI

Figure 12. Wave energy fraction passing pocket versus significant wave height incident to pocket, Pentwater, MI, first deployment.

Figure 13. Wave energy fraction passing pocket versus peak wave period incident to pocket, Pentwater, MI, first deployment.

Figure 14. Wave energy fraction passing pocket versus wave direction measured at NDBC buoy 45007, Pentwater, Ml, first deployment.

Figure 15. Ratio of $H_{s}$ in the channel to incident $H_{s}$ versus incident wave direction; highest 20 percent of incident $H_{s}\left(H_{s, i n c}>0.4 \mathrm{~m}\right)$ and longest 15 percent of $T_{p}\left(T_{p, \text { inc }}>4.9\right.$ $\mathrm{sec}$ ) from field data, second deployment..

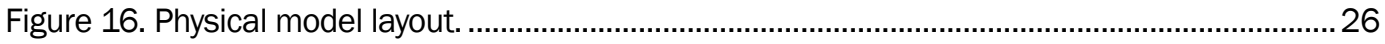

Figure 17. Automated data acquisition and control system............................................................. 29

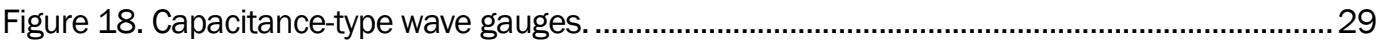

Figure 19. Wave gauge layout for physical model testing. .................................................................30

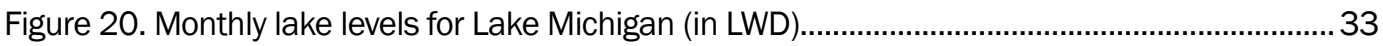

Figure 21. Physical model validation; ratio of $H_{s}$ in the channel to incident $H_{s}$ versus incident wave direction.

Figure 22. Effect of $H_{s, i n c}$ on pocket absorber performance, existing condition, $s w l=0$ LWD.

Figure 23. Effect of $T_{p}$ and wave direction on pocket absorber performance, existing condition, $\mathrm{SWl}=0 \mathrm{LWD}$.

Figure 24. Effect of water level on pocket absorber performance, existing condition. 
Figure 25. Effect of pocket configuration on absorber performance, Line 1 to Line 2, existing condition and Plans $1-3, H_{\mathrm{s}, i n c}=1 \mathrm{~m}(3.3 \mathrm{ft}), \mathrm{swl}=0 \mathrm{LWD}$.

Figure 26. Effect of pocket configuration on absorber performance, Line 1 to Line 2,

Plans 4-8, $H_{\mathrm{s}, \text { inc }}=1 \mathrm{~m}$ (3.3 ft), swl = 0 LWD.

Figure 27. Effect of pocket configuration on absorber performance, Line 1 to Line 3, Plan 1 and Plans 4-8, $H_{\mathrm{s}, \text { inc }}=1 \mathrm{~m}(3.3 \mathrm{ft})$, swl = 0 LWD.

Figure 28. Energy transmitted vs. traversed length of wave absorber, average of all physical model wave and water level tests for each configuration. 49

Figure 29. Numerical model bathymetry, existing harbor 52

Figure 30. Numerical model gauge locations for calibration. 56

Figure 31. Numerical model gauge locations for production runs (shown as green squares). 60

Figure 32. Index line layout, Plan 8A. 62

Figure 33. Offshore wave rose, WIS Station 47 transformed to 8-m (26-ft) depth 63

Figure 34. Performance index comparison, numerical vs. physical model, $+0.9 \mathrm{~m}$ (3 ft) swl. 66

Figure 35. Energy transmitted vs. traversed length of wave absorber, Pentwater wave climate, physical model, $+0.9 \mathrm{~m}$ (3 ft) swl.

Figure 36. Energy transmitted vs. traversed length of wave absorber, Pentwater wave climate, numerical model, +0.9 m (3 ft) swl. 68

Figure A1. Saugatuck Harbor, MI 139

Figure A2. White Lake Harbor, MI 140

Figure A3. Pentwater Harbor, MI. 141

Figure A4. Portage Lake Harbor, M 142

Figure A5. Charlevoix Harbor, MI....................................................................................................143

Figure A6. Ontonagon Harbor, MI ............................................................................................. 144

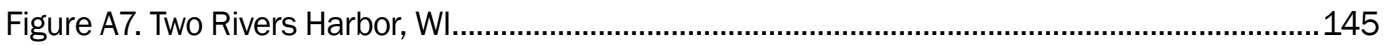

Figure B1. Wave height rose, Saugatuck, MI ...............................................................................146

Figure B2. Wave height rose, White Lake, Ml ................................................................................. 147

Figure B3. Wave height rose, Pentwater, MI ............................................................................. 147

Figure B4. Wave height rose, Portage Lake, MI ............................................................................148

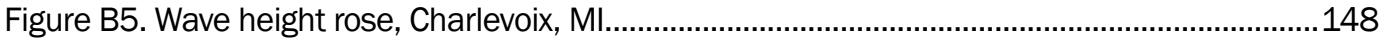

Figure B6. Wave height rose, Ontonagon, MI ..................................................................................149

Figure B7. Wave height rose, Two Rivers, WI .............................................................................149

Figure B8. Wave period rose, Saugatuck, MI..................................................................................150

Figure B9. Wave period rose, White Lake, MI ...............................................................................150

Figure B10. Wave period rose, Pentwater, MI............................................................................. 151

Figure B11. Wave period rose, Portage Lake, Ml .......................................................................... 151

Figure B12. Wave period rose, Charlevoix, MI .............................................................................152

Figure B13. Wave period rose, Ontonagon, MI...........................................................................152

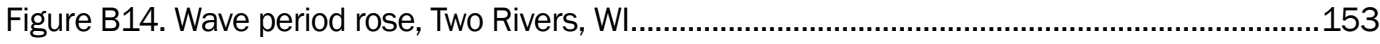

Figure C1. Aerial view, Saugatuck Harbor, MI...............................................................................154 
Figure C2. Aerial view, White Lake Harbor, MI ...........................................................................155

Figure C3. Aerial view, Pentwater Harbor, MI.................................................................................155

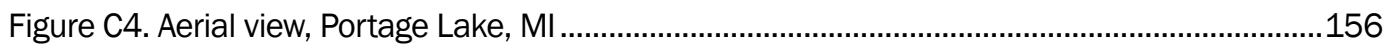

Figure C5. Aerial view, Charlevoix Harbor, MI ...............................................................................156

Figure C6. Ground-level view, Two Rivers, Wl............................................................................... 157

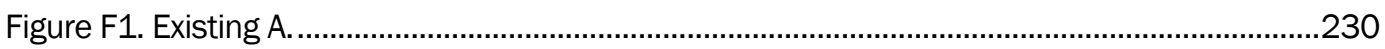

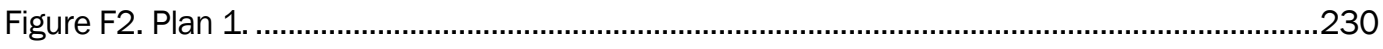

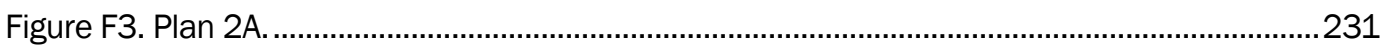

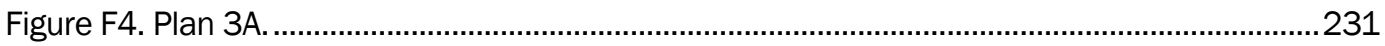

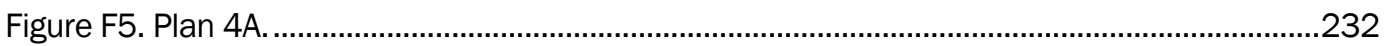

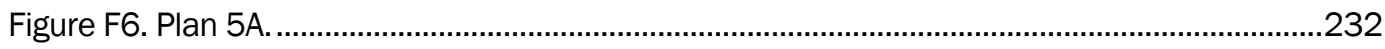

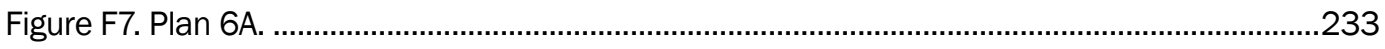

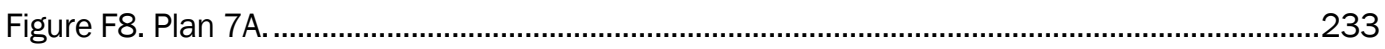

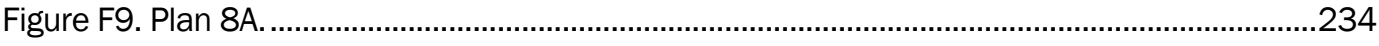

\section{Tables}

Table 1. Wave absorber projects in the Great Lakes. ................................................................. 6

Table 2. Strengths and limitations, previous physical model experiments........................................12

Table 3. Strengths and limitations, previous field data (Carpenter 2001) ....................................... 18

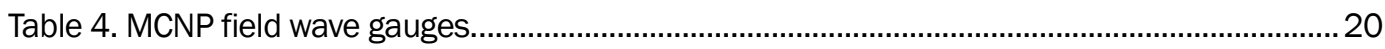

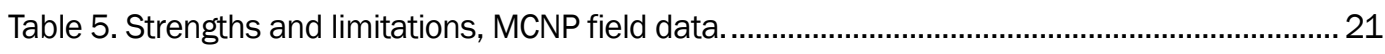

Table 6. Physical model scale relations. ........................................................................................... 27

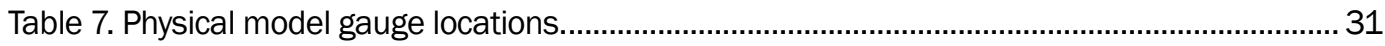

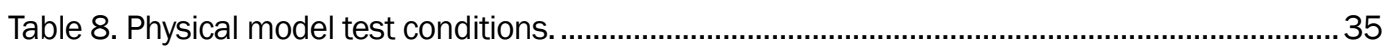

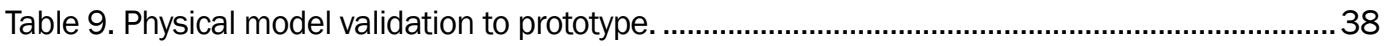

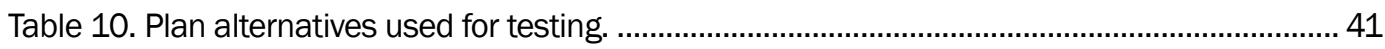

Table 11. Energy fraction transmitted versus traversed length of wave absorber, average of all physical model wave and water level tests for each configuration. ..........................................48

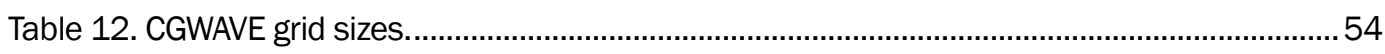

Table 13. Parameter values used in CGWAVE. ..............................................................................5

Table 14. Numerical versus physical model wave height RMS and ME for various reflection coefficient combinations, gauges 1-7, 293-deg incident wave direction, $\mathrm{sWl}=+0.9-\mathrm{m}$ LWD.

Table 15. Numerical versus physical model percent differences for final calibration,

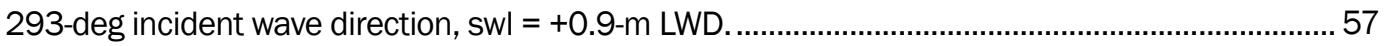

Table 16. Summary of incident wave conditions. ............................................................................58

Table 17. Spectral numerical model magnitude of percent differences, $H_{s, \text { cGWAVE versus }}$ $H_{s, p h y s}$ for 293-deg incident wave direction, swl = +0.9 m LWD.................................................6 60

Table 18. Monochromatic numerical model magnitude of percent differences, $H_{\text {CGWAVE }}$ versus $H_{\mathrm{s} \text {, phys }}$ for 293-deg incident wave direction, swl = +0.9 m LWD.

Table 19. Standard deviations of wave height percent differences for 293-deg incident wave direction, $\mathrm{swl}=+0.9 \mathrm{~m}$ LWD. 


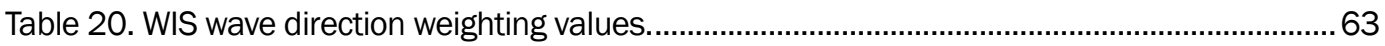

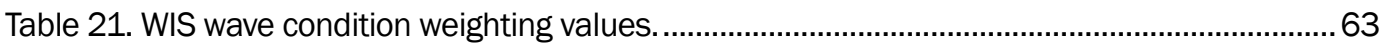

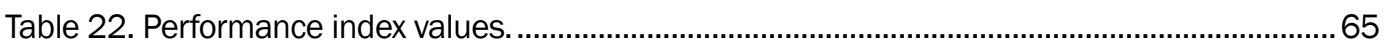

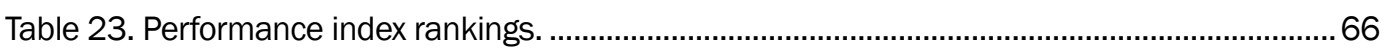

Table 24. Percent energy transmitted versus traversed length of wave absorber, Pentwater

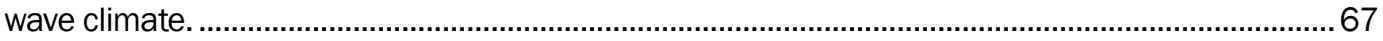

Table D1. Wave heights for waves from 45 degrees South; +0.9 m swl .....................................158

Table D2. Wave heights for waves from 45 degrees North; +0.9 m swl.........................................166

Table D3. Wave heights for waves from 0 degrees; +0.9 m swl.................................................... 174

Table D4. Wave heights for waves from 45 degrees South; 0.0 m swl..........................................182

Table D5. Wave heights for waves from 45 degrees North; 0.0 m swl. ...........................................190

Table D6. Wave heights for waves from 0 degrees; $0.0 \mathrm{~m} \mathrm{swl.} \mathrm{......................................................198}$

Table E1. RMS $H_{s}$ across channel transect lines for waves from 45 degrees South;

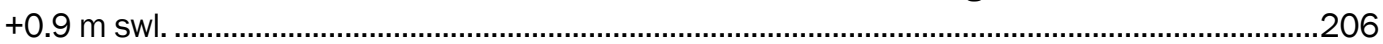

Table E2. RMS $H_{s}$ across channel transect lines for waves from 45 degrees North; +0.9 m swl.

Table E3. RMS $H_{s}$ across channel transect lines for waves from 0 degrees; +0.9 m swl.............. 214

Table E4. RMS $H_{s}$ across channel transect lines for waves from 45 degrees South; +0.0 m swl.

Table E5. RMS $H_{s}$ across channel transect lines for waves from 45 degrees North; +0.0 m swl.

Table E6. RMS $H_{s}$ across channel transect lines for waves from 0 degrees; +0.0 m swl. 226

Table G1. RMS $H_{s}$ across channel transect lines for waves from 45 degrees South......................235

Table G2. RMS $H_{s}$ across channel transect lines for waves from 0 degrees..................................236

Table G3. RMS $H_{s}$ across channel transect lines for waves from 45 degrees North. 


\section{Preface}

The study was conducted as part of the Monitoring Completed Navigation Projects (MCNP) Program (formerly Monitoring Completed Coastal Projects Program). Work was carried out under Work Unit A1050, "Pocket Wave Absorbers." Overall program management for MCNP is accomplished by Headquarters, U.S. Army Corps of Engineers (HQUSACE). The Coastal and Hydraulics Laboratory (CHL), U.S. Army Engineer Research and Development Center (ERDC), is responsible for technical and data management and support for HQUSACE review and technology transfer. Program Monitors for the MCNP Program are Barry W. Holliday, Charles B. Chesnutt, and, formerly, David B. Wingerd (HQUSACE). Management of the MCNP Program at CHL was provided by Robert R. Bottin, Jr., former Program Manager, and Dr. Lyndell Z. Hales, Program Manager.

The work was conducted during January 2002 through September 2005 under the general supervision of Thomas W. Richardson, Director, CHL, and under direct supervision of Dennis G. Markle, former Chief, Harbors, Entrances, and Structures Branch (HESB), CHL, and Jose E. Sanchez, Chief, HESB. Principal Investigators for the study were Bottin, research physical scientist, CHL, Dr. Edward F. Thompson, research hydraulic engineer, CHL, Glenn B. Myrick, research physical scientist, CHL, Margaret A. Sabol, computer scientist, CHL, and Dr. James P. Selegean, hydraulic engineer, U.S. Army Engineer District, Detroit (CELRE). Field measurement for this study was conducted by Sabol and James P. McKinney, mathematician, CHL. Physical modeling for the study was conducted by Myrick and Hugh F. Acuff, Jr., senior civil engineering technician, CHL. Numerical modeling for the study was conducted by Nicholas J. Zager, hydraulic engineer, CELRE, and Dr. Zeki Demirbilek, research hydraulic engineer, CHL. This report was prepared by Dr. Thompson and Myrick and Zager.

Acknowledgements also are extended to the following for their contributions during the study as noted:

Prototype gauges: John R. Bull, engineering technician, CHL, was the leader of field installation and retrieval operations. The Grand Haven Field Office, CELRE, monitored gauge equipment in the field. The Village of 
Pentwater, MI, provided gracious and helpful assistance during field deployment, with particular acknowledgement to Earl Raczkowski, Marina Manager, and Tim Taylor, Village Manager. The Great Lakes Environmental Research Laboratory, National Oceanic and Atmospheric Administration, contributed the use of their facilities in Muskegon, MI, to aid in field operations. Dr. Selegean, CELRE, provided valuable photographic coverage of the first deployment.

Physical model setup, operation, and data analysis: David A. Daily and Tim Nisley, electronics technicians, Instrumentation Services Division, ERDC, were responsible for laboratory instrumentation. Julie Cohen, civil engineering technician, CHL, assisted in configuring data analysis software.

COL James R. Rowan was Commander and Executive Director of ERDC. Dr. James R. Houston was Director. 


\section{Notation}

$\left(A_{a m p}\right)_{e f f} \quad$ Spectral amplification factor calculated from model results for various regular wave heights, periods, and directions

$H \quad$ Wave height, regular wave

$H_{C G W A V E} \quad$ Wave height from CGWAVE numerical model, regular wave

$\bar{H}_{\text {CGWAVE }} \quad$ Average wave height in cross-channel transect from CGWAVE numerical model, regular wave

$H_{\text {inc }} \quad$ Incident wave height, regular wave

$H_{\text {lakeward }} \quad$ Wave height on lakeward side of pocket wave absorber, regular waves

$H_{\text {landward }}$ Wave height on harbor side of pocket wave absorber, regular waves

$H_{m o} \quad$ Spectral-based (zero-moment) significant wave height, irregular waves

$H_{s} \quad$ Significant wave height, irregular waves

$H_{s, C G W A V E}$ Significant wave height from CGWAVE numerical model, irregular waves

$\bar{H}_{s, C G W A V E} \quad$ Average significant wave height in cross-channel transect from CGWAVE numerical model, irregular waves

$H_{s, \text { channel }} \quad$ Significant wave height in navigation channel, irregular waves

$H_{s, \text { inc }} \quad$ Incident significant wave height, irregular waves

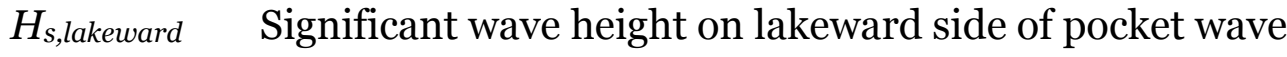
absorber, irregular waves 


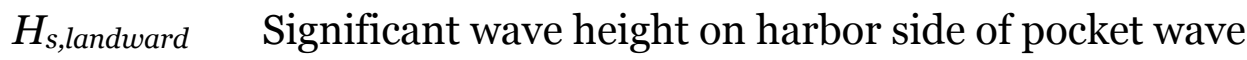
absorber, irregular waves

$H_{s, \text { Line1 }} \quad$ Root-mean-square significant wave height in cross-channel transect at Line 1; defined similarly for Lines 2 and 3 , irregular waves

$H_{s, \text { MIoo1 }} \quad$ Significant wave height from prototype gauge MIoo1; defined similarly for other prototype gauges

$H_{s, p h y s} \quad$ Significant wave height from physical model, irregular waves

$K_{r} \quad$ Wave reflection coefficient; ratio of reflected to incident wave height

$P_{12} \quad$ Performance index calculated between cross-channel transect Lines 1 and 2

$P_{13} \quad$ Performance index calculated between cross-channel transect Lines 1 and 3

$T \quad$ Wave period, regular wave

$T_{\text {inc }} \quad$ Incident wave period, regular wave

$T_{p} \quad$ Peak spectral wave period, irregular waves

$T_{p \text {,inc }} \quad$ Incident peak spectral wave period, irregular waves

$T_{p, \text { MIoo1 }} \quad$ Peak spectral wave period from prototype gauge MIoo1; defined similarly for other prototype gauges

$\theta_{\text {inc }} \quad$ Incident wave direction

$\theta_{N D B C} \quad$ Dominant spectral wave direction from NDBC buoy

$\theta_{p} \quad$ Peak spectral wave direction, irregular waves 


\section{Introduction}

\section{Monitoring Completed Navigation Projects Program}

The goal of the Monitoring Completed Navigation Projects (MCNP) Program (formerly Monitoring Completed Coastal Projects Program) is the advancement of coastal and hydraulic engineering technology. It is designed to determine how well projects are accomplishing their purposes and are resisting attacks from the physical environment. These determinations, combined with concepts and understanding already available, will lead to:

1. more credibility in predicting engineering solutions to coastal and hydraulic problems;

2. strengthening and improving design criteria and methodology;

3. improving construction practices and cost effectiveness;

4. improving operation and maintenance techniques;

5. identifying where current technology is inadequate or where additional research is required.

To develop the direction for the MCNP Program, the Corps of Engineers established an ad hoc committee of coastal and hydraulic engineers and scientists. The committee formulated the program's objectives, developed its operational philosophy, recommended funding levels, and established criteria and procedures for project selection. A significant result of their efforts was a prioritized listing of problem areas to be addressed, essentially a listing of the program's areas of interest. Subsequently, an engineer regulation (USACE 1997) was developed that governs the program.

Corps Division offices are invited to nominate projects for inclusion in the monitoring program as funds become available. A selection committee reviews and prioritizes the projects nominated based on criteria covered in the engineer regulation. Projects are then reviewed by members of the MCNP Program Field Review Group (representatives from District and Division offices). The prioritized list finally is reviewed by the Program Monitors at Headquarters, U.S. Army Corps of Engineers (HQUSACE). Final selection of projects to be monitored is based on this prioritized list, national priorities, and the availability of funding. 
The overall monitoring program is under the management of the U.S. Army Engineer Research and Development Center (ERDC), Coastal and Hydraulics Laboratory (CHL), with guidance from HQUSACE. Operation of individual monitoring projects is a cooperative effort between the submitting District/Division office and CHL. Development of monitoring plans and the conduct of data collection and analyses are dependent upon the combined resources of CHL and the District/Divisions. Pentwater, MI, was nominated by the U.S. Army Engineer District, Detroit (CELRE), and subsequently approved for inclusion in the MCNP program in 2002.

\section{Project location and history}

Wave attenuation in federal navigation channels has become a pressing issue throughout the Great Lakes. Waves on the Great Lakes can reach

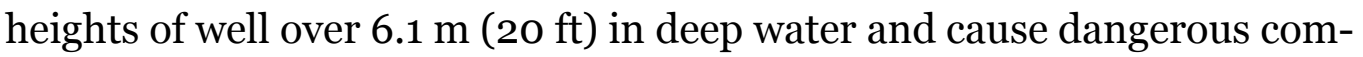
mercial and recreational boating conditions. Additionally, wave energy passing through entrance channels can accelerate erosion in protected areas, putting private and public property in jeopardy.

\section{History}

The U.S. Army Corps of Engineers is responsible for dozens of Great Lakes harbor entrances constructed with parallel jetties. These jetties, many in operation for more than 100 years, were typically constructed of rockfilled timber cribs that were floated to a desired location, filled with stone, and sunk. The purpose of these structures is to be impermeable to waves and littoral sediments such that adequate channel depths and safe navigation can be maintained. Over many years of physical, chemical, and biological weathering, the wood cribbing has experienced significant deterioration, thus causing the jetty to be rather porous, although not permeable to wave energy. The deterioration typically begins at the water surface, and, if left unchecked for long periods of time, can spread below the water.

Many of these structures have been rehabilitated. The typical rehabilitation approach has been to drive steel sheet pile around the existing structure and place a concrete cap on top, thereby encasing the original structure. After completion of the rehabilitation projects, wave energy between the jetties appears to increase significantly, which can cause navigational difficulties, damage to moored vessels within the harbor, and river bank erosion. This result is apparently due to the timber crib jetties 
being rough, porous structures, especially in their deteriorated state, and much more effective at dampening wave energy than the rehabilitated, sheet-pile-encased jetties. The steel sheet pile structures, being considerably more reflective than the deteriorating timber structures, are largely responsible for the increasingly energetic wave climate near the newer structures. It should be noted that the more energetic wave climate observed after rehabilitation with steel sheet pile is likely similar to that of the original rock-filled, timber-crib structure, since both structures were solid, reflective surfaces. Additionally, in almost every case, the wave climate between the jetties, with or without wave absorbers, will provide greater navigation safety than that in the open lake.

To mitigate for the more energetic wave climate, the Corps has designed small (61-122 m, 200-400 ft) pockets of stone to be incorporated into the steel sheet piling at selected harbors. A pocket wave absorber is created when a section of the sheet pile wall is recessed from the remainder of the jetty and stone is placed in the area to provide a rough, porous sloping surface that is intended to dissipate wave energy. The crest of the stone is usually offset from the steel sheet pile wall, thus creating a pocket. The typical length of a pocket is 61 to $122 \mathrm{~m}$ (200 to $400 \mathrm{ft}$ ). The pocket wave absorber at Pentwater, MI, is shown in Figures 1 and 2.

The first pocket absorber in the Great Lakes was created in 1981. During reconstruction of the Charlevoix Harbor, MI, north jetty, field engineers attempted to mitigate for the increased reflection that was expected at completion of the project. They substituted a 122-m (400-ft) section of heavy armor stone (3.5-6.0 ton) for the sheet piling along a portion of the rehabilitated structure, essentially creating a steel sheet pile/rubble mound hybrid structure. The rubble-mound portion was recessed into a pocket so that the toe of the rubble mound would not encroach into the navigation channel, and these became known as pocket wave absorbers. The local community found this method to work very well in attenuating waves. When the southern jetty was being rehabilitated in 1989, a 61-m (200-ft) section of similar rubble mound was placed. From that project forward, the application of a wave absorber at all new rehabilitation projects was examined. Figure 3 illustrates the impact a pocket absorber can have on storm waves. 


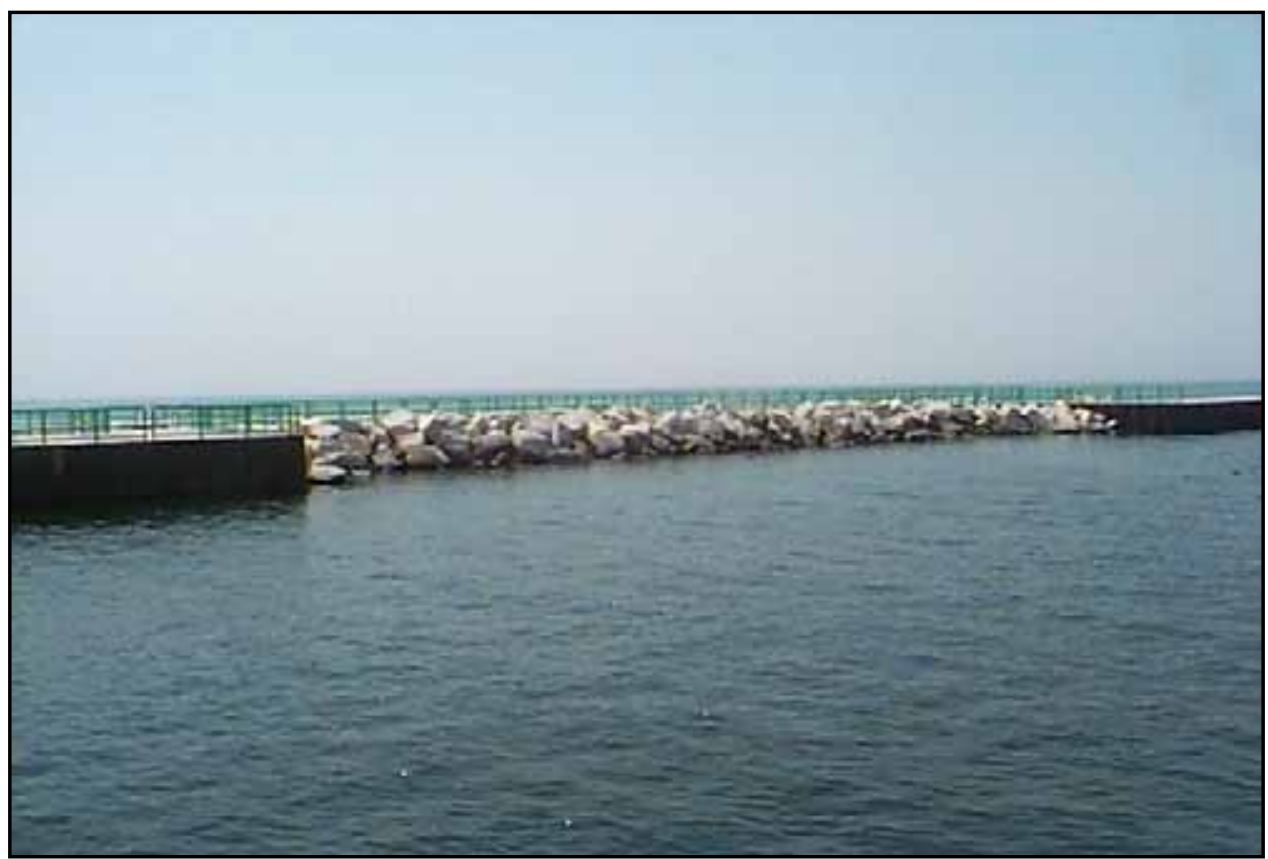

Figure 1. View of south jetty pocket wave absorber at Pentwater, Ml, looking south from north jetty.

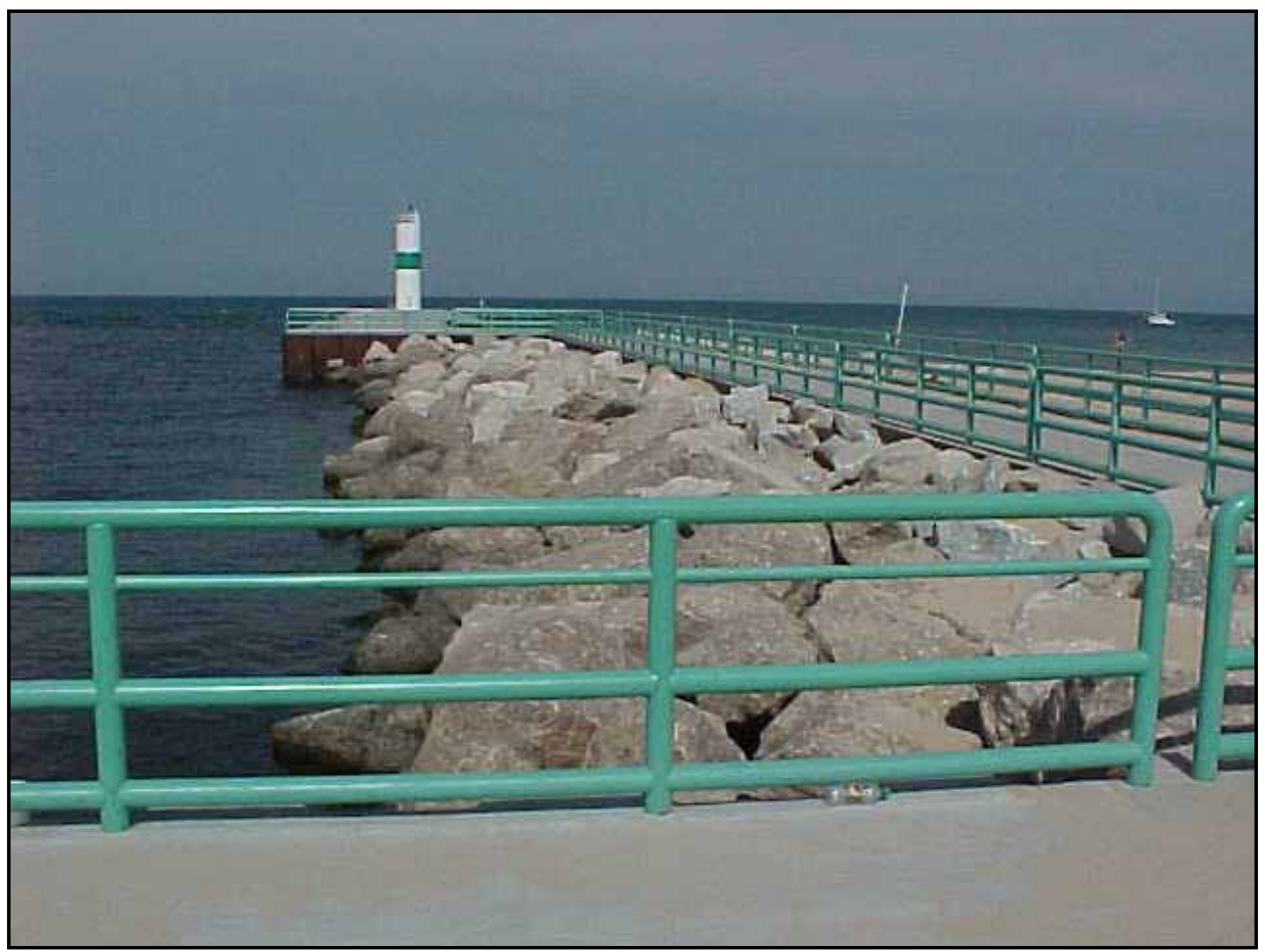

Figure 2. View of north jetty pocket wave absorber at Pentwater, Ml, looking west. 

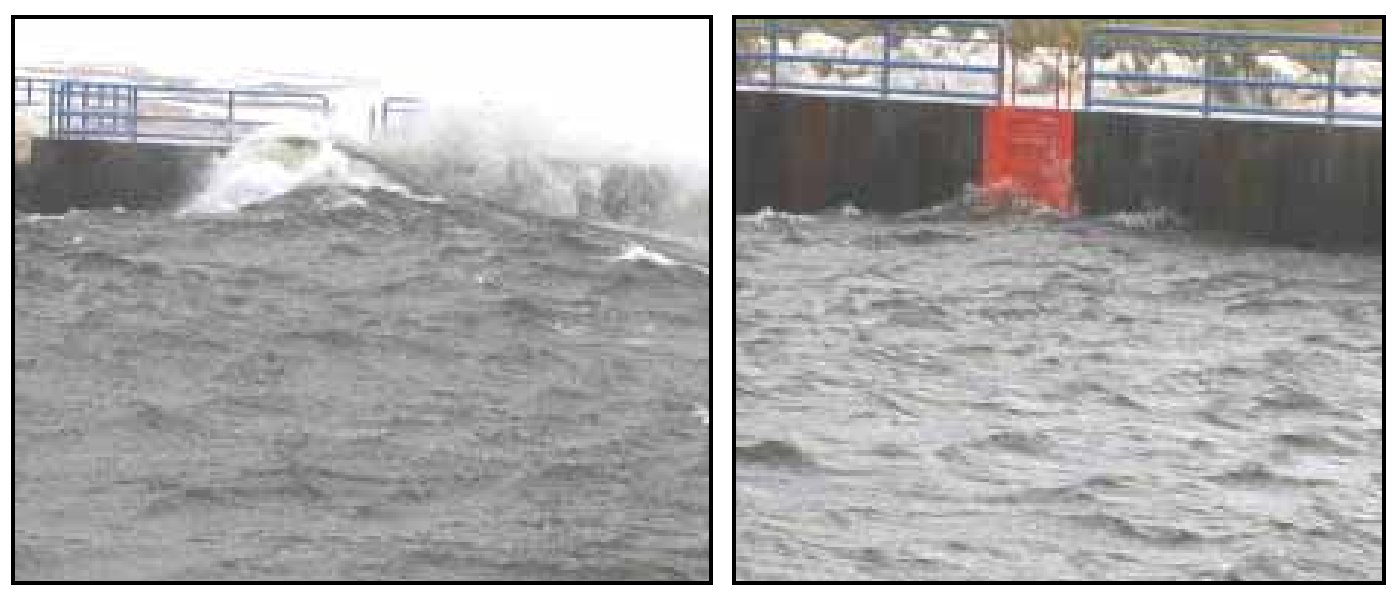

Figure 3. Waves along south jetty and entrance channel, Pentwater, MI, June 1999, looking south from north jetty: a) waves lakeward of pocket; b) waves attenuated landward of pocket (from Dr. Donald D. Carpenter).

The length and placement of wave absorbers varied from project to project as some harbors only called for small sections of the jetties to be reconstructed. Lengths of $61 \mathrm{~m}$ and $122 \mathrm{~m}$ (200 ft and $400 \mathrm{ft}$ ) were traditionally used since they were shown to work at the original harbor installation. Wave absorbers have been installed both as a single pocket and in pairs on opposite sides of the channel. Little design guidance was available for predicting the effectiveness of the many variations of wave absorbers and for the optimization of future structures.

\section{Great Lakes Harbors with pocket absorbers}

Currently, wave absorbers have been installed at seven harbors (Figure 4). Five of them are on the east coast of Lake Michigan: Saugatuck, White Lake, Pentwater, Portage Lake, and Charlevoix. The other two are at Ontonagon, on the southern shore of Lake Superior, and at Two Rivers, located on the west coast of Lake Michigan. Grand Haven Harbor is also scheduled to have one constructed within the next few years.

Although design considerations among the various wave absorber sites have some commonalities, each project typically has distinctive special considerations. Table 1 summarizes some key elements of the harbors with absorbers presently in place. Pocket absorber cross-sections are shown in Appendix A. Wave roses indicating the primary directions of wave attack are shown in Appendix B, based on hindcasts by Hubertz et al. (1991) and Driver et al. (1992). These and other considerations at each harbor are discussed in more detail in the following subsections. Aerial photographs 


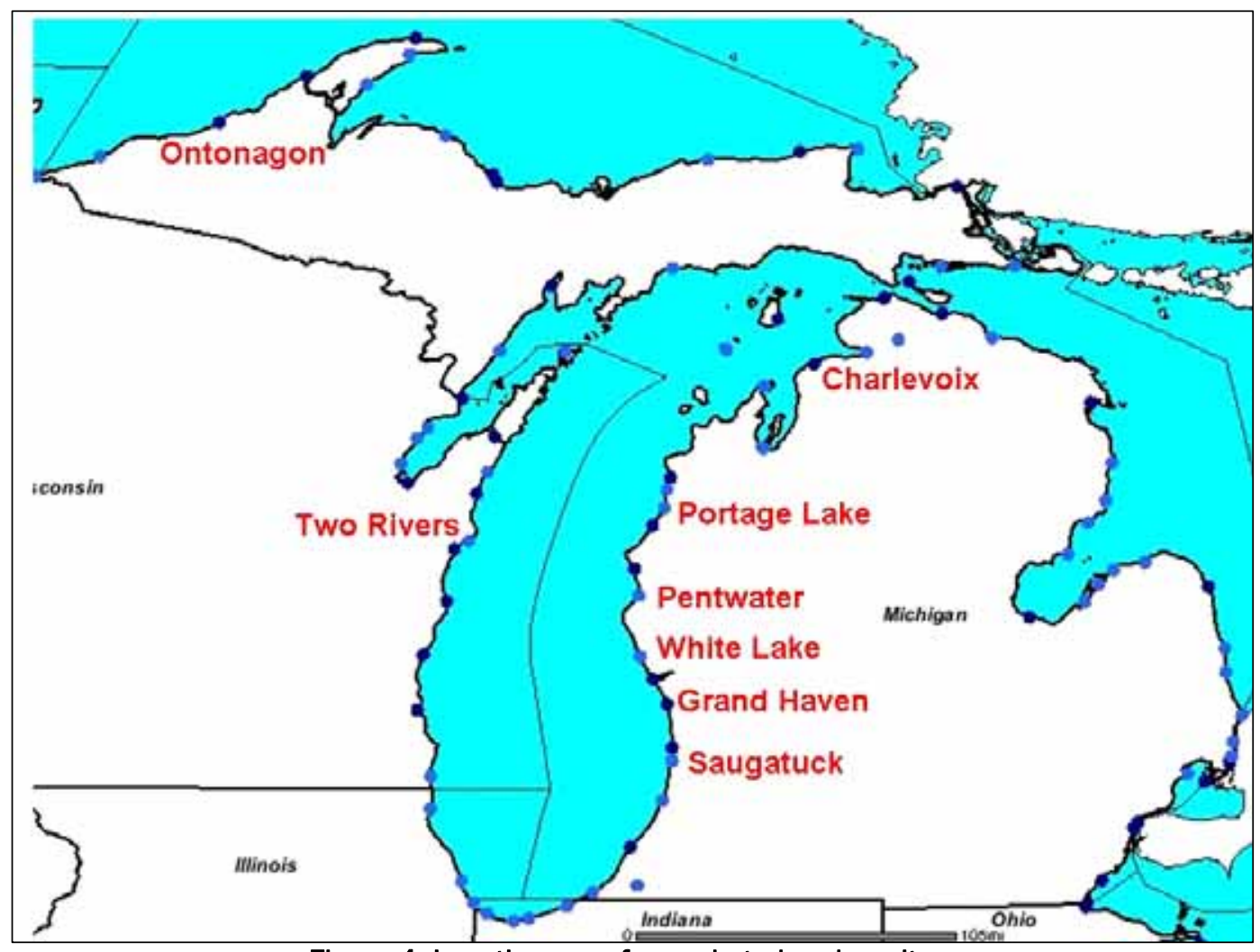

Figure 4. Location map for pocket absorber sites.

Table 1. Wave absorber projects in the Great Lakes.

\begin{tabular}{|l|l|l|l|l|l|l|l|}
\hline & Saugatuck & $\begin{array}{l}\text { White } \\
\text { Lake }\end{array}$ & Pentwater & $\begin{array}{l}\text { Portage } \\
\text { Lake }\end{array}$ & Charlevoix & Ontonagon & Two Rivers \\
\hline Project depth (ft) & 16 & 16 & 16 & 18 & 18 & $22-23$ & 18 \\
\hline $\begin{array}{l}\text { Channel width } \\
\text { between jetties } \\
\text { (ft) }\end{array}$ & 190 & 186 & 150 & 362 & 160 & 250 & 245 \\
\hline $\begin{array}{l}\text { Structure } \\
\text { slope(H:V) }\end{array}$ & $2: 1$ & $2: 1$ & $2: 1$ & $2: 1$ & $2: 1$ & $\begin{array}{l}\text { East 1.75:1 } \\
\text { West 2:1 }\end{array}$ & $2: 1$ \\
\hline Armor stone (ton) & $2.5-5$ & $5.5-11$ & $2.5-5$ & $2.5-5$ & $3.5-6$ & $4-6$ & $3-9$ \\
\hline $\begin{array}{l}\text { Underlayer stone } \\
\text { (Ib) }\end{array}$ & $500-1000$ & $35-125$ & $1000-1500$ & $\begin{array}{l}500- \\
1500\end{array}$ & $700-1300$ & $750-1500$ & $50-1000$ \\
\hline Bedding stone (Ib) & $1-50$ & $2-15$ & $1-50$ & $1-50$ & $1-50$ & $2-40$ & $1-50$ \\
\hline Year installed & 1999 & 1998 & $\begin{array}{l}\text { North 2001 } \\
\text { South 1998 }\end{array}$ & 2003 & $\begin{array}{l}\text { North 1981 } \\
\text { South 1989 }\end{array}$ & $\begin{array}{l}\text { East 1998 } \\
\text { West 2002 }\end{array}$ & 2003 \\
\hline
\end{tabular}


of all sites on the east side of Lake Michigan are included in Appendix C. Aerial photographs for Ontonagon and Two Rivers were not available.

Saugatuck, MI: Saugatuck Harbor has two wave absorbers, one on either side of the entrance channel. The absorbers were completed in December 1999. Both are approximately $61 \mathrm{~m}$ (200 ft) long, with the pockets recessed 9.1-12.2 $\mathrm{m}$ (30-40 ft). They are slightly offset, with the north absorber positioned farther lakeward. The absorbers are open to wave action on both the lake and channel sides, with a concrete walkway in the middle supported by H-piles. From the wave rose in Appendix B (Figure B1), it is evident that no direction is strongly predominant at this location. However, the highest percentage of deepwater waves come from the southwest.

White Lake, MI: Wave absorbers at White Lake were completed by end of summer 1998. Similar to Saugatuck, White Lake Harbor has wave absorbers on both the north and south jetties that are each approximately $61 \mathrm{~m}$ (200 ft) long and recessed 9.1-12.2 $\mathrm{m}(30-40 \mathrm{ft})$. These wave absorbers are also offset slightly. However, opposite to the Saugatuck layout, the southern absorber is more lakeward than the northern. The cells are located just lakeward of the revetment along the landward part of the entrance. Thus, the sloped armor stone is only on the channel side with a limited amount of large splash stone on the landside. A concrete walkway was placed adjacent to the cell. Predominant deepwater wave direction is from the south-southwest. Users of the harbor report favorably on the effectiveness of the pocket wave absorbers.

Portage Lake, MI: The wave absorber at Portage Lake was completed in summer 2003. A 122-m (400-ft) cell recessed 6.1-9.1 m (20-30 ft) was constructed in the north jetty. The wave absorber is open to wave action on both sides with a concrete walk on the top supported by H-piles. The channel is relatively wide ( $110 \mathrm{~m}, 362 \mathrm{ft}$ ), which may diminish pocket absorber effectiveness. Predominant deepwater wave direction is from the south-southwest.

Charlevoix, MI: Charlevoix Harbor was the first to have wave absorbers installed. The north jetty was rehabilitated in 1981, which included construction of a pocket absorber and addition of armor stone around the harbor interior. The absorber cell is approximately $122 \mathrm{~m}$ (400 ft) long and

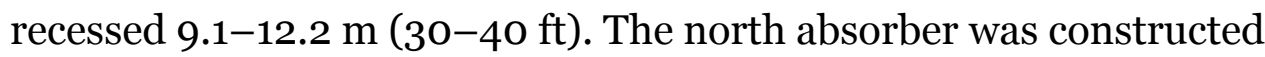


experimentally to evaluate its impact on wave attenuation. Since the absorber proved to be very beneficial in reducing wave height within the harbor, a south absorber was added in 1989. The two are offset significantly with the south absorber starting over $30 \mathrm{~m}$ (100 ft) further lakeward than the north absorber. The south cell is approximately $61 \mathrm{~m}(200 \mathrm{ft})$ long and recessed 15.2-18.3 m (50-6o ft). Cross-sections are not available for the north jetty. Records indicate that the armor stone placed was over $1200 \mathrm{lb}$ with smaller varieties used for the underlayer and mattress stone. Predominant deepwater wave direction is from the southwest.

Ontonagon, MI: Ontonagon Harbor has the only parallel jetties with wave absorbers on Lake Superior. The construction of the east cell was completed in the fall of 1998 and the west in fall 2002. The wave absorbers are approximately $61 \mathrm{~m}(200 \mathrm{ft})$ long and recessed 15.2-22.9 $\mathrm{m}(5 \mathrm{O}-75 \mathrm{ft})$. The two absorbers are offset over $396 \mathrm{~m}(1300 \mathrm{ft})$, with the west absorber being nearly at the lakeward tip of the western jetty. The two were constructed slightly differently, as indicated in Table 1 . The eastern cell encompasses the landward end of the jetty. The western cell lies near the lakeward end of the jetty. For cell areas exposed to the lake on the jetty side opposite the channel, both the lakeside and channel side slopes are covered with armor stone. The channel is relatively wide (76 m, 250 ft), which may affect pocket absorber performance. Predominant deepwater waves come from the west-northwest.

Two Rivers, WI: Two Rivers Harbor is the only harbor on the Wisconsin side with wave absorbers. Installation of a 61-m (200-ft) cell along the south jetty was completed in September 2003. The cell begins at the lakeward end of the south jetty and proceeds landward. The structure is a freestanding rubble mound with a width of approximately $24 \mathrm{~m}(80 \mathrm{ft})$. The wave absorber is open to wave action on both sides with a concrete walk on the top of the rubble mound. The channel is relatively wide $(75 \mathrm{~m}$, $245 \mathrm{ft}$ ), which may affect pocket absorber performance. The predominant deepwater wave direction is from the south.

Grand Haven, MI: A 183-m (600-ft) wave absorber is planned for construction in the north jetty. Placement of the wave absorber is expected to be in conjunction with a more comprehensive rehabilitation project to be completed in 2006 or later. 
Pentwater, MI: Pentwater Harbor is similar to Saugatuck and White Lake in that it has absorbers on both jetties (Figure 5). However, the absorbers are symmetrically placed, not offset from one another. The wave absorber on the south jetty at Pentwater was constructed from October 1996 to August 1998. The north jetty absorber was constructed from August 1999 to May 2001. Both absorbers are approximately $61 \mathrm{~m}(200 \mathrm{ft})$ long and recessed 9.1-12.2 $\mathrm{m}$ (30-40 ft). The absorbers are open to wave action on both the lake and channel sides, with a concrete walkway in the middle supported by H-piles. Predominant deepwater wave direction is from the south-southwest. The channel alignment is $289 \mathrm{deg}$ azimuth. The response from the local residents has been positive concerning the effectiveness of the wave absorber cells.

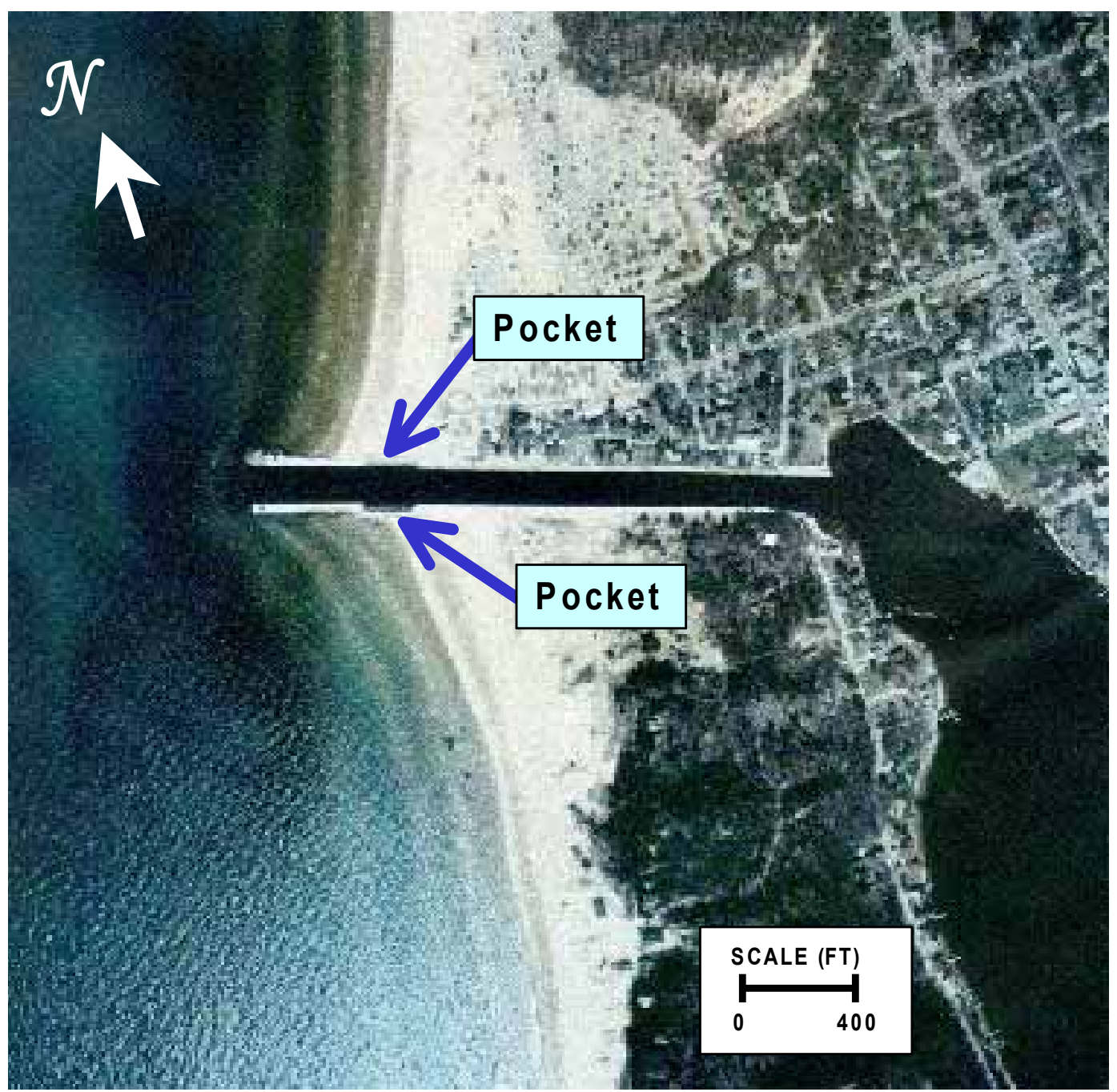

Figure 5. Aerial view of Pentwater Harbor entrance. 
Since Pentwater Harbor is the MCNP study site, some additional background is provided. Between 1856 and 1858, lumberman Charles Mears built a channel connecting Pentwater Lake to Lake Michigan. Because of the burden of constant pier repair and channel dredging, he sought help from the federal government. Congress appropriated funding for the U.S. Army Corps of Engineers in 1867 to widen the channel to $46 \mathrm{~m}$ (150 ft), extend the piers, and open the channel to a minimum planned

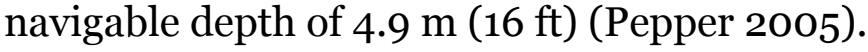

The original navigation structures consisted of a 185-m (6o6-ft) long north pier and a 189-m (620-ft) long south pier. Stone-filled wood pilings and stone-filled timber crib structures were used. In 1872, the north pier was

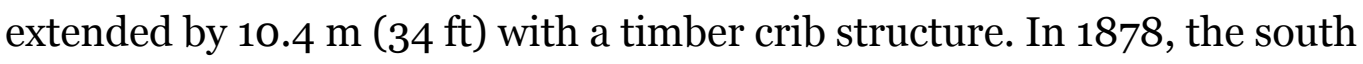
pier was extended by $30.8 \mathrm{~m}(101 \mathrm{ft})$. These structures remained unchanged until 1938, when the north and south piers were capped with concrete and stone superstructures. In 1959, an 18.3-m (6o-ft) long rubble-mound extension was added to the north pier. Riprap was added to the north pier in 1971 and the south pier in 1981 (Bottin 1988). Subsequently, major rehabilitation resulted in steel sheet piling encasing the old structures, a concrete cap/walkway on each jetty, and installation of pocket wave absorbers on either side of the channel. Elevation of the jetty cap and walkway is $+2.1 \mathrm{~m}(+7 \mathrm{ft})$ low water datum (LWD).

Pentwater Harbor was chosen as a representative of pocket wave absorber locations in the Great Lakes. Its selection for field, physical model, and numerical model studies was based on the following factors:

1. Some data are available from previous field and physical model studies conducted by the University of Michigan.

2. Pocket wave absorbers are a typical length and symmetrically placed along the channel.

3. Prototype access was relatively convenient and landward public infrastructure was available.

\section{Predicted design performance}

This MCNP study is aimed at evaluating the design of pocket wave absorbers at Pentwater, MI, as well as establishing better design guidance for future pocket wave absorber projects. To design the pocket absorbers at Pentwater, the Detroit District relied mainly on past experience at other harbors. This experience was summarized in the previous section. The 
design was further influenced by the local layout, including availability of space for placing the absorbers. The District also had access to limited physical model test data. Physical model results available prior to construction of the Pentwater wave absorbers are summarized in the following section.

\section{Previous physical model}

To predict design performance of pocket wave absorbers, physical model experiments were conducted by the University of Michigan, Department of Civil and Environmental Engineering (Wright and Carpenter 1999; Carpenter 2001). These experiments were supported by the Detroit District. A generic model, representative of typical dimensions for various rehabilitated harbor jetties, was constructed to a scale of 1:50. The model layout consisted of two parallel jetties $1.2 \mathrm{~m}(4 \mathrm{ft})$ apart and $9.4 \mathrm{~m}(31 \mathrm{ft})$ long with a water depth of $9.8 \mathrm{~cm}$ ( $0.32 \mathrm{ft}$ ) (corresponding to prototype dimensions of 61-m [200-ft] width and 472-m [1550-ft] length with water depth of $4.9 \mathrm{~m}[16 \mathrm{ft}])$. Design parameters such as pocket length, slope of stone, and stone size were varied.

Table 2 summarizes strengths and limitations of the physical model experiments. The experiments were conducted under controlled conditions, enabling various experimental parameters to be changed and evaluated relative to pocket wave absorber performance. Wave gauges were initially placed adjacent to the jetty on both the lakeside and harbor side of the pocket wave absorber to determine percent dissipation. However, observed nonuniformity across the channel width prompted additional experiments in which 3-gauge arrays were placed across the channel width lakeward of the pocket and at two locations landward of the pocket. Incident waves were generated to produce near-breaking heights, prototype wave periods ranged from $5.2 \mathrm{sec}$ to $6.7 \mathrm{sec}$, and wave angles were 0,15 , and 30 deg relative to the channel alignment. Although most experiments were performed with a single pocket, several other configurations were constructed and evaluated (Figure 6). Waves were reproduced by a plunger-type wave machine that was capable of producing only monochromatic waves. 
Table 2. Strengths and limitations, previous physical model experiments.

\begin{tabular}{|l|l|}
\hline Strengths & Limitations \\
\hline $\begin{array}{l}\text { Controlled experiments with accurate } \\
\text { measurements }\end{array}$ & Unidirectional, monochromatic waves \\
\hline Multiple gauges & No incident wave data lakeward of entrance \\
\hline Multiple incident wave conditions & $\begin{array}{l}\text { 3-gauge transects may not sufficiently capture } \\
\text { cross-channel variations }\end{array}$ \\
\hline Multiple pocket configurations & $\begin{array}{l}\text { Flat bottom, rather than representative channel } \\
\text { bathymetry }\end{array}$ \\
\cline { 2 - 2 } & No river currents \\
\hline
\end{tabular}

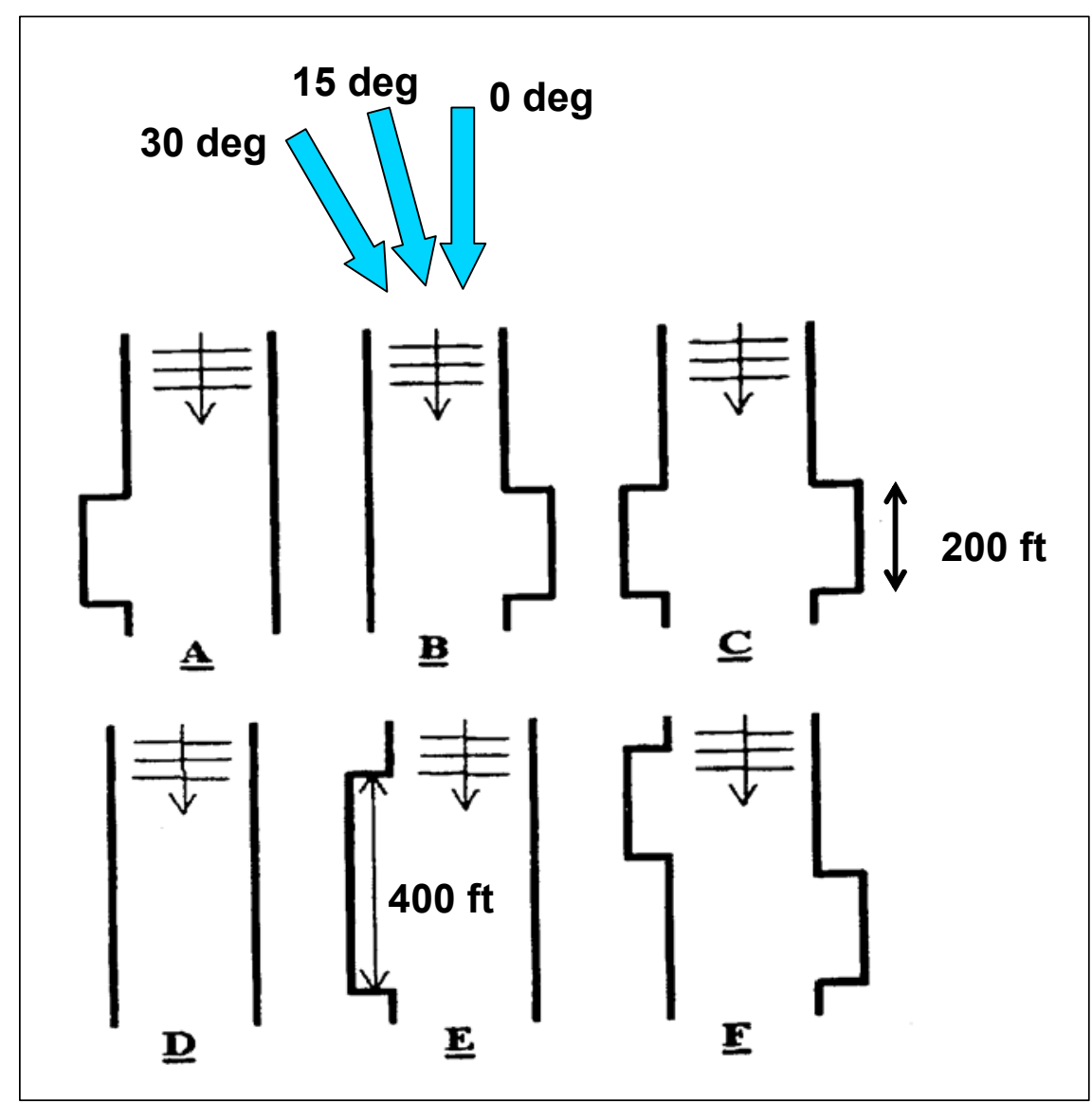

Figure 6. Pocket configurations evaluated in previous physical model studies (prototype dimensions, from Carpenter 2001).

The constraint of unidirectional, monochromatic waves is a major limitation. Wave irregularity is an important component of wave interaction with harbor entrances, and monochromatic waves are prone to exaggerating reflections and spatial variability in both physical and numerical models. However, wave irregularity may be less critical in applications involving wave propagation between long, parallel jetty walls. Since 
experiments were limited in this study, several of the pocket wave absorber parameters tested yielded inconclusive results. It was recommended that a more detailed study be conducted before significant conclusions could be made for some of the configurations tested.

Despite limitations of the physical model study, some preliminary conclusions could be deduced. For uniform stone size, the study revealed that the effect of stone size on dissipation was negligible, and that graded stone yielded slightly lower wave dissipation rates than uniform stone. The study also suggested that varying the slope of the stone revetment had little impact on dissipation. It was found that dissipation increased rather erratically with pocket length. This observation led to the consideration that the pocket length alone may not be a determining factor in wave energy dissipation, but rather the ratio of pocket length to wavelength might be more significant, at least for pocket lengths less than about one wavelength. Figure 7 shows the parameter $\left(H_{\text {landward }} / H_{\text {lakeward }}\right)^{2}$ versus pocket length for the case of $\mathrm{o}-\mathrm{deg}$ wave approach, where $H_{\text {landward }}$ is average wave height measured at a 3-gauge array on the landward side of the pocket and

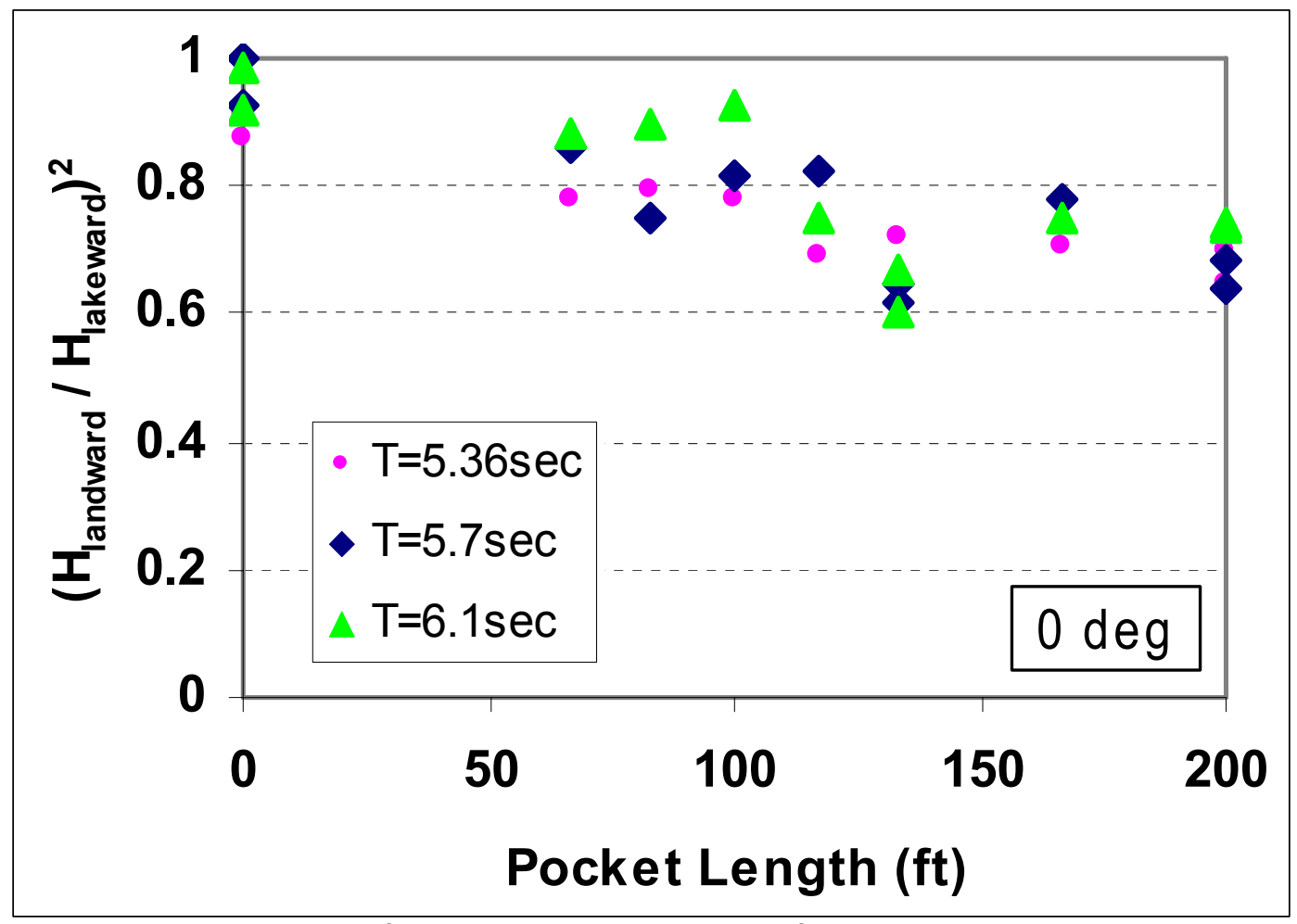

Figure 7. Wave energy fraction passing single pocket for various pocket lengths; wave direction aligned with channel; from physical model (prototype dimensions, from Carpenter 2001). 
$H_{\text {lakeward }}$ is average wave height measured at the array on the lakeward side of the pocket. (See page xi for a list of notations commonly used in this report.) The square of the ratio indicates the fraction of wave energy passing the pocket. Local wavelengths for the wave periods shown range from 33.2 to $38.1 \mathrm{~m}$ (109 to $125 \mathrm{ft}$ ).

From experiments in which direction of wave approach varied, it was determined that waves approaching from straight down the channel represent overall worst-case scenarios in the channel (as opposed to waves approaching from various angles). Figure 8 shows wave energy parameter $\left(H_{\text {landward }} / H_{\text {lakeward }}\right)^{2}$ values for each configuration in Figure 6 for 0-, 15-, and 30-deg wave direction. For every configuration tested, wave energy past the pocket decreases as incident wave obliquity increases. As would be expected, pocket configuration can have a major impact on performance. For Configuration D, the case of no pockets, waves from o deg experience little dissipation, as would be expected. However, obliquely approaching waves in Configuration D appear to lose substantial energy. This apparent dissipation may be an artifact of the relative sparsity of gauges in each cross-channel transect.

Figure 9 shows wave energy parameter averaged over the three periods and directions tested, which is more representative of the overall effectiveness of the various configurations. Configurations $\mathrm{C}, \mathrm{E}$, and $\mathrm{F}$ would be expected to perform better than $\mathrm{A}, \mathrm{B}$, and $\mathrm{D}$, based on the general expectation that wave dissipation correlates with total length of pocket, regardless of configuration details. Configuration $\mathrm{C}$, the double pocket similar to those constructed at Pentwater and White Lake Harbors, appears to be most effective at reducing wave energy in the channel. For Configuration $\mathrm{C}$, only about one-third of the energy remains after waves pass the pockets. Configuration F, identical to Configuration C except that the pockets are offset along the channel length rather than opposite each other, performs similarly to $\mathrm{C}$ for $\mathrm{O}-$ and 15 -deg wave directions. However, $\mathrm{F}$ is not as effective as $\mathrm{C}$ for $30-\mathrm{deg}$ wave direction. This behavior can be attributed to the pocket geometry of Configuration $\mathrm{F}$, which affords wave energy approaching at 30-deg a fairly clear path to reflect off the jetty walls and avoid direct impact with either pocket. The same process appears to be detrimental to the performance of Configuration $\mathrm{E}$ for 15-deg wave direction. 


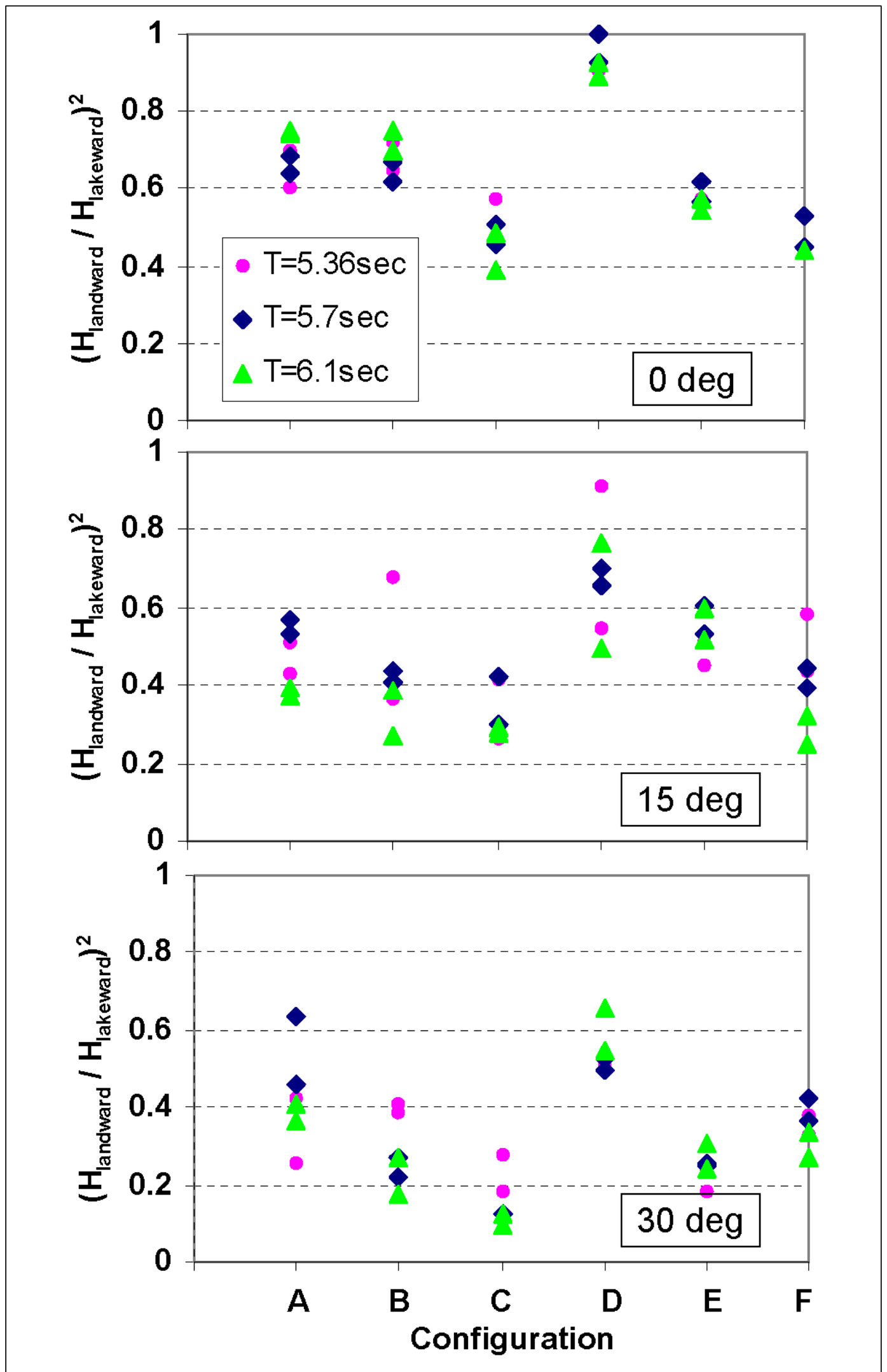

Figure 8. Wave energy fraction passing pocket for various pocket configurations and incident wave directions; from physical model (prototype dimensions, from Carpenter 2001). 


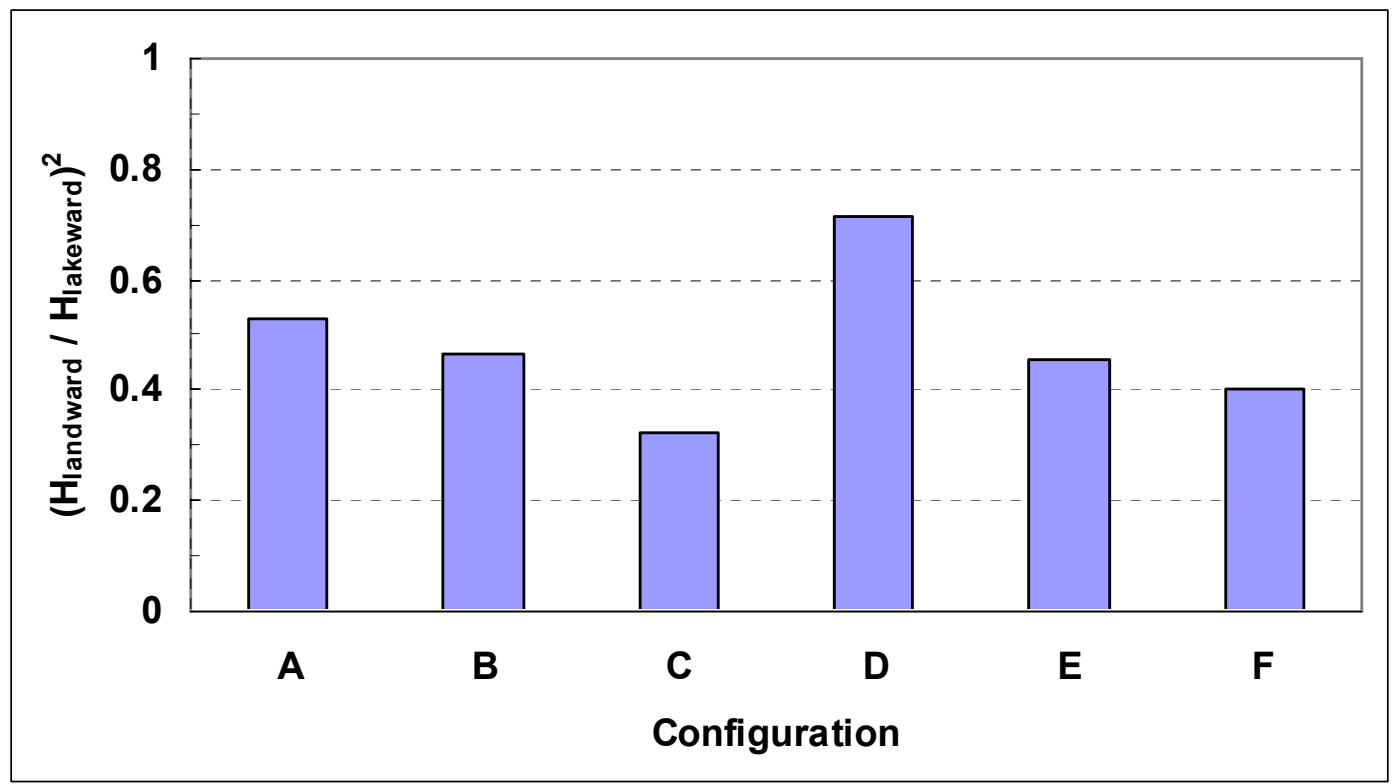

Figure 9. Wave energy fraction passing pocket for various pocket configurations; average from three incident wave directions studied in physical model (prototype dimensions, from Carpenter 2001).

\section{Summary of predicted design performance}

In summary, the predicted performance of the pocket wave absorbers designed for Pentwater was that wave energy transmitted past the pockets toward the harbor area would be reduced to about 35 percent of the wave energy incident to the pocket location. The corresponding reduction in $H_{s}$ is 59 percent (the square root of 35 percent). Further, it was predicted that the reduction in transmitted wave energy in the navigation channel and harbor area landward of the pockets would be sufficient to ensure that no new or aggravated wave problems would be experienced in these areas as a result of jetty rehabilitation. 


\section{Monitoring Program}

\section{Monitoring plan}

As part of the MCNP Program, pocket wave absorbers at the Pentwater Harbor entrance were selected for monitoring. Figure 5 shows an aerial view of the site (see page 9). The objective of the monitoring program was to determine the effectiveness of pocket wave absorbers in reducing wave heights in entrance channels and harbor areas where they are utilized in parallel steel sheet-pile jetty configurations. Additional prototype wave data would be obtained and a physical model would be constructed. After validation of the physical model with prototype data, it was anticipated that design guidance relative to pocket wave absorber parameters would be developed. Finally, a numerical model would be tested and evaluated relative to the physical model and prototype data. The numerical model would be valuable for extending design guidance to include configurations not tested in the physical model and for future use in analyzing potential projects. All three MCNP study components (prototype, physical model, and numerical model) contributed significantly to the successful conclusion of the study. The physical model experiments are the main basis for design guidance produced in this study.

This chapter describes the prototype data collection component of the MCNP study. In the following section, a previous, less-comprehensive prototype data collection effort is also described. The MCNP physical model studies are presented in Chapters 3-5. The numerical model studies are covered in Chapter 6. Conclusions and recommendations are given in Chapter 7.

The University of Michigan, Department of Civil Engineering, conducted a very limited field measurement effort to supplement their previous physical model studies (Carpenter 2001). Field investigations were conducted at Pentwater and White Lake Harbors, Lake Michigan. Similar data were obtained also at Ontonagon Harbor, Lake Superior, during one week in November 2000 by Michigan Technological University, Department of Civil and Environment Engineering, as part of this effort. White Lake and Pentwater have similar configurations. Ontonagon has a different configuration and wider channel ( $76 \mathrm{~m}$ or $250 \mathrm{ft}$ wide). Ontonagon data were collected to quantify the effect of a single $61 \mathrm{~m}(200 \mathrm{ft})$ long pocket. 
Strengths and limitations of the University of Michigan field investigations are summarized in Table 3. Wave heights were measured adjacent to one of the jetties on lakeward and landward sides of the pocket with submerged pressure transducers. Due to logistical problems with collecting data during periods of high wave energy at the Lake Michigan sites and lack of directional incident wave data at all sites, results are considered preliminary. Figure 10 summarizes data from three events at each site. Incident wave directions are rough approximations. The results indicated that about 20-50 percent of the wave energy passed the pocket at the Lake Michigan sites and about 60-80 percent at Ontonagon. No strong dependence on incident wave direction is evident.

Table 3. Strengths and limitations, previous field data (Carpenter 2001).

\begin{tabular}{|l|l|}
\hline Strengths & Limitations \\
\hline $\begin{array}{l}\text { Quantitative data on actual performance of } \\
\text { prototype pockets in presence of real waves }\end{array}$ & $\begin{array}{l}\text { Very limited length of record and range of } \\
\text { conditions }\end{array}$ \\
\hline $\begin{array}{l}\text { Includes time series data and spectral } \\
\text { analysis }\end{array}$ & $\begin{array}{l}\text { No measurements of incident waves or } \\
\text { directionality }\end{array}$ \\
\cline { 2 - 2 } & Gauges adjacent to jetty walls \\
\hline
\end{tabular}

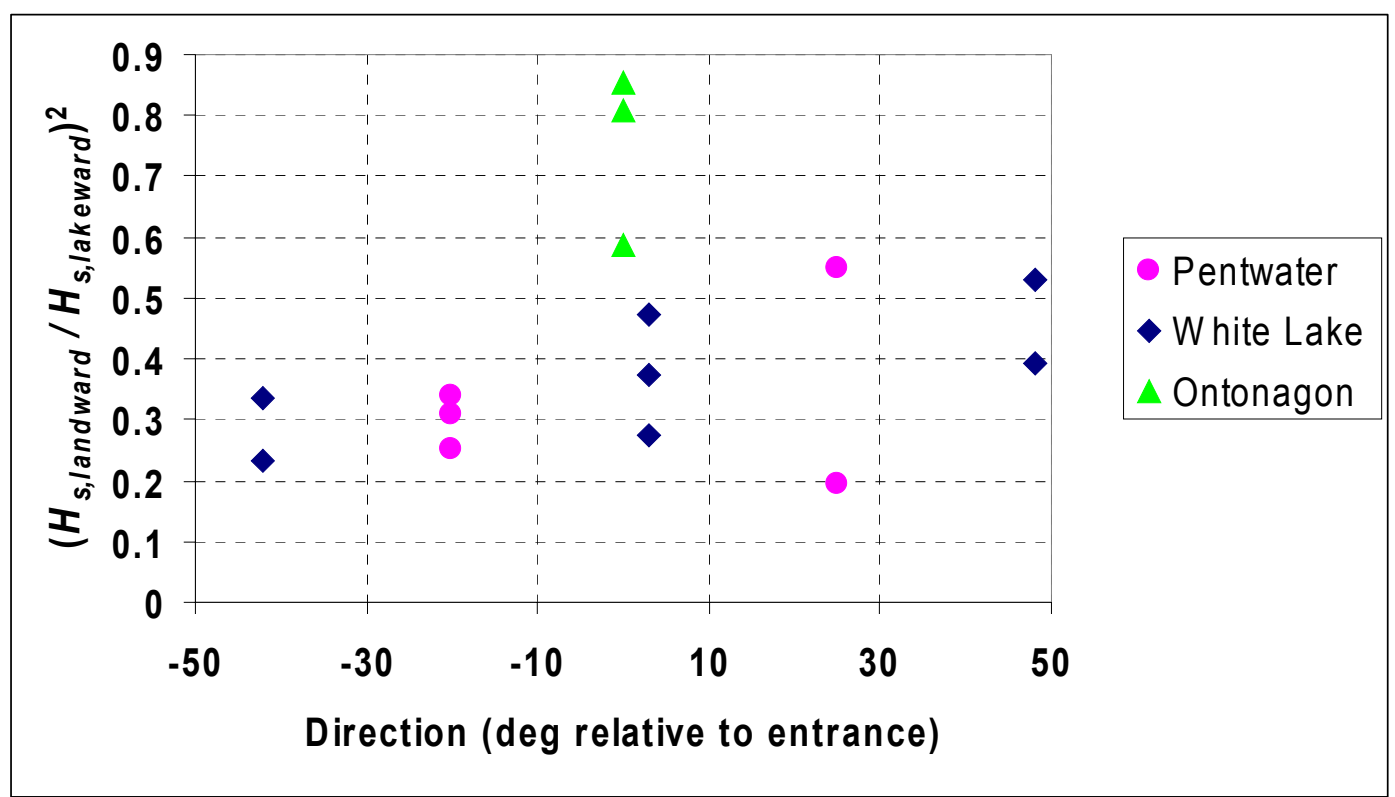

Figure 10. Wave energy fraction passing pocket for three field sites; relative direction is wave approach direction minus direction aligned with entrance channel (Carpenter 2001).

These field results provide some information about the effectiveness of a double versus single pocket absorber. The Lake Michigan results compare reasonably well with corresponding physical model data for 
Configuration C in Figure 9 (see page 16). However, the pocket effect on waves does not appear to vary with incident wave direction as much as in the physical model studies (Figure 8, page 15). This difference in behavior can be attributed to the unidirectional, monochromatic waves used in the physical model. Distance between the pockets and the jetty entrance may also affect comparability of field and physical model data, though this effect cannot be evaluated with existing data. The Ontonagon results, which were selected to represent waves coming straight into the entrance, compare reasonably well with corresponding physical model data for Configurations A and B, o-deg direction, in Figure 8. It was noted, however, that these were single-point field measurements in a system with potentially significant cross-channel variation.

\section{Equipment and data collection}

First deployment

The MCNP-supported prototype data collection effort was planned for the fall of 2002. It included an offshore directional pressure wave gauge array lakeward of the Pentwater jetties and nondirectional pressure wave gauges along the north side of the channel lakeward and landward of the pocket absorbers (Figure 11 and Table 4). Gauge deployment was delayed until April 2003. The channel gauges on either side of the pocket absorber, designated MIoO2 and MIoO4, collected hourly data during the 2-month deployment. The offshore gauge failed to provide any incident wave data.

Time series data from the channel gauges were subjected to spectral analysis and interpretation by McKinney and Sabol (2003). Long-period motions, with possible periods as long or longer than the 1024-sec time series, were evident in some records. The long periods may be related to natural oscillations in Lake Michigan and inlet/harbor resonance at Pentwater, as described by Seelig and Sorensen (1977), but record lengths are too short to evaluate this possibility. For the long-period motion events highlighted by McKinney and Sabol (2003), the National Oceanic Atmospheric Administration/National Ocean Service 6-min water level record at Ludington, MI, $16 \mathrm{~km}$ (10 miles) north of Pentwater, shows prominent oscillations with approximate height and period of $30 \mathrm{~cm}$ and $1 \mathrm{hr}$, respectively. A recent study using water level data and numerical modeling to identify natural oscillation modes in Lake Michigan, shows several 


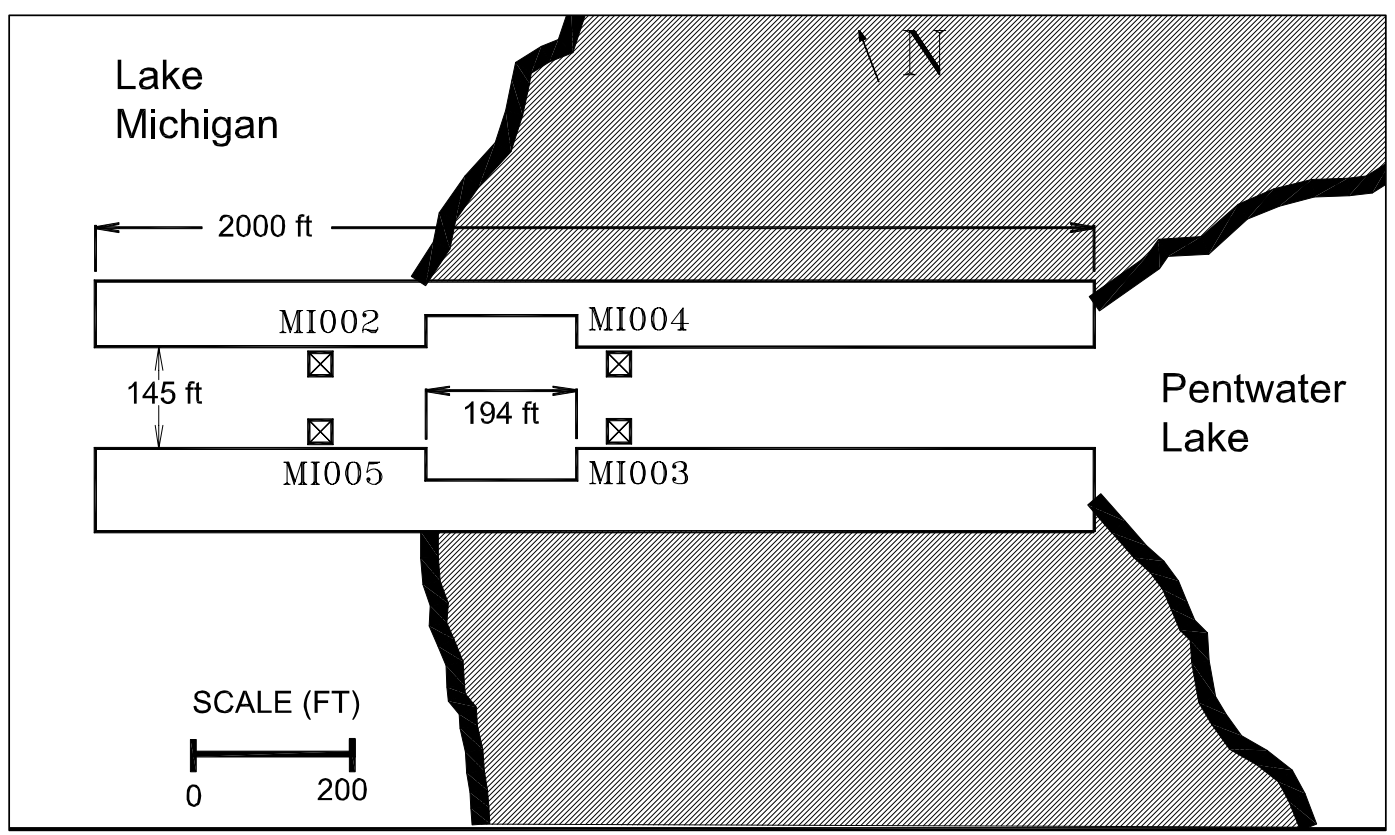

Figure 11. Location of MCNP wave gauges, Pentwater, MI.

Table 4. MCNP field wave gauges.

\begin{tabular}{|l|l|l|l|}
\hline Gauge & $\begin{array}{l}\text { Dates, First } \\
\text { Deployment }\end{array}$ & $\begin{array}{l}\text { Dates, Second } \\
\text { Deployment }\end{array}$ & $\begin{array}{l}\text { Water Depth, } \\
\mathrm{m}(\mathrm{ft})\end{array}$ \\
\hline $\begin{array}{l}\text { MI001, open water, directional, } \\
\text { 43 deg 47.109 min N, 86 deg } \\
27.157 \mathrm{~min} \mathrm{~W}\end{array}$ & None & $\begin{array}{l}23 \mathrm{Apr}-12 \mathrm{Aug} \\
2004\end{array}$ & $10.0(32.8)$ \\
\hline $\begin{array}{l}\text { MI002, N side of channel, 37 m } \\
(121 \mathrm{ft}) \text { lakeward of pocket }\end{array}$ & $\begin{array}{l}10 \mathrm{Apr}-31 \mathrm{May} \\
2003\end{array}$ & $\begin{array}{l}23 \mathrm{Apr}-13 \mathrm{Aug} \\
2004\end{array}$ & $3.4(11.2)$ \\
\hline $\begin{array}{l}\text { MI003, S side of channel, 22 } \mathrm{m} \\
(72 \mathrm{ft}) \text { landward of pocket }\end{array}$ & None & $\begin{array}{l}23 \mathrm{Apr}-23 \text { May } \\
2004\end{array}$ & $3.4(11.2)$ \\
\hline $\begin{array}{l}\text { MI004, N side of channel, 22 } \mathrm{m} \\
(72 \mathrm{ft}) \text { landward of pocket }\end{array}$ & $\begin{array}{l}10 \mathrm{Apr}-24 \mathrm{Jun} \\
2003\end{array}$ & None & $2.4(7.9)$ \\
\hline $\begin{array}{l}\text { MI005, S side of channel, 37 } \mathrm{m} \\
(121 \mathrm{ft}) \text { lakeward of pocket }\end{array}$ & None & $\begin{array}{l}28 \mathrm{Apr}-12 \mathrm{Aug} \\
2004\end{array}$ & $2.4(7.9)$ \\
\hline
\end{tabular}

modes with periods near $1 \mathrm{hr}$ and antinodes located in the coastal scallop between Big Sable Point and Little Sable Point, which includes both Ludington and Pentwater (As-Salek and Schwab 2004). Strengths and limitations of this field data collection effort are summarized in Table 5.

\section{Second deployment}

Because the offshore directional wave gauge was unsuccessful in the first deployment, a second deployment occurred the following year. Five gauges were deployed at Pentwater in April 2004 (Figure 11 and Table 4). 
Table 5. Strengths and limitations, MCNP field data.

\begin{tabular}{|l|l|}
\hline Strengths & Limitations \\
\hline $\begin{array}{l}\text { Quantitative data on actual performance of } \\
\text { prototype pockets in presence of real waves }\end{array}$ & $\begin{array}{l}\text { Limited length of record and range of } \\
\text { conditions (no fall or winter storms) }\end{array}$ \\
\hline Hourly data over a multi-week time period & $\begin{array}{l}\text { No measurements of incident waves in first } \\
\text { deployment }\end{array}$ \\
\hline $\begin{array}{l}\text { Includes time series data and spectral } \\
\text { analysis }\end{array}$ & Gauges adjacent to jetty walls \\
\hline
\end{tabular}

These were labeled MIoo1-MIoo5. MIoo1 was a directional pressure wave gauge array lakeward of the Pentwater jetty entrance, approximately 1530 $\mathrm{m}(0.95 \mathrm{mi})$ northwest of the channel. MIoO2-MIoo5 were nondirectional pressure gauges placed $15.2 \mathrm{~cm}(0.5 \mathrm{ft})$ from the bottom of the channel and $15 \mathrm{~cm}(0.5 \mathrm{ft})$ from the edge of the wall.

Data were collected hourly from all gauges except MIoo4, which provided no data due to malfunction. Data collection at MIo01 was for $30 \mathrm{~min}$ at a 1-Hz sampling rate. Data collection at the other gauges was for $1024 \mathrm{sec}$ at a 2-Hz sampling rate. Spectral analysis of time series data from the gauges was accomplished as in the first deployment. The four functional gauges provided critical wave data for calibrating and validating waves for the MCNP physical model.

\section{Data results and discussion}

Results from both deployments are available from the CHL website http://sandbar.wes.army.mil/public_html/pmab2web/htdocs/michigan/pentwater/mi001.html. Data from the first deployment were used for preliminary analysis of pocket wave absorber performance. Data from the second deployment were used for calibration and validation of the physical model.

\section{First deployment}

Results from the first deployment were helpful in preliminary analysis of pocket wave absorber performance and in planning for the second deployment. Results from the first deployment are discussed in the following paragraphs.

Based on cases with significant height from gauge MIoO2, $H_{s, M I o o 2}$, greater than $0.1 \mathrm{~m}$, the average ratio of significant wave height from the landward side of the absorber, $H_{s, M I o o 4}$, to that on the lakeward side of the absorber is 0.621 . The corresponding energy ratio is 0.39 , indicating that wave 
energy after the pocket absorbers was 39 percent of the energy level before the absorbers. The percent energy passing the pocket exhibits a mild tendency to increase with significant height, reaching 45 percent for cases with $H_{s, M I o o 2}$ greater than $0.5 \mathrm{~m}$ (McKinney and Sabol 2003). This field data set suggests that the Pentwater absorbers are slightly less effective than indicated by the University of Michigan field data (Figure 10) and physical model data (Configuration C, Figure 9).

Although the first deployment MCNP field study has limitations, it provides a much more extensive suite of field data than was previously available for pocket absorbers. Pocket absorber effectiveness as a function of various wave parameters can be examined. As before, absorber effectiveness is expressed with a parameter indicative of relative transmitted wave energy, $\left(H_{s, M I o o 4} / H_{s, M I o o}\right)^{2}$. An indication of incident wave direction can be obtained from National Data Buoy Center (NDBC) buoy 45007, which operated through the time period of the MCNP study. The NDBC buoy is located in the middle of the southern lobe of Lake Michigan, about $145 \mathrm{~km}$ (90 miles) south-southwest of Pentwater.

The dependence of absorber effectiveness on significant wave height lakeward of the pocket is shown in Figure 12. Only cases with dominant deepwater waves traveling toward the entrance are included (cases for which wave direction from the NDBC buoy, $\theta_{N D B C}$, fell within the range 225$360 \mathrm{deg}$ ). Similar plots for dependence of absorber effectiveness on peak wave period, $T_{p, M I o o 2}$, and incident wave direction $\theta_{N D B C}$ are given in Figures 13 and 14. The fraction of wave energy passing the absorber appears to be relatively independent of wave height, period, and direction. It should be noted that wave refraction changes the deepwater $\theta_{N D B C}$ as waves approach the jettied entrance such that even the most oblique waves will enter the channel at angles of about 30 deg or less relative to the channel alignment.

\section{Second deployment}

Results from the second MCNP deployment were the basis for calibrating and validating the MCNP physical model. Most of the data represented cases with lower values of $H_{s}$ and $T_{p}$ than the lowest chosen for testing in the physical model. Field data for very low incident wave conditions cannot be expected to provide reliable data on the dissipation effects of pocket wave absorbers. Therefore, the field data were filtered to retain 


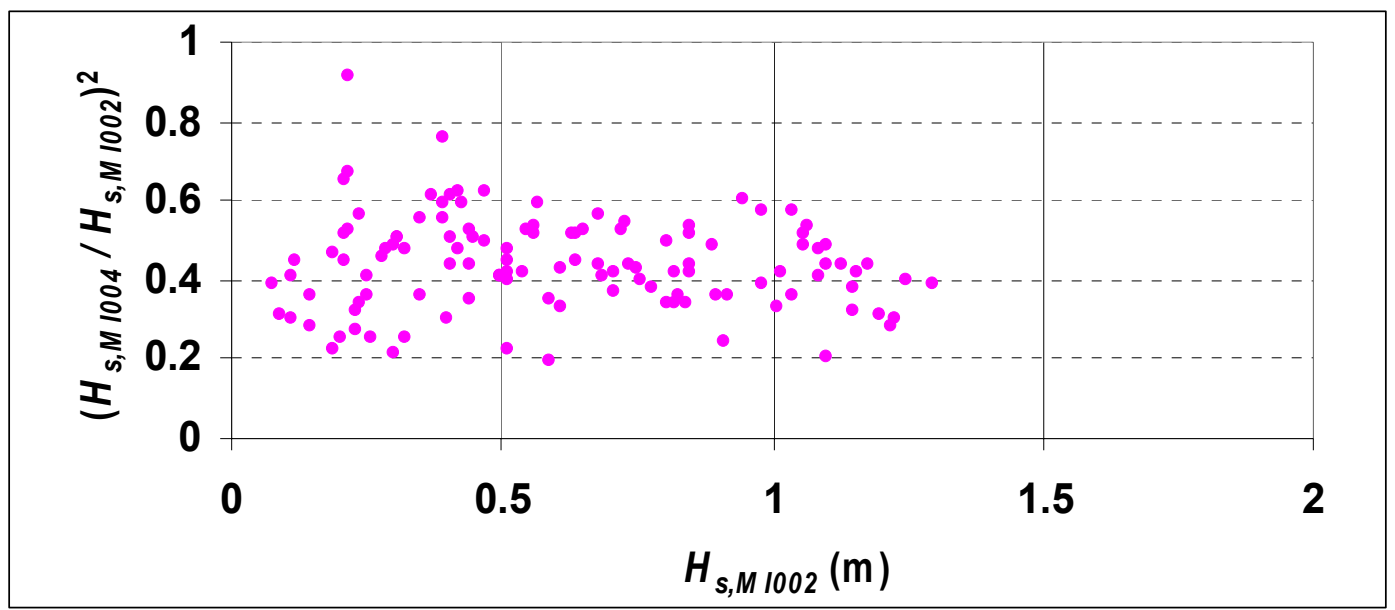

Figure 12. Wave energy fraction passing pocket versus significant wave height incident to pocket, Pentwater, Ml, first deployment.

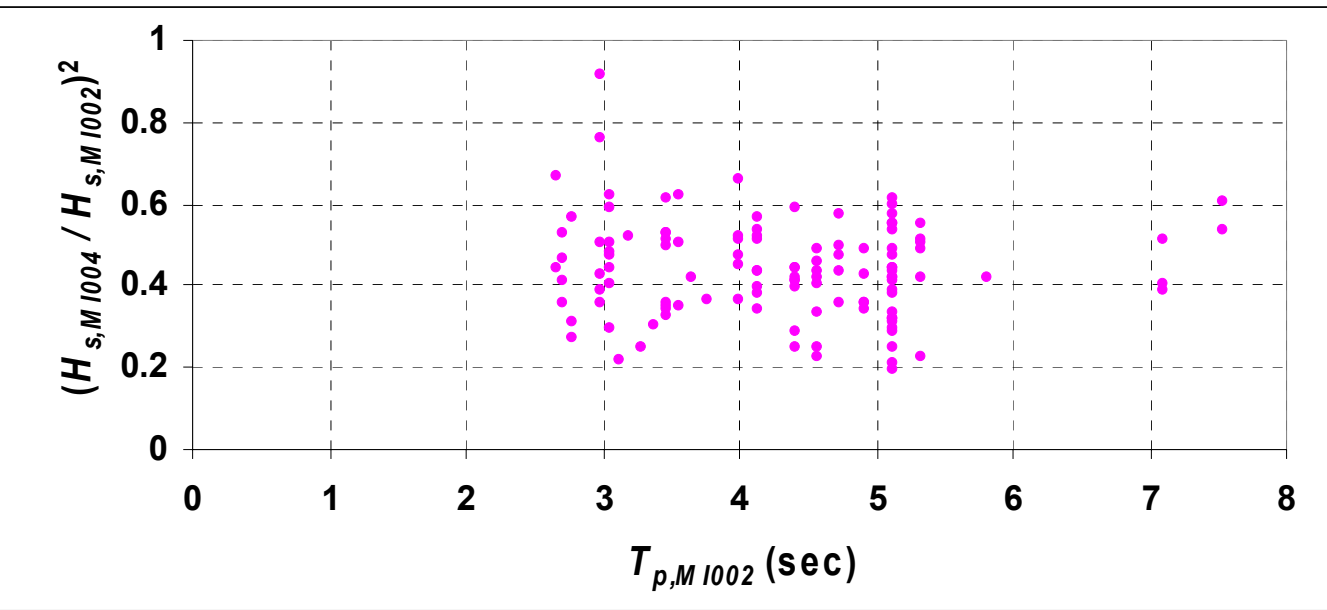

Figure 13. Wave energy fraction passing pocket versus peak wave period incident to pocket, Pentwater, MI, first deployment.

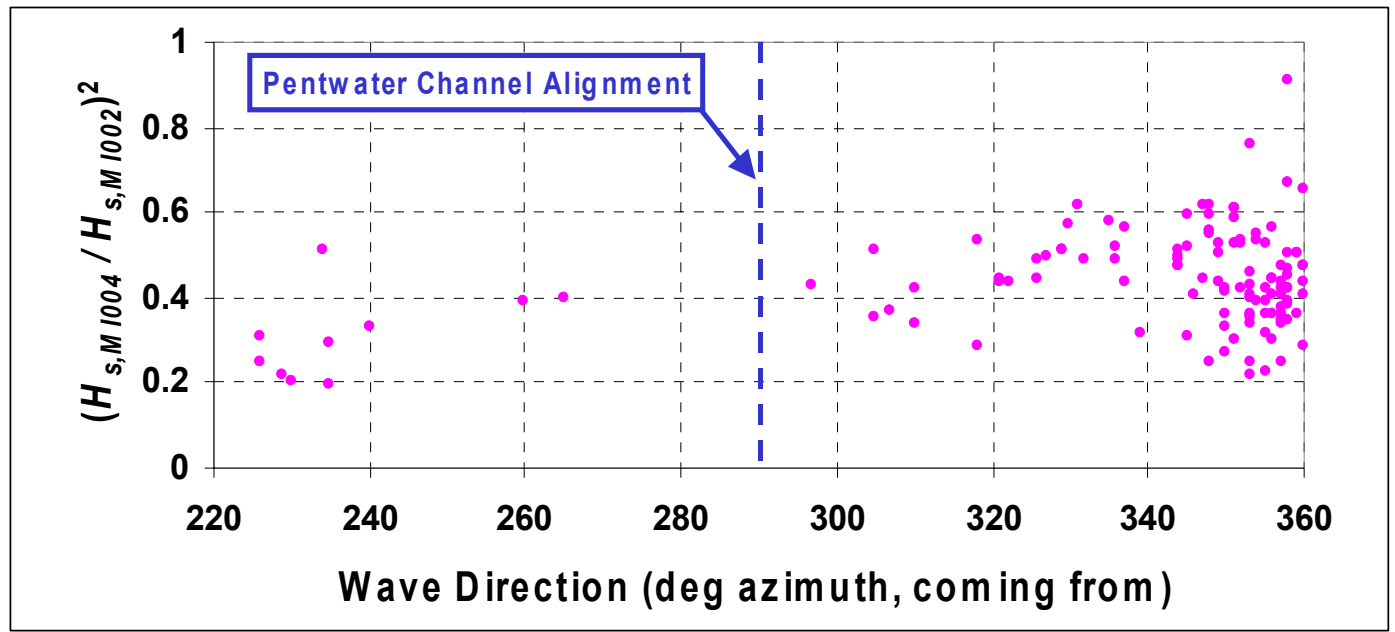

Figure 14. Wave energy fraction passing pocket versus wave direction measured at NDBC buoy 45007, Pentwater, MI, first deployment. 
only the highest 20 percent of $H_{s}$ cases and the longest 15 percent of $T_{p}$ cases. The resulting ranges were $0.4-1.4 \mathrm{~m}$ for $H_{s}$ and 4.9-6.6 sec for $T_{p}$. These cases were considered sufficiently representative of energetic field conditions and physical model test conditions to provide a meaningful basis for calibrating and validating the physical model.

For the filtered data, the ratio of $H_{s}$ in the channel to incident $H_{s}$ as a function of incident wave direction measured at gauge MIoo1 is shown in Figure 15. The cases formed three wave direction clusters. Most were waves coming from the west, slightly south of a direct approach to the channel. The other clusters were waves coming from the southwest (220-230 deg) and northwest (310-330 deg). The general notation $H_{s, \text { channel }}$ is used in the figure to represent significant wave height from the three field gauges shown. For many cases at the gauges lakeward of the pocket, $H_{s, \text { channel }} /$ $H_{s, \text { inc }}$ is greater than one, ranging between 0.69 and 1.21. For the gauge landward of the channel, the ratio ranges from 0.27 to 0.70 , showing clearly that wave heights landward of the pocket were reduced. The ratio tended to decrease as the incident wave direction became more oblique to the harbor entrance, as would be expected.

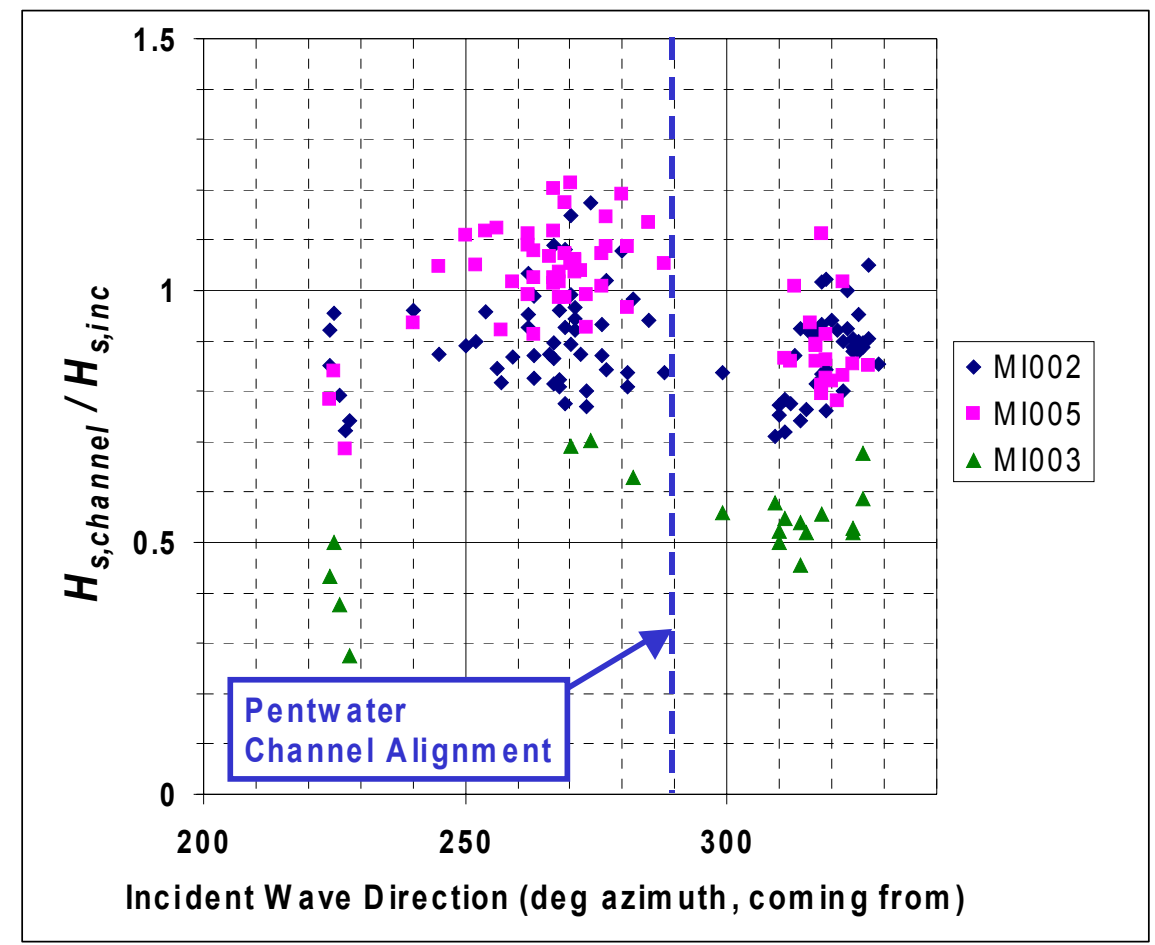

Figure 15. Ratio of $H_{s}$ in the channel to incident $H_{s}$ versus incident wave direction; highest 20 percent of incident $H_{s}\left(H_{s, i n c}>0.4 \mathrm{~m}\right)$ and longest 15 percent of $T_{p}\left(T_{p, i n c}>4.9 \mathrm{sec}\right)$ from field data, second deployment. 


\section{Physical Model}

The physical model was constructed and unidirectional spectral waves reproduced to study the pocket wave absorber design parameters. Once the wave conditions were validated at various locations in the model with the prototype data, model wave heights throughout the region between jetties were obtained with a high degree of confidence. Experiments determine the impacts of pocket wave absorbers on wave conditions in the navigation channel, as opposed to only those adjacent to the vertical jetty wall. In addition, once validated, the model can be used to study a wide range of incident wave conditions (wave heights, periods, and directions). Changes in pocket wave absorber parameters (lengths, locations, stone sizes, slopes, etc.) can then be made to develop design guidance.

The physical model design and layout are discussed in this chapter. Wave and water level conditions selected for the experiments and the data analysis procedures applied are described in Chapter 4. The experiments and results are presented in Chapter 5 .

\section{Design of model}

The Pentwater physical model was constructed to an undistorted linear scale of 1:60; model to prototype (Figure 16). Scale selection was based on the following factors:

1. Available shelter dimensions and area required for model construction;

2. Model construction costs;

3. Available wave-generating and wave-measuring equipment;

4. Absolute size of model waves;

5. Depth of water required to preclude excessive bottom friction.

A geometrically undistorted model was necessary to ensure accurate reproduction of wave patterns. Following selection of the linear scale, the model was designed and operated in accordance with Froude's model law (ASCE 1942; Hughes 1993). The scale relations used for design and operation of the model are given in Table 6 . 
ERDC/CHL TR-06-3

26

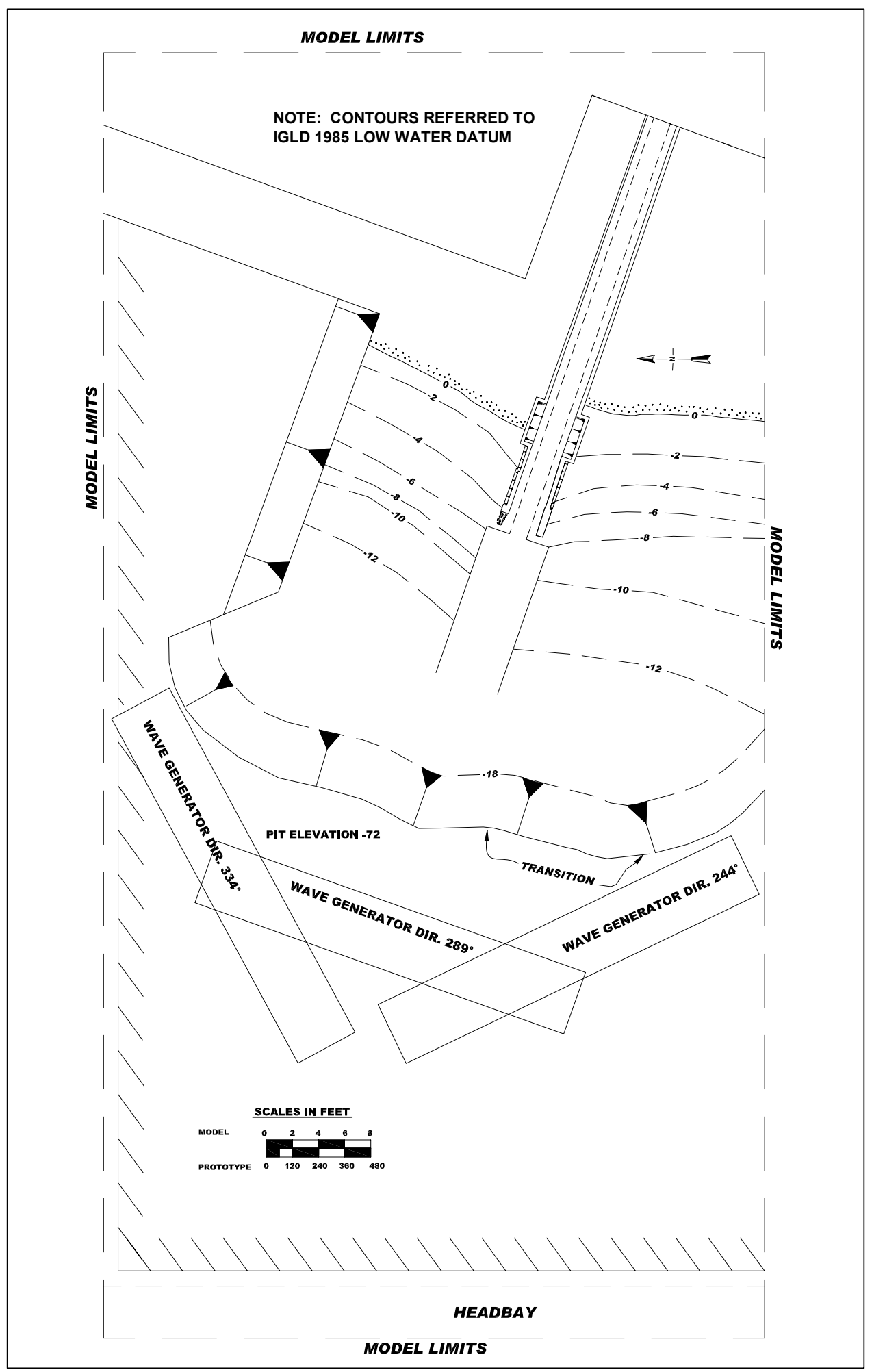

Figure 16. Physical model layout. 
Table 6. Physical model scale relations.

\begin{tabular}{|l|l|l|}
\hline Characteristic & Model-Prototype Dimension & \\
\hline Length & $\mathrm{L}$ & Scale Relations \\
\hline Area & $\mathrm{L}^{2}$ & $\mathrm{~L}_{r}=1: 60$ \\
\hline Volume & $\mathrm{L}^{3}$ & $\mathrm{~A}_{\mathrm{r}}=\mathrm{L}_{r}^{2}=1: 3600$ \\
\hline Time & $\mathrm{T}$ & $\mathrm{V}_{\mathrm{r}}=\mathrm{L}_{r}^{3}=1: 216,000$ \\
\hline Velocity & $\mathrm{L} / \mathrm{T}$ & $\mathrm{T}_{\mathrm{r}}=\mathrm{L}_{\mathrm{r}}^{1 / 2}=1: 7.746$ \\
\hline
\end{tabular}

1 Dimensions are in terms of length $(\mathrm{L})$ and time $(\mathrm{T})$.

\section{Model and appurtenances}

The physical model was constructed by molding mortar to represent the prototype Pentwater bathymetry and jetties. Stone was added in several locations to represent prototype conditions, including the tip of the north jetty, the outside surface of both jetties, and inside the pocket wave absorbers. Stone size was scaled and validated by comparing prototype data to model test data. Some adjustments in stone size were made through trial and error to accurately reproduce prototype results. To minimize reflected energy in the model basin, walls were lined with a o.6-m (2-ft) layer of fiber wave absorber.

In prototype units, the model comprised approximately $500 \mathrm{~m}(1640 \mathrm{ft})$ of Michigan shoreline, the navigation channel, north and south jetties (including the pocket wave absorbers), and underwater Lake Michigan bathymetry to offshore depths of $-5.5 \mathrm{~m}(-18 \mathrm{ft})$. A 1:5 (V:H) slope transitioned from the $-5 \cdot 5-\mathrm{m}(-18-\mathrm{ft})$ depth contour to the flat basin floor at a

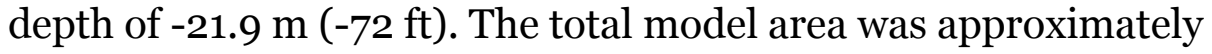
$882.6 \mathrm{sq} \mathrm{m}$ (9500 sq ft), representing $3.18 \mathrm{sq} \mathrm{km} \mathrm{(1.23} \mathrm{sq} \mathrm{mi)} \mathrm{in} \mathrm{prototype.}$ The represented prototype channel width was $43.3 \mathrm{~m}(142 \mathrm{ft})$ and the center-line depth ranged from 4.0 to $4.2 \mathrm{~m}$ (13 to $14.5 \mathrm{ft}$ ).

Pocket wave absorbers were initially constructed to represent the 59.1-m (194-ft) long prototype absorbers at Pentwater. The model was constructed so that the pocket length could be easily extended farther toward the harbor by breaking out mortar sections and remolding the pocket to desired length. Pockets were recessed $11.4 \mathrm{~m}(37.5 \mathrm{ft})$ from the interior jetty walls and stone was placed on a 1:2 (V:H) slope. Vertical control for model construction was based on LWD for Lake Michigan and horizontal control was referenced to a local prototype grid system. 
Unidirectional model waves were generated by a 9.1-m (30-ft) long electrohydraulic, vertical-displacement wave generator. The wave generator is capable of producing both regular (monochromatic) and spectral waves via programmable control of vertical motion of the wedge-shaped plunger. The wave generator is designed with retractable casters so that it can be moved to different positions in the basin as needed to produce various incident wave directions. To reduce directional spreading of wave energy into the basin outside the test area, guide vanes extended from each end of the wave generator to the edge of the model bathymetry. The guide vanes were repositioned whenever incident wave direction was changed.

The standard CHL system was used to create and transmit control signals to the wave generator, monitor wave generator feedback, and collect water level time series data at selected locations in the model (Figure 17). The system, known as the Automated Data Acquisition and Control System (ADACS), was designed and constructed at CHL. A detailed description of the ADACS is given by Markle and Greer (1992).

Twenty capacitance-type wave gauges were available for measuring the time-varying water surface displacement (Figure 18). Two gauge layout plans were used during the course of the experiments. One plan, used for model validation, matched the locations of MCNP field gauges in the Pentwater channel. Figure 18 shows gauges in this layout plan. The other plan, used for all production testing, was designed to document changes in wave energy as waves propagate into the channel entrance, along the channel, and past the pocket wave absorbers (Figure 19). Between three and five gauges were placed in each cross-channel transect because of expected wave height variations across the channel width. Transect location distances are given in Table 7. Each transect was also designated with a line number, given in the table and in Figure 19, for convenient reference. The offshore gauge, Gauge 1, measured incident waves in the flat bottom basin incident to the molded bathymetry. Thus, water depth and surrounding bathymetry at Gauge 1 did not match the conditions at the offshore prototype gauge MIoo1. 


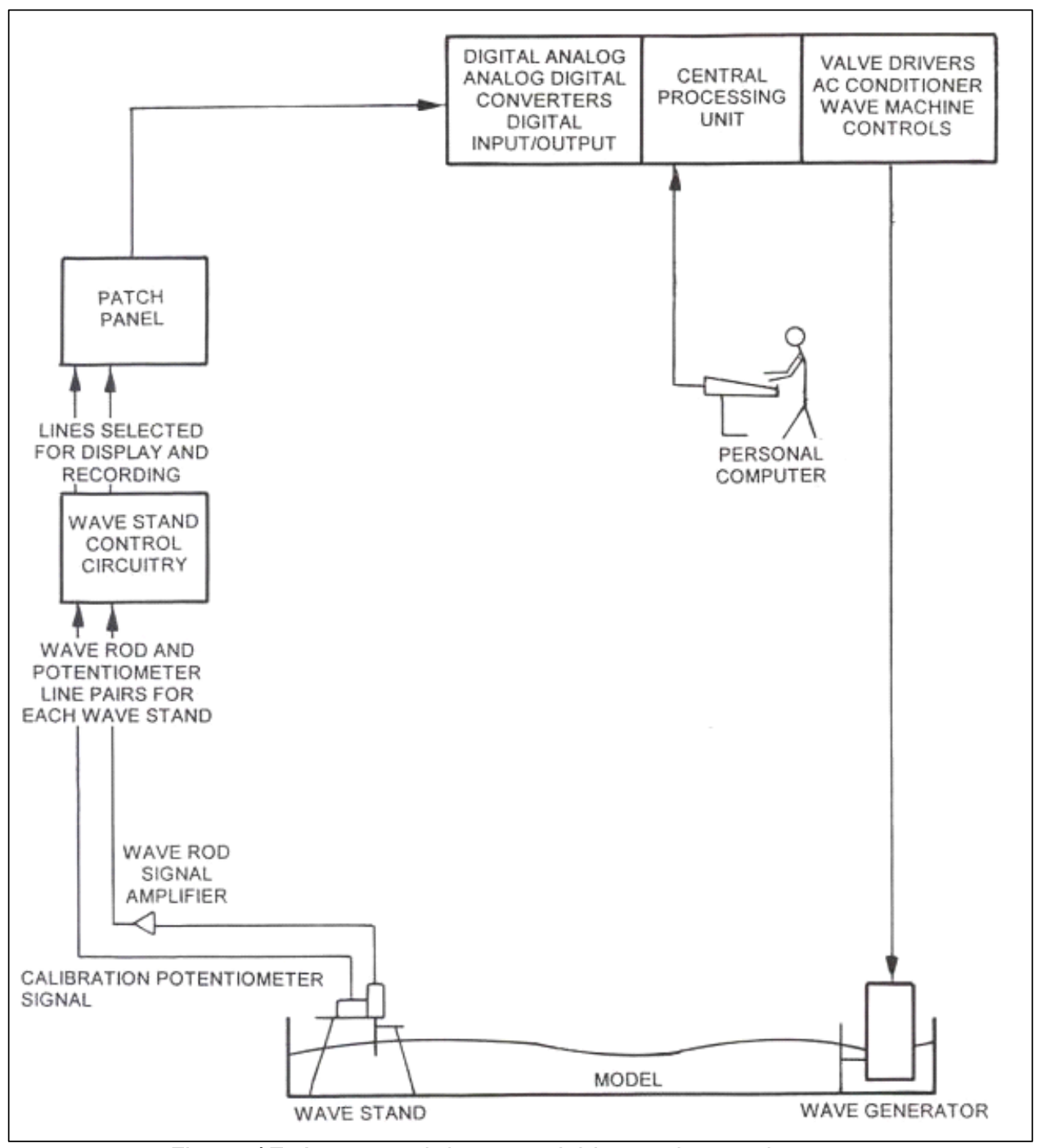

Figure 17. Automated data acquisition and control system.

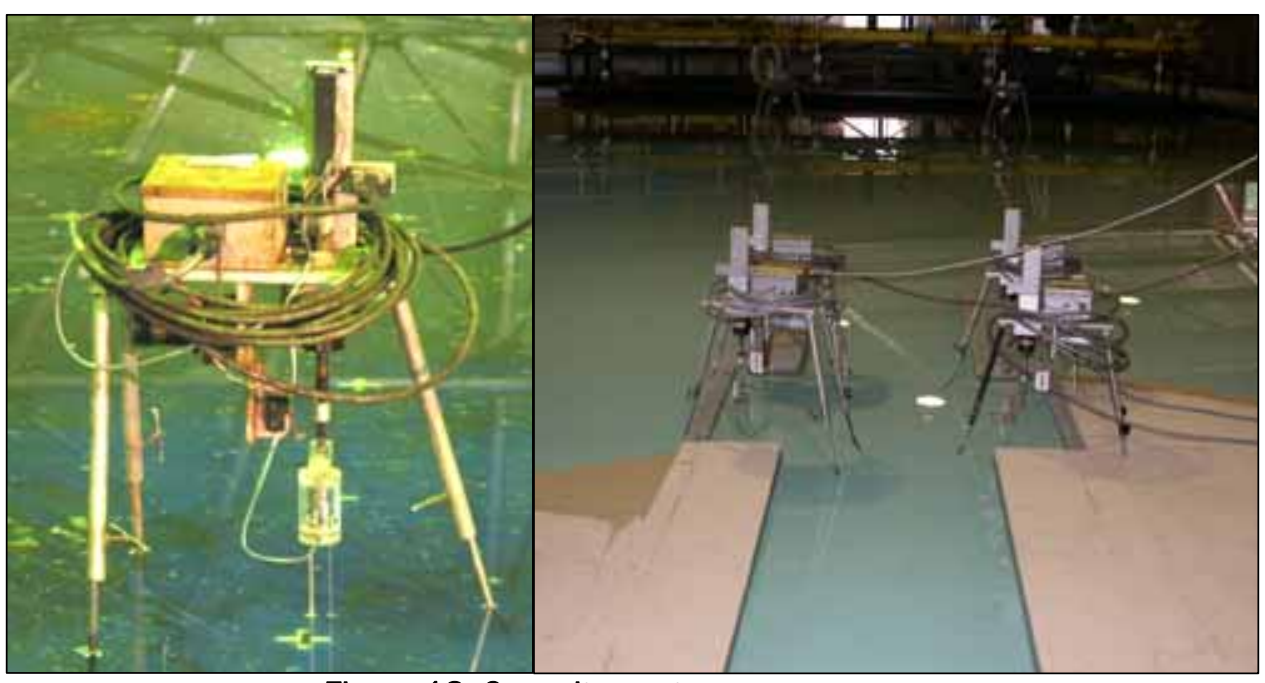

Figure 18. Capacitance-type wave gauges. 


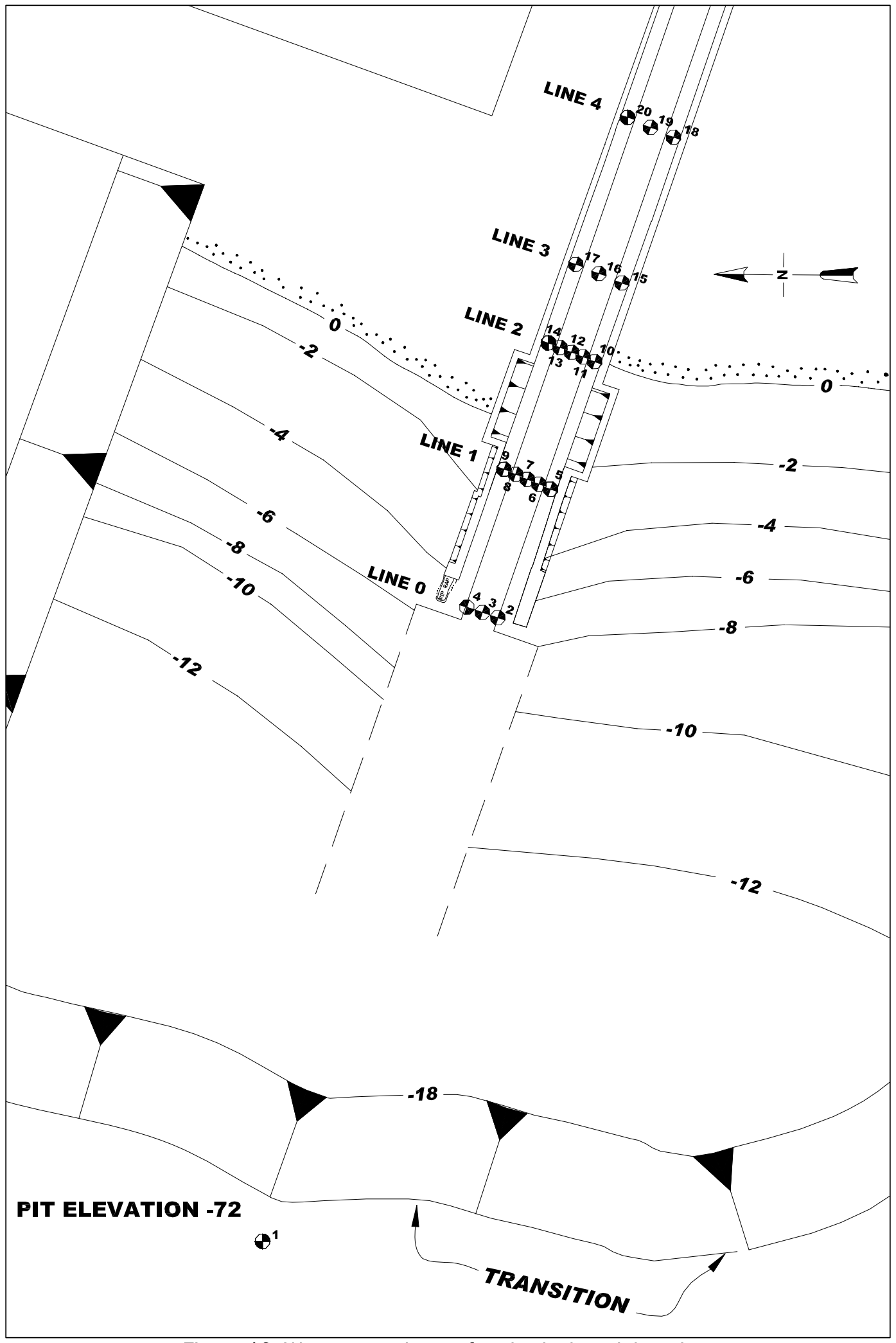

Figure 19. Wave gauge layout for physical model testing. 
Table 7. Physical model gauge locations.

\begin{tabular}{|l|l|l|}
\hline $\begin{array}{l}\text { Line } \\
\text { Number }\end{array}$ & Gauges & Location (prototype units) \\
\hline & 1 & Offshore in front of wave generator, 22-m (72-ft) depth \\
\hline 0 & $2-4$ & Jetty entrance \\
\hline 1 & $5-9$ & $\begin{array}{l}18.3 \mathrm{~m}(60 \mathrm{ft}) \text { lakeward of existing pocket absorbers; } 96.0 \mathrm{~m}(315 \mathrm{ft}) \\
\text { landward of jetty entrance }\end{array}$ \\
\hline 2 & $10-14$ & $\begin{array}{l}18.3 \mathrm{~m}(60 \mathrm{ft}) \text { landward of existing pocket absorbers; } 191.7 \mathrm{~m}(629 \mathrm{ft}) \\
\text { landward of jetty entrance }\end{array}$ \\
\hline 3 & $15-17$ & $240.6 \mathrm{~m}(789 \mathrm{ft})$ landward of jetty entrance \\
\hline 4 & $18-20$ & $350.3 \mathrm{~m}(1183 \mathrm{ft})$ landward of jetty entrance \\
\hline
\end{tabular}




\section{Experimental Conditions and Procedures}

\section{Selection of experimental conditions}

\section{Still-water level}

Still-water level (swl) for harbor wave action models is selected so that various wave-induced phenomena that depend on water depth are accurately reproduced in the model. These phenomena include refraction of waves in the project area, overtopping of harbor structures by waves, reflection of wave energy from various structures, and transmission of wave energy through porous structures.

Although Lake Michigan does not experience any significant astronomical tide, water levels change slowly over time due to variations in rainfall and runoff in the Great Lakes drainage area. Historical water level in the Great Lakes is usually tracked as monthly mean values. Recent and long-term water level variations in Lake Michigan are represented in a summary plot, an example of plots routinely published by the U.S. Army Engineer District, Detroit (Figure 20). The monthly means have a strong seasonal variation, with high levels in the summer and low levels in the winter. Year-to-year variations can also be significant, resulting in multi-year sequences of high or low lake levels with seasonal variations superimposed.

Lake water levels are expressed in terms of International Great Lakes Datum, 1985 (IGLD 1985) and chart datum or LWD. The IGLD 1985 is the standard absolute reference datum for water levels in the Great Lakes system. The LWD is a relative datum defined for each component of the Great Lakes system based on a specific value of IGLD 1985 that represents a relatively low water level for that component. For example, LWD for Lake Michigan (and Lake Huron, which shares a common water level) is 176.0 m (577.5 ft) IGLD 1985. Historical extreme low values of monthly mean water level in Lake Michigan range from about $-0.3 \mathrm{~m}(-1 \mathrm{ft})$ to $-0.2 \mathrm{~m}(-0.7 \mathrm{ft})$ LWD. Extreme high water levels range from $+1.1 \mathrm{~m}$ $(+3.6 \mathrm{ft})$ to $+1.5 \mathrm{~m}(+4.9 \mathrm{ft})$ LWD. 


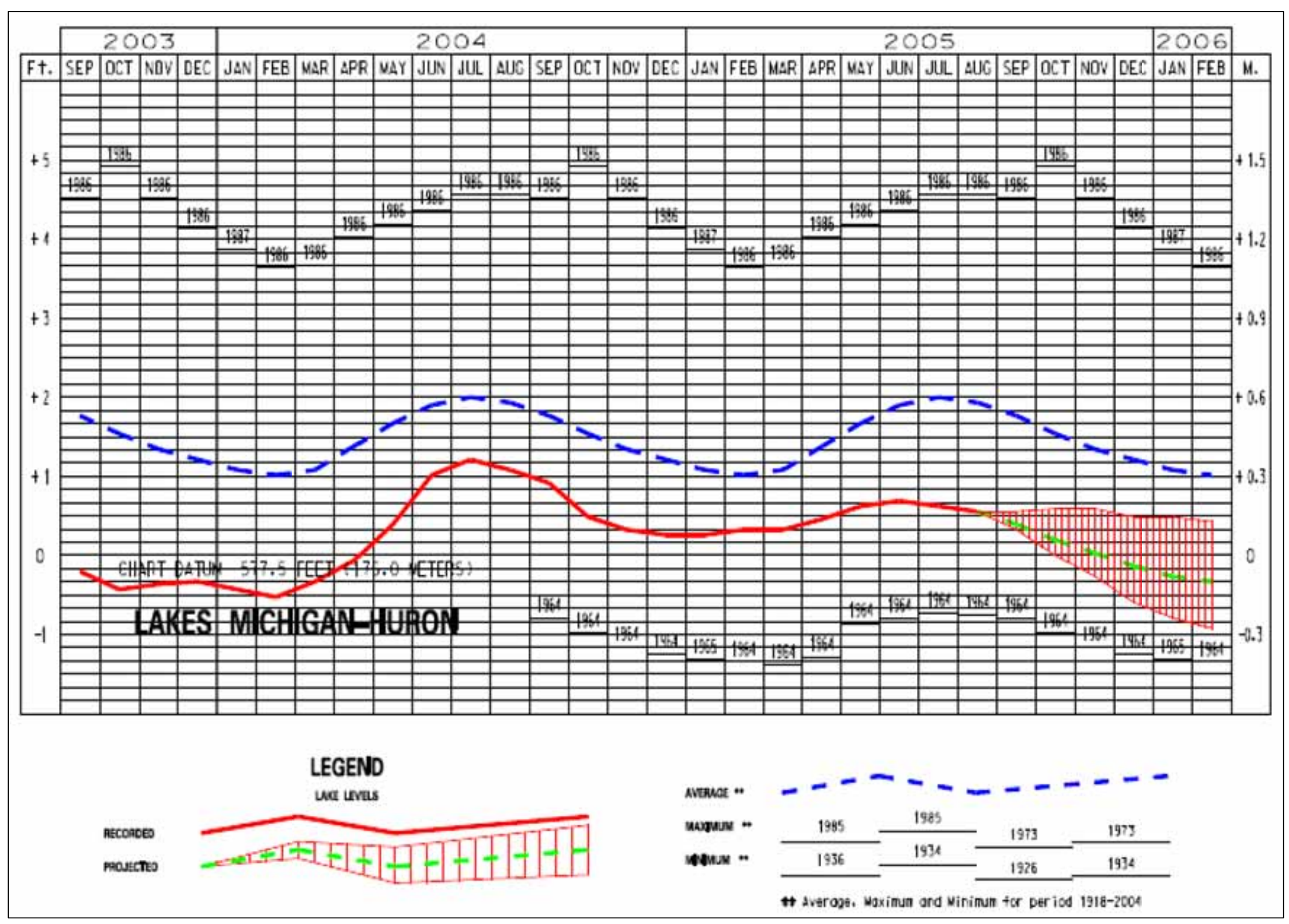

Figure 20. Monthly lake levels for Lake Michigan (in LWD). 
The swl values +0.0 and $+0.9 \mathrm{~m}(+2.95 \mathrm{ft})$ LWD were selected by the Detroit District for use during model experiments. These values represent both low and high water scenarios, and they bracket the range of water levels expected under normal conditions.

\section{Factors influencing selection of experimental wave characteristics}

In planning the testing program for a model investigation of harbor waveaction problems, it is necessary to select heights, periods, and directions for test waves that allow for realistic tests of the proposed improvement plans and an accurate evaluation of each.

Surface-wind waves are generated primarily by the interactions between tangential stresses of wind flowing over water, resonance between the water surface and atmospheric turbulence, and interactions between individual wave components. The height and period of the maximum significant wave that can be generated by a given storm depend on wind speed, length of time that wind of a given speed continues to blow, and water distance over which the wind blows (fetch). Selection of test wave conditions entails evaluation of such factors as:

1. Fetch distances for various directions from which waves can approach the study area.

2. Frequency of occurrence and duration of storm winds from the different directions.

3. Alignment, size, and relative geographic position of the navigation entrance to the harbor.

4. Alignments, lengths, and locations of the various reflecting surfaces inside the harbor.

5. Refraction of waves caused by differentials in depth in the area lakeward of the harbor, which may create either a concentration or a diffusion of wave energy at the site.

\section{Selection of experimental wave conditions}

Measured prototype data covering a sufficiently long duration from which to base a comprehensive statistical analysis of wave conditions were unavailable for the Pentwater area. A suite of experimental test wave conditions was determined by the Detroit District based on available information (Table 8). The available wave sources were Wave Information Studies (WIS) hindcasts covering the years 1956-1997, short-term MCNP 
Table 8. Physical model test conditions.

\begin{tabular}{|l|l|l|l|}
\hline $\begin{array}{l}\text { Direction (deg, relative } \\
\text { to channel alignment) }\end{array}$ & $\mathrm{swl}, \mathrm{m}(\mathrm{ft})$ & $T_{p}, \mathrm{sec}$ & $H_{\mathrm{s}, \mathrm{nn}, \mathrm{m}(\mathrm{ft})}$ \\
\hline From 45 south & $0.0,+0.9(+2.95)$ & $5,6,7,8$ & $1.0(3.28), 2.0(6.56), 2.5(8.2)$ \\
\hline 0 & $0.0,+0.9(+2.95)$ & $5,6,7,8$ & $1.0(3.28), 2.0(6.56), 2.5(8.2)$ \\
\hline From 45 north & $0.0,+0.9(+2.95)$ & $5,6,7,8$ & $1.0(3.28), 2.0(6.56), 2.5(8.2)$ \\
\hline
\end{tabular}

field data collected in the present study, and data from NDBC buoy 45007, located in the middle of the southern lobe of Lake Michigan, about $145 \mathrm{~km}$ (90 miles) south-southwest of Pentwater. The WIS hindcasts are described by Hubertz et al. (1991).

Since the physical model experiments were intended to develop general guidance for pocket wave absorber design rather than extensive testing of the specific Pentwater site, wave conditions were more generic than in a normal project study. In particular, wave directions were chosen relative to the channel alignment. The directions were from $45 \mathrm{deg}$ south, o deg (wave approaching directly into the channel), and 45 deg north relative to the Pentwater channel. The highest incident significant wave height, $H_{s, i n c}$, was $2.5 \mathrm{~m}(8.2 \mathrm{ft})$ because testing showed that higher waves caused breaking within the channel and inaccurate test results.

Unidirectional wave spectra were generated to match the selected test wave parameters and used throughout the model investigation. Spectra were based on the Texel-MARSEN-ARSLOE (TMA) form for locally generated waves in shallow water. The spectral peak enhancement factor, $\gamma$, was set to 3.3 for all spectra, representing actively growing waves with a relatively wide frequency spread. A series of calibration tests was needed because no practical relationship exists for converting from sea surface elevation time series to equivalent wave board stroke time series for plunging-type wave generators. Based on past experience with this wave generator, an approximate stroke command time series was created. This signal was run in the basin at the design water level, and measurements were made at the deep-water wave gauge so that model bathymetry did not influence the waves. These measurements were analyzed, and a gain factor was calculated that would uniformly increase or decrease the wave board stroke signal to match the target spectrum. Then the test was repeated with the new board signal. Once the measured spectra matched 
the target spectra, the command signals were saved for future use. This was repeated for each desired wave condition.

\section{Analysis of model data}

Relative merits of the various plans tested were evaluated by:

1. Comparison of wave heights and wave energy at selected locations in the model.

2. Visual observations and wave pattern photographs.

For each test, water level time series were collected at the rate of 20 points per second for a duration of $435 \mathrm{sec}$. Data collection was initiated $45 \mathrm{sec}$ after the wave generator was started to allow time for wave energy to propagate across the model area. The water level time series record from each gauge was analyzed with standard control signal Generation and Data Analysis Package (GEDAP ${ }^{1}$ ) software to produce a wave energy spectrum and various parameters, including the spectral-based significant wave height $H_{m o}$ and $T_{p}$. For convenience, this estimate of significant height is referenced with the more general symbol $H_{s}$ in this report.

The wave generator is programmed to make energy only at frequencies appropriate to wind waves. However, low frequency energy also appears in the model basin due to several factors, such as reflections, standing waves, and natural resonances in the model basin and imperfect generation of bound long waves that accompany the wind waves. A small amount of low frequency energy was consistently measured at the offshore gauge. Similar low frequency energy appeared in all the other gauge records, but the amount of low frequency energy was an order of magnitude higher at all the channel gauges as compared to the offshore gauge. For the offshore gauge and gauges lakeward of the pocket absorbers, the low frequency energy was a small fraction of the total spectral energy. However, the low frequency energy was a significant part of the total at more sheltered gauges. The parameter $H_{m o}$ is based on the total energy in the wave spectrum. Since the low frequency energy appearing in the model was relatively constant at all the channel gauges and did not appear to be related to the entrance and pocket configurations, the estimate of $H_{m o}$ was based only on the portion of the spectrum relevant to wind waves, a frequency

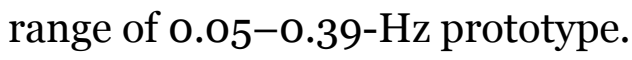

1 GEDAP is a registered mark of the National Research Council of Canada. 


\section{Model validation}

The final step prior to production testing was to validate the model against MCNP field data. This step entails selecting events measured in the field, reproducing those incident wave and water level conditions in the physical model, and evaluating wave measurements in the model channel relative to the field data. The model configuration for validation matched the existing Pentwater configuration. This validation is necessary to ensure the model will produce accurate results when testing the suite of wave and water levels in the various alternative plans.

For validation of the Pentwater model, a water level of $+0.3 \mathrm{~m}(0.98 \mathrm{ft})$ LWD was used to match the water level at the time MCNP second deployment field data were collected. Model wave gauges were placed in the same positions as prototype gauges (Figure 11, page 20). Wave conditions for validation were chosen from the very limited times when field gauge MIoo3, landward of the pocket absorbers, was operational. Prototype wave conditions were chosen with the objective of having relatively high waves for a duration of several hours while multiple field gauges were operational. The validation cases included waves coming from approximately 275 and 320 deg azimuth (14 deg south and 31 deg north relative to the channel alignment). Field data for waves coming from 225 deg azimuth (64 deg south relative to channel) were also available, but the model basin wall prevented moving the wave generator to that highly oblique angle.

Table 9 gives the validation results. At gauge MIoo3, the physical model and field $H_{s}$ agree within 10 percent, with no apparent tendency for the model $H_{s}$ to be higher or lower than the field gauge result (no apparent bias). At the more exposed gauges, differences are generally 10 percent or less and no bias is evident. Physical model validation results are shown relative to a wider range of prototype results presented earlier (Figure 21). For the validation, only the physical model cases with corresponding prototype data are shown. The physical model results are reasonably consistent with the very limited prototype data. The physical model was considered sufficiently validated. Results from Line 2, the cross-channel transect at the location of gauge MIoo3, are also shown for perspective. These results are root-mean-square (RMS) $H_{s}$ values computed from the five physical model gauges at Line 2, so they are not expected to match the single-point field gauge data as well. RMS values from the two physical model incident wave height and period conditions that resemble the prototype incident conditions $\left(H_{s}=1 \mathrm{~m}, T_{p}=5\right.$ and $\left.6 \mathrm{sec}\right)$ are averaged for plotting. 
Table 9. Physical model validation to prototype.

\begin{tabular}{|c|c|c|c|c|c|c|c|c|c|}
\hline & $\begin{array}{l}\theta_{n c} \\
\text { deg } \\
\text { az. }\end{array}$ & $\begin{array}{l}T_{p} \\
\text { sec }\end{array}$ & $\begin{array}{l}H_{s, M 1001} \\
\mathrm{~m}\end{array}$ & $\begin{array}{l}H_{s, M 1002} \\
\mathrm{~m}\end{array}$ & $\begin{array}{l}H_{s, \text { MIOOL2/ }} \\
H_{s, \text { MIO01 }}\end{array}$ & $\begin{array}{l}H_{\mathrm{s}, \mathrm{M} 1005} \\
\mathrm{~m}\end{array}$ & $\begin{array}{l}H_{s, \text { M1005/ }} \\
H_{s, \text { MIO01 }}\end{array}$ & $\begin{array}{l}H_{\mathrm{s}, \mathrm{MIO03}} \\
\mathrm{m}\end{array}$ & $\begin{array}{l}H_{s, \text { MIOO3/ }} \\
H_{s, \text { MIO01 }}\end{array}$ \\
\hline \multicolumn{10}{|c|}{ Case 1: 140024 May 2004} \\
\hline Prototype & 313 & 5.1 & 1.32 & 1.15 & 0.87 & 1.33 & 1.01 & $n d^{*}$ & nd \\
\hline Model & 318 & 5.1 & 1.32 & 1.14 & 0.86 & 1.36 & 1.03 & 0.86 & 0.65 \\
\hline \multicolumn{10}{|c|}{ Case 2: 120030 April 2004} \\
\hline Prototype & 326 & 5.4 & 0.62 & 0.55 & 0.89 & nd & nd & 0.42 & 0.68 \\
\hline Model & 318 & 5.2 & 0.62 & 0.50 & 0.81 & 0.51 & 0.82 & 0.38 & 0.61 \\
\hline \multicolumn{10}{|c|}{ Case 3: 090030 April 2004} \\
\hline Prototype & 318 & 4.7 & 0.68 & 0.57 & 0.84 & 0.68 & 1.00 & 0.41 & 0.60 \\
\hline Model & 318 & 4.7 & 0.66 & 0.67 & 1.02 & 0.66 & 1.00 & 0.42 & 0.64 \\
\hline \multicolumn{10}{|c|}{ Case 4: 170027 April 2004} \\
\hline Prototype & 322 & 3.7 & 0.83 & 0.73 & 0.88 & nd & nd & 0.45 & 0.63 \\
\hline Model & 318 & 4.6 & 0.79 & 0.70 & 0.89 & 0.71 & 0.90 & 0.48 & 0.61 \\
\hline \multicolumn{10}{|c|}{ Case 5: 110011 August 2004} \\
\hline Prototype & 277 & 4.9 & 0.96 & 0.98 & 1.02 & 1.10 & 1.15 & nd & nd \\
\hline Model & 276 & 5.0 & 1.00 & 0.98 & 0.98 & 1.01 & 1.01 & 0.53 & 0.53 \\
\hline \multicolumn{10}{|c|}{ Case 6: 030012 August 2004} \\
\hline Prototype & 273 & 5.0 & 1.31 & 1.05 & 0.80 & 1.30 & 0.99 & nd & nd \\
\hline Model & 276 & 5.0 & 1.29 & 1.15 & 0.89 & 1.30 & 1.01 & 0.60 & 0.47 \\
\hline \multicolumn{10}{|c|}{ Case 7: 130010 August 2004} \\
\hline Prototype & 271 & 4.9 & 1.20 & 1.16 & 0.97 & 1.27 & 1.06 & nd & nd \\
\hline Model & 276 & 5.0 & 1.22 & 1.14 & 0.93 & 1.28 & 1.05 & 0.60 & 0.49 \\
\hline
\end{tabular}



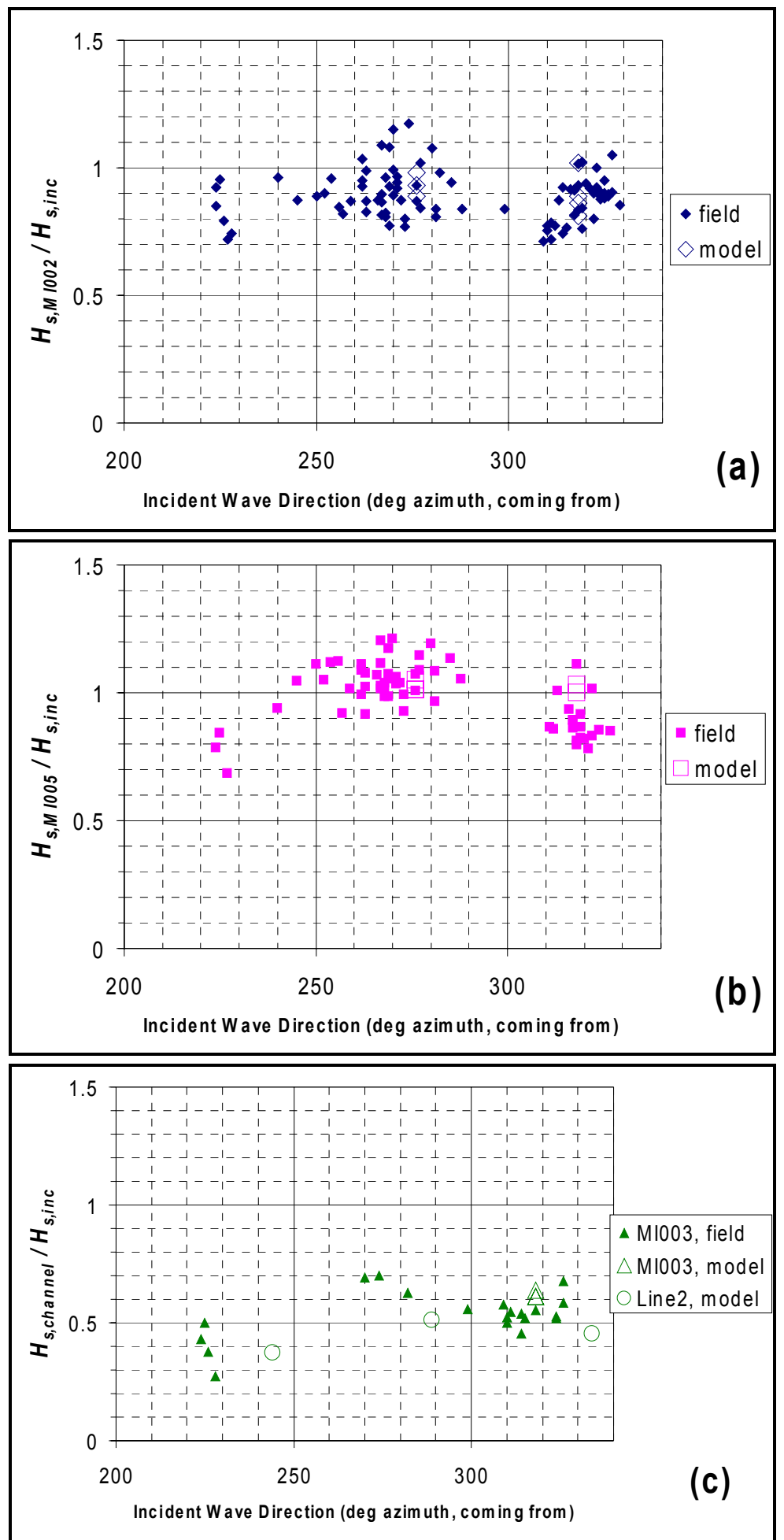

Figure 21. Physical model validation; ratio of $H_{s}$ in the channel to incident $H_{s}$ versus incident wave direction. Field data as in Figure 15.

(a) gauge MIOO2 location for field and model; (b) gauge MIOO5 location for field and model; (c) gauge MIOO3 location for field and model and model Line 2 average for $H_{s, i n c}=1 \mathrm{~m}, T_{p}=5$ and $6 \mathrm{sec}$, $\mathrm{sWl}=0 \mathrm{~m}$ LWD. 


\section{Experiments and Results}

\section{Experiments}

In the initial production testing, comprehensive studies were conducted for existing conditions (Plate 1, page 129) to establish base conditions by which to compare and evaluate the effectiveness of plan alternatives. Data ${ }^{1}$ were collected at one offshore gauge and 19 gauges at various locations in the channel, as described in Chapter 3. Gauge locations were fixed for all production testing. In addition, wave pattern photographs (pages 75 through 128) were obtained for representative wave conditions. Photographs were taken after all production tests were completed so that gauges could be removed and wave patterns were clearly visible.

All combinations of the test conditions described in Table 8, Chapter 4, were run, including two water levels, three $H_{s, i n c}$, four $T_{p}$, and three wave directions. A total of 72 runs were done for the existing condition.

After completion of the existing condition runs, the pocket configuration was modified and test runs repeated with a new plan. This process was repeated until the same 72 production runs were completed for eight additional plans (Table 10 and Plates 2-9, pages 130-137). The plans are:

1. Existing condition. Existing pocket absorber configuration at Pentwater, MI.

2. Plan 1. Both pocket absorbers covered with $0.95-\mathrm{mm}$ (0.0375-in.) thick galvanized steel sheet metal, to give a straight vertical-walled channel.

3. Plans 2 and 3. Same as existing condition, but with either the pocket on the north or south jetty open, and the other covered with sheet metal.

4. Plans 4, 5, and 6. Pockets twice as long as in the existing condition, extending toward the harbor from the existing pockets along the jetties; plans represent one, or the other, or both pockets open.

5. Plans 7 and 8. Combinations of double-length pocket on one side of the channel and existing length pocket on the other side.

${ }^{1}$ All measurements herein are referred to in prototype, unless otherwise noted. 
Table 10. Plan alternatives used for testing.

\begin{tabular}{|c|c|c|}
\hline Plan Alternatives & Description, Prototype Scale & $\begin{array}{l}\text { Total Absorber Length, } \\
\text { Prototype Scale }\end{array}$ \\
\hline Existing Condition (Plate 1) & 59.1-m (194-ft) absorber, both sides & $118.3 \mathrm{~m} \mathrm{(388 \textrm {ft } )}$ \\
\hline Plan 1 (Plate 2) & No absorbers & \\
\hline Plan 2 (Plate 3) & 59.1-m (194-ft) south absorber & $59.1 \mathrm{~m}(194 \mathrm{ft})$ \\
\hline Plan 3 (Plate 4) & 59.1-m (194-ft) north absorber & $59.1 \mathrm{~m} \mathrm{(194 \textrm {ft } )}$ \\
\hline Plan 4 (Plate 5) & 118.3-m (388-ft) south absorber & $118.3 \mathrm{~m} \mathrm{(388 \textrm {ft } )}$ \\
\hline Plan 5 (Plate 6) & 118.3-m (388-ft) north absorber & $118.3 \mathrm{~m} \mathrm{(388 \textrm {ft } )}$ \\
\hline Plan 6 (Plate 7) & $\begin{array}{l}\text { 118.3-m (388-ft) absorber; both } \\
\text { sides }\end{array}$ & $236.5 \mathrm{~m}(776 \mathrm{ft})$ \\
\hline Plan 7 (Plate 8) & $\begin{array}{l}\text { 59.1-m (194-ft) north absorber; } \\
\text { 118.3-m (388-ft) south absorber }\end{array}$ & $177.4 \mathrm{~m}(582 \mathrm{ft})$ \\
\hline Plan 8 (Plate 9) & $\begin{array}{l}\text { 118.3-m (388-ft) north absorber; } \\
\text { 59.1-m (194-ft) south absorber }\end{array}$ & $177.4 \mathrm{~m}(582 \mathrm{ft})$ \\
\hline
\end{tabular}

\section{Experimental results}

Significant wave height was computed from the spectral energy at each gauge for each test run, excluding low frequency energy as discussed in Chapter 4. Significant heights for all gauges and all test runs are presented in Appendix D. Oblique photographs of wave patterns for selected wave conditions are included in the report. These are the main results from the physical model tests.

The $H_{s}$ often varies greatly among gauges in a cross-channel transect, with variations on the order of 40-50 percent or more due to wave reflections and other interactions with jetty walls. The cross-channel wave variability is evident in many of the photographs. To get a representative value of $H_{s}$ for each transect location, the RMS of $H_{s}$ values for gauges in the transect was computed. Since $H_{s}{ }^{2}$ is proportional to wave energy, its average value across a transect represents average energy at that channel location, and its square root gives an average value of $H_{s}$, representative of energy across the channel. The cross-channel transects are assigned numbers from $o$ to 4 (Table 7 and Figure 19). The RMS $H_{s}$ values are denoted by the line number as a subscript and listed for all tests in Appendix E. As waves propagate along the channel past pocket absorbers, energy is dissipated and, for example, $H_{s, \text { Line } 2}$ is less than $H_{s, \text { Linee }}$.

The experimental results are discussed in the following sections. Each section addresses the sensitivity of results to one of the test parameters. Most results shown represent a water level of o $\mathrm{m}$ LWD, since effects of various 
experimental conditions are more clearly illustrated for that water level. The effect of water level is also discussed. These results are generally consistent with the more limited experimental results of Wright and Carpenter (1999) and Carpenter (2001) summarized in Chapter 1.

\section{Effect of $\boldsymbol{H}_{\mathrm{s} \text {,inc }}$}

The effect of incident significant wave height, $H_{s, i n c}$, at gauge 1 on pocket absorber performance is illustrated in Figure 22 for the existing condition and swl $=0$ LWD. All of the $T_{p}$ and wave direction cases are included. For all cases, the pocket has a significant impact in reducing wave height and energy. The ratio $H_{s, \text { Line } 2} / H_{s, \text { Line1 }}$ ranges from 0.42 to 0.66 . However, the range of ratio values is nearly the same for each of the three values of $H_{s, i n c}$, indicating that the amount of energy dissipation caused by the pocket absorber does not depend on this parameter.

\section{Effect of $T_{p}$}

The effect of incident peak spectral wave period, $T_{p}$, on pocket absorber performance is illustrated in Figure 23 for the existing condition and swl $=\mathrm{o}$ LWD. All of the $H_{s}$ and wave direction cases are included. The ratio $H_{s, \text { Line2 }} / H_{s, \text { Line1 }}$ for each of the three incident wave directions has a clear tendency to decrease as $T_{p}$ increases. Hence, the pocket wave absorbers become more effective for longer wave periods.

Wavelength is proportional to wave period in shallow water and the square of wave period in deep water. Waves in the physical model navigation channel were in intermediate depth, so wavelength in the experiments has a strong correlation with $T_{p}$. Thus, Figure 23 also shows that pocket wave absorbers become more effective for longer wavelengths over the range of test conditions.

\section{Effect of incident wave direction}

The effect of incident wave direction, $\theta_{i n c}$, on pocket absorber performance is illustrated in Figure 23 for the existing condition and swl = o LWD. All of the $H_{s}$ and $T_{p}$ cases are included. For each value of $T_{p}$, the ratio $H_{s, L i n e z} /$ $H_{s, \text { Line }}$ is higher when waves approach directly into the channel (o deg) than when they approach from 45 deg south or north. Hence, the pocket wave absorbers appear to become more effective for wave approach directions oblique to the channel alignment. For the oblique wave approaches, 


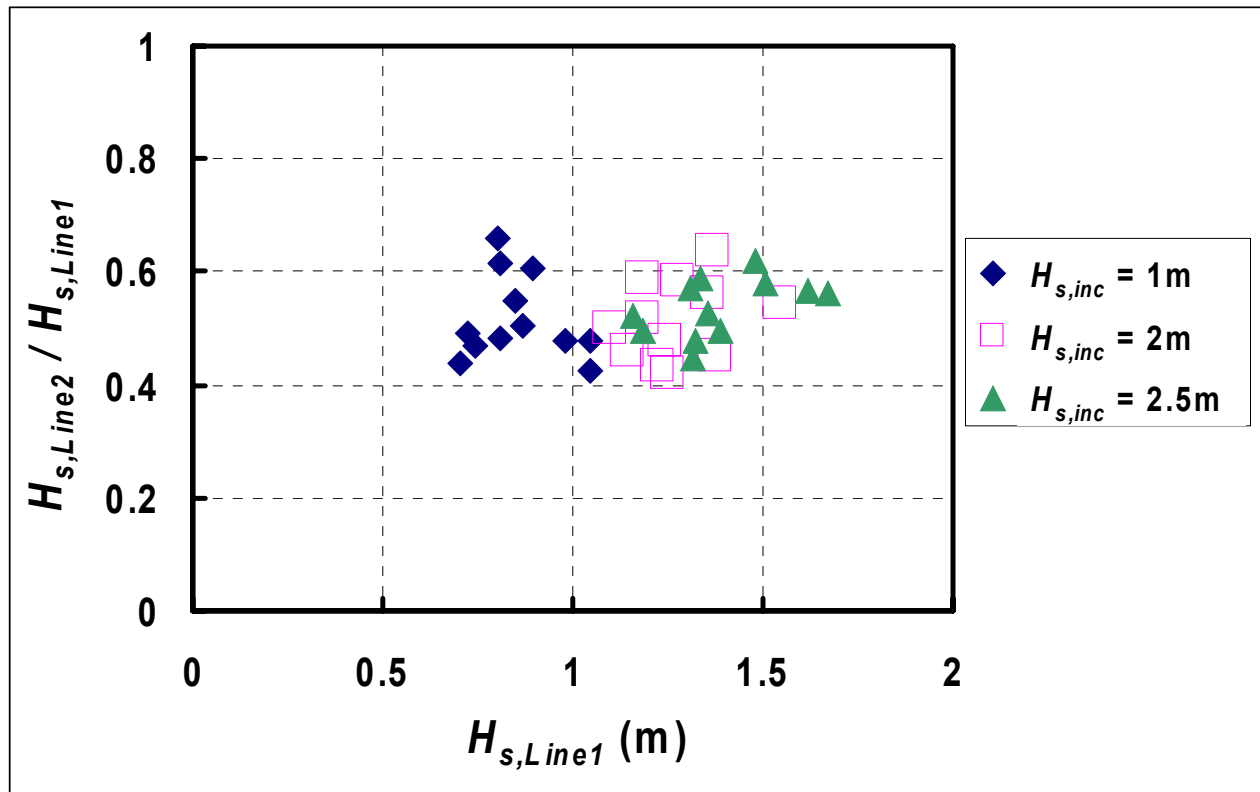

Figure 22. Effect of $H_{s, i n c}$ on pocket absorber performance, existing condition, sWl $=0$ LWD.

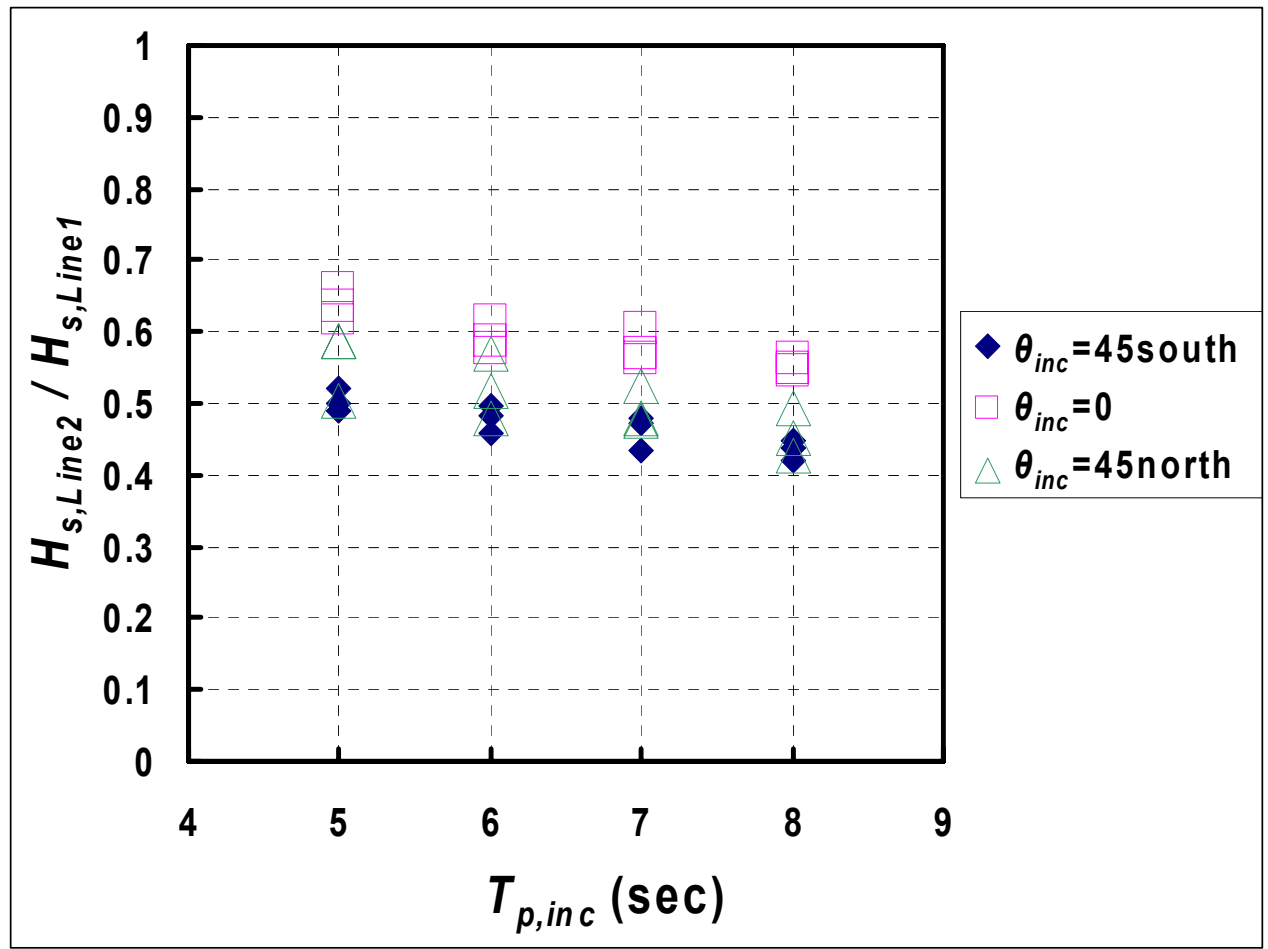

Figure 23. Effect of $T_{p}$ and wave direction on pocket absorber performance, existing condition, $\mathrm{swl}=0$ LWD.

model absorber effectiveness was about the same for both incident directions. The exception was cases with $H_{s}=2.5 \mathrm{~m}$ and one case with $H_{s}=2 \mathrm{~m}$ coming from 45 deg north, where the absorbers were not as effective as for the other oblique direction cases. 
The results for cases with $\theta_{i n c}=\mathrm{o}$ deg may be exaggeratedly high. The physical model experiments were conducted with unidirectional waves, whereas prototype waves are better characterized by a directional spread of energy around the dominant wave direction. Various prototype experiments have contributed to development of equations for quantifying directional spread (e.g., Headquarters, U.S. Army Corps of Engineers 2002). Waves undergoing active generation by wind have wide directional spread of energy, and ocean swell that has traveled far from the original generation area has narrow directional spread. Storm waves in Lake Michigan, actively growing due to local storm winds, would be characterized by a wide directional spread around the dominant wave direction. Thus, even the case of $\theta_{i n c}$ $=\mathrm{odeg}$ in the prototype would be expected to resemble the oblique wave physical model experiments more than the o-deg experiments.

\section{Effect of water level}

The effect of water level on pocket absorber performance is illustrated in Figure 24 for the existing condition. All of the $H_{s}, T_{p}$, and wave direction cases are included. The ratio $H_{s, \text { Line } 2} / H_{s, \text { Line }}$ for swl $=0.9 \mathrm{~m}(3.0 \mathrm{ft}) \mathrm{LWD}$

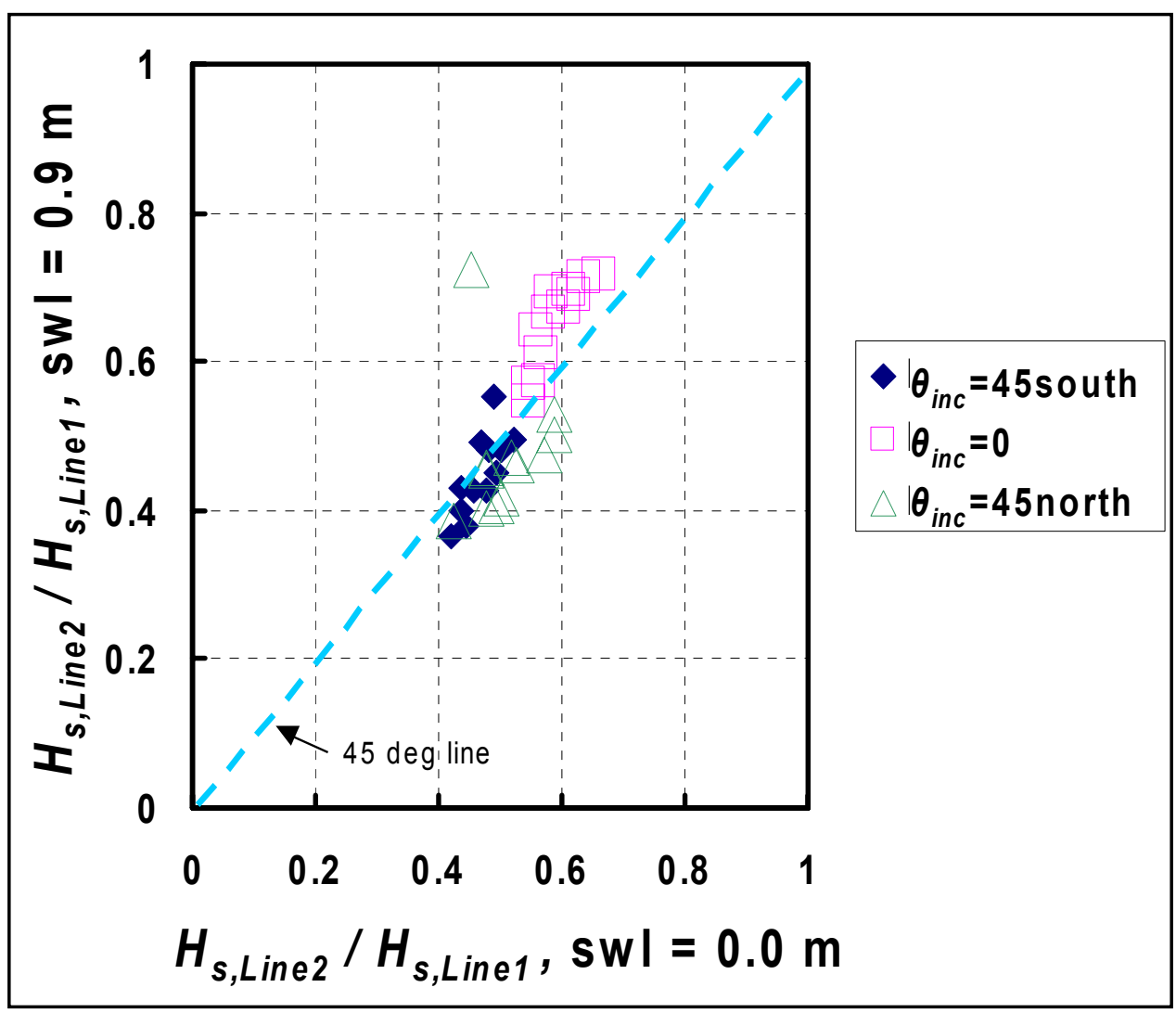

Figure 24. Effect of water level on pocket absorber performance, existing condition. 
is plotted against the same ratio for swl $=0 \mathrm{~m}$ LWD. The effect of water level is generally small, but several trends are evident. Most notably, for cases when the absorber is least effective (waves from o deg), the effectiveness is further decreased by high water level. The exceptions are the three cases with $T_{p}=8 \mathrm{sec}$ and waves from o deg, which had the lowest ratios (less than 0.6) and showed almost no impact from water level. As noted earlier, however, the o-deg physical model experiments may not fully represent prototype conditions because directional spread in the incident waves was not modeled.

For oblique approach directions, where the absorber is already relatively effective (ratios less than about 0.55), high water levels show a small tendency to further increase effectiveness. The oblique approach directions lead to significant cross-channel reflections (see photographs) and exposure of the pockets to wave energy with cross-channel components of travel. As $H_{s, \text { inc }}$ increases, $H_{s, \text { Line1 }}$ increases, and the values of $H_{s, \text { Line }}$ at the higher water level are higher than for the lower water level. The values of $H_{s, \text { Linee }}$ also increase as $H_{s, \text { inc }}$ increases. However, $H_{s, \text { Linee }}$ does not increase with water level for the obliquely incident wave cases, indicating that the increased wave energy entering the channel at high water level is removed by an increasingly effective absorber. At the higher water level, waves can encounter a greater expanse of absorber, which apparently results in a small increase in energy dissipation. Since $H_{s, L i n e 1}$ increases due to higher water level and $H_{s, \text { Linez }}$ is not much affected by water level, the net impact of water level on the ratio $H_{s, \text { Linez }} / H_{s, \text { Line }}$ is a small decrease for the higher water level.

\section{Effect of pocket absorber configuration}

The existing condition was used above to illustrate the effect of various parameters on pocket wave absorber performance. The effects illustrated are representative of the other pocket absorber configurations modeled. However, differences in performance are significant between the various configurations. The existing condition performance is compared with the cases where one or the other or both existing pocket absorbers are removed (Figure 25). Only the cases with $H_{s}=1 \mathrm{~m}(3.3 \mathrm{ft})$ and swl $=0 \mathrm{~m}$ LWD are shown. As would be expected, the double absorber (Existing) is more effective overall than the other cases, and the no-absorber case (Plan 1) is least effective. For both single-absorber cases, waves from one of the three wave directions are much more effectively absorbed than the 


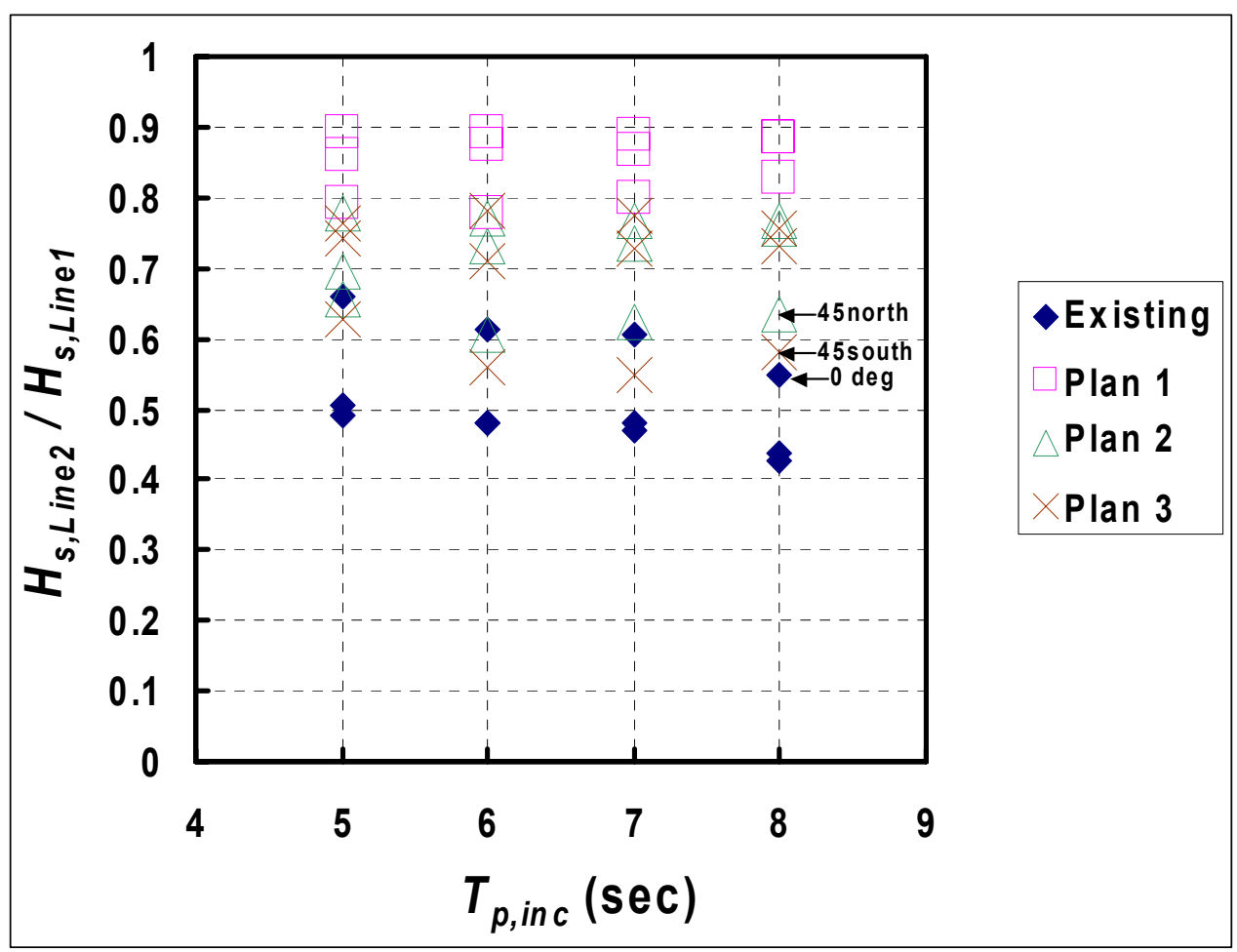

Figure 25. Effect of pocket configuration on absorber performance, Line 1 to Line 2, existing condition and Plans 1-3, $H_{\mathrm{s}, \text { inc }}=1 \mathrm{~m}$ (3.3 ft), swl $=0$ LWD.

others. That direction is from 45 deg north for the south absorber (Plan 2) and from 45 deg south for the north absorber (Plan 3). The effect of $T_{p}$ is less evident for the single-absorber and no-absorber cases than for the double-absorber case.

All of the absorber configurations which included a double-length pocket are compared in Figure 26 . The ratio $H_{s, \text { Linez }} / H_{s, \text { Line }}$ is used as before although the pockets extend beyond Line 2 in these configurations. As expected, those with single pocket absorbers (Plans 4 and 5) were generally least effective, and the double pockets (Plan 6) were most effective. The single double-length pocket configurations were not as effective as the existing condition for most wave directions. The double double-length pocket was significantly more effective than the existing condition. As with the single-length pockets, the configuration with only one pocket absorber on the south jetty (Plan 4) was exceptionally effective for waves coming from 45 deg north and the configuration with only one pocket absorber on the north jetty (Plan 5) was exceptionally effective for waves coming from 45 deg south. The configurations with combinations of single- and doublelength pockets were nearly as effective as the double double-length case 


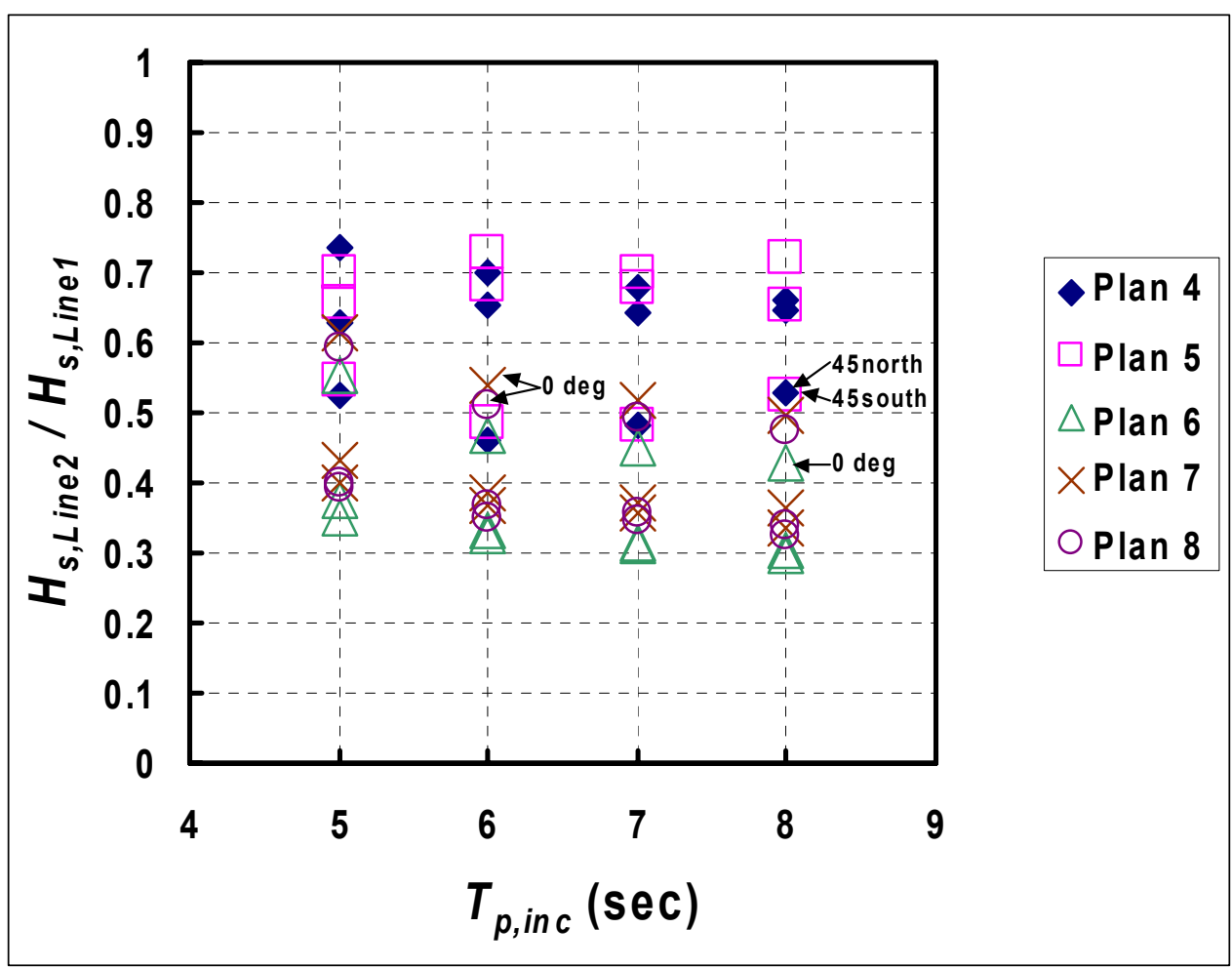

Figure 26. Effect of pocket configuration on absorber performance, Line 1 to Line 2, Plans 4-8, $H_{\mathrm{s}, \text { inc }}=1 \mathrm{~m}$ (3.3 ft), swl = 0 LWD.

for oblique directions but less effective for waves coming directly into the channel.

Since the pockets extend beyond Line 2 in Plans 4-8, an additional comparison was made between Lines 1 and 3 (Figure 27). Although a small amount of additional wave dissipation is evident at Line 3, the general conclusions are similar to those from the Line 1 and 2 comparisons. The case with no pocket absorbers (Plan 1) is also shown to illustrate the major impact of all configurations with double-length pockets.

The relationship between wave energy transmitted past the wave absorber (expressed as the ratio of cross-channel average wave energy at transects along and upstream from the pocket, to wave energy just lakeward of the pocket) and the traversed length of wave absorber is given in Table 11 and Figure 28. The values of transmitted energy fraction are averages over all incident wave and water level experiments for each configuration. Hence, they provide a composite representation of the effectiveness of each configuration over the range of test conditions. Transmitted significant wave height fraction can be calculated as the square root of transmitted energy. 


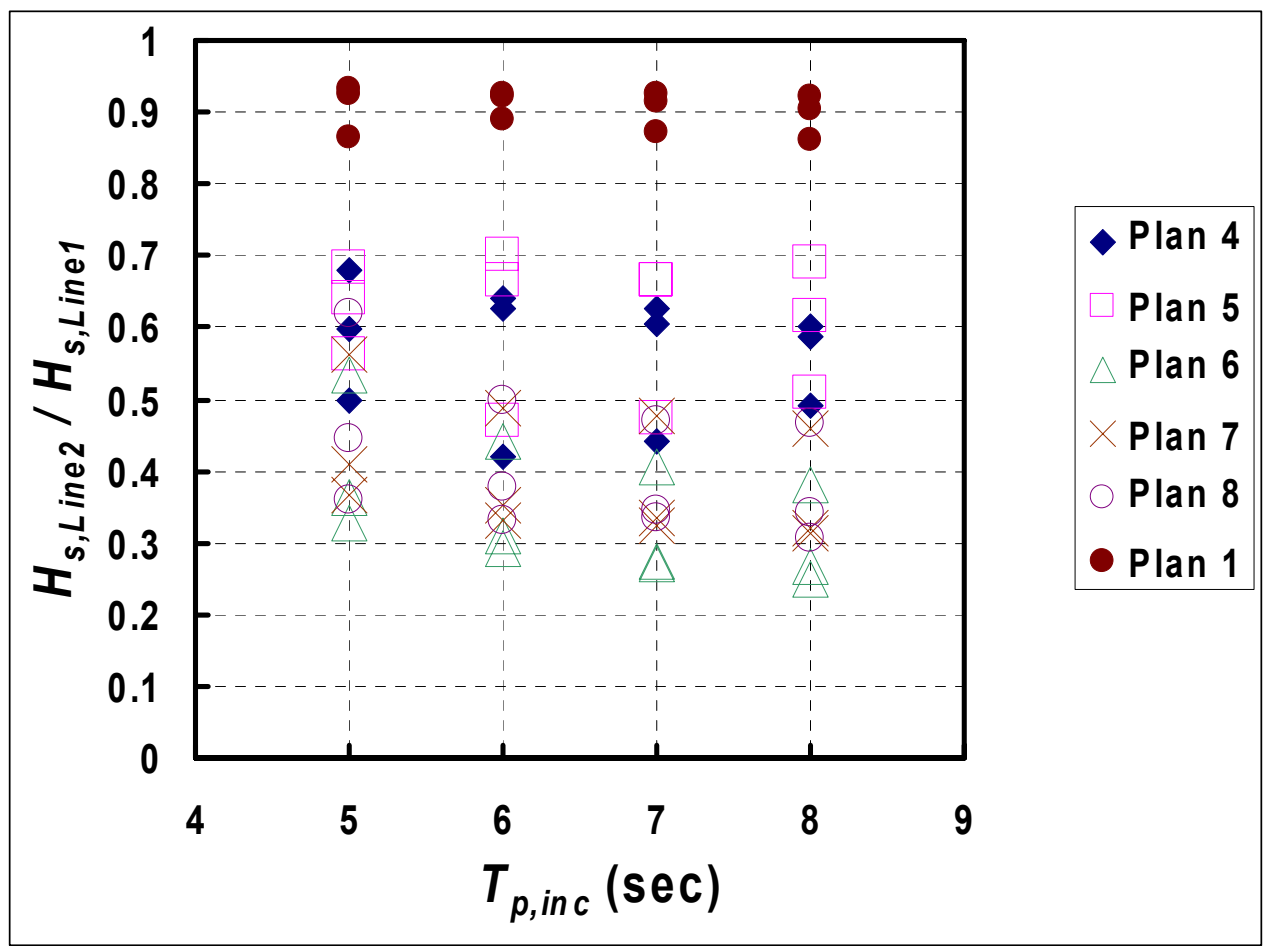

Figure 27. Effect of pocket configuration on absorber performance, Line 1 to Line 3 , Plan 1 and Plans 4-8, $H_{\mathrm{s}, \mathrm{inc}}=1 \mathrm{~m}$ (3.3 ft), swl = 0 LWD.

Table 11. Energy fraction transmitted versus traversed length of wave absorber, average of all physical model wave and water level tests for each configuration.

\begin{tabular}{|l|l|l|l|}
\hline Alternative & Lines & Traversed Length of Wave Absorber, $m$ & $\begin{array}{l}\text { Energy Transmitted } \\
\text { fraction }\end{array}$ \\
\hline Existing & 1 to 2 & 118.3 & 0.279 \\
\hline Plan 1 & 1 to 2 & $\begin{array}{l}\text { 95.7 (distance between lines; no } \\
\text { absorber) }\end{array}$ & 0.764 \\
\hline Plan 1 & 1 to 3 & $\begin{array}{l}\text { 154.97 (distance between lines; no } \\
\text { absorber) }\end{array}$ & 0.860 \\
\hline Plan 2 & 1 to 2 & 59.1 & 0.522 \\
\hline Plan 3 & 1 to 2 & 59.1 & 0.498 \\
\hline Plan 4 & 1 to 2 & 77.4 & 0.393 \\
\hline Plan 4 & 1 to 3 & 118.3 & 0.347 \\
\hline Plan 5 & 1 to 2 & 77.4 & 0.425 \\
\hline Plan 5 & 1 to 3 & 118.3 & 0.381 \\
\hline Plan 6 & 1 to 2 & 154.9 & 0.156 \\
\hline Plan 6 & 1 to 3 & 236.6 & 0.131 \\
\hline Plan 7 & 1 to 2 & 136.6 & 0.201 \\
\hline Plan 7 & 1 to 3 & 177.4 & 0.175 \\
\hline Plan 8 & 1 to 2 & 136.6 & 0.199 \\
\hline Plan 8 & 1 to 3 & 177.4 & \\
\hline
\end{tabular}




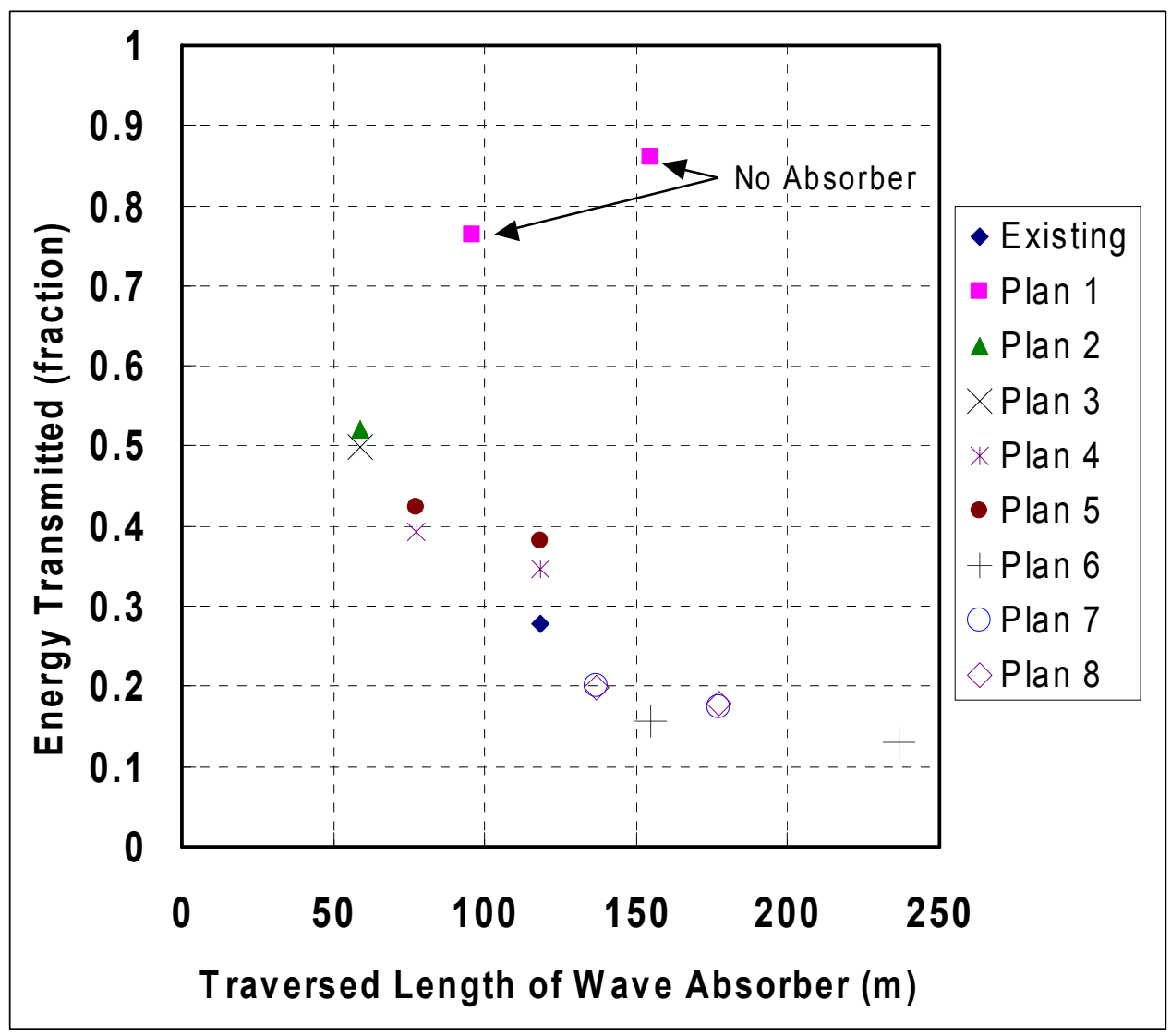

Figure 28. Energy transmitted vs. traversed length of wave absorber, average of all physical model wave and water level tests for each configuration.

The traversed length of wave absorber is the total length of constructed absorber that the wave has passed to reach a given cross-channel transect location. Thus the traversed length for a symmetric double pocket configuration is twice the traversed length for a single pocket configuration. For Plan 1, the configuration with no pockets, traversed length is the distance between transects. The Plan 1 results help to show the relative reduction in wave energy achieved by constructing wave absorbers.

The relationship between pocket length and transmitted energy is approximately linear up to a 150-m (492-ft) length. This length covers the range of lengths used in existing Great Lakes pocket wave absorbers. For lengths greater than $150 \mathrm{~m}$ ( $492 \mathrm{ft}$ ), the reduction in transmitted wave energy per unit length of constructed absorber is less favorable. Wave absorbers on both sides of the channel reduce transmitted wave energy by approximately $5^{-10}$ percent more than a single pocket of the same total constructed length. 


\section{Numerical Model}

Prototype and physical model data were used to validate the numerical model, CGWAVE, for development of a pocket wave absorber "performance index," which is relevant to the objectives of the MCNP study. The performance of Boussinesq (BOUSS-2D) model will also be evaluated using the available prototype and physical model data.

The numerical model study had three main objectives:

1. Calibrate and validate the numerical model with physical model and field data.

2. Use the numerical model to evaluate the effect of the various pocket wave absorber configurations on waves landward of the pocket.

3. Develop recommendations about application of the numerical model on future projects, including recommended parameter values and expected accuracy of model results.

The numerical model used for the studies, CGWAVE, is the standard CHL tool for numerical harbor wave investigations. The model includes the following assumptions:

1. No wave transmission through jetty structures.

2. No wave overtopping of structures.

3. Structure crest elevations above the water surface cannot be tested or optimized.

4. Currents in the channel cannot be evaluated.

5. Diffraction around structure ends is represented by diffraction around a blunt vertical wall with specified reflection coefficient.

Despite limitations imposed by the aforementioned assumptions, CGWAVE is considered suitable for meeting the numerical modeling objectives of the MCNP pocket wave absorbers study.

The harbor wave response model is described in the following section, including a general description of the CGWAVE model and implementation of the model at Pentwater. The next two sections cover model calibration and validation. Validation was accomplished in two steps. First, 
the model was validated relative to physical model data collected in the present study. Second, the model was calibrated and validated with a combination of storm wave events selected from recent field data. The final section of this chapter describes the test procedures and calculations.

As part of the test procedures, a suite of incident wave conditions must be specified at the seaward boundary of the area covered by CGWAVE. Incident waves are determined by consideration of the wave climate.

The existing Pentwater entrance and eight pocket modifications were studied, as with the physical model experiments. Results are presented with a focus on wave conditions in the vicinity of the pockets, but results over the full entrance area are also available.

\section{Model description}

\section{Model formulation}

The numerical wave model CGWAVE is a steady state finite element model used in the calculation of wave response in harbors of varying size and depth. It may also be applied along open coastal regions, at coastal inlets, around islands, and around fixed or floating structures. CGWAVE simulates the combined effects of wave refraction and diffraction included in the basic mild-slope equation. It can also include effects of wave dissipation by friction, breaking, nonlinear amplitude dispersion, and harbor entrance losses. The basic model deals with regular waves, but irregular (spectral) wave conditions can be simulated by combining regular wave results.

Several fundamental theoretical and computational advances are included in the model. The open boundary condition (seaward boundary of the model domain) is treated with a new parabolic approximation method along with the classical super-element technique. An efficient iterative procedure (conjugate gradient method) is used to solve the discretized model equations, enabling the model to be used practically for larger domains.

The CGWAVE model is interfaced with commercially available Corps of Engineers-supported software to assist in preparing model grids and other inputs and in displaying model results. This software-assisted pre- and post-processing is needed in any practical application. 
More information on CGWAVE is available from Demirbilek and Panchang (1998) and from the model Internet Web site (http://chl.wes.army.mil/ research/wave/wavesprg/numeric/wentrances/cgwave.htp). The software package for preand post-processing is part of the Surface-Water Modeling System (SMS). The SMS software is also described through the model Web site.

\section{Finite element grids}

Bathymetric data for the Pentwater entrance, navigation channel, and surrounding area were from the same sources as for the physical model. A 2002 Detroit District hydrographic survey was used for the navigation channel and a bathymetric chart was used for depth contours outside of the harbor.

The numerical model seaward boundary is a semicircle (Figure 29). This boundary is normally extended far enough seaward to encompass complex nearshore bathymetry, including reefs, shoals, and channels. However, the number of grid elements and model run time increases as grid coverage

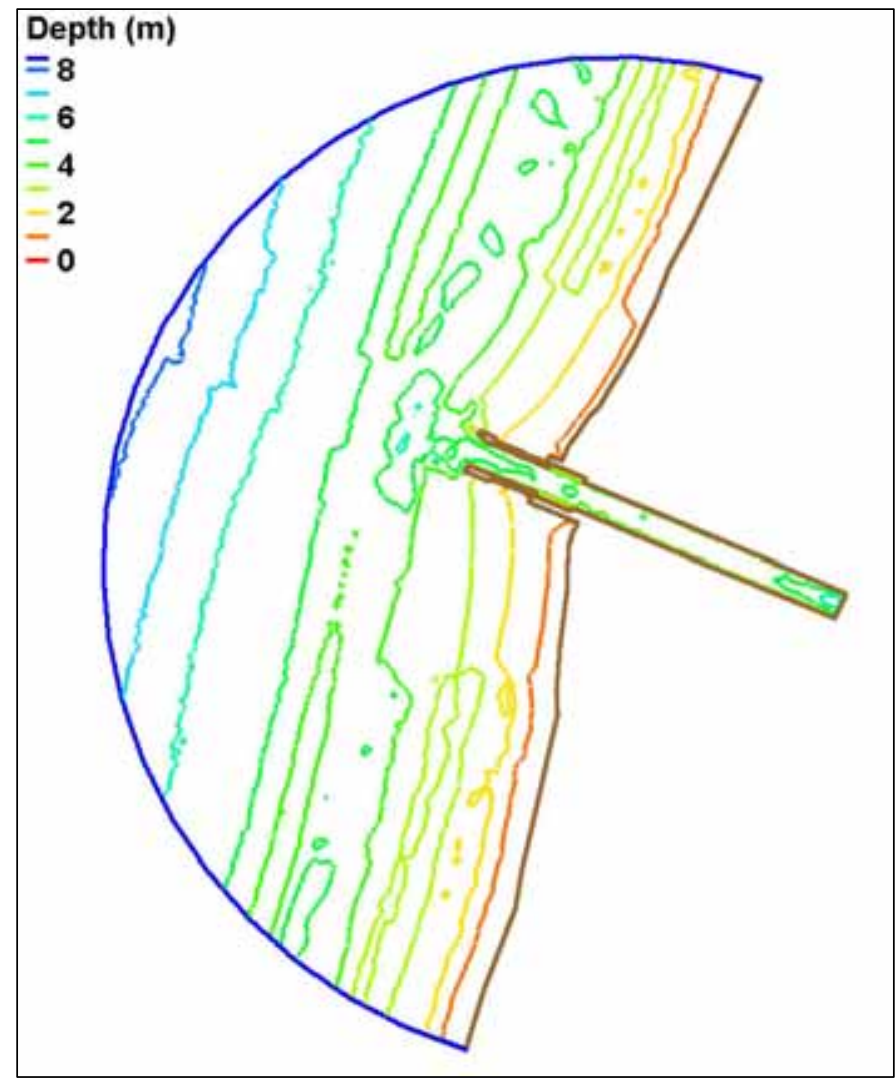

Figure 29. Numerical model bathymetry, existing harbor 
area increases. The final grid is usually a balance between covering key parts of the study area, while maintaining a workable grid size. For this

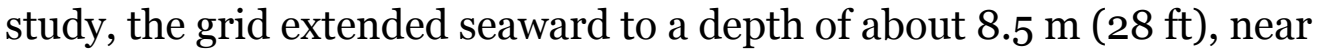
the location of the prototype directional wave gauge.

A finite element grid of the existing harbor entrance was constructed over the model domain. Grid element size is based on the needed model resolution for the shortest period waves in the shallowest water depth of concern in the study. For the longer period waves, the grid gives a higher degree of resolution. In this study, grid elements were sized to give 10 elements per wavelength for a 5 -sec wave period. The grid in the vicinity of physical model gauge locations in the navigation channel was further refined to give 40 elements per wavelength. Grid characteristics are summarized in Table 12. Bathymetric data discussed previously were transferred onto the finite element grid. The SMS software, Version 8.1, was used for all bathymetry and grid development.

Reflection coefficients, $K_{r}$, are needed for all solid boundaries. The $K_{r}$ values were estimated based on numerical model calibration tests with physical model data discussed in the following section. Reflection coefficients range from 0.001 for beaches north and south of the harbor to 0.7 for pockets areas and 0.98 for steel sheet pile. These values were determined as part of the model calibration discussed in the following section. Bottom friction was set to zero. Additional parameter values used in the numerical model are summarized in Table 13.

In addition to the existing condition, eight variations of pocket configuration were evaluated, as with the physical model. The numerical model configurations are nearly identical to those in the physical model, but pockets are slightly longer to give rounded lengths in English units of $61 \mathrm{~m}$ and $122 \mathrm{~m}$ (200 ft and $400 \mathrm{ft}$ ). The numerical model configurations have the same names as those in the physical model, but " $\mathrm{A}$ " is added in the name to denote that the pocket lengths are not exactly the same. The existing harbor grid boundaries and bathymetry were modified to match the alternative plans (Appendix F). Grid characteristics for each configuration are included in Table 12. Wave reflection coefficients were modified as appropriate for the various cases. 
Table 12. CGWAVE grid sizes.

\begin{tabular}{|c|c|c|c|c|}
\hline Configuration & Elements & Nodes & $\begin{array}{l}\text { Semicircle Boundary } \\
\text { Nodes }\end{array}$ & $\begin{array}{l}\text { Length of Typical } \\
\text { Element } \mathrm{m}(\mathrm{ft})\end{array}$ \\
\hline Existing $\mathrm{A}$ & 541,564 & 273,836 & \multirow[t]{9}{*}{909} & \multirow{9}{*}{$\begin{array}{l}1 \text { (3) (pocket area) } \\
2 \text { (6) (channel areas } \\
\text { before \& after pocket) }\end{array}$} \\
\hline Plan 1 & 532,962 & 269,372 & & \\
\hline Plan 2A & 537,963 & 271,955 & & \\
\hline Plan 3A & 538,925 & 272,459 & & \\
\hline Plan 4A & 550,997 & 278,558 & & \\
\hline Plan 5A & 409,164 & 206,964 & & \\
\hline Plan 6A & 560,259 & 283,344 & & \\
\hline Plan 7A & 554,016 & 280,155 & & \\
\hline Plan 8A & 553,865 & 280,081 & & \\
\hline
\end{tabular}

Table 13. Parameter values used in CGWAVE.

\begin{tabular}{|l|l|}
\hline & Value \\
\hline Number of terms in series & 35 \\
\hline Maximum number of iterations for convergence & 500,000 \\
\hline Maximum number of iterations for nonlinear mechanisms & 10 \\
\hline Bottom friction & off \\
\hline Wave breaking & off \\
\hline Nonlinear dispersion & off \\
\hline Exterior reflection (shore boundaries outside grid domain) & 0.0 \\
\hline Tolerance for equations & $10^{-9}$ \\
\hline Tolerance for nonlinear mechanisms & $10^{-4}$ \\
\hline $\begin{array}{l}\text { Semicircle orthogonal orientation, deg counterclockwise from +x axis } \\
(0=\text { east, 90 = north, 180 = west) }\end{array}$ & 163.2 \\
\hline
\end{tabular}

\section{Model calibration to physical model data}

A CGWAVE grid was developed to match the physical model layout of the prototype Pentwater Harbor entrance. The primary calibration objective was to determine appropriate reflection coefficients for the jetty and pocket absorber boundaries. Numerous comparisons were run between CGWAVE and the physical model to evaluate effects of incident wave parameters, boundary reflection coefficients, and wave breaking parameter. 
Two incident wave height/period combinations, one wave direction (from $293 \mathrm{deg}$ ), one water level (+0.9 $\mathrm{m}$ or $+3.0 \mathrm{ft}$ LWD), and one entrance configuration were used for calibration. The two wave conditions were $H$ $=1 \mathrm{~m}, T=5 \mathrm{sec}$, and $H=2 \mathrm{~m}, T=7 \mathrm{sec}$. The incident wave approach direction was nearly parallel to the entrance channel centerline, oriented at $289 \mathrm{deg}$, and the calibration runs were considered comparable to the o-deg physical model experiments. All calibration runs were done with regular (monochromatic) waves.

Initial $K_{r}$ values were calculated using formulas from laboratory investigations (Seelig and Ahrens 1981; Seelig 1983; Allsop and Hettiarachchi 1988) and were as follows: 0.95 for vertical sheet piling, 0.4 for the pocket wave absorber stone and 0.001 for the 1:10o beach to the north and south of the harbor. Boundary $K_{r}$ values along the sheet piling and pocket absorber were then varied and results evaluated relative to the physical model data. The beach $K_{r}$ remained the same throughout the entire calibration.

Although 20 gauges were placed in both the physical and numerical models, only gauges $1-17$ were used to calibrate the numerical model. This focused calibration on the channel area in the vicinity of the entrance and pocket locations.

Numerical models such as CGWAVE typically exaggerate periodic spatial variations in waves when applied with regular waves over prototype bathymetry. To help smooth the spatial variability, each gauge in the numerical model was represented as an $8-\mathrm{m}$ (26-ft) diameter circle centered on the actual physical model gauge location (Figure 30). Thus, each gauge in the numerical model encompassed about 110-150 grid nodes, instead of just one. Maximum, minimum, and average wave height were determined at each gauge location for each calibration run.

Average wave height at each gauge, $\bar{H}_{C G W A V E}$, was the basis for refining reflection coefficient values. Maximum and minimum wave height values were too variable to be useful for calibration. Table 14 shows the RMS and mean error (ME) percentages of gauges 1-17 for the various reflection coefficient, $K_{r}$, combinations. RMS error indicates the average absolute value of error between $\bar{H}_{C G W A V E}$ and the physical model wave height, $H_{s, p h y s}$. ME preserves signs of model errors and indicates model bias. 


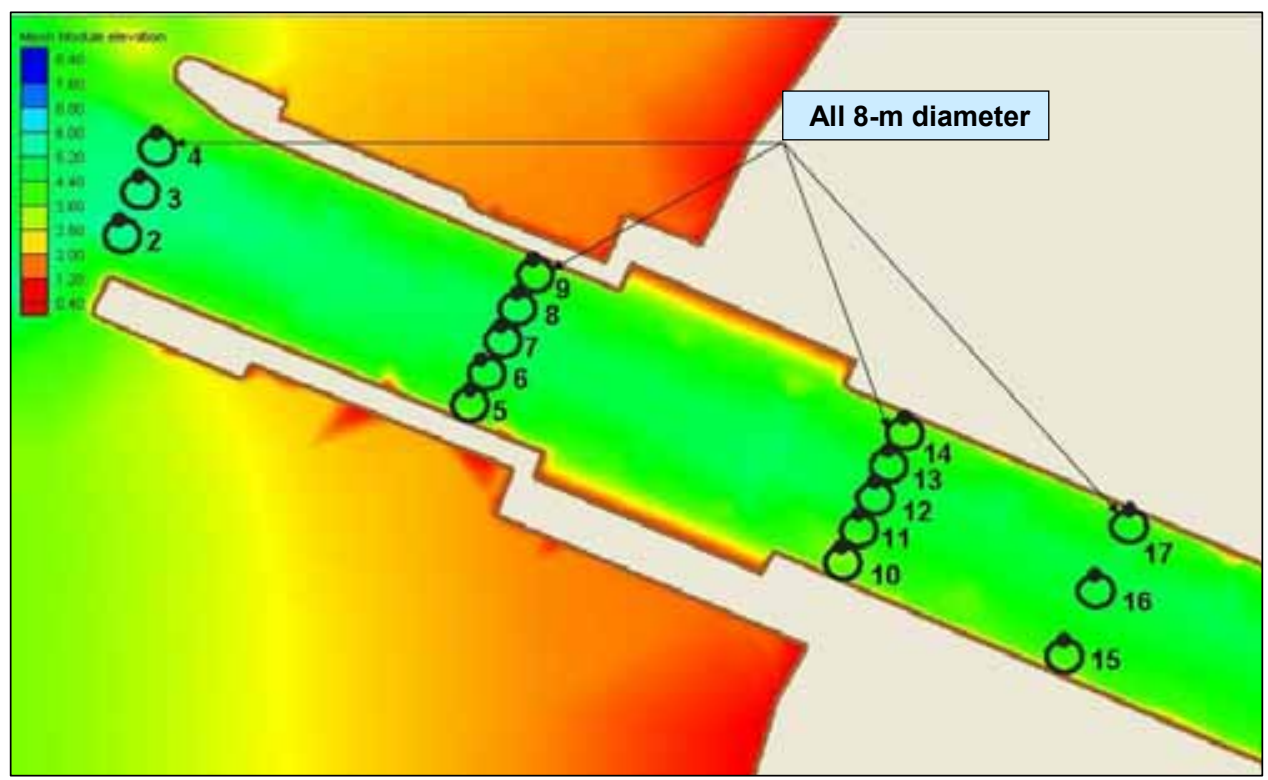

Figure 30. Numerical model gauge locations for calibration.

Table 14. Numerical versus physical model wave height RMS and ME for various reflection coefficient combinations, gauges 1-7, 293-deg incident wave direction, swl = +0.9-m LWD.

\begin{tabular}{|c|c|c|c|c|c|c|c|}
\hline \multicolumn{2}{|c|}{ Reflection Coeff., $K_{r}$} & \multicolumn{2}{|c|}{$H_{\text {inc }}=1 \mathrm{~m}, T=5 \mathrm{sec}$} & \multicolumn{2}{|c|}{$H_{\text {inc }}=2 \mathrm{~m}, T=7 \mathrm{sec}$} & \multicolumn{2}{|c|}{$\begin{array}{l}\text { Summed Values for } \\
\text { Coefficient Selection }\end{array}$} \\
\hline $\begin{array}{l}\text { Steel Sheet } \\
\text { Pile }\end{array}$ & $\begin{array}{l}\text { Wave } \\
\text { Absorber }\end{array}$ & $\begin{array}{l}\text { RMS } \\
\%\end{array}$ & $\begin{array}{l}\text { ME } \\
\%\end{array}$ & \begin{tabular}{|l|} 
RMS \\
$\%$
\end{tabular} & $\begin{array}{l}\text { ME } \\
\%\end{array}$ & $\begin{array}{l}\text { RMS } \\
\%\end{array}$ & $\begin{array}{l}\mathrm{ME} \\
\%\end{array}$ \\
\hline 0.95 & 0.4 & 21.3 & 18.0 & 30.7 & 24.6 & 52.0 & 42.5 \\
\hline 0.97 & 0.5 & 19.0 & 14.6 & 30.3 & 24.6 & 49.3 & 39.2 \\
\hline 0.97 & 0.6 & 19.2 & 14.1 & 29.5 & 24.0 & 48.7 & 38.1 \\
\hline 0.97 & 0.7 & 19.7 & 14.1 & 28.5 & 23.0 & 48.2 & 37.1 \\
\hline 0.98 & 0.5 & 18.1 & 13.7 & 30.7 & 24.8 & 48.7 & 38.5 \\
\hline 0.98 & 0.6 & 18.4 & 13.4 & 29.8 & 24.1 & 48.3 & 37.5 \\
\hline 0.98 & 0.7 & 19.1 & 13.6 & 28.9 & 23.1 & 48.0 & 36.6 \\
\hline 1.00 & 0.8 & 19.3 & 14.6 & 29.6 & 23.6 & 48.8 & 38.1 \\
\hline 0.98 & 0.65 & 18.7 & 13.3 & 29.4 & 23.6 & 48.1 & 36.9 \\
\hline
\end{tabular}

Results are given for two representative incident wave conditions. Overall, the error measures show only small variation over the limited choices of $K_{r}$ value. The error magnitudes increase as incident wave height increases. To get an overall measure of the numerical model performance for the two incident wave conditions, the sum of individual RMS and ME values was calculated and included in the table. The minimum total of each is a basis for choosing the best $K_{r}$ combination. For both RMS and ME, the 0.98, $0.7 K_{r}$ combination was the best choice. These values were used for all subsequent model runs. 
Differences between numerical and physical model wave heights were documented for cases with $K_{r}$ set to the final values determined in the above calibration (Table 15). A reasonable standard for percent difference between physical and numerical model values is about 20 percent or less, since gauge measurements in open water typically agree to within about 10 percent. Most of the cases in the table meet or approach this standard. For the cases with differences significantly greater than 20 percent, the numerical model estimates appear to be somewhat erratic relative to the physical model data. This behavior can be attributed to the regular waves, rather than spectral waves, used in the numerical model.

Table 15. Numerical versus physical model percent differences for final calibration, 293-deg incident wave direction, $\mathrm{swl}=+0.9-\mathrm{m}$ LWD.

\begin{tabular}{|l|l|l|l|l|l|l|}
\hline \multirow{2}{*}{ Gauge } & \multicolumn{3}{|c|}{$H_{\text {inc }}=1 \mathrm{~m}, T=5 \mathrm{sec}$} & \multicolumn{3}{c|}{$H_{\text {inc }}=2 \mathrm{~m}, T=7 \mathrm{sec}$} \\
\cline { 2 - 7 } & $\begin{array}{l}\bar{H}_{\text {CGWAVE }} \\
\mathrm{m}\end{array}$ & $\begin{array}{l}H_{\text {s,phys }} \\
\mathrm{m}\end{array}$ & $\begin{array}{l}\text { Difference } \\
\%\end{array}$ & $\begin{array}{l}\bar{H}_{\text {CGWAVE }} \\
\mathrm{m}\end{array}$ & $\begin{array}{l}H_{\mathrm{s}, \text { phys }} \\
\mathrm{m}\end{array}$ & $\begin{array}{l}\text { Difference } \\
\%\end{array}$ \\
\hline 1 & 0.991 & 0.99 & 0.1 & 2.046 & 1.88 & 8.8 \\
\hline 2 & 0.683 & 0.70 & -2.4 & 1.673 & 1.38 & 21.2 \\
\hline 3 & 1.109 & 0.87 & 27.5 & 1.558 & 1.41 & 10.5 \\
\hline 4 & 0.919 & 0.93 & -1.2 & 1.362 & 1.53 & -11.0 \\
\hline 5 & 0.403 & 0.69 & -41.6 & 1.248 & 1.28 & -2.5 \\
\hline 6 & 0.763 & 0.76 & 0.4 & 1.037 & 1.23 & -15.7 \\
\hline 7 & 0.85 & 0.88 & -3.4 & 0.978 & 1.37 & -28.6 \\
\hline 8 & 0.676 & 0.80 & -15.5 & 1.225 & 1.48 & -17.2 \\
\hline 9 & 0.628 & 0.76 & -17.4 & 1.792 & 1.66 & 8.0 \\
\hline 10 & 0.459 & 0.59 & -22.2 & 1.03 & 1.10 & -6.4 \\
\hline 11 & 0.507 & 0.47 & 7.9 & 0.197 & 0.46 & -57.2 \\
\hline 12 & 0.616 & 0.55 & 12.0 & 0.469 & 0.49 & -4.3 \\
\hline 13 & 0.46 & 0.55 & -16.4 & 0.221 & 0.51 & -56.7 \\
\hline 14 & 0.516 & 0.62 & -16.8 & 0.993 & 0.68 & 46.0 \\
\hline 15 & 0.53 & 0.53 & 0.0 & 0.823 & 0.60 & 37.2 \\
\hline 16 & 0.311 & 0.55 & -43.5 & 0.391 & 0.51 & -23.3 \\
\hline 17 & 0.687 & 0.67 & 2.5 & 0.839 & 0.61 & 37.5 \\
\hline & & & & & & \\
\hline
\end{tabular}


Test procedures and calculations

Incident wave conditions

A representative range of incident wave heights, periods, and directions which may cause damaging waves inside Pentwater harbor entrance was considered based on incident wave climate at the CGWAVE seaward boundary (Table 16). These are the same wave conditions considered in the physical model experiments, except the wave directions are shifted 4 deg toward north. The small difference in offshore incident directions was not intended, but it is expected to have little impact on the numerical model versus physical model comparisons.

These conditions provide reasonable coverage of the incident wave climate. The shortest wave period is representative of mildly energetic local waves. The longest period represents an intense local storm. Directions were chosen to give a coarse representation of the full directional exposure of the harbor entrance.

For the study of existing entrance conditions and variations, CGWAVE was run with the full set of incident wave conditions applied to the existing entrance and all pocket variations included in the physical model experiments. CGWAVE model results could then be used directly as regular wave cases. An alternative analysis approach to represent the same incident wave conditions as directional spectra is discussed in the following subsection. Because of the demanding computational requirements, production runs were done at the ERDC High Performance Computing Center.

One water level was tested. The same level used in the high water scenario for the physical model was used for the numerical model: $176.9 \mathrm{~m}$ (580 ft), IGLD 1985 (0.9 m, $3 \mathrm{ft}$, above LWD). This was thought to be a reasonable value considering water levels on Lake Michigan have historically ranged from 175.5 to $177.5 \mathrm{~m}$ (575.8 to $582.4 \mathrm{ft})$. 


\section{Calculation of spectra}

Numerical model test results can also be based on spectral post-processing of monochromatic CGWAVE runs. With this approach, wave amplification factors are calculated in the form of $\left(A_{a m p}\right)_{\text {eff }}$ as described by Thompson et al. (1996). This approach requires, first, that CGWAVE be run with the range of wave heights, periods, and directions to be considered in the spectral calculations. In this study, wave conditions run in CGWAVE for the spectral approach were the same three $H$-T combinations but a much more refined range of directions. Wave directions ranged in 10-deg increments from 243 to 343 degrees azimuth (coming from) for a total of 11 directions. Second, for each value of peak wave period, $T_{p}$, and wave approach direction, $\theta_{p}$, a spectral peak enhancement factor, $\gamma$, and directional spreading factor, $s$, must be specified. The $T_{p}$ and $\theta_{p}$ values were taken directly from the physical model test conditions. Values for $\gamma$ and $s$ were approximated by the same procedure developed in the previous study cited. Then the monochromatic wave runs can be properly weighted and recombined to represent directional spectra. This procedure has become a standard approach in CHL spectral wave model studies. Thus, spectral wave conditions can be reconstructed at any point in the model domain.

Wave gauge locations were defined as 8-m (26-ft) squares centered on the physical model gauge locations (Figure 31). Squares were used rather than the circular areas used during calibration because of post-processing code input requirements. As during calibration, wave height at the gauge locations represents an average over all nodes within each local gauge area.

The spectral analysis approach was applied for the same incident wave conditions and configurations as used in the physical model. Average significant wave heights, $\bar{H}_{s, C G W A V E}$, were extracted at the gauge locations for each case. For the 293-deg direction only, these and the monochromatic wave results were compared with physical model data for all plans to ensure that the spectral approach was leading to improved numerical model accuracy. The magnitude of percent difference between the spectral numerical model $\bar{H}_{s, C G W A V E}$ and physical model $H_{s, p h y s}$ ranged from 13.9 percent to 31.6 percent for the cases where $H_{\text {inc }}=1 \mathrm{~m}$ and $2 \mathrm{~m}$ (Table 17). Differences for the highest wave height, $H_{\text {inc }}=2.5 \mathrm{~m}$, tend to be higher and are considered less representative due to occasional wave 


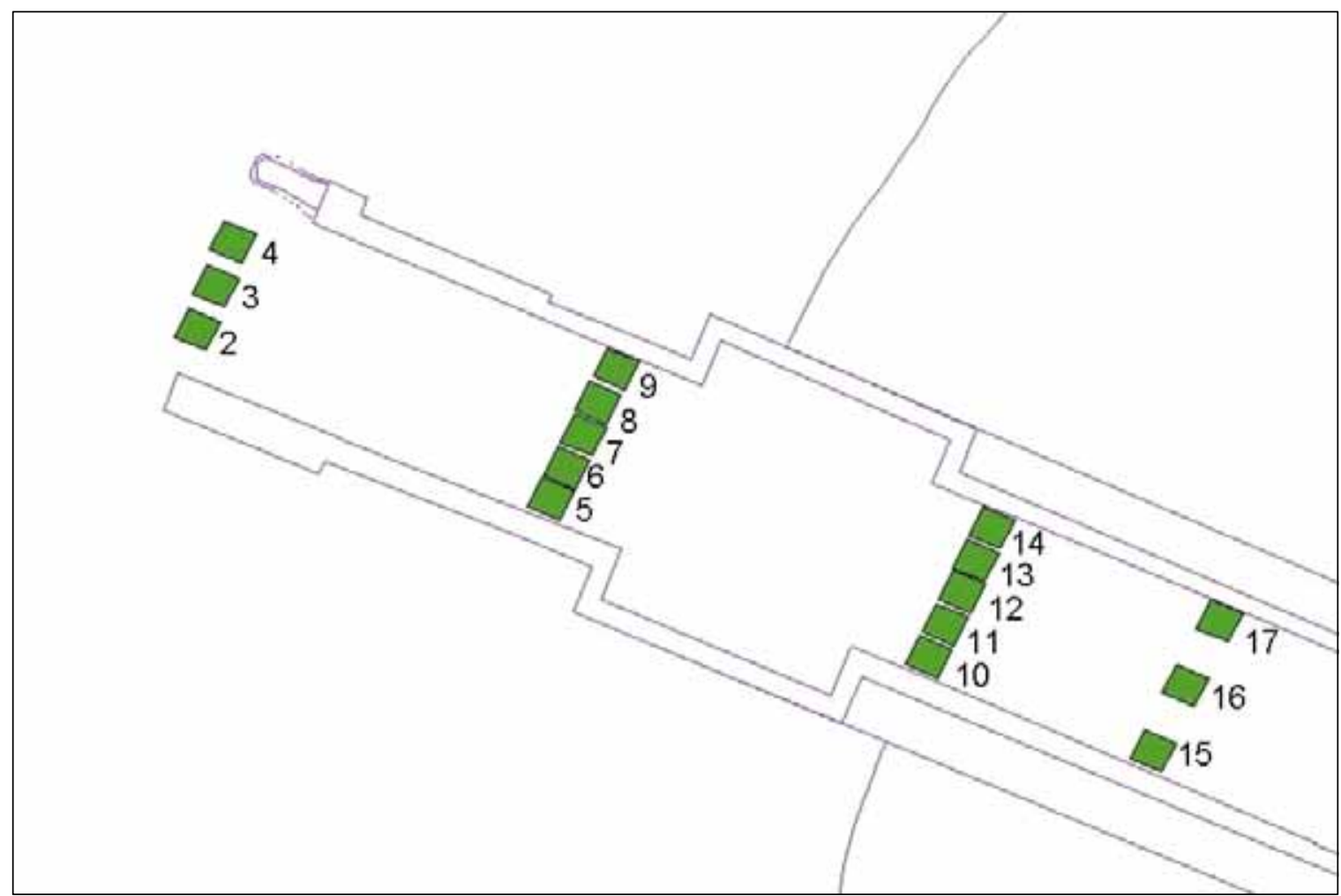

Figure 31. Numerical model gauge locations for production runs (shown as green squares).

Table 17. Spectral numerical model magnitude of percent differences, $H_{s, \text { cGWAVE }}$ versus $H_{\text {s.phys }}$ for 293-deg incident wave direction, swl = +0.9 m LWD.

\begin{tabular}{|l|l|l|l|l|l|l|l|l|l|}
\hline & \multicolumn{8}{|c|}{ Percent Difference, Spectral Numerical Model } \\
\cline { 2 - 11 } & \multicolumn{2}{|c}{$H_{\text {inc }}=1 \mathrm{~m}, T_{\text {inc }}=5 \mathrm{sec}$} & \multicolumn{2}{c|}{$H_{\text {inc }}=2 \mathrm{~m}, T_{\text {inc }}=7 \mathrm{sec}$} & \multicolumn{2}{c|}{$H_{\text {inc }}=2.5 \mathrm{~m}, T_{\text {inc }}=8 \mathrm{sec}$} \\
\cline { 2 - 12 } Configuration & $\min$ & $\max$ & avg & $\min$ & $\max$ & avg & $\min$ & $\max$ & avg \\
\hline Existing A & 1.9 & 56.9 & 31.0 & 4.5 & 58.8 & 31.6 & 2.1 & 66.9 & 40.3 \\
\hline Plan 1 & 0.8 & 32.2 & 15.4 & 1.8 & 35.4 & 18.6 & 1.5 & 45.7 & 26.0 \\
\hline Plan 2A & 1.7 & 60.7 & 25.3 & 0.7 & 47.2 & 24.9 & 0.5 & 51.2 & 29.5 \\
\hline Plan 3A & 2.6 & 54.2 & 22.3 & 4.8 & 51.3 & 25.4 & 0.7 & 56.3 & 33.3 \\
\hline Plan 4A & 2.6 & 60.2 & 21.4 & 1.2 & 47.6 & 24.0 & 0.5 & 42.8 & 25.5 \\
\hline Plan 5A & 0.5 & 46.4 & 18.0 & 4.7 & 55.4 & 28.2 & 1.6 & 63.2 & 33.6 \\
\hline Plan 6A & 3.6 & 35.0 & 13.9 & 4.7 & 51.9 & 26.6 & 1.5 & 55.9 & 31.3 \\
\hline Plan 7A & 1.2 & 51.0 & 19.7 & 7.2 & 50.7 & 26.6 & 1.6 & 57.8 & 32.0 \\
\hline Plan 8A & 2.7 & 50.3 & 22.6 & 6.5 & 52.3 & 24.0 & 1.5 & 58.3 & 30.5 \\
\hline
\end{tabular}

breaking in the physical model. The magnitude of percent difference between the monochromatic numerical model and physical model results ranged from 10.2 percent to 34.7 percent for the cases where $H_{\text {inc }}=1 \mathrm{~m}$ and $2 \mathrm{~m}$ (Table 18). 
Table 18. Monochromatic numerical model magnitude of percent differences, $H_{\text {CGWAVE }}$ versus $H_{s, \text { phys }}$ for 293-deg incident wave direction, swl = +0.9 m LWD.

\begin{tabular}{|l|l|l|l|l|l|l|l|l|l|}
\hline \multirow{3}{*}{ Configuration } & \multicolumn{8}{|c|}{ Percent Difference, Monochromatic Model } \\
\cline { 2 - 10 } & \multicolumn{3}{|c|}{$H_{\text {inc }}=1 \mathrm{~m}, T_{\text {inc }}=5 \mathrm{sec}$} & \multicolumn{3}{c|}{$H_{\text {inc }}=2 \mathrm{~m}, T_{\text {inc }}=7 \mathrm{sec}$} & \multicolumn{2}{c|}{$H_{\text {inc }}=2.5 \mathrm{~m}, T_{\text {inc }}=8 \mathrm{sec}$} \\
\cline { 2 - 11 } & $\min$ & $\max$ & avg & $\min$ & $\max$ & avg & $\min$ & $\max$ & avg \\
\hline Existing A & 0.9 & 48.5 & 24.9 & 6.4 & 70.6 & 32.6 & 5.7 & 88.3 & 58.2 \\
\hline Plan 1 & 1.6 & 46.8 & 10.2 & 3.2 & 29.6 & 16.7 & 6.4 & 56.4 & 30.6 \\
\hline Plan 2A & 1.8 & 81.3 & 29.3 & 4.9 & 45.4 & 23.1 & 6.9 & 58.6 & 35.2 \\
\hline Plan 3A & 0.2 & 48.9 & 20.4 & 3.0 & 73.5 & 26.5 & 4.4 & 52.8 & 37.8 \\
\hline Plan 4A & 0.7 & 68.0 & 24.5 & 1.4 & 55.6 & 22.2 & 3.0 & 50.5 & 30.9 \\
\hline Plan 5A & 0.9 & 54.4 & 15.8 & 1.0 & 68.2 & 28.4 & 5.1 & 75.4 & 37.7 \\
\hline Plan 6A & 2.7 & 68.5 & 24.0 & 8.9 & 78.5 & 34.7 & 5.2 & 92.4 & 53.2 \\
\hline Plan 7A & 0.9 & 46.3 & 16.5 & 3.8 & 69.1 & 29.7 & 5.1 & 88.2 & 50.7 \\
\hline Plan 8A & 0.8 & 43.5 & 17.9 & 4.4 & 67.3 & 27.9 & 5.1 & 86.2 & 51.4 \\
\hline
\end{tabular}

Additionally, standard deviations were examined to determine how tightly the percent differences were clustered (Table 19). The standard deviation computed for all three incident wave cases together is also included for both monochromatic and spectral results. It is evident that the spectral results are less variable than the monochromatic results. With a few exceptions, the spectral standard deviations were consistently smaller than the monochromatic standard deviations. Overall, the spectral approach appeared to provide a more stable and more accurate approximation to the physical model.

Table 19. Standard deviations of wave height percent differences for 293-deg incident wave direction, swl = +0.9 m LWD.

\begin{tabular}{|l|l|l|l|l|l|l|l|l|}
\hline \multirow{2}{*}{ Alternative } & \multicolumn{2}{|c|}{$H_{\text {inc }}=1 \mathrm{~m}, T_{\text {inc }}=5 \mathrm{sec}$} & \multicolumn{2}{c|}{$H_{\text {inc }}=\mathbf{2} \mathrm{m}, T_{\text {inc }}=7 \mathrm{sec}$} & \multicolumn{2}{c|}{$H_{\text {inc }}=2.5 \mathrm{~m}, T_{\text {inc }}=8 \mathrm{sec}$} & \multicolumn{2}{|c|}{ All } \\
\cline { 2 - 9 } & Mono. & Spect. & Mono. & Spect. & Mono. & Spect. & Mono. & Spect. \\
\hline Existing A & 14.2 & 16.3 & 21.1 & 16.8 & 27.6 & 19.2 & 25.7 & 17.7 \\
\hline Plan 1 & 13.3 & 10.2 & 7.8 & 9.1 & 13.0 & 13.0 & 14.3 & 11.5 \\
\hline Plan 2A & 24.0 & 19.1 & 13.6 & 14.9 & 14.5 & 16.5 & 18.3 & 16.7 \\
\hline Plan 3A & 15.9 & 15.8 & 18.9 & 15.0 & 13.2 & 16.8 & 17.5 & 16.2 \\
\hline Plan 4A & 22.0 & 14.5 & 16.0 & 15.1 & 13.6 & 15.1 & 17.6 & 14.7 \\
\hline Plan 5A & 15.4 & 13.3 & 19.7 & 15.5 & 15.5 & 17.6 & 18.9 & 16.6 \\
\hline Plan 6A & 20.4 & 8.9 & 21.3 & 13.2 & 29.1 & 15.9 & 26.4 & 14.7 \\
\hline Plan 7A & 14.3 & 13.8 & 20.5 & 13.5 & 26.7 & 16.7 & 25.1 & 15.3 \\
\hline Plan 8A & 13.8 & 14.6 & 19.4 & 14.2 & 26.9 & 16.5 & 24.8 & 15.2 \\
\hline All & 17.9 & 14.8 & 18.3 & 14.3 & 22.9 & 16.5 & 21.9 & 15.8 \\
\hline
\end{tabular}




\section{Model results}

Numerical model results were evaluated with the objective of developing practical guidance for future engineering work. The guidance was to be presented as a performance index that would help to give design engineers a systematic way of finding the most efficient and cost-effective wave absorber alternative.

Spectral results for gauges $5-17$ were used to develop the performance index. These gauges were grouped into three index lines (Figure 32). Gauges $5-9$ were assigned to index line 1 , gauges $10-14$ were assigned to index line 2, and gauges $15-17$ were assigned to index line 3 . These index lines are identical to Lines 1-3 used in the physical model data analysis. The index wave height for each line was defined as the RMS value of significant wave heights at gauges located on the line (Appendix G).

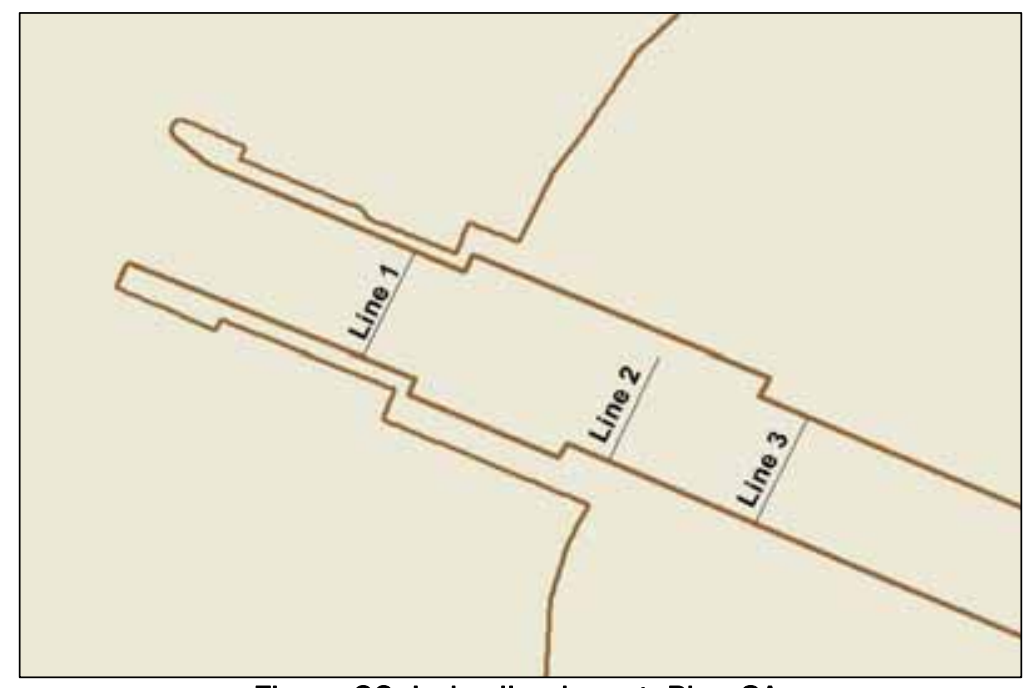

Figure 32. Index line layout, Plan 8A.

To relate model results to the actual wave climate at Pentwater, the closest WIS Station (Station 47) was examined. Linear refraction over straight parallel bottom contours was used to transform the deepwater WIS waves to a depth near the model boundary $(8 \mathrm{~m}, 26 \mathrm{ft})$. The resulting wave rose is shown in Figure 33.

The transformed WIS information was grouped into three direction bins, with each bin representing a sector of approximately 45 deg centered on one of the physical model test wave directions $(338,293,248 \mathrm{deg})$. The percentage of wave events falling in each bin was computed from the wave rose information (Table 20). 


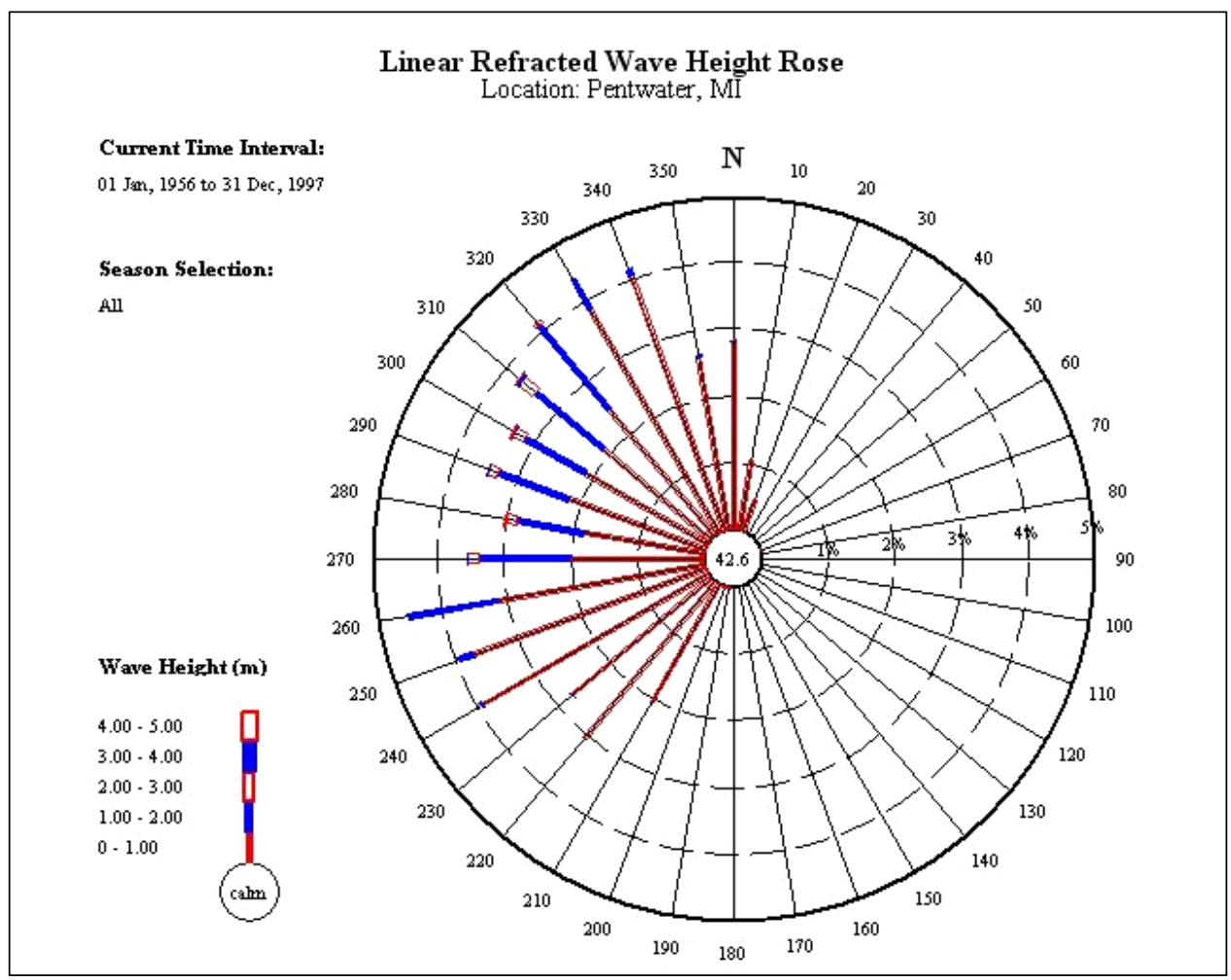

Figure 33. Offshore wave rose, WIS Station 47 transformed to 8-m (26-ft) depth.

Table 20. WIS wave direction weighting values.

\begin{tabular}{|l|l|l|}
\hline Wave Direction & WIS Bin Range & Weighting, \% \\
\hline 338 deg azimuth & $\theta_{p}=316-361 \mathrm{deg}$ & 30 \\
\hline 293 deg azimuth & $\theta_{p}=271-315 \mathrm{deg}$ & 30 \\
\hline 248 deg azimuth & $\theta_{p}=225-270 \mathrm{deg}$ & 40 \\
\hline
\end{tabular}

The WIS information was also grouped into $H_{s}$ and $T_{p}$ bins. WIS bins were associated with the three physical model test wave $H_{s}-T_{p}$ conditions as shown in Table 21. A weighting was then computed, representing the relative importance of the three test conditions in the local wave climate. For example, the test wave condition $H_{s}=1 \mathrm{~m}, T_{p}=5 \mathrm{sec}$, was taken as representative of 78 percent of the wave climate.

Table 21. WIS wave condition weighting values.

\begin{tabular}{|l|l|l|}
\hline Wave Condition & WIS Bin Range & Weighting, \% \\
\hline$H_{s}=1 \mathrm{~m}, T_{p}=5 \mathrm{sec}$ & $H_{s}=0-1 \mathrm{~m}, T_{p}=0-5 \mathrm{sec}$ & 78 \\
\hline$H_{\mathrm{s}}=2 \mathrm{~m}, T_{p}=7 \mathrm{sec}$ & $H_{\mathrm{s}}=1-2 \mathrm{~m}, T_{p}=5-7 \mathrm{sec}$ & 20 \\
\hline$H_{s}=2.5 \mathrm{~m}, T_{p}=8 \mathrm{sec}$ & $H_{s}=2-3 \mathrm{~m}, T_{p}=7 \mathrm{sec} \&$ above & 2 \\
\hline
\end{tabular}


The wave direction and $H_{s}-T_{p}$ weightings were applied to both the CGWAVE spectral results and physical model data to determine, for each configuration, a single performance index incorporating wave climate. Performance index is defined by the ratio of wave energy remaining after waves pass the pocket absorbers to energy incident to the absorbers. The transmitted fraction of wave energy, which is proportional to $H_{s}^{2}$, is calculated as:

$$
\begin{aligned}
& \left(E_{t}\right)_{\text {Line } 1,2}=\sum_{n_{D}=1}^{3} \sum_{n_{H T}=1}^{3}\left\{\left[\frac{H_{s, \text { Line } 2}}{H_{s, \text { Line } 1}}\right]_{D, H T}^{2} * w_{D}^{*} w_{H T}\right\} \\
& \left(E_{t}\right)_{\text {Line } 1,3}=\sum_{n_{D}=1}^{3} \sum_{n_{H T}=1}^{3}\left\{\left[\frac{H_{s, \text { Line } 3}}{H_{s, \text { Line } 1}}\right]_{D, H T}^{2} * w_{D} * w_{H T}\right\}
\end{aligned}
$$

where

$\left(E_{t}\right)_{\text {Line1,2 }}=$ fraction of wave energy at Line 1 that is transmitted to Line 2 $\left(E_{t}\right)_{\text {Line }, 3}=$ fraction of wave energy at Line 1 that is transmitted to Line 3 $n_{D}, n_{H T}=$ number of wave direction and $H_{s}-T_{p}$ bins, respectively

$D, H T=$ subscripts denoting a particular wave direction and $H_{s}-T_{p}$ bin, respectively

$w_{D}, w_{H T}=$ weighting factors for a particular wave direction and $H_{s}-T_{p}$ bin, respectively, based on wave climate, and expressed as a fraction, rather than percent

Performance index is defined as the percentage of wave energy dissipated between cross-channel lines before and after waves encounter the pocket:

$$
\begin{aligned}
& P I_{12}=100 \% *\left[1-\left(E_{t}\right)_{\text {Line } 1,2}\right] \\
& P I_{13}=100 \% *\left[1-\left(E_{t}\right)_{\text {Line } 1,3}\right]
\end{aligned}
$$

where

$P I_{12}=$ performance index calculated between Lines 1 and 2 $P I_{13}=$ performance index calculated between Lines 1 and 3 
Performance index values were calculated from both numerical and physical model results (Table 22). For this calculation, only the physical model test conditions matching the numerical model incident wave conditions in Table 16 were used. A perfect wave absorber would have a performance index of 100 percent. The case of no wave energy dissipation along the channel would give a performance index of zero percent. Performance index values calculated in this study from CGWAVE results range from 25.6 to 74.2. Values from the physical model range from 0.9 to 83.0. Overall, the numerical and physical model performance indices are quite similar (Figure 34). For performance index values determined between Lines 1 and 2, the numerical and physical model values have a mean difference of 3.3 percent and standard deviation of 4.0 percent. For performance index values determined between Lines 1 and 3, differences are similar in most cases, but they show more variability.

Table 22. Performance index values.

\begin{tabular}{|l|l|l|l|l|}
\hline Alternative & $\left(P l_{12}\right)_{\text {CGWAVE }}$ & $\left(P l_{13}\right)_{\text {CGWAVE }}$ & $\left(P l_{12}\right)_{\text {phys }}$ & $\left(P l_{13}\right)_{\text {phys }}$ \\
\hline Existing A & 64.8 & 62.9 & 68.0 & 64.8 \\
\hline Plan 1 & 27.5 & 25.6 & 21.7 & 0.9 \\
\hline Plan 2A & 45.8 & 55.5 & 48.8 & 36.5 \\
\hline Plan 3A & 46.8 & 52.9 & 48.1 & 43.4 \\
\hline Plan 4A & 51.0 & 53.6 & 55.9 & 60.0 \\
\hline Plan 5A & 48.5 & 52.0 & 56.8 & 62.7 \\
\hline Plan 6A & 73.9 & 74.2 & 80.5 & 83.0 \\
\hline Plan 7A & 71.4 & 66.3 & 75.4 & 78.6 \\
\hline Plan 8A & 70.6 & 64.5 & 74.5 & 76.1 \\
\hline
\end{tabular}

The performance indices can be used to rank the configurations tested, with the lowest ranking assigned to the configuration that provides the greatest wave energy reduction (Table 23). As expected, configurations with long pockets received better ratings than configurations with short or no pockets.

The relationship between wave energy transmitted past the wave absorber (expressed as the ratio of cross-channel average wave energy at transects along and upstream from the pocket, to wave energy just lakeward of the pocket, converted to percent) and the traversed length of wave absorber is given in Table 24 and Figures 35 and 36. Both numerical model and physical model results incorporating wave climate are shown. Transmitted 


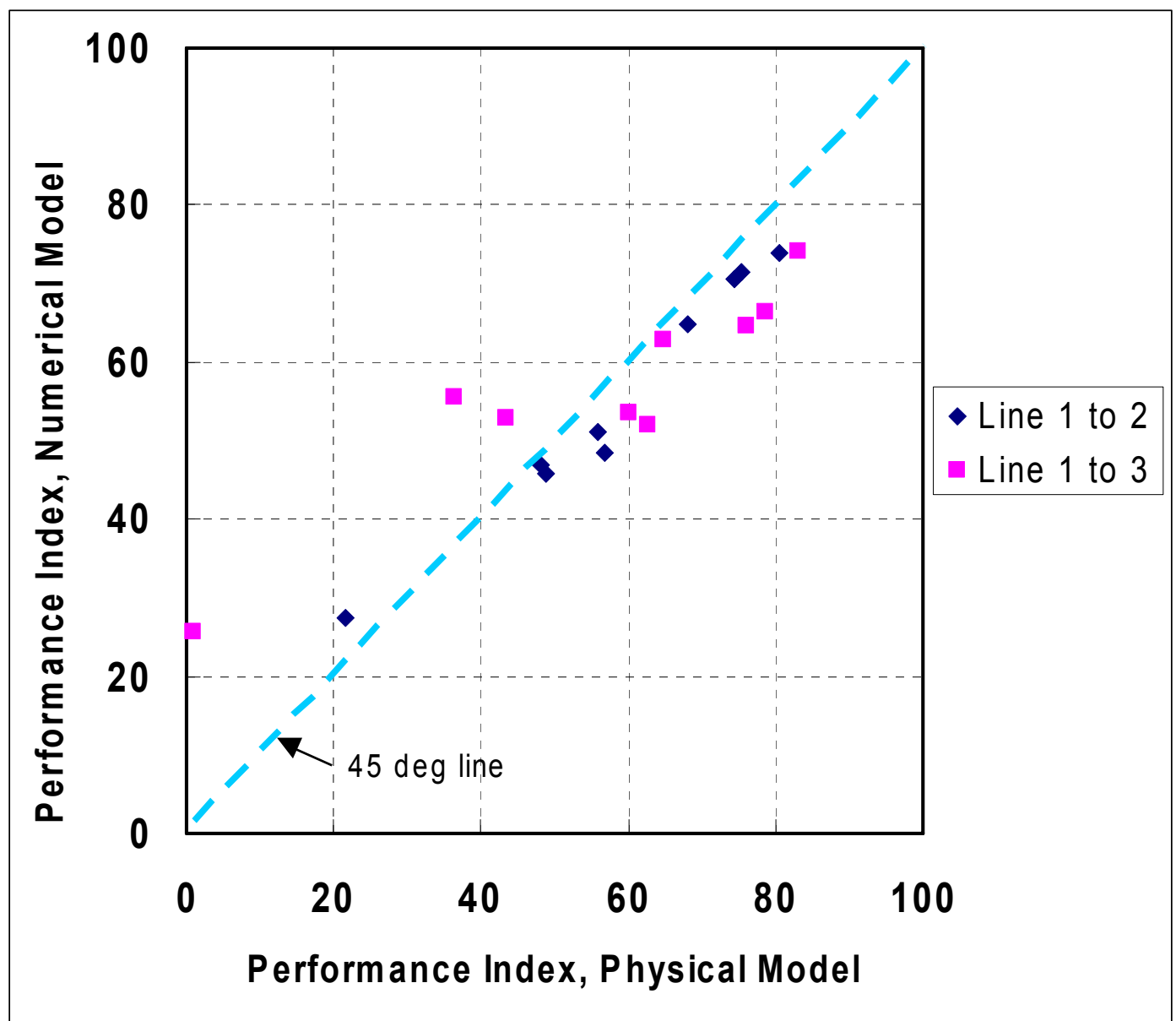

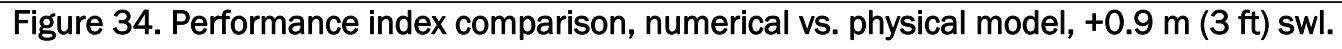

Table 23. Performance index rankings.

\begin{tabular}{|l|l|l|l|l|}
\hline Alternative & $\begin{array}{l}\text { Rank of } \\
\left(P I_{12}\right)_{\text {GGWAVE }}\end{array}$ & $\begin{array}{l}\text { Rank of } \\
\left(P I_{13}\right)_{\text {GGWAVE }}\end{array}$ & $\begin{array}{l}\text { Rank of } \\
\left(P I_{12}\right)_{\text {phys }}\end{array}$ & $\begin{array}{l}\text { Rank of } \\
\left(P I_{13}\right)_{\text {phys }}\end{array}$ \\
\hline Existing A & 4 & 4 & 4 & 4 \\
\hline Plan 1 & 9 & 9 & 9 & 9 \\
\hline Plan 2A & 8 & 5 & 7 & 8 \\
\hline Plan 3A & 7 & 7 & 8 & 7 \\
\hline Plan 4A & 5 & 6 & 6 & 6 \\
\hline Plan 5A & 6 & 8 & 5 & 5 \\
\hline Plan 6A & 1 & 1 & 1 & 1 \\
\hline Plan 7A & 2 & 2 & 2 & 2 \\
\hline Plan 8A & 3 & 3 & 3 & 3 \\
\hline
\end{tabular}


Table 24. Percent energy transmitted versus traversed length of wave absorber, Pentwater wave climate.

\begin{tabular}{|c|c|c|c|c|}
\hline Alternative & Lines & Traversed Length of Wave Absorber, $m$ & $\begin{array}{l}\text { Physical Model } \\
\text { Energy Transmitted, \% }\end{array}$ & $\begin{array}{l}\text { Numerical Model Energy } \\
\text { Transmitted, \% }\end{array}$ \\
\hline Existing & 1 to 2 & 118.3 & 32.1 & 35.2 \\
\hline Plan 1 & 1 to 2 & 95.7 (distance between lines; no absorber) & 78.3 & 72.5 \\
\hline Plan 1 & 1 to 3 & 154.97 (distance between lines; no absorber) & 99.1 & 74.4 \\
\hline Plan 2 & 1 to 2 & 59.1 & 51.3 & 54.2 \\
\hline Plan 3 & 1 to 2 & 59.1 & 51.9 & 53.2 \\
\hline Plan 4 & 1 to 2 & 77.4 & 44.1 & 49.0 \\
\hline Plan 4 & 1 to 3 & 118.3 & 40.0 & 46.4 \\
\hline Plan 5 & 1 to 2 & 77.4 & 43.2 & 51.5 \\
\hline Plan 5 & 1 to 3 & 118.3 & 37.3 & 48.0 \\
\hline Plan 6 & 1 to 2 & 154.9 & 19.5 & 26.1 \\
\hline Plan 6 & 1 to 3 & 236.6 & 17.0 & 25.8 \\
\hline Plan 7 & 1 to 2 & 136.6 & 24.6 & 28.6 \\
\hline Plan 7 & 1 to 3 & 177.4 & 21.4 & 33.7 \\
\hline Plan 8 & 1 to 2 & 136.6 & 25.5 & 29.4 \\
\hline Plan 8 & 1 to 3 & 177.4 & 23.9 & 35.5 \\
\hline
\end{tabular}

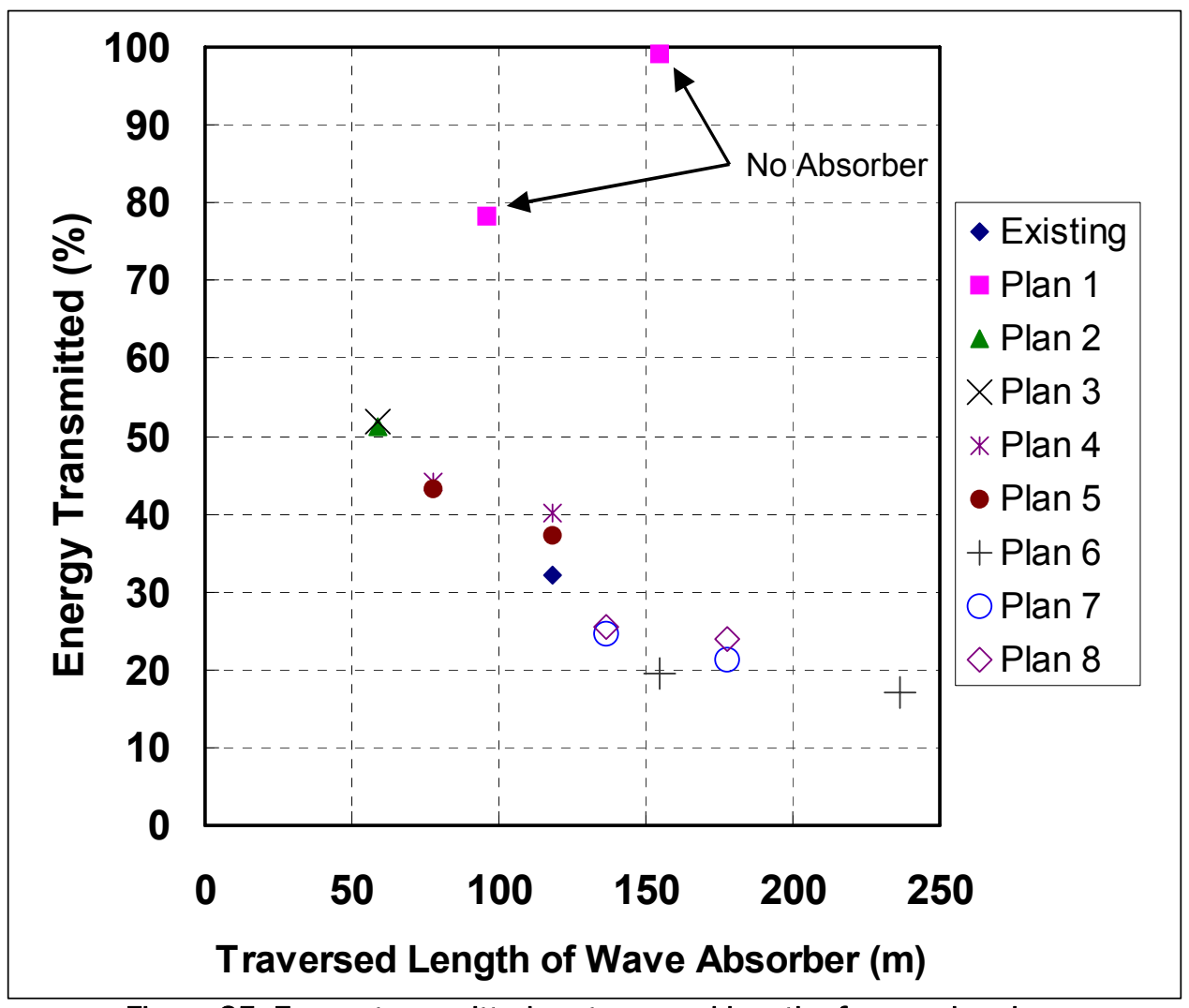

Figure 35. Energy transmitted vs. traversed length of wave absorber, Pentwater wave climate, physical model, $+0.9 \mathrm{~m}(3 \mathrm{ft}) \mathrm{swl}$. 


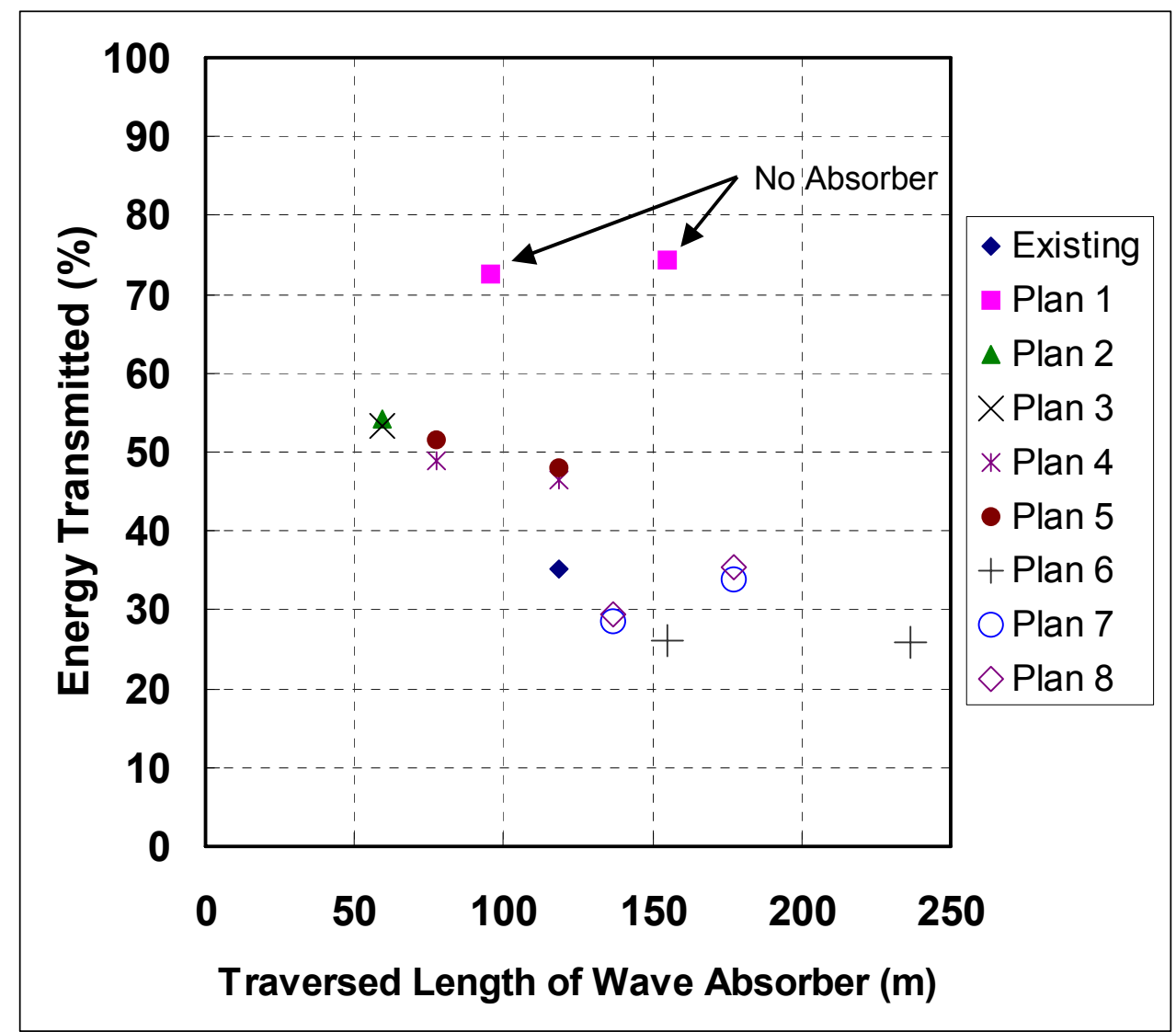

Figure 36. Energy transmitted vs. traversed length of wave absorber,

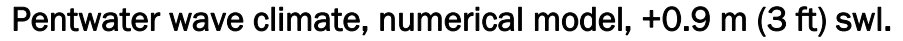

significant wave height, in percent, can be calculated as the square root of transmitted energy. The traversed length of wave absorber is the total length of constructed absorber that the wave has passed to reach a given cross-channel transect location. Thus the traversed length for a symmetric double pocket configuration is twice the traversed length for a single pocket configuration. For Plan 1, the configuration with no pockets, traversed length is the distance between transects. The Plan 1 results help to show the relative reduction in wave energy achieved by constructing wave absorbers.

The relationship between pocket length and transmitted energy is approximately linear up to a $150-\mathrm{m}$ (492-ft) length. This length covers the range of lengths used in existing Great Lakes pocket wave absorbers. For lengths greater than $150 \mathrm{~m}$ (492 ft), the reduction in transmitted wave energy per unit length of constructed absorber is less favorable. Wave absorbers on both sides of the channel reduce transmitted wave energy by around 5 to 10 percent more than a single pocket of the same total constructed length. The numerical model also showed a reduction in transmitted wave energy 
with increasing traversed length of the wave absorber, but the numerical model predicted more transmitted energy than the physical model for every pocket configuration, with differences ranging from 2 to 12 percent.

Several conclusions can be made from the numerical model analysis:

1. Numerical modeling with CGWAVE can provide good results for analyzing wave absorber configurations in narrow channels, provided the finite element mesh is sufficiently refined.

2. 60 points per wavelength is recommended for the finite element mesh in the navigation channel.

3. The spectral reconstruction approach used in this study provides more reliable results than monochromatic runs. It would have been useful to do some full spectral CGWAVE runs to compare to the reconstructed spectral and monochromatic scenarios, but those runs were beyond the scope of this study.

4. The most appropriate reflection coefficient values at Pentwater were 0.98 for steel sheet piling and 0.7 for the wave absorber cells. This information will be helpful for modeling other sites, though differences in wave absorber design (such as the presence or absence of a solid back wall to the absorber cell) could have some influence on wave reflection.

5. The final index rankings for the physical model results and spectral CGWAVE results yielded basically the same conclusion. 


\section{Conclusions and Recommendations}

This MCNP study evaluated the design of pocket wave absorbers at Pentwater, MI, and established better design guidance for future pocket wave absorber projects. The study included collection of field wave data at Pentwater, physical modeling, and numerical modeling. The field data provided a basis for validating the physical model. The physical model provided extensive data for the Pentwater configuration and eight other plans, as well as data for calibrating and validating the CGWAVE numerical model.

The Pentwater Harbor physical and numerical modeling has produced valuable information about pocket wave absorbers and their direct effect on wave attenuation. This study has provided a systematic way of examining harbors where wave absorbers are proposed and determining the most cost-effective way to mitigate navigation problems.

The following conclusions can be made from this study:

1. Physical modeling is an effective tool for analyzing wave absorber configurations in narrow channels. Bathymetry, structures, and incident waves can be accurately reconstructed and precise, detailed wave measurements can be collected at various locations in the model. Results compare well with prototype data.

2. The fraction of wave energy transmitted up the channel decreases as traversed length of pocket increases.

3. Local wave energy and significant wave height are quite variable across the channel width between jetty walls. When waves enter the channel obliquely, significant wave height can vary by 50 percent across the channel width.

4. Incident significant wave height has little influence on wave absorber performance.

5. Incident peak wave period influences absorber performance; energy transmitted decreases as wave period increases over the range tested.

6. Water level has a relatively small impact on absorber performance, with high water level and direct wave approach causing the highest transmitted energy. 
7. Waves approaching the entrance, aligned with the channel, transmit more energy past the absorber than do obliquely incident waves.

8. Pocket wave absorbers placed symmetrically on both jetties reduce transmitted energy compared with a single absorber of the same total constructed length (unless the incident storm wave climate is oblique exclusively from one side of the entrance; see item 9). The existing Pentwater Harbor double absorber configuration reduced transmitted wave energy by approximately five percent more than single absorbers of the same total length.

9. For oblique wave approach to the entrance, a single absorber along the more exposed interior jetty wall performs similarly to a double absorber with each pocket of the same length as the single absorber.

10. For oblique wave approach to the entrance, a single absorber along the more protected interior jetty wall is relatively ineffective.

11. The fraction of wave energy transmitted decreases approximately linearly with the traversed length of absorber up to a length of about $150 \mathrm{~m}$ (492 ft).

12. For absorbers of constructed length longer than about $150 \mathrm{~m}$ ( $492 \mathrm{ft}$ ), the reduction in transmitted energy per unit length of absorber becomes less favorable.

13. The absorber design at Pentwater, 59.1-m (194-ft) long pockets, placed symmetrically on either side of the channel, is very effective, maximizing energy dissipation per unit length of constructed absorber. Only 32 percent of wave energy incident to the absorber is transmitted past the absorber, corresponding to a reduction in significant wave height of nearly 50 percent. Local experience has indicated that this level of performance is sufficient.

14. Numerical modeling with CGWAVE provides a useful tool for evaluating pocket wave absorber performance.

Seven Great Lakes harbors presently have pocket wave absorbers and more harbors are candidates for absorbers during expected future entrance rehabilitation projects. A detailed analysis of pocket wave absorbers was needed to examine effectiveness and increase design efficiency. The results of this study will be valuable for future wave absorber design.

Although the present study is representative of Great Lakes harbor entrances, there are several important limitations. All physical model experiments were done with unidirectional waves. All experiments were 
done with the bathymetry of Pentwater Harbor, and with the Pentwater Harbor channel width of $46 \mathrm{~m}$ ( $150 \mathrm{ft}$ ). All wave absorber configurations tested were set upstream from the jetty tips the same distance as the Pentwater absorbers are located. Some of the summaries presented made use of the WIS hindcast wave climate for Pentwater. If more accurate wave climate information becomes available, either through updated WIS hindcasts or other sources, the climate-based Pentwater Harbor results should be reconsidered.

All of the above limitations affect the applicability of study results to locations other than Pentwater Harbor. In particular, channel width is expected to affect wave absorber performance, and it is quite variable even among the harbors with absorbers presently installed. Also, wave climate naturally varies with location in the Great Lakes. The limitation of unidirectional waves in the physical model is expected to most affect the o-deg incident wave results; and directionally spread incident waves are recommended for any future physical model experiments with pocket wave absorbers in entrance channels.

Since the numerical model CGWAVE provided useful evaluation of the various pocket wave absorber configurations, it is recommended as a tool for evaluating future projects. The model provides a flexible, economical tool for quantifying the performance of a wide variety of sites and configurations. 


\section{References}

Allsop, N. W. H., and S. S. L. Hettiarachchi. 1988. Reflections from coastal structures. In Proceedings, 21st International Conference on Coastal Engineering, American Society of Civil Engineers (ASCE), 782-794.

ASCE. 1942. Hydraulic models. In Manuals of engineering practice No. 25. New York: American Society of Civil Engineers.

As-Salek, Junaid A., and David J. Schwab. 2004. High-frequency water level fluctuations in Lake Michigan. Journal of Waterway, Port, Coastal and Ocean Engineering, ASCE, 130(1):45-53.

Bottin, Robert R., Jr. 1988. Case histories of Corps breakwater and jetty structures; Report 3: North Central Division. Repair, Evaluation, Maintenance, and Research Program, Technical Report No. 2-805, U.S. Army Engineer Waterways Experiment Station, Vicksburg, MS.

Carpenter, Donald D. 2001. Wave energy dissipation in Great Lake harbor entrances. PhD diss., University of Michigan, Ann Arbor, MI.

Demirbilek, Z., and V. Panchang. 1998. CGWAVE: a coastal surface water wave model of the mild slope equation. Technical Report CHL-98-26, U.S. Army Engineer Waterways Experiment Station, Vicksburg, MS.

Driver, David B., Robin D. Reinhard, Jon M. Hubertz. 1992. Hindcast wave information for the Great Lakes: Lake Superior. WIS Report 23, U.S. Army Engineer Waterways Experiment Station, Vicksburg, MS.

Headquarters, U.S. Army Corps of Engineers. 2002. Coastal Engineering Manual, EM 1110-2-1100. Washington, DC.

Hubertz, Jon M., David B. Driver, and Robin D. Reinhard. 1991. Hindcast wave information for the Great Lakes: Lake Michigan. WIS Report 24, U.S. Army Engineer Waterways Experiment Station, Vicksburg, MS.

Hughes, Steven A. 1993. Physical models and laboratory techniques in coastal engineering, World Scientific.

McKinney, James P., and Margaret A. Sabol. 2003. Evaluation of the wave absorber at Pentwater, Michigan. U.S. Army Engineer Research and Development Center, Vicksburg, MS. http://sandbar.wes.army.mil/public_html/pmab2web/htdocs/michigan/ pentwater/channel_summary_final.pdf.

Markle, D. G., and H. C. Greer III. 1992. Crescent City instrumented model dolos study: Coastal model investigation. Technical Report CERC-92-15, U.S Army Engineer Waterways Experiment Station, Vicksburg, MS.

Pepper, T. 2005. Pentwater Pierhead Light, Pentwater, Michigan. Seeing the Light, Lighthouses of the Western Great Lakes. http://terrypepper.com/lights/michigan/ pentwater/index.htm 
Seelig, W. N. 1983. Wave reflection from coastal structures. Proceedings, Coastal Structures '83, American Society of Civil Engineers, 961-973.

Seelig, W. N., and J. P. Ahrens. 1981. Estimation of wave reflection and energy dissipation coefficients for Beaches, Revetments and Breakwaters. Technical Paper 81-1, U.S. Army Engineer Waterways Experiment Station, Vicksburg, MS.

Seelig, William N., and Robert M. Sorensen. 1977. Hydraulics of Great Lakes inlets. Technical Paper No. 77-8, U.S. Army Coastal Engineering Research Center, Fort Belvoir, VA.

Thompson, E. F., L. L. Hadley, W. A. Brandon, D. D. McGehee, and J. M. Hubertz. 1996. Wave response of Kahului Harbor, Maui, Hawaii. Technical Report CERC-9611, U.S. Army Engineer Waterways Experiment Station, Vicksburg, MS.

U.S. Army Corps of Engineers (USACE). 1997. Monitoring completed navigation projects. Engineer Regulation 1110-2-8151, Washington, DC.

Wright, Steven J. and Donald D. Carpenter. 1999. Final project report, hydraulic model study, pocket wave absorbers. Report UMCEE 99-15, University of Michigan, Department of Civil and Environmental Engineering, Ann Arbor, MI. 


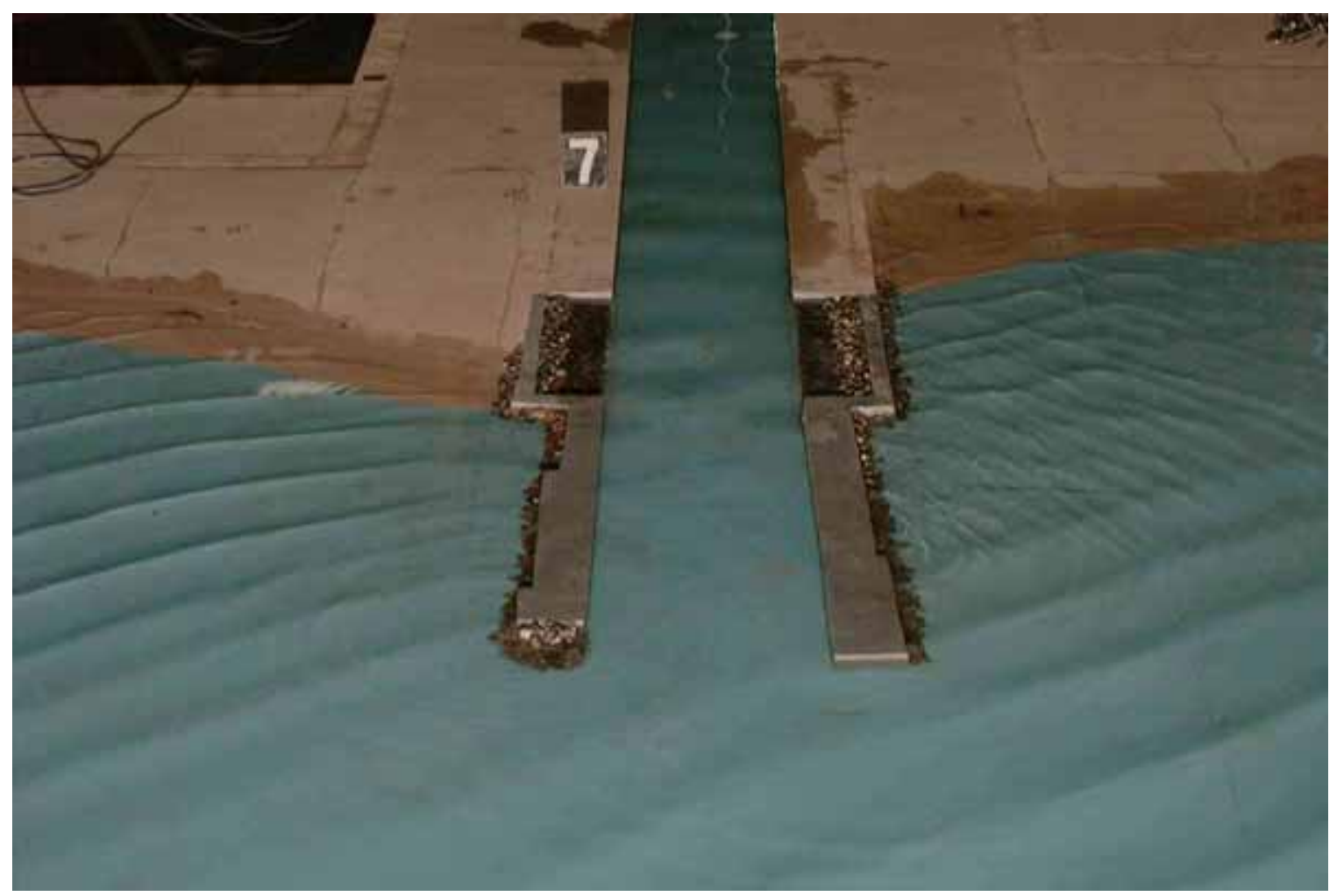

Photograph 1a. Typical wave patterns for existing conditions; 5-sec, 1-m waves from 45 deg South; swl $=+0.9 \mathrm{~m}$ LWD, closeup.

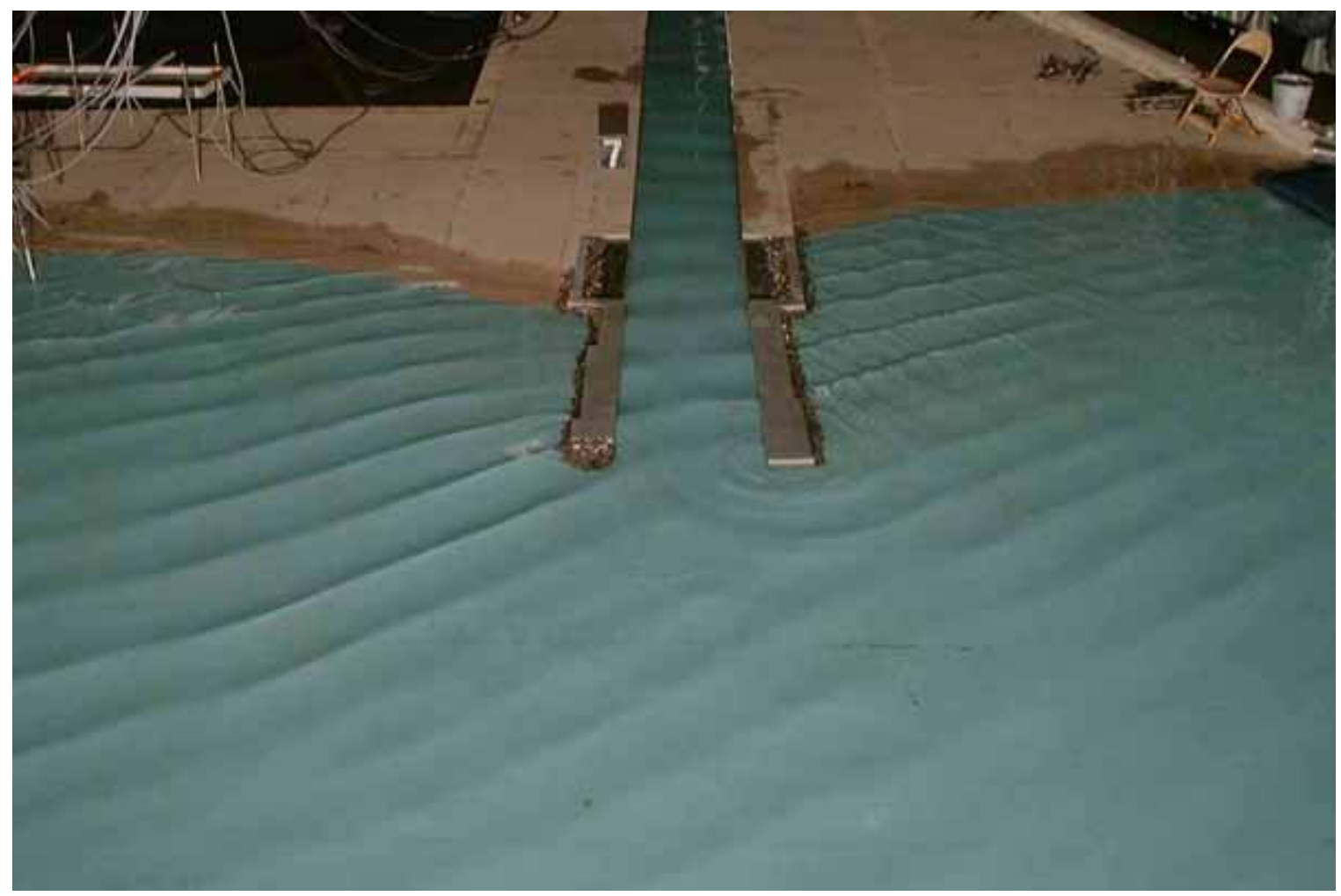

Photograph 1b. Typical wave patterns for existing conditions; 5-sec, 1-m waves from 45 deg South; swl = +0.9m LWD. 


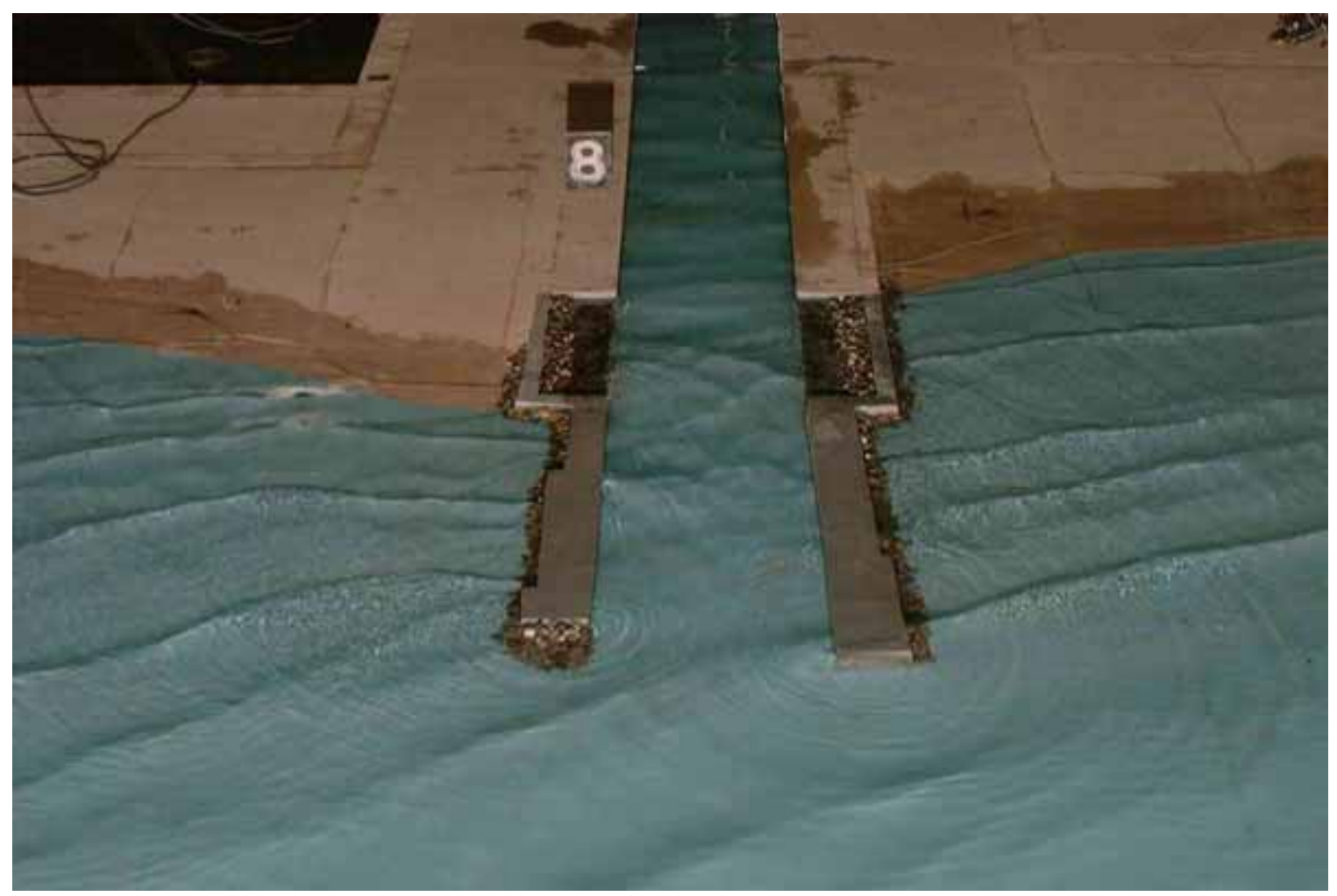

Photograph 2a. Typical wave patterns for existing conditions; 8-sec, 2-m waves from 45 deg South; swl $=+0.9 \mathrm{~m}$ LWD, closeup.

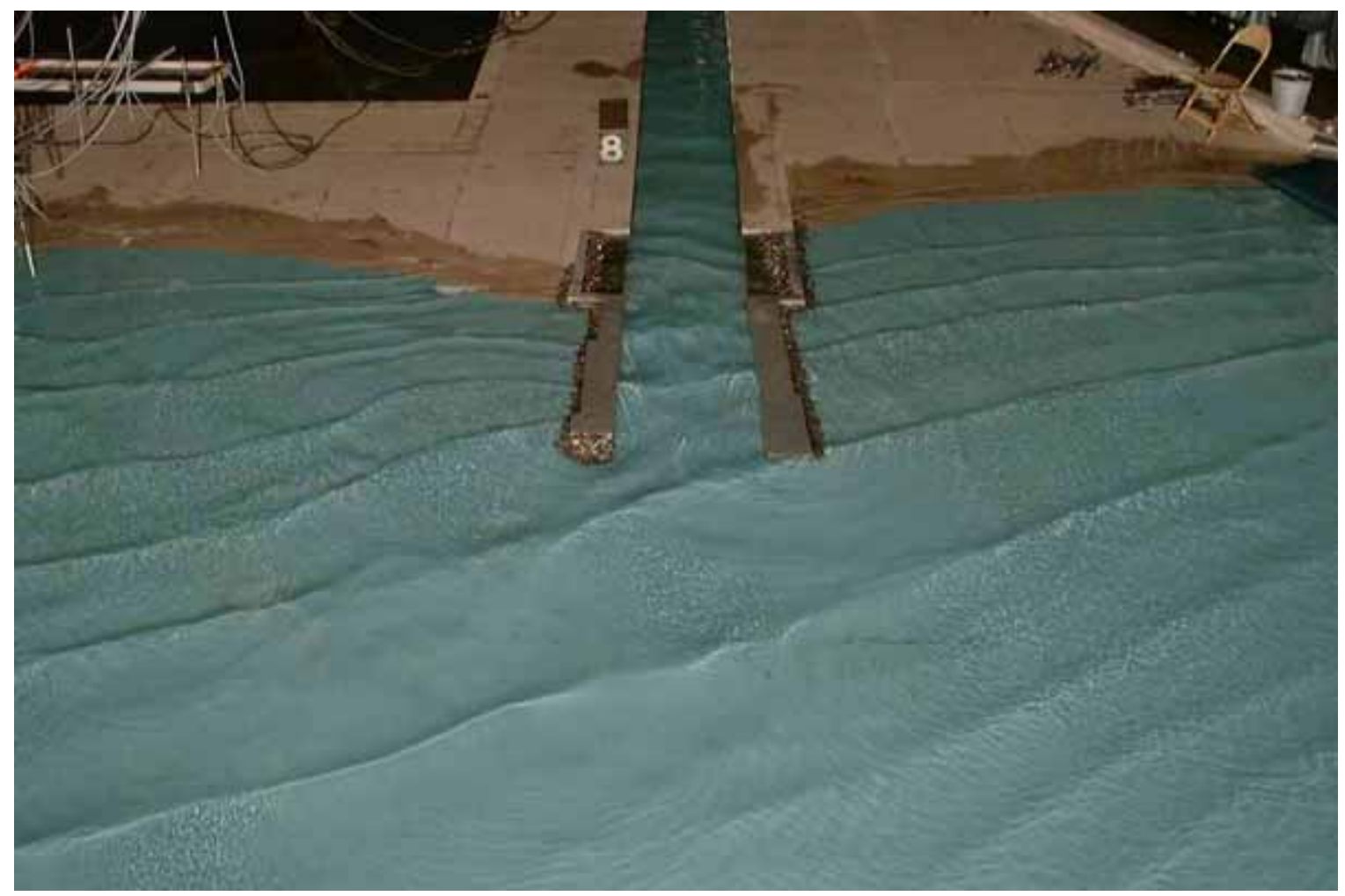

Photograph 2b. Typical wave patterns for existing conditions; 8-sec, 2-m waves from $45 \mathrm{deg}$ South; swl = +0.9m LWD. 


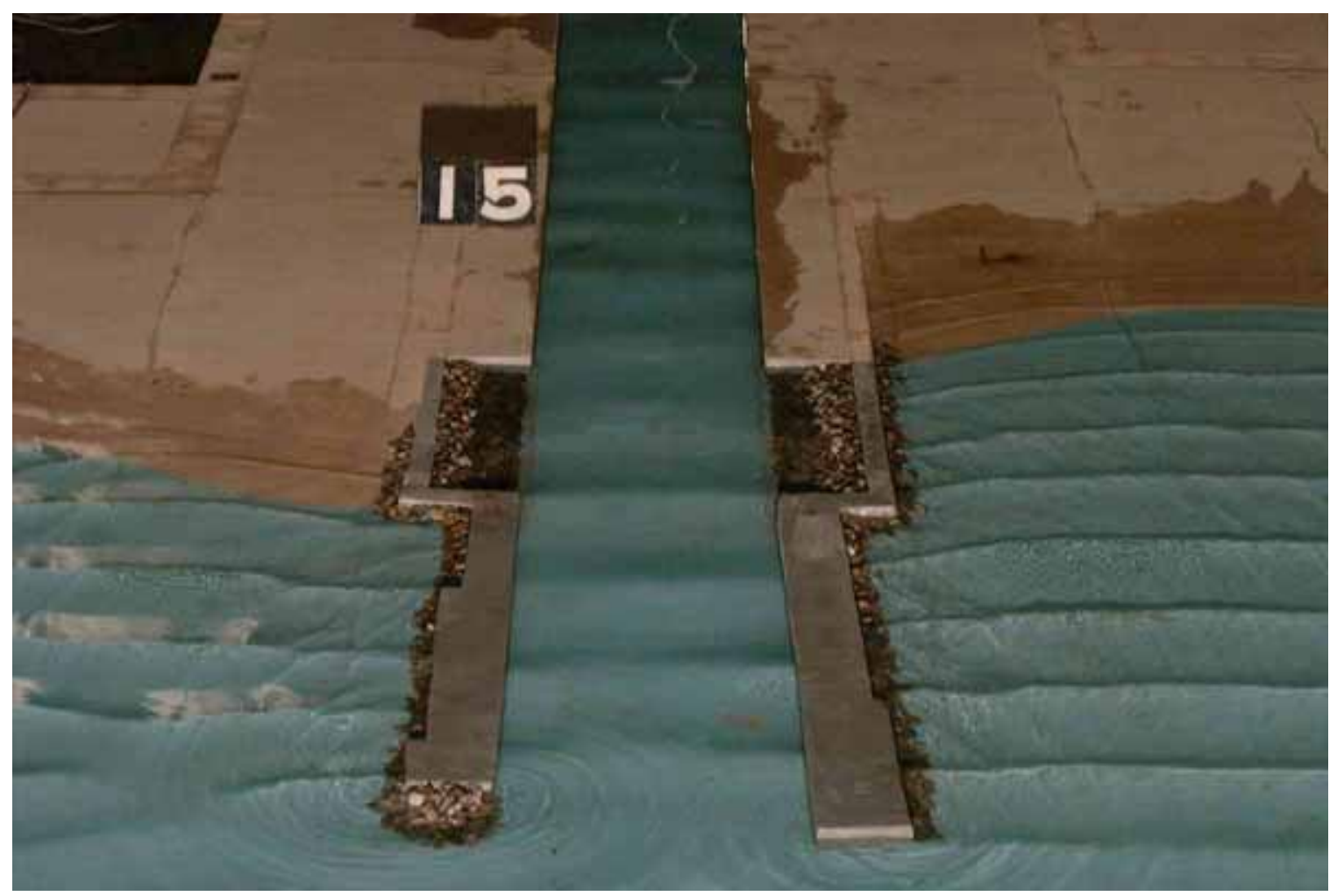

Photograph 3a. Typical wave patterns for existing conditions; 5-sec, 1-m waves from 0 deg; $\mathrm{sWl}=+0.9 \mathrm{~m}$ LWD, closeup.

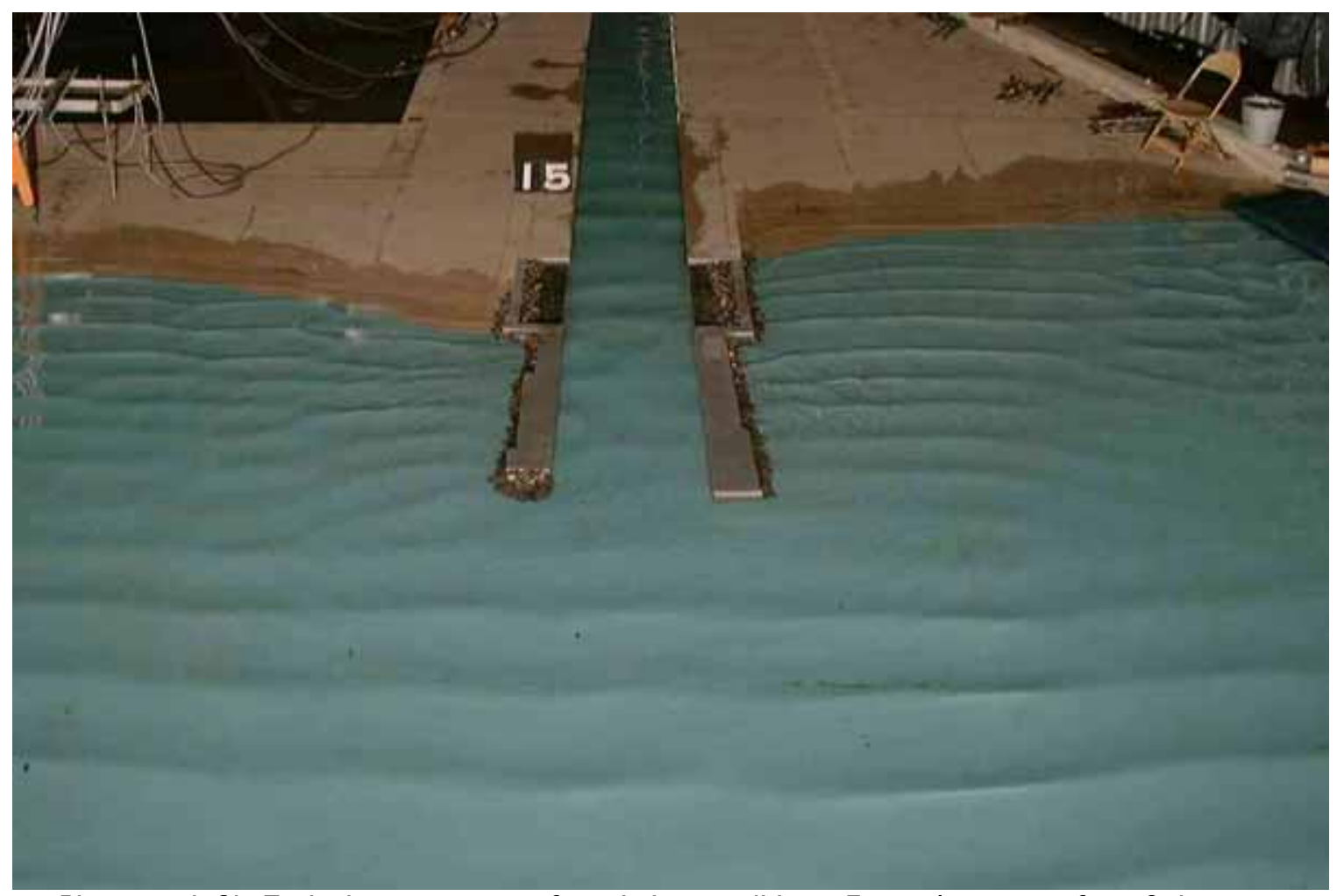

Photograph 3b. Typical wave patterns for existing conditions; 5-sec, 1-m waves from 0 deg; $\mathrm{sWl}=+0.9 \mathrm{~m}$ LWD. 


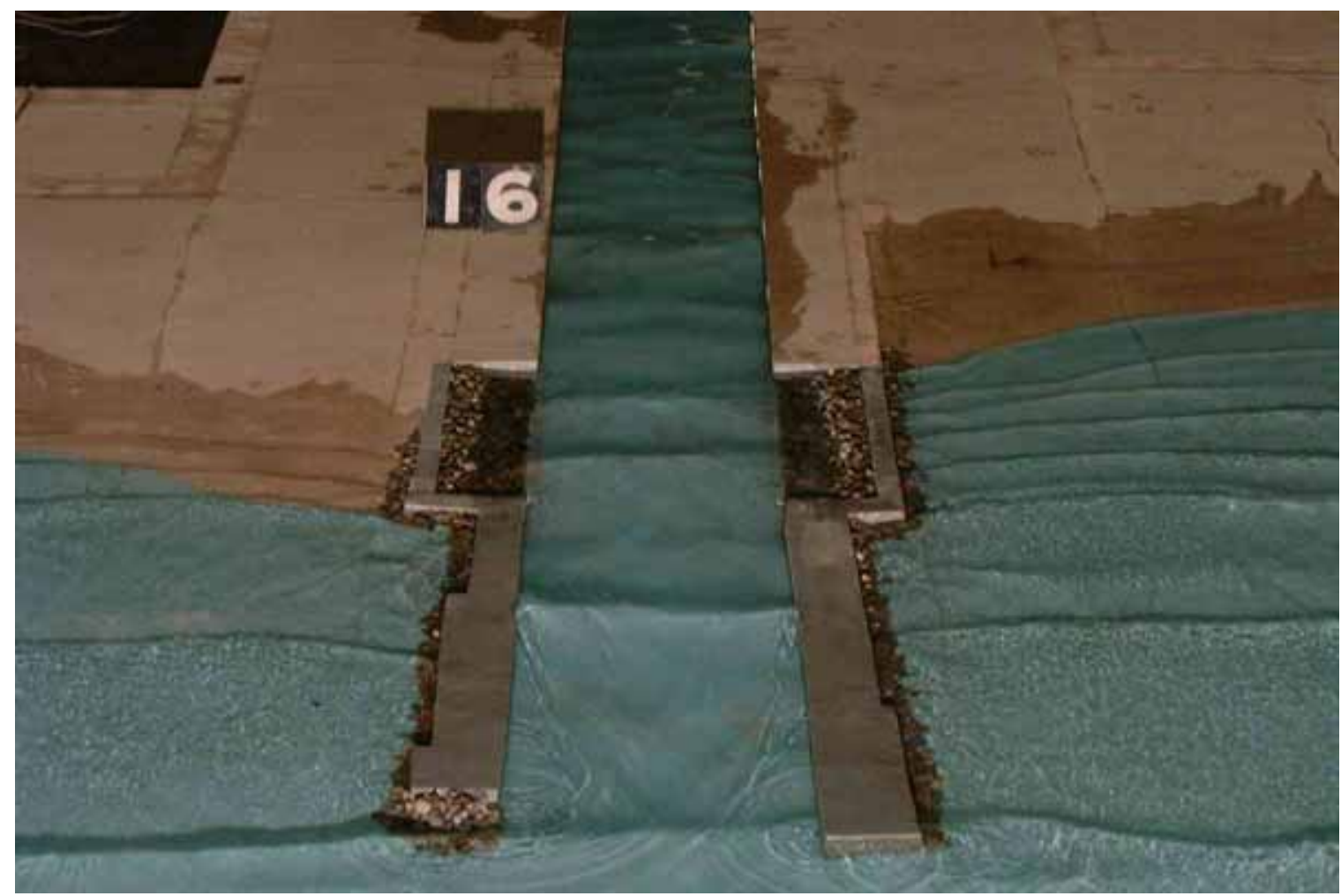

Photograph 4a. Typical wave patterns for existing conditions; 8-sec, 2-m waves from 0 deg; $\mathrm{sWl}=+0.9 \mathrm{~m}$ LWD, closeup.

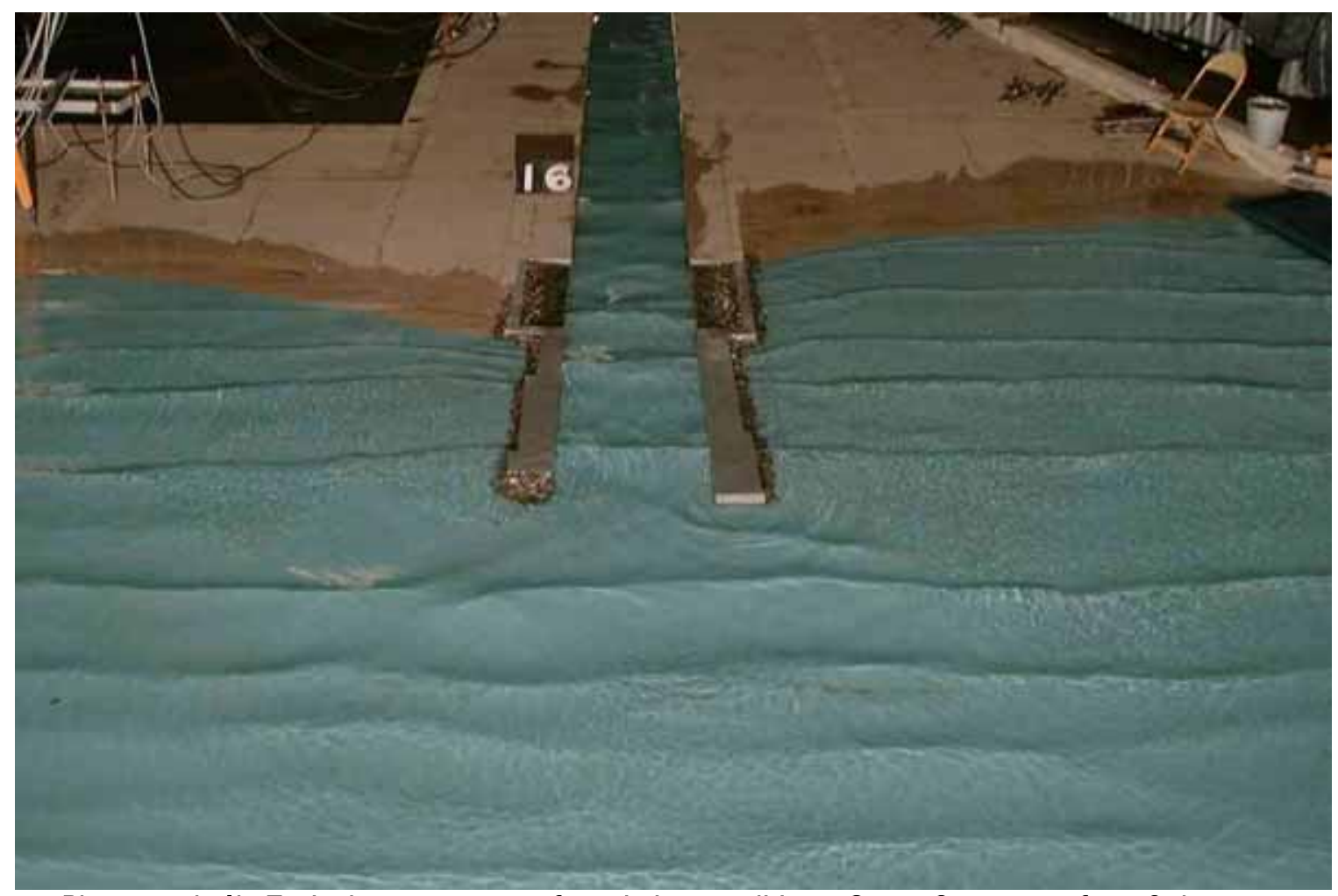

Photograph 4b. Typical wave patterns for existing conditions; 8-sec, 2-m waves from 0 deg; swl $=+0.9 \mathrm{~m}$ LWD. 


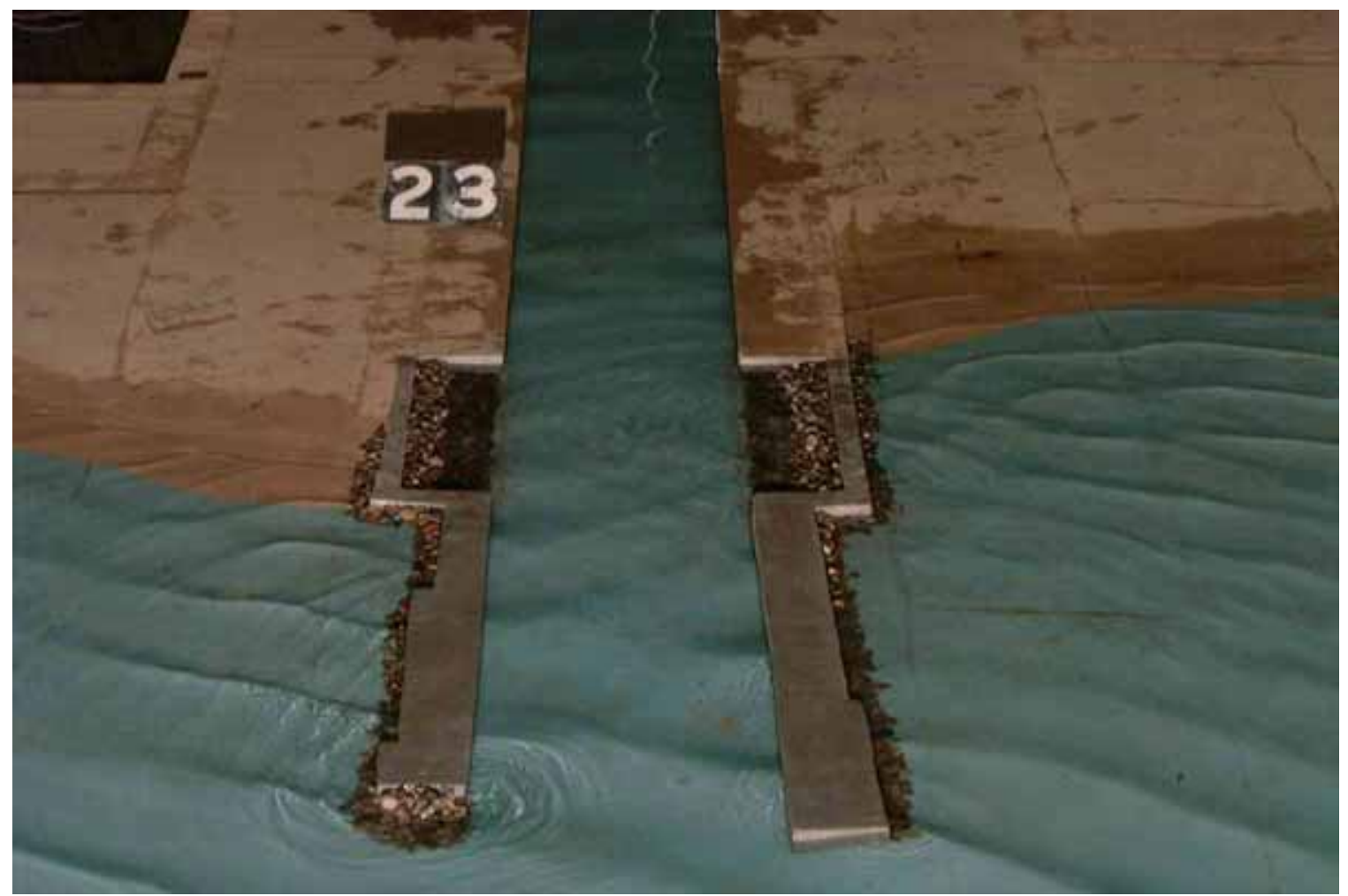

Photograph 5a. Typical wave patterns for existing conditions; 5-sec, 1-m waves from 45 deg North; swl $=+0.9 \mathrm{~m}$ LWD, closeup.

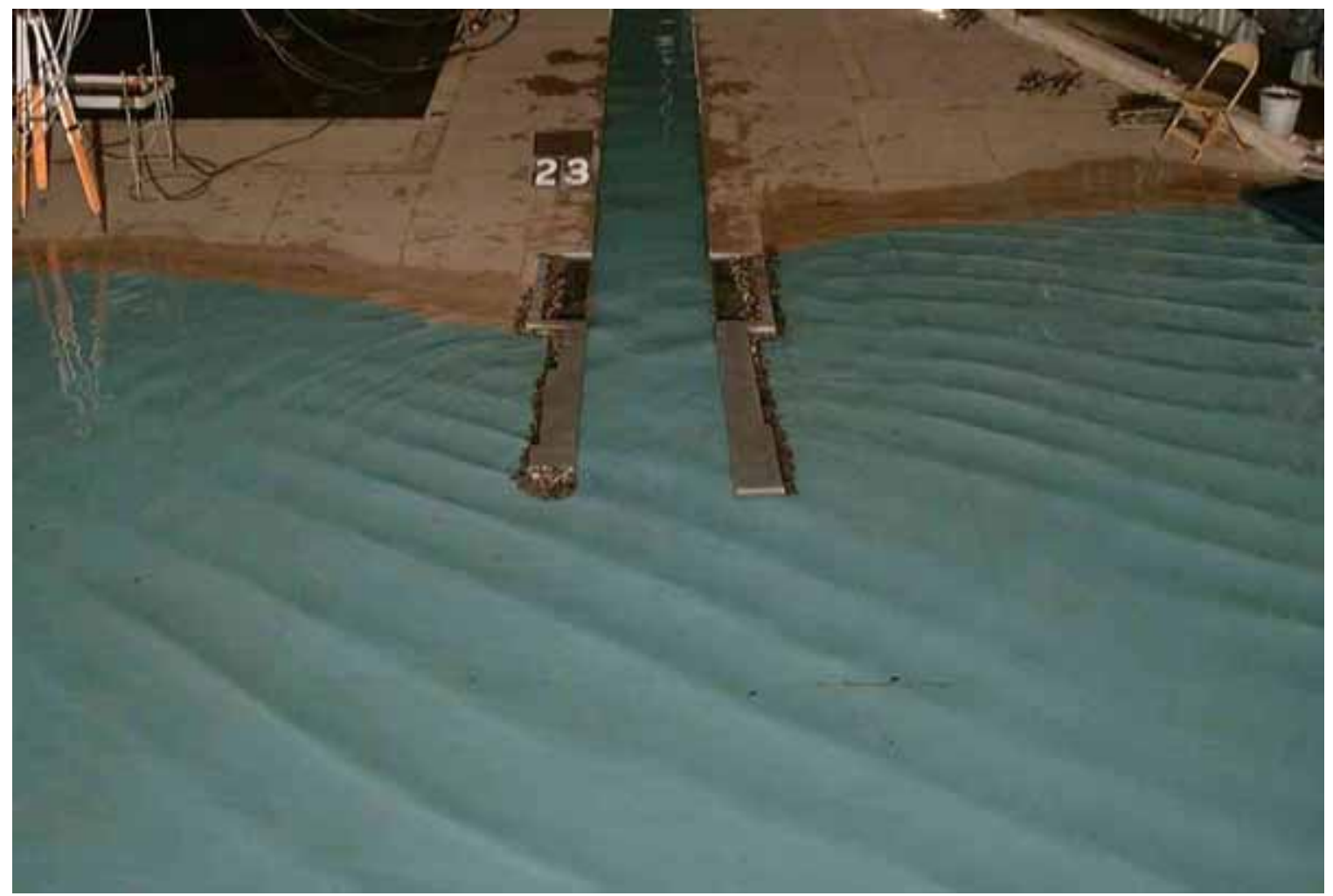

Photograph 5b. Typical wave patterns for existing conditions; 5-sec, 1-m waves from 45 deg North; swl = +0.9m LWD. 


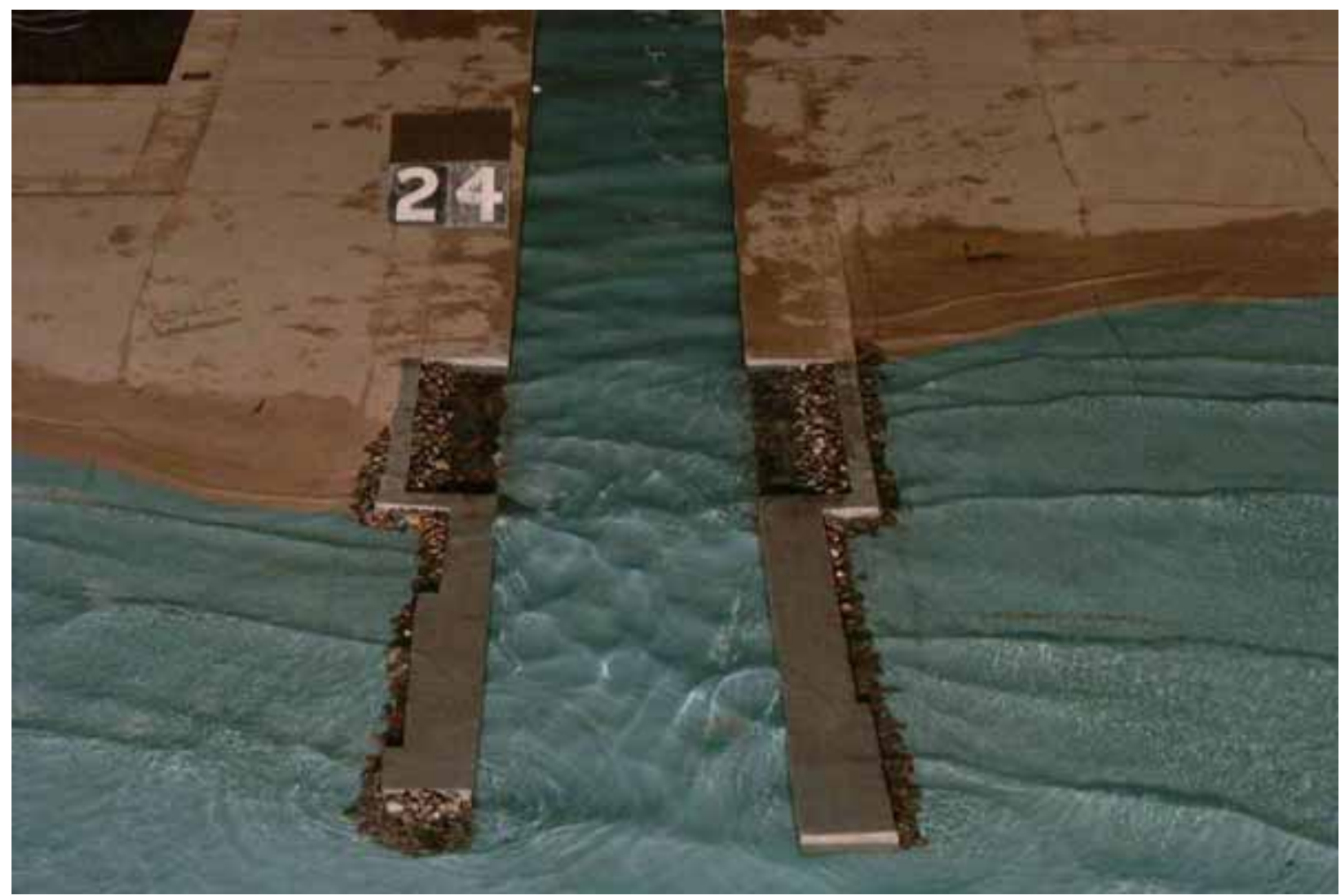

Photograph 6a. Typical wave patterns for existing conditions; 8-sec, 2-m waves from 45 deg North; swl $=+0.9 \mathrm{~m}$ LWD, closeup.

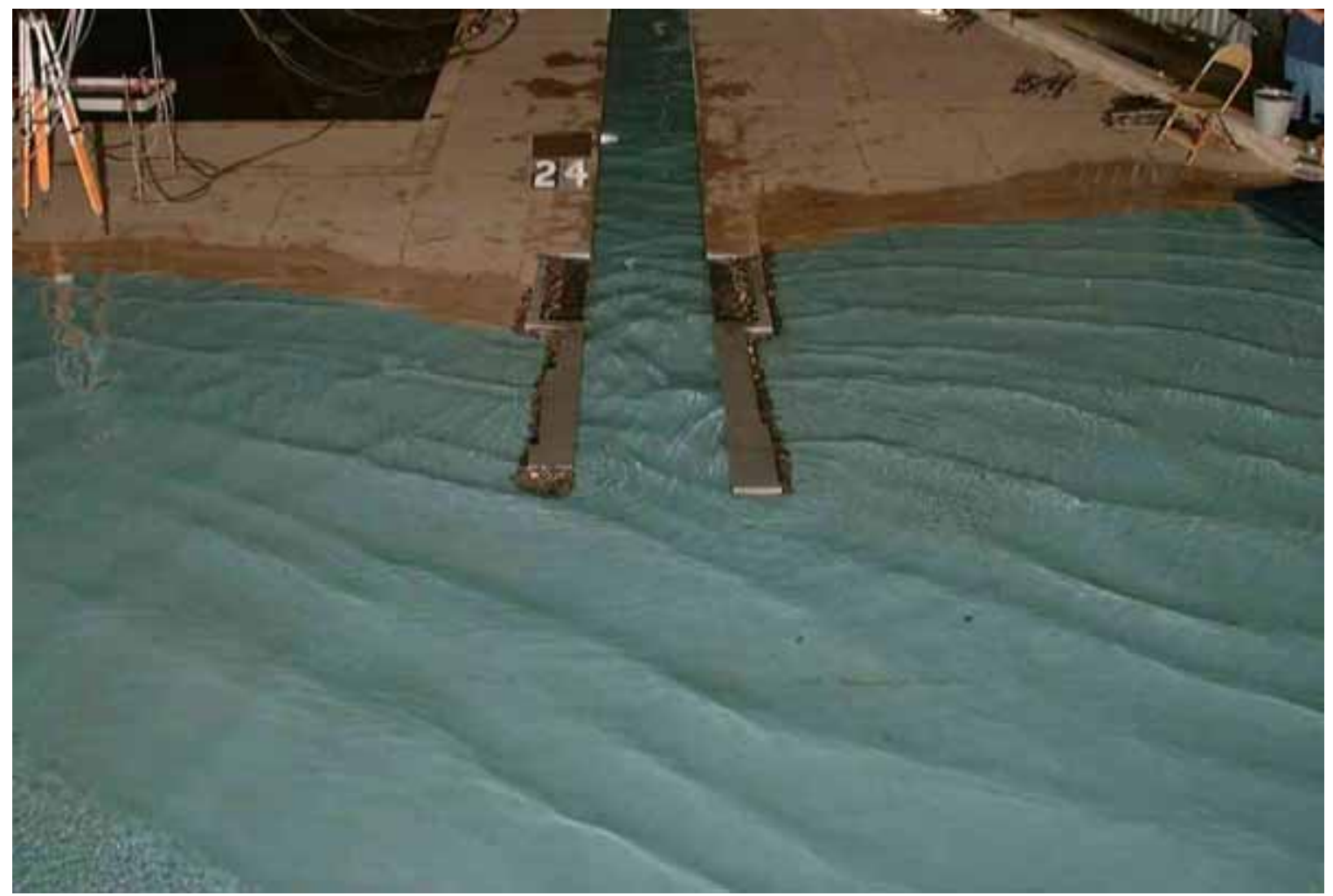

Photograph 6b. Typical wave patterns for existing conditions; 8-sec, 2-m waves from 45 deg North; swl = +0.9m LWD. 


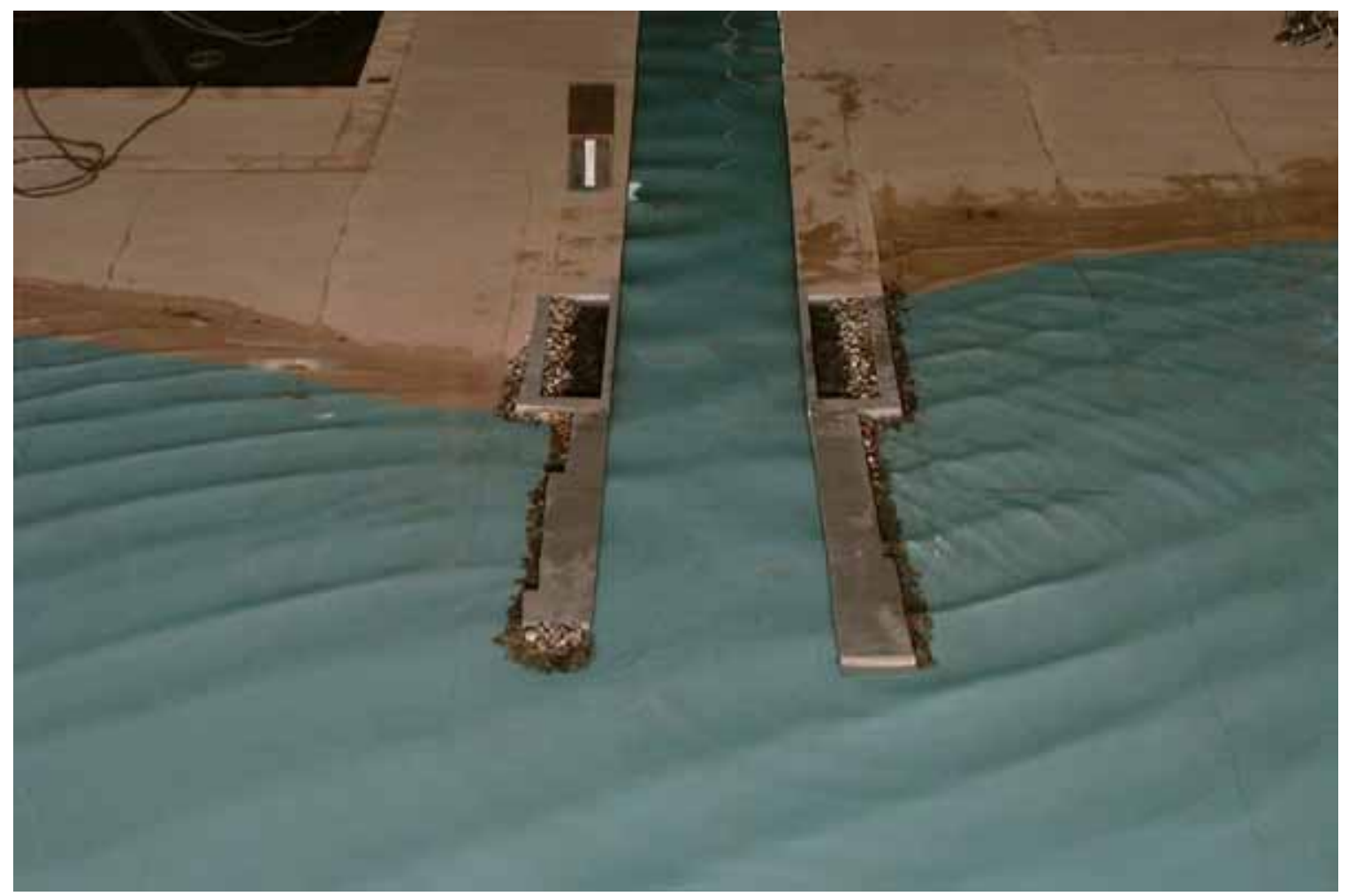

Photograph 7a. Typical wave patterns for Plan 1; 5-sec, 1-m waves from 45 deg South; $\mathrm{sWl}=+0.9 \mathrm{~m}$ LWD, closeup.

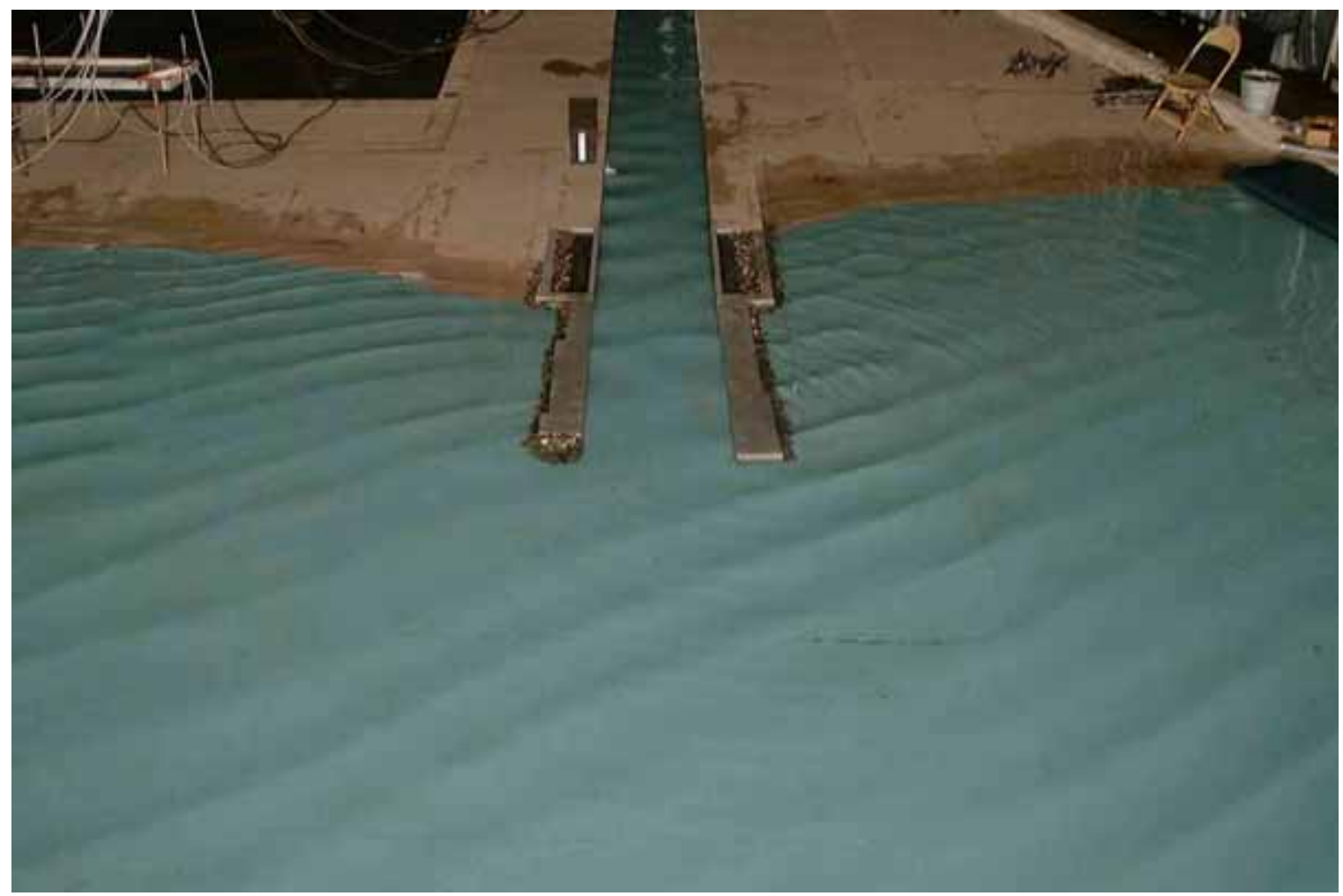

Photograph 7b. Typical wave patterns for Plan 1; 5-sec, 1-m waves from 45 deg South; $\mathrm{sWl}=+0.9 \mathrm{~m}$ LWD. 


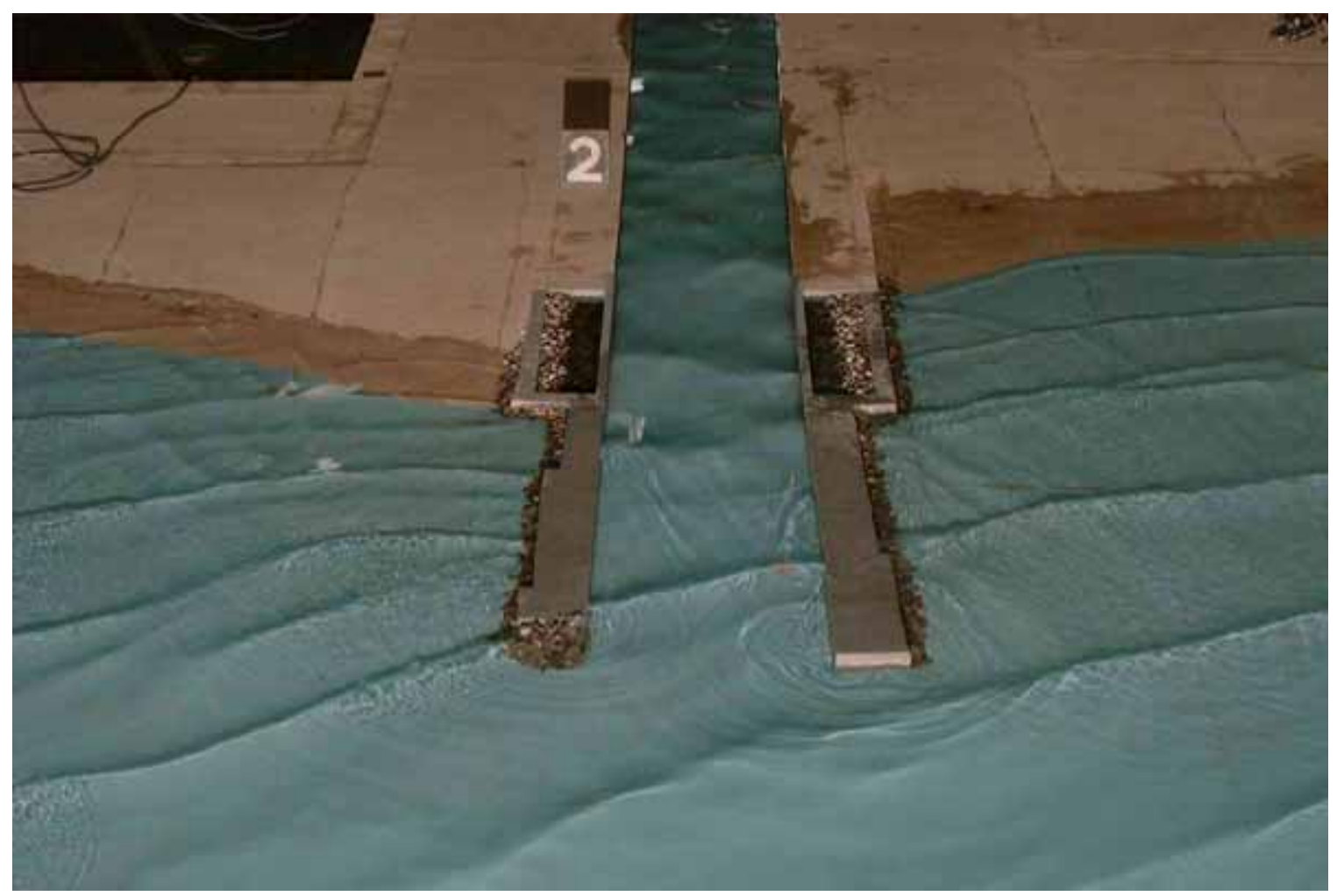

Photograph 8a. Typical wave patterns for Plan 1; 8-sec, 2-m waves from 45 deg South; $\mathrm{sWl}=+0.9 \mathrm{~m}$ LWD, closeup.

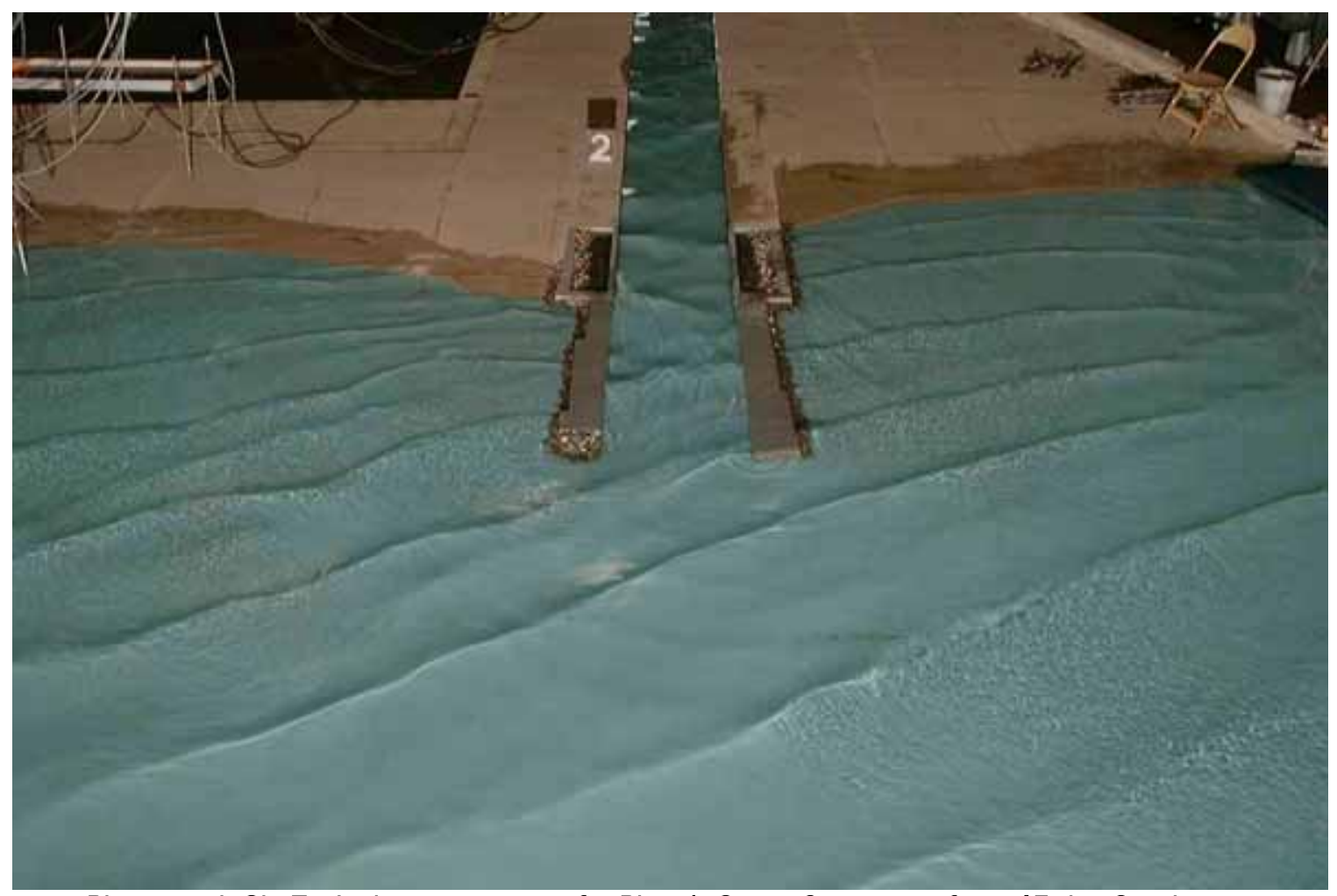

Photograph 8b. Typical wave patterns for Plan 1; 8-sec, 2-m waves from 45 deg South; $\mathrm{sWl}=+0.9 \mathrm{~m}$ LWD. 


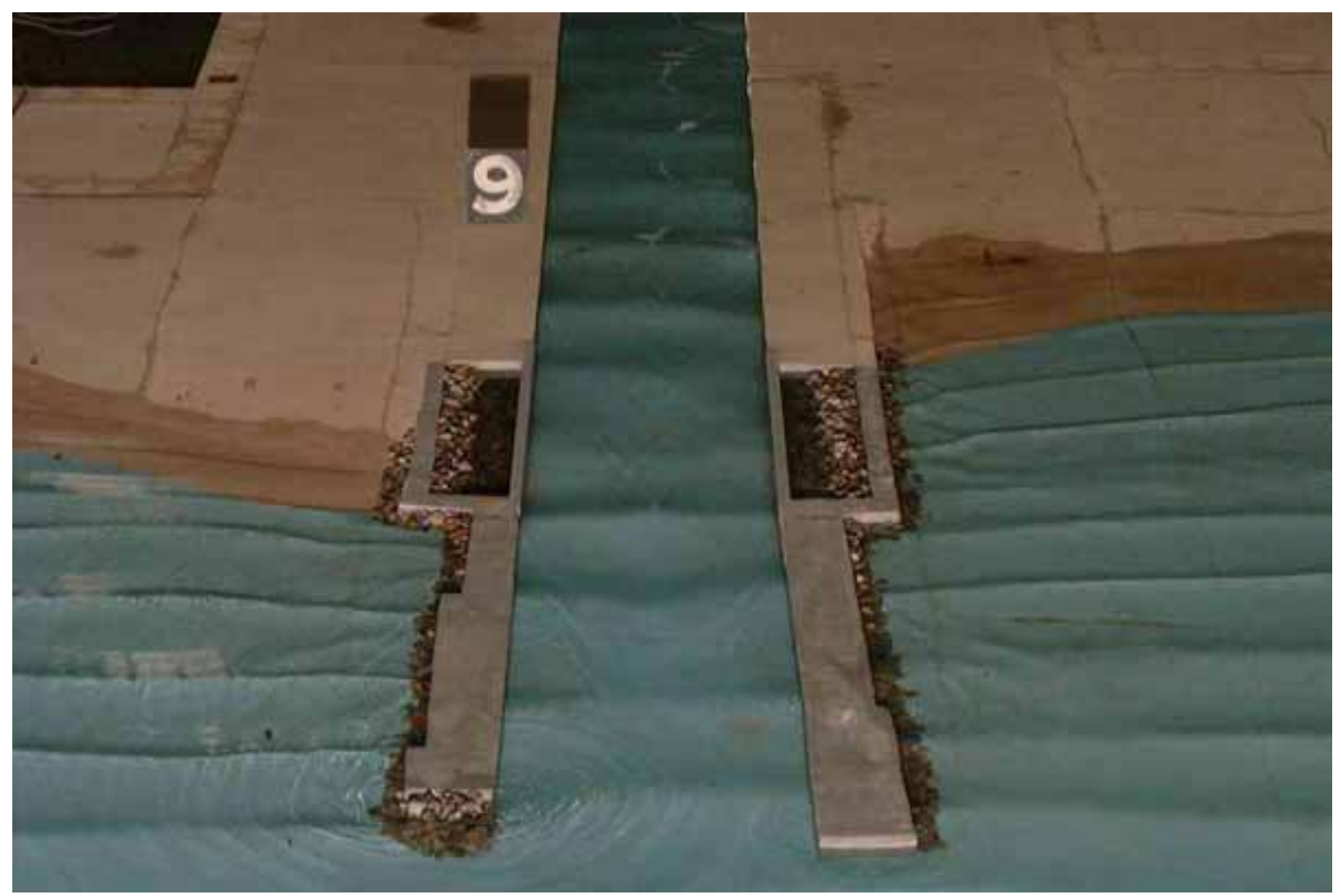

Photograph 9a. Typical wave patterns for Plan 1; 5-sec, 1-m waves from 0 deg; $\mathrm{sWl}=+0.9 \mathrm{~m}$ LWD, closeup.

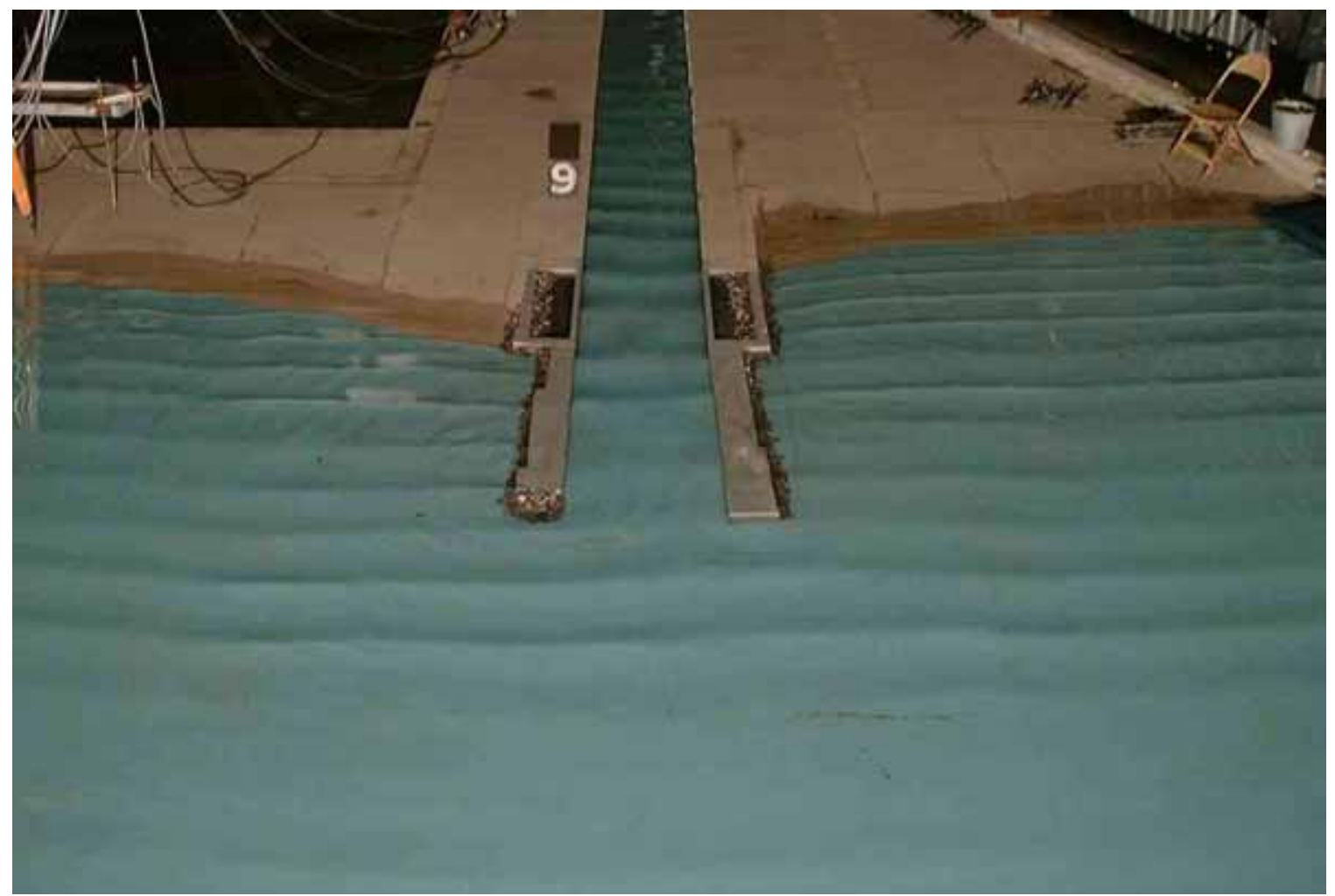

Photograph 9b. Typical wave patterns for Plan 1; 5-sec, 1-m waves from 0 deg; $\mathrm{sWl}=+0.9 \mathrm{~m}$ LWD. 


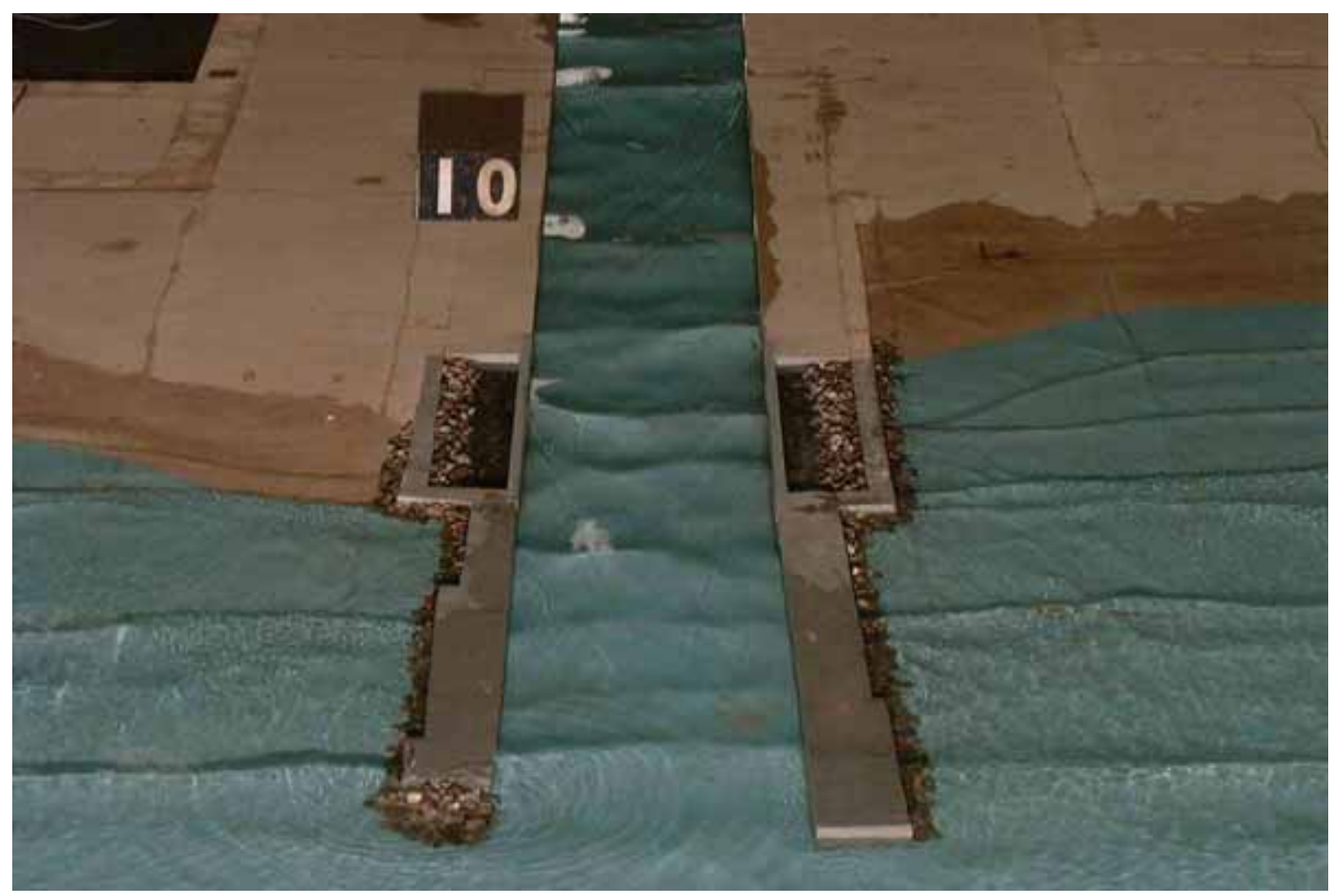

Photograph 10a. Typical wave patterns for Plan 1; 8-sec, 2-m waves from 0 deg; $s W l=+0.9 m$ LWD, closeup.

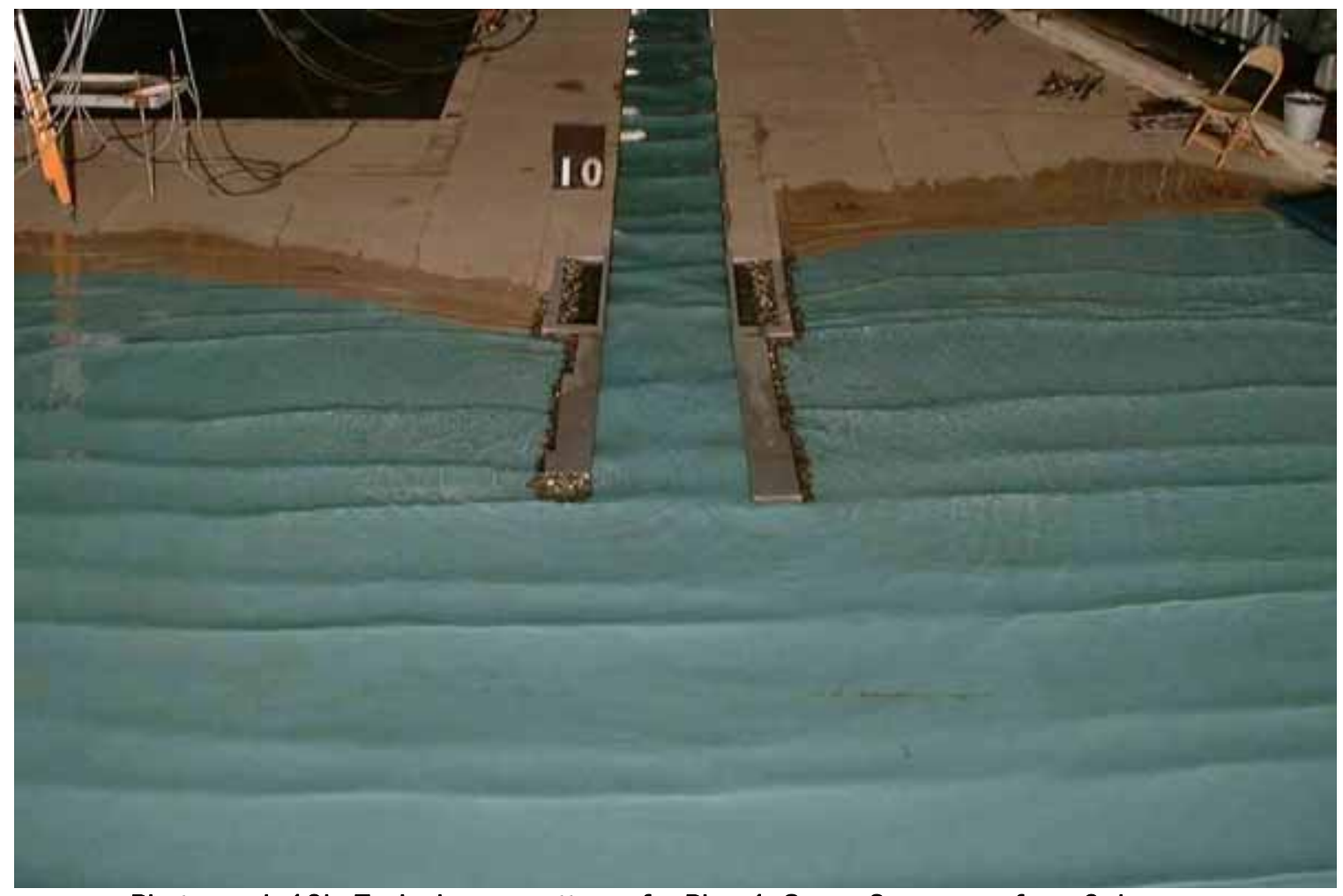

Photograph 10b. Typical wave patterns for Plan 1; 8-sec, 2-m waves from 0 deg; $\mathrm{sWl}=+0.9 \mathrm{~m}$ LWD. 


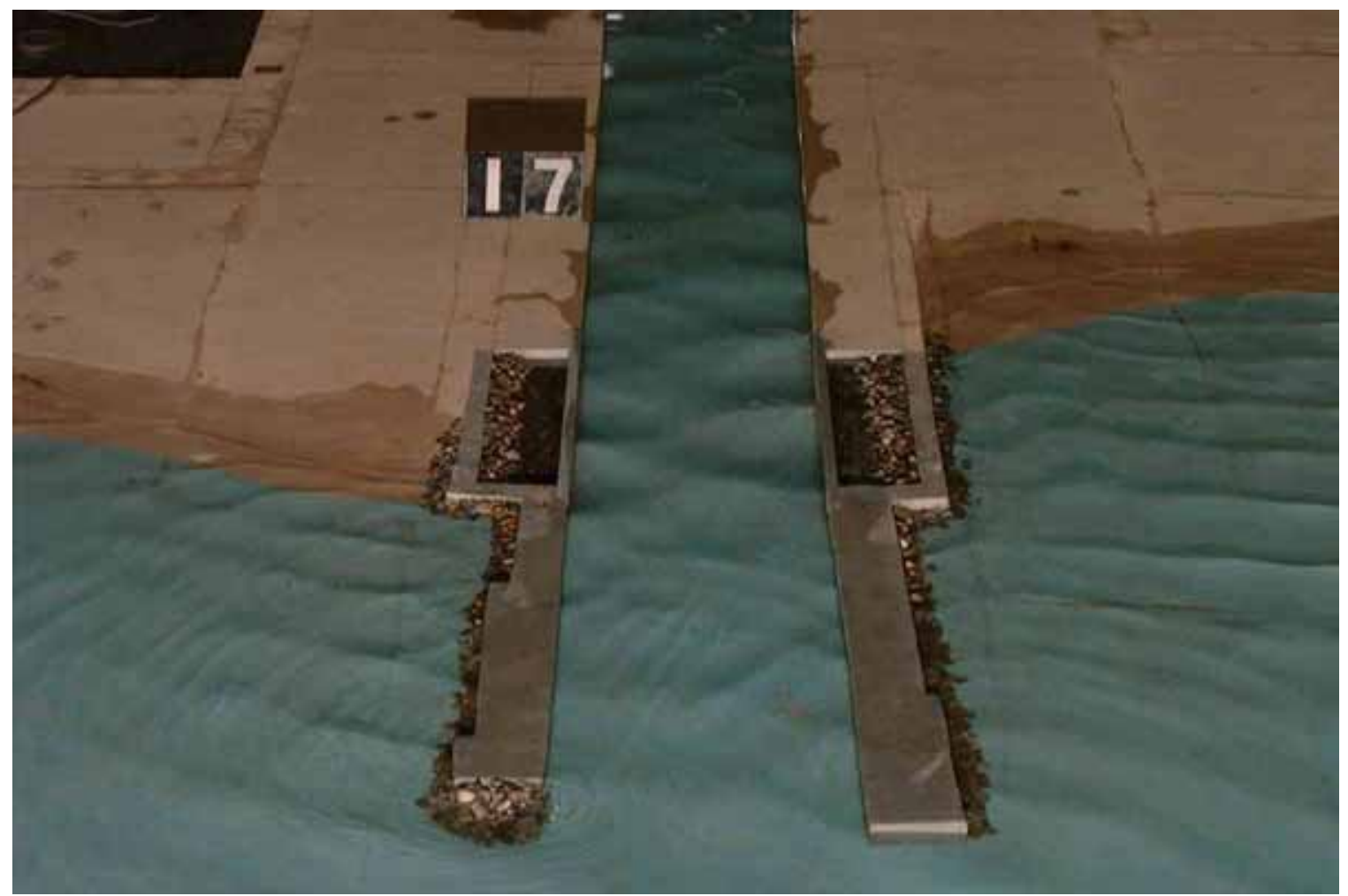

Photograph 11a. Typical wave patterns for Plan 1; 5-sec, 1-m waves from 45 deg North; $\mathrm{sWl}=+0.9 \mathrm{~m}$ LWD, closeup.

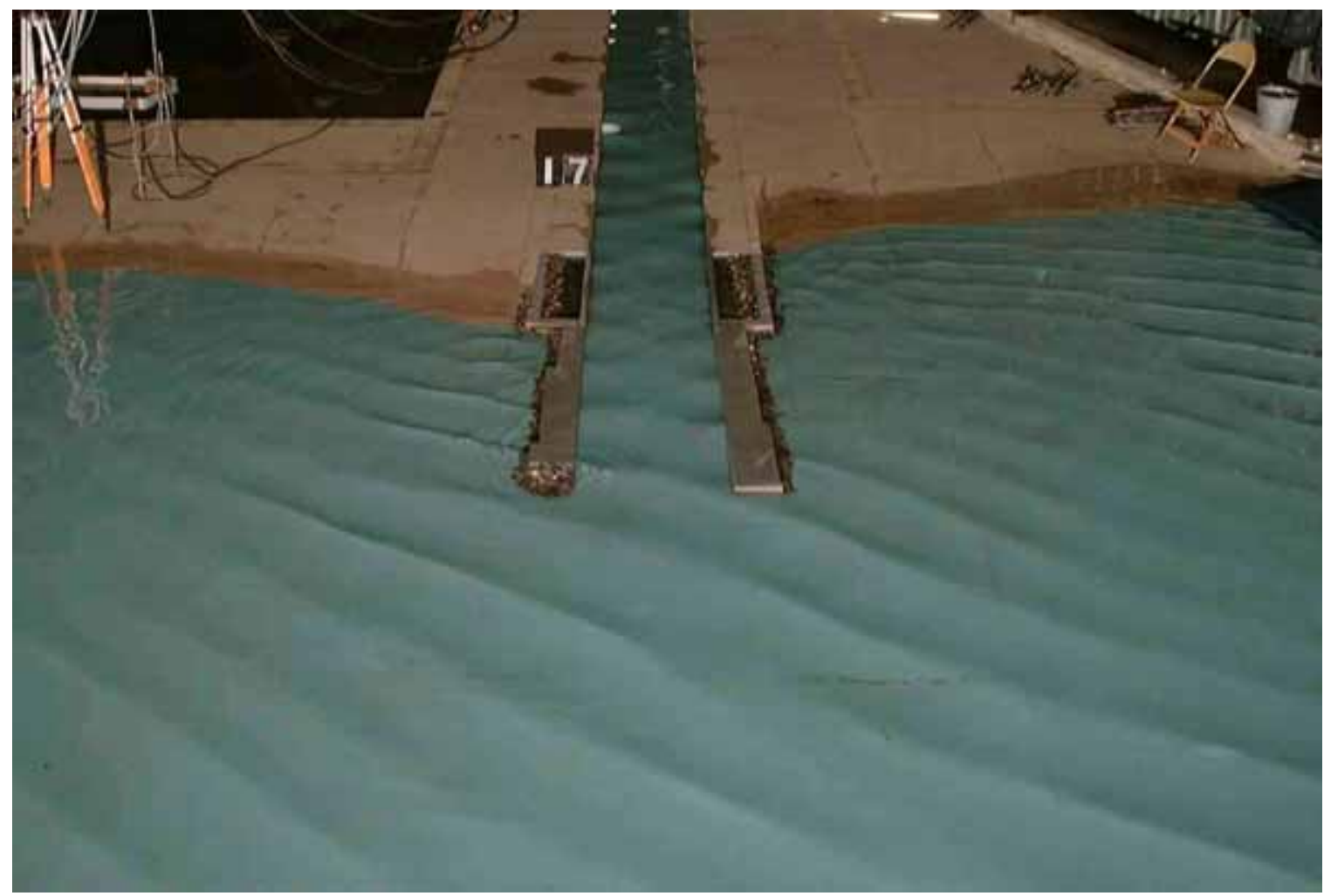

Photograph 11b. Typical wave patterns for Plan 1; 5-sec, 1-m waves from 45 deg North; $\mathrm{sWl}=+0.9 \mathrm{~m}$ LWD. 


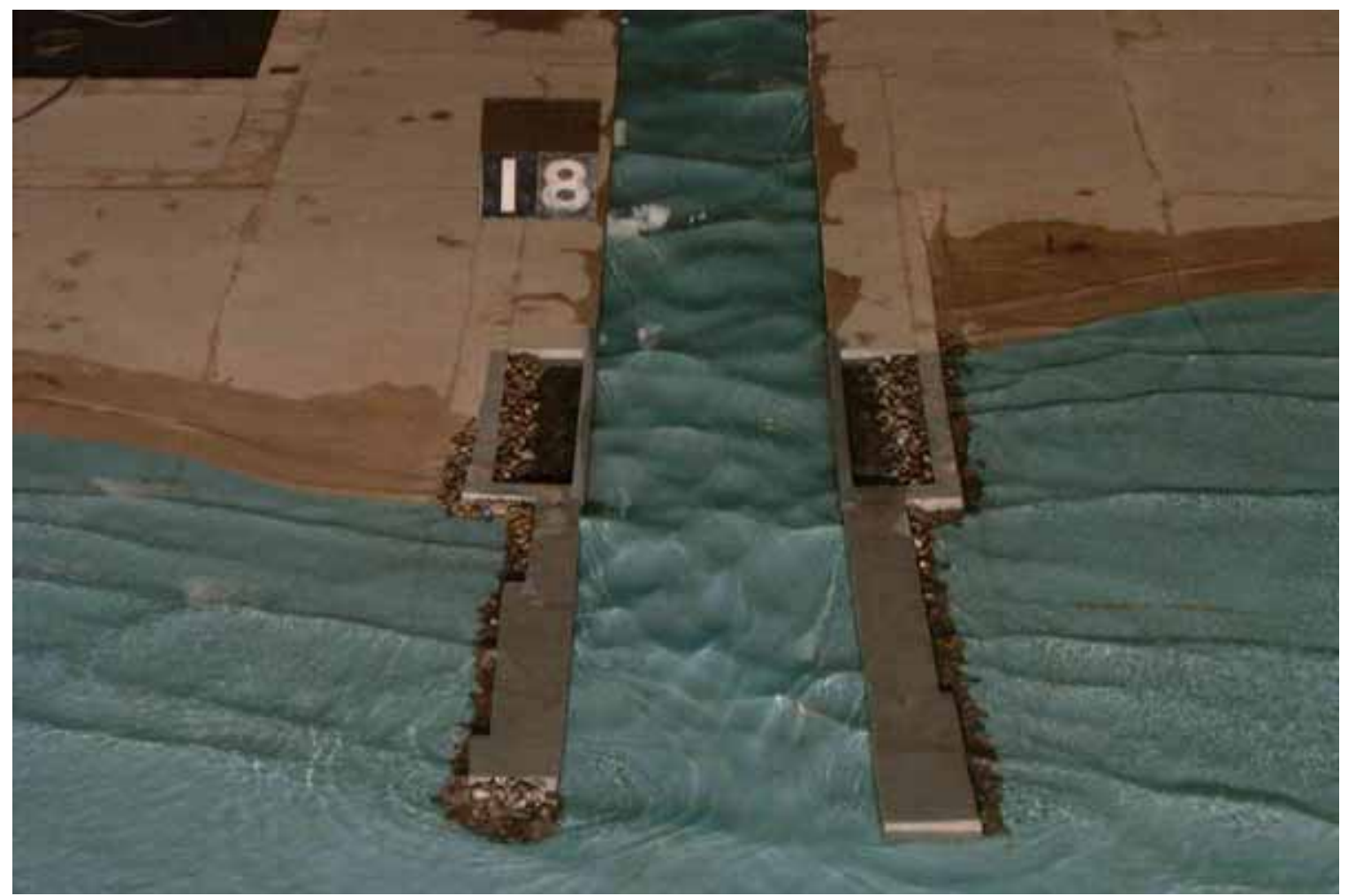

Photograph 12a. Typical wave patterns for Plan 1; 8-sec, 2-m waves from 45 deg North; $\mathrm{sWl}=+0.9 \mathrm{~m}$ LWD, closeup.

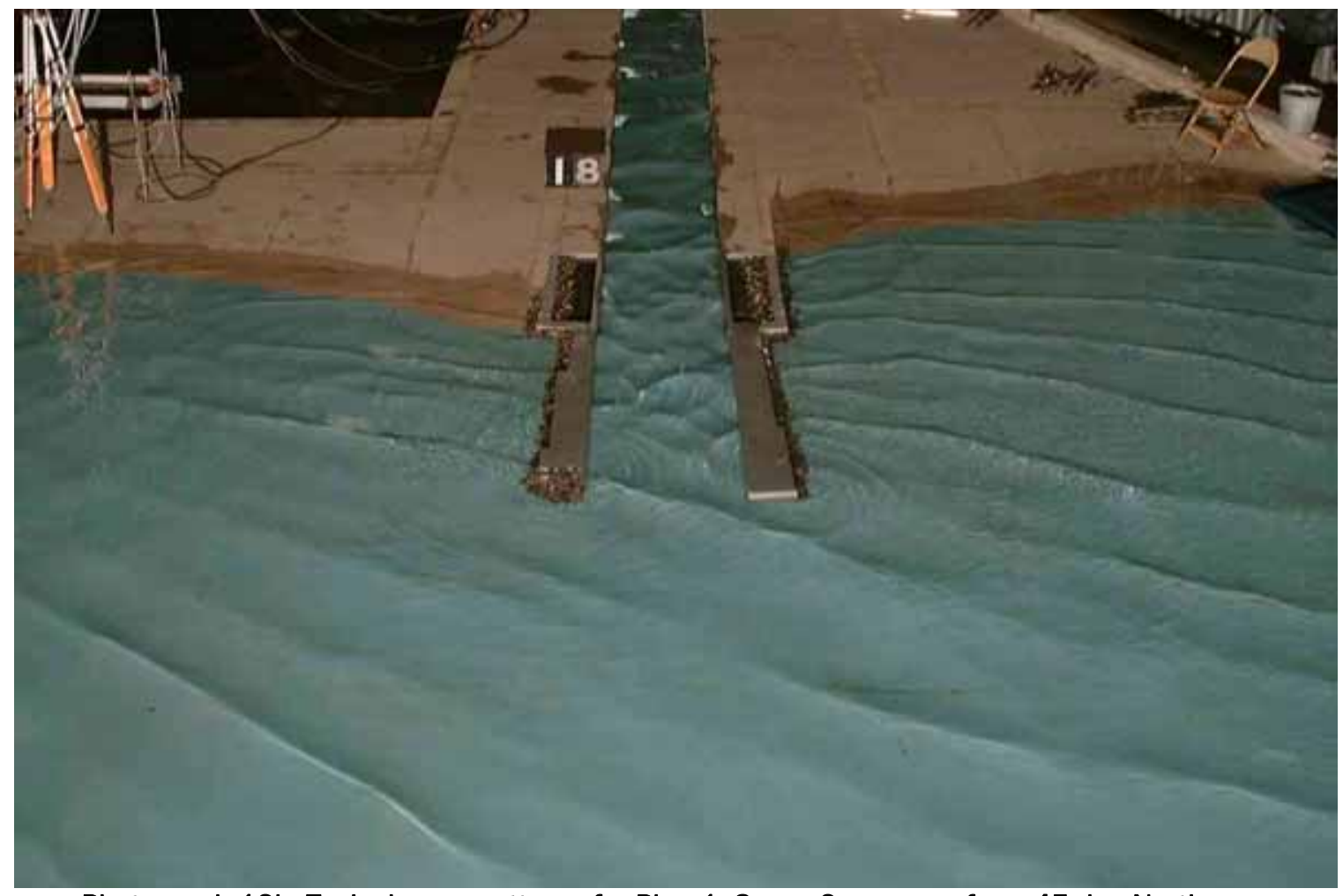

Photograph 12b. Typical wave patterns for Plan 1; 8-sec, 2-m waves from 45 deg North; $\mathrm{sWl}=+0.9 \mathrm{~m}$ LWD. 


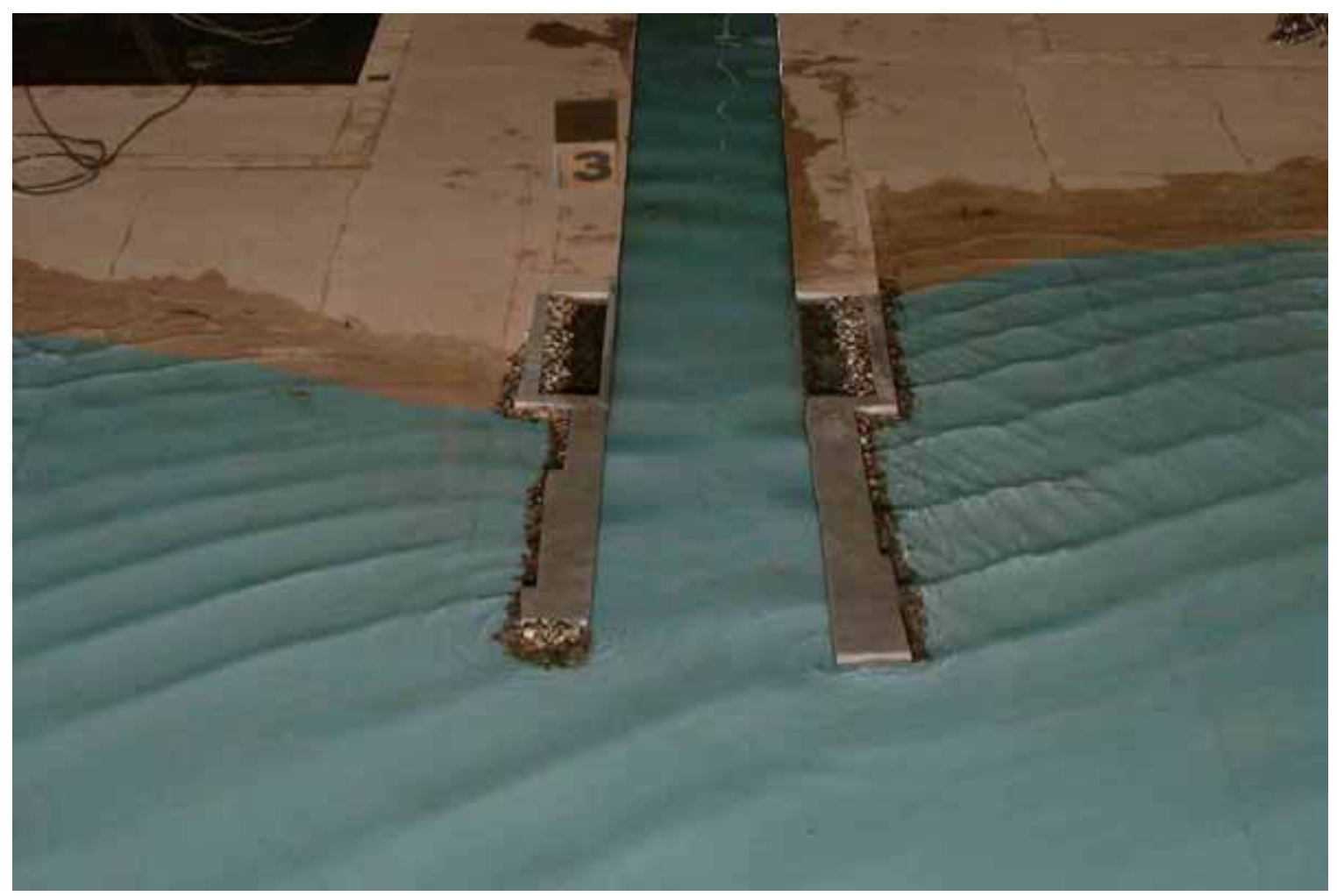

Photograph 13a. Typical wave patterns for Plan 2; 5-sec, 1-m waves from 45 deg South; $\mathrm{sWl}=+0.9 \mathrm{~m}$ LWD, closeup.

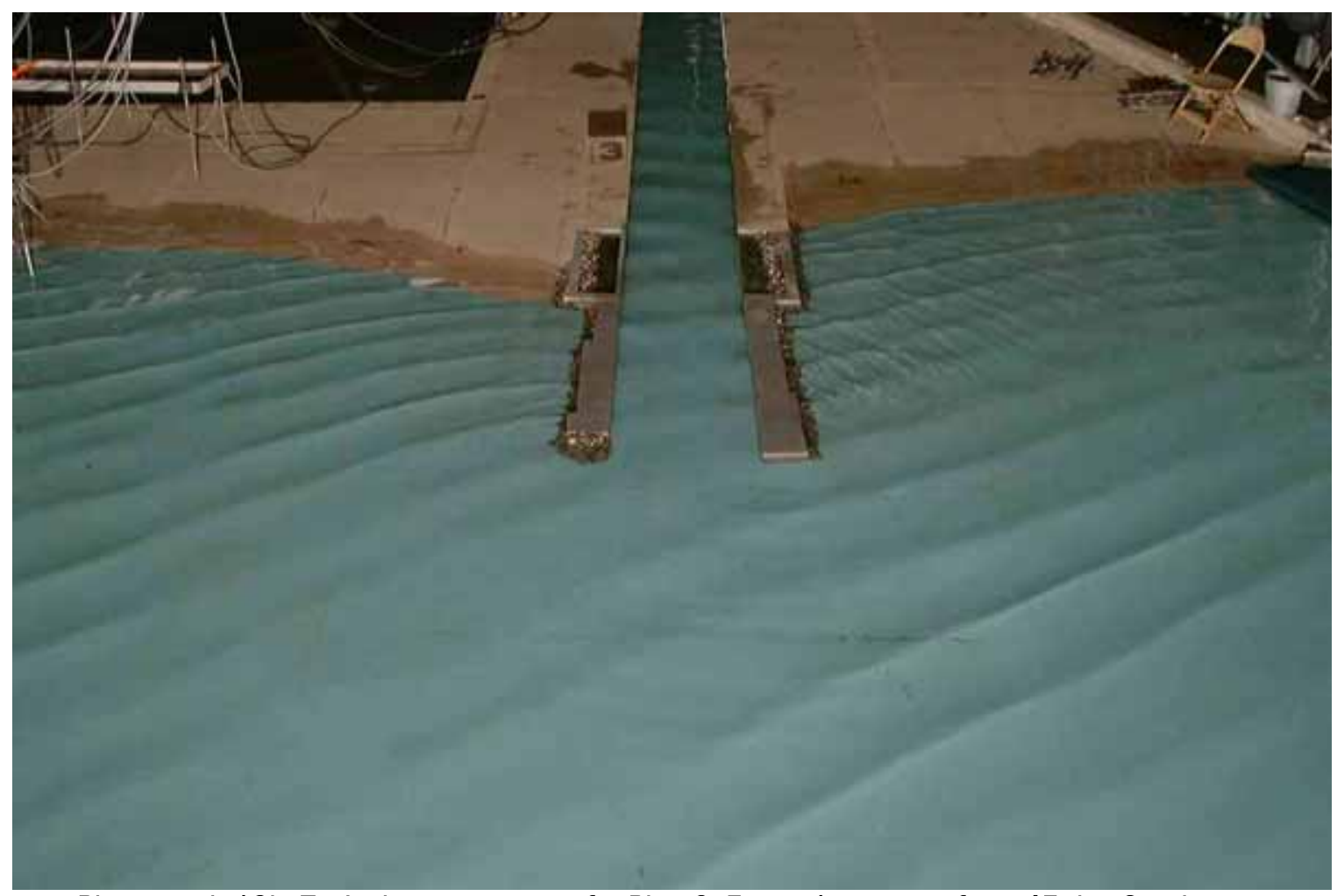

Photograph 13b. Typical wave patterns for Plan 2; 5-sec, 1-m waves from 45 deg South; $\mathrm{sWl}=+0.9 \mathrm{~m}$ LWD. 


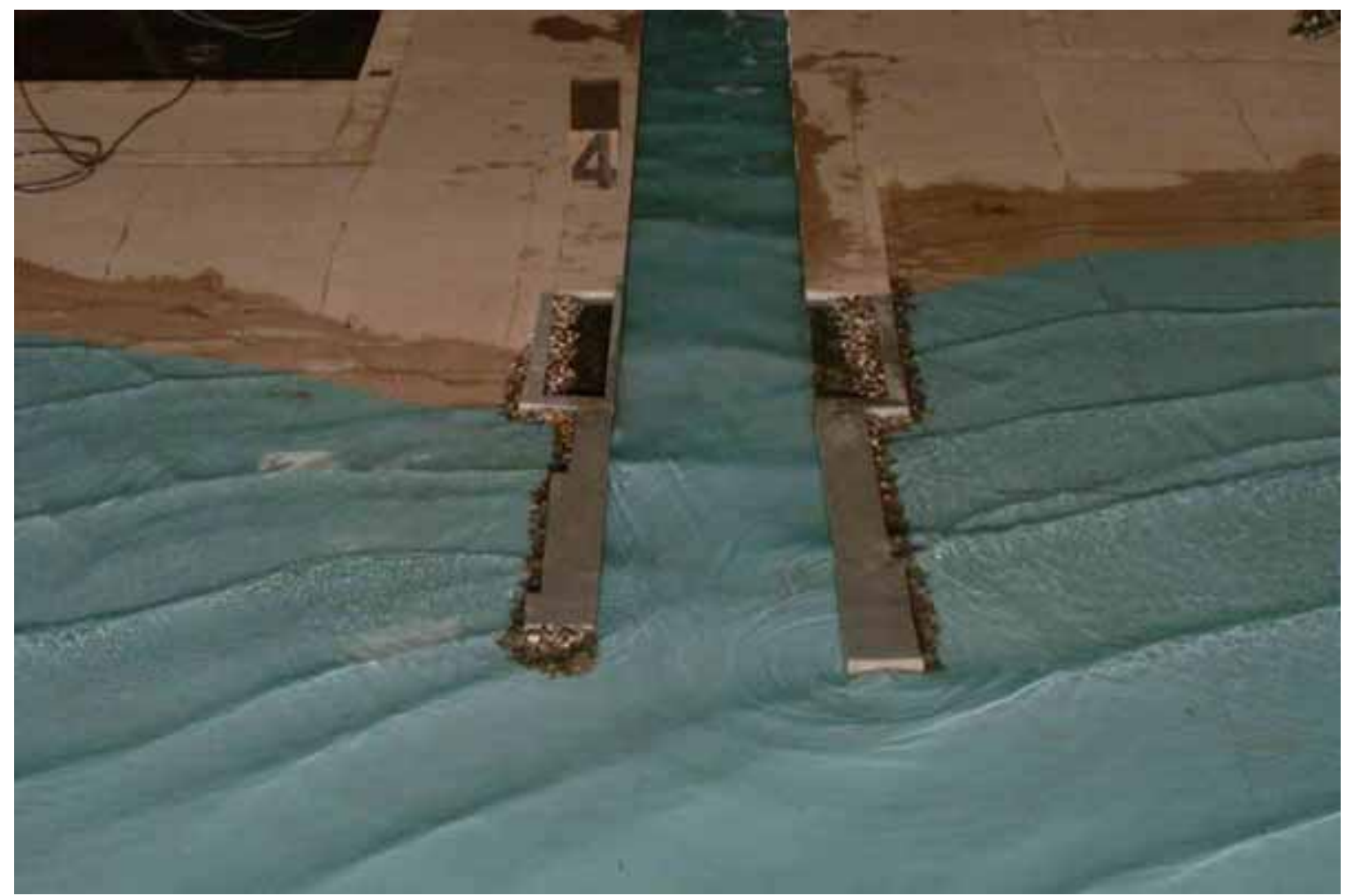

Photograph 14a. Typical wave patterns for Plan 2; 8-sec, 2-m waves from 45 deg South; $\mathrm{sWl}=+0.9 \mathrm{~m}$ LWD, closeup.

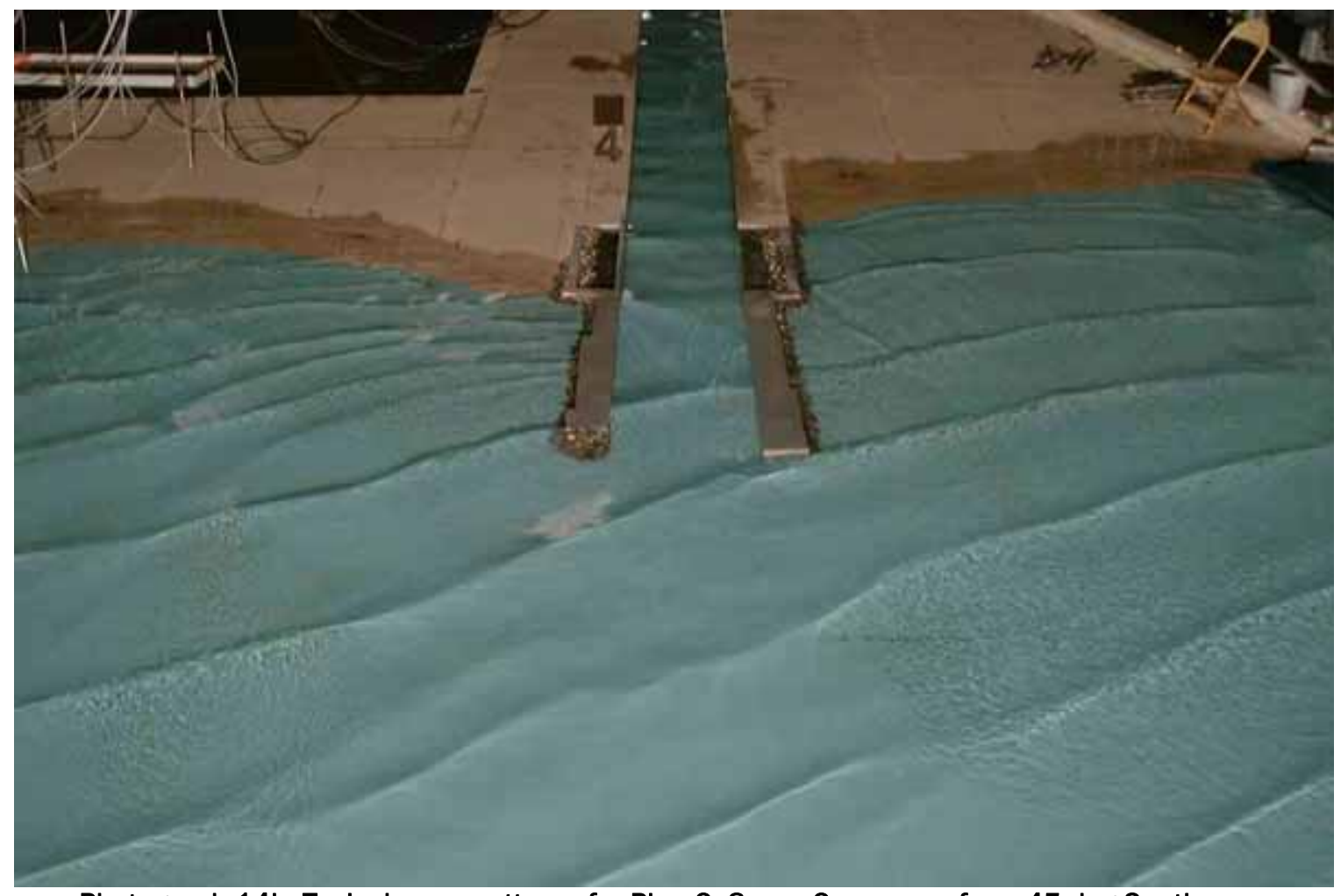

Photograph 14b. Typical wave patterns for Plan 2; 8-sec, 2-m waves from 45 deg South; $\mathrm{sWl}=+0.9 \mathrm{~m}$ LWD. 


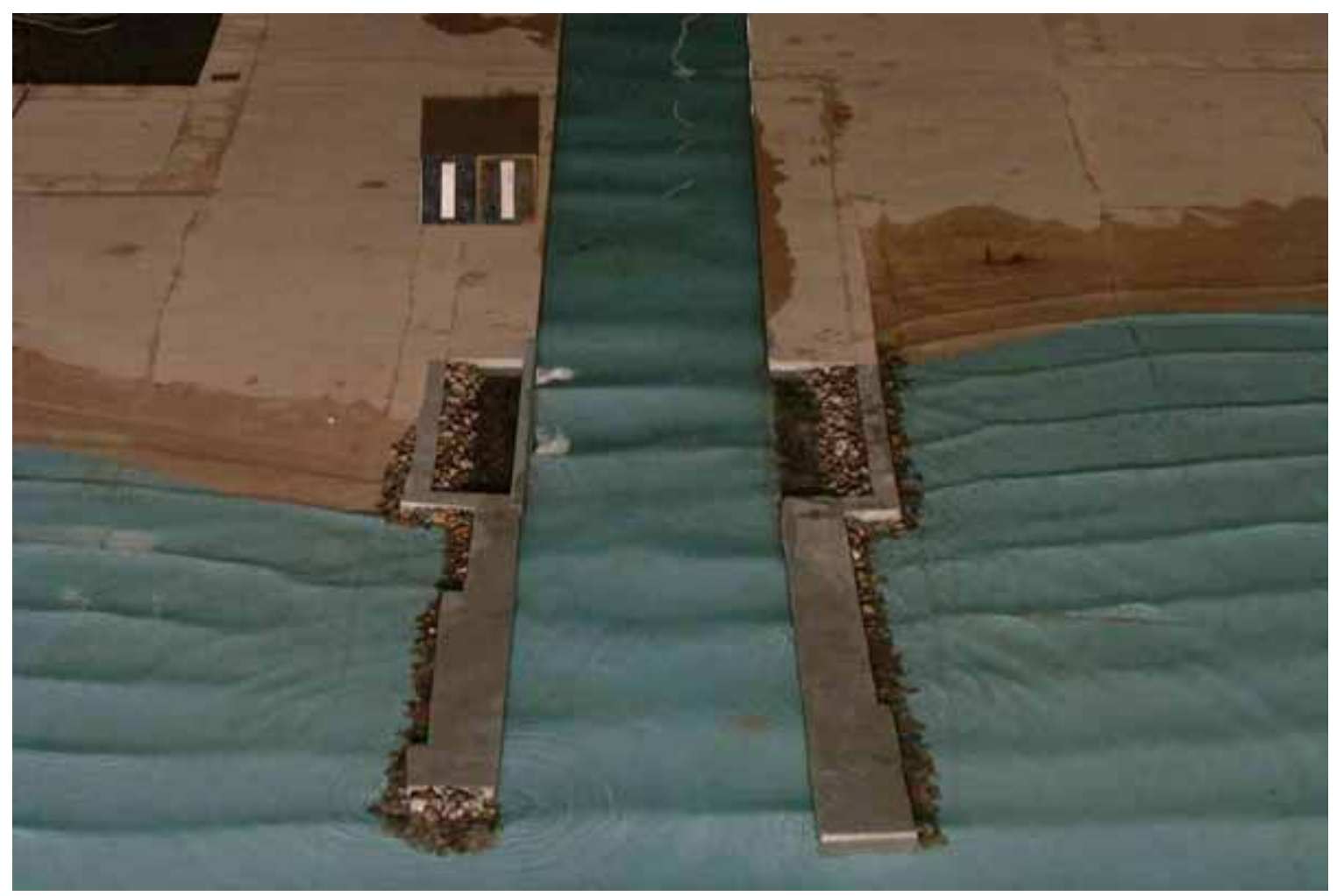

Photograph 15a. Typical wave patterns for Plan 2; 5-sec, 1-m waves from 0 deg; $\mathrm{sWl}=+0.9 \mathrm{~m}$ LWD, closeup.

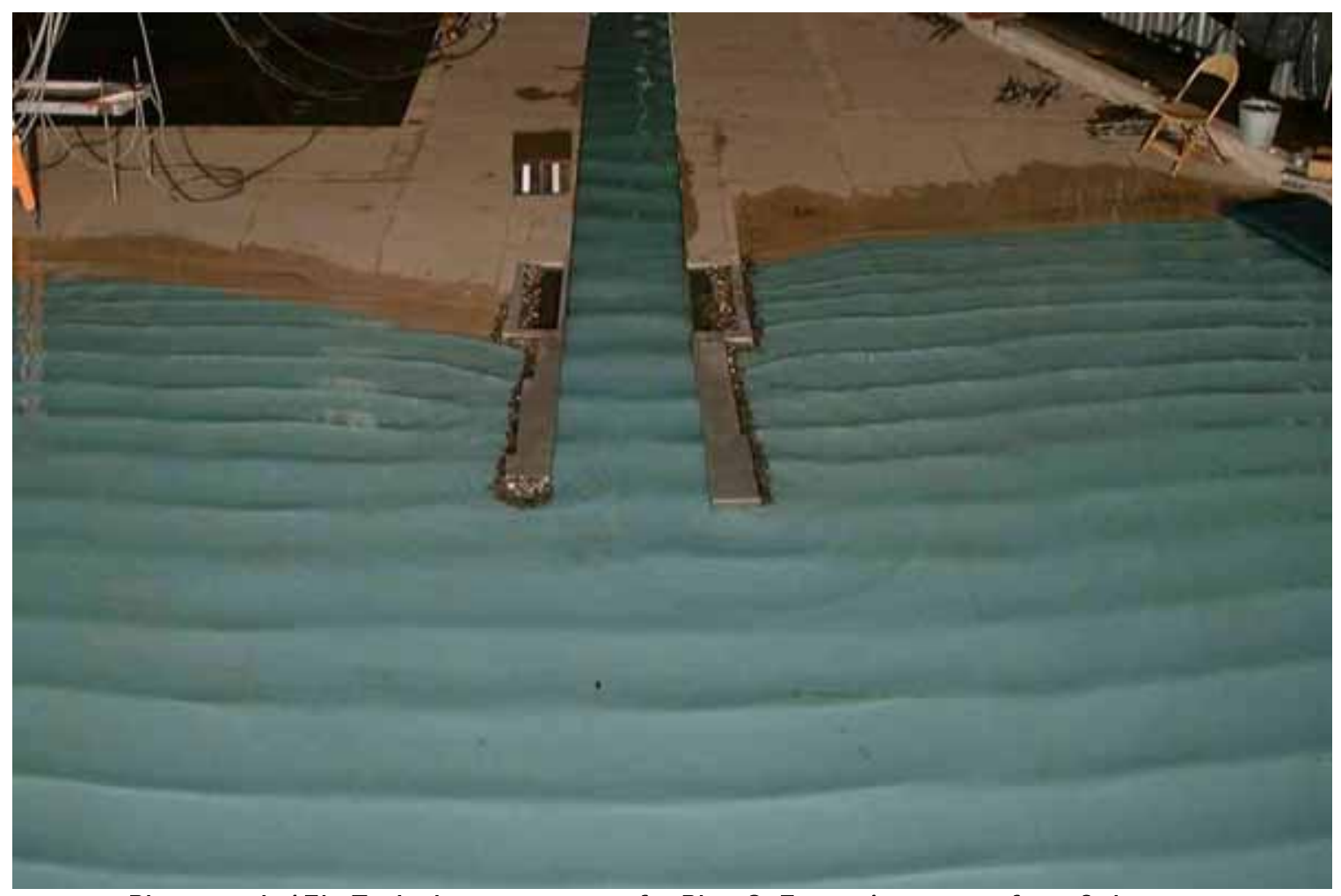

Photograph 15b. Typical wave patterns for Plan 2; 5-sec, 1-m waves from 0 deg; $\mathrm{sWl}=+0.9 \mathrm{~m}$ LWD. 


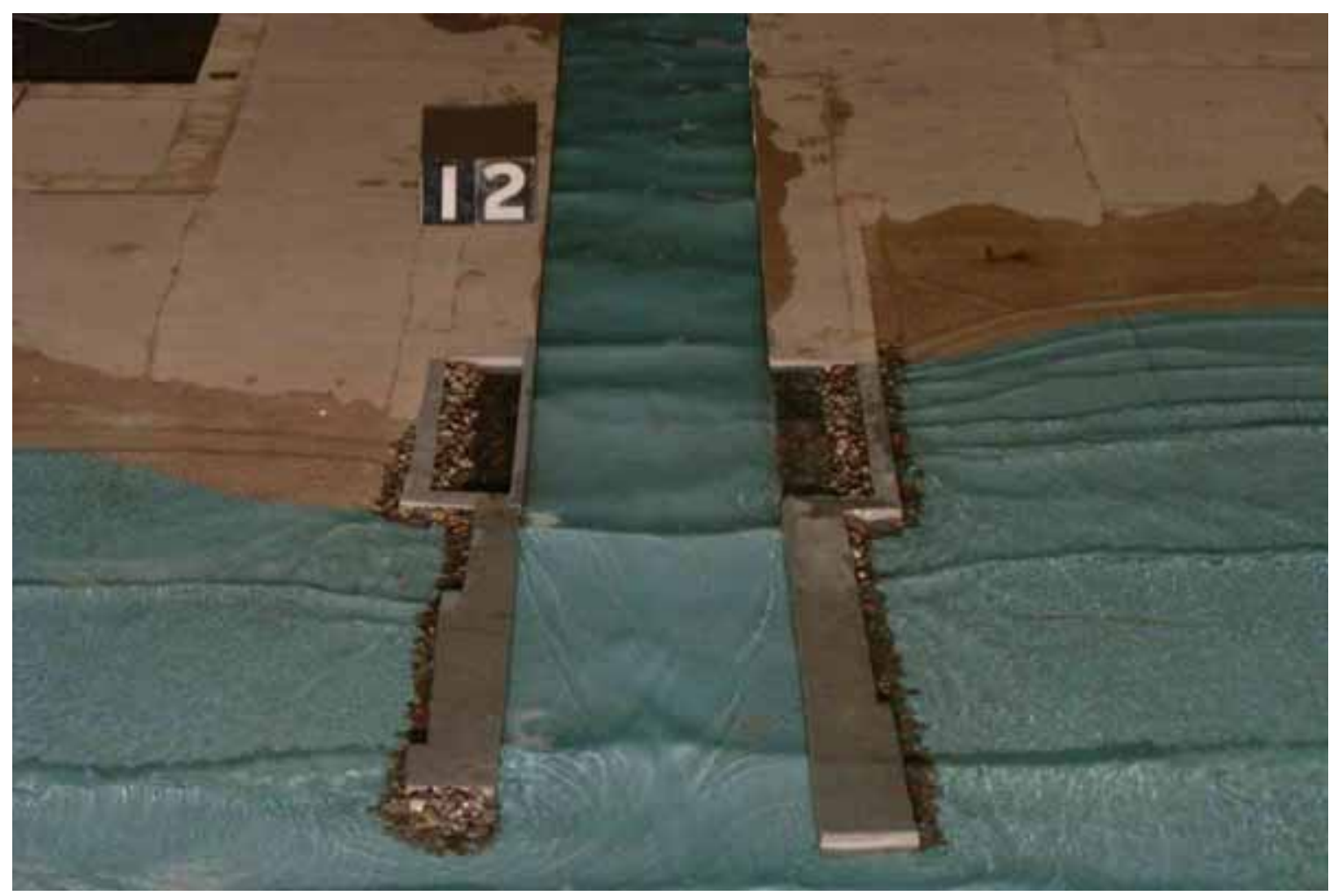

Photograph 16a. Typical wave patterns for Plan 2; 8-sec, 2-m waves from 0 deg; $\mathrm{sWl}=+0.9 \mathrm{~m}$ LWD, closeup.

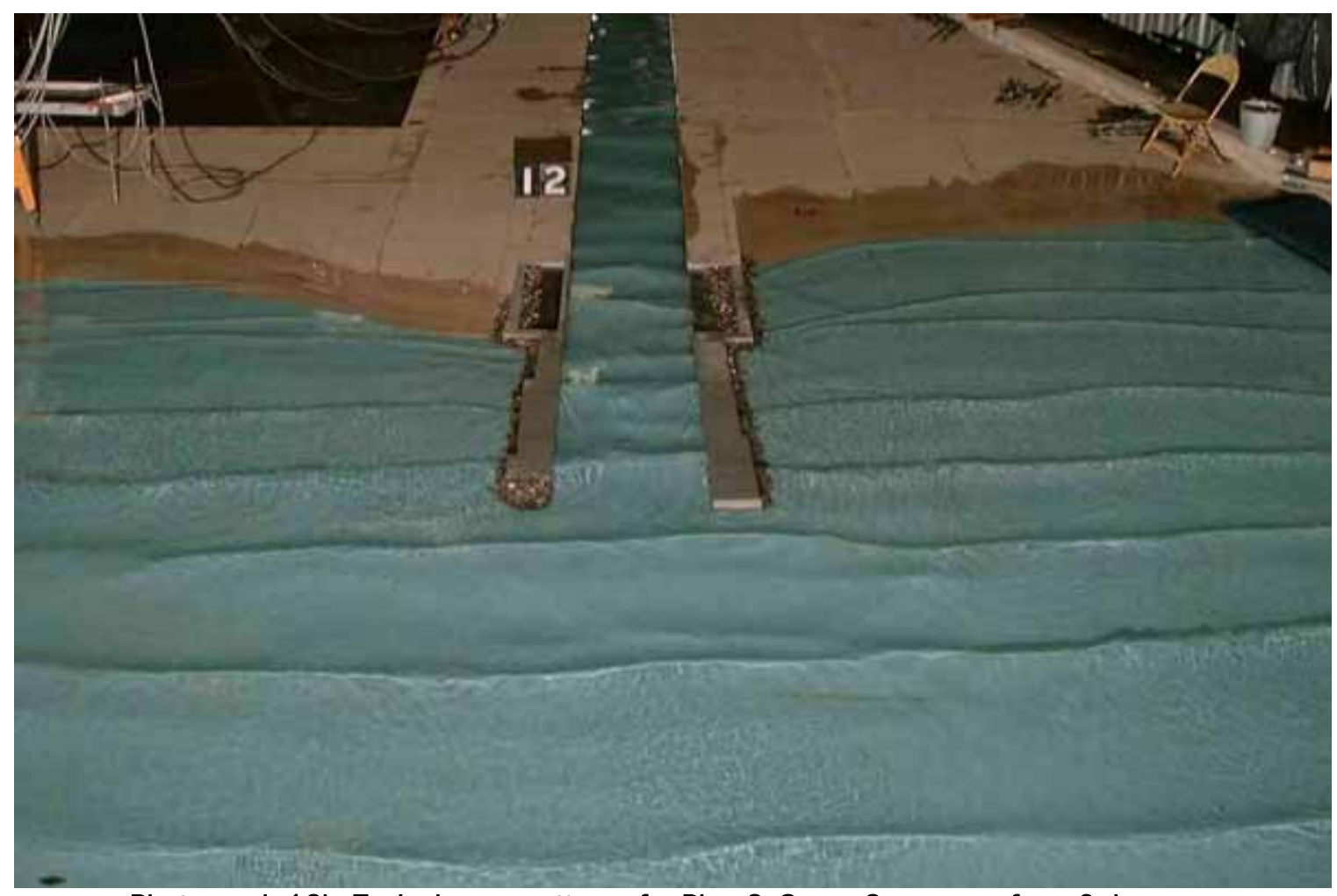

Photograph 16b. Typical wave patterns for Plan 2; 8-sec, 2-m waves from 0 deg; $\mathrm{sWl}=+0.9 \mathrm{~m}$ LWD. 


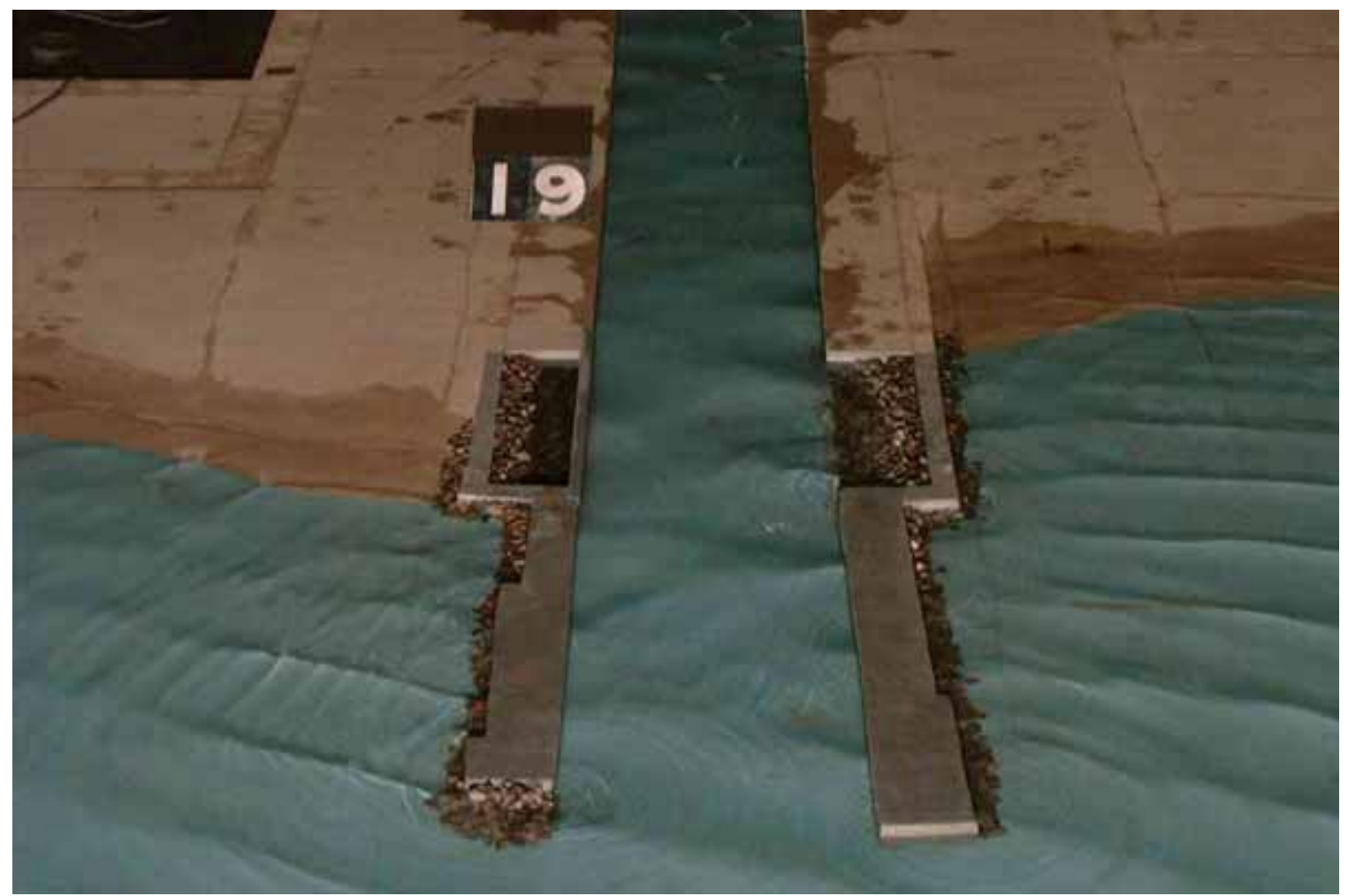

Photograph 17a. Typical wave patterns for Plan 2; 5-sec, 1-m waves from 45 deg North; $\mathrm{sWl}=+0.9 \mathrm{~m}$ LWD, closeup.

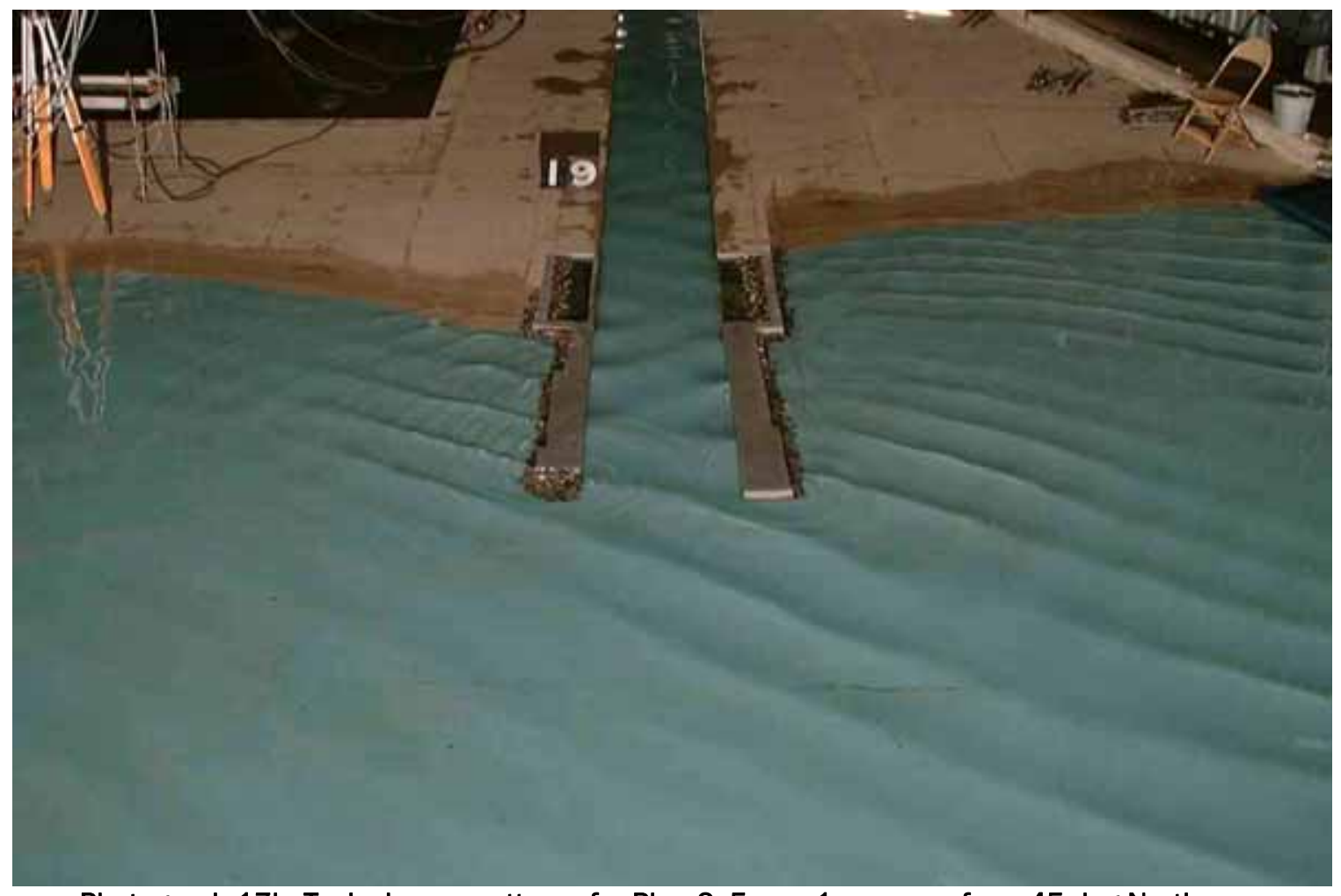

Photograph 17b. Typical wave patterns for Plan 2; 5-sec, 1-m waves from 45 deg North; $\mathrm{sWl}=+0.9 \mathrm{~m}$ LWD. 


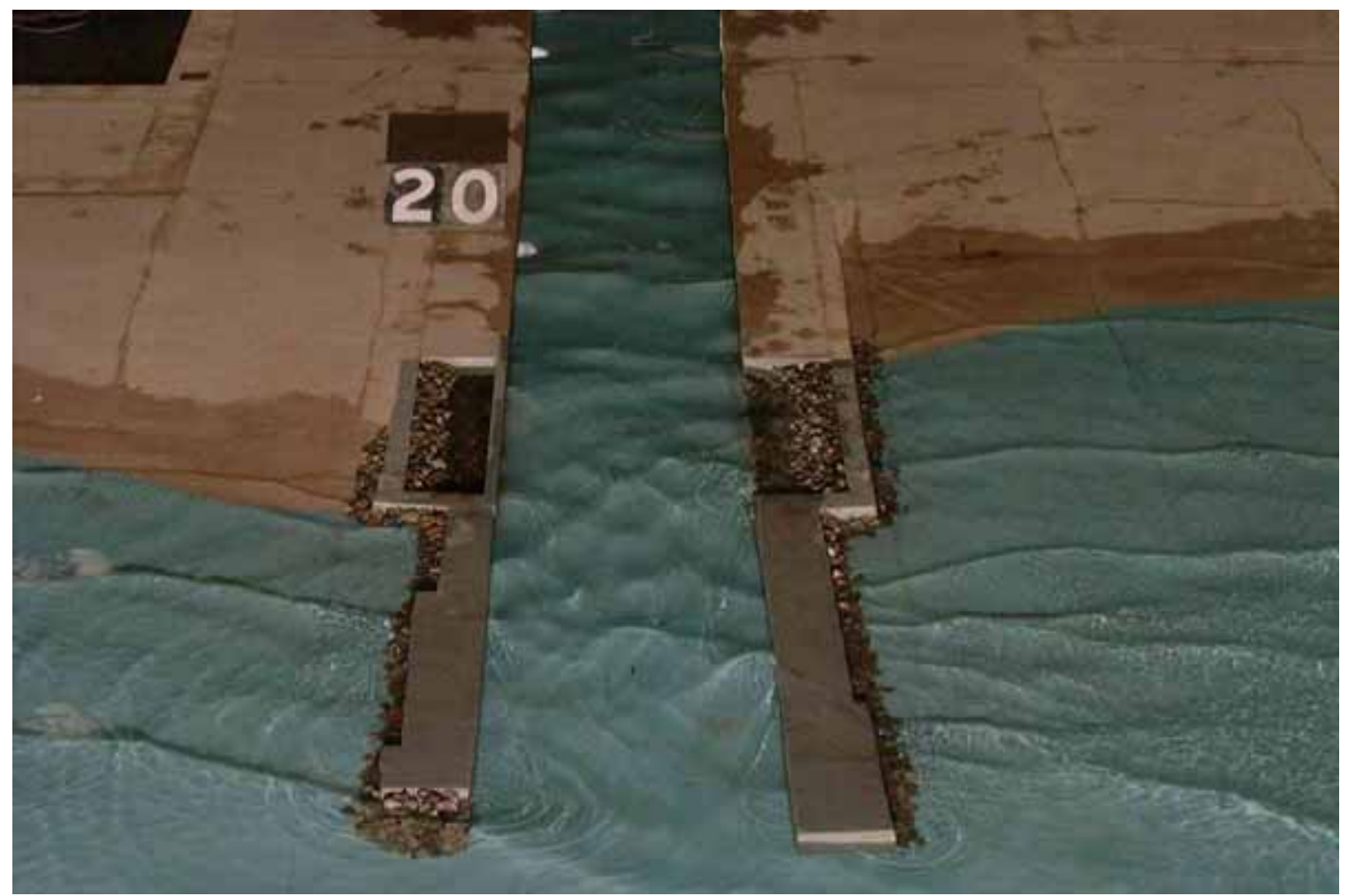

Photograph 18a. Typical wave patterns for Plan 2; 8-sec, 2-m waves from 45 deg North; $\mathrm{sWl}=+0.9 \mathrm{~m}$ LWD, closeup.

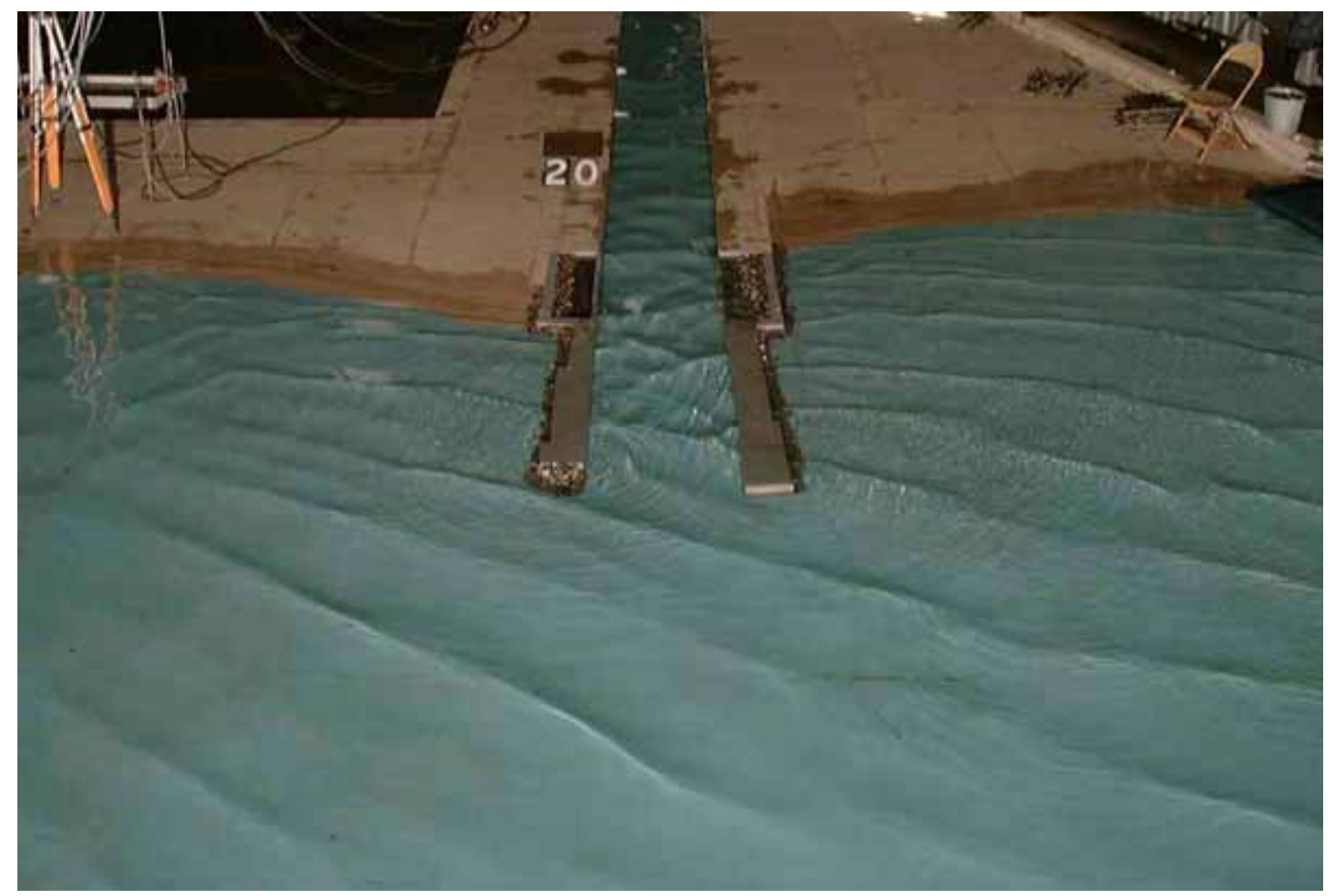

Photograph 18b. Typical wave patterns for Plan 2; 8-sec, 2-m waves from 45 deg North; $\mathrm{sWl}=+0.9 \mathrm{~m}$ LWD. 


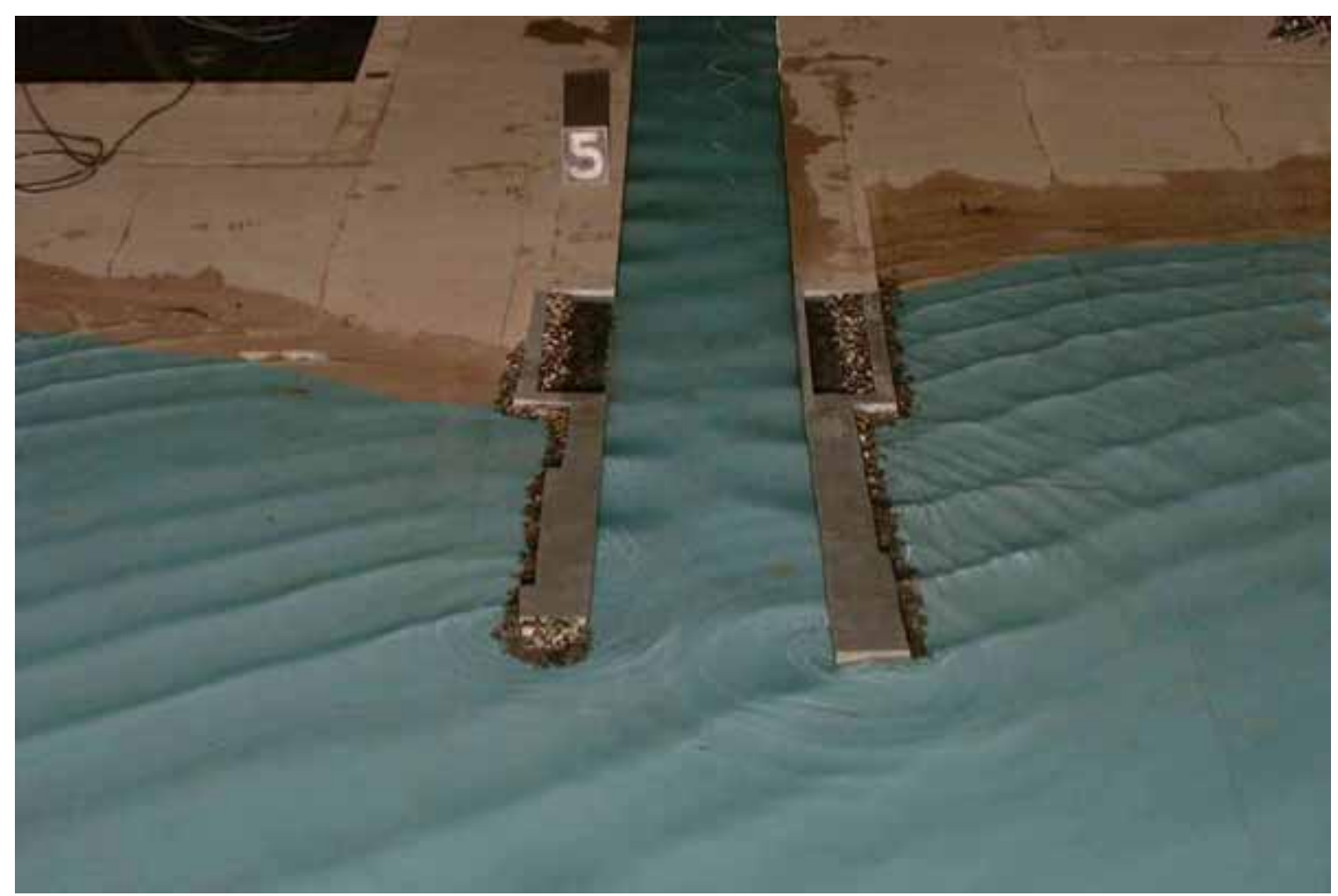

Photograph 19a. Typical wave patterns for Plan 3; 5-sec, 1-m waves from 45 deg South; $\mathrm{sWl}=+0.9 \mathrm{~m}$ LWD, closeup.

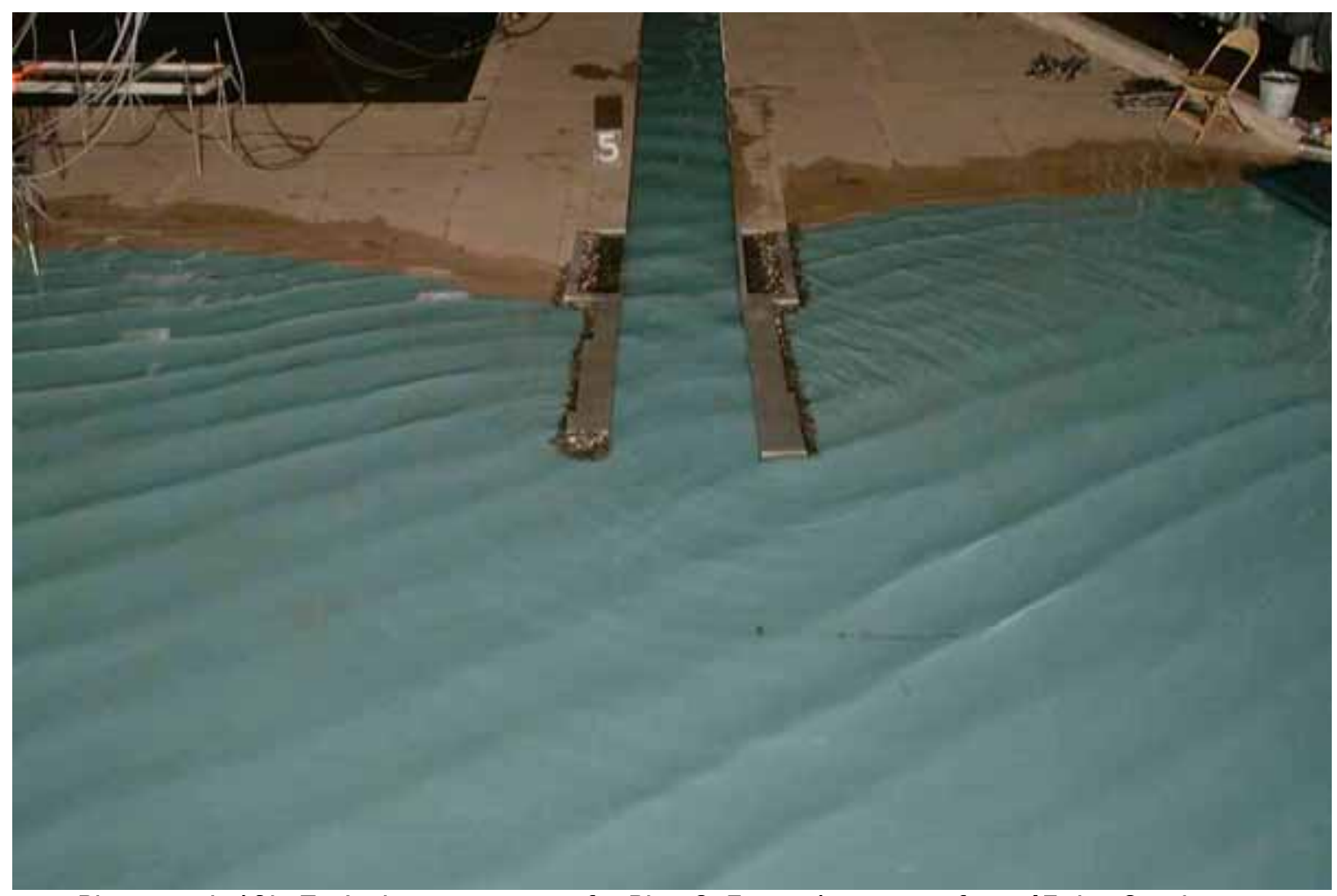

Photograph 19b. Typical wave patterns for Plan 3; 5-sec, 1-m waves from 45 deg South; $\mathrm{sWl}=+0.9 \mathrm{~m}$ LWD. 


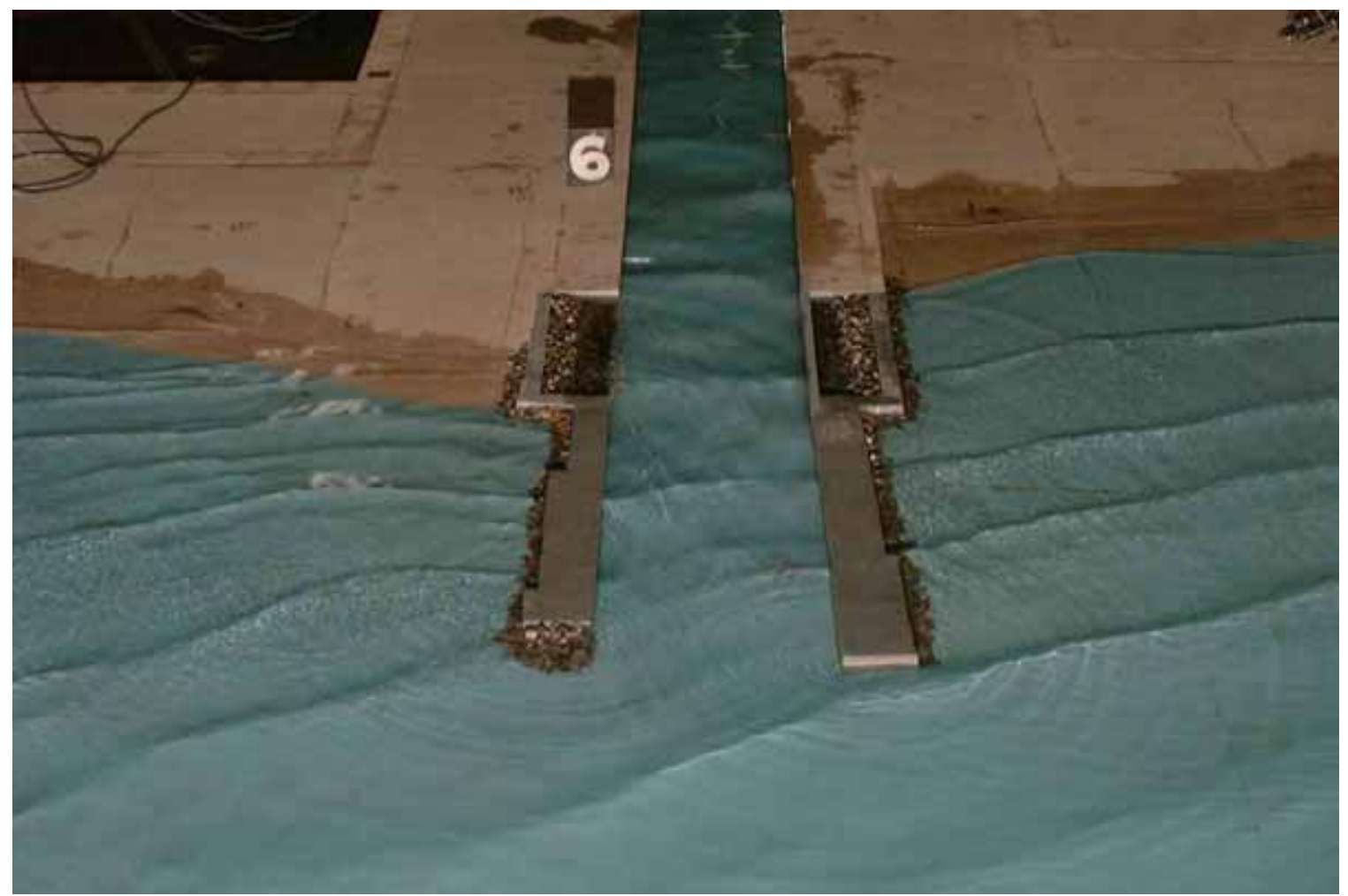

Photograph 20a. Typical wave patterns for Plan 3; 8-sec, 2-m waves from 45 deg South; $s W l=+0.9 m$ LWD, closeup.

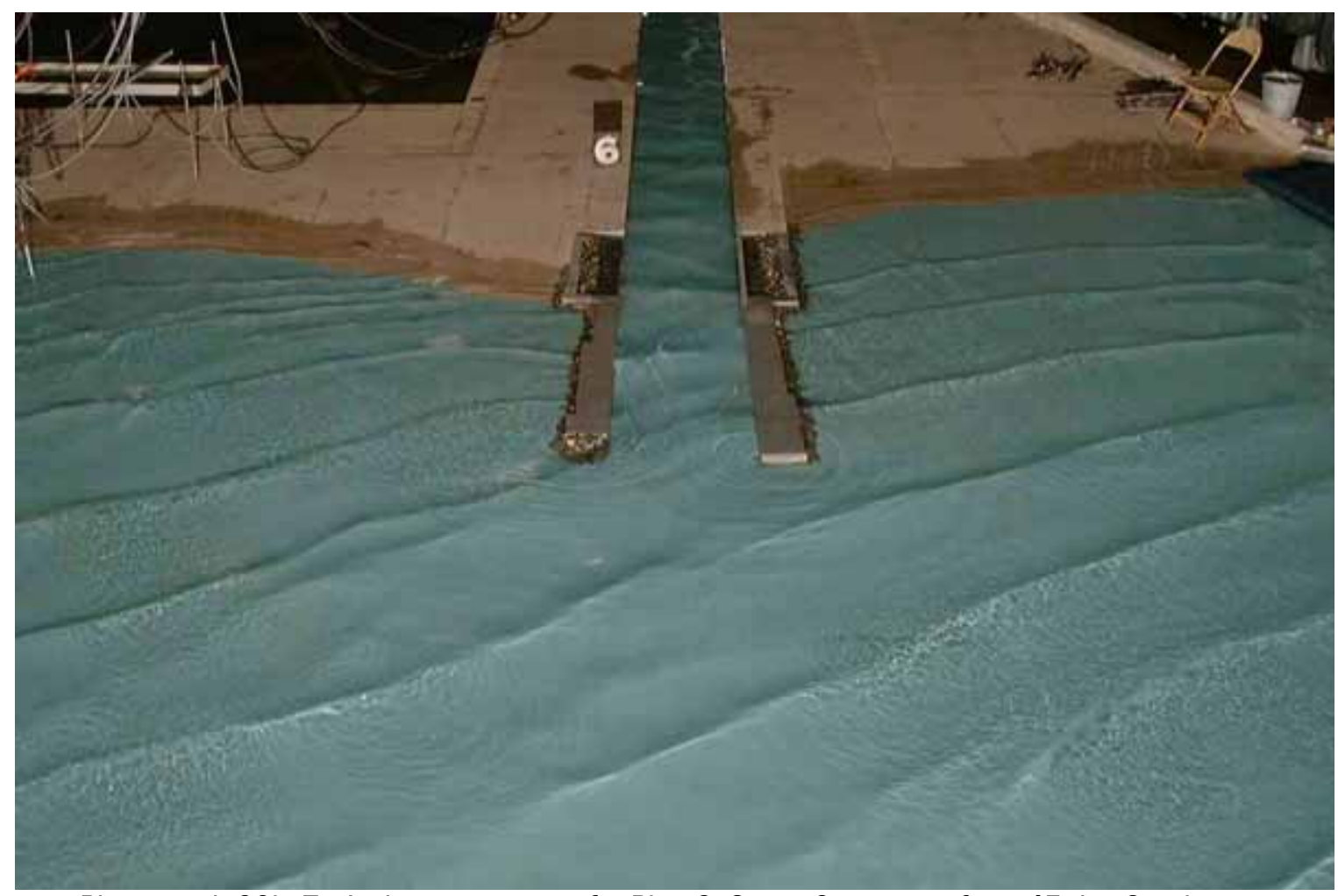

Photograph 20b. Typical wave patterns for Plan 3; 8-sec, 2-m waves from 45 deg South; $\mathrm{sWl}=+0.9 \mathrm{~m}$ LWD. 


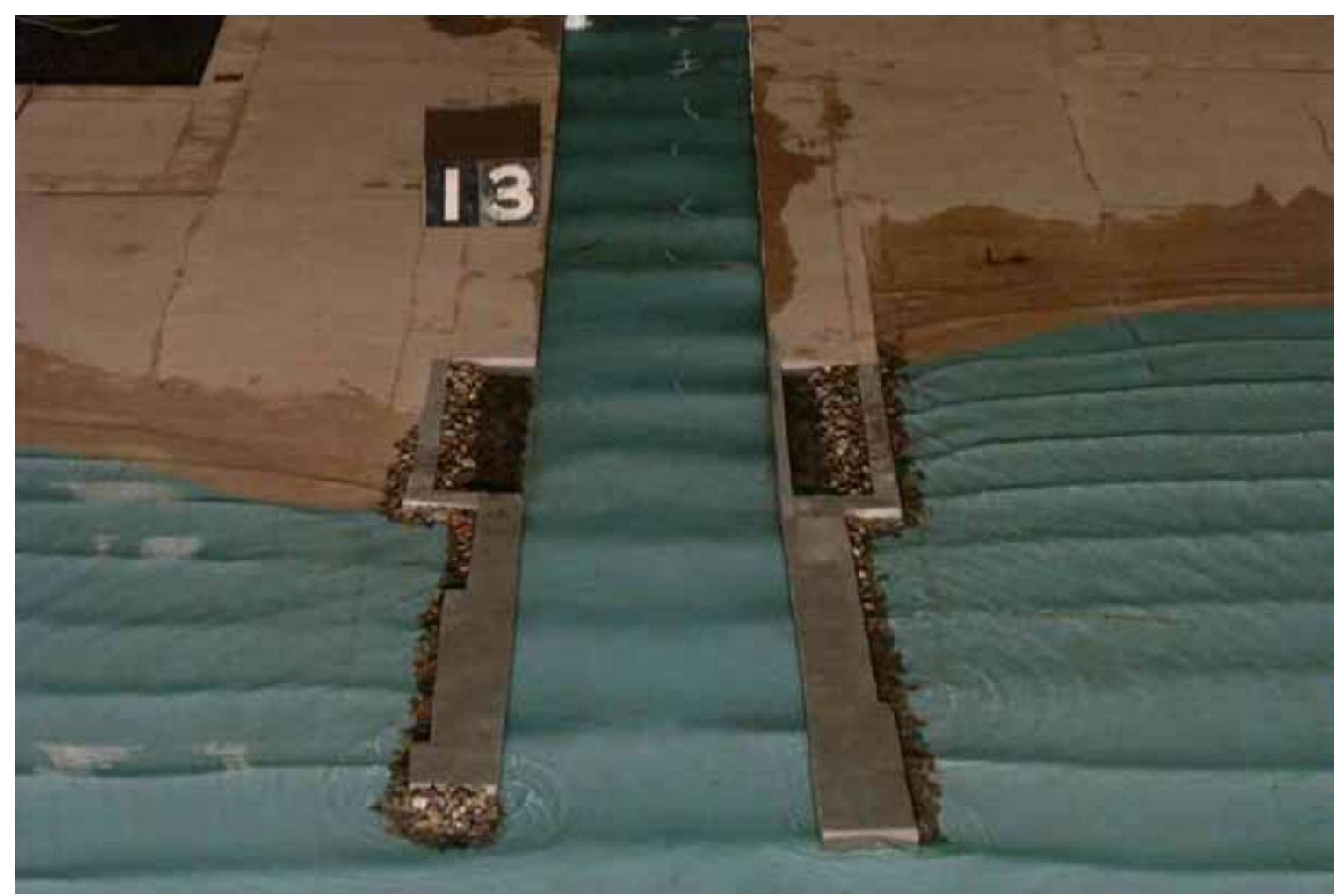

Photograph 21a. Typical wave patterns for Plan 3; 5-sec, 1-m waves from 0 deg; $\mathrm{sWl}=+0.9 \mathrm{~m}$ LWD, closeup.

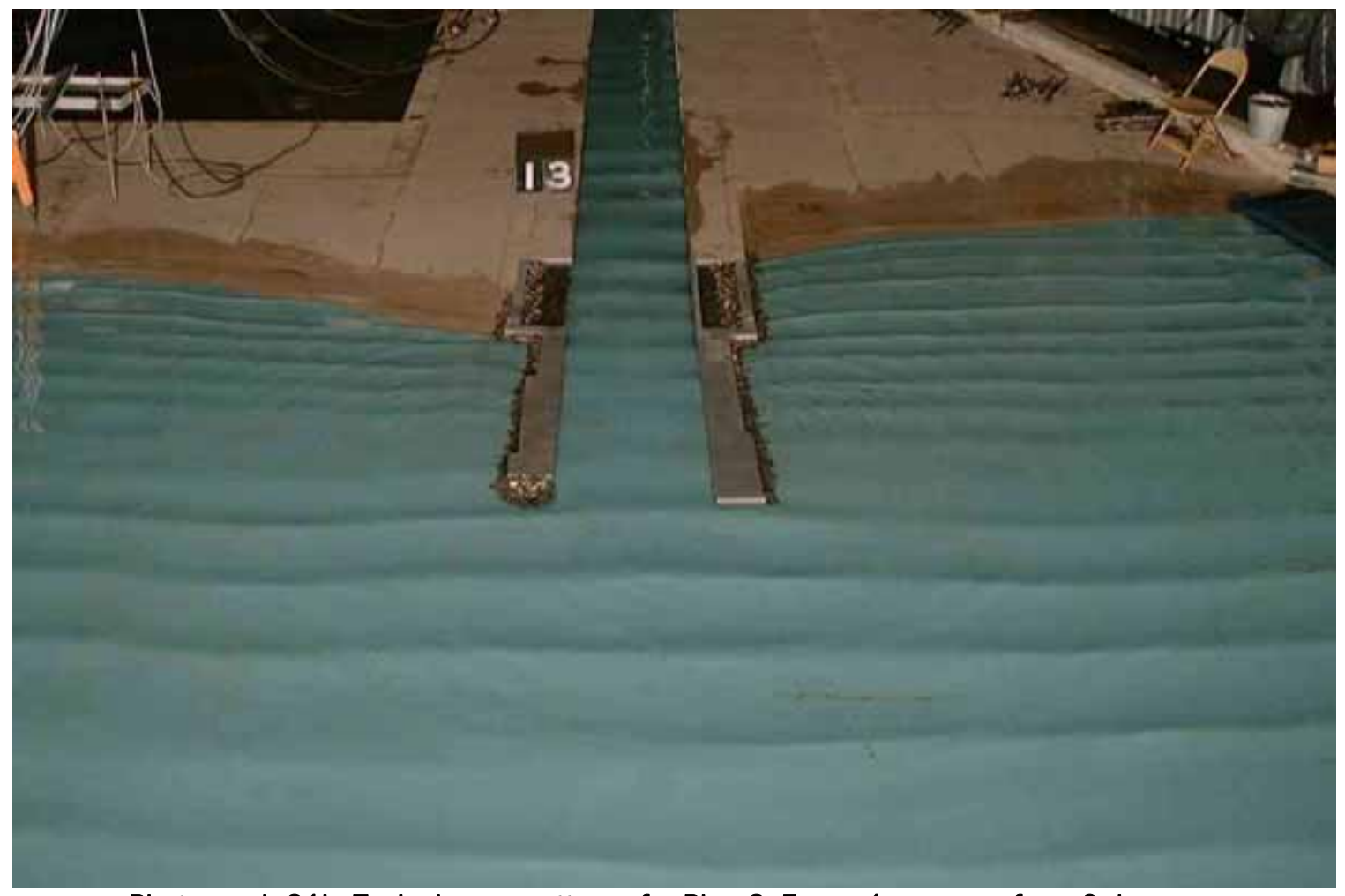

Photograph 21b. Typical wave patterns for Plan 3; 5-sec, 1-m waves from 0 deg; $\mathrm{sWl}=+0.9 \mathrm{~m}$ LWD. 


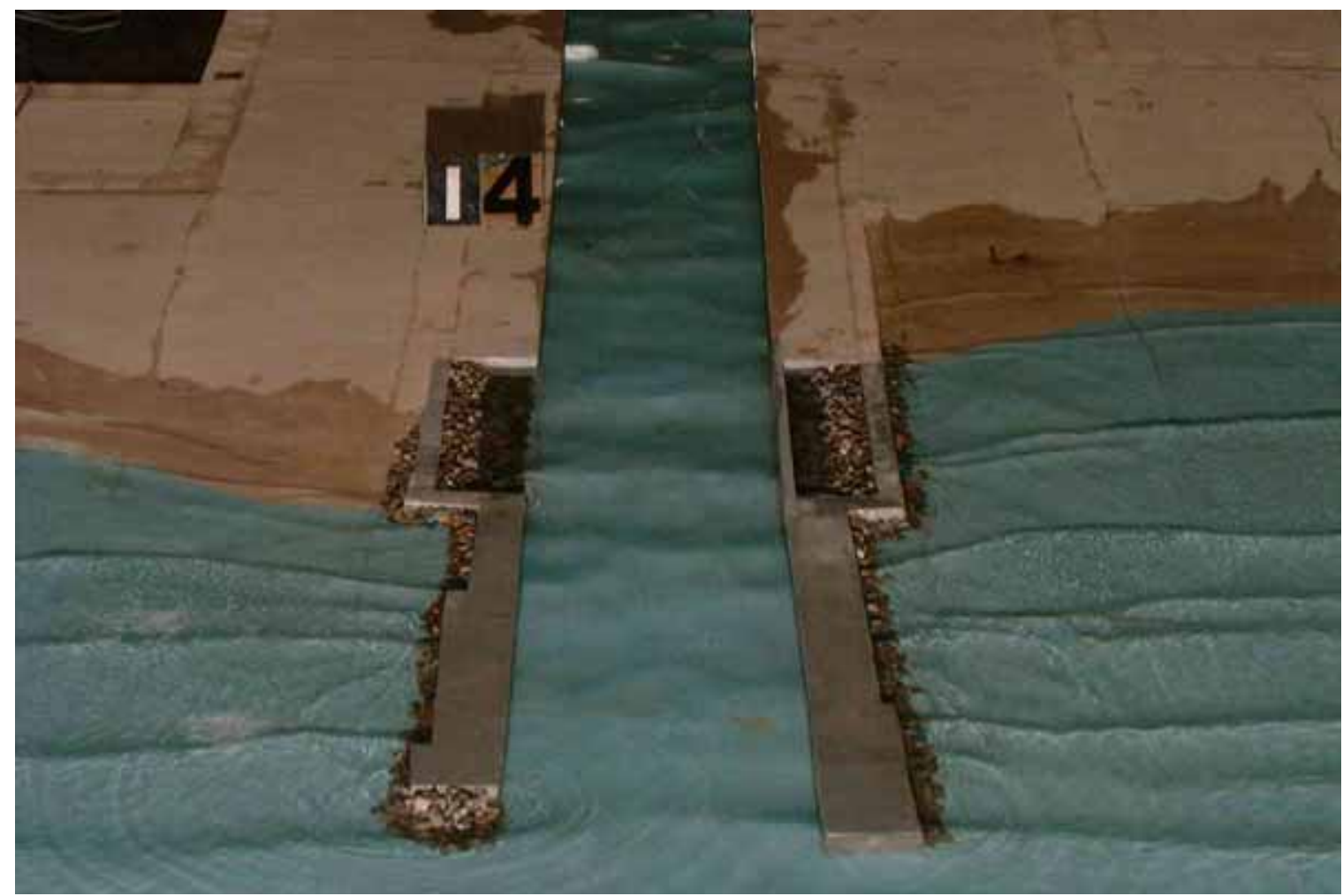

Photograph 22a. Typical wave patterns for Plan 3; 8-sec, 2-m waves from 0 deg; $s W l=+0.9 m$ LWD, closeup.

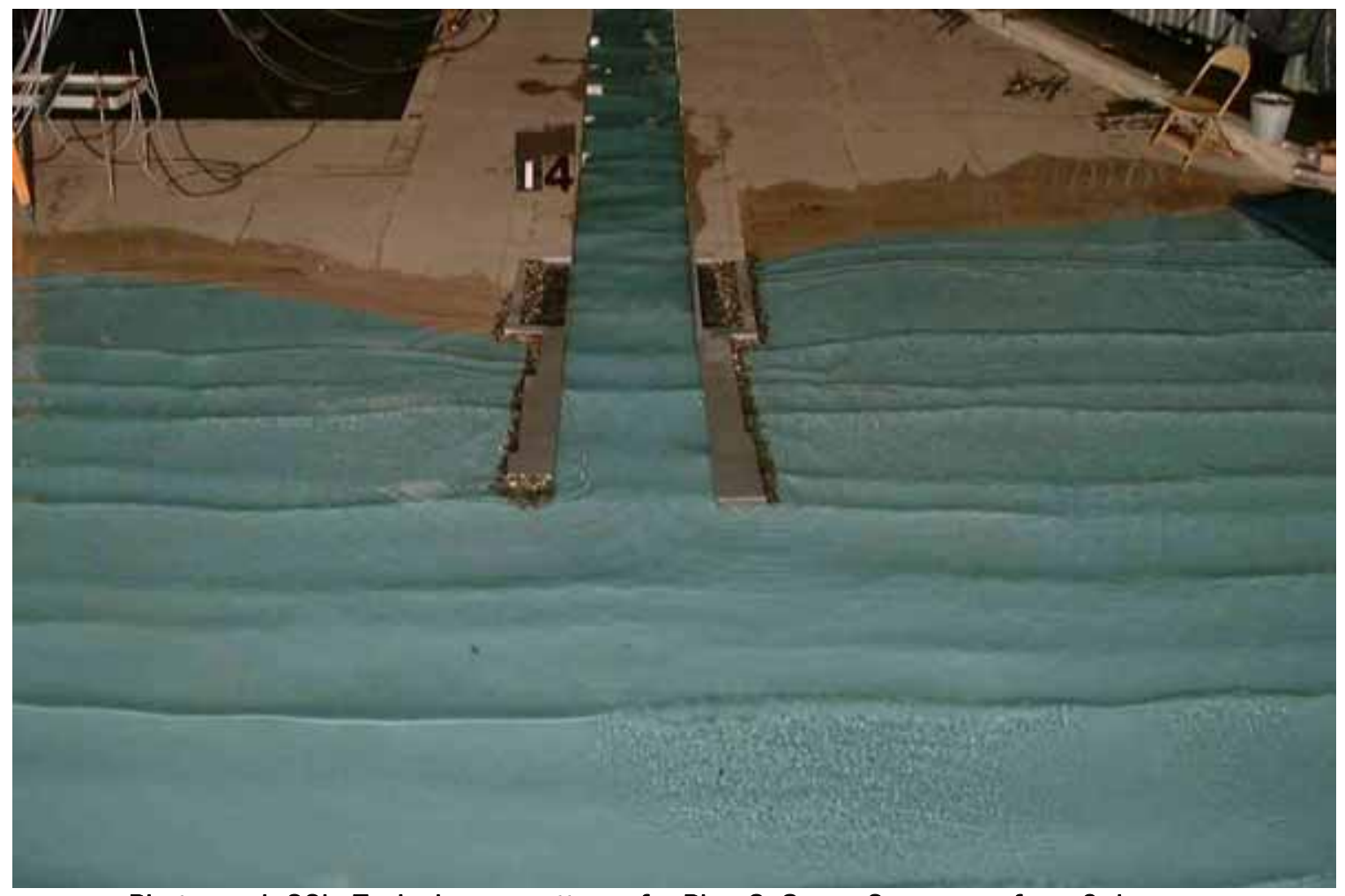

Photograph 22b. Typical wave patterns for Plan 3; 8-sec, 2-m waves from 0 deg; $\mathrm{sWl}=+0.9 \mathrm{~m}$ LWD. 


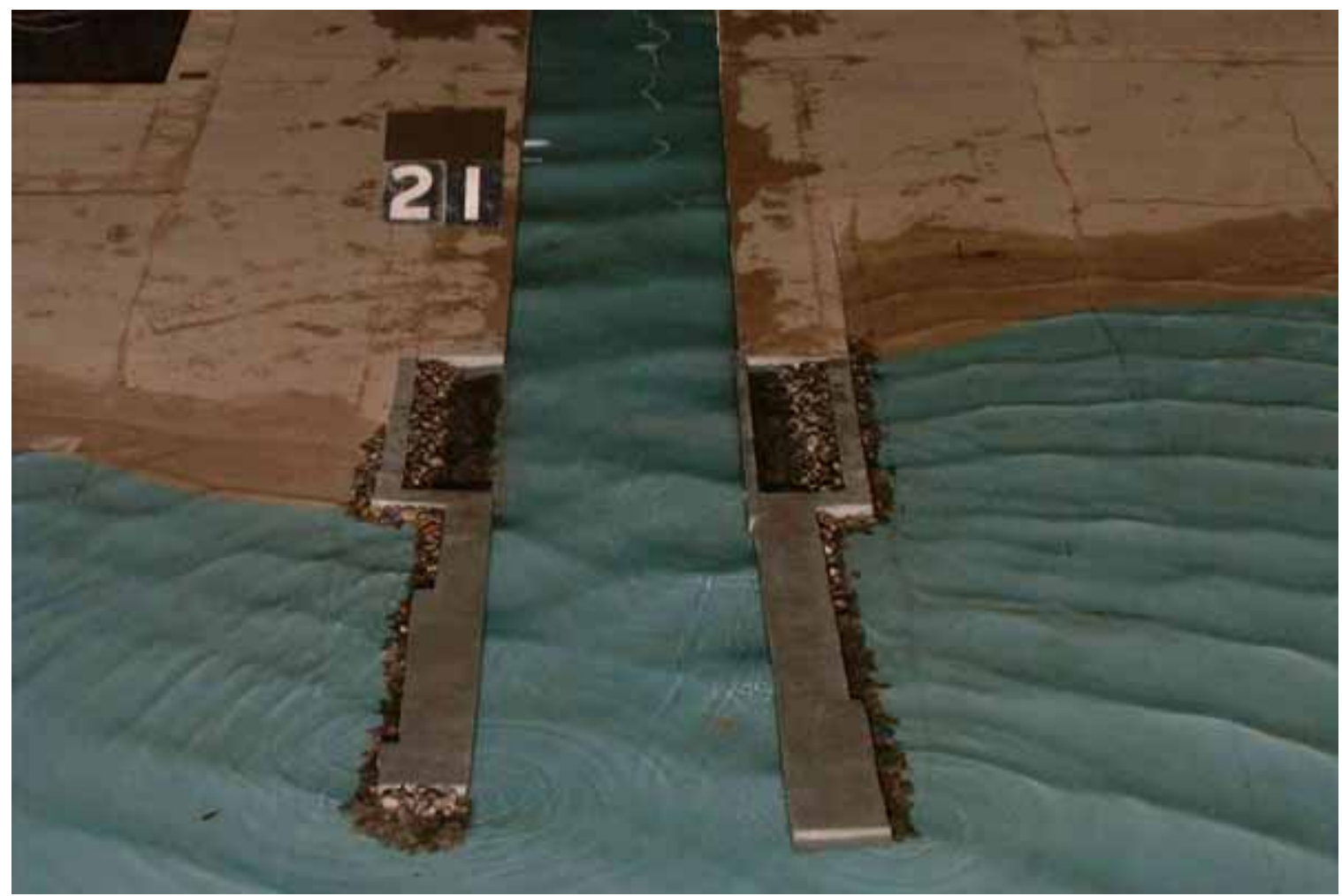

Photograph 23a. Typical wave patterns for Plan 3; 5-sec, 1-m waves from 45 deg North; $\mathrm{sWl}=+0.9 \mathrm{~m}$ LWD, closeup.

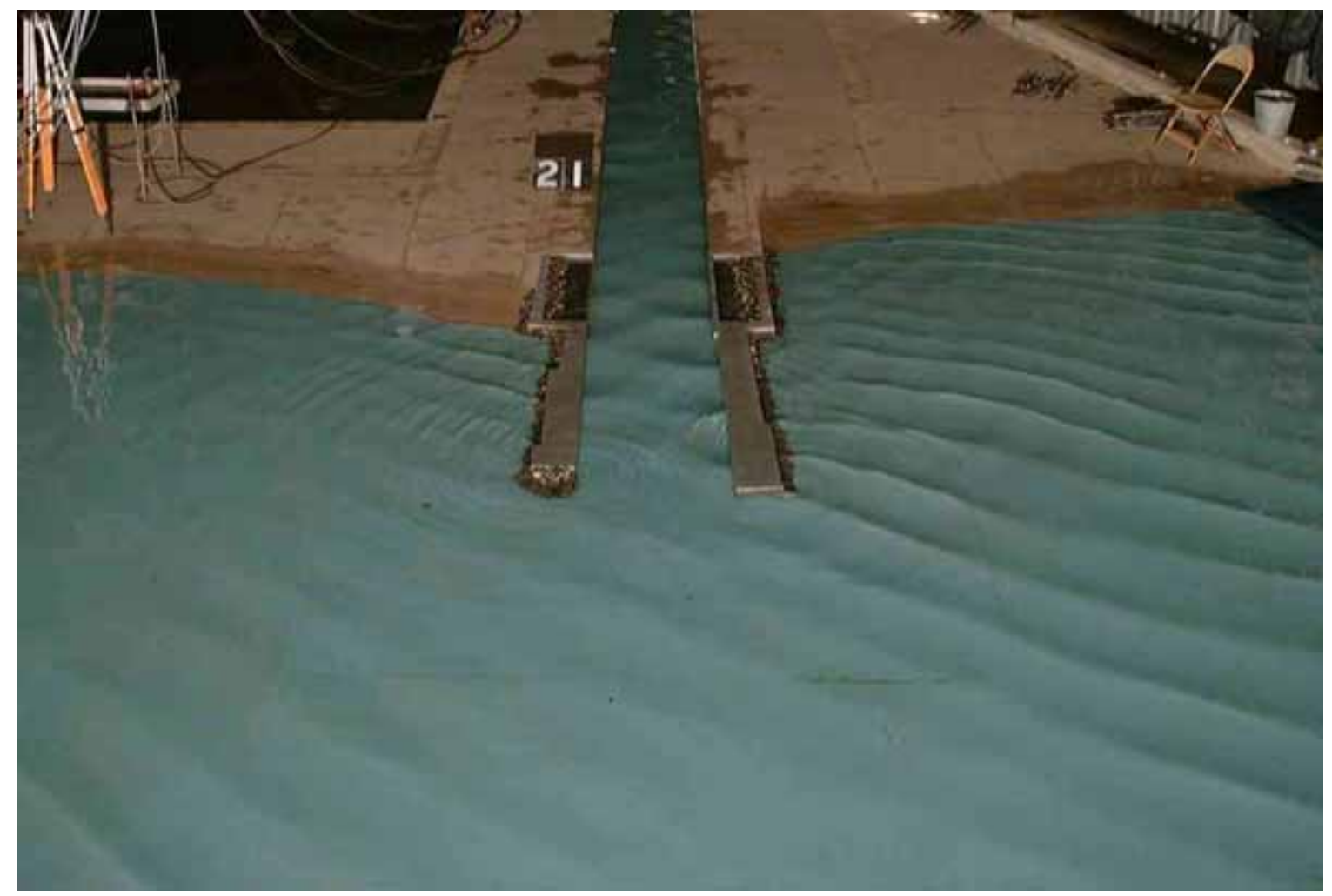

Photograph 23b. Typical wave patterns for Plan 3; 5-sec, 1-m waves from 45 deg North; $\mathrm{sWl}=+0.9 \mathrm{~m}$ LWD. 


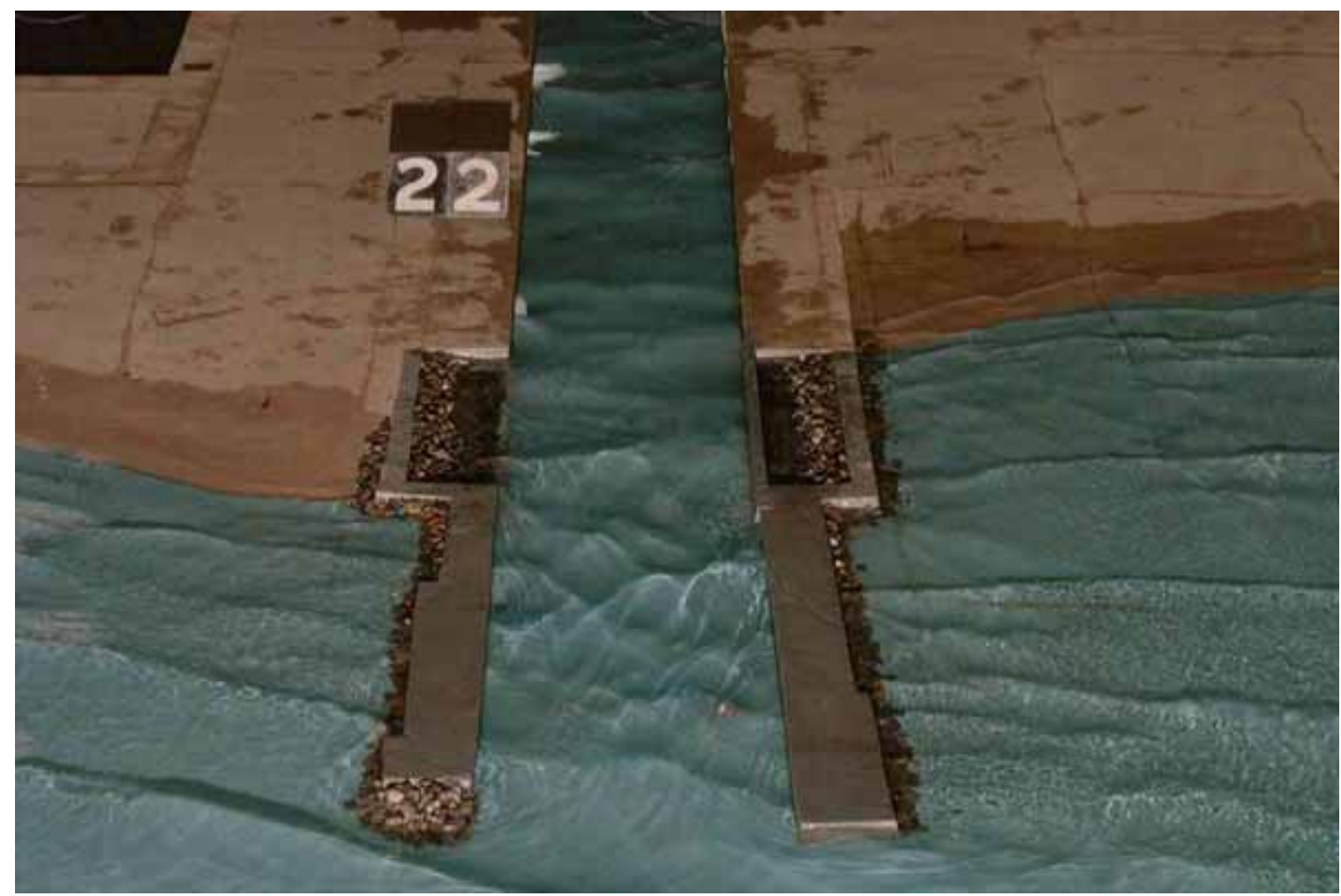

Photograph 24a. Typical wave patterns for Plan 3; 8-sec, 2-m waves from 45 deg North; $s W l=+0.9 m$ LWD, closeup.

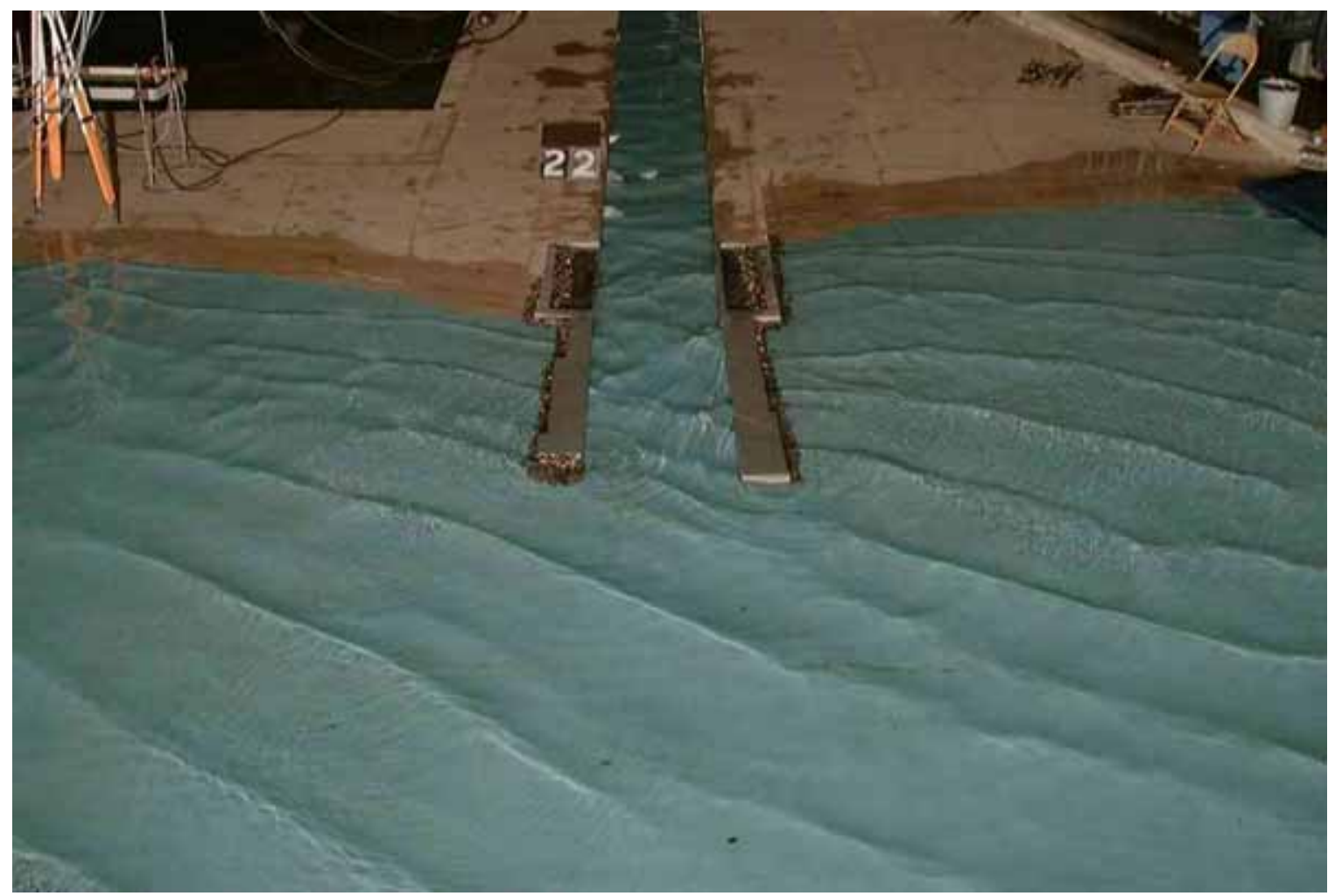

Photograph 24b. Typical wave patterns for Plan 3; 8-sec, 2-m waves from 45 deg North; $\mathrm{sWl}=+0.9 \mathrm{~m}$ LWD. 


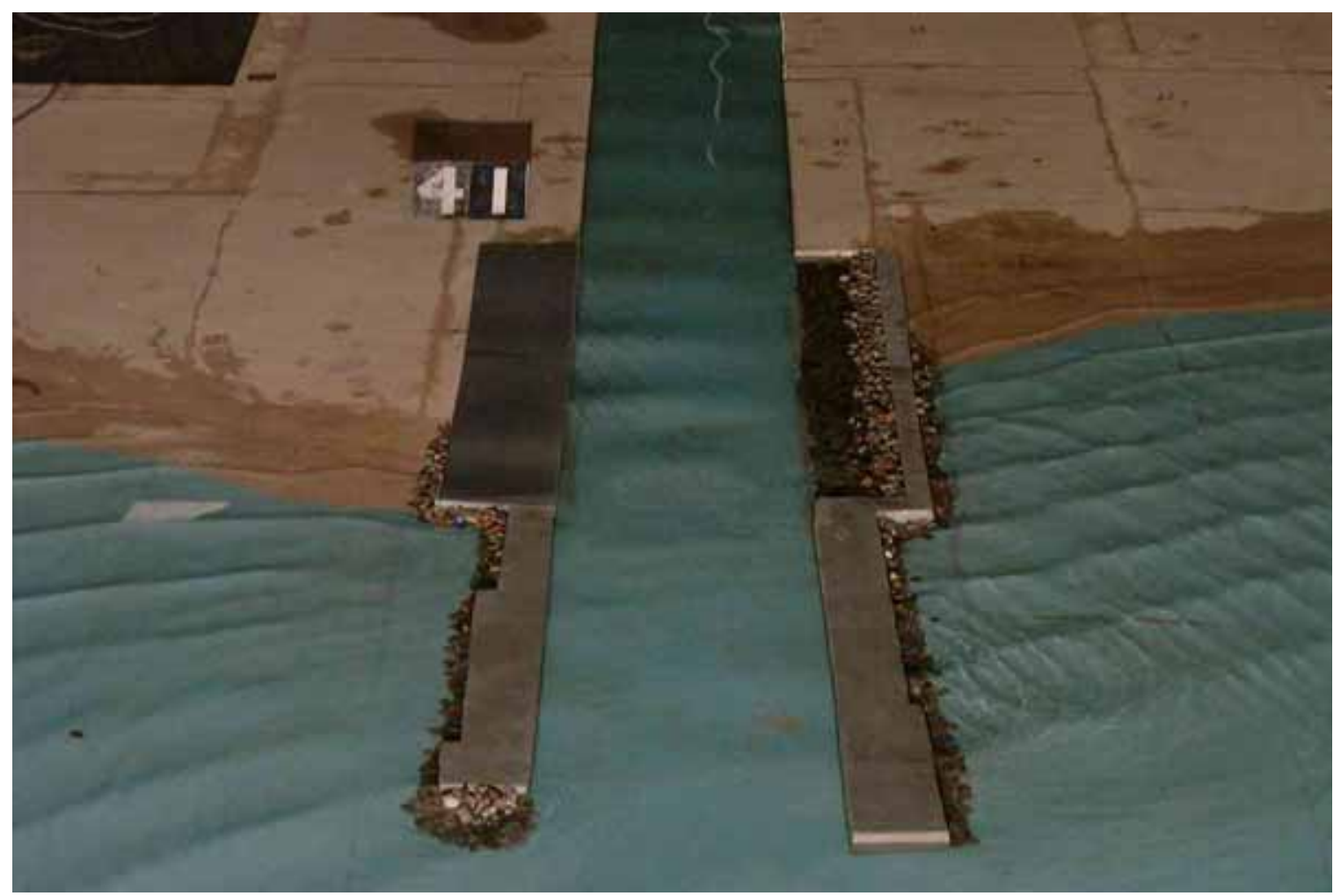

Photograph 25a. Typical wave patterns for Plan 4; 5-sec, 1-m waves from 45 deg South; $\mathrm{sWl}=+0.9 \mathrm{~m}$ LWD, closeup.

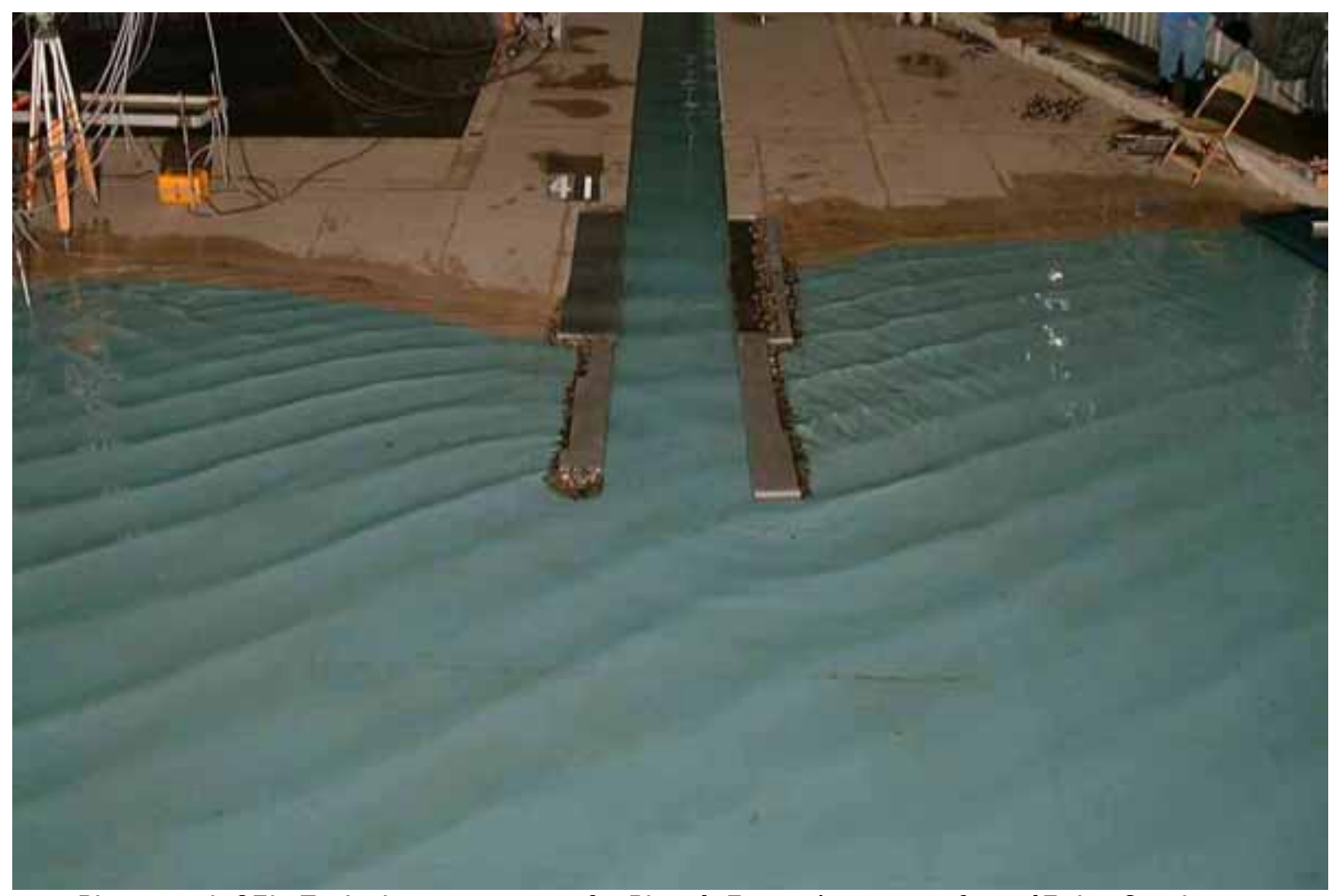

Photograph 25b. Typical wave patterns for Plan 4; 5-sec, 1-m waves from 45 deg South; $\mathrm{sWl}=+0.9 \mathrm{~m}$ LWD. 


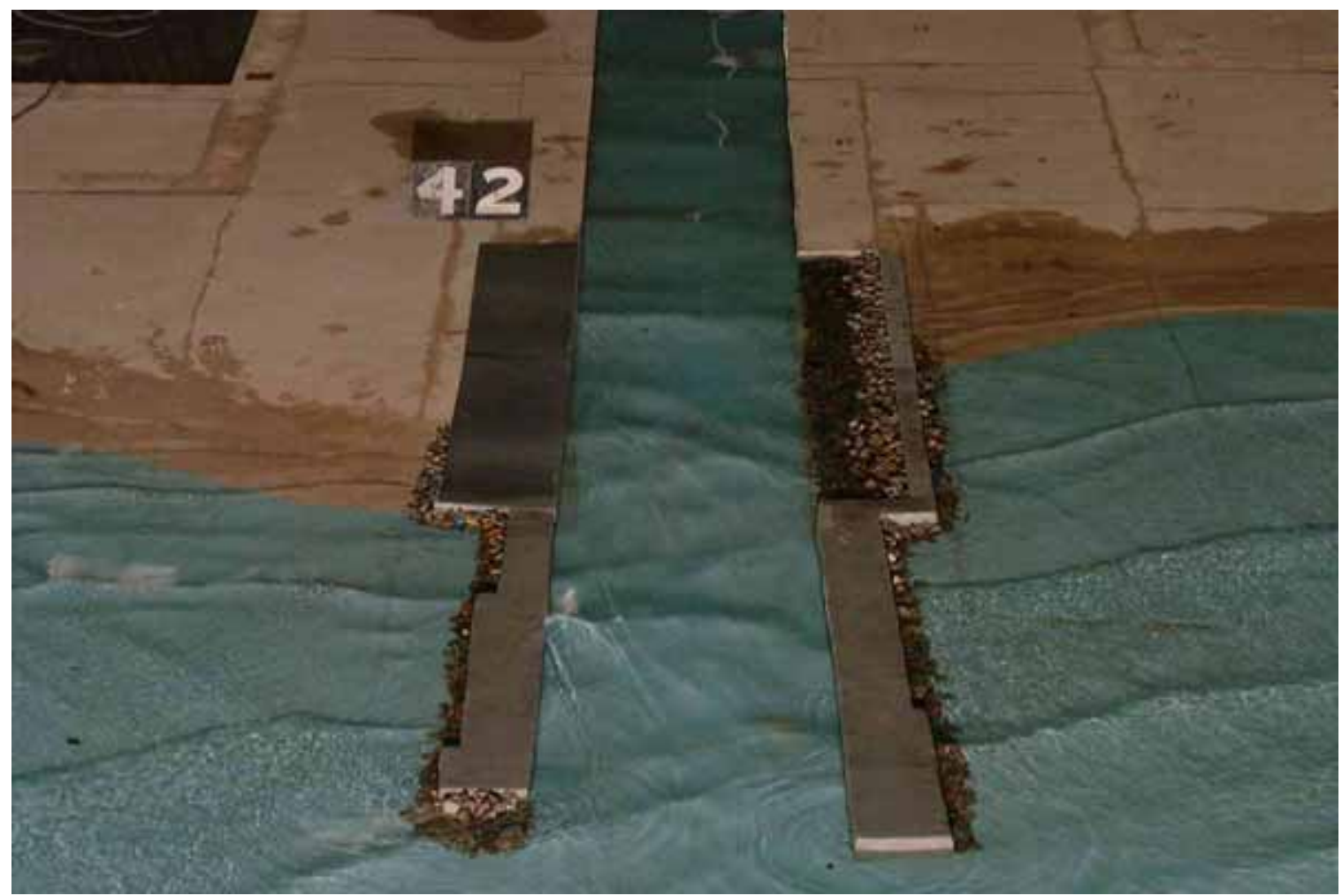

Photograph 26a. Typical wave patterns for Plan 4; 8-sec, 2-m waves from 45 deg South; $s W l=+0.9 m$ LWD, closeup.

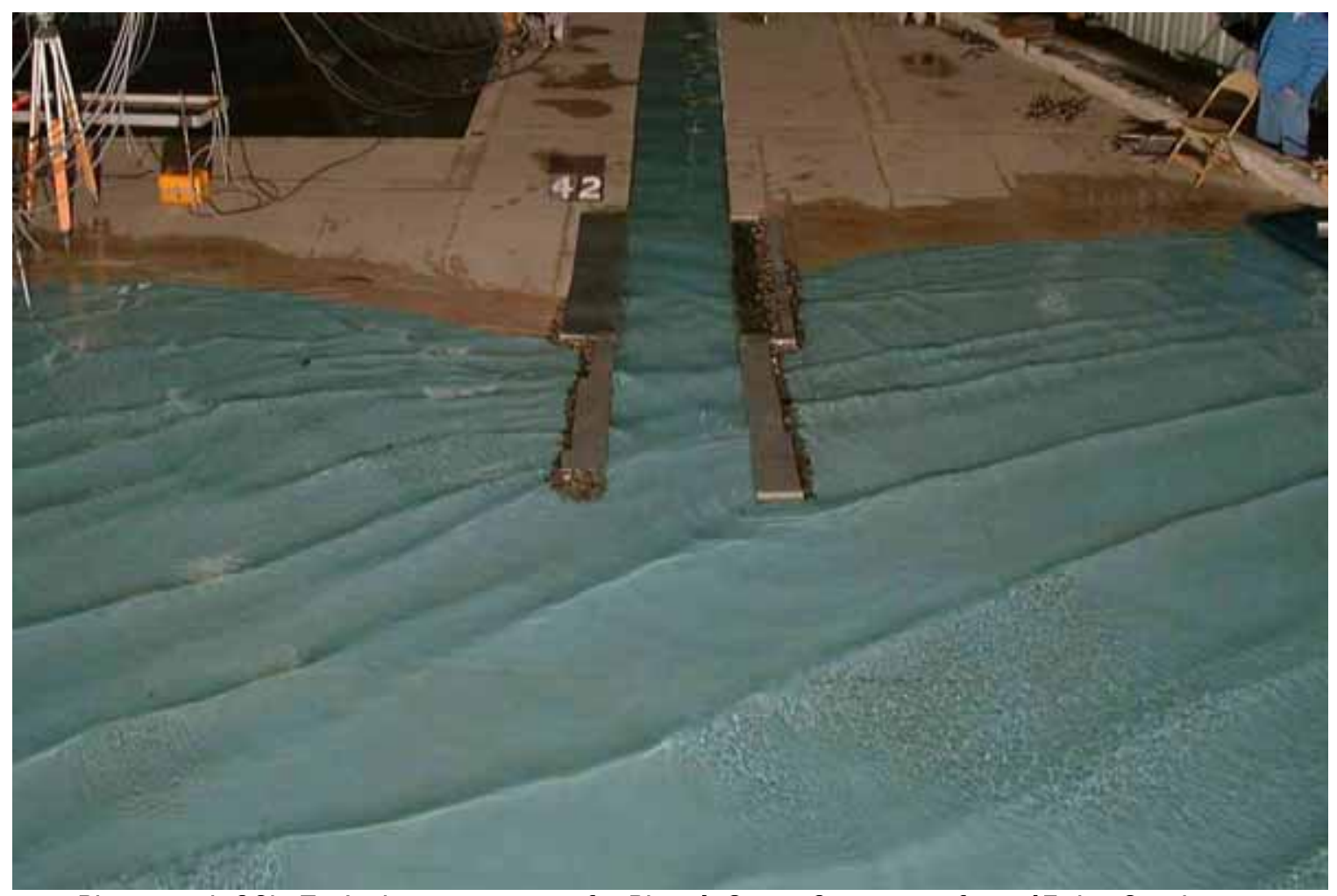

Photograph 26b. Typical wave patterns for Plan 4; 8-sec, 2-m waves from 45 deg South; $\mathrm{sWl}=+0.9 \mathrm{~m} \mathrm{LWD}$. 


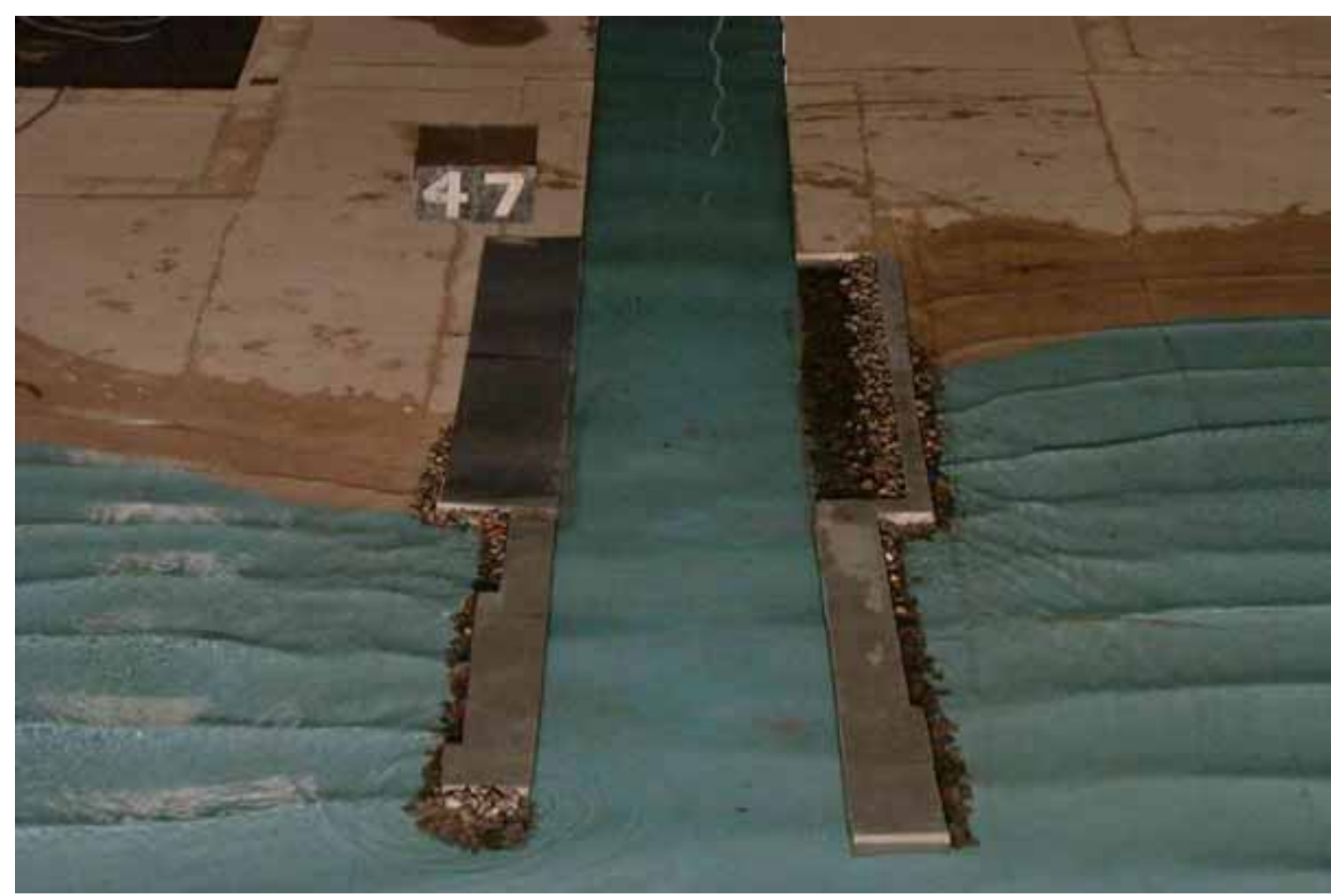

Photograph 27a. Typical wave patterns for Plan 4; 5-sec, 1-m waves from 0 deg; $\mathrm{sWl}=+0.9 \mathrm{~m}$ LWD, closeup.

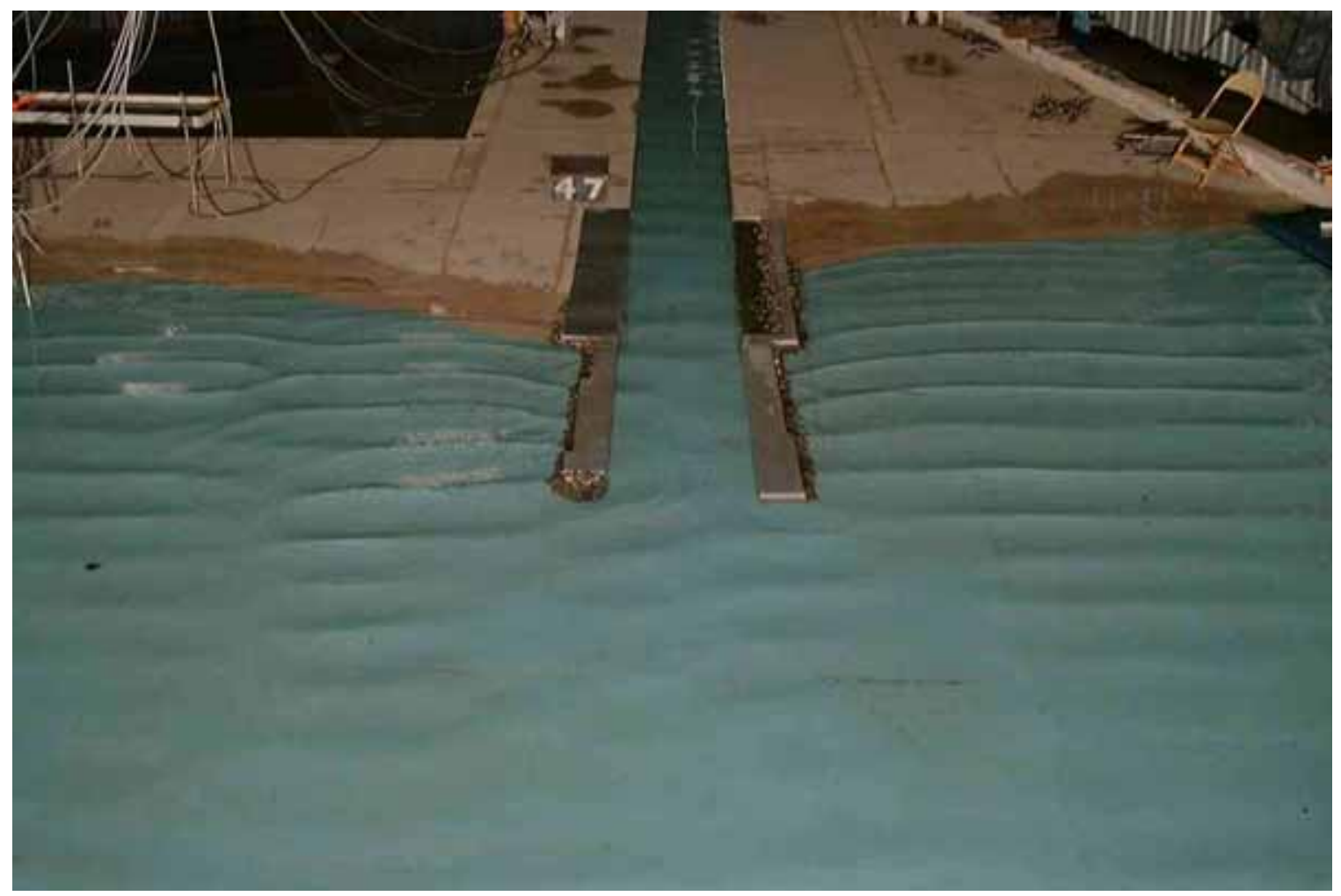

Photograph 27b. Typical wave patterns for Plan 4; 5-sec, 1-m waves from 0 deg; $\mathrm{sWl}=+0.9 \mathrm{~m}$ LWD. 


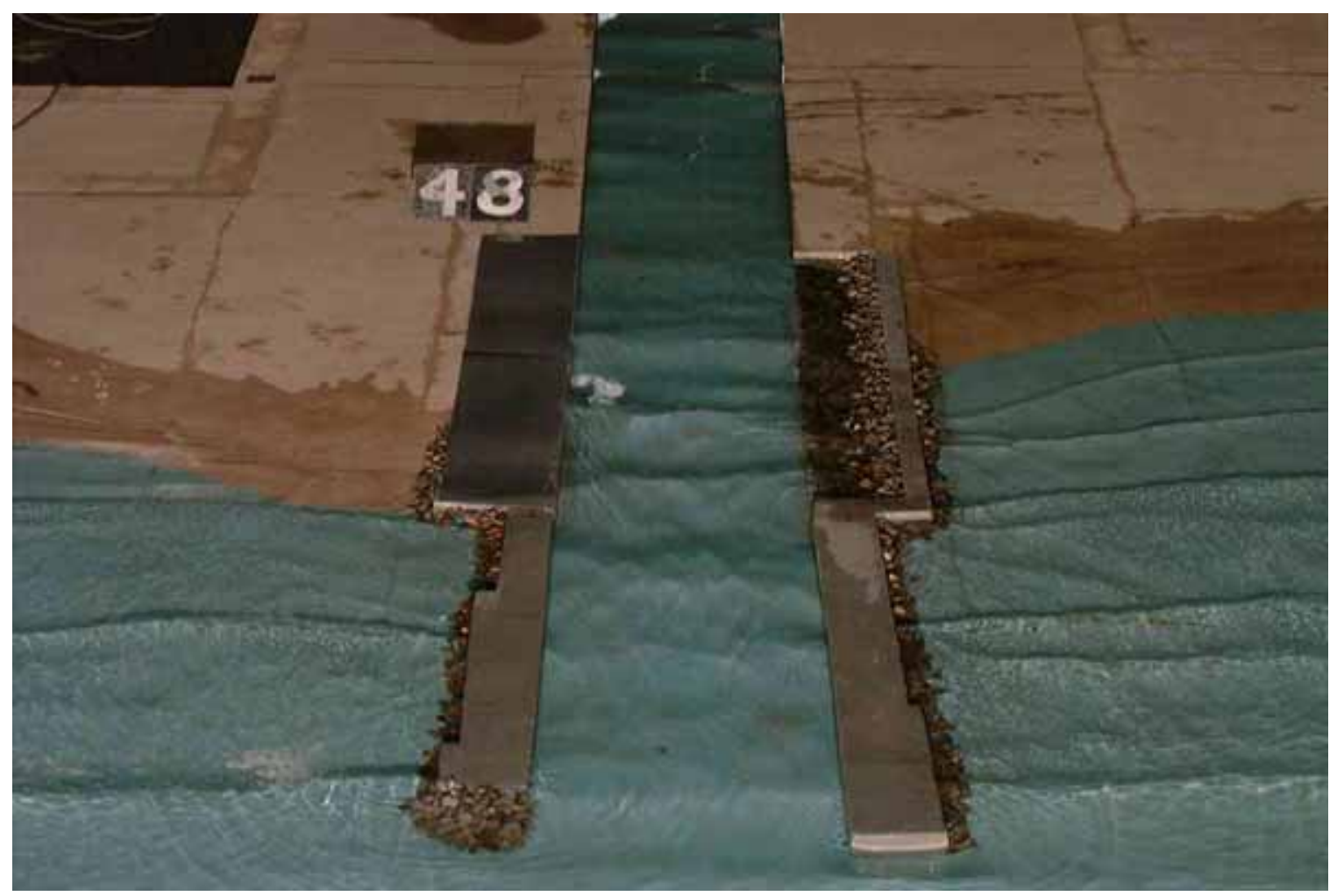

Photograph 28a. Typical wave patterns for Plan 4; 8-sec, 2-m waves from 0 deg; $\mathrm{sWl}=+0.9 \mathrm{~m}$ LWD, closeup.

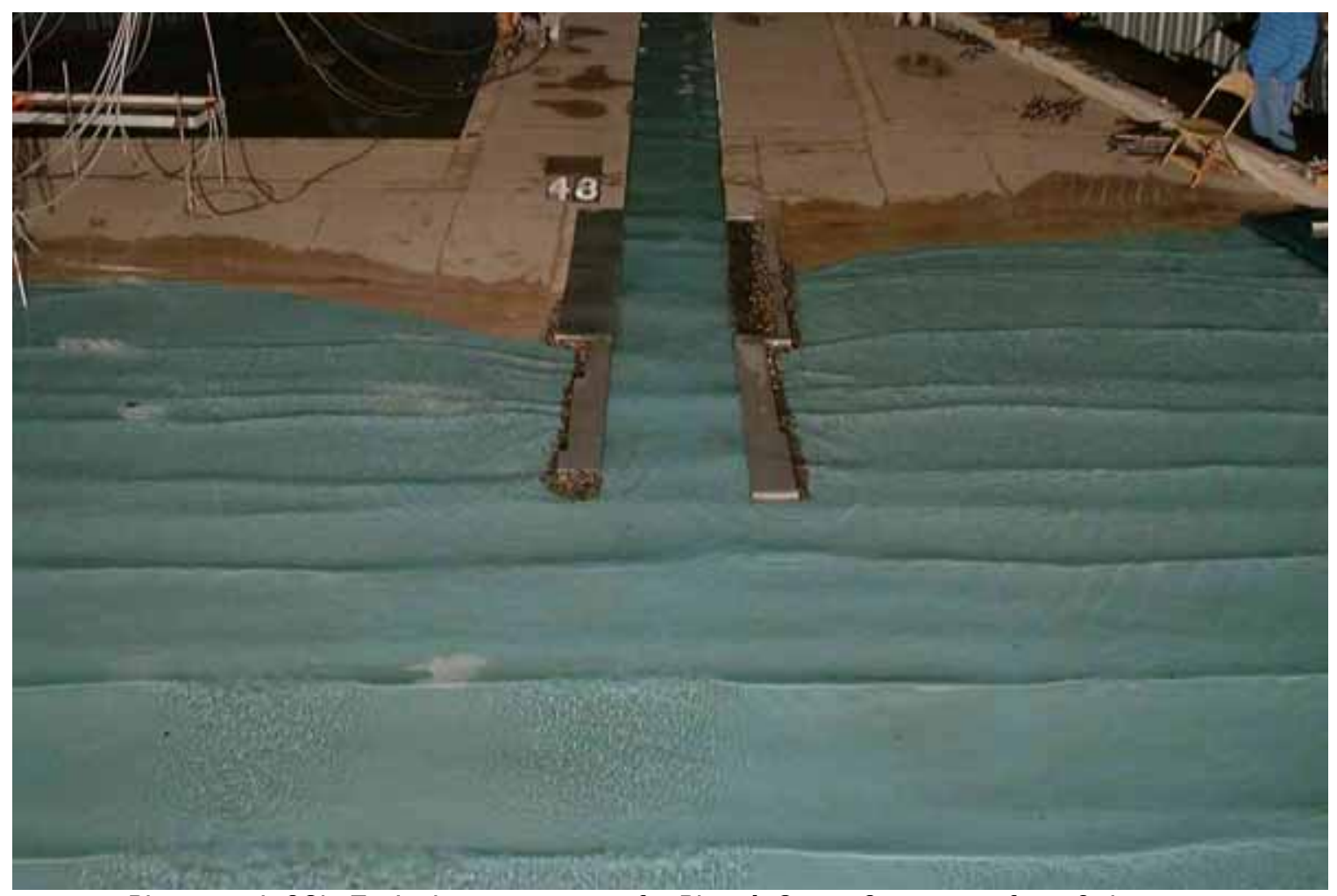

Photograph 28b. Typical wave patterns for Plan 4; 8-sec, 2-m waves from 0 deg; $\mathrm{sWl}=+0.9 \mathrm{~m}$ LWD. 


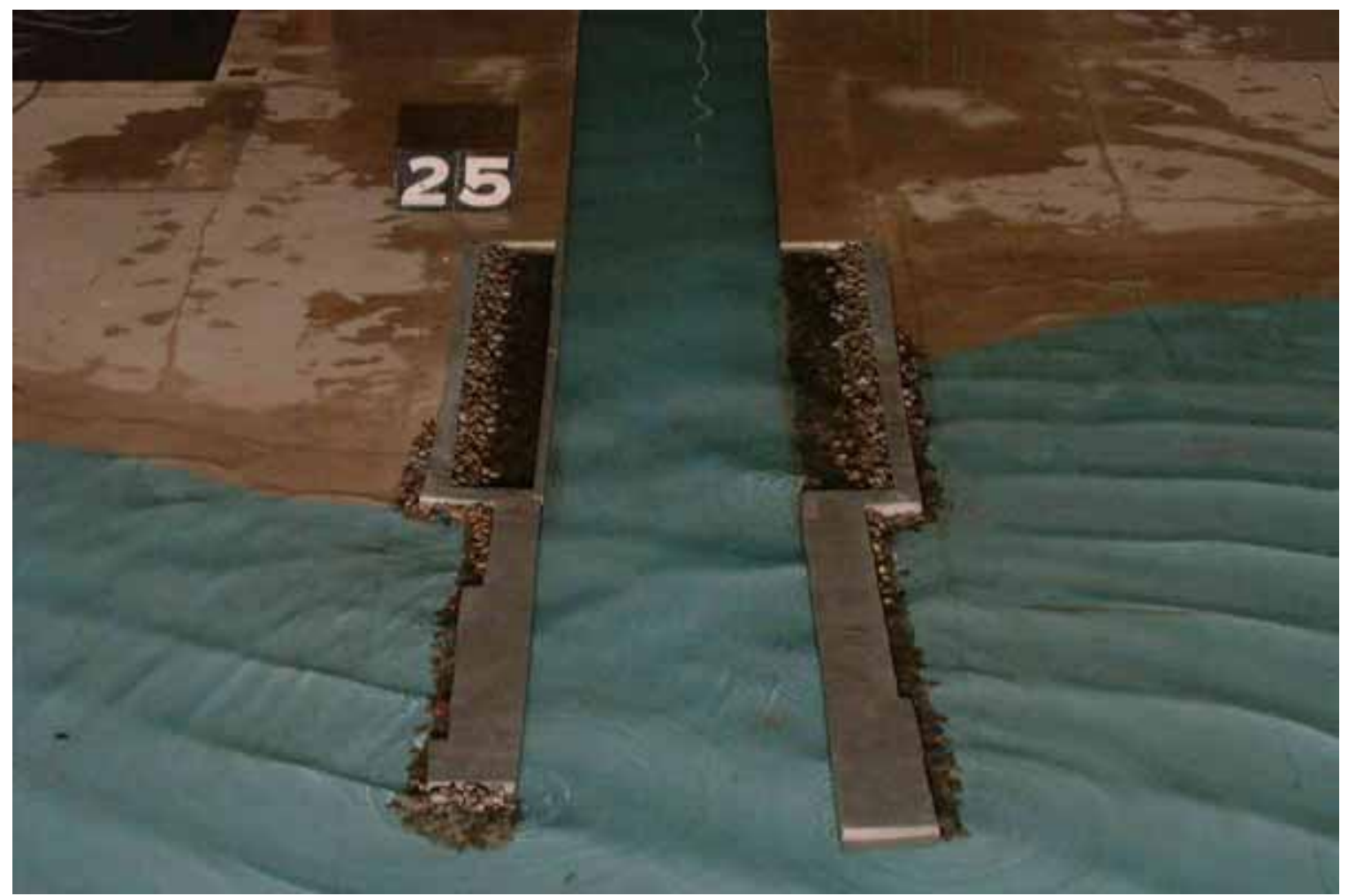

Photograph 29a. Typical wave patterns for Plan 4; 5-sec, 1-m waves from 45 deg North; $\mathrm{sWl}=+0.9 \mathrm{~m}$ LWD, closeup.

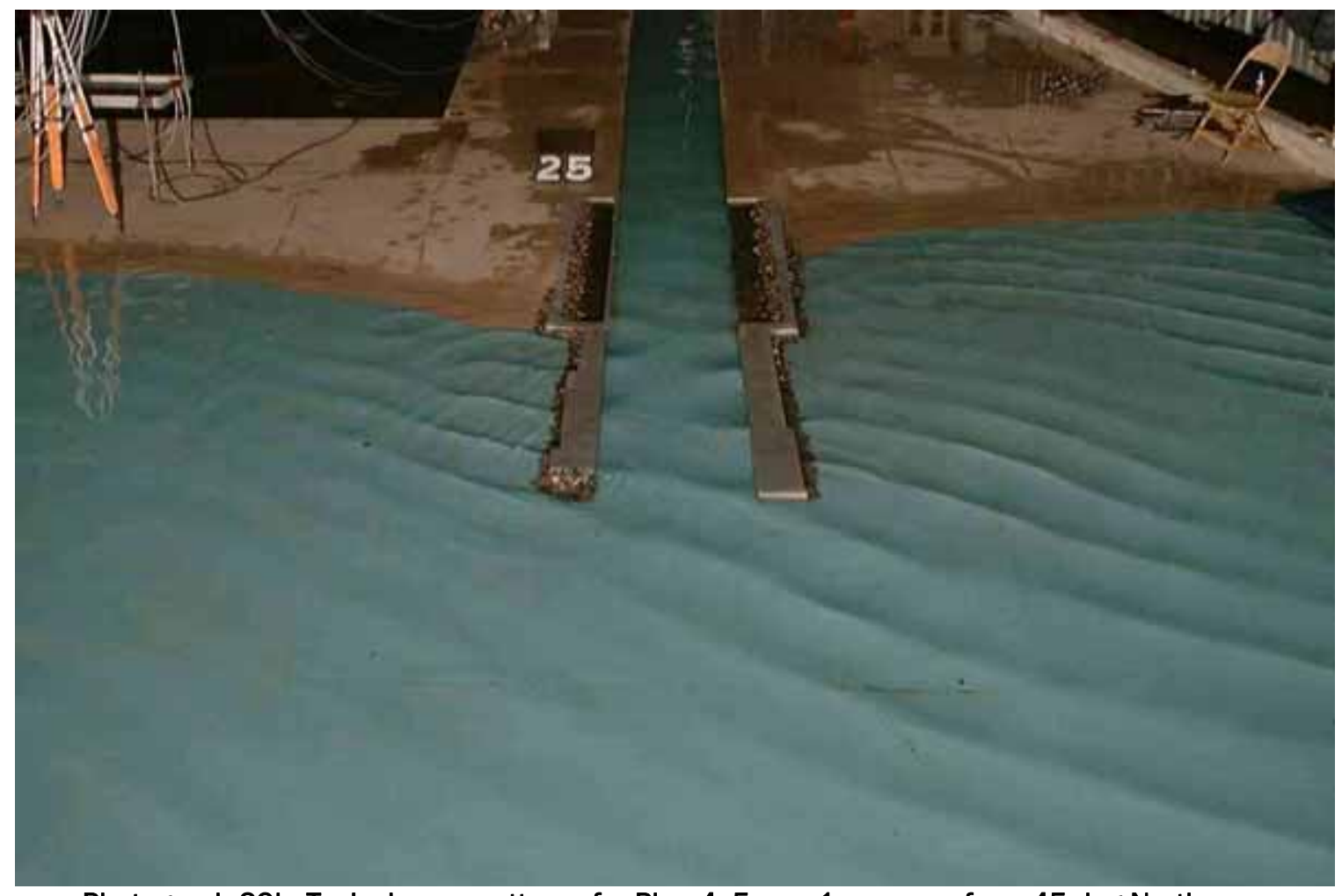

Photograph 29b. Typical wave patterns for Plan 4; 5-sec, 1-m waves from 45 deg North; $\mathrm{sWl}=+0.9 \mathrm{~m}$ LWD. 


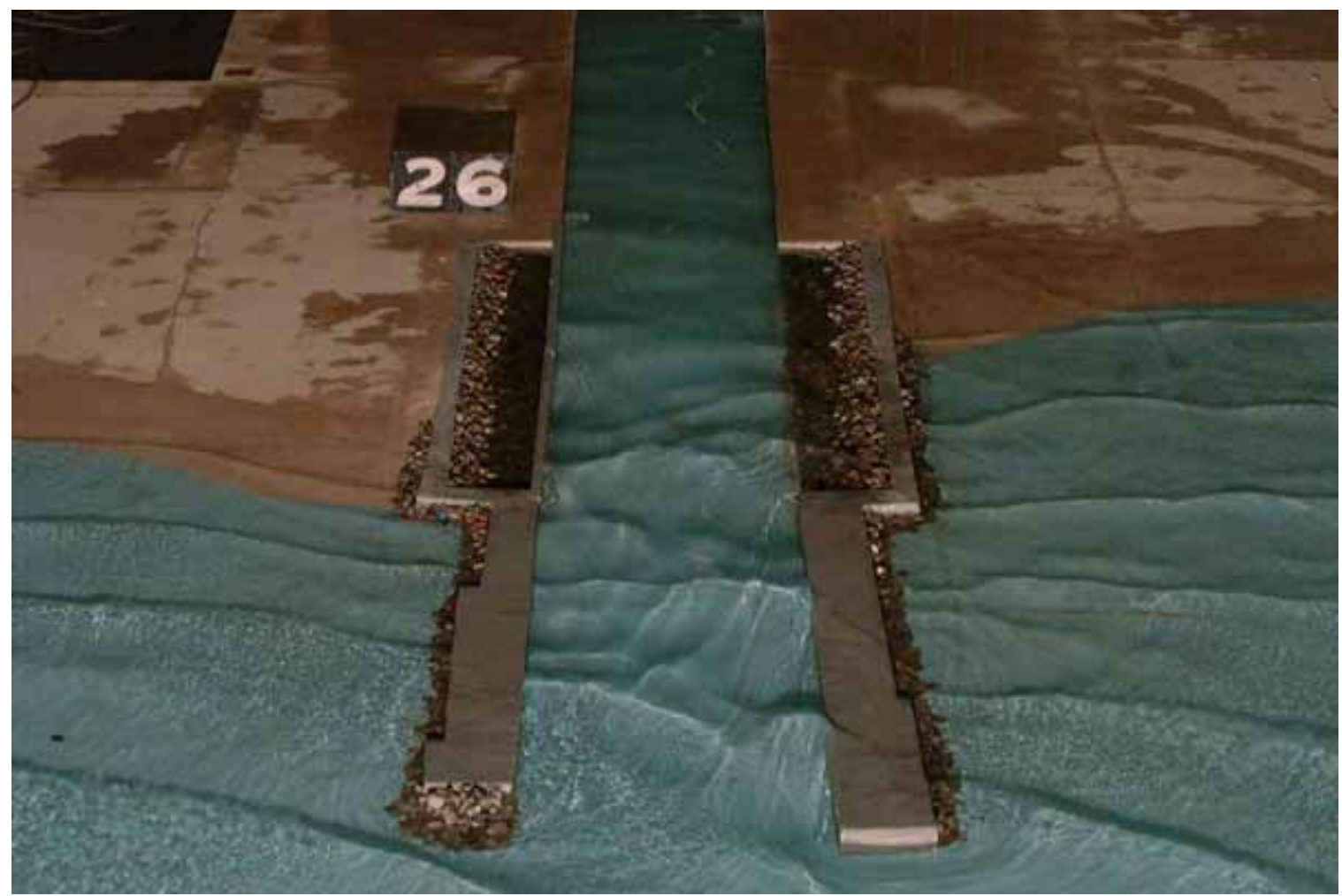

Photograph 30a. Typical wave patterns for Plan 4; 8-sec, 2-m waves from 45 deg North; $\mathrm{sWl}=+0.9 \mathrm{~m}$ LWD, closeup.

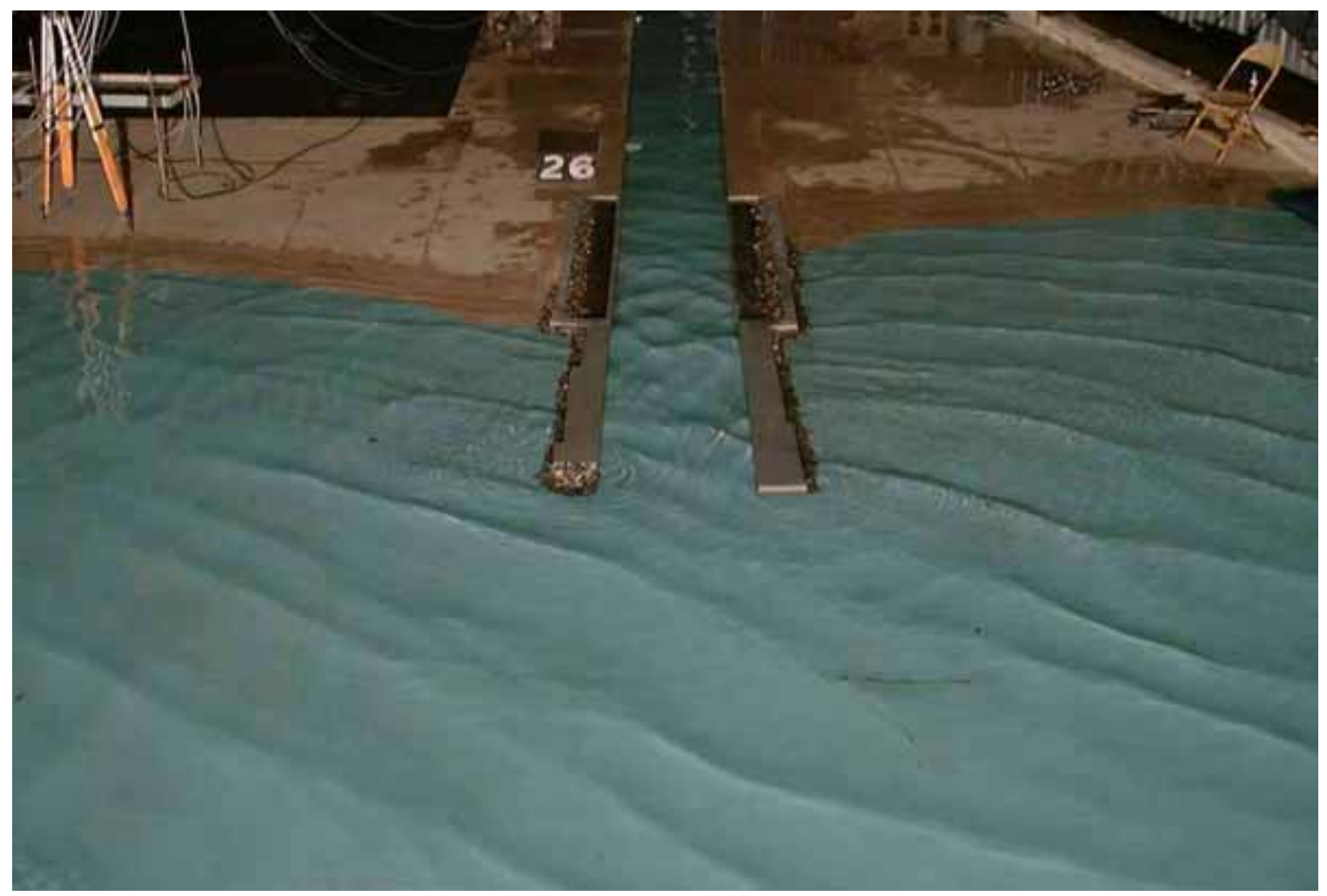

Photograph 30b. Typical wave patterns for Plan 4; 8-sec, 2-m waves from 45 deg North; $\mathrm{sWl}=+0.9 \mathrm{~m}$ LWD. 


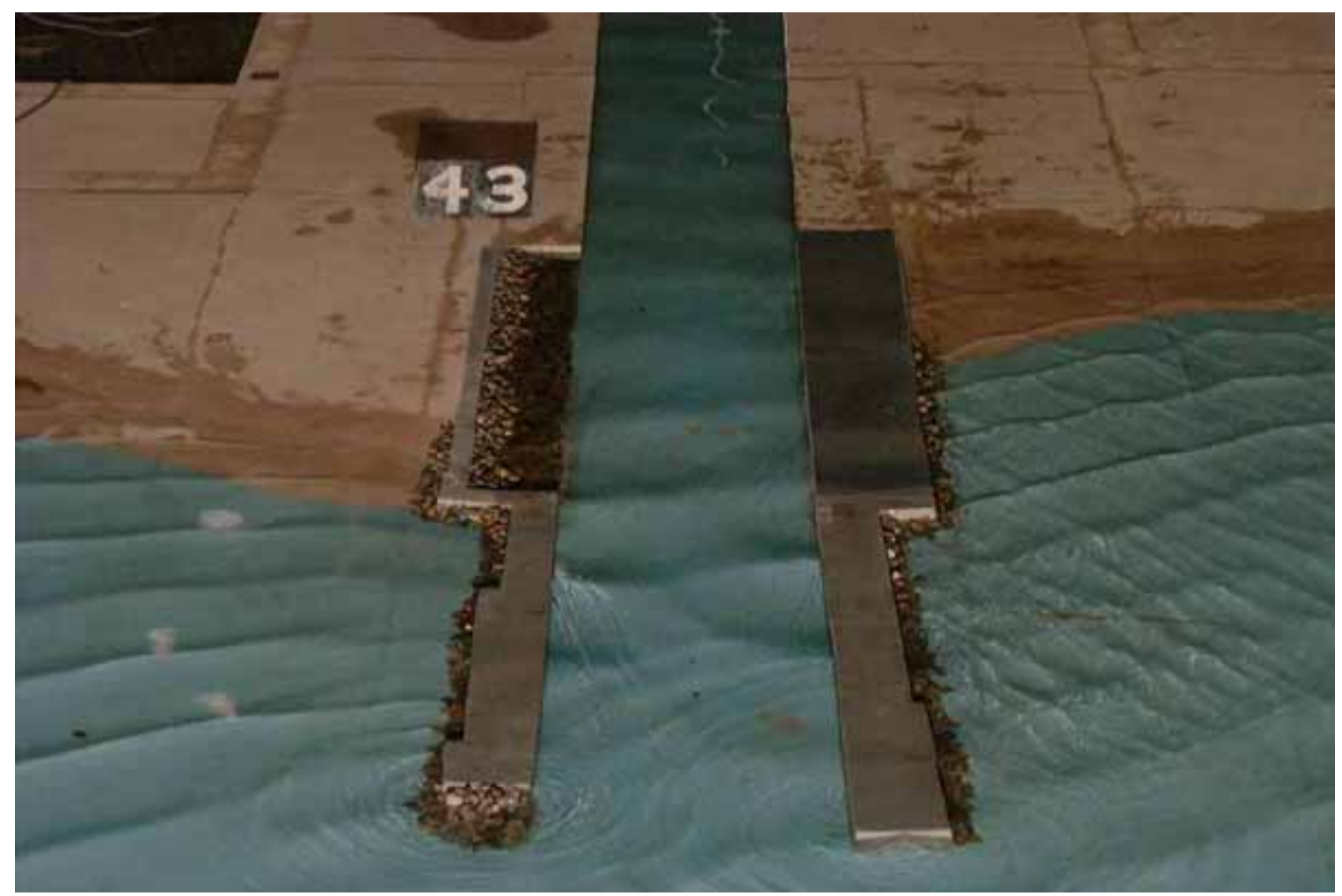

Photograph 31a. Typical wave patterns for Plan 5; 5-sec, 1-m waves from 45 deg South; swl $=+0.9 \mathrm{~m}$ LWD, closeup.

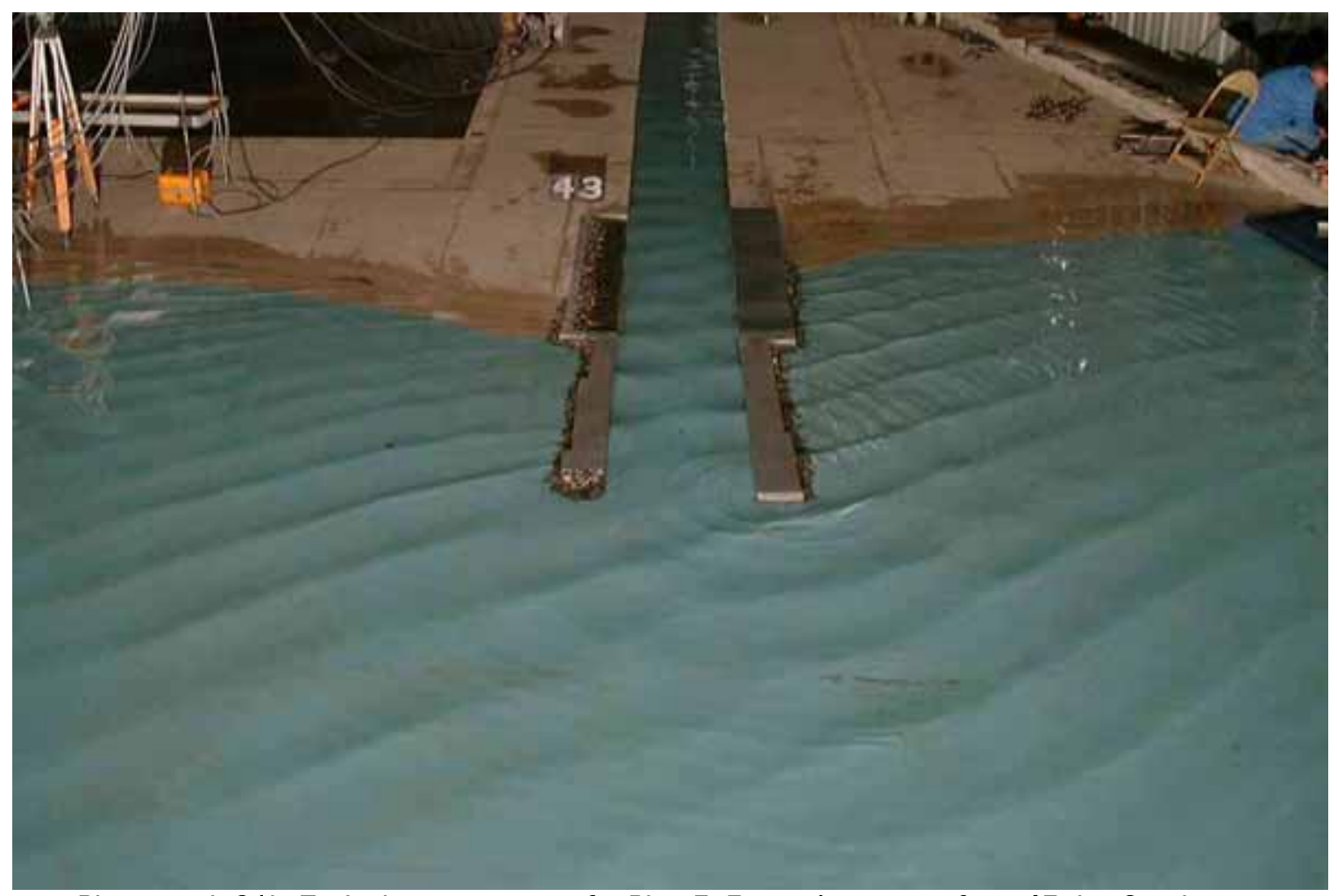

Photograph 31b. Typical wave patterns for Plan 5; 5-sec, 1-m waves from 45 deg South; $\mathrm{sWl}=+0.9 \mathrm{~m}$ LWD. 


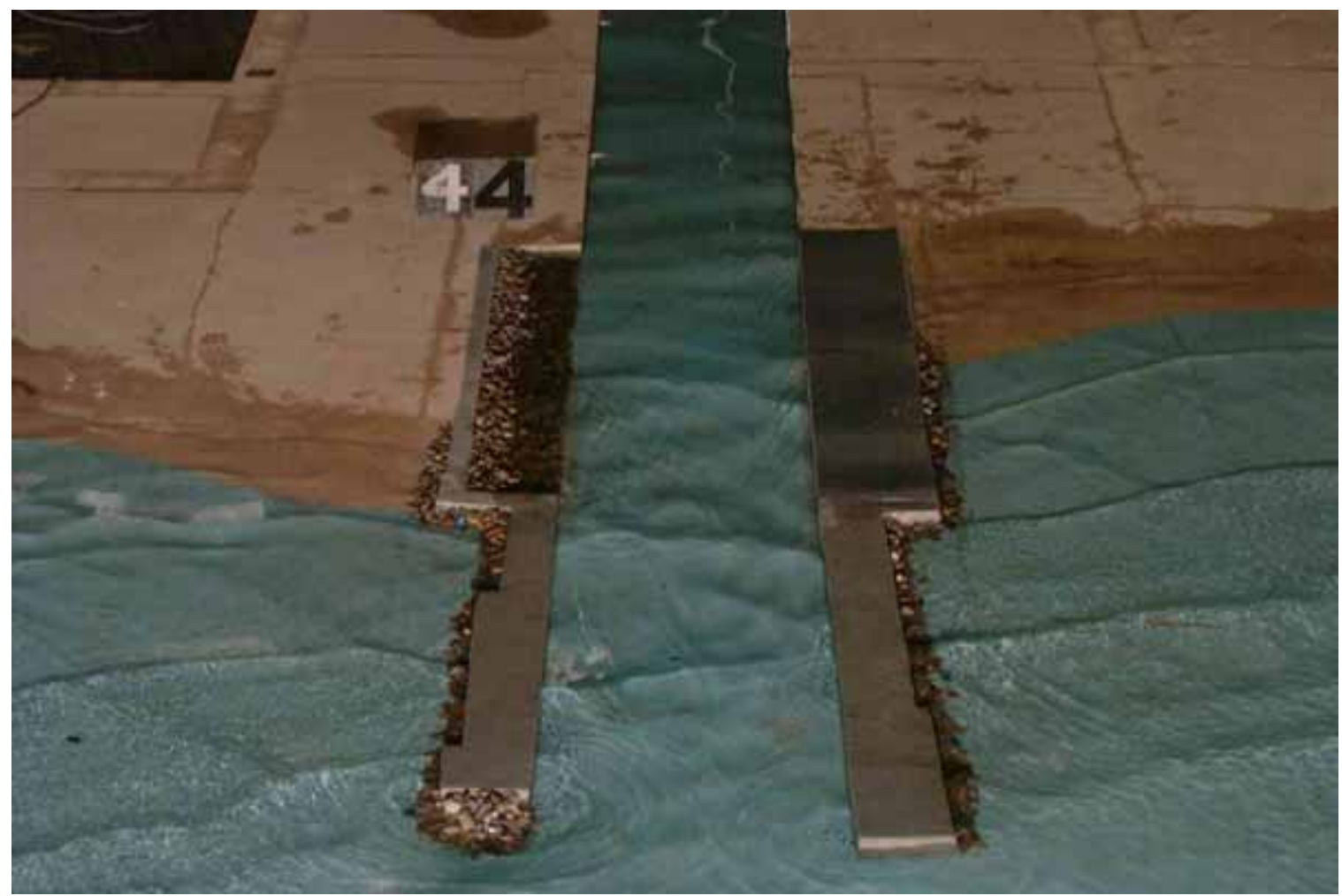

Photograph 32a. Typical wave patterns for Plan 5; 8-sec, 2-m waves from 45 deg South; $s W l=+0.9 m$ LWD, closeup.

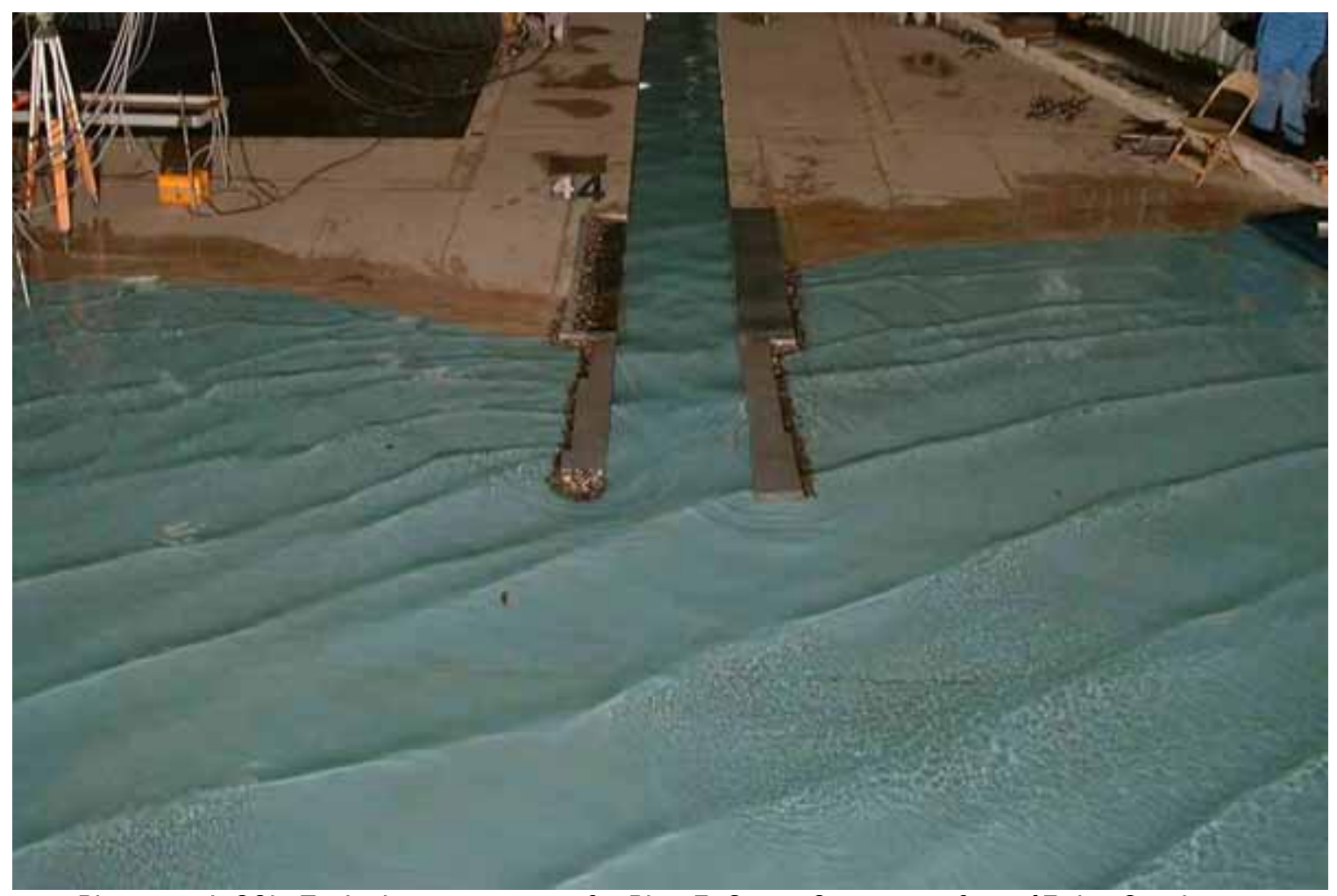

Photograph 32b. Typical wave patterns for Plan 5; 8-sec, 2-m waves from 45 deg South; $\mathrm{sWl}=+0.9 \mathrm{~m}$ LWD. 


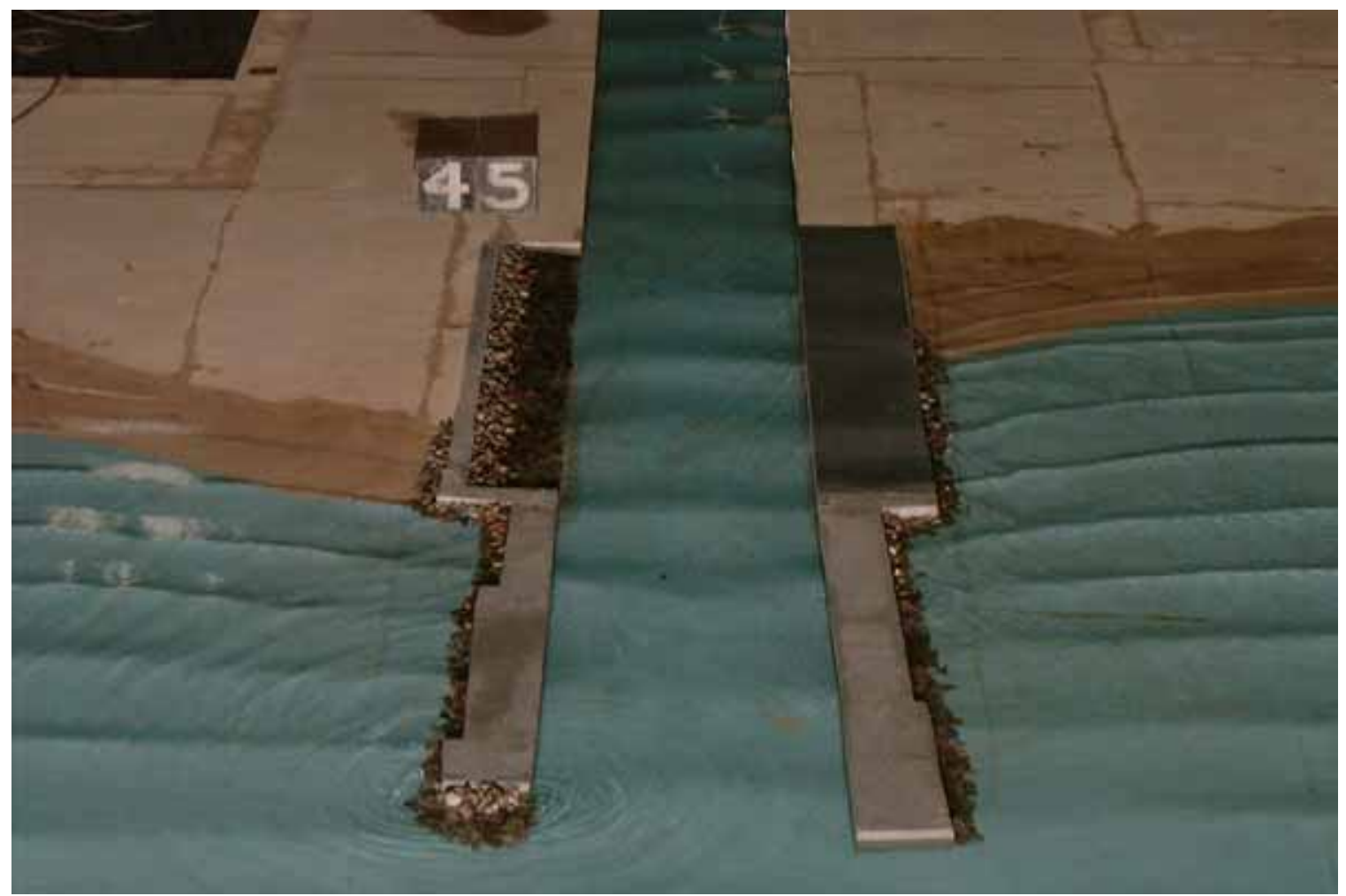

Photograph 33a. Typical wave patterns for Plan 5; 5-sec, 1-m waves from 0 deg; $\mathrm{sWl}=+0.9 \mathrm{~m}$ LWD, closeup.

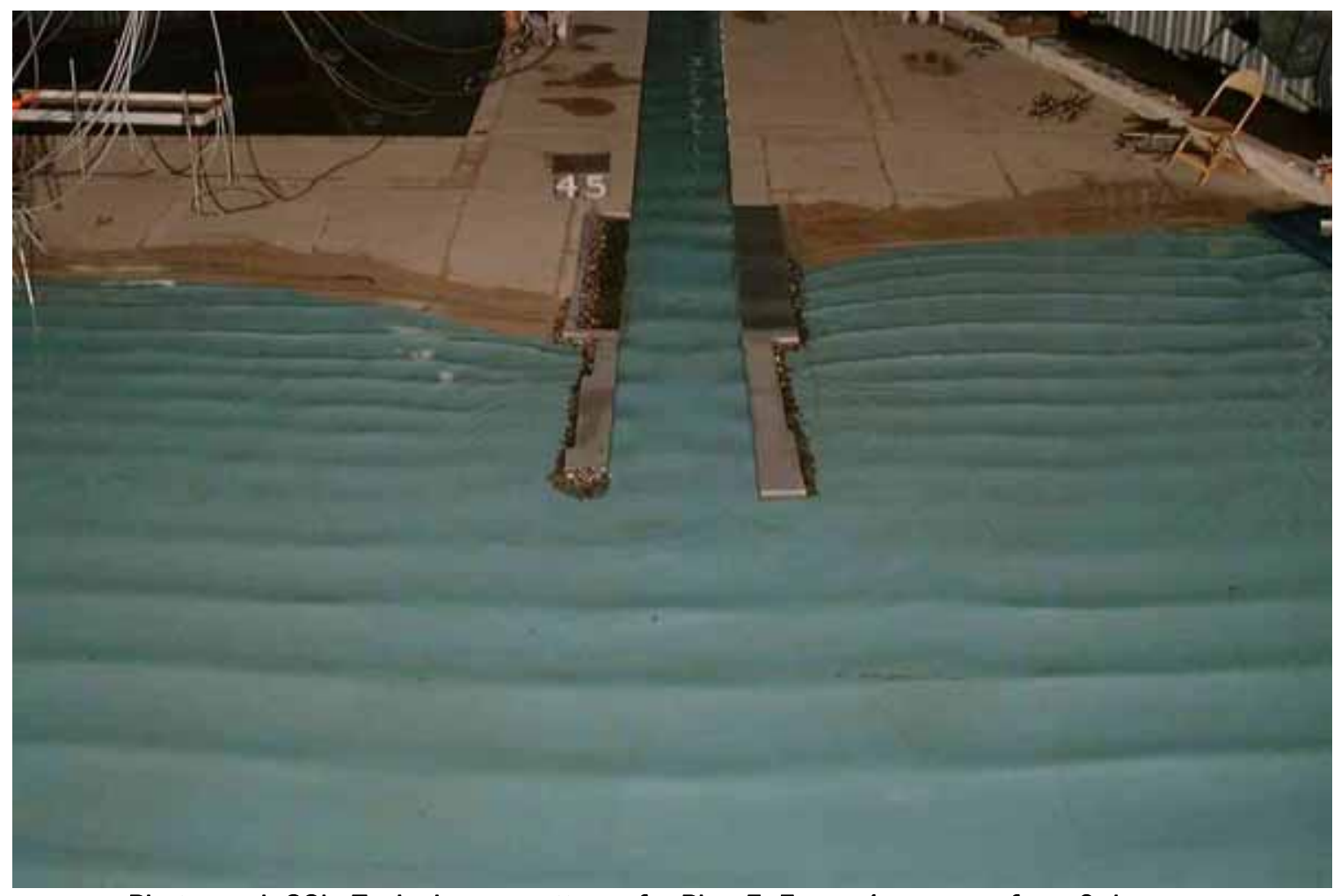

Photograph 33b. Typical wave patterns for Plan 5; 5-sec, 1-m waves from 0 deg; $\mathrm{sWl}=+0.9 \mathrm{~m}$ LWD. 


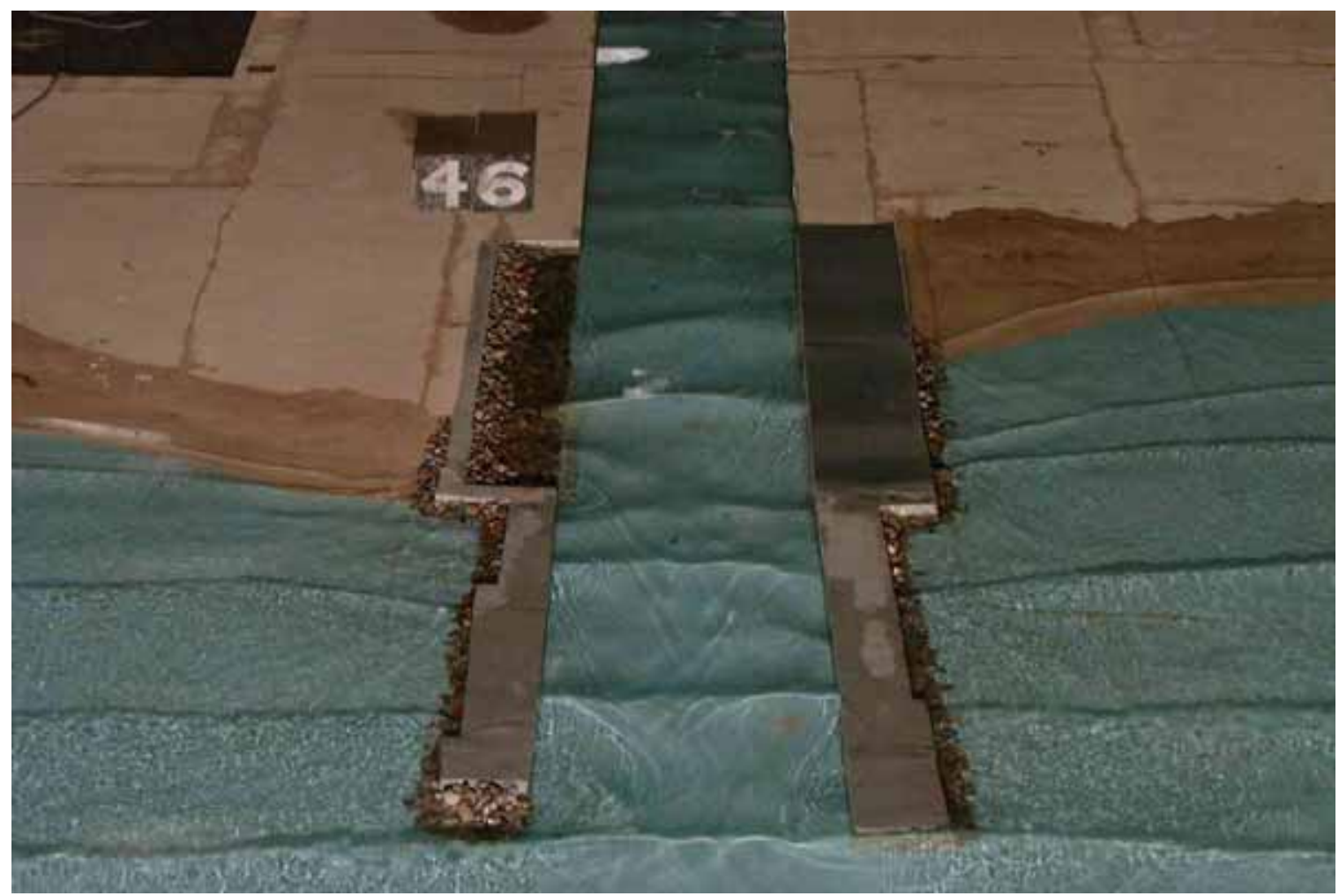

Photograph 34a. Typical wave patterns for Plan 5; 8-sec, 2-m waves from 0 deg; $\mathrm{sWl}=+0.9 \mathrm{~m}$ LWD, closeup.

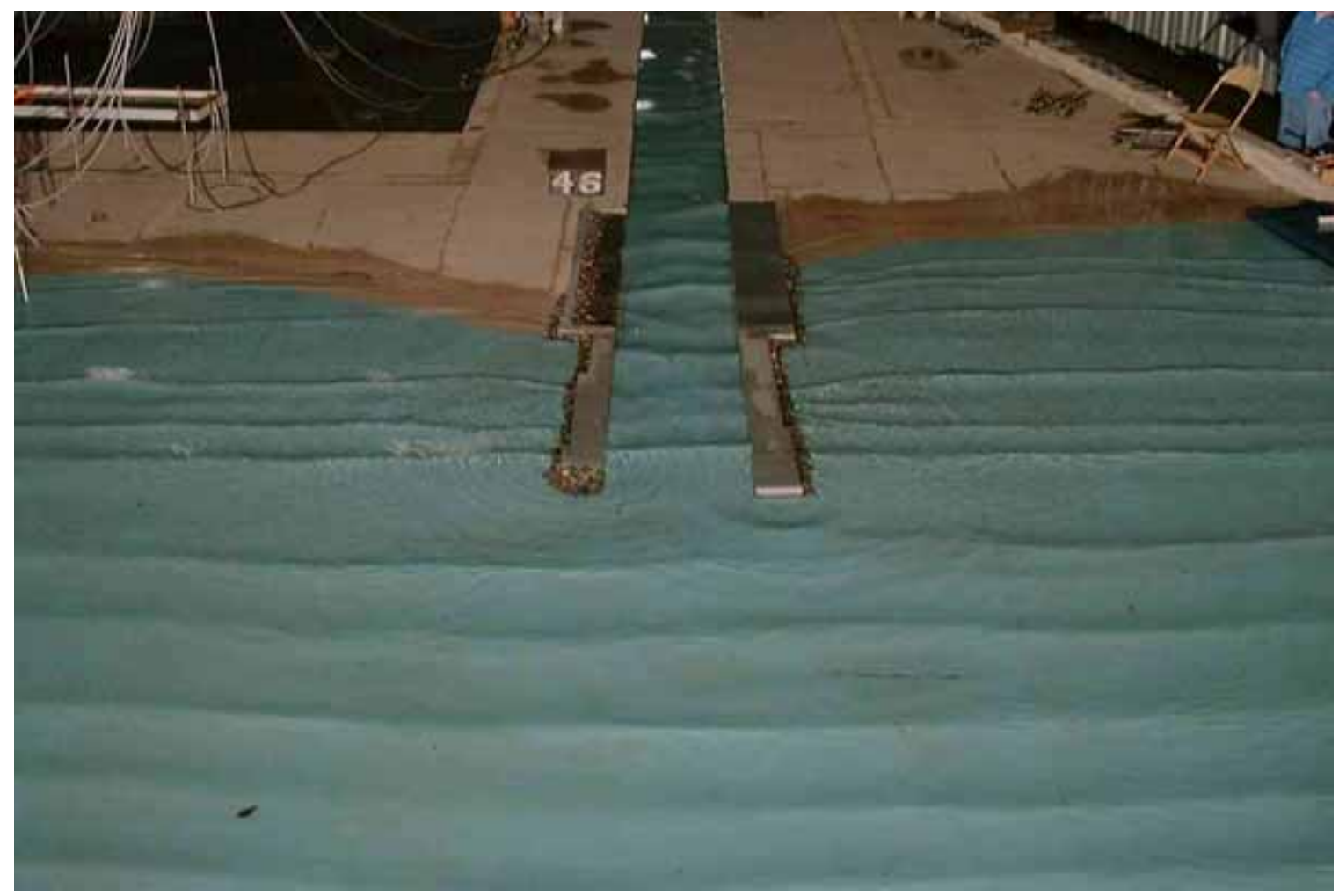

Photograph 34b. Typical wave patterns for Plan 5; 8-sec, 2-m waves from 0 deg; $\mathrm{sWl}=+0.9 \mathrm{~m}$ LWD. 


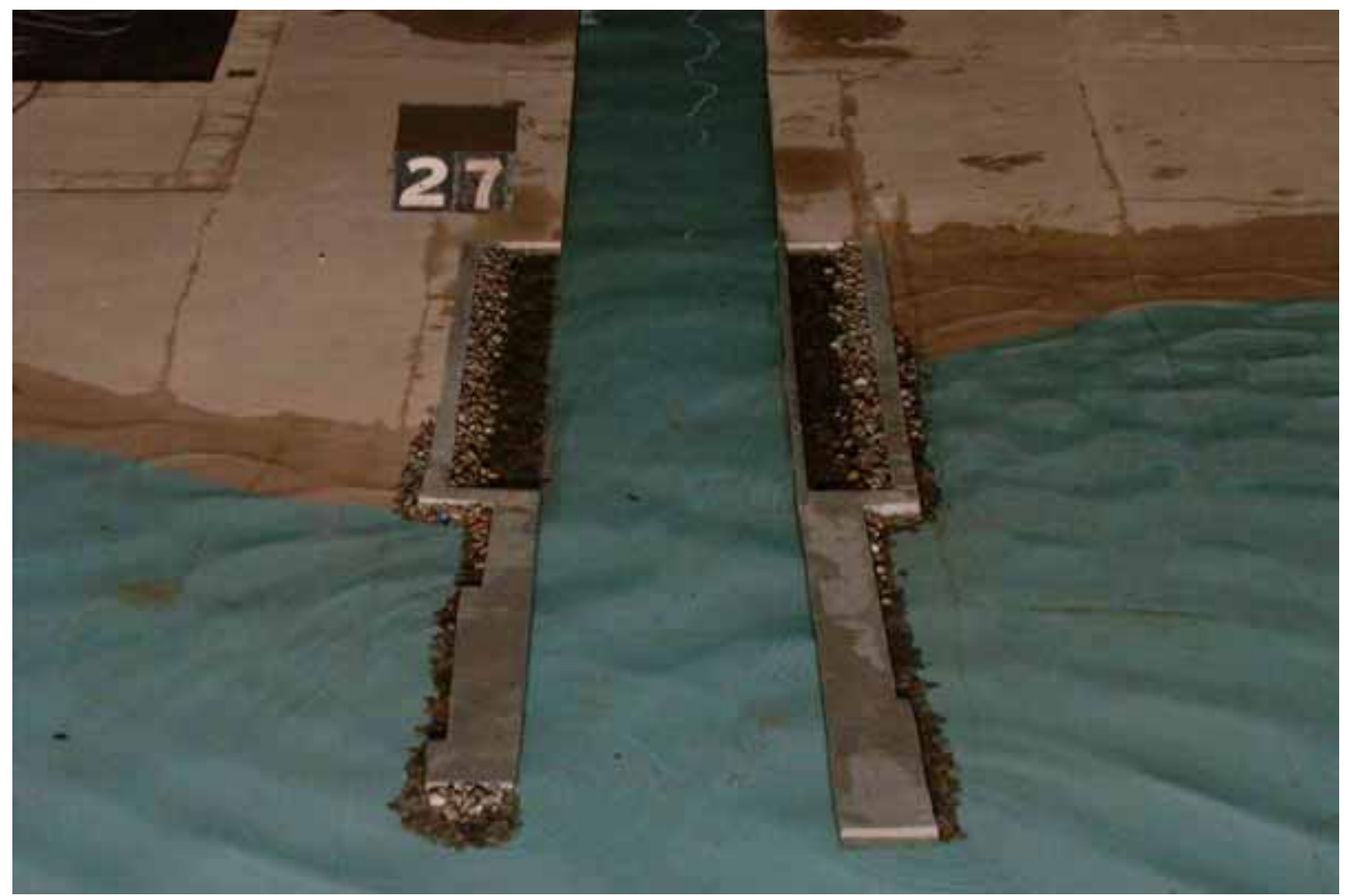

Photograph 35a. Typical wave patterns for Plan 5; 5-sec, 1-m waves from 45 deg North; $\mathrm{sWl}=+0.9 \mathrm{~m}$ LWD, closeup.

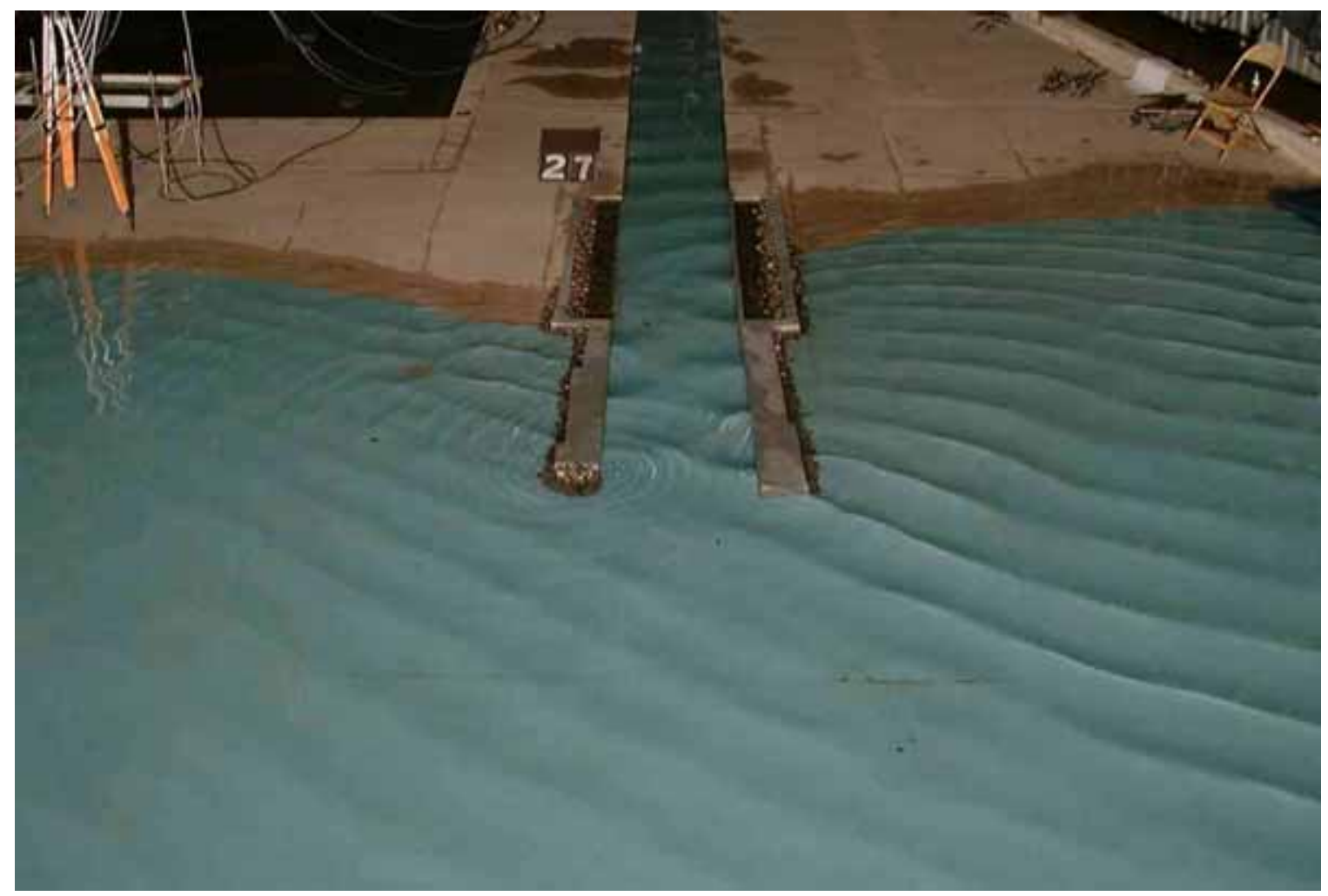

Photograph 35b. Typical wave patterns for Plan 5; 5-sec, 1-m waves from 45 deg North; $\mathrm{sWl}=+0.9 \mathrm{~m}$ LWD. 


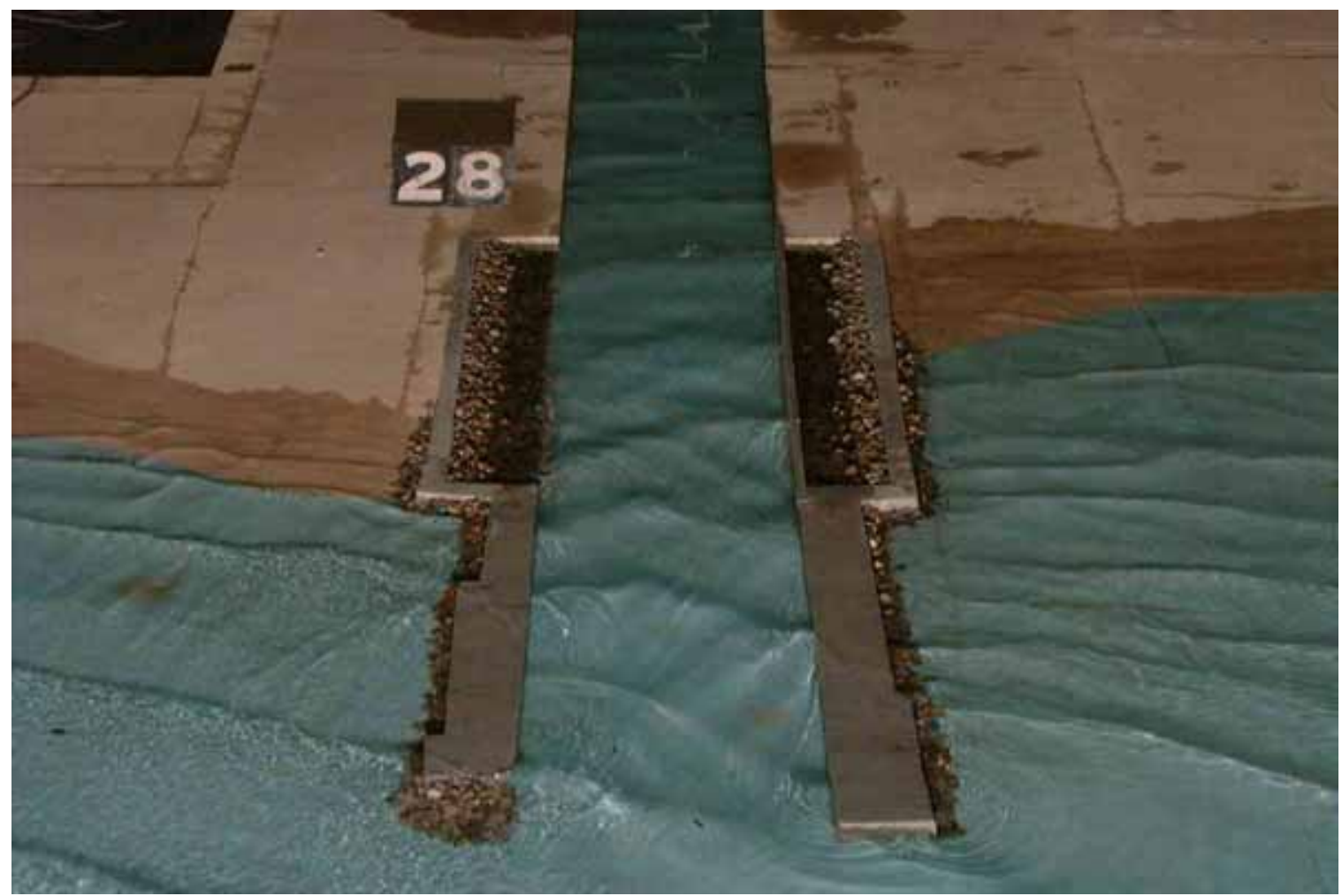

Photograph 36a. Typical wave patterns for Plan 5; 8-sec, 2-m waves from 45 deg North; $\mathrm{sWl}=+0.9 \mathrm{~m}$ LWD, closeup.

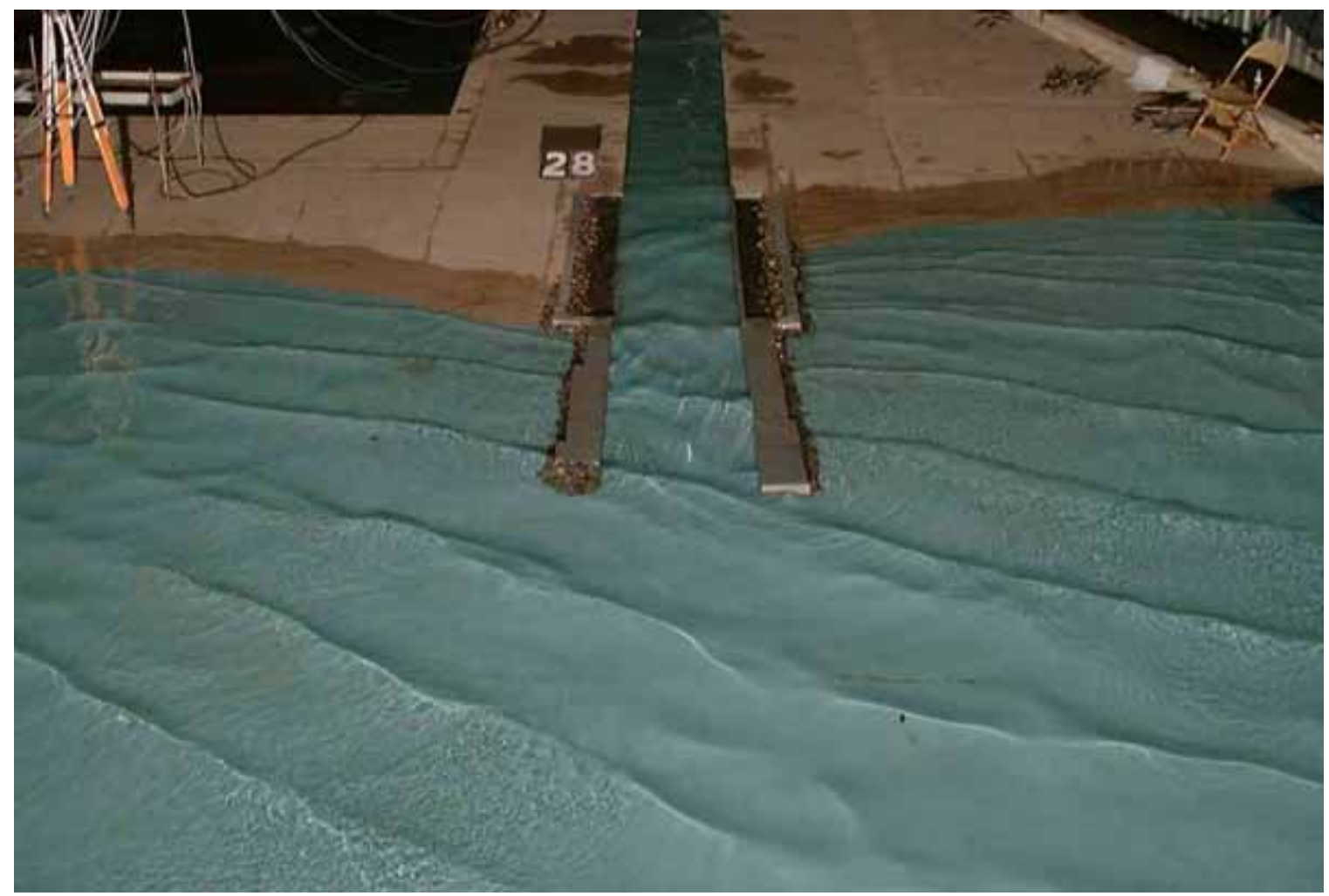

Photograph 36b. Typical wave patterns for Plan 5; 8-sec, 2-m waves from 45 deg North; $\mathrm{sWl}=+0.9 \mathrm{~m}$ LWD. 


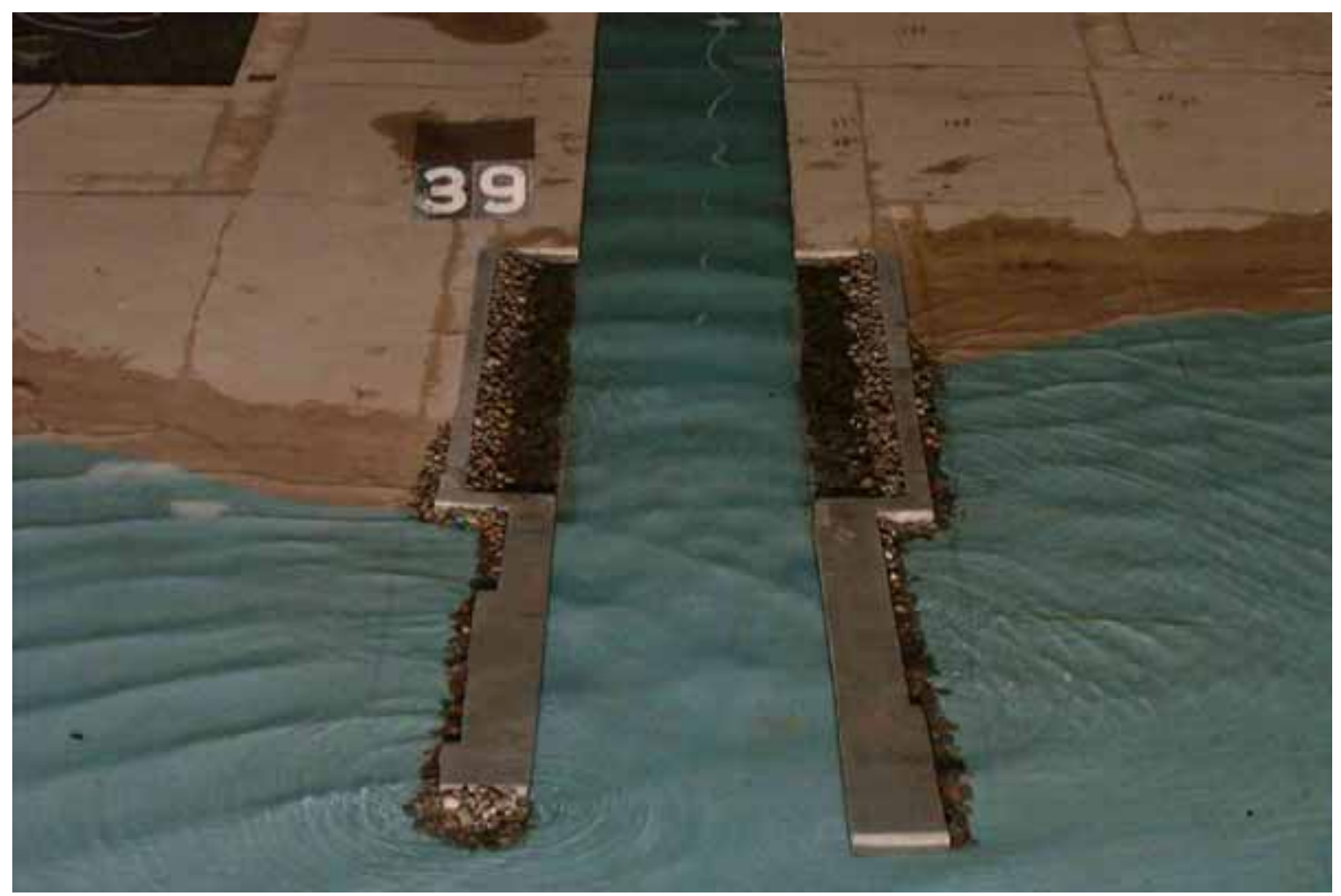

Photograph 37a. Typical wave patterns for Plan 6; 5-sec, 1-m waves from 45 deg South; $s W l=+0.9 m$ LWD, closeup.

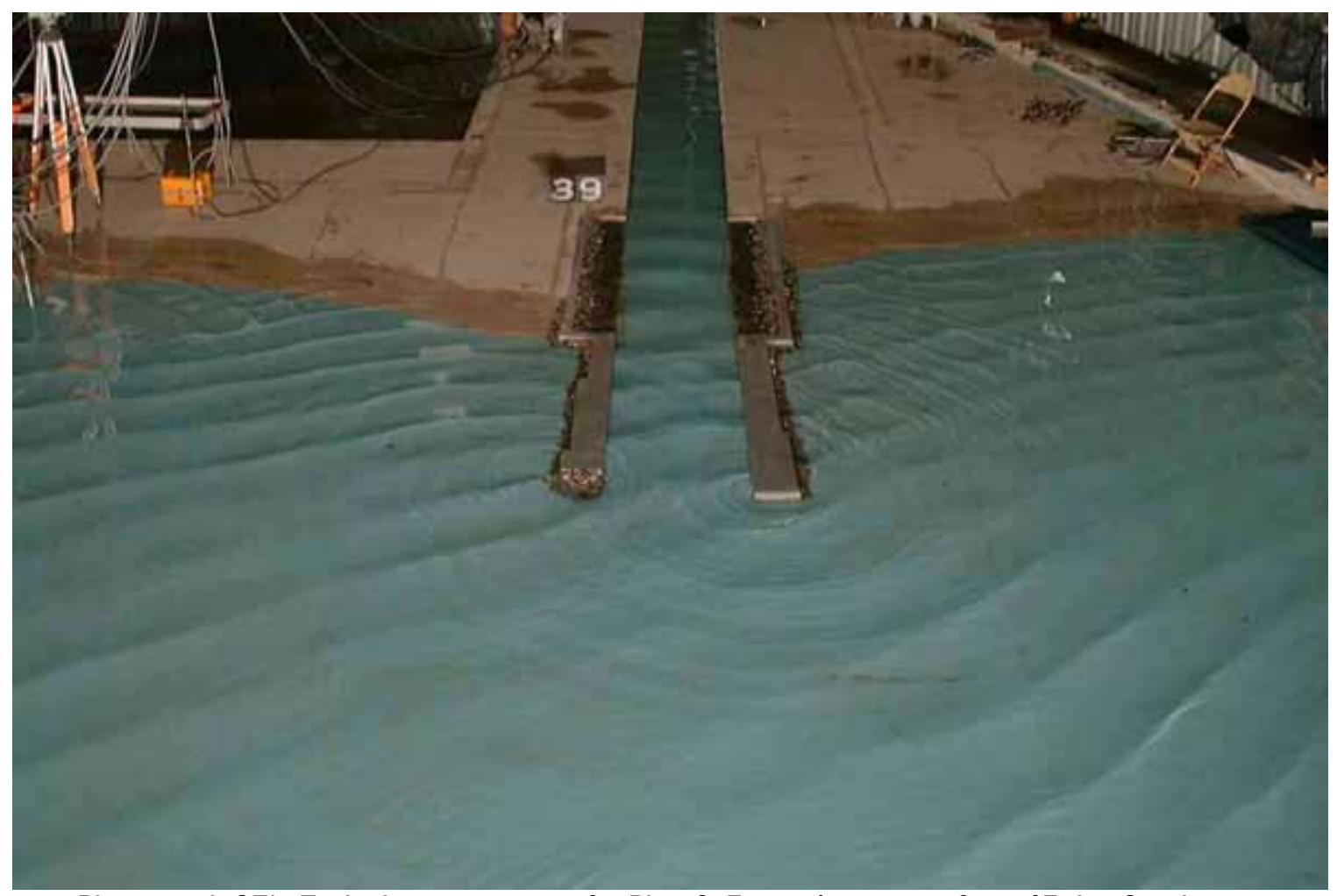

Photograph 37b. Typical wave patterns for Plan 6; 5-sec, 1-m waves from 45 deg South; $\mathrm{sWl}=+0.9 \mathrm{~m}$ LWD. 


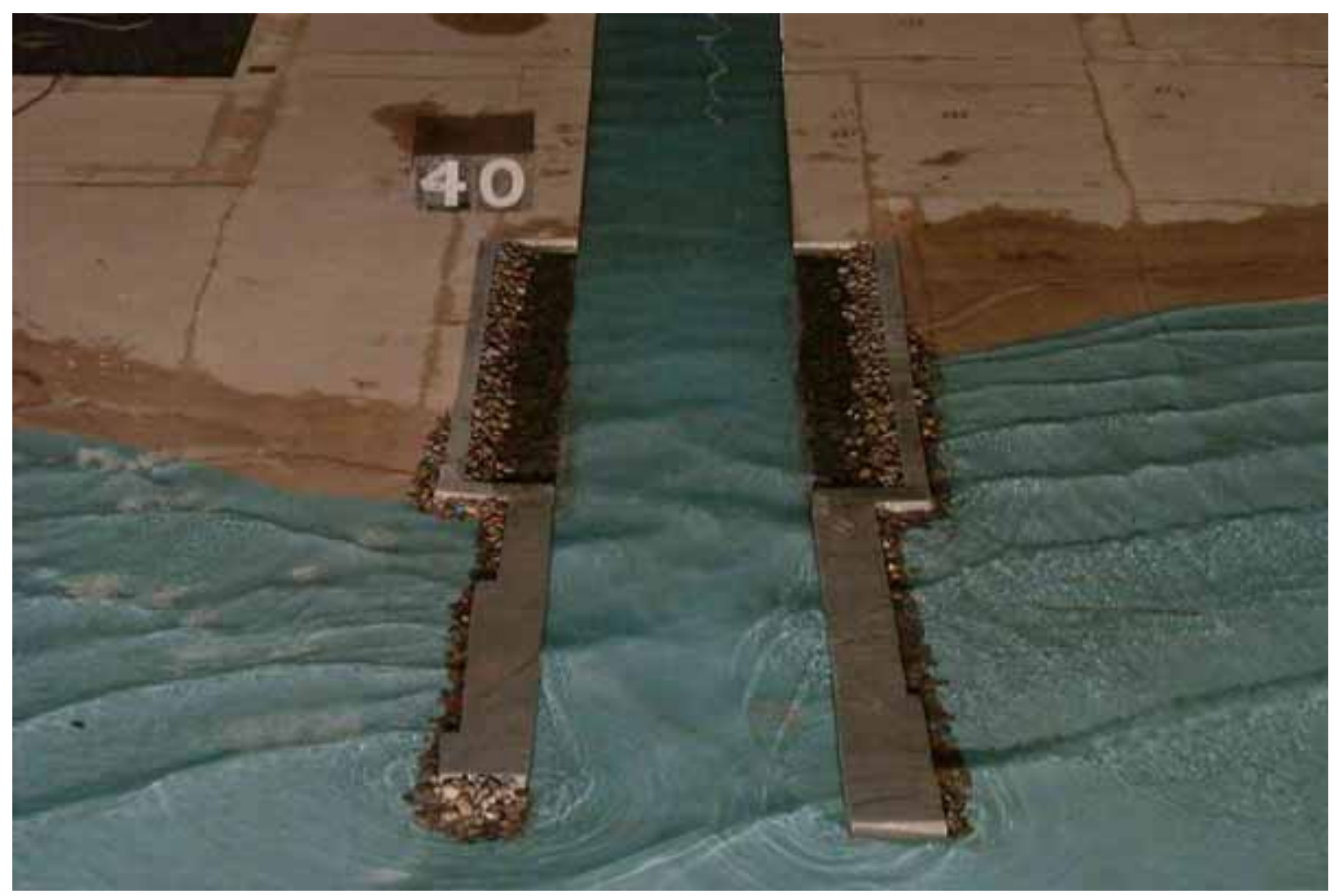

Photograph 38a. Typical wave patterns for Plan 6; 8-sec, 2-m waves from 45 deg South; $s W l=+0.9 m$ LWD, closeup.

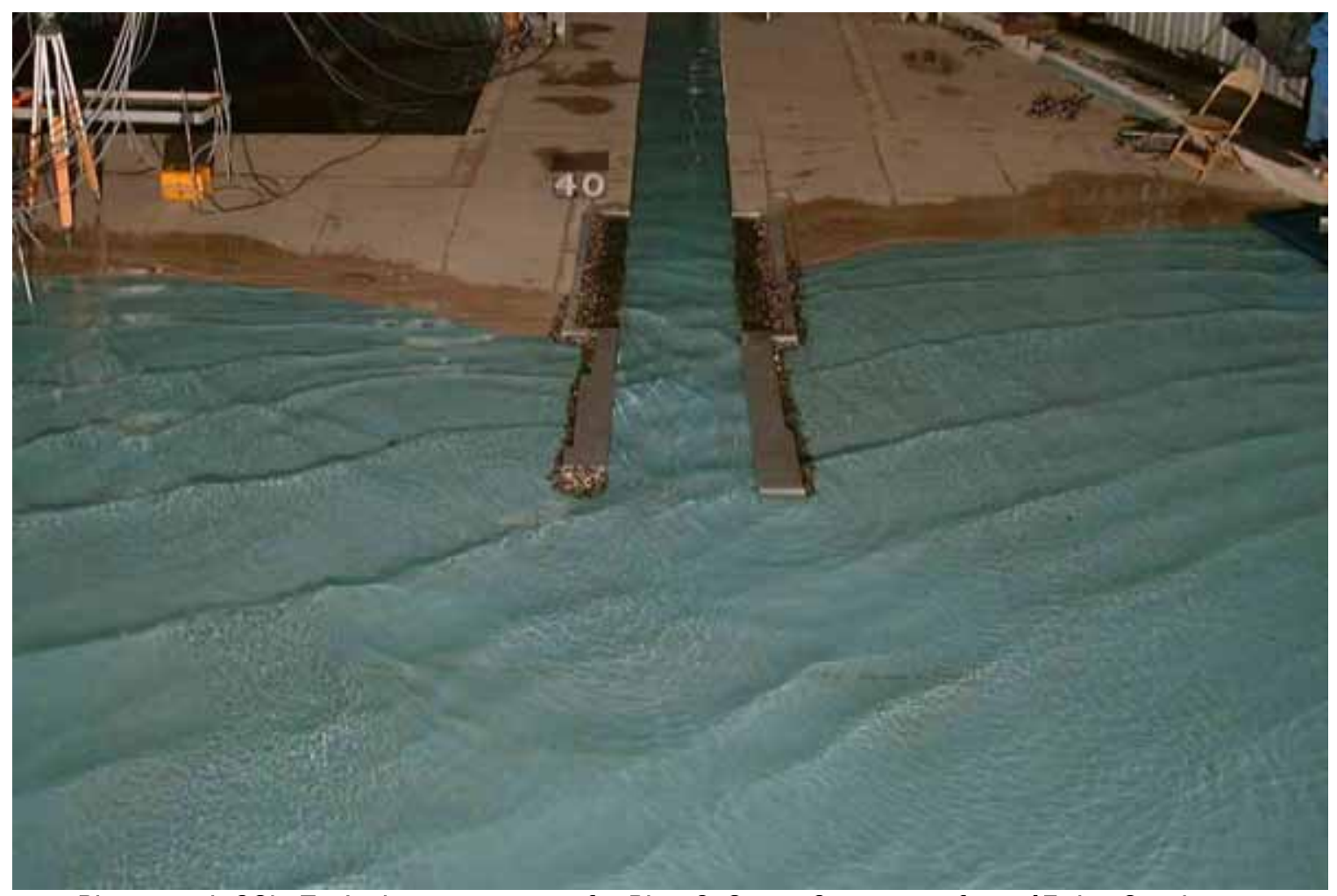

Photograph 38b. Typical wave patterns for Plan 6; 8-sec, 2-m waves from 45 deg South; $\mathrm{sWl}=+0.9 \mathrm{~m}$ LWD. 


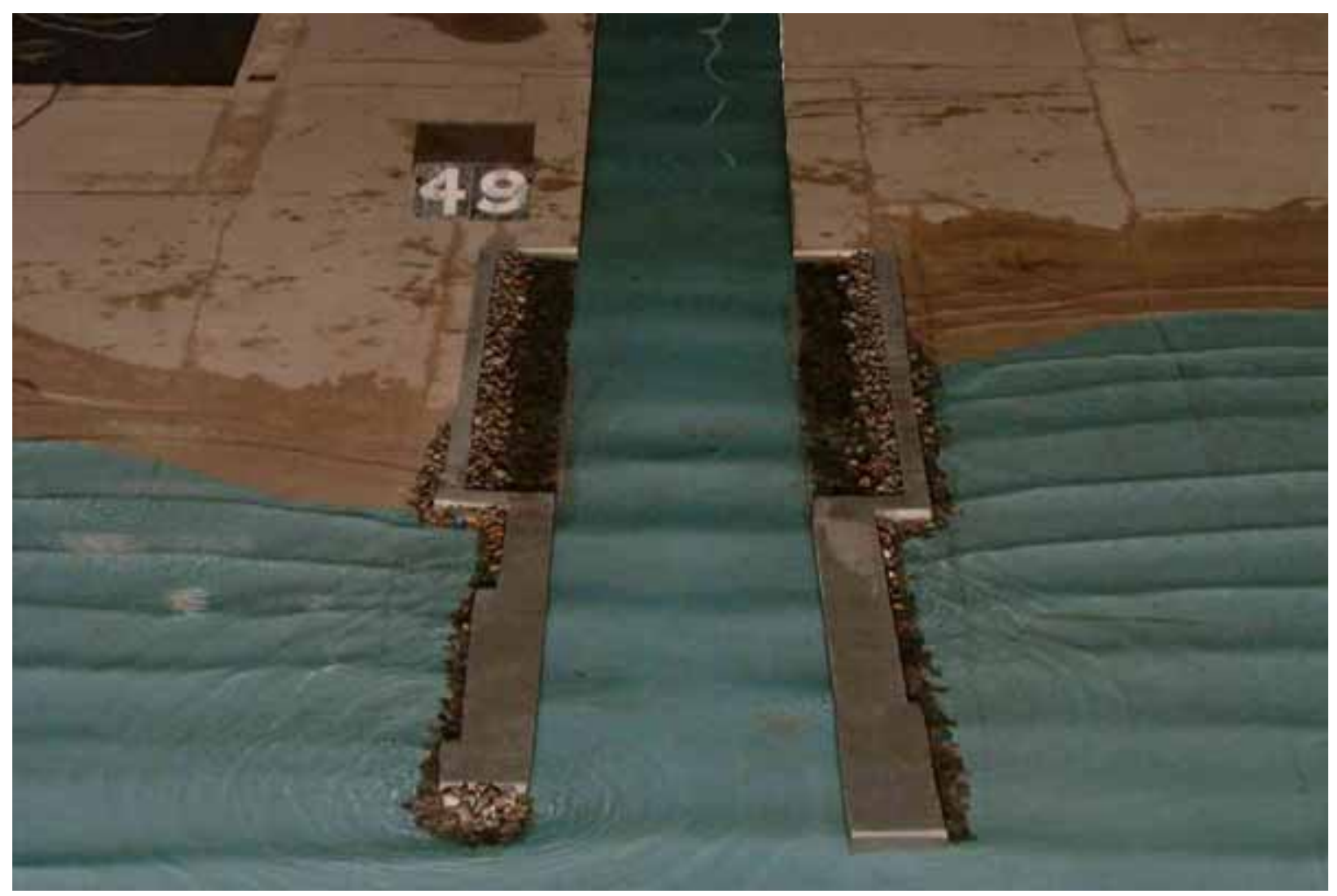

Photograph 39a. Typical wave patterns for Plan 6; 5-sec, 1-m waves from 0 deg; $\mathrm{sWl}=+0.9 \mathrm{~m}$ LWD, closeup.

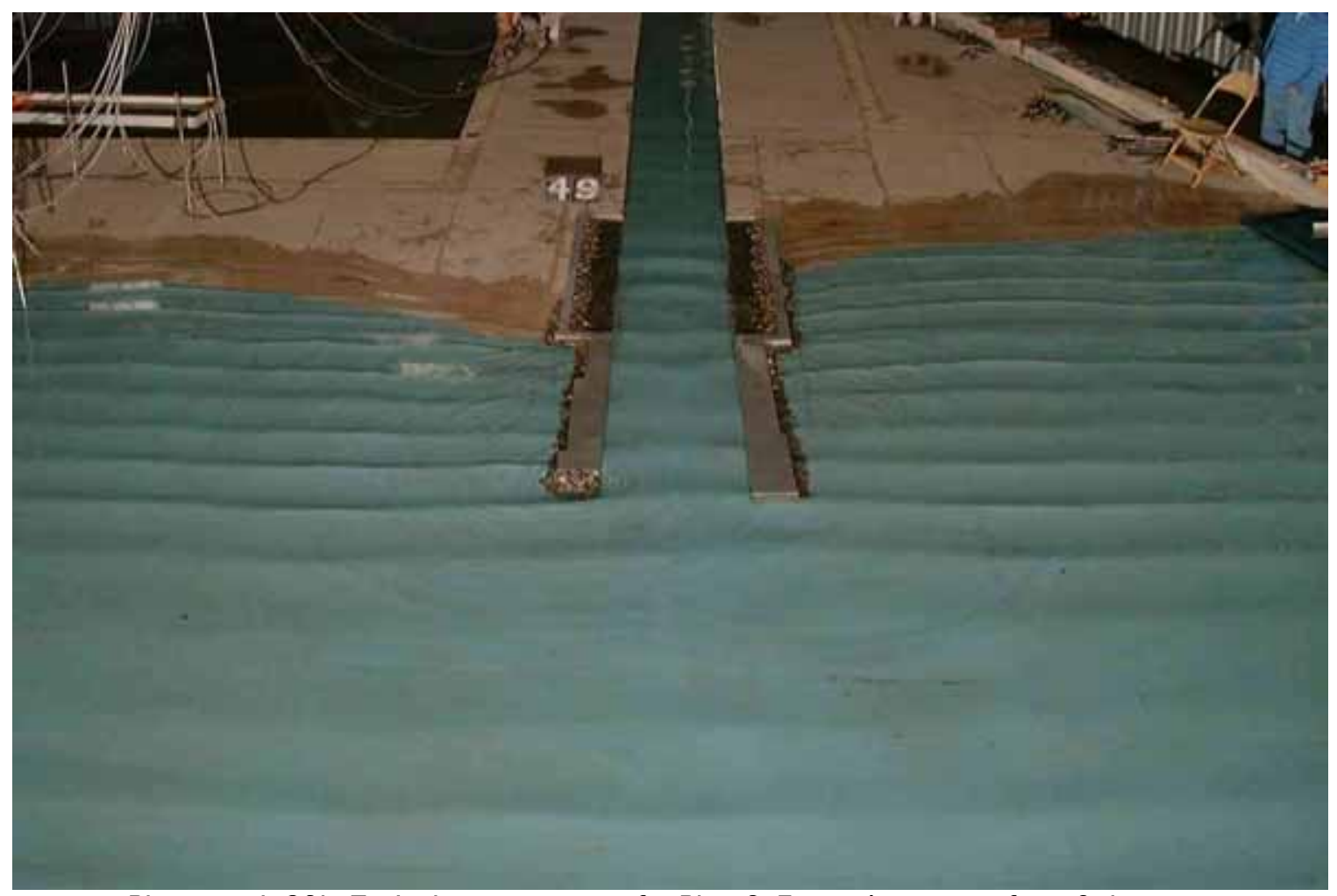

Photograph 39b. Typical wave patterns for Plan 6; 5-sec, 1-m waves from 0 deg; $\mathrm{sWl}=+0.9 \mathrm{~m}$ LWD. 


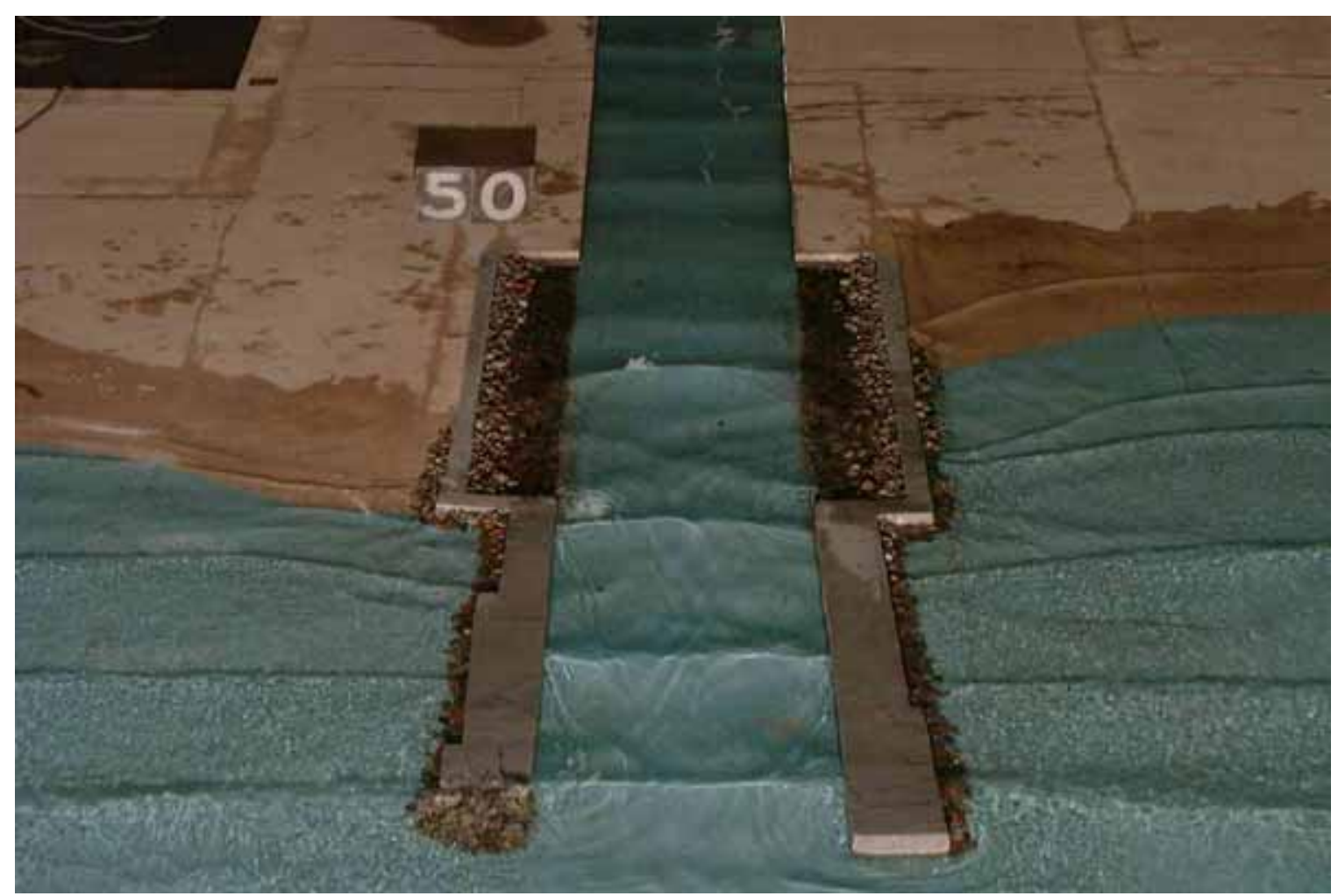

Photograph 40a. Typical wave patterns for Plan 6; 8-sec, 2-m waves from 0 deg; $s W l=+0.9 m$ LWD, closeup.

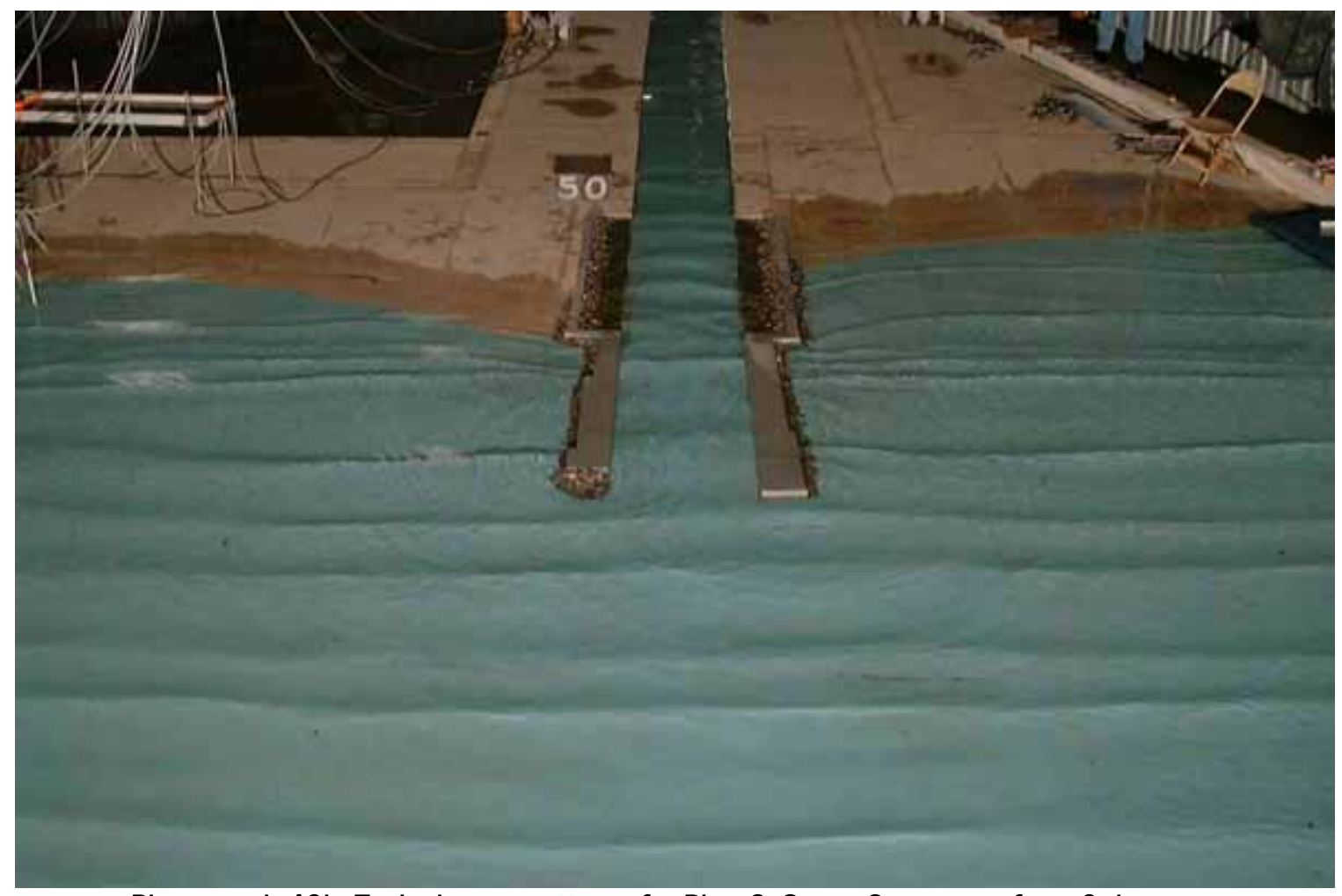

Photograph 40b. Typical wave patterns for Plan 6; 8-sec, 2-m waves from 0 deg; $\mathrm{sWl}=+0.9 \mathrm{~m}$ LWD. 


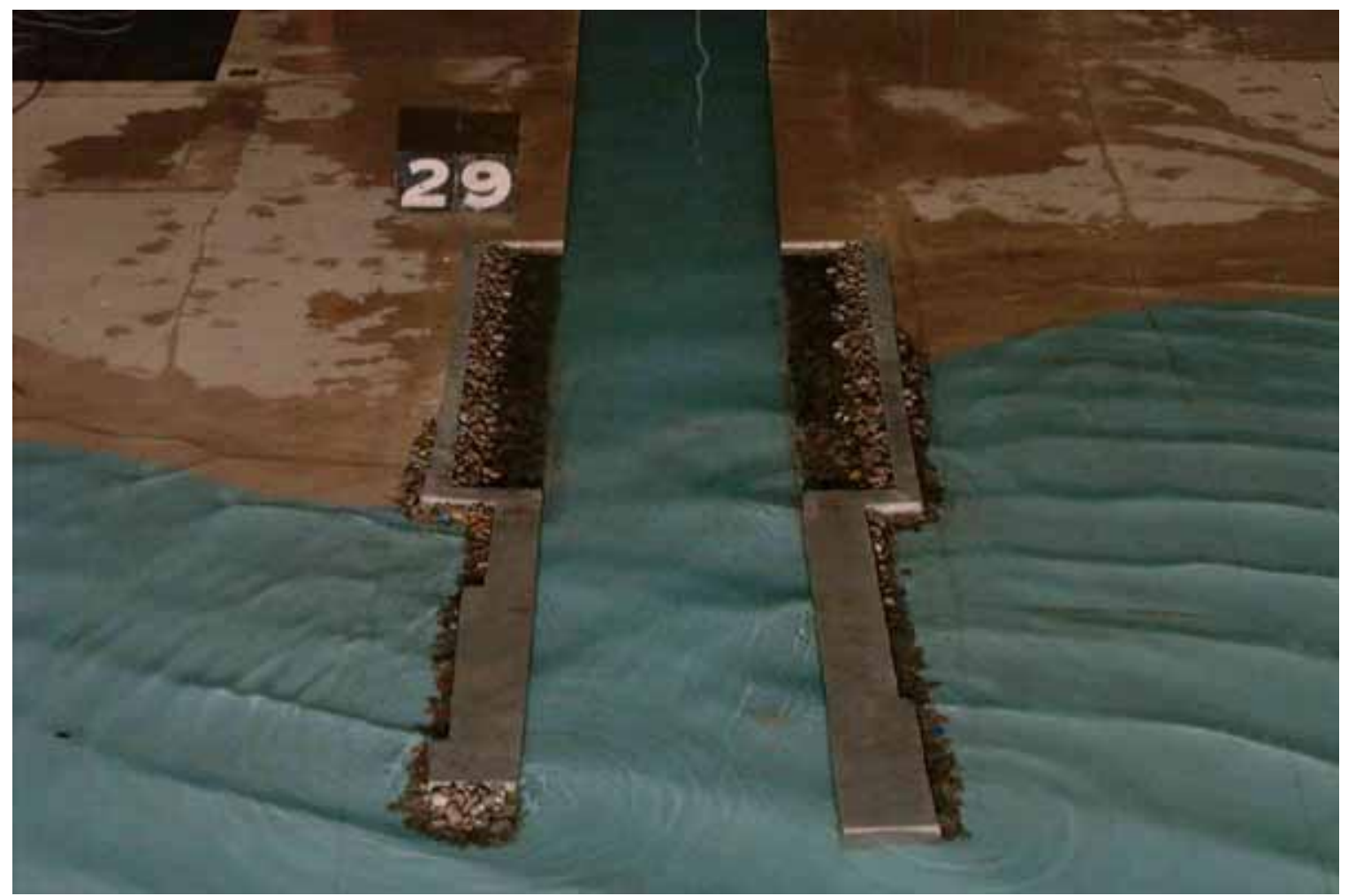

Photograph 41a. Typical wave patterns for Plan 6; 5-sec, 1-m waves from 45 deg North; $\mathrm{sWl}=+0.9 \mathrm{~m}$ LWD, closeup.

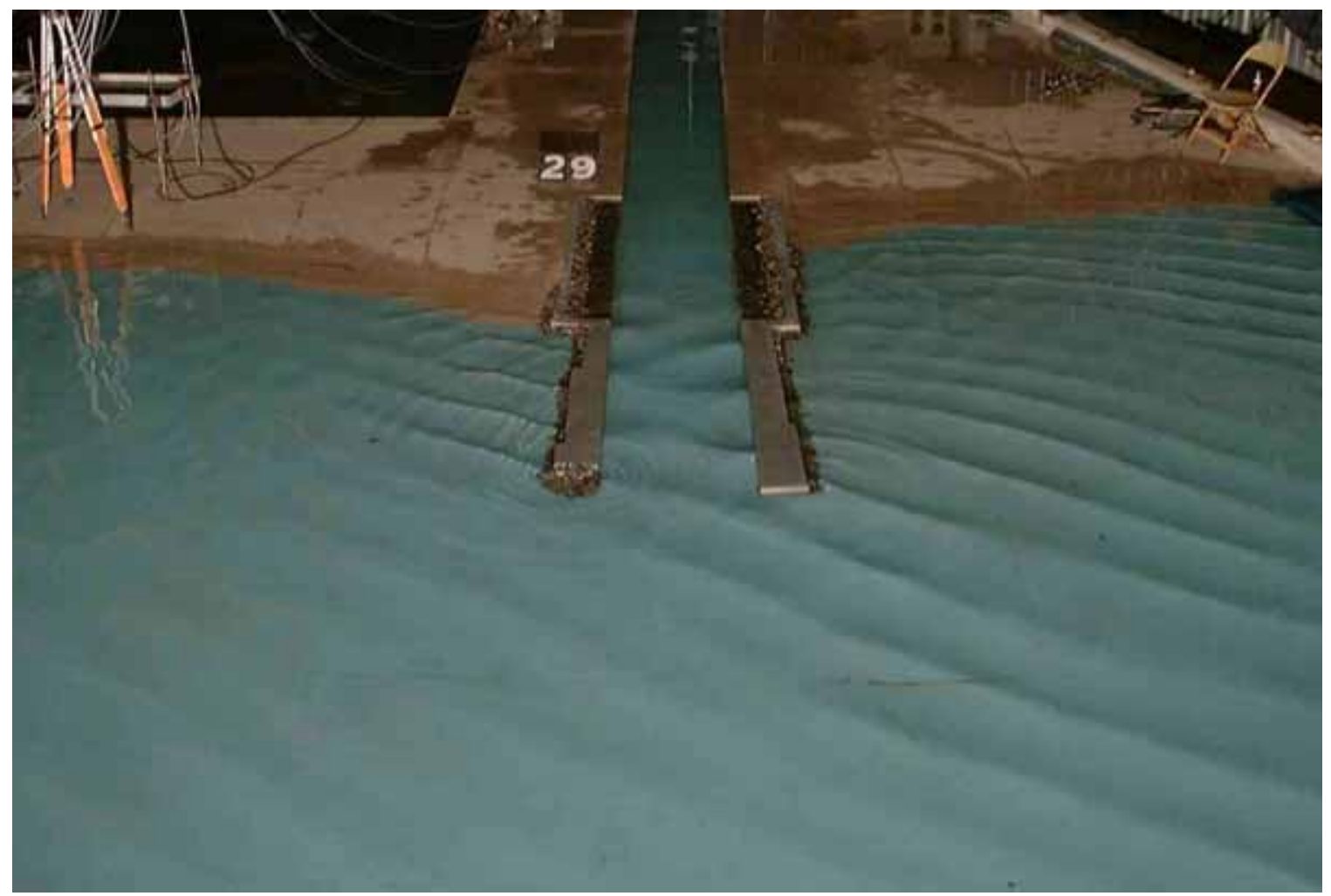

Photograph 41b. Typical wave patterns for Plan 6; 5-sec, 1-m waves from 45 deg North; $\mathrm{sWl}=+0.9 \mathrm{~m}$ LWD. 


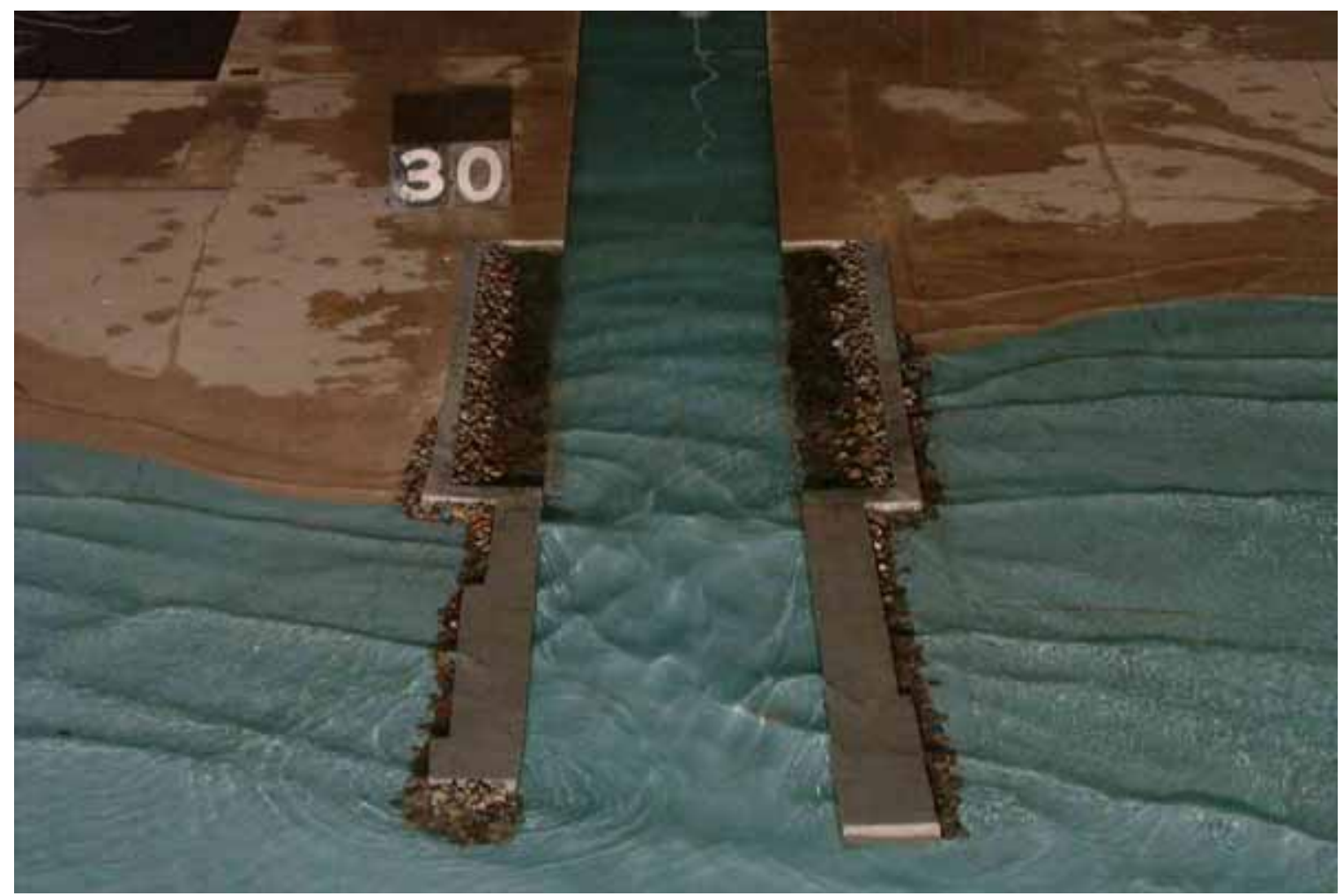

Photograph 42a. Typical wave patterns for Plan 6; 8-sec, 2-m waves from 45 deg North; $\mathrm{sWl}=+0.9 \mathrm{~m}$ LWD, closeup.

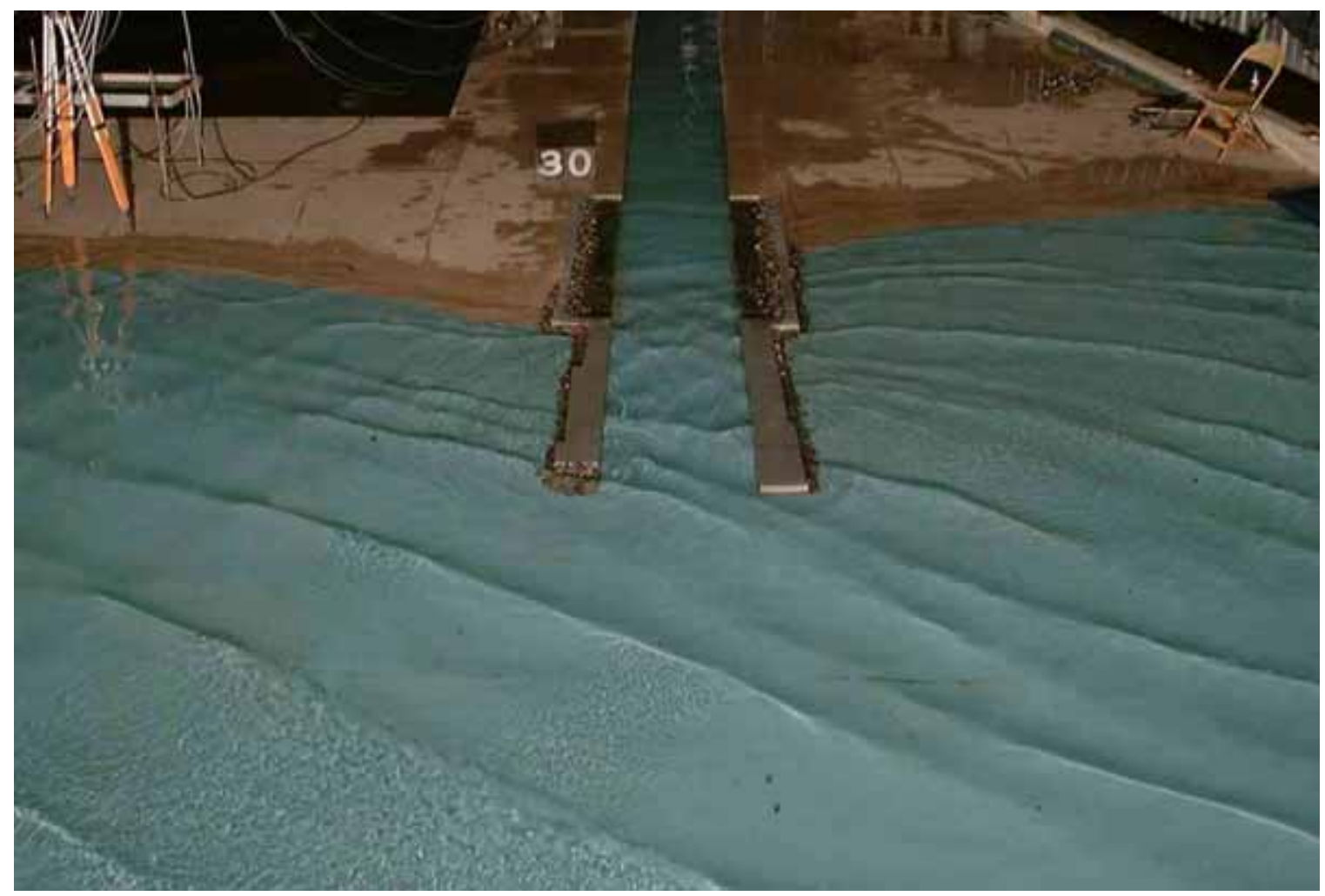

Photograph 42b. Typical wave patterns for Plan 6; 8-sec, 2-m waves from 45 deg North; $\mathrm{sWl}=+0.9 \mathrm{~m}$ LWD. 


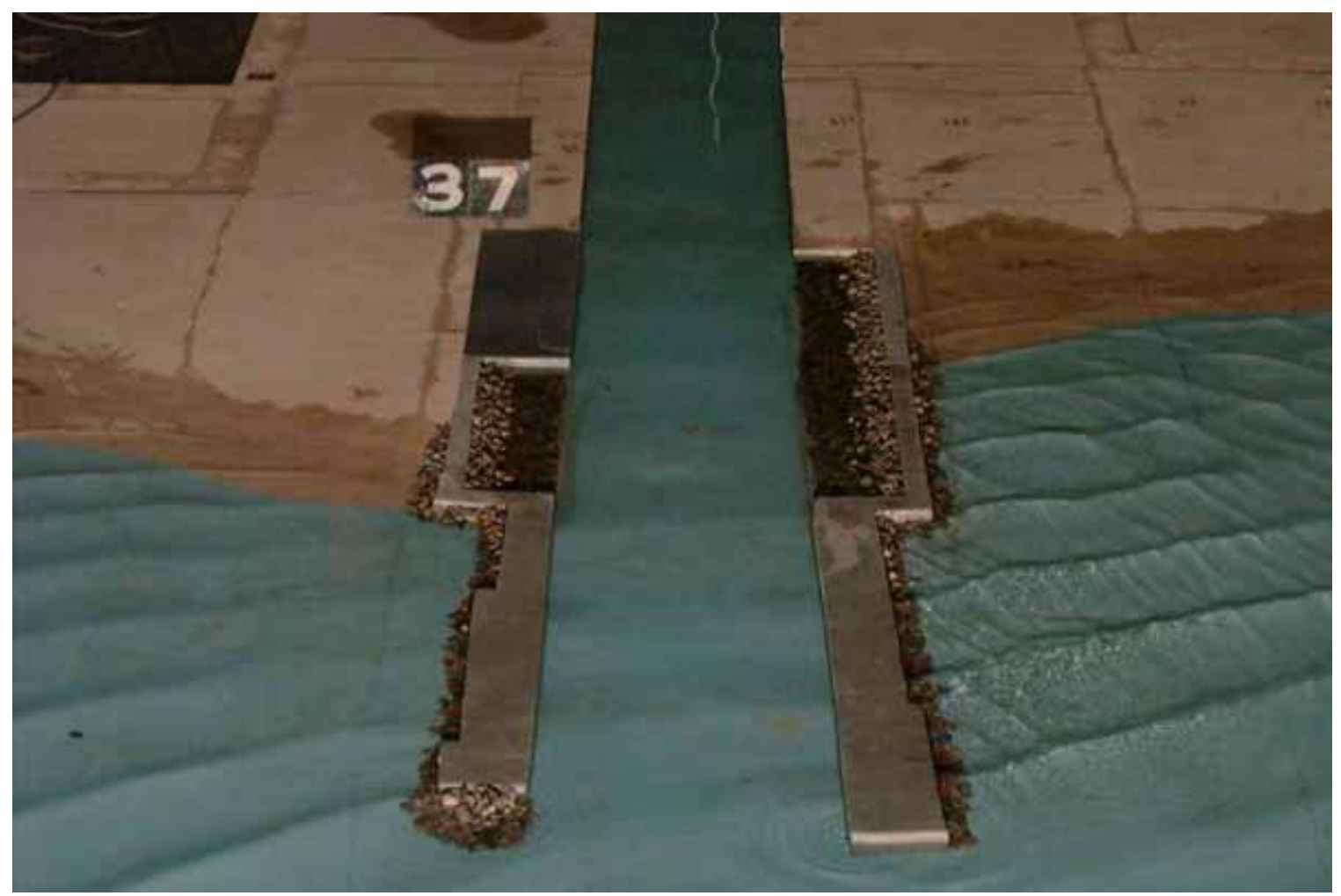

Photograph 43a. Typical wave patterns for Plan 7; 5-sec, 1-m waves from 45 deg South; $\mathrm{sWl}=+0.9 \mathrm{~m}$ LWD, closeup.

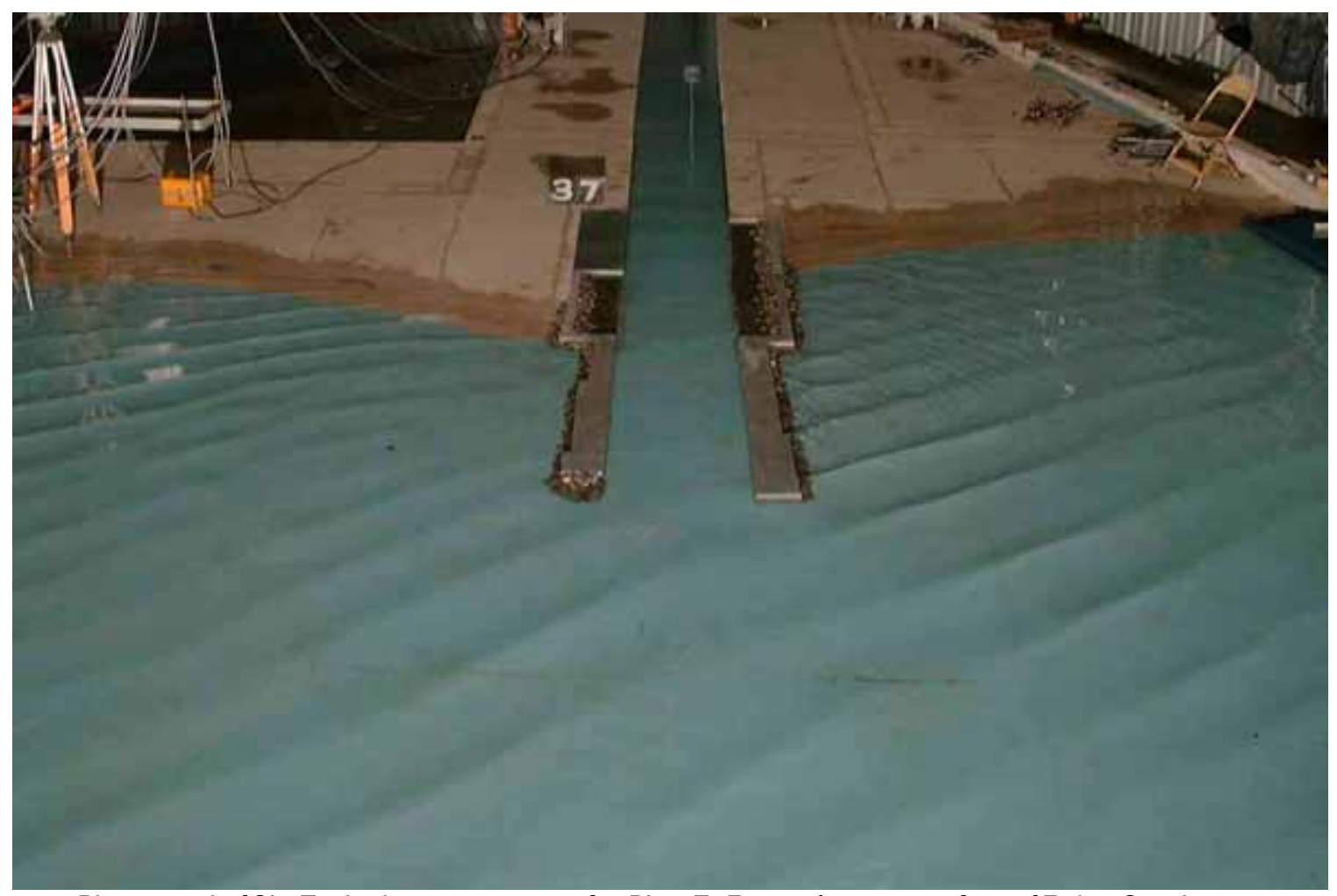

Photograph 43b. Typical wave patterns for Plan 7; 5-sec, 1-m waves from 45 deg South; $\mathrm{sWl}=+0.9 \mathrm{~m}$ LWD. 


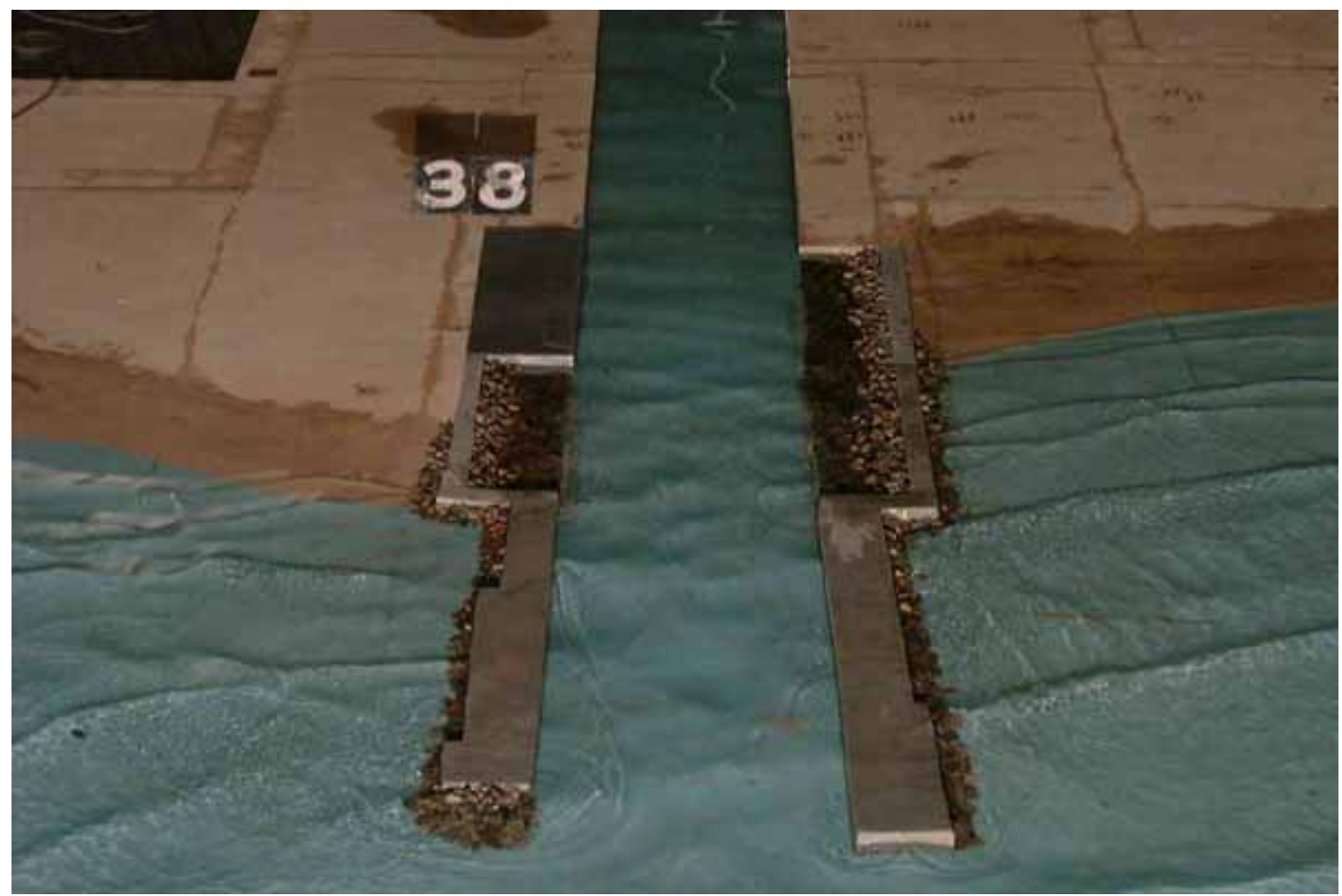

Photograph 44a. Typical wave patterns for Plan 7; 8-sec, 2-m waves from 45 deg South; $s W l=+0.9 m$ LWD, closeup.

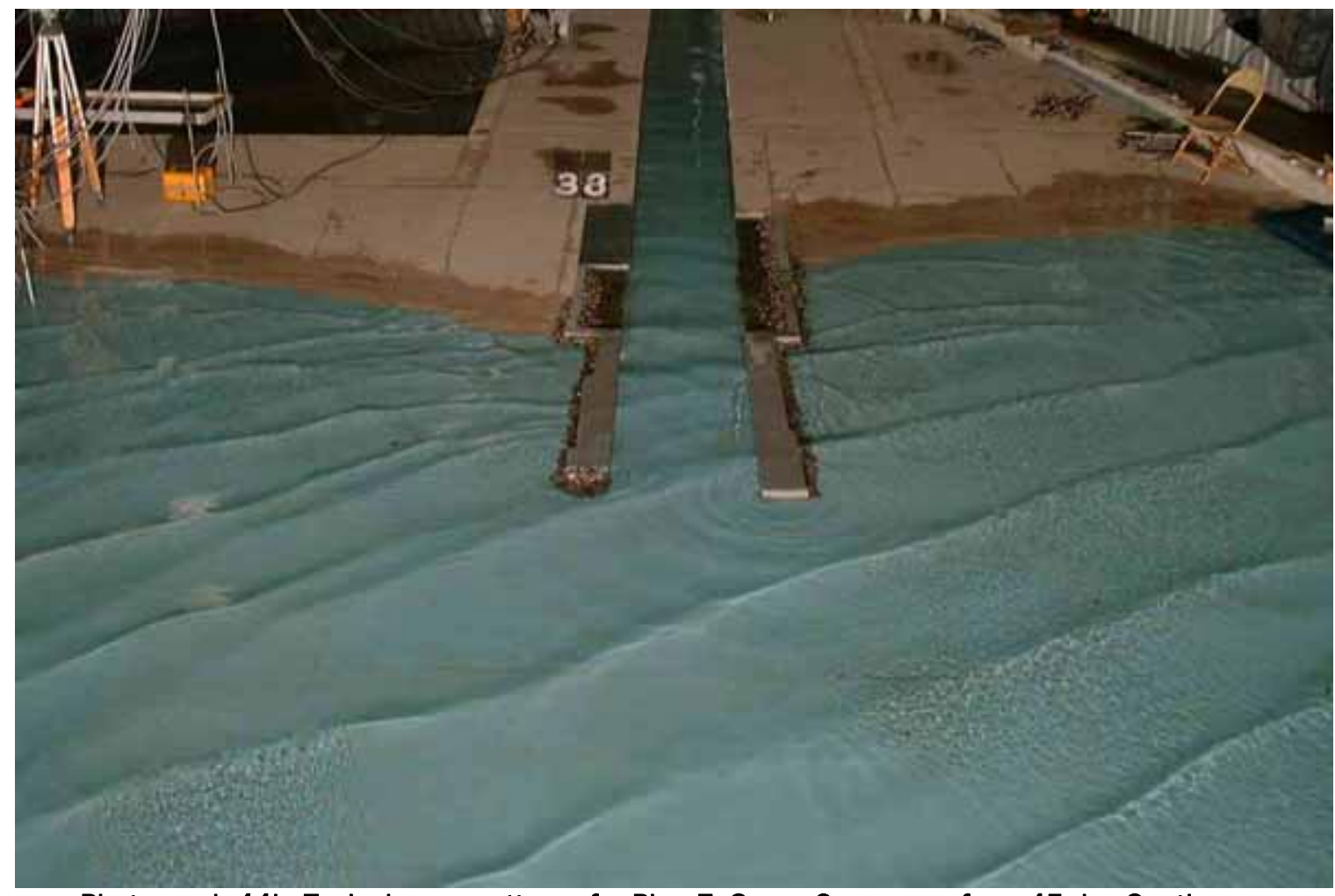

Photograph 44b. Typical wave patterns for Plan 7; 8-sec, 2-m waves from 45 deg South; $\mathrm{sWl}=+0.9 \mathrm{~m}$ LWD. 


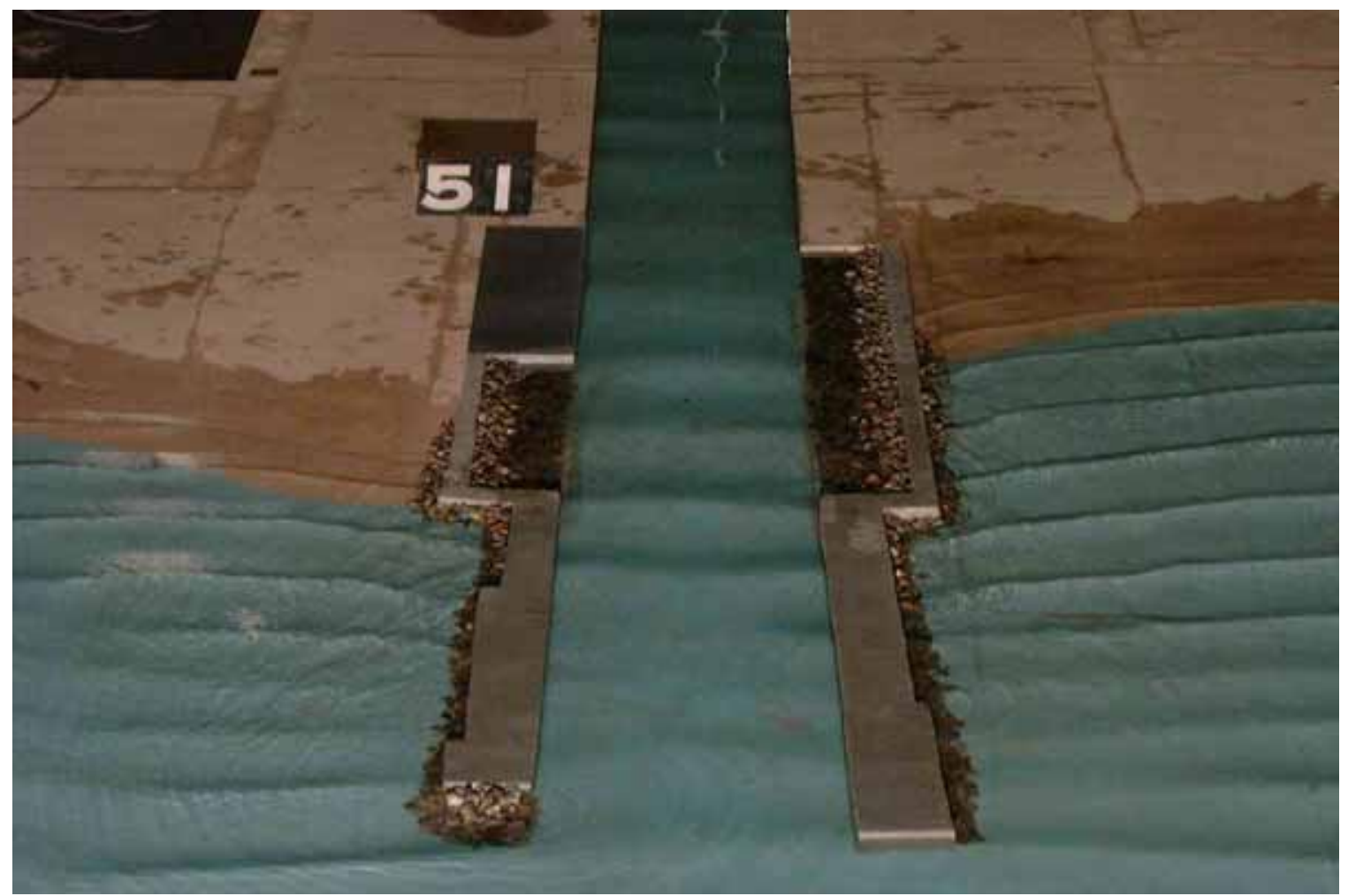

Photograph 45a. Typical wave patterns for Plan 7; 5-sec, 1-m waves from 0 deg; $\mathrm{sWl}=+0.9 \mathrm{~m}$ LWD, closeup.

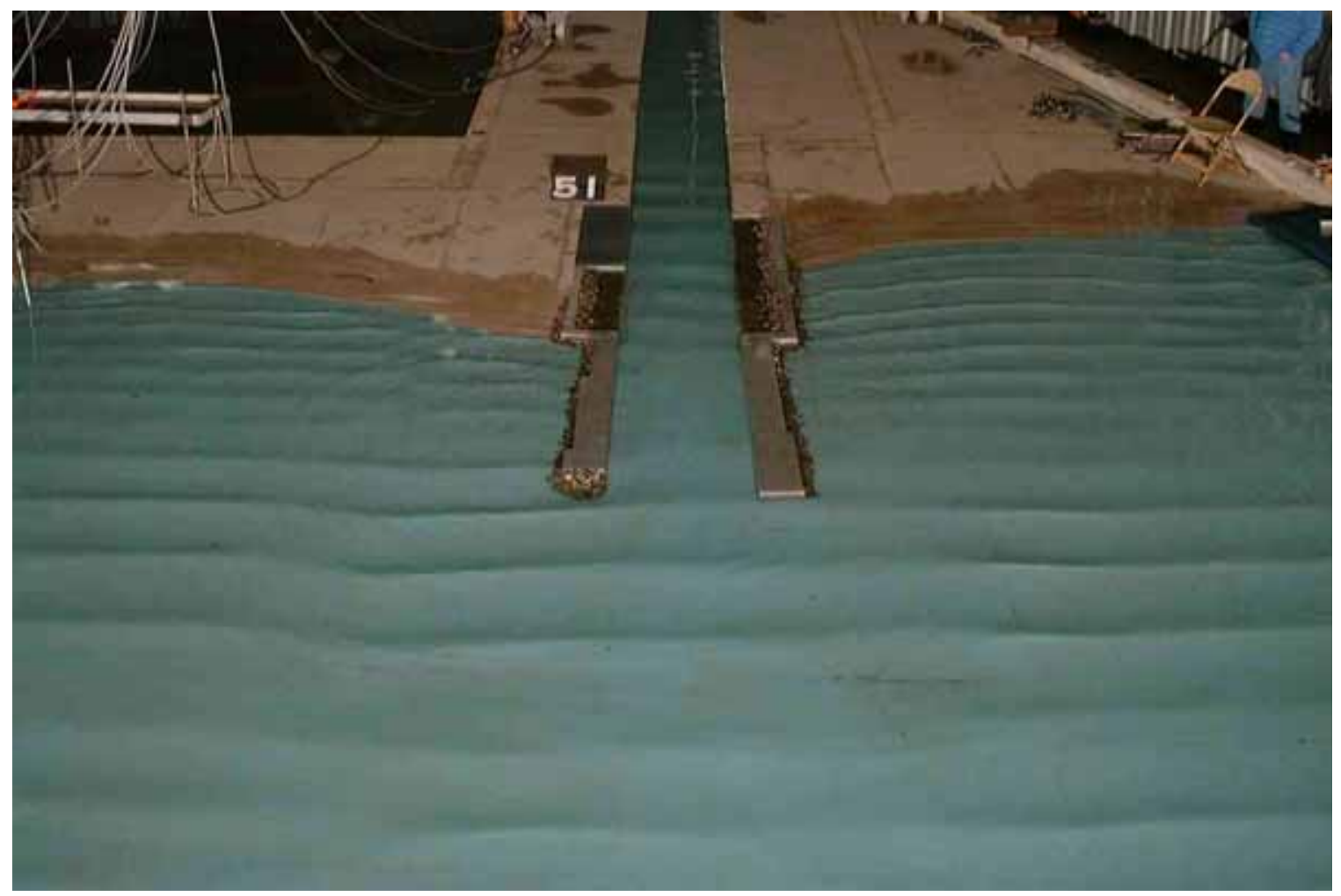

Photograph 45b. Typical wave patterns for Plan 7; 5-sec, 1-m waves from 0 deg; $\mathrm{sWl}=+0.9 \mathrm{~m}$ LWD. 


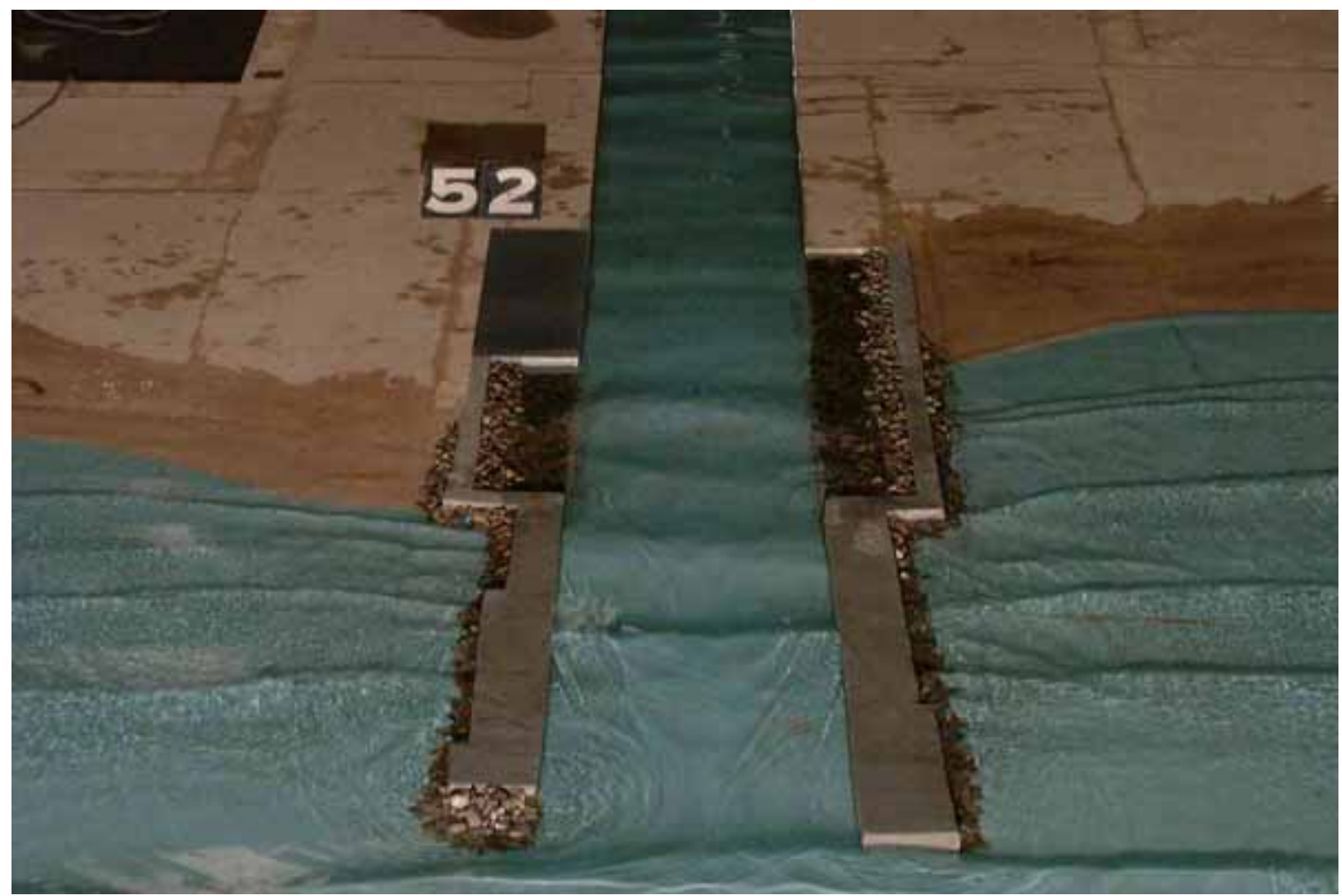

Photograph 46a. Typical wave patterns for Plan 7; 8-sec, 2-m waves from 0 deg; $\mathrm{sWl}=+0.9 \mathrm{~m}$ LWD, closeup.

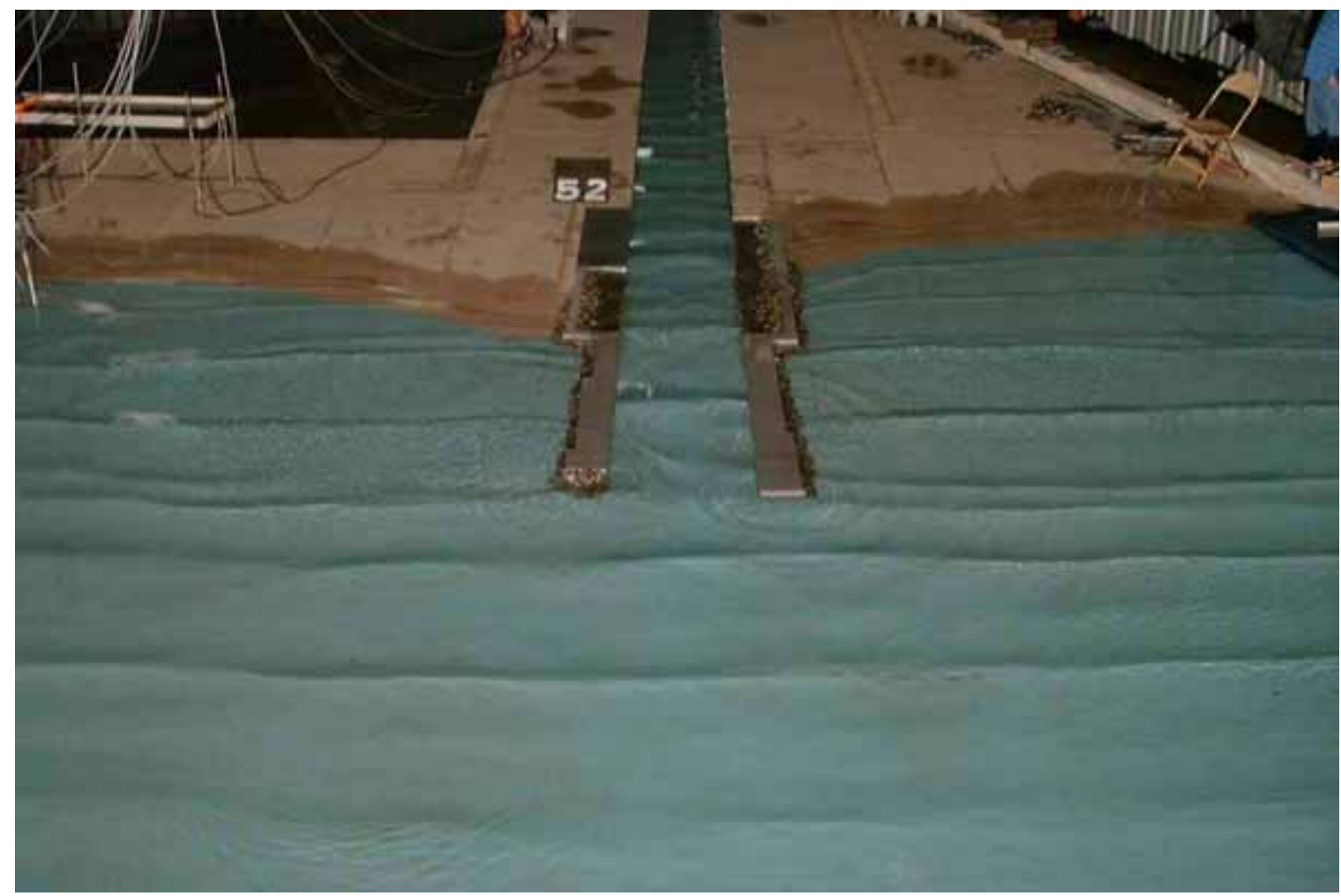

Photograph 46b. Typical wave patterns for Plan 7; 8-sec, 2-m waves from 0 deg; $\mathrm{sWl}=+0.9 \mathrm{~m}$ LWD. 


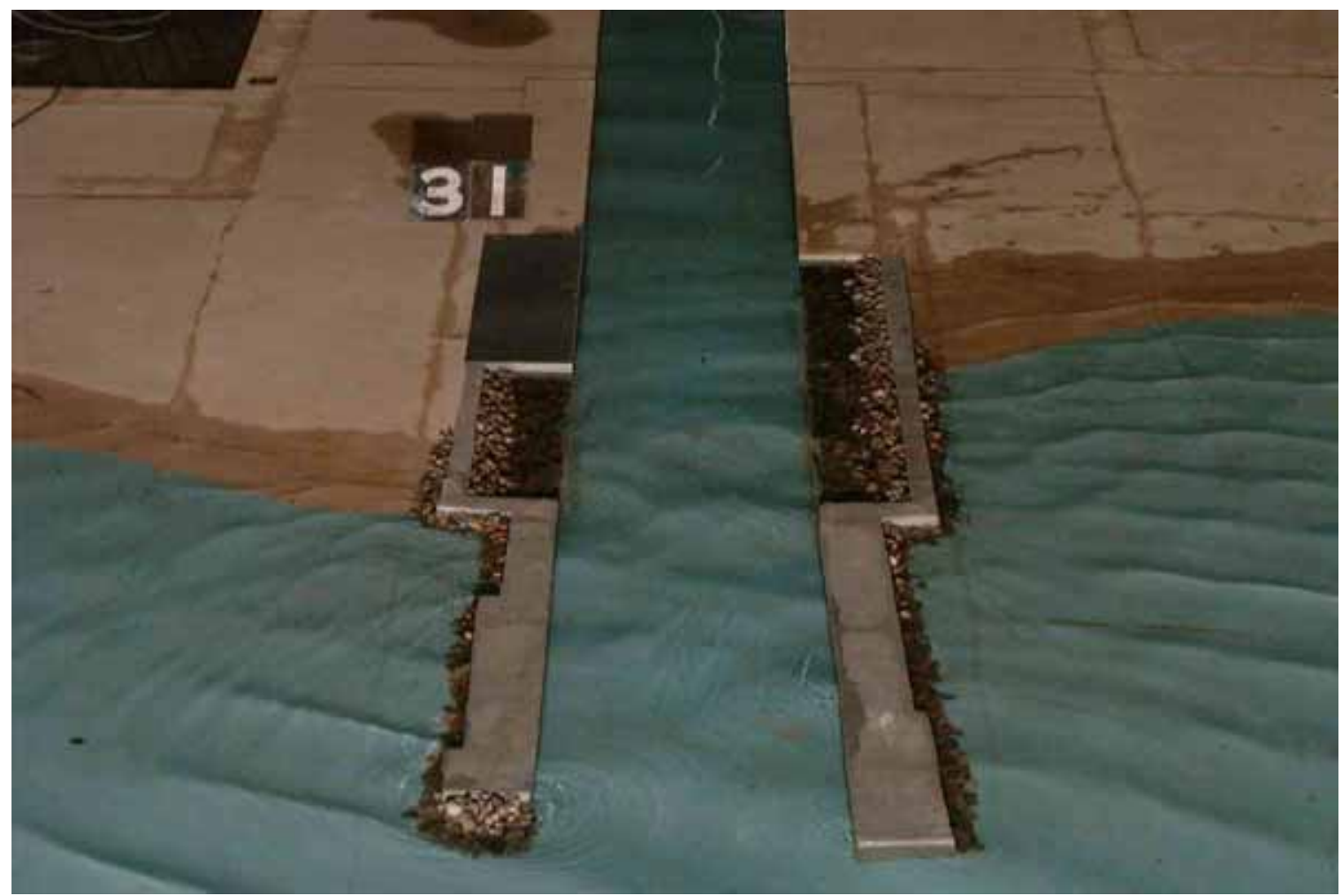

Photograph 47a. Typical wave patterns for Plan 7; 5-sec, 1-m waves from 45 deg North; $\mathrm{sWl}=+0.9 \mathrm{~m}$ LWD, closeup.

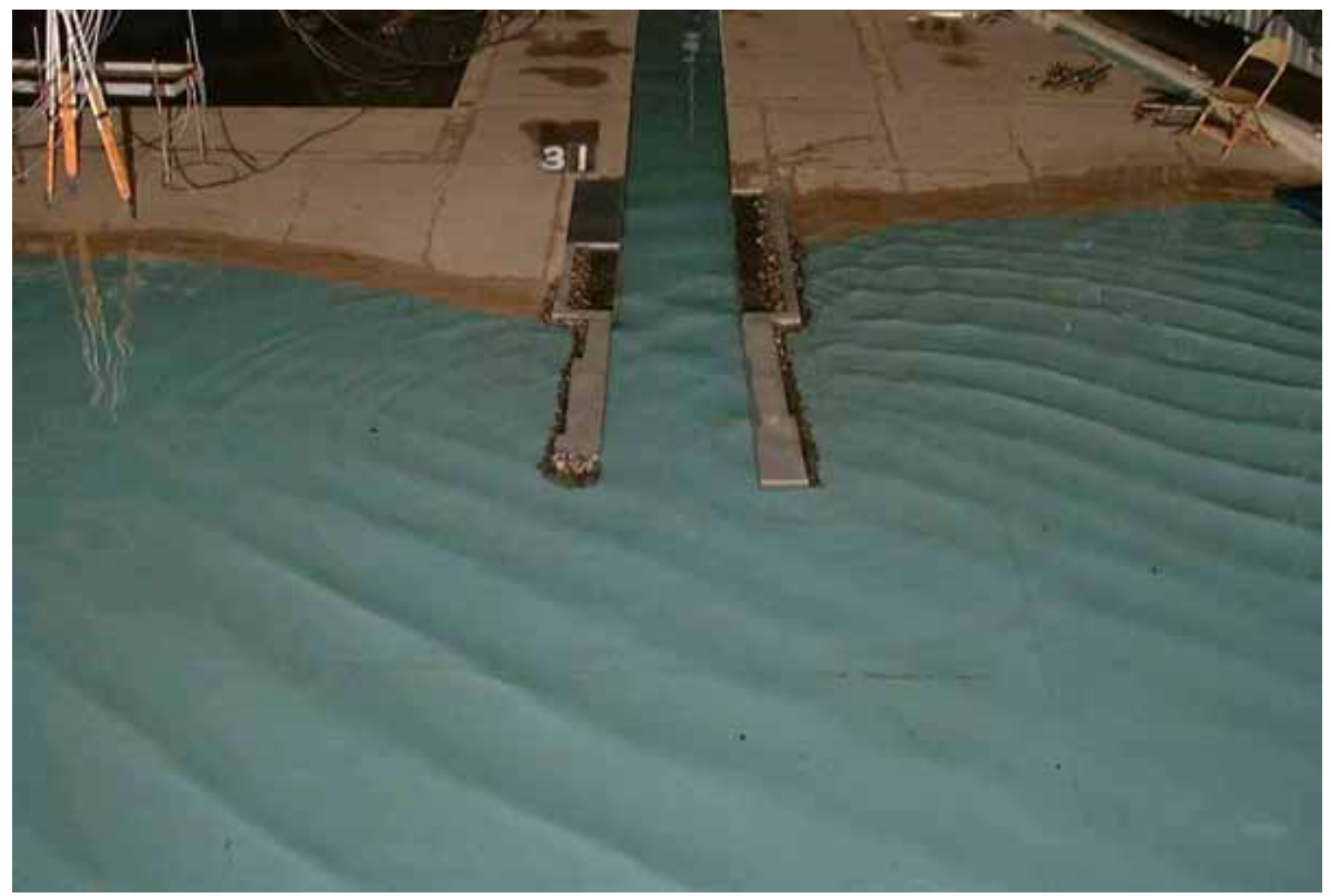

Photograph 47b. Typical wave patterns for Plan 7; 5-sec, 1-m waves from 45 deg North; $\mathrm{sWl}=+0.9 \mathrm{~m}$ LWD. 


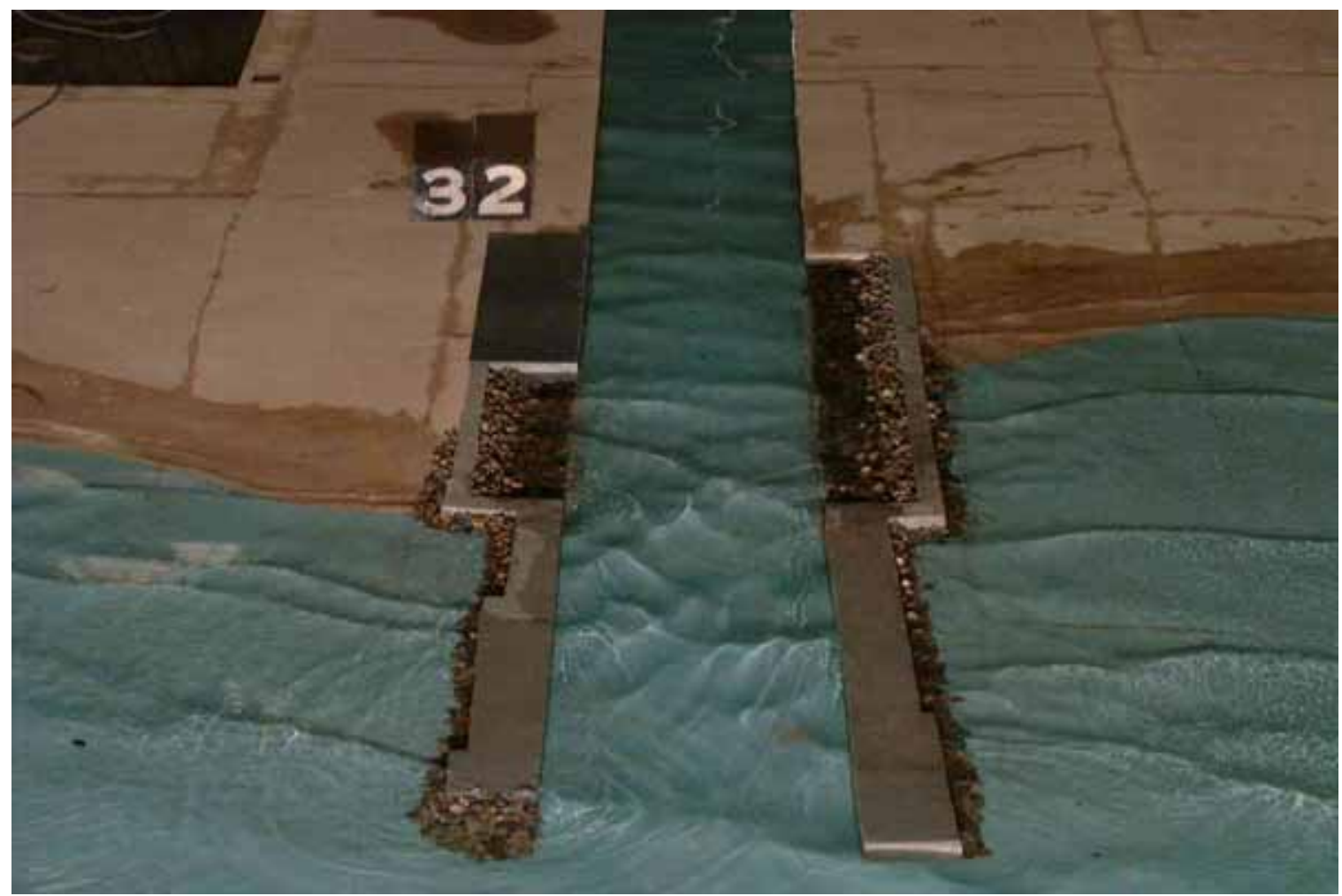

Photograph 48a. Typical wave patterns for Plan 7; 8-sec, 2-m waves from 45 deg North; $\mathrm{sWl}=+0.9 \mathrm{~m}$ LWD, closeup.

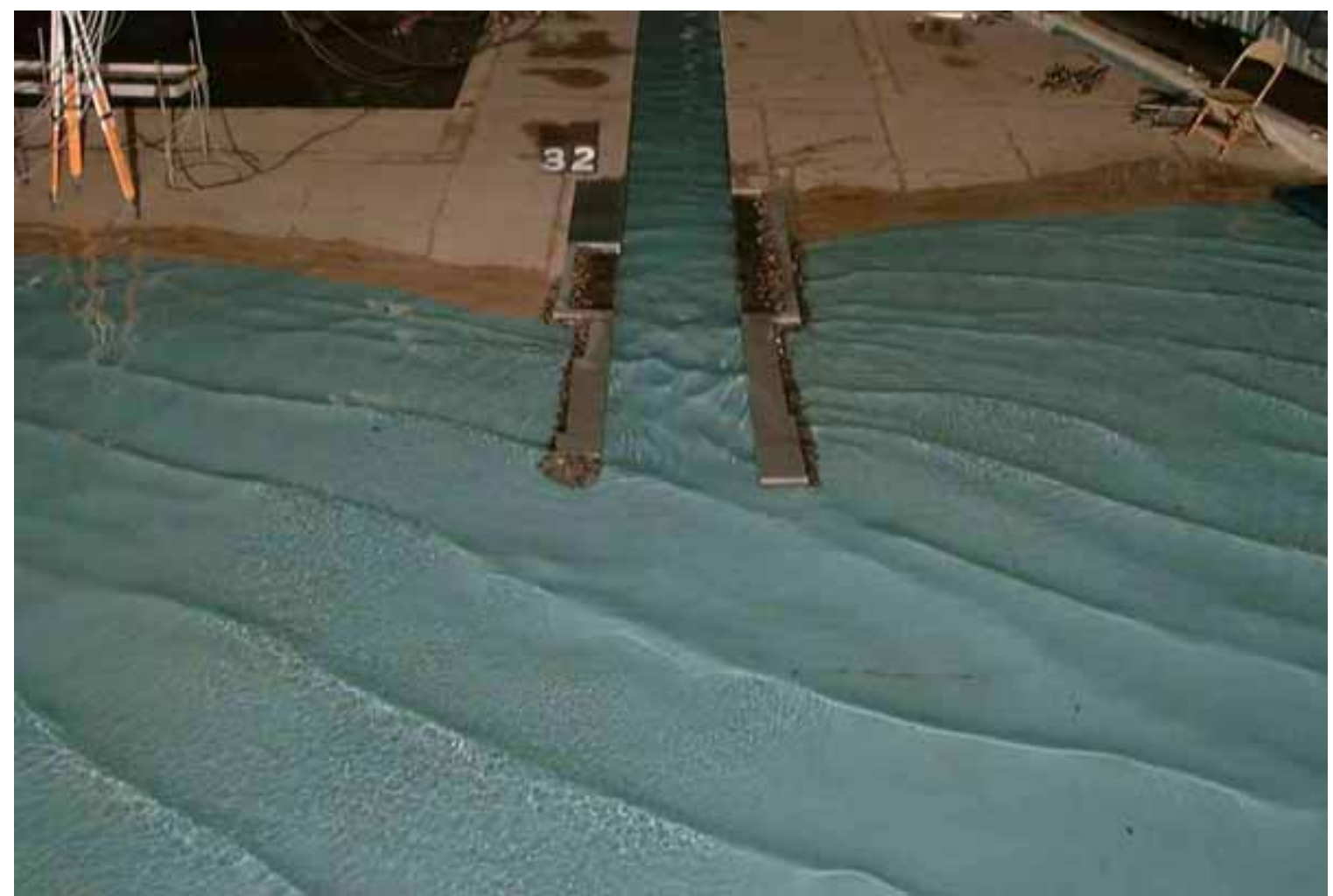

Photograph 48b. Typical wave patterns for Plan 7; 8-sec, 2-m waves from 45 deg North; $\mathrm{sWl}=+0.9 \mathrm{~m}$ LWD. 


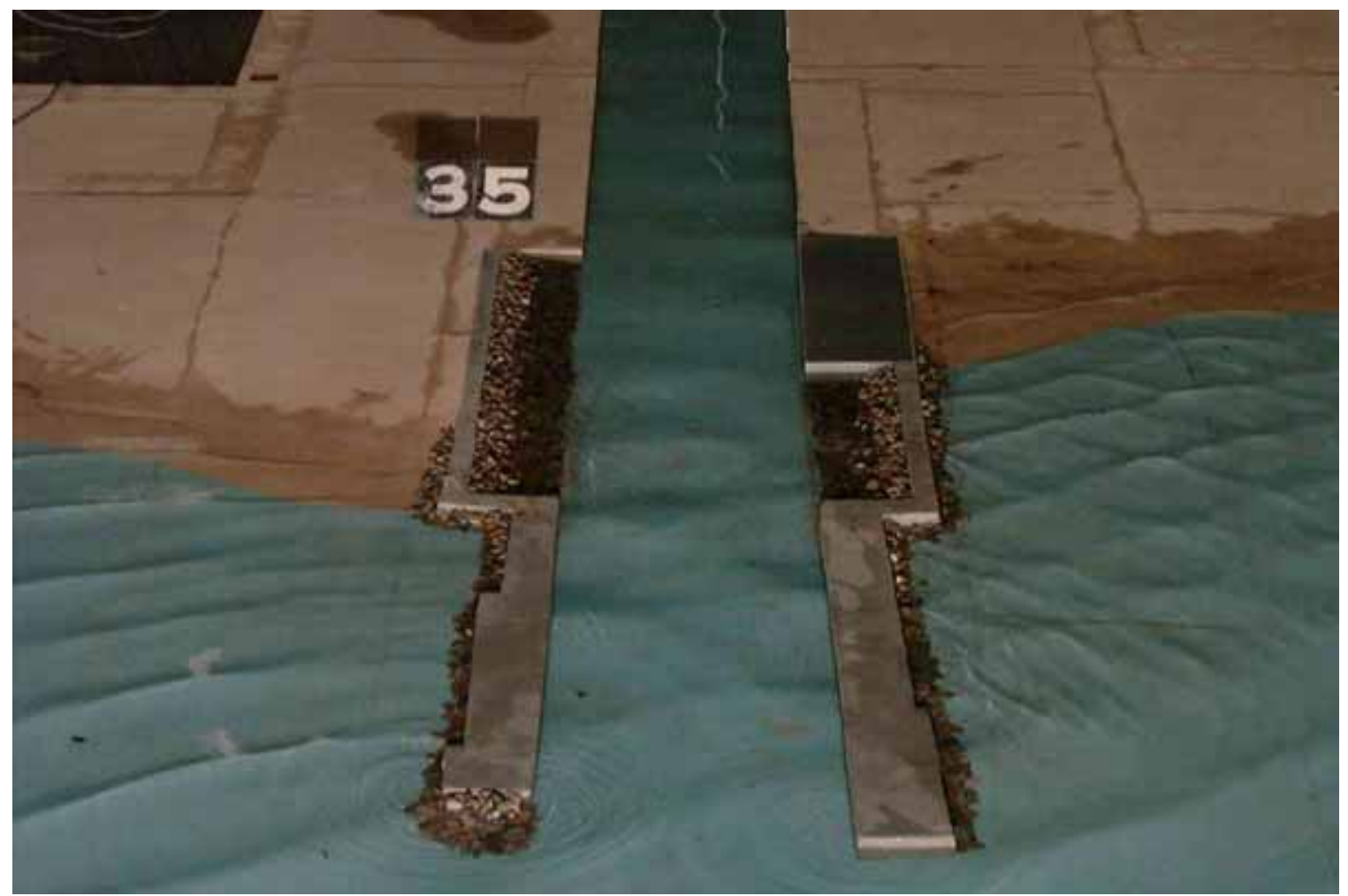

Photograph 49a. Typical wave patterns for Plan 8; 5-sec, 1-m waves from 45 deg South; $\mathrm{sWl}=+0.9 \mathrm{~m}$ LWD, closeup.

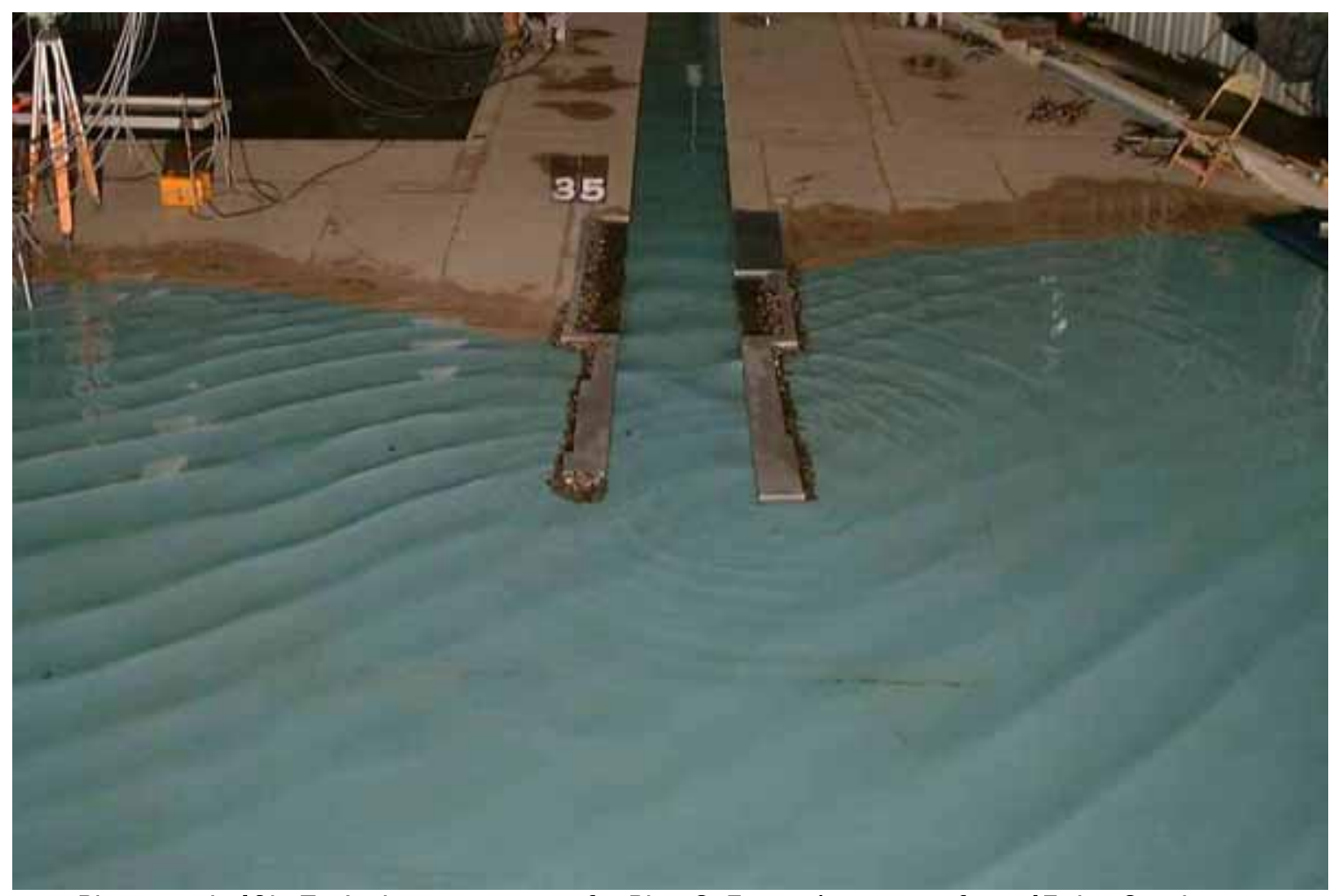

Photograph 49b. Typical wave patterns for Plan 8; 5-sec, 1-m waves from 45 deg South; $\mathrm{sWl}=+0.9 \mathrm{~m}$ LWD. 


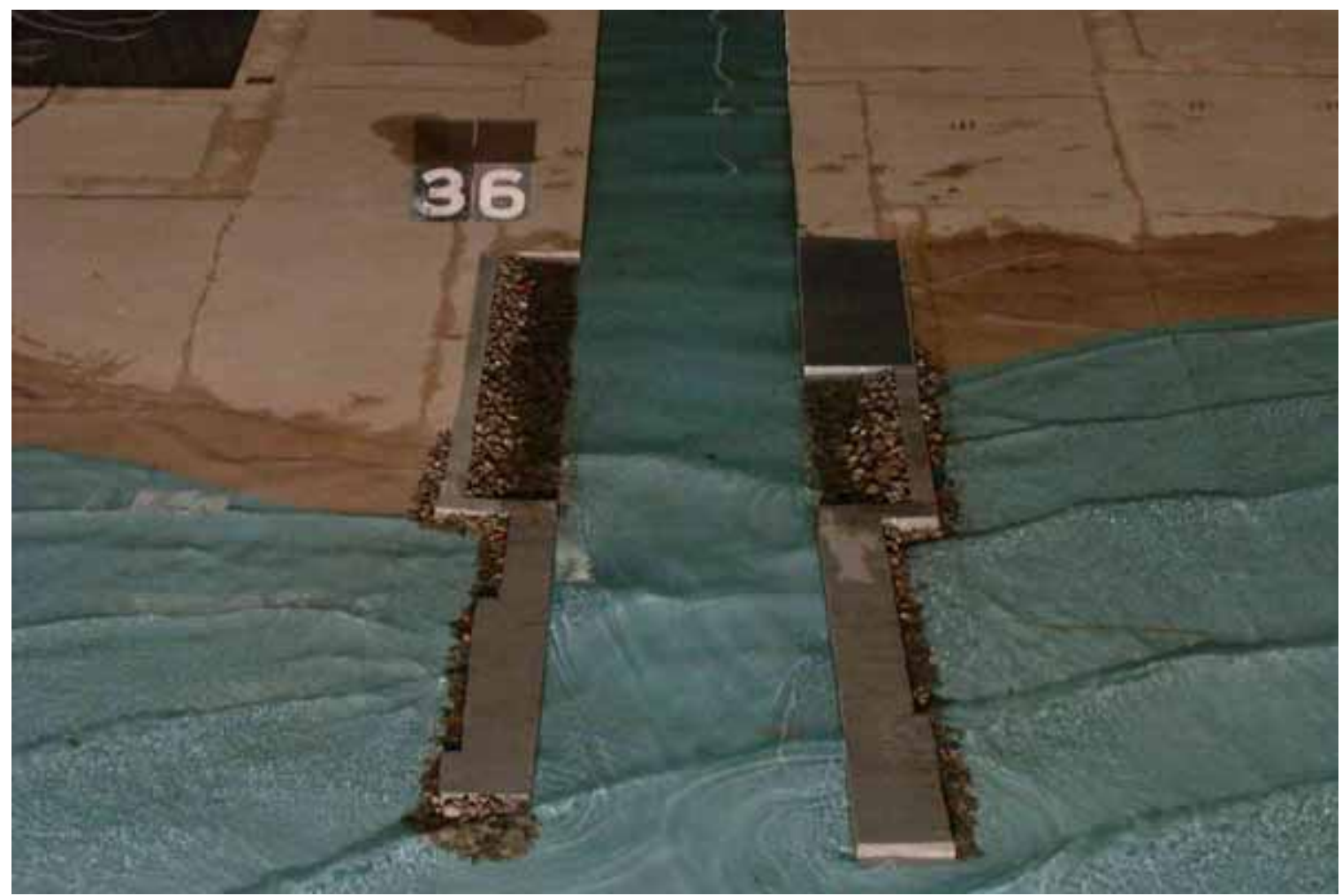

Photograph 50a. Typical wave patterns for Plan 8; 8-sec, 2-m waves from 45 deg South; $s W l=+0.9 m$ LWD, closeup.

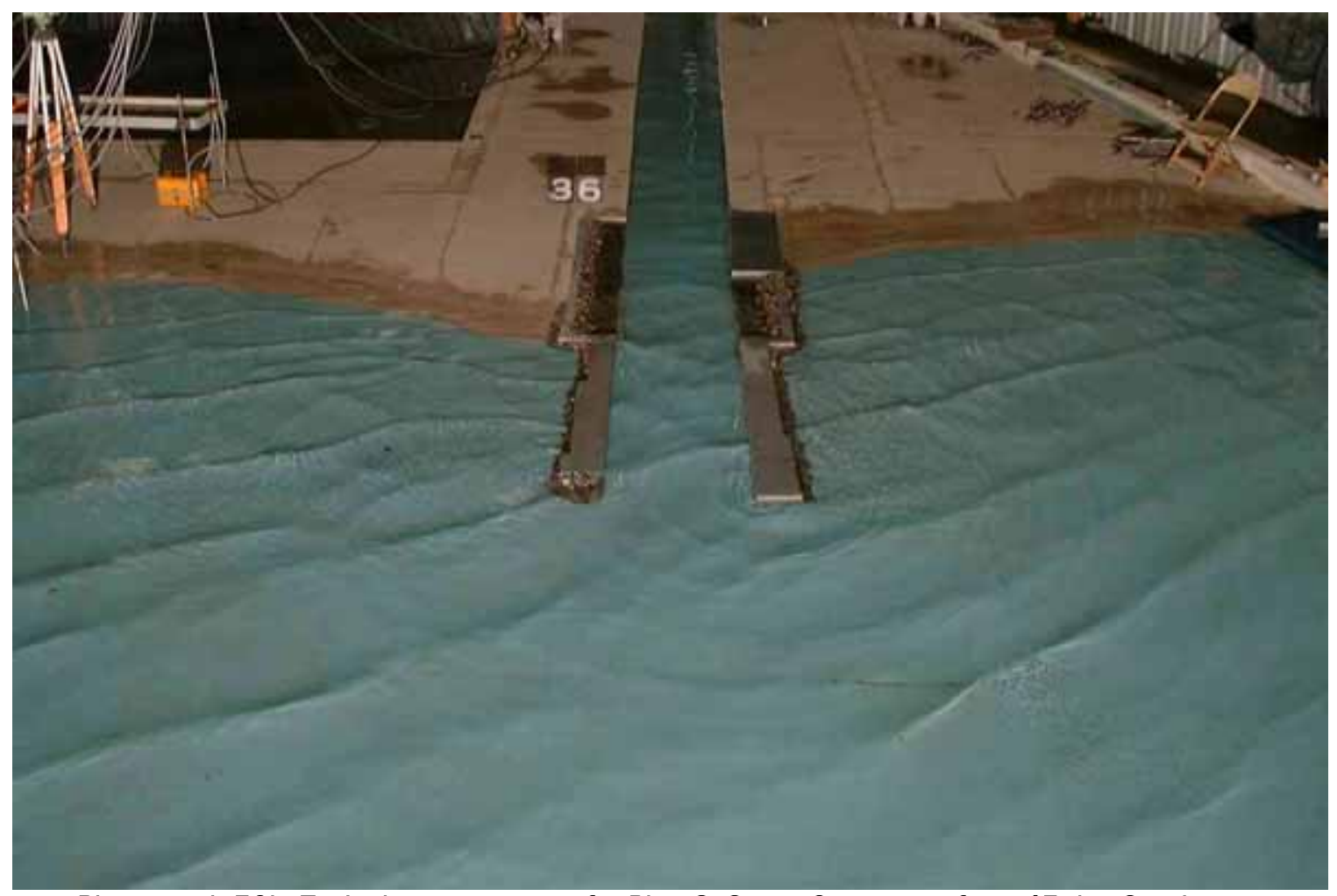

Photograph 50b. Typical wave patterns for Plan 8; 8-sec, 2-m waves from 45 deg South; $\mathrm{sWl}=+0.9 \mathrm{~m}$ LWD. 


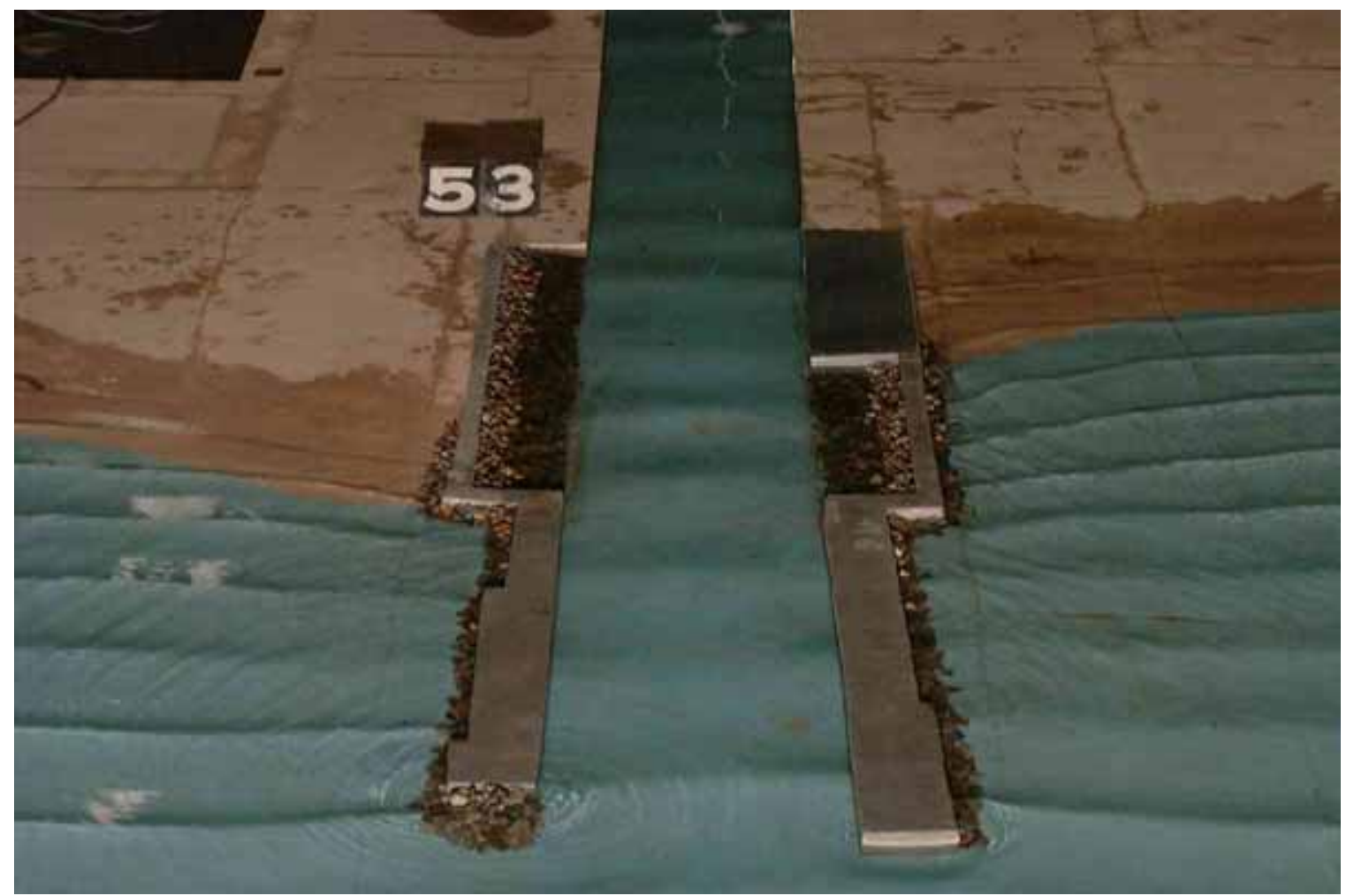

Photograph 51a. Typical wave patterns for Plan 8; 5-sec, 1-m waves from 0 deg; $s W l=+0.9 m$ LWD, closeup.

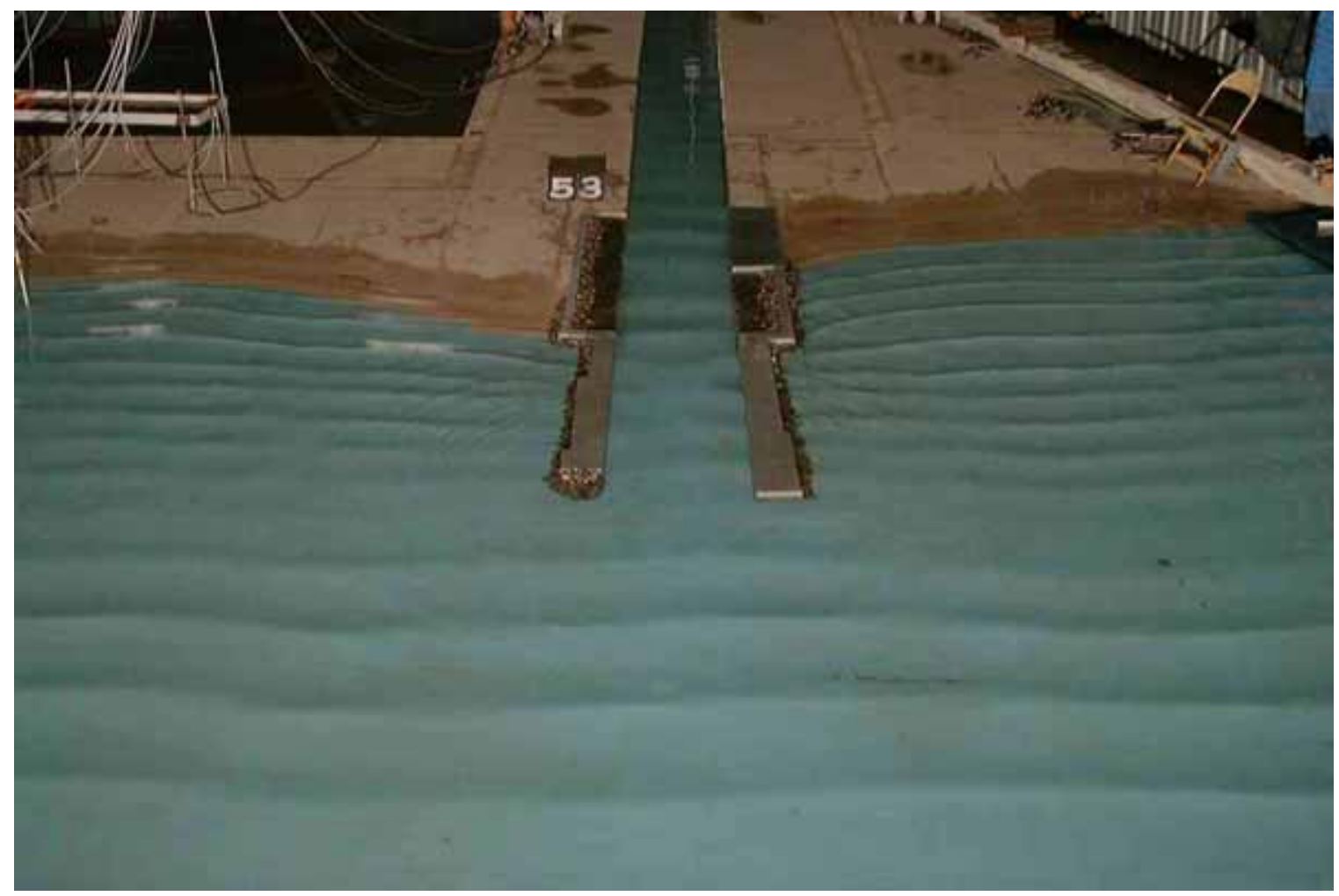

Photograph 51b. Typical wave patterns for Plan 8; 5-sec, 1-m waves from 0 deg; $\mathrm{sWl}=+0.9 \mathrm{~m}$ LWD. 


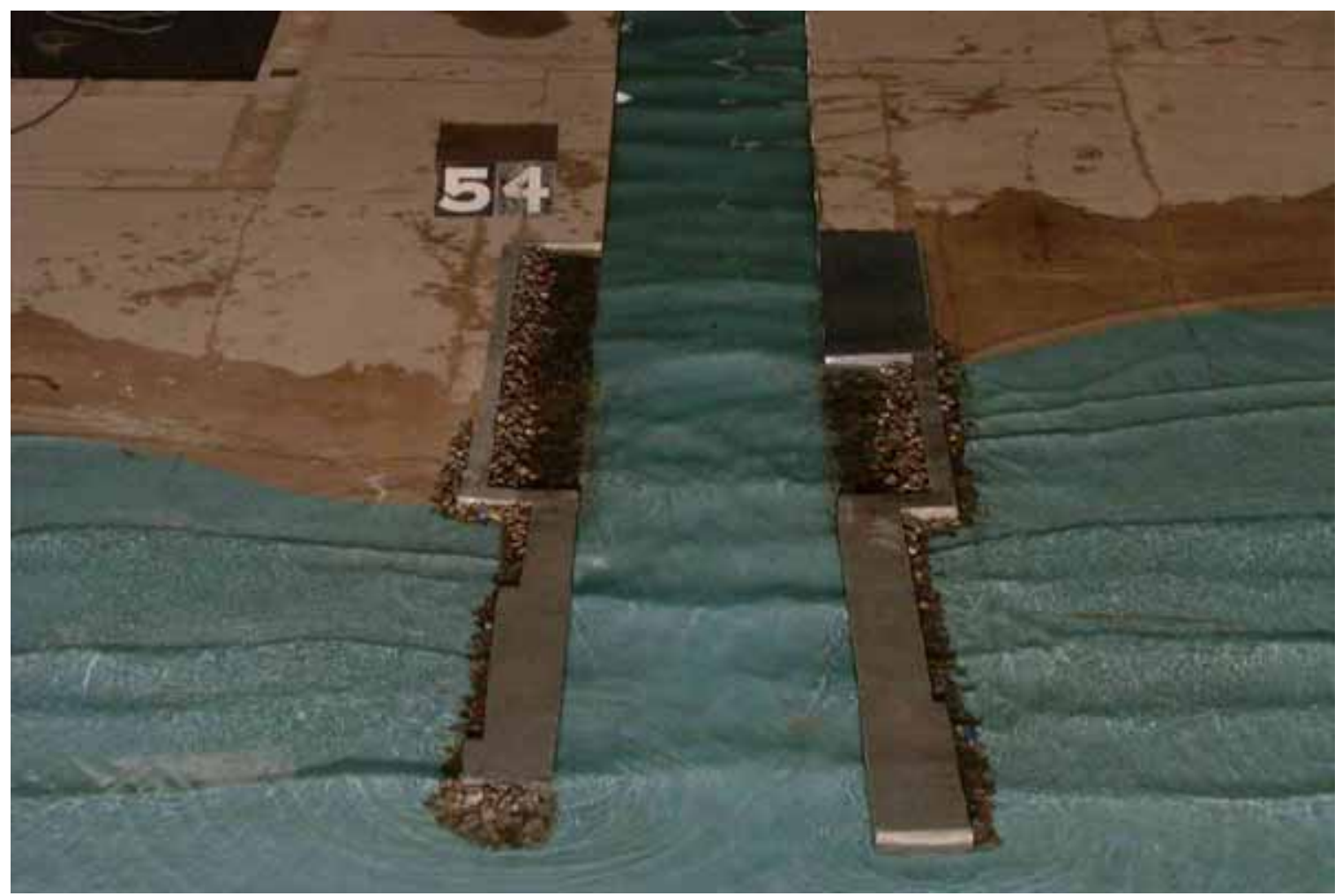

Photograph 52a. Typical wave patterns for Plan 8; 8-sec, 2-m waves from 0 deg; $s W l=+0.9 m$ LWD, closeup.

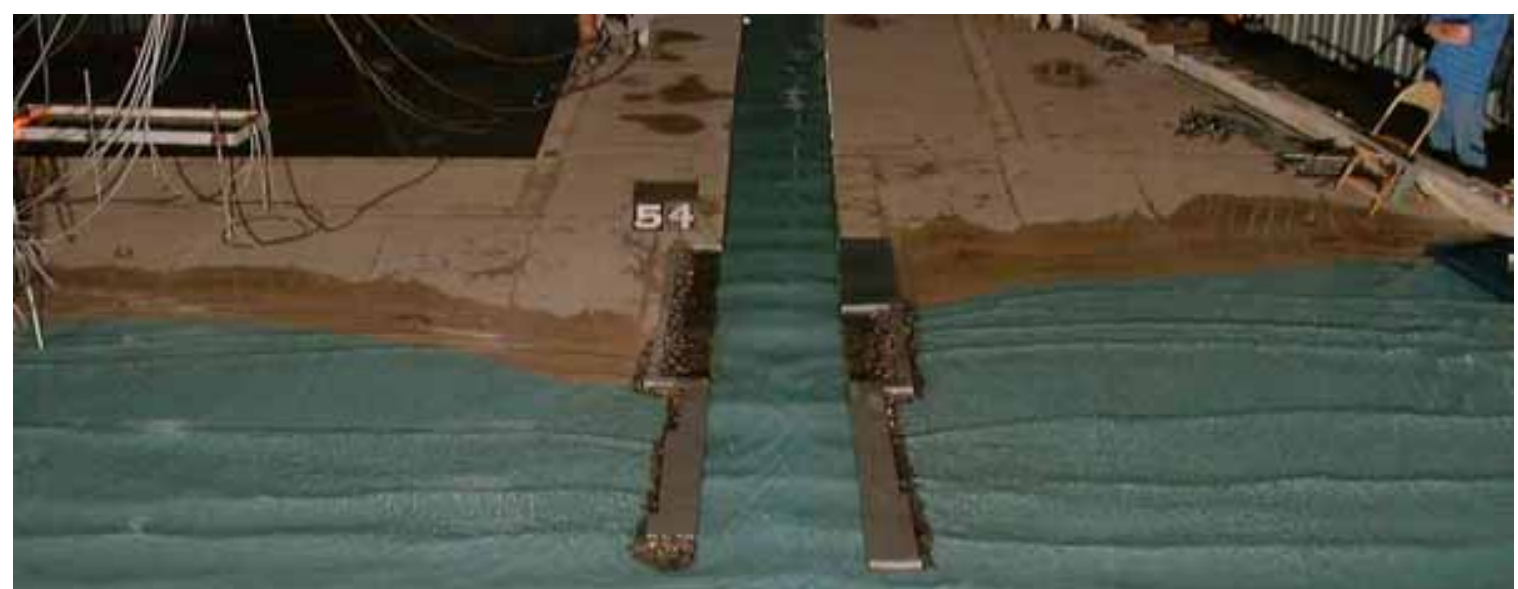

Photograph 52b. Typical wave patterns for Plan 8; 8-sec, 2-m waves from 0 deg; $\mathrm{sWl}=+0.9 \mathrm{~m}$ LWD. 


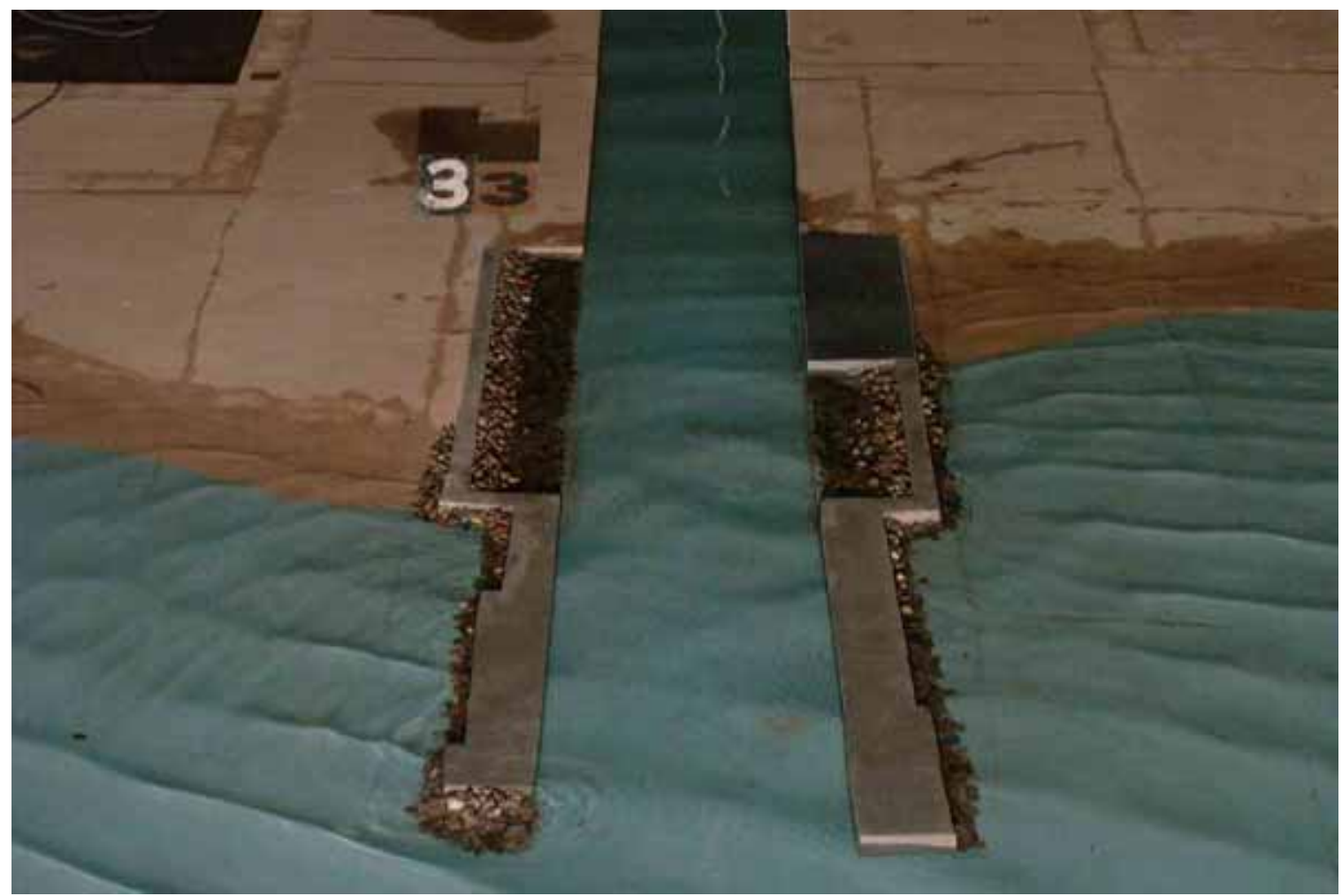

Photograph 53a. Typical wave patterns for Plan 8; 5-sec, 1-m waves from 45 deg North; $\mathrm{sWl}=+0.9 \mathrm{~m}$ LWD, closeup.

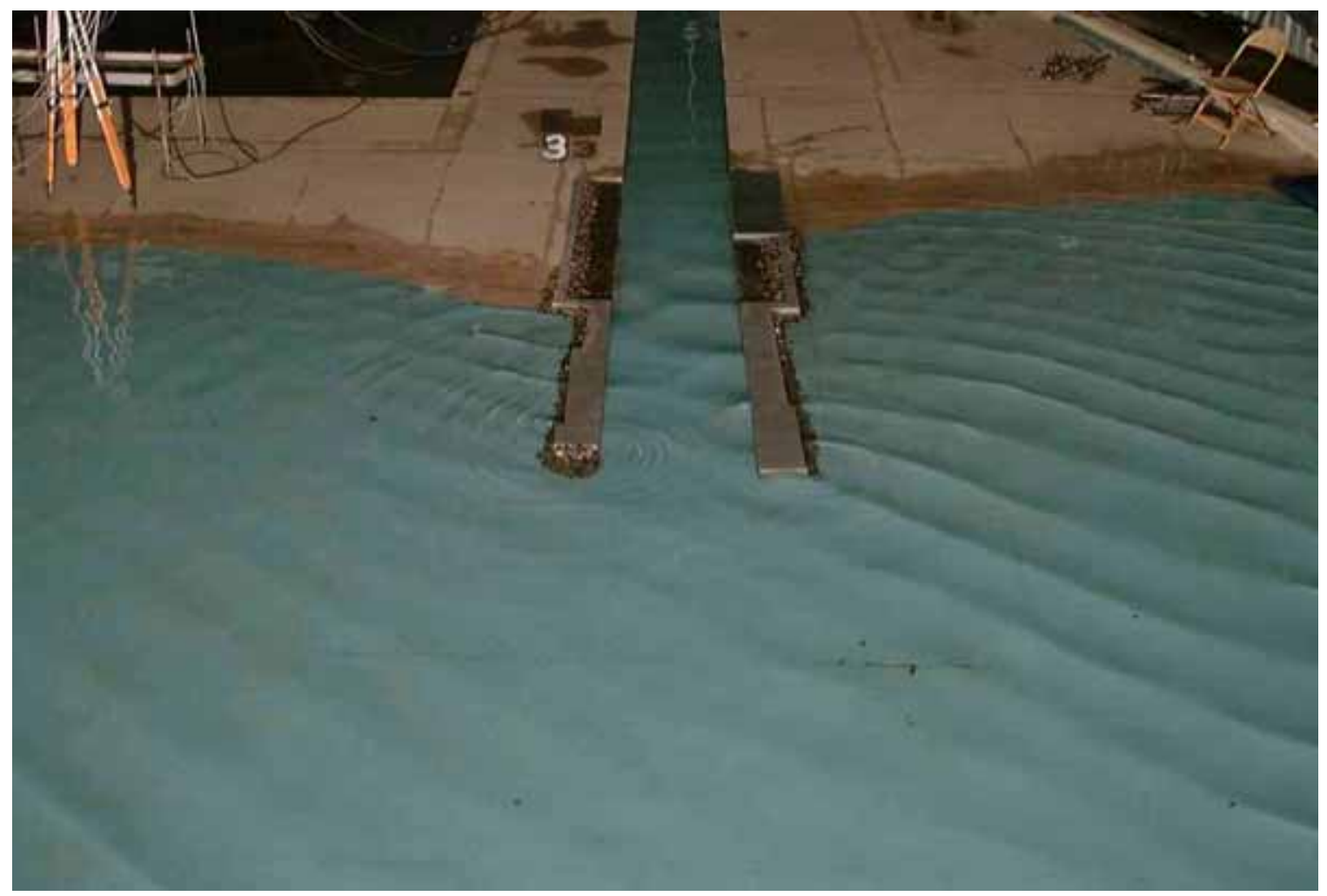

Photograph 53b. Typical wave patterns for Plan 8; 5-sec, 1-m waves from 45 deg North; $\mathrm{sWl}=+0.9 \mathrm{~m}$ LWD. 


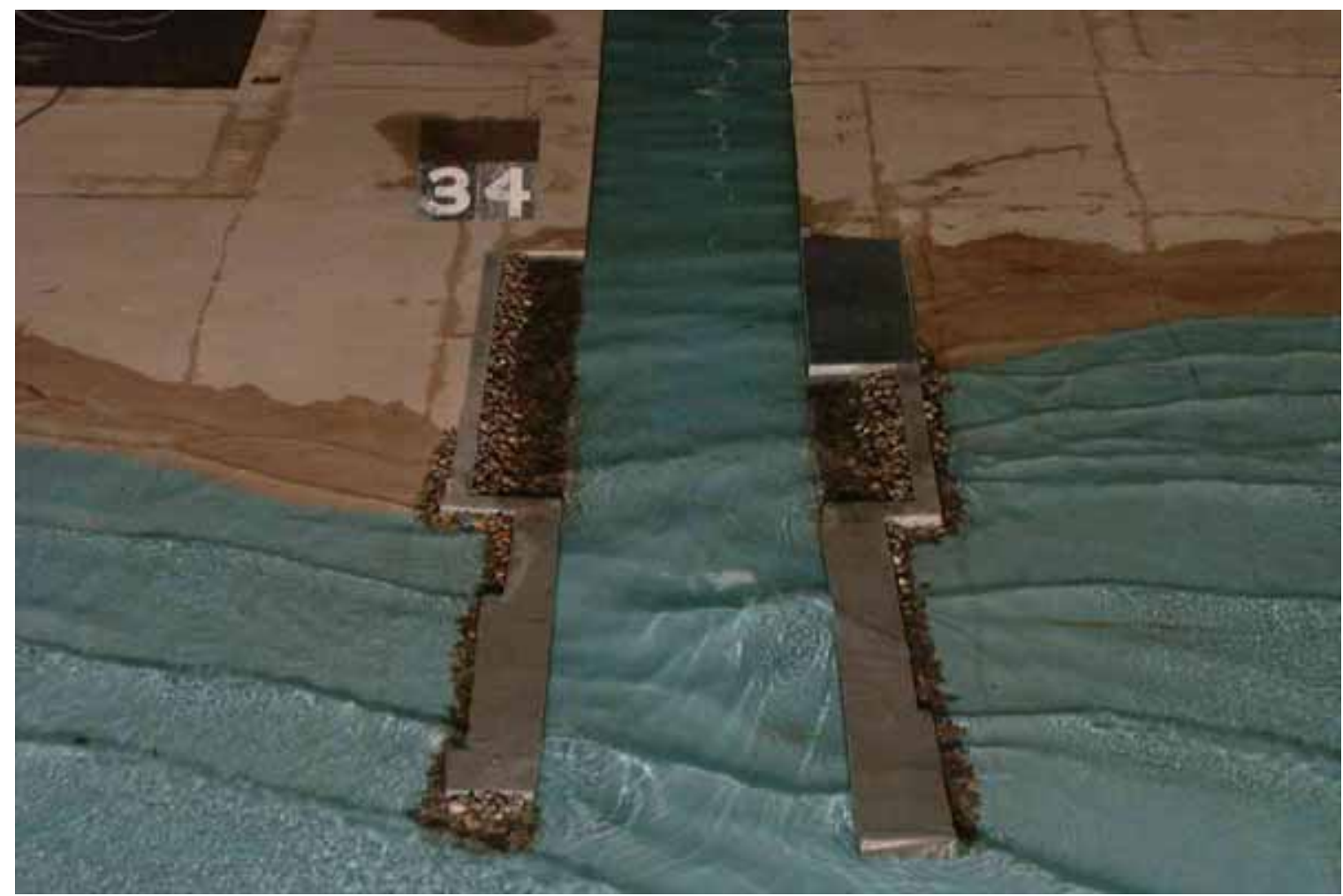

Photograph 54a. Typical wave patterns for Plan 8; 8-sec, 2-m waves from 45 deg North; $\mathrm{sWl}=+0.9 \mathrm{~m}$ LWD, closeup.

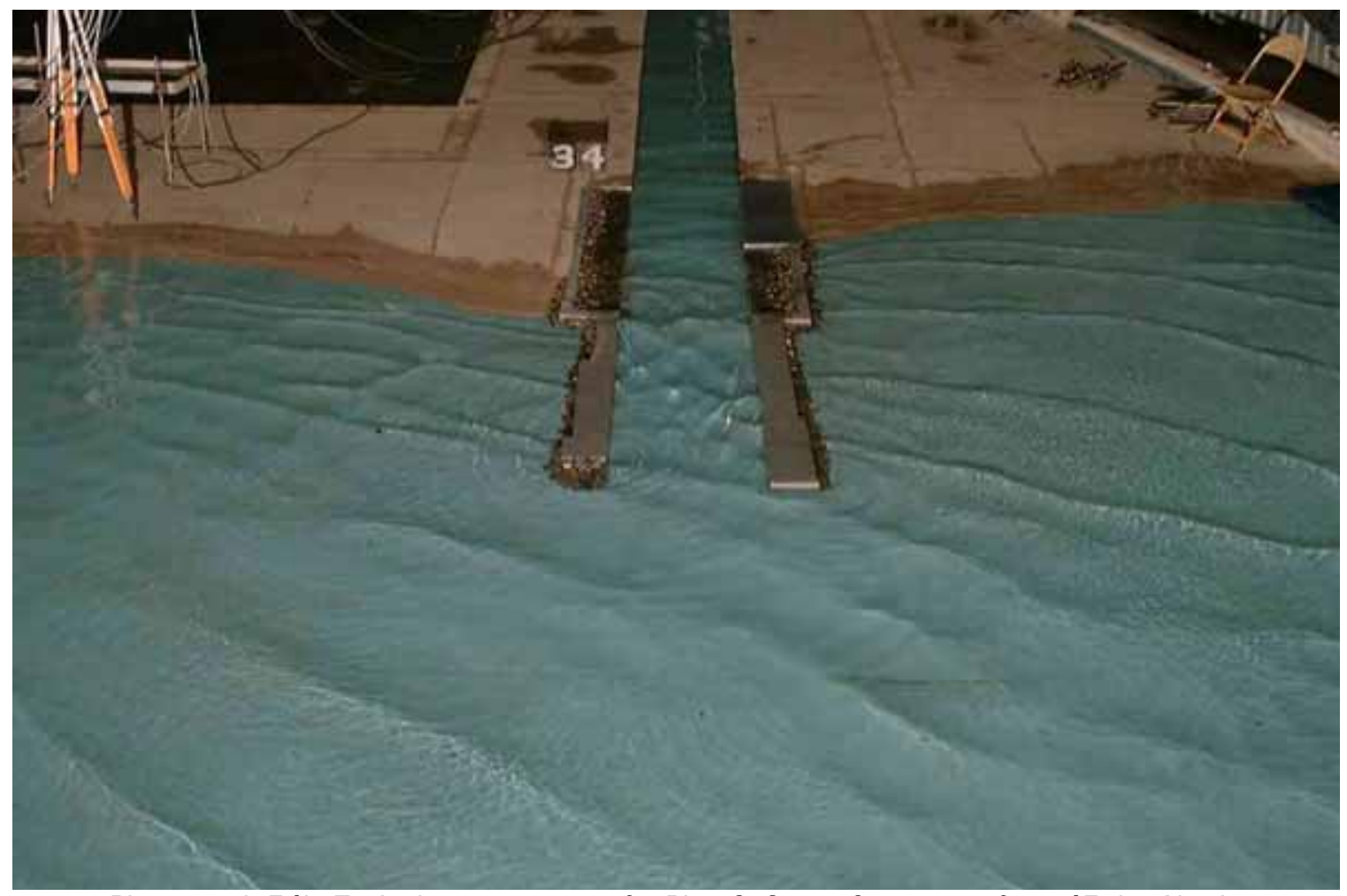

Photograph 54b. Typical wave patterns for Plan 8; 8-sec, 2-m waves from 45 deg North; $\mathrm{sWl}=+0.9 \mathrm{~m}$ LWD. 


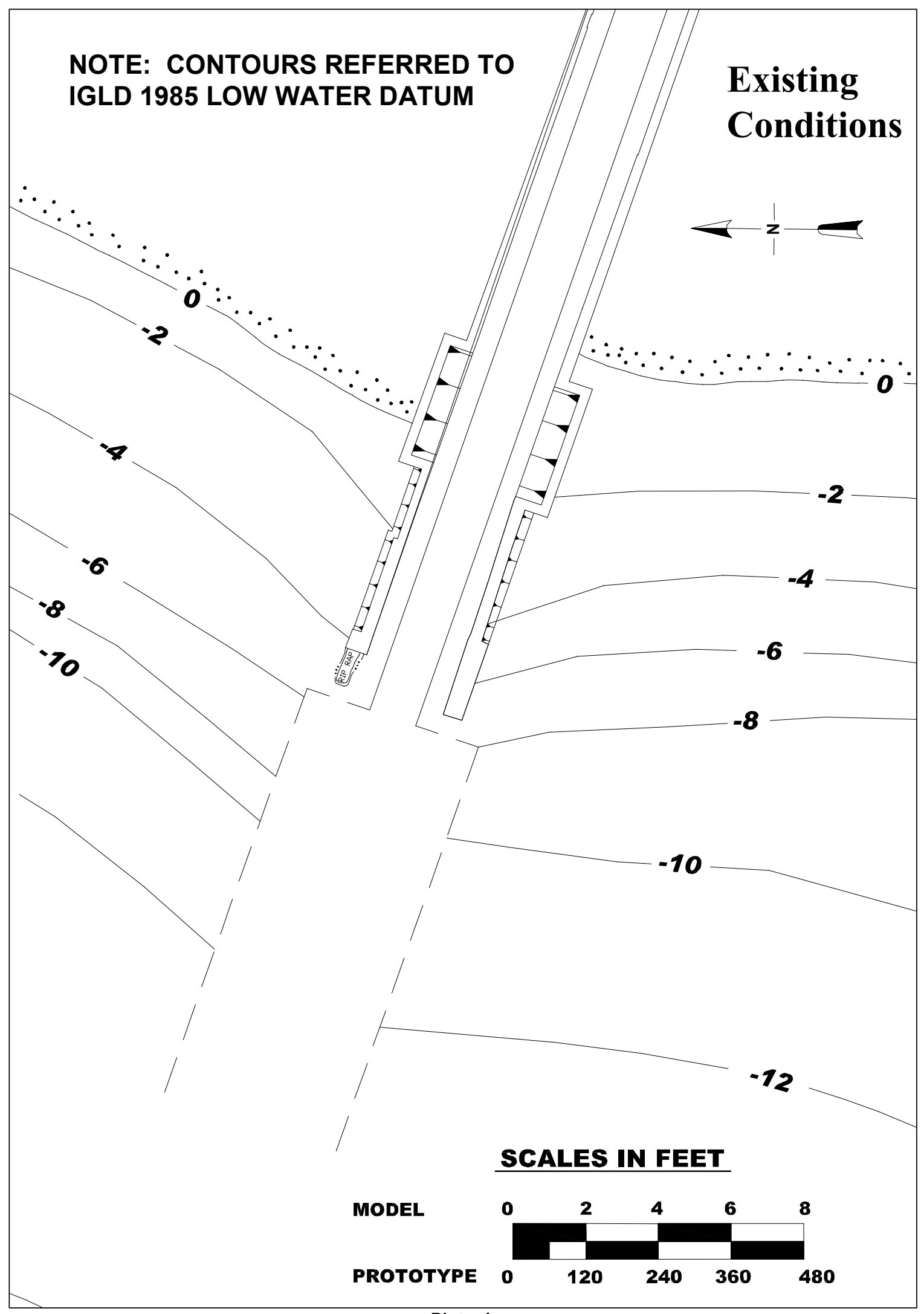

Plate 1 


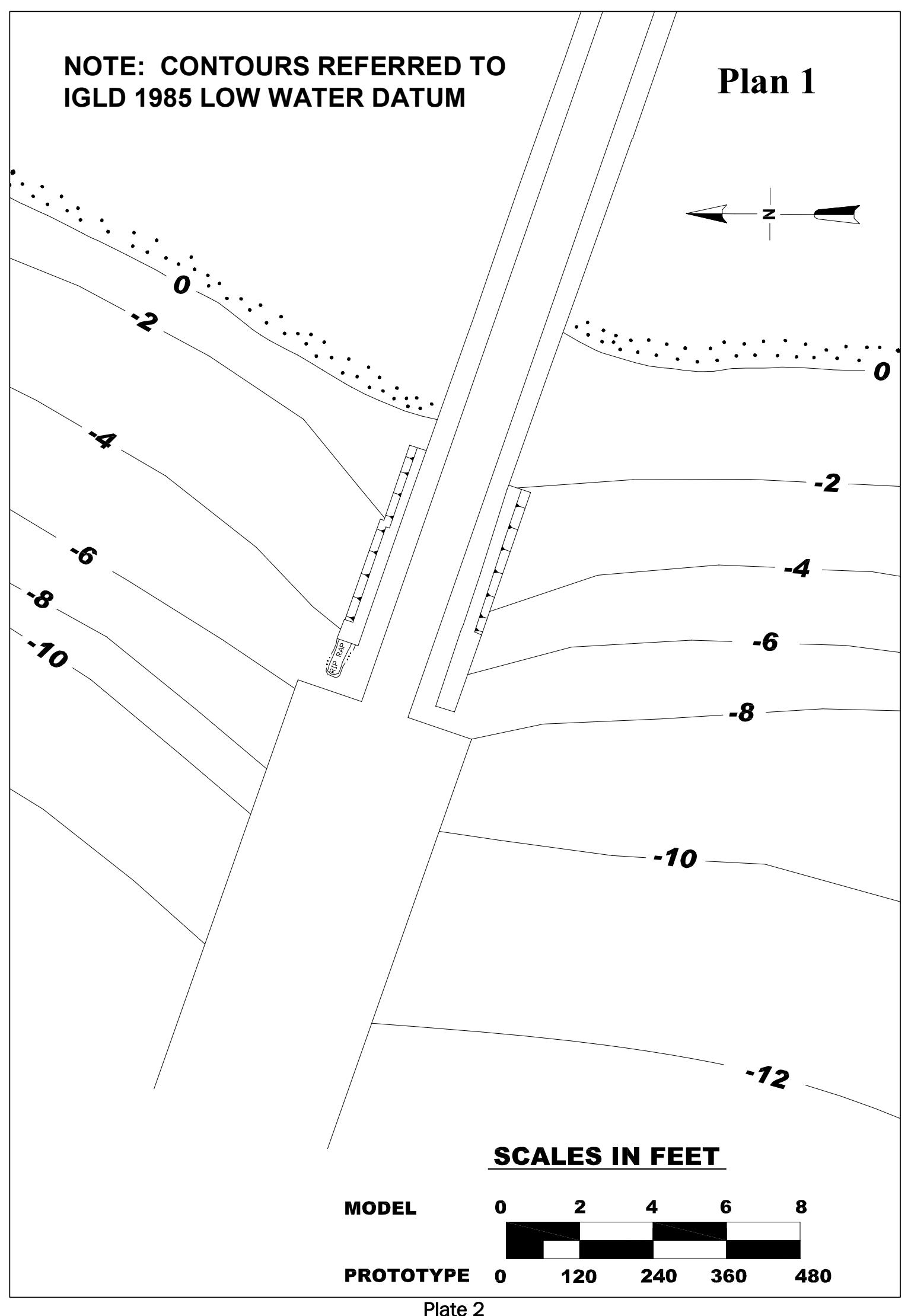

Plate 2 


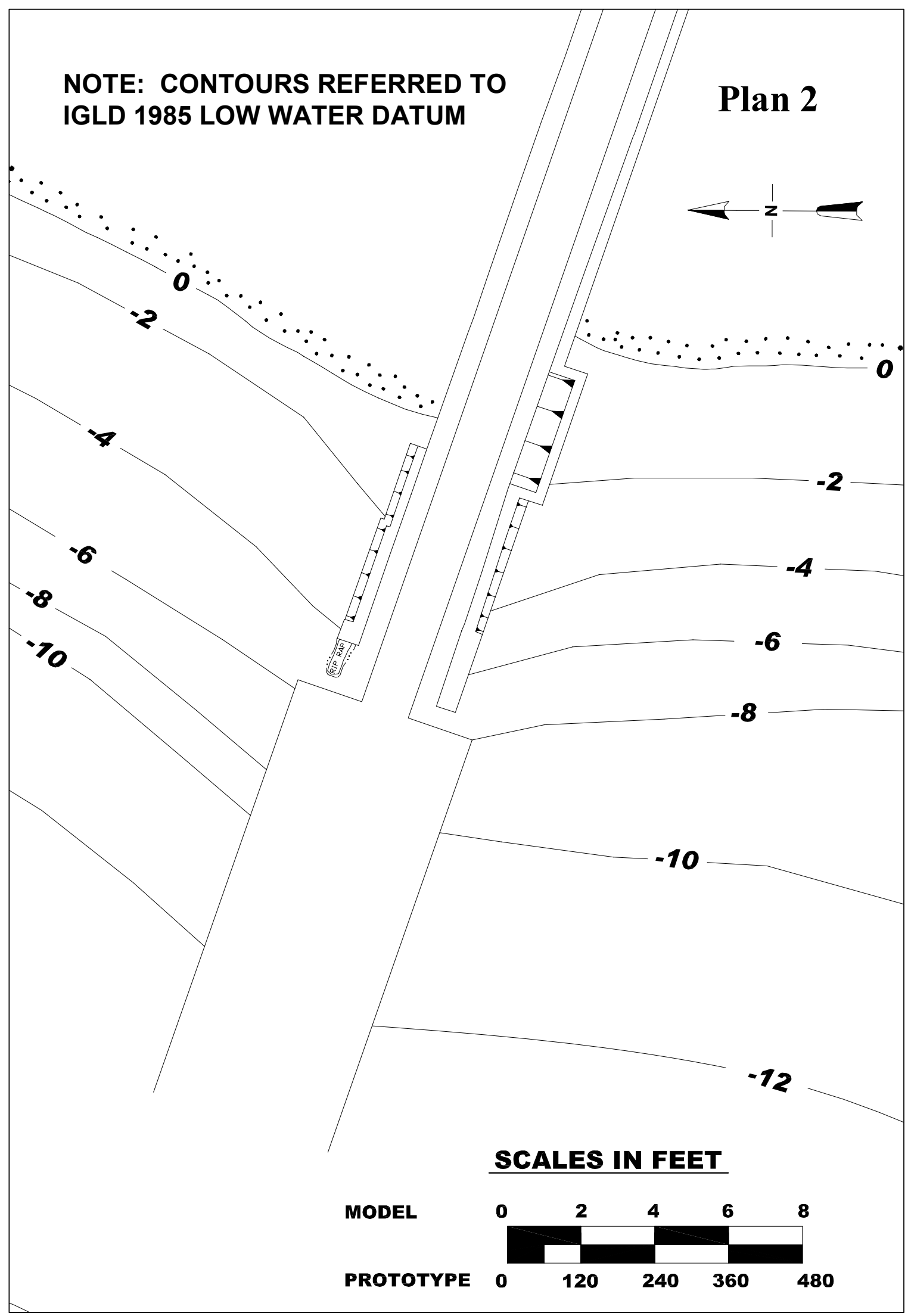

Plate 3 


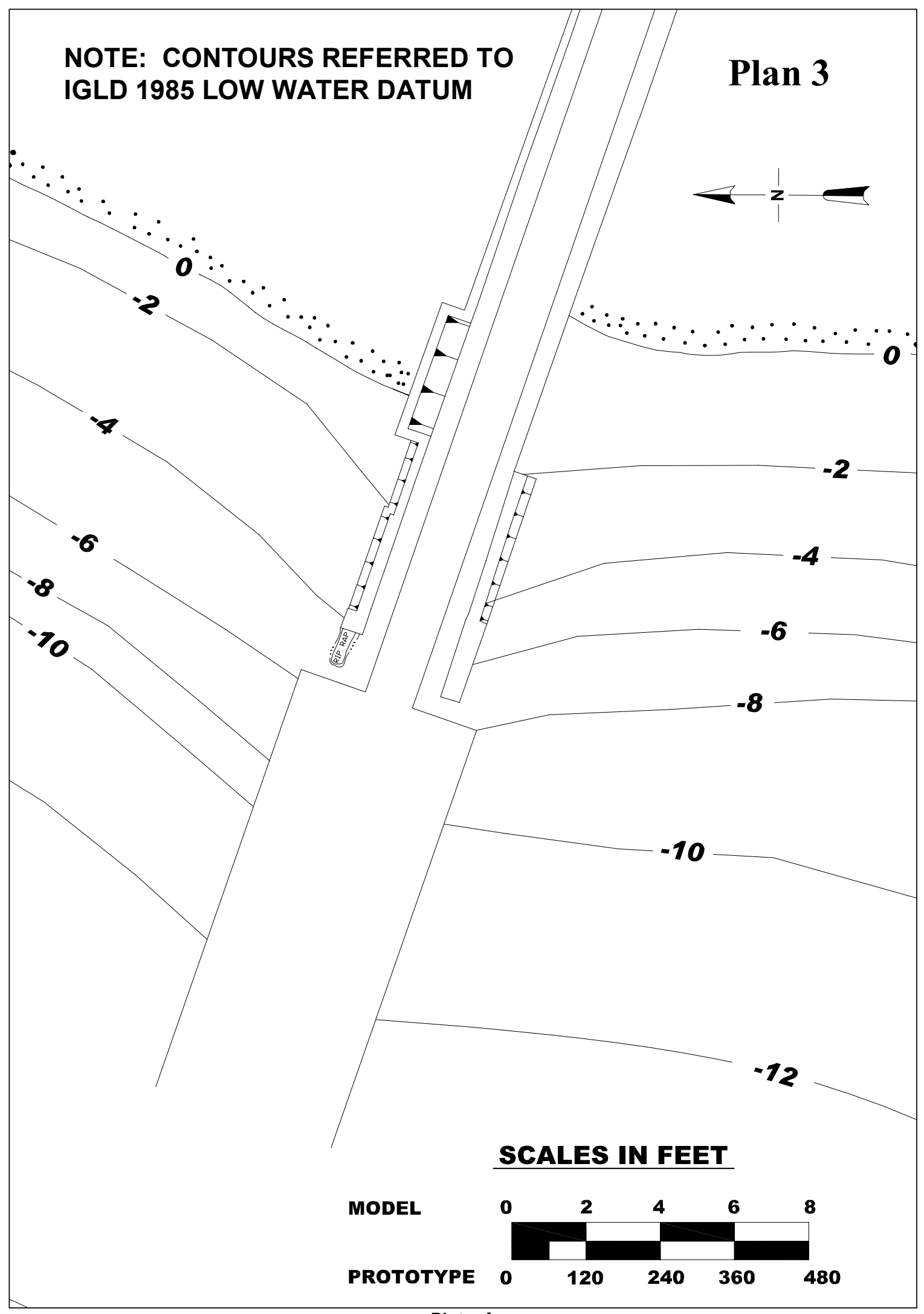

Plate 4 


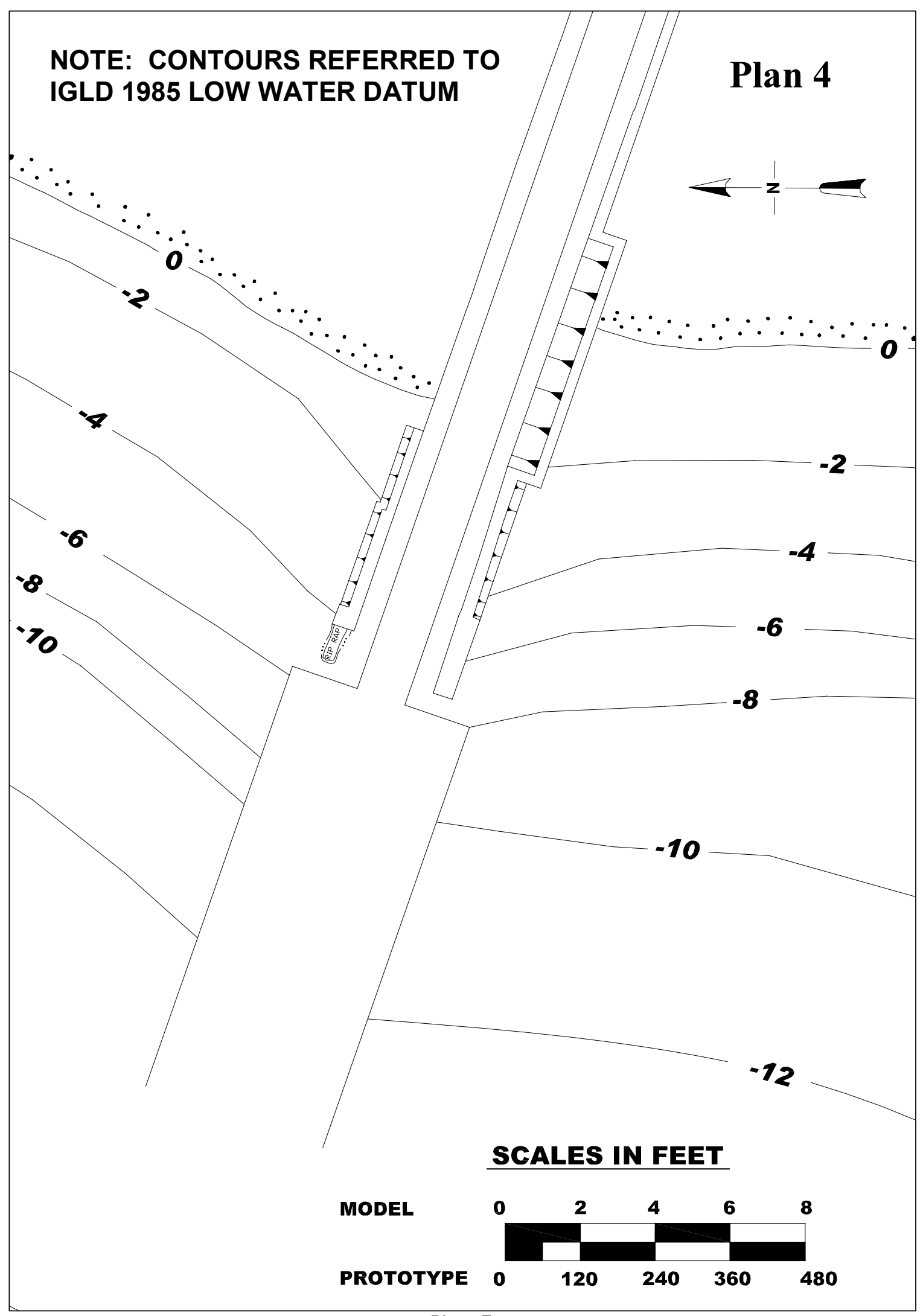

Plate 5 


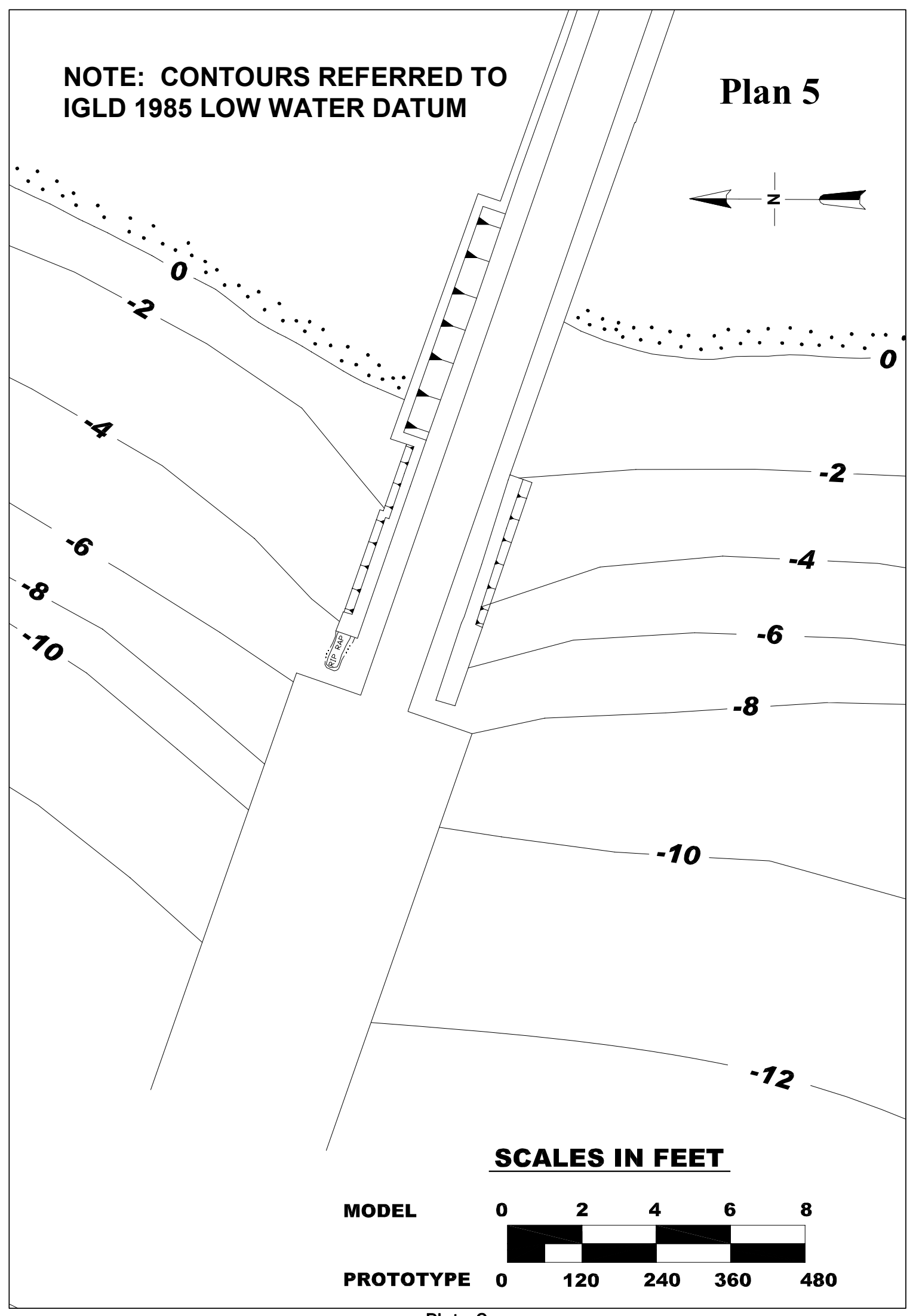

Plate 6 


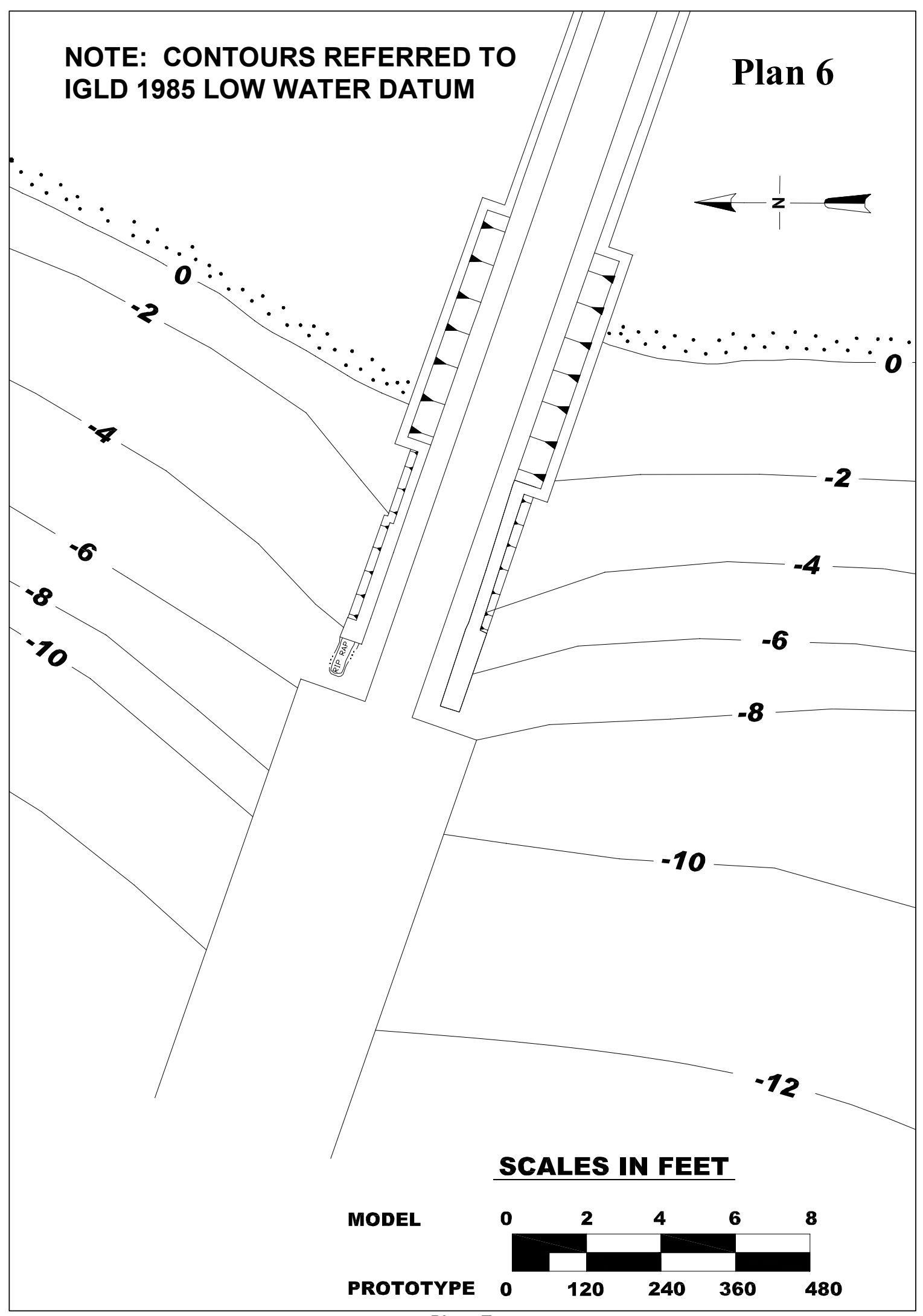

Plate 7 


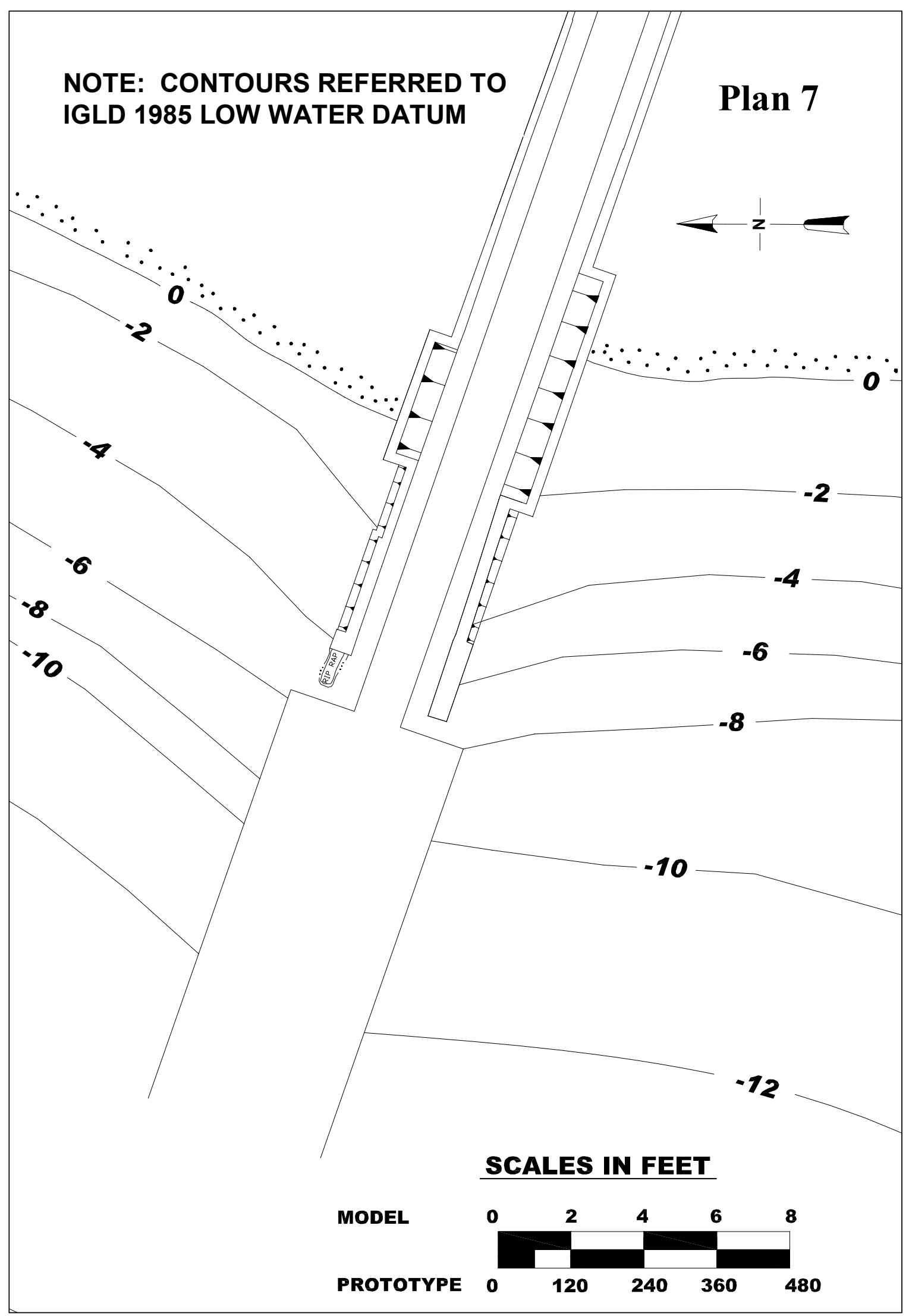

Plate 8 


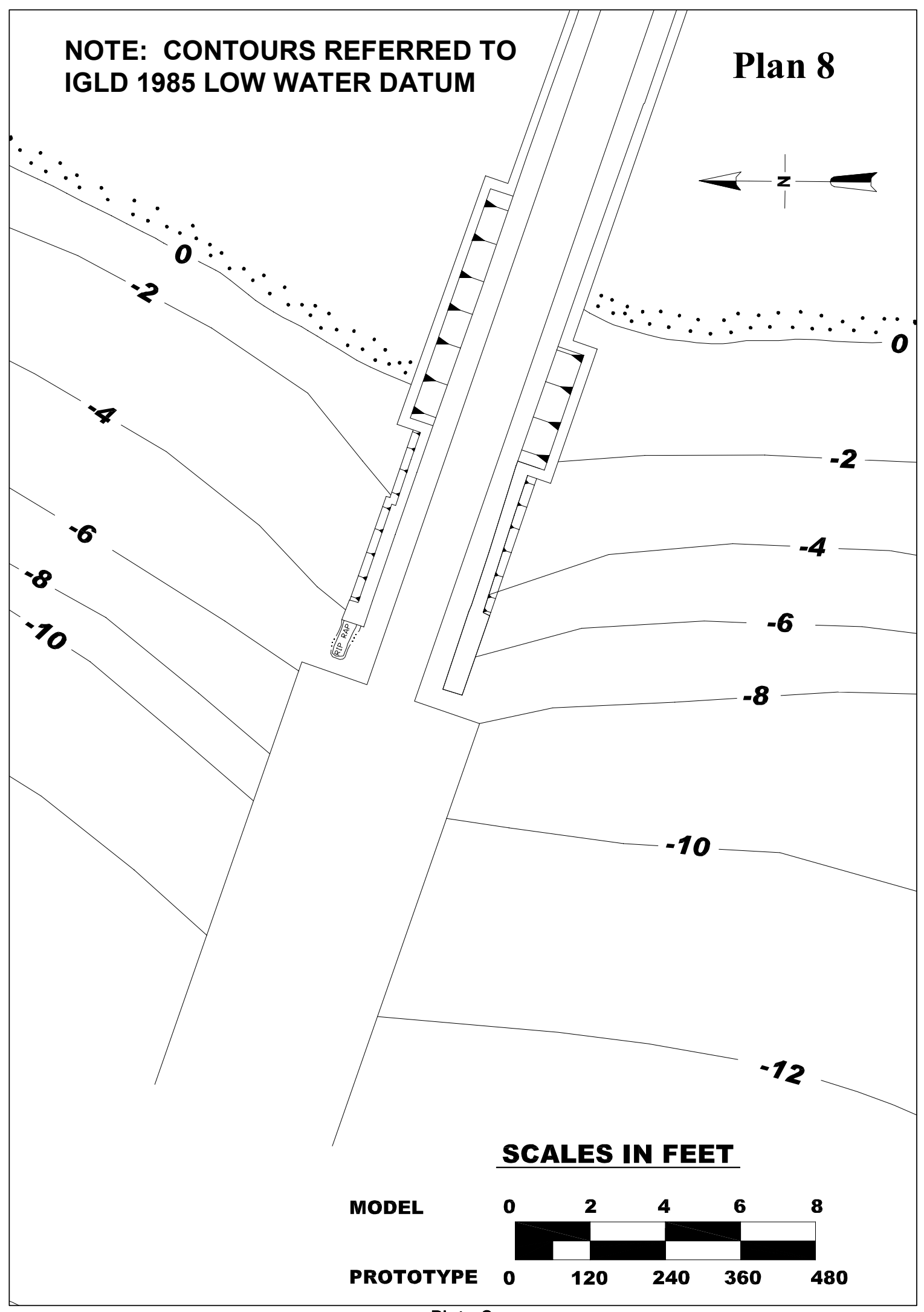

Plate 9 


\section{Appendix A: Pocket Wave Absorber Cross Sections}




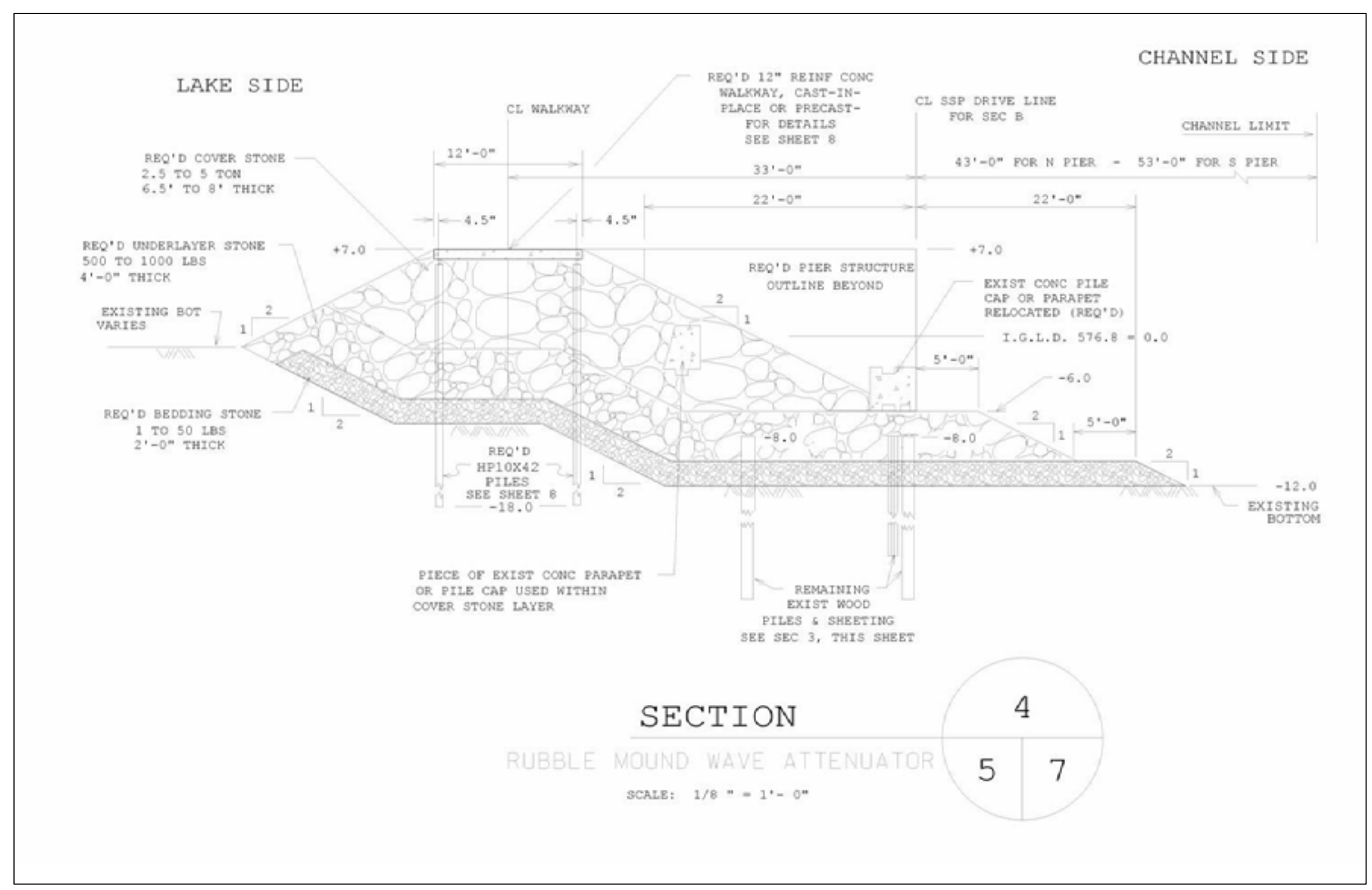

Figure A1. Saugatuck Harbor, MI. 


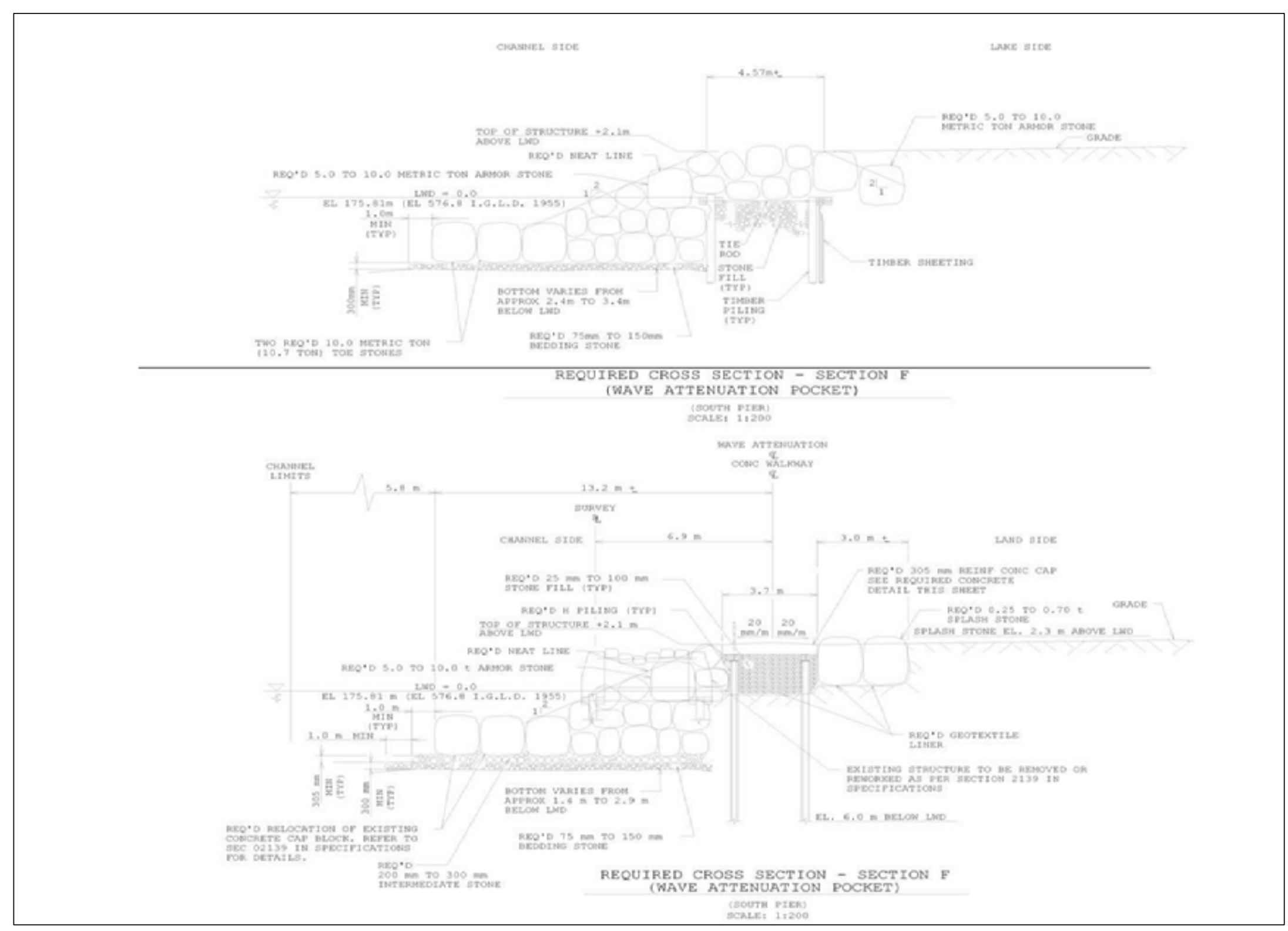

Figure A2. White Lake Harbor, MI. 


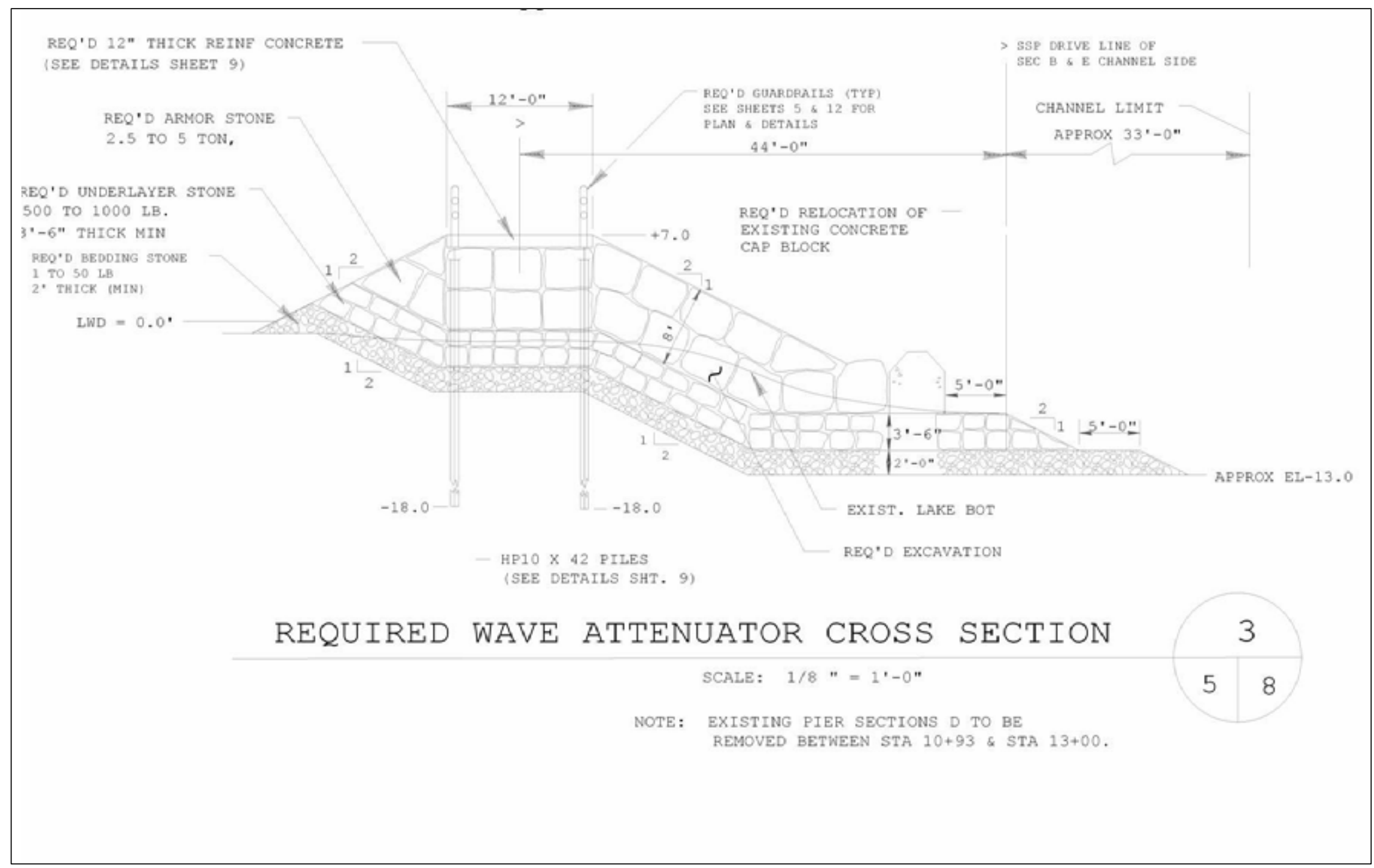

Figure A3. Pentwater Harbor, MI. 


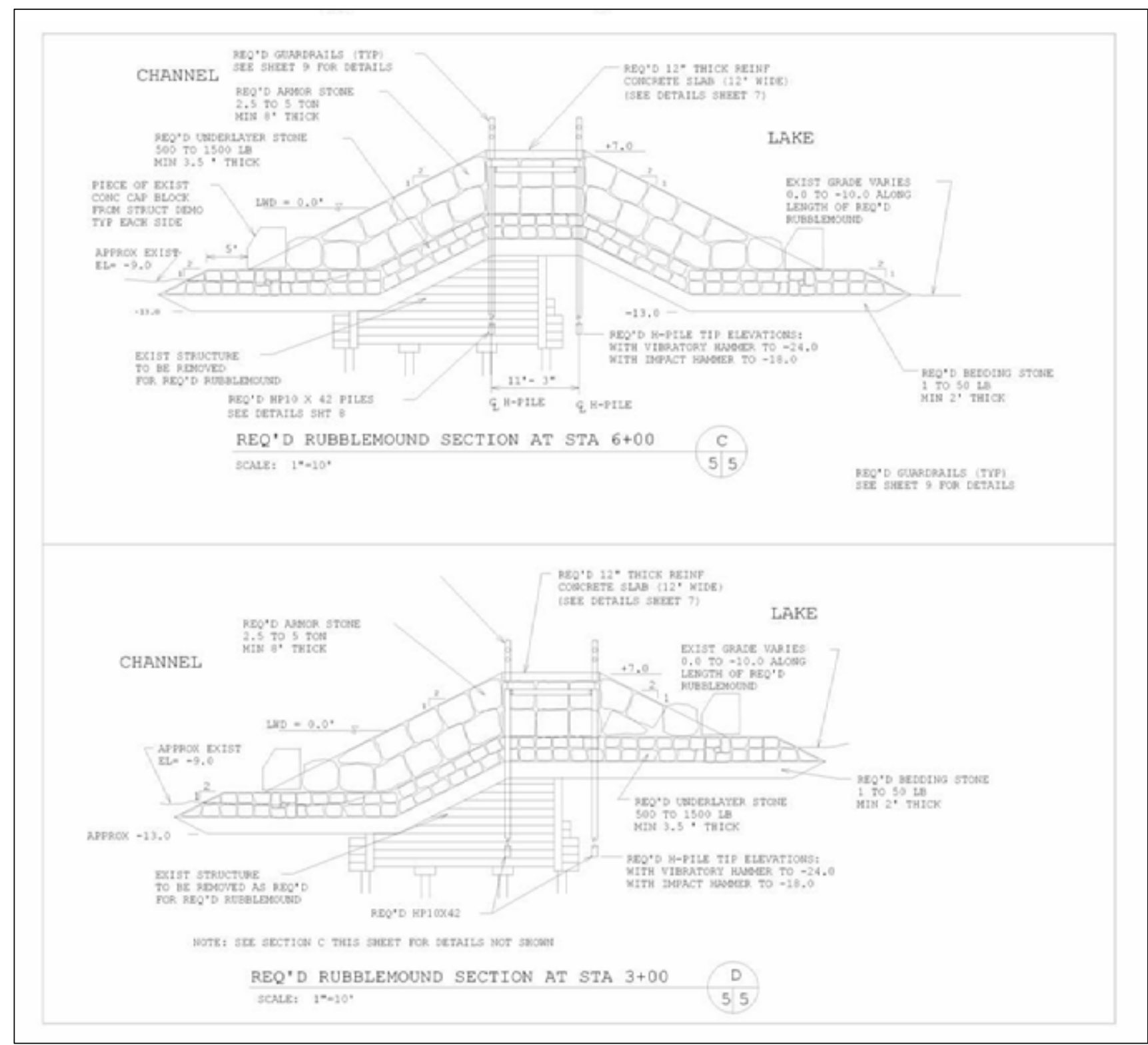

Figure A4. Portage Lake Harbor, MI. 


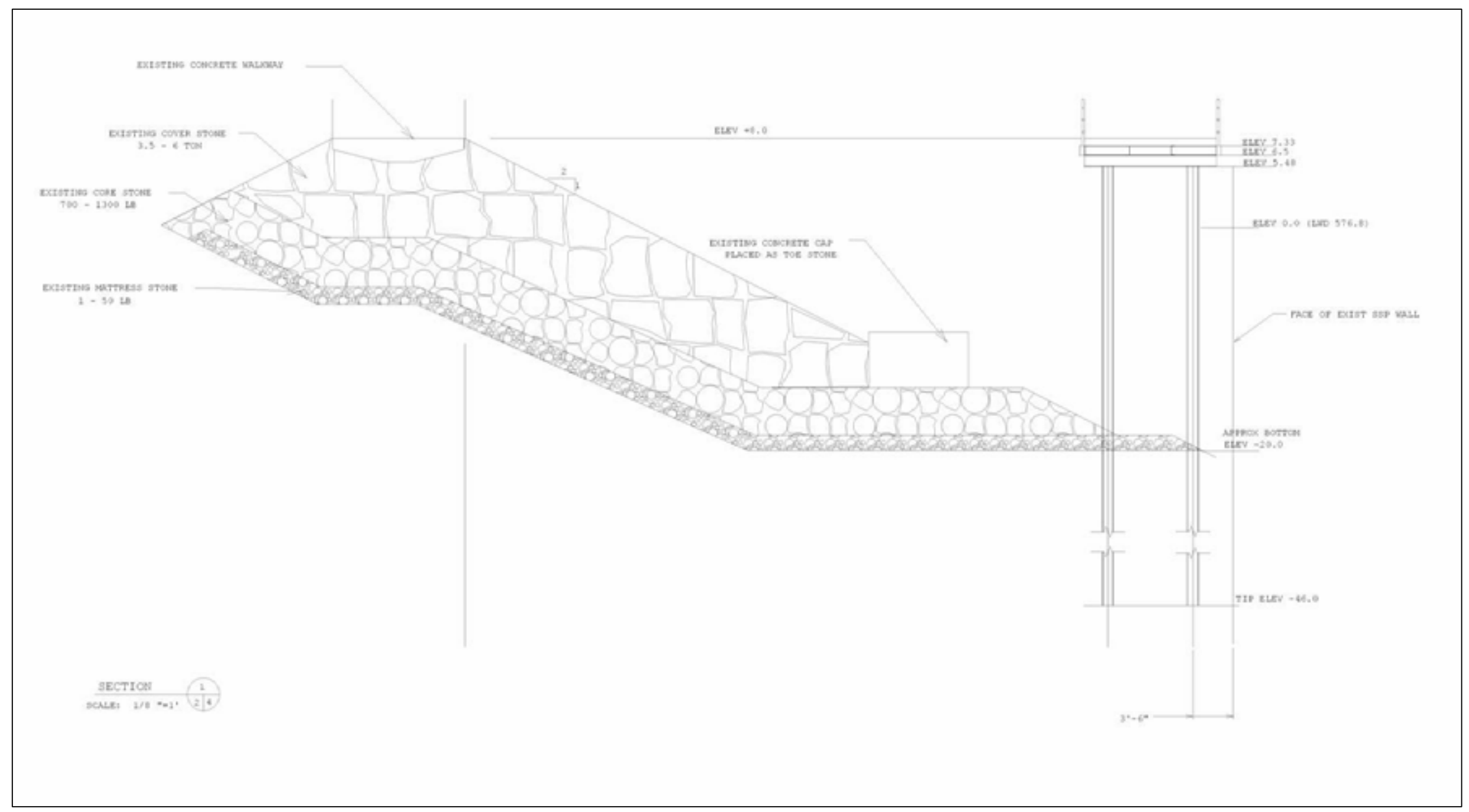




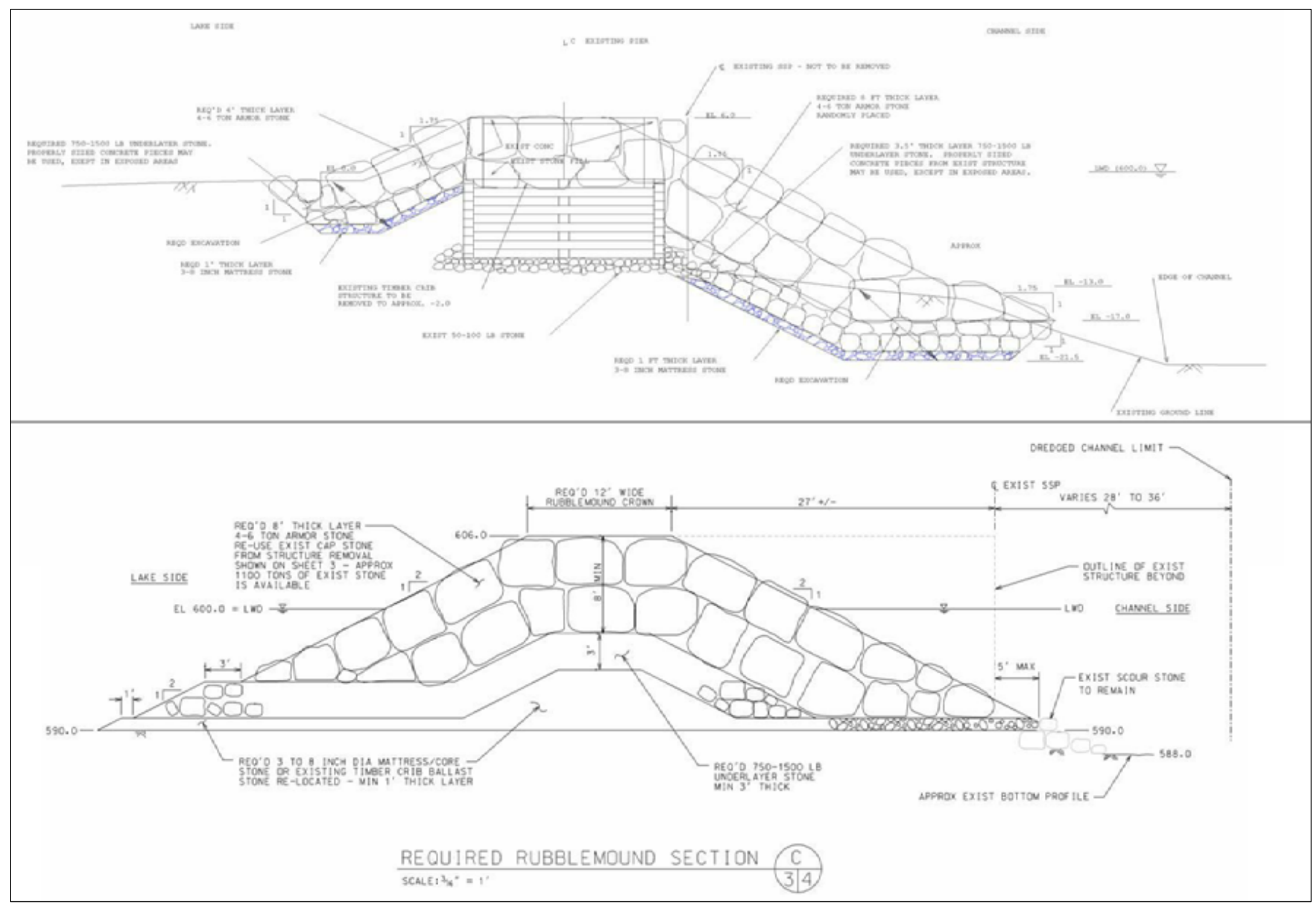

Figure A6. Ontonagon Harbor, MI. 


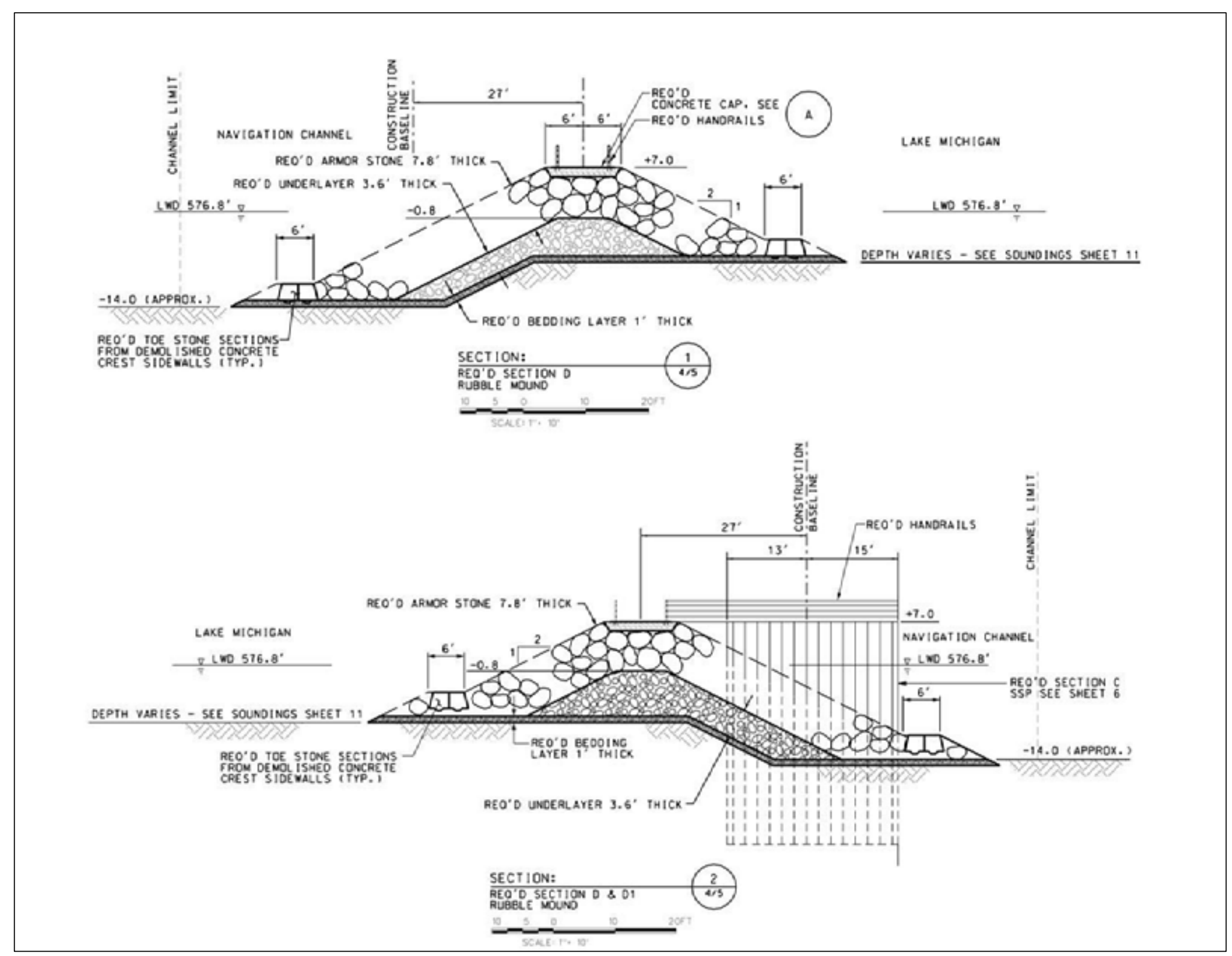

Figure A7. Two Rivers Harbor, WI. 


\section{Appendix B: Wave Roses}

Wave Information Studies (WIS) hindcasts were gathered for all of the wave absorber locations. The hindcasts, representing deepwater waves, cover the years 1956-1997 for Lake Michigan and 1956-1987 for Lake Superior. Wave roses were developed for each location using ESWave. All of the information was downloaded from the CHL website. The roses are shown in the following figures. Figures B1-B7 are significant wave height roses for all locations. Figures B8-B14 are peak wave period roses for all locations.

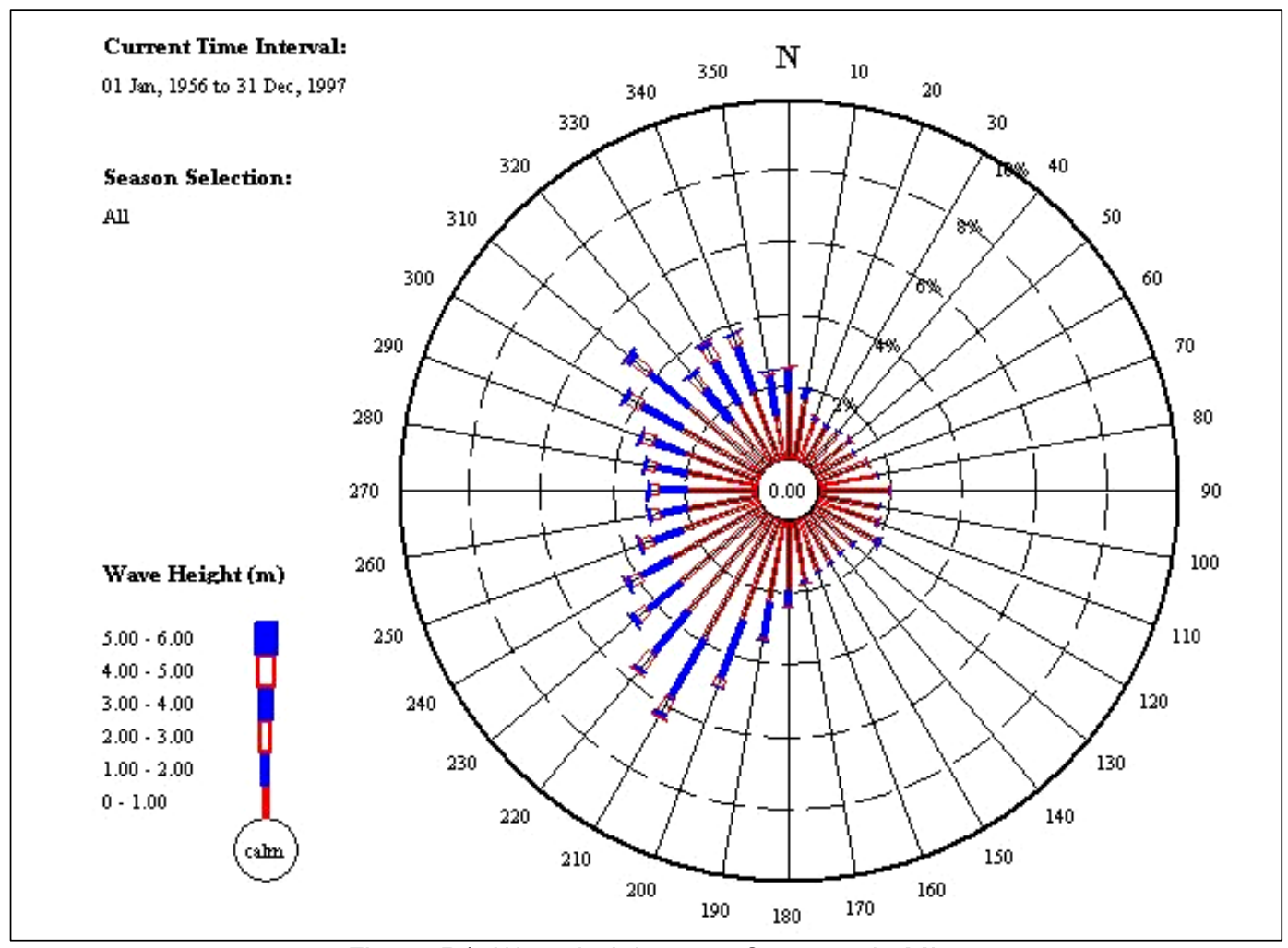

Figure B1. Wave height rose, Saugatuck, MI. 


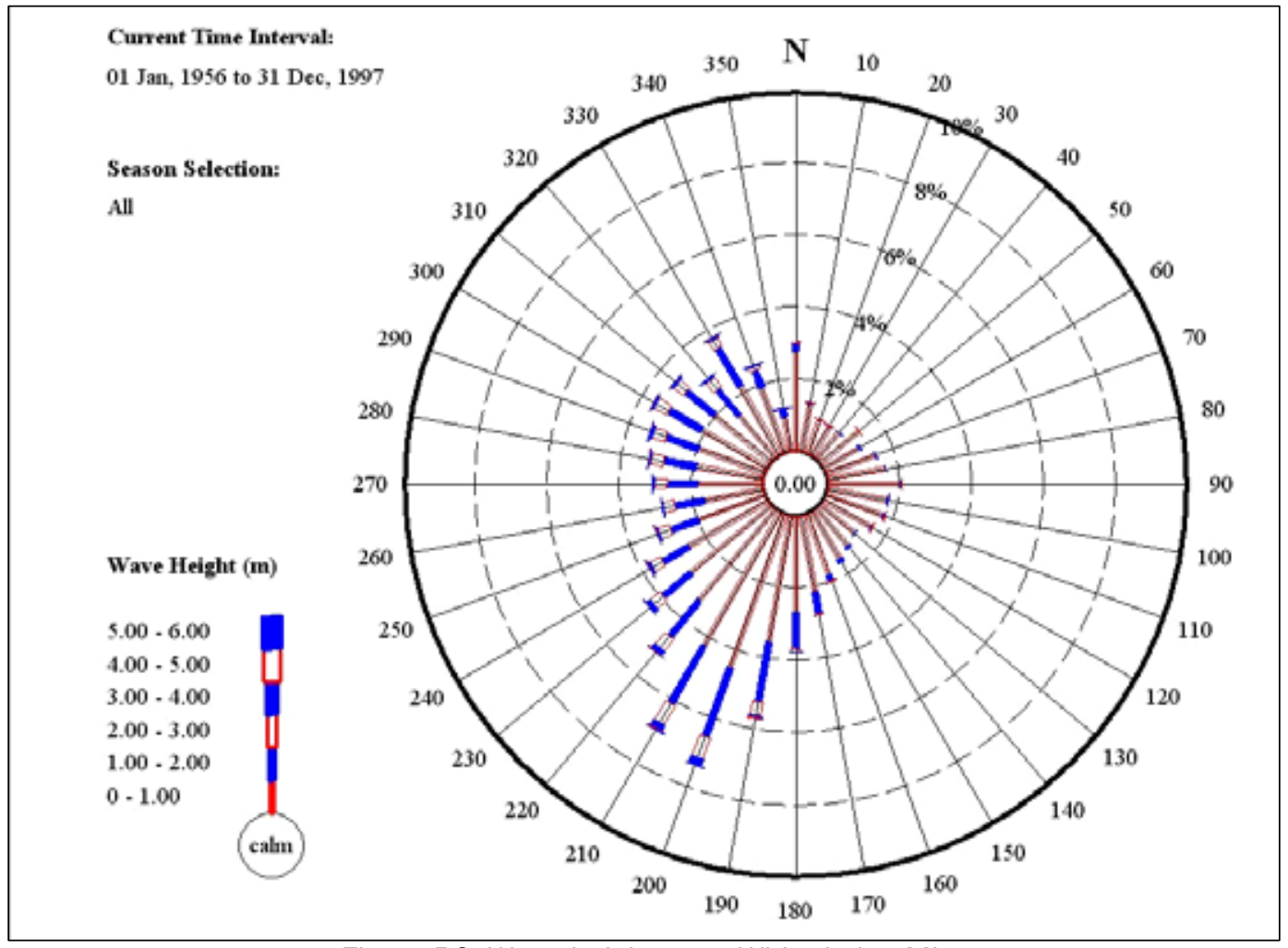

Figure B2. Wave height rose, White Lake, MI.

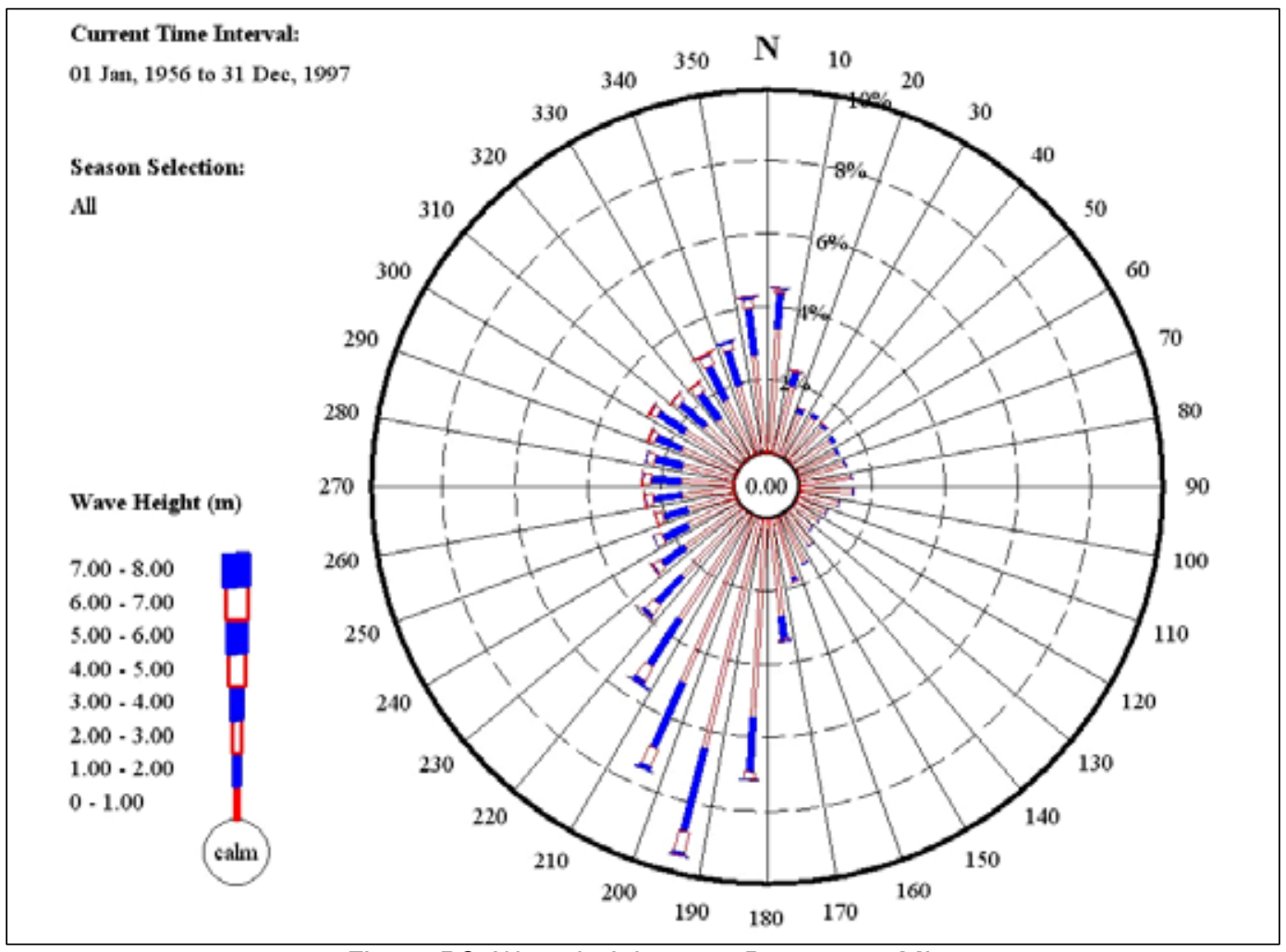

Figure B3. Wave height rose, Pentwater, Ml. 


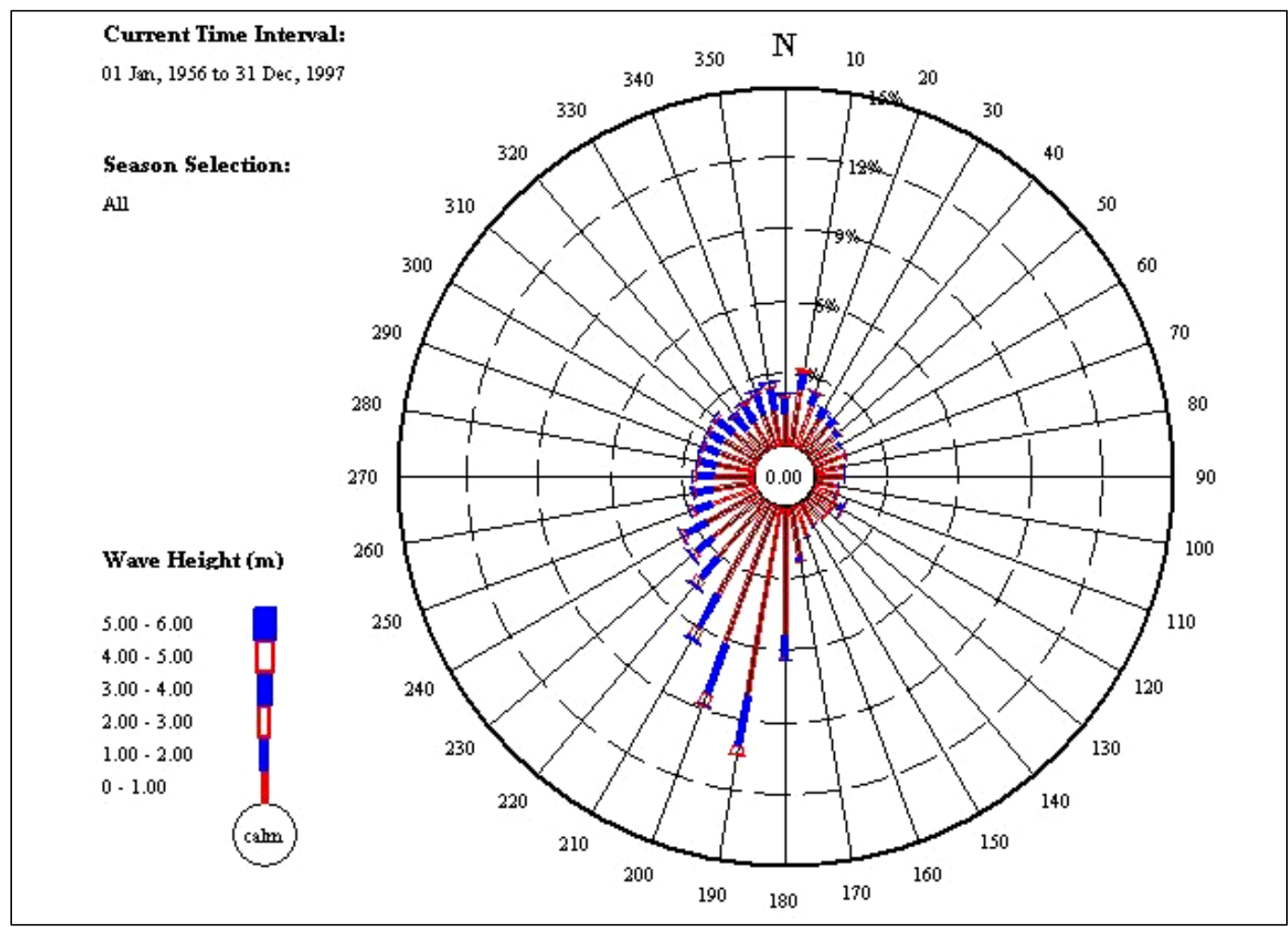

Figure B4. Wave height rose, Portage Lake, MI.

Current Time Interval:

$01 \mathrm{Jam}, 1956$ to $31 \mathrm{Dec}, 1997$

Season Selection:

All

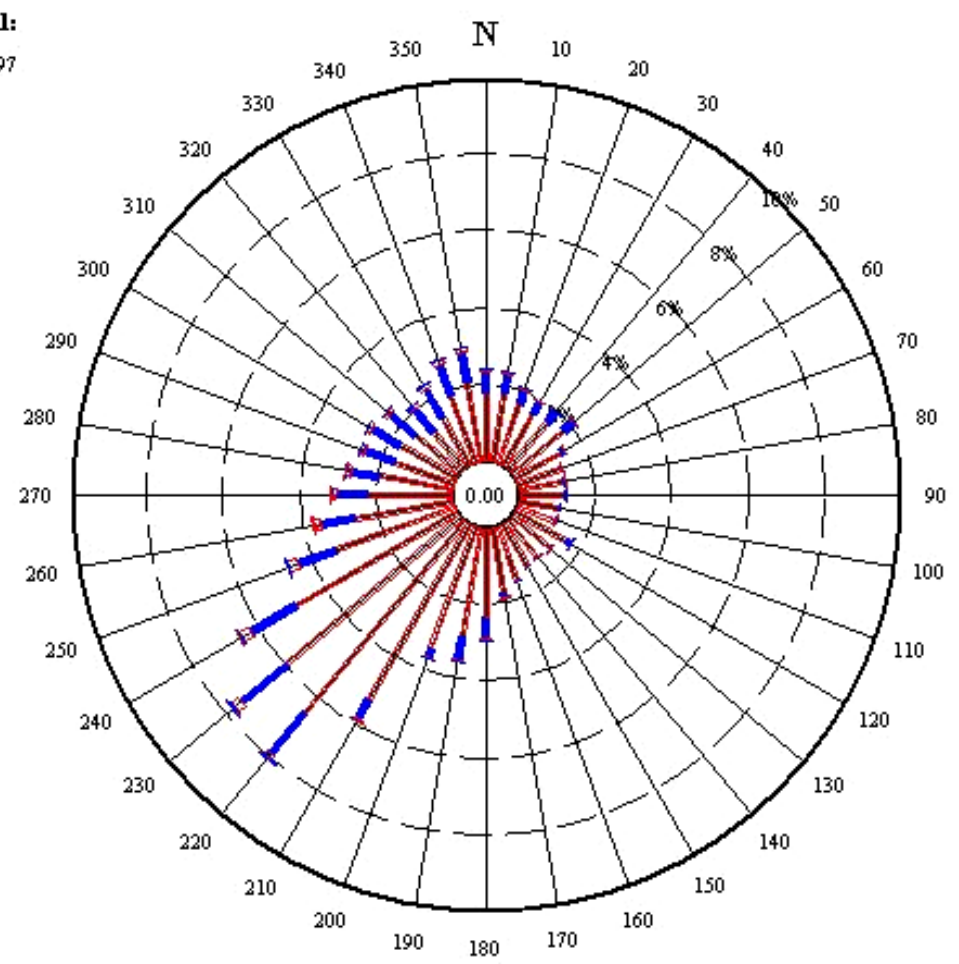

Figure B5. Wave height rose, Charlevoix, MI. 


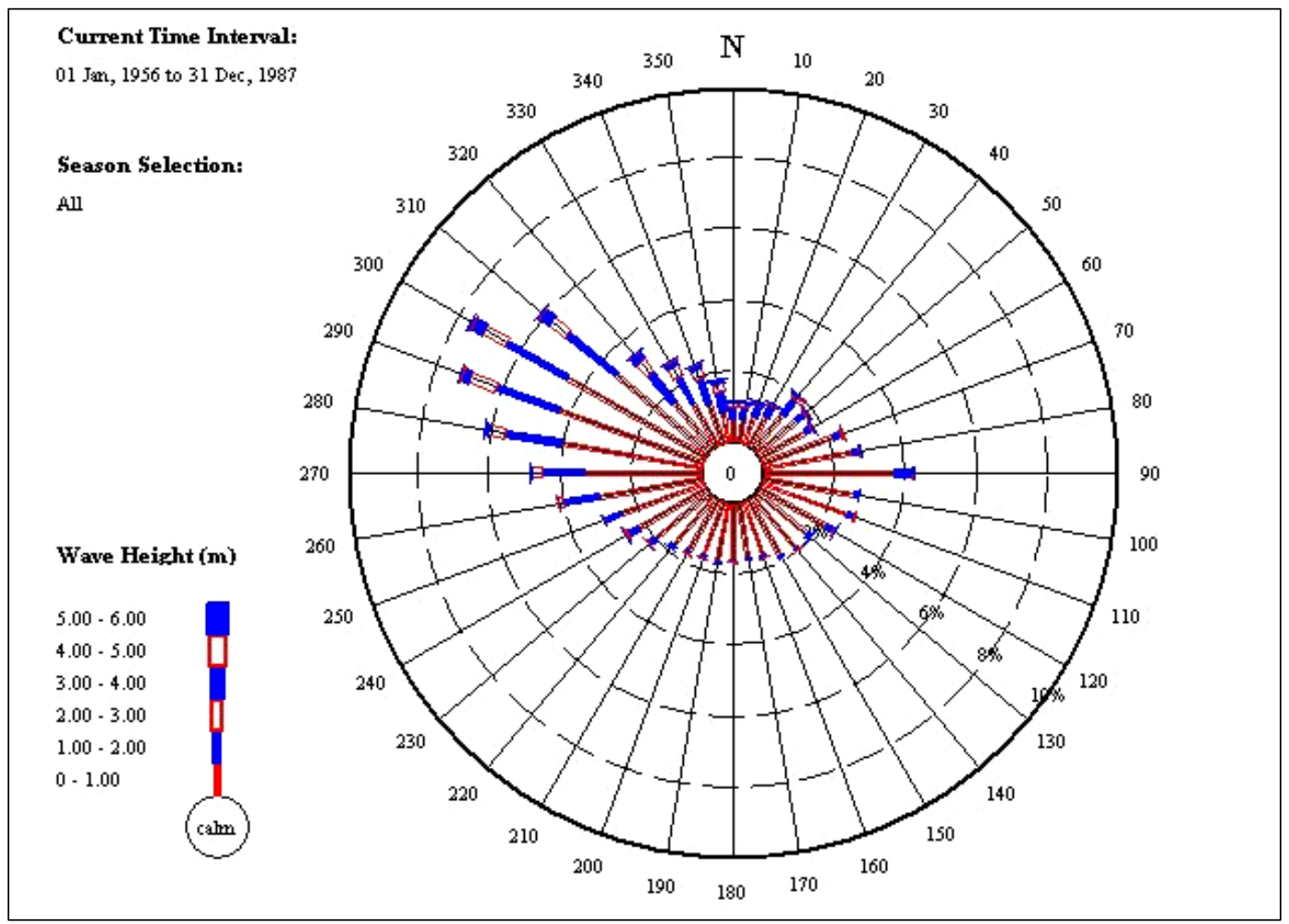

Figure B6. Wave height rose, Ontonagon, MI.

Current Time Interval:

01 Jan, 1956 to 31 Dec, 1997

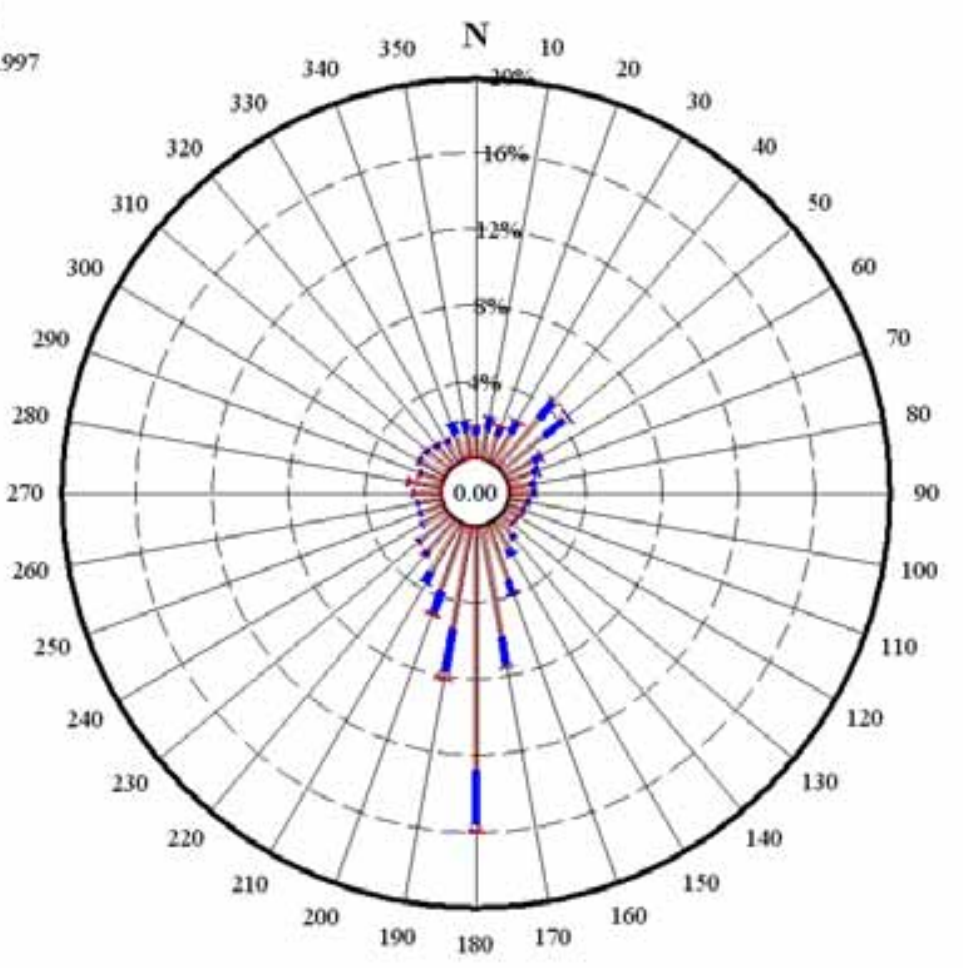

Figure B7. Wave height rose, Two Rivers, WI. 


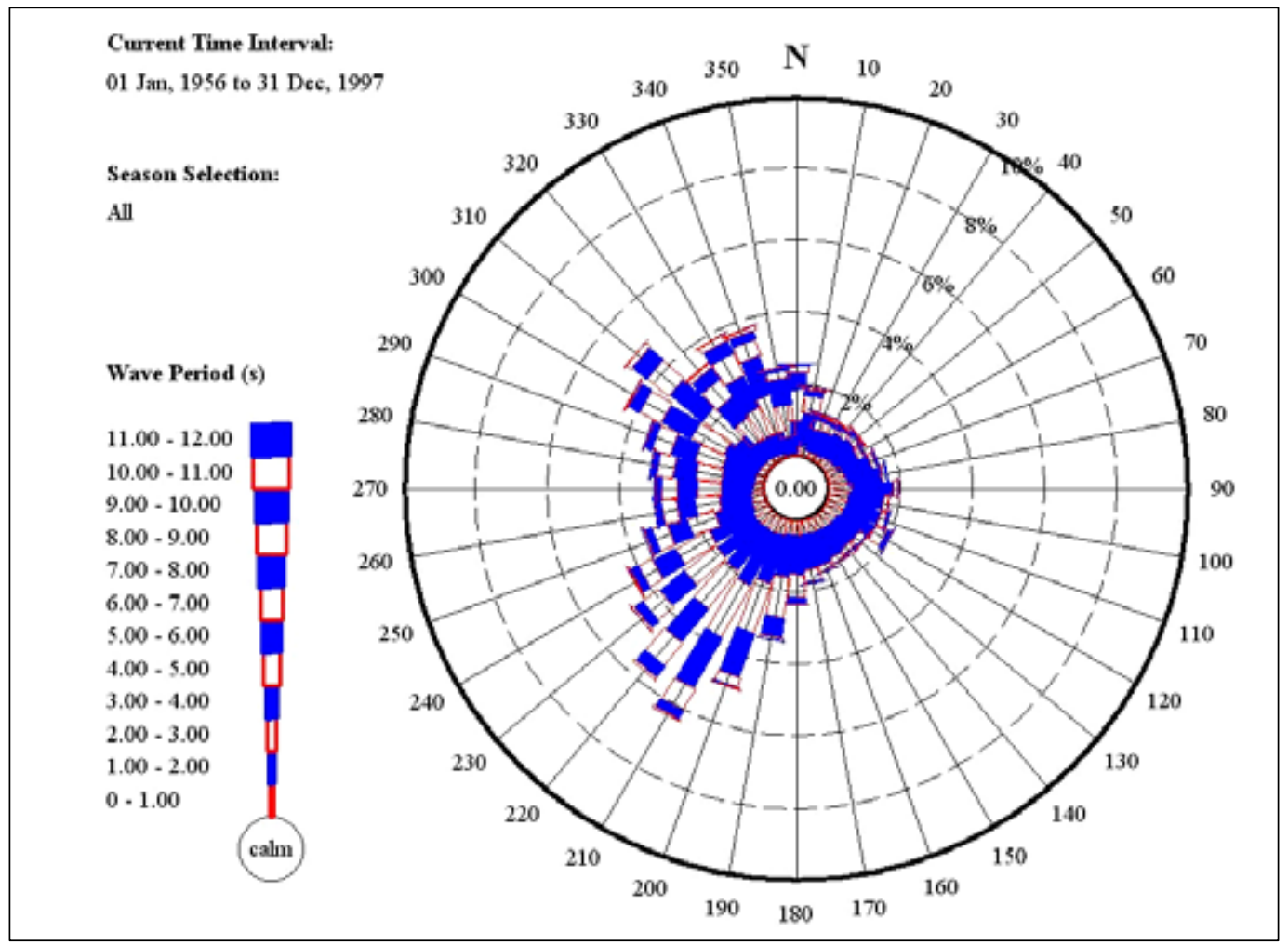

Figure B8. Wave period rose, Saugatuck, MI.

Current Time Interval:

$01 \mathrm{Jan}, 1956$ to 31 Dec, 1997

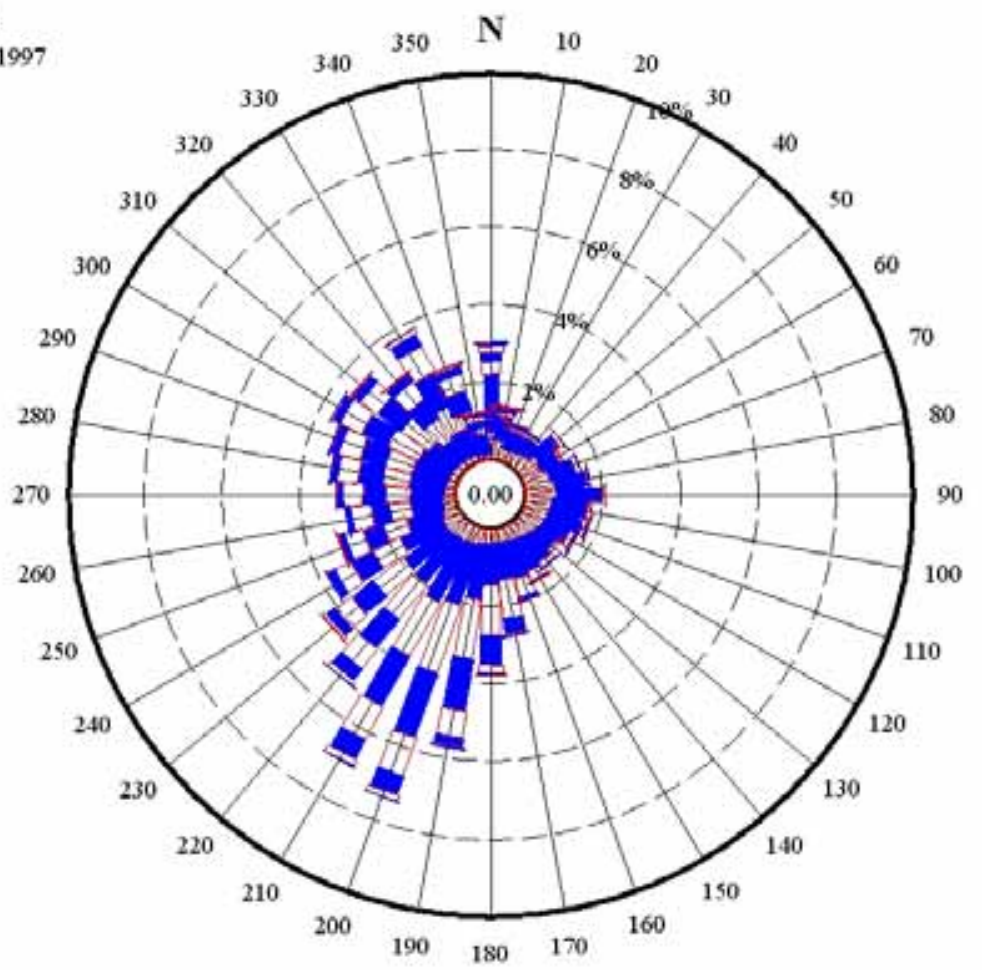

Season Selection:

AII

Wave Period (s)

$11.00 \cdot 12.00$ $10.00 \cdot 11.00$ $9.00 \cdot 10.00$

$8.00-9.00$

$7.00-8.000$

$6.00 \cdot 7.00$

$5.00 \cdot 6.00$

$4.00 \cdot 5.00$

$3.00-4.00$

$2.00 \cdot 3.00$

$1.00 \cdot 2.00$

$0 \cdot 1.00$

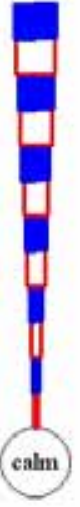

Figure B9. Wave period rose, White Lake, MI. 


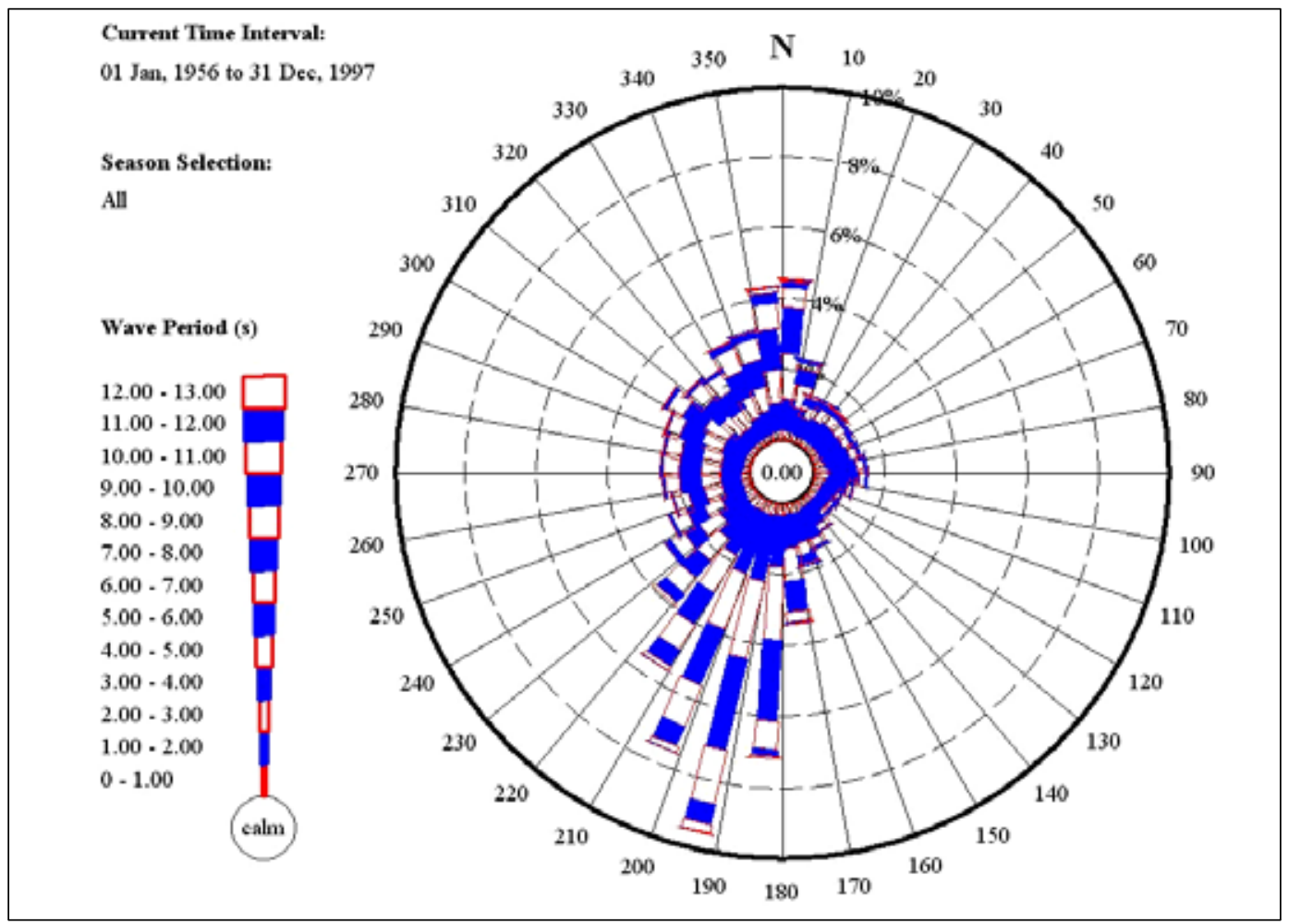

Figure B10. Wave period rose, Pentwater, MI.

Current Time Interval:

$01 \mathrm{Jan}, 1956$ to $31 \mathrm{Dec}, 1997$

Season Selection:

All

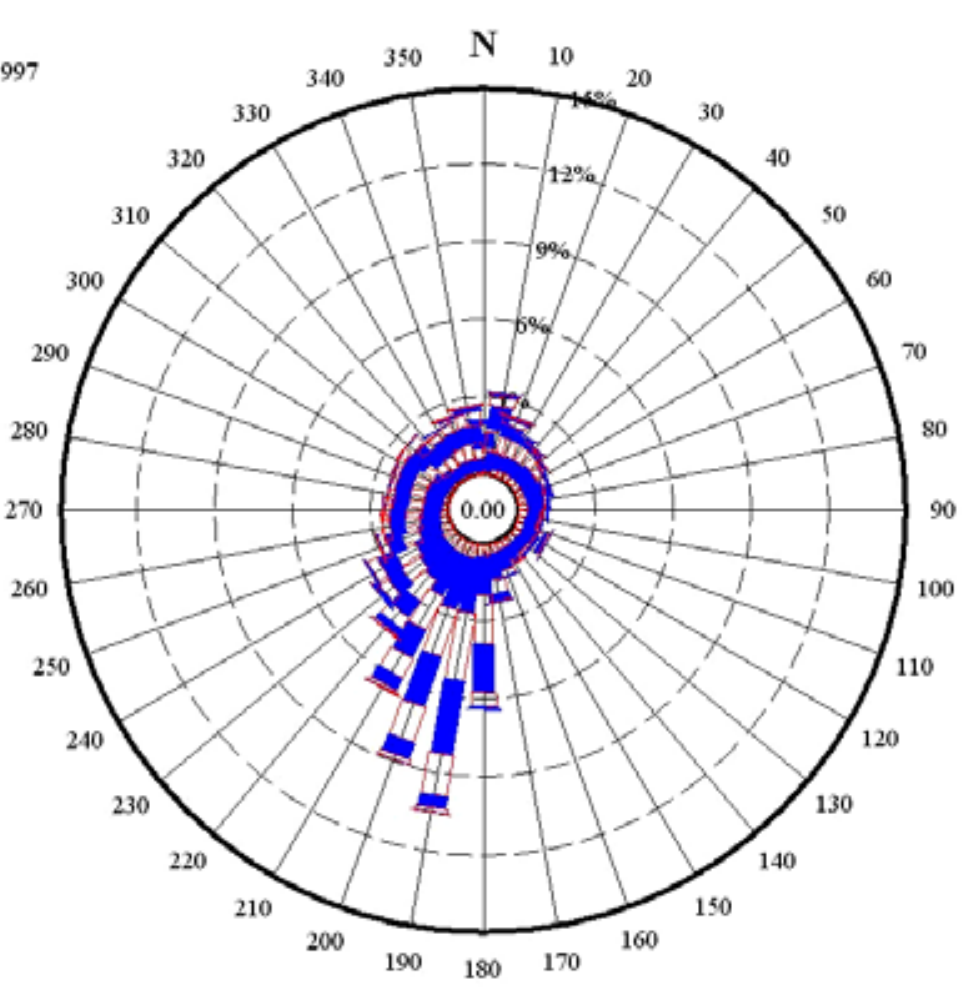

Figure B11. Wave period rose, Portage Lake, MI. 


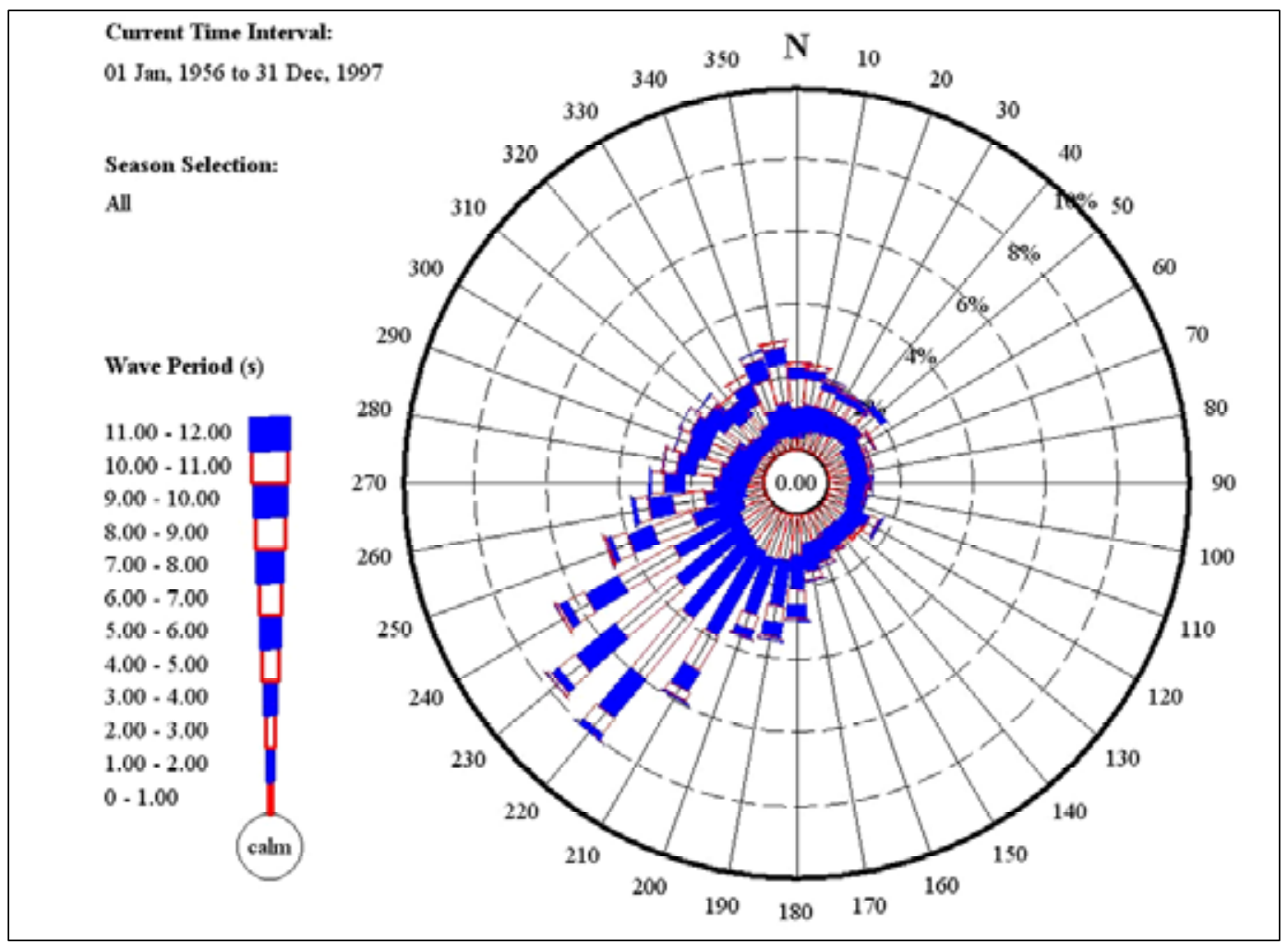

Figure B12. Wave period rose, Charlevoix, MI.

Curreut Time Interval:

01 Jan, 1956 to 31 Dec, 1987

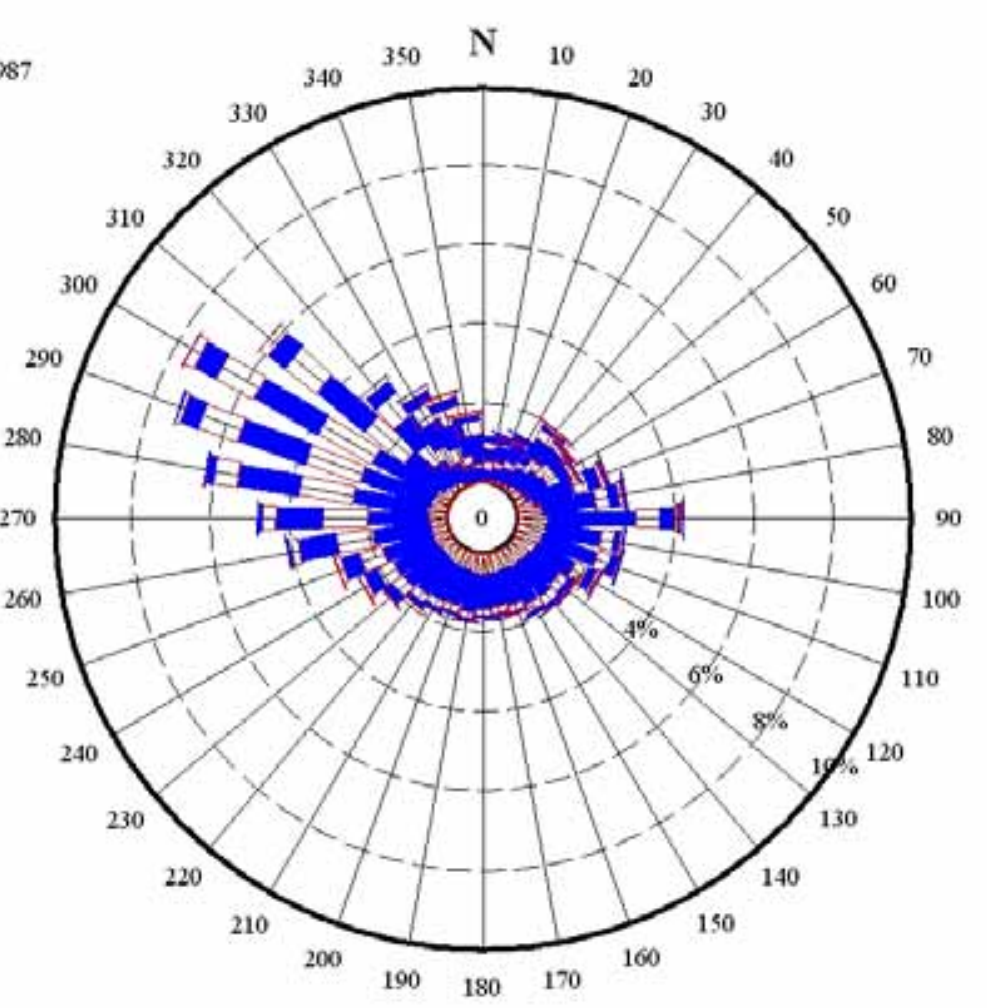

Figure B13. Wave period rose, Ontonagon, MI. 


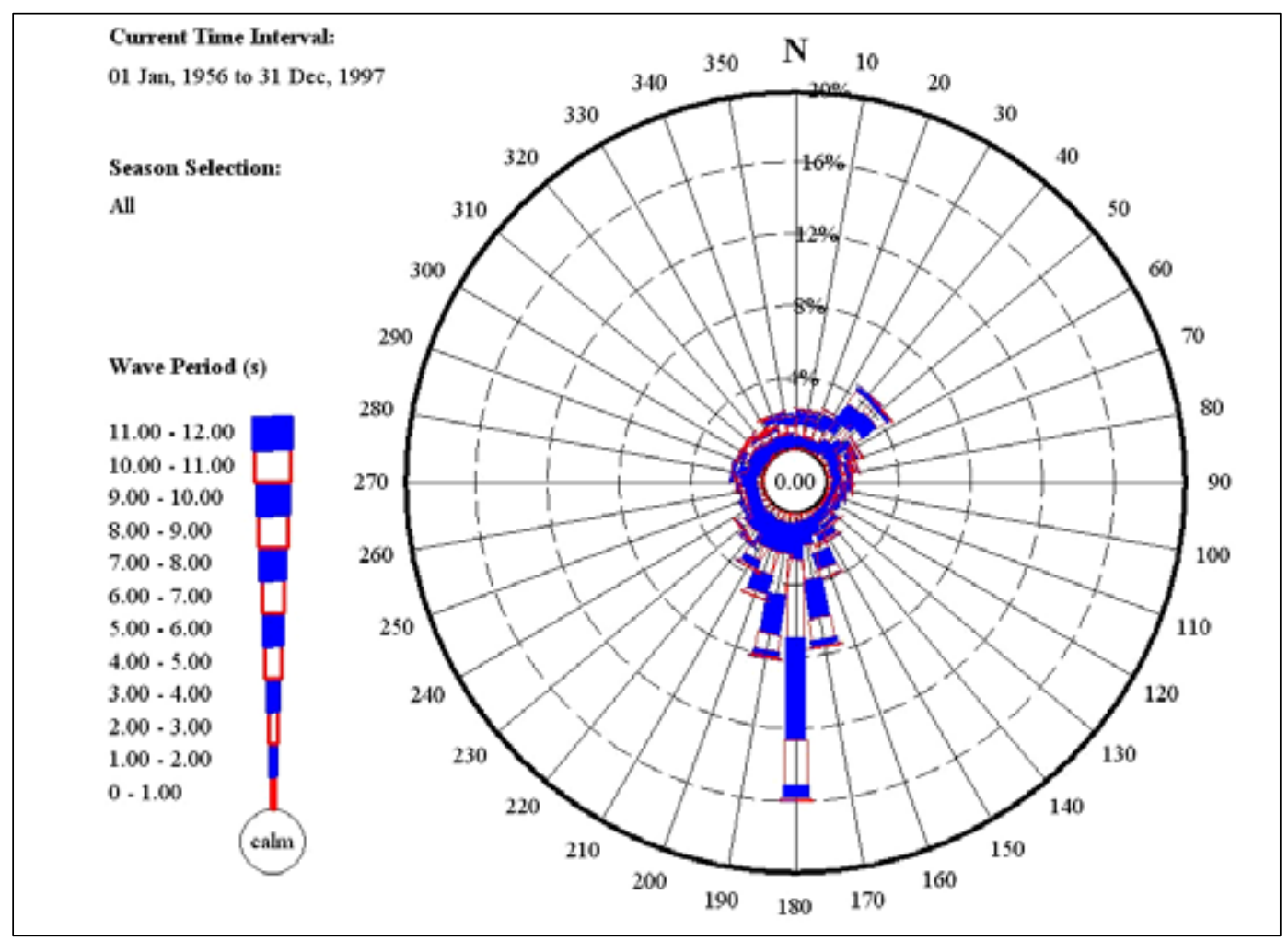

Figure B14. Wave period rose, Two Rivers, WI. 


\section{Appendix C: Aerial Photographs}

This appendix contains aerial photographs of Great Lakes harbor entrances with pocket wave absorbers installed. Aerial photographs were available for all sites described in this report except Ontonagon, MI, and Two Rivers, WI. A ground-level photograph of the absorber at Two Rivers is included.

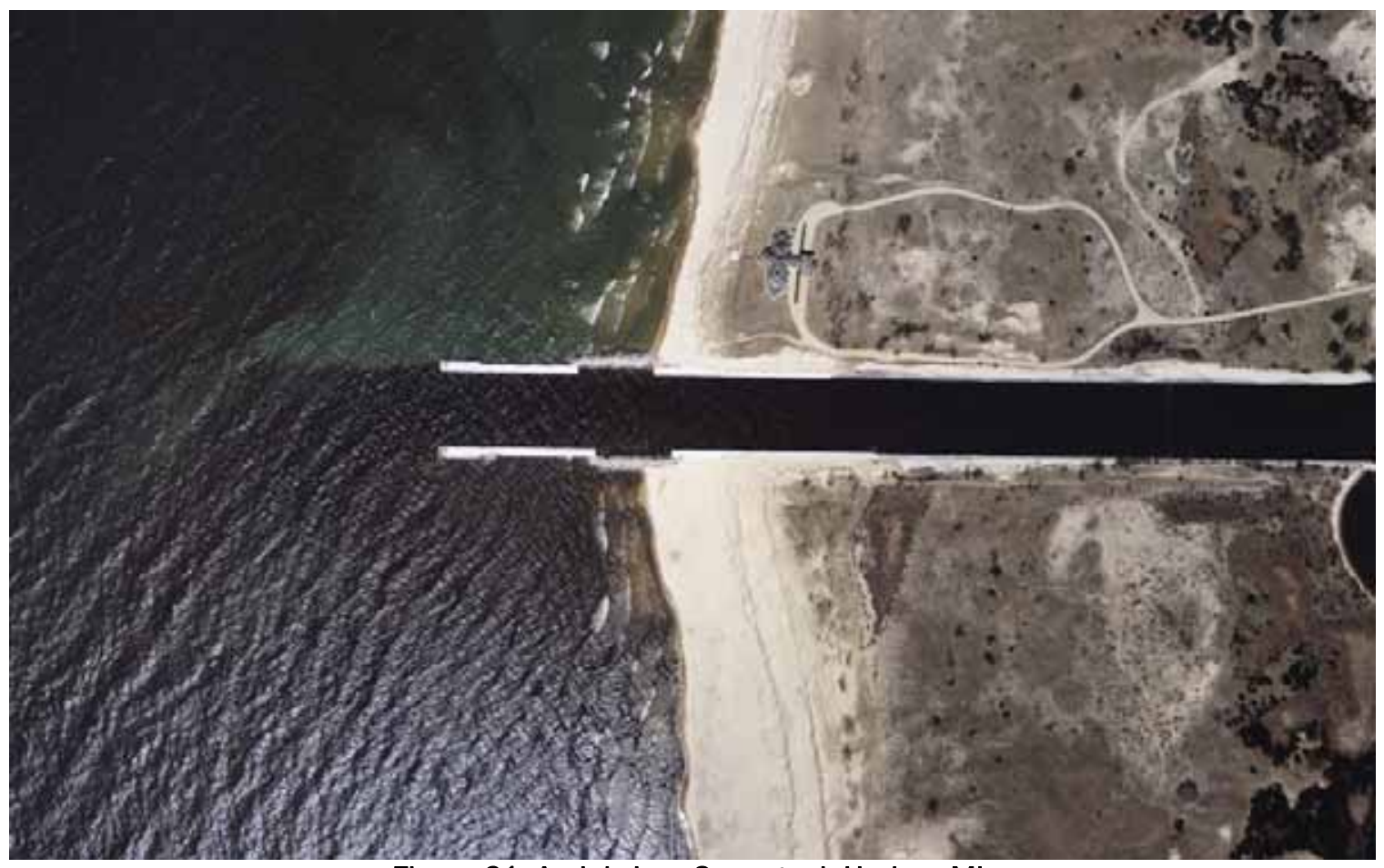

Figure C1. Aerial view, Saugatuck Harbor, MI. 


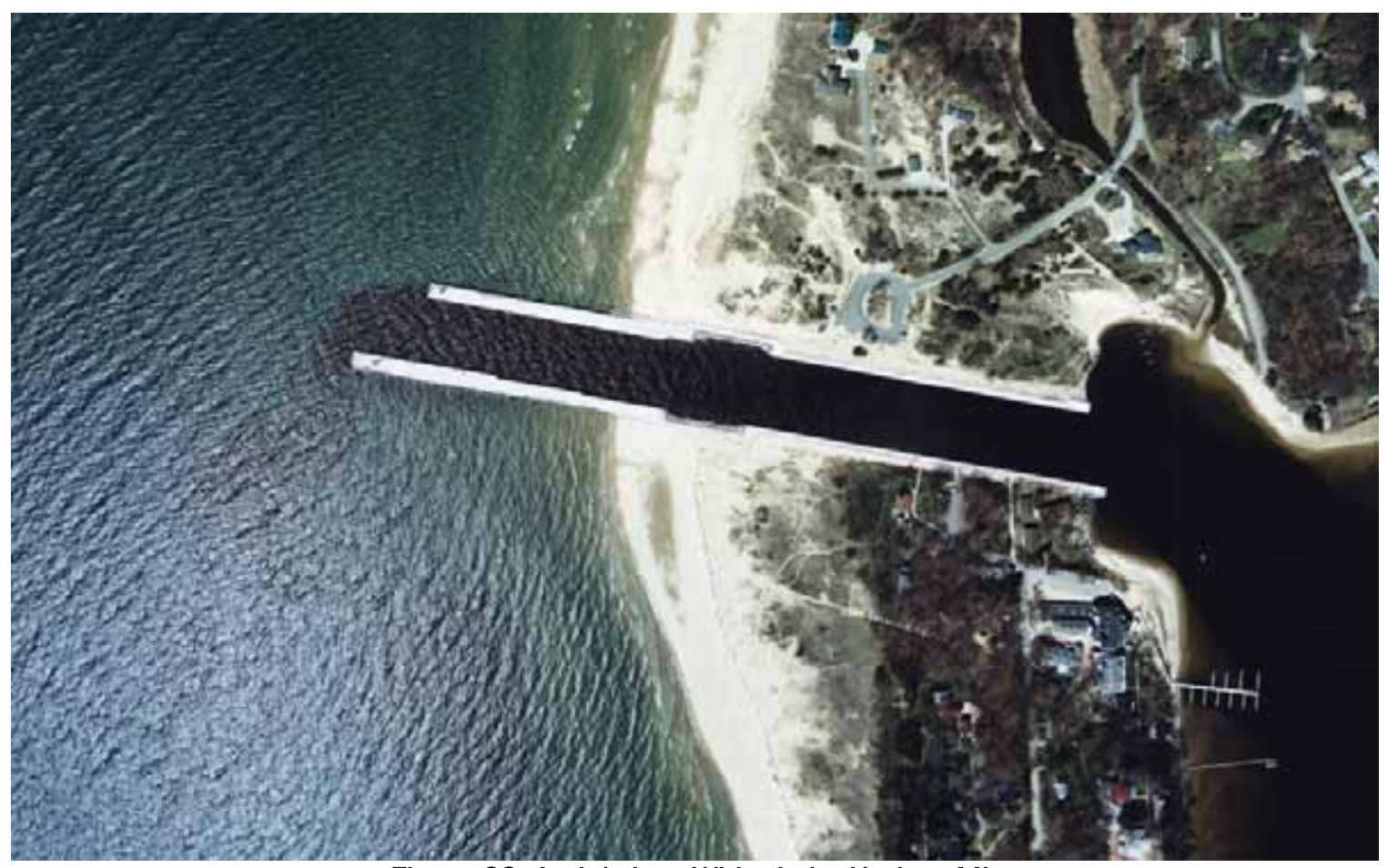

Figure C2. Aerial view, White Lake Harbor, MI.

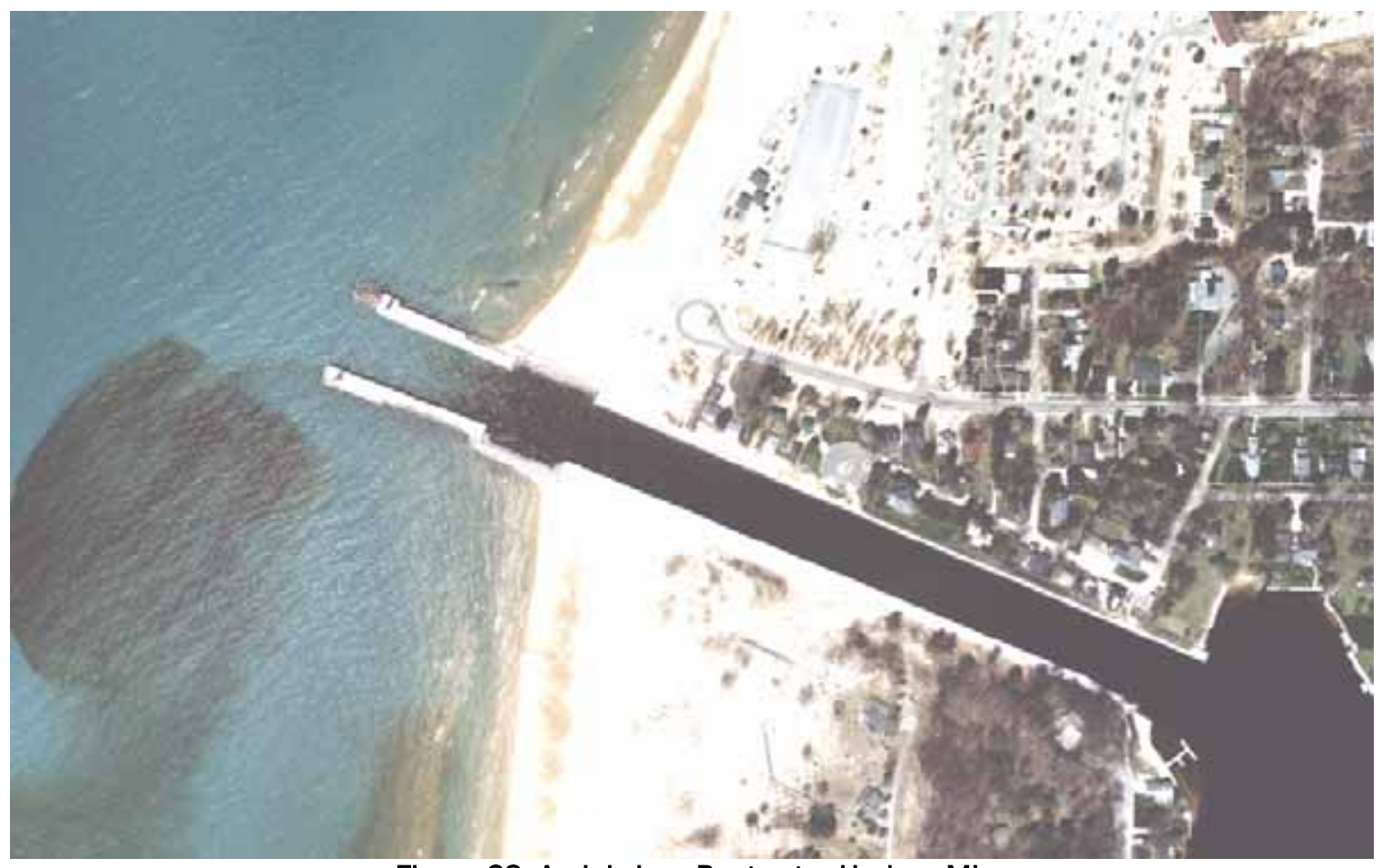

Figure C3. Aerial view, Pentwater Harbor, MI. 


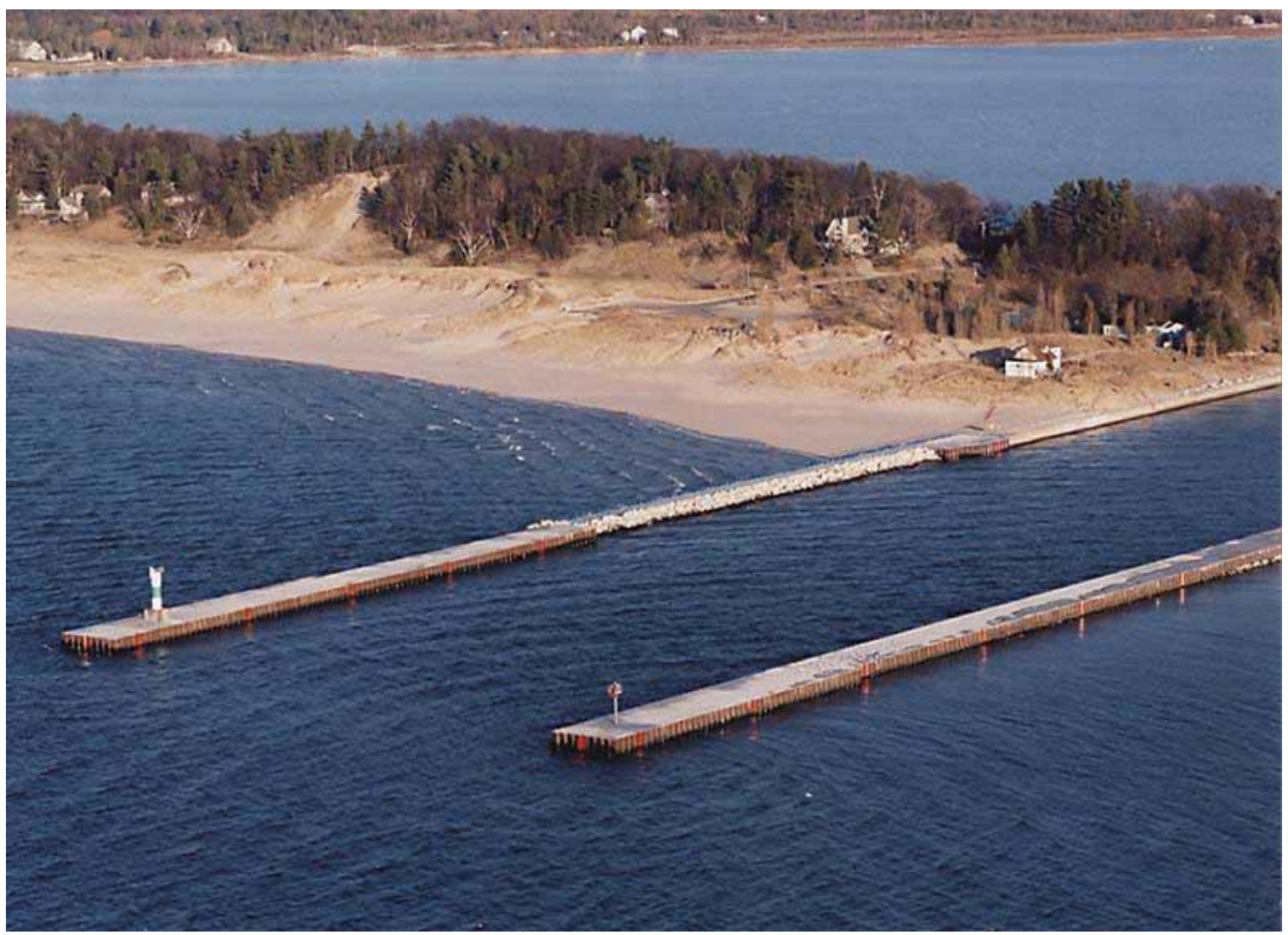

Figure C4. Aerial view, Portage Lake, MI.

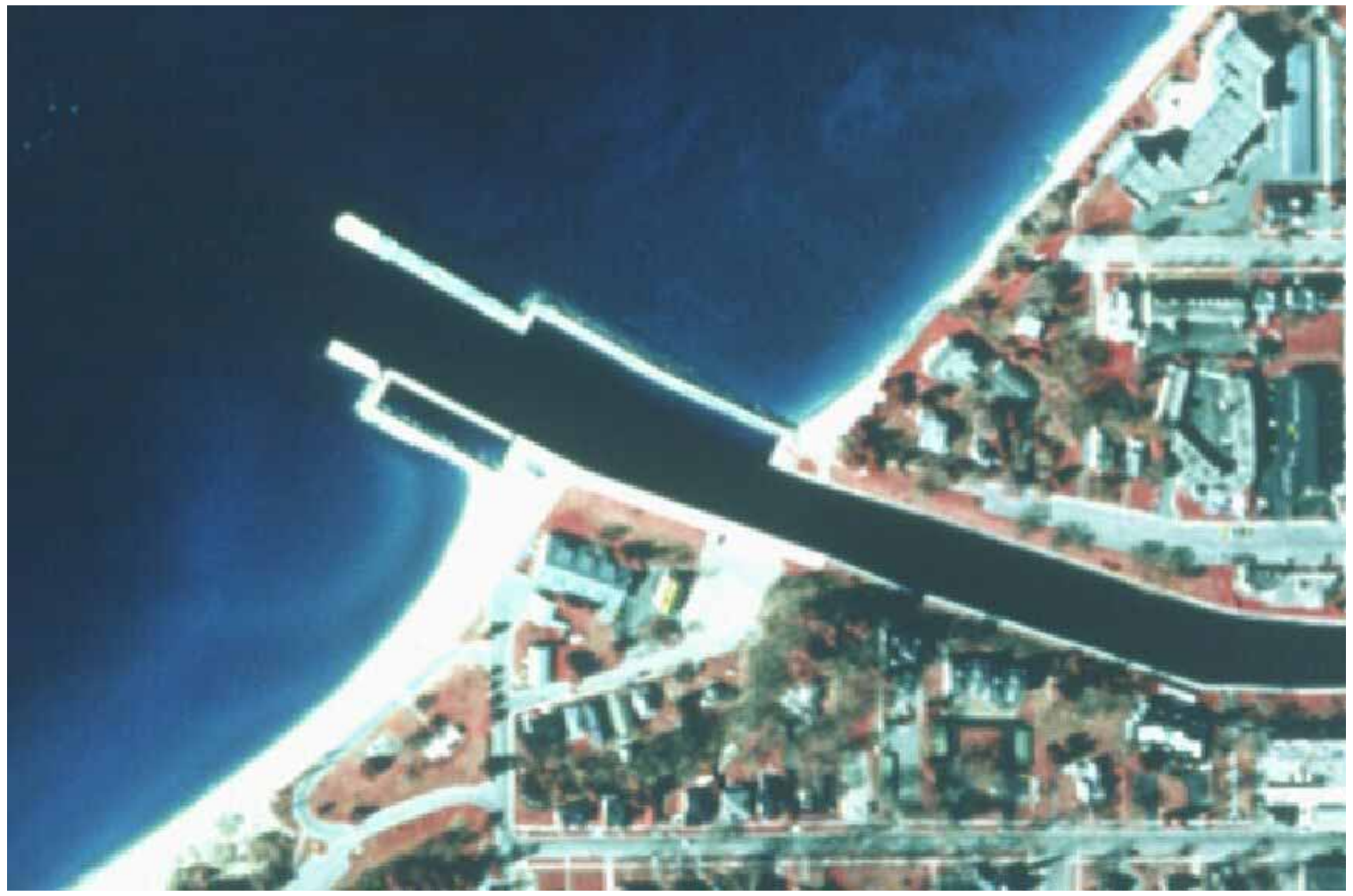

Figure C5. Aerial view, Charlevoix Harbor, MI. 


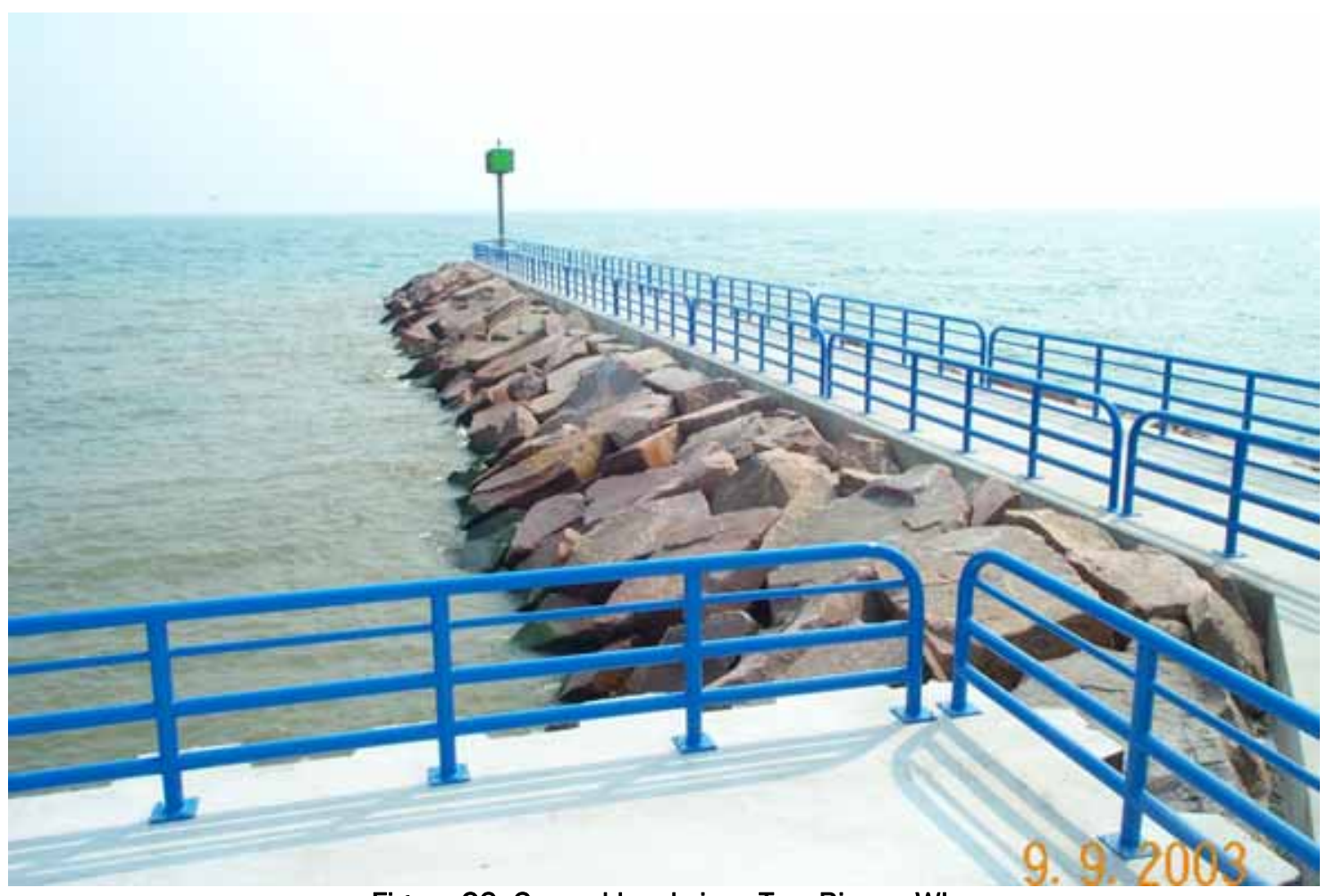

Figure C6. Ground-level view, Two Rivers, WI. 


\section{Appendix D: Significant Wave Heights from Physical Model Experiments}

Table D1. Wave heights for waves from 45 degrees South; +0.9 m swl.

\begin{tabular}{|c|c|c|c|c|c|c|c|c|c|c|c|c|}
\hline \multicolumn{2}{|c|}{$\begin{array}{l}\text { Experimental } \\
\text { Wave }\end{array}$} & \multicolumn{11}{|c|}{ Wave Height $(\mathrm{m})$ at Indicated Gauge Location; swl $=+0.9 \mathrm{~m}$} \\
\hline $\begin{array}{l}\text { Period } \\
(\mathrm{sec})\end{array}$ & $\begin{array}{l}\text { Height } \\
\text { (m) }\end{array}$ & Plan & $\begin{array}{l}\text { Gauge } \\
1\end{array}$ & $\begin{array}{l}\text { Gauge } \\
2\end{array}$ & $\begin{array}{l}\text { Gauge } \\
3\end{array}$ & $\begin{array}{l}\text { Gauge } \\
4\end{array}$ & $\begin{array}{l}\text { Gauge } \\
5\end{array}$ & $\begin{array}{l}\text { Gauge } \\
6\end{array}$ & $\begin{array}{l}\text { Gauge } \\
7\end{array}$ & $\begin{array}{l}\text { Gauge } \\
8\end{array}$ & $\begin{array}{l}\text { Gauge } \\
9\end{array}$ & $\begin{array}{l}\text { Gauge } \\
10\end{array}$ \\
\hline \multirow[t]{27}{*}{5} & \multirow[t]{9}{*}{1} & EC & 0.87 & 0.52 & 0.37 & 0.48 & 0.67 & 0.29 & 0.42 & 0.45 & 0.54 & 0.31 \\
\hline & & Plan 1 & 0.85 & 0.64 & 0.43 & 0.53 & 0.80 & 0.33 & 0.43 & 0.52 & 0.65 & 0.38 \\
\hline & & Plan 2 & 0.88 & 1.00 & 0.58 & 0.64 & 1.17 & 0.50 & 0.60 & 0.70 & 0.88 & 0.49 \\
\hline & & Plan 3 & 0.92 & 0.86 & 0.60 & 0.60 & 1.13 & 0.52 & 0.64 & 0.67 & 0.84 & 0.48 \\
\hline & & Plan 4 & 0.92 & 0.87 & 0.46 & 0.52 & 0.99 & 0.42 & 0.54 & 0.61 & 0.76 & 0.19 \\
\hline & & Plan 5 & 0.92 & 0.82 & 0.58 & 0.58 & 1.06 & 0.46 & 0.62 & 0.65 & 0.81 & 0.39 \\
\hline & & Plan 6 & 0.92 & 0.78 & 0.53 & 0.57 & 1.08 & 0.48 & 0.59 & 0.66 & 0.80 & 0.20 \\
\hline & & Plan 7 & 0.90 & 0.76 & 0.53 & 0.54 & 1.02 & 0.45 & 0.60 & 0.64 & 0.74 & 0.23 \\
\hline & & Plan 8 & 0.92 & 0.72 & 0.47 & 0.54 & 1.01 & 0.45 & 0.54 & 0.61 & 0.73 & 0.33 \\
\hline & \multirow[t]{9}{*}{2} & EC & 1.80 & 1.38 & 0.97 & 1.11 & 1.74 & 0.61 & 1.05 & 1.05 & 1.30 & 0.70 \\
\hline & & Plan 1 & 1.76 & 1.41 & 0.97 & 1.13 & 1.62 & 0.59 & 1.00 & 1.02 & 1.26 & 0.81 \\
\hline & & Plan 2 & 1.80 & 1.41 & 0.92 & 1.07 & 1.64 & 0.60 & 0.97 & 1.03 & 1.23 & 0.66 \\
\hline & & Plan 3 & 1.85 & 1.43 & 1.10 & 1.21 & 1.79 & 0.74 & 1.15 & 1.12 & 1.39 & 0.85 \\
\hline & & Plan 4 & 1.86 & 1.48 & 0.92 & 1.10 & 1.74 & 0.69 & 0.99 & 1.09 & 1.36 & 0.33 \\
\hline & & Plan 5 & 1.84 & 1.25 & 1.00 & 1.07 & 1.65 & 0.67 & 1.06 & 1.05 & 1.27 & 0.62 \\
\hline & & Plan 6 & 1.82 & 1.32 & 1.05 & 1.13 & 1.80 & 0.74 & 1.09 & 1.12 & 1.35 & 0.35 \\
\hline & & Plan 7 & 1.85 & 1.29 & 1.02 & 1.09 & 1.78 & 0.71 & 1.08 & 1.09 & 1.31 & 0.41 \\
\hline & & Plan 8 & 1.87 & 1.34 & 1.02 & 1.13 & 1.84 & 0.75 & 1.07 & 1.13 & 1.36 & 0.60 \\
\hline & \multirow[t]{9}{*}{2.5} & EC & 2.38 & 1.48 & 1.12 & 1.35 & 1.78 & 0.72 & 1.24 & 1.23 & 1.57 & 0.83 \\
\hline & & Plan 1 & 2.38 & 1.40 & 1.19 & 1.36 & 1.70 & 0.82 & 1.17 & 1.21 & 1.59 & 1.00 \\
\hline & & Plan 2 & 2.39 & 1.50 & 1.06 & 1.30 & 1.69 & 0.73 & 1.14 & 1.18 & 1.51 & 0.84 \\
\hline & & Plan 3 & 2.42 & 1.42 & 1.18 & 1.38 & 1.73 & 0.84 & 1.27 & 1.23 & 1.52 & 0.91 \\
\hline & & Plan 4 & 2.38 & 1.56 & 1.06 & 1.36 & 1.72 & 0.82 & 1.20 & 1.22 & 1.61 & 0.43 \\
\hline & & Plan 5 & 2.39 & 1.38 & 1.17 & 1.37 & 1.77 & 0.86 & 1.26 & 1.25 & 1.55 & 0.81 \\
\hline & & Plan 6 & 2.37 & 1.33 & 1.14 & 1.36 & 1.74 & 0.85 & 1.22 & 1.23 & 1.52 & 0.40 \\
\hline & & Plan 7 & 2.37 & 1.36 & 1.16 & 1.38 & 1.79 & 0.86 & 1.26 & 1.25 & 1.54 & 0.48 \\
\hline & & Plan 8 & 2.41 & 1.43 & 1.19 & 1.41 & 1.83 & 0.90 & 1.32 & 1.28 & 1.60 & 0.72 \\
\hline
\end{tabular}




\begin{tabular}{|c|c|c|c|c|c|c|c|c|c|c|c|c|}
\hline \multicolumn{2}{|c|}{$\begin{array}{l}\text { Experimental } \\
\text { Wave }\end{array}$} & \multicolumn{11}{|c|}{ Wave Height $(\mathrm{m})$ at Indicated Gauge Location; swl $=+0.9 \mathrm{~m}$} \\
\hline $\begin{array}{l}\text { Period } \\
\text { (sec) }\end{array}$ & $\begin{array}{l}\text { Height } \\
(\mathrm{m})\end{array}$ & Plan & $\begin{array}{l}\text { Gauge } \\
11\end{array}$ & $\begin{array}{l}\text { Gauge } \\
12\end{array}$ & $\begin{array}{l}\text { Gauge } \\
13\end{array}$ & $\begin{array}{l}\text { Gauge } \\
14\end{array}$ & $\begin{array}{l}\text { Gauge } \\
15\end{array}$ & $\begin{array}{l}\text { Gauge } \\
16\end{array}$ & $\begin{array}{l}\text { Gauge } \\
17\end{array}$ & $\begin{array}{l}\text { Gauge } \\
18\end{array}$ & $\begin{array}{l}\text { Gauge } \\
19\end{array}$ & $\begin{array}{l}\text { Gauge } \\
20\end{array}$ \\
\hline \multirow[t]{27}{*}{5} & \multirow[t]{9}{*}{1} & EC & 0.17 & 0.23 & 0.27 & 0.35 & 0.22 & 0.26 & 0.38 & 0.34 & 0.24 & 0.19 \\
\hline & & Plan 1 & 0.20 & 0.43 & 0.52 & 0.69 & 0.45 & 0.43 & 0.75 & 0.60 & 0.42 & 0.42 \\
\hline & & Plan 2 & 0.19 & 0.41 & 0.60 & 0.77 & 0.57 & 0.42 & 0.80 & 0.73 & 0.41 & 0.41 \\
\hline & & Plan 3 & 0.27 & 0.42 & 0.49 & 0.69 & 0.37 & 0.46 & 0.73 & 0.54 & 0.45 & 0.53 \\
\hline & & Plan 4 & 0.17 & 0.36 & 0.58 & 0.68 & 0.41 & 0.38 & 0.52 & 0.53 & 0.38 & 0.24 \\
\hline & & Plan 5 & 0.27 & 0.36 & 0.46 & 0.35 & 0.46 & 0.17 & 0.33 & 0.44 & 0.19 & 0.27 \\
\hline & & Plan 6 & 0.27 & 0.36 & 0.37 & 0.24 & 0.36 & 0.20 & 0.26 & 0.34 & 0.21 & 0.25 \\
\hline & & Plan 7 & 0.24 & 0.23 & 0.32 & 0.43 & 0.12 & 0.27 & 0.36 & 0.32 & 0.27 & 0.18 \\
\hline & & Plan 8 & 0.23 & 0.32 & 0.33 & 0.23 & 0.45 & 0.13 & 0.25 & 0.42 & 0.16 & 0.21 \\
\hline & \multirow[t]{9}{*}{2} & EC & 0.36 & 0.48 & 0.59 & 0.70 & 0.52 & 0.53 & 0.73 & 0.71 & 0.50 & 0.39 \\
\hline & & Plan 1 & 0.41 & 0.83 & 0.97 & 1.41 & 1.04 & 0.85 & 1.34 & 1.16 & 0.83 & 0.90 \\
\hline & & Plan 2 & 0.33 & 0.65 & 0.90 & 1.11 & 0.88 & 0.61 & 1.10 & 1.06 & 0.64 & 0.56 \\
\hline & & Plan 3 & 0.43 & 0.61 & 0.75 & 1.14 & 0.64 & 0.73 & 1.11 & 0.88 & 0.68 & 0.85 \\
\hline & & Plan 4 & 0.37 & 0.68 & 1.01 & 1.16 & 0.79 & 0.68 & 0.84 & 0.95 & 0.65 & 0.50 \\
\hline & & Plan 5 & 0.41 & 0.52 & 0.69 & 0.53 & 0.71 & 0.25 & 0.52 & 0.66 & 0.26 & 0.41 \\
\hline & & Plan 6 & 0.47 & 0.59 & 0.58 & 0.40 & 0.60 & 0.34 & 0.40 & 0.53 & 0.36 & 0.41 \\
\hline & & Plan 7 & 0.43 & 0.44 & 0.55 & 0.73 & 0.27 & 0.45 & 0.61 & 0.56 & 0.45 & 0.38 \\
\hline & & Plan 8 & 0.42 & 0.57 & 0.60 & 0.43 & 0.78 & 0.24 & 0.44 & 0.73 & 0.28 & 0.38 \\
\hline & \multirow[t]{9}{*}{2.5} & EC & 0.45 & 0.55 & 0.65 & 0.80 & 0.62 & 0.60 & 0.83 & 0.80 & 0.56 & 0.46 \\
\hline & & Plan 1 & 0.55 & 0.97 & 1.14 & 1.53 & 1.26 & 0.93 & 1.48 & 1.38 & 0.94 & 1.07 \\
\hline & & Plan 2 & 0.43 & 0.76 & 1.02 & 1.23 & 1.03 & 0.68 & 1.29 & 1.25 & 0.68 & 0.67 \\
\hline & & Plan 3 & 0.50 & 0.65 & 0.77 & 1.17 & 0.72 & 0.72 & 1.15 & 0.92 & 0.71 & 0.90 \\
\hline & & Plan 4 & 0.50 & 0.80 & 1.10 & 1.26 & 0.90 & 0.76 & 0.95 & 1.07 & 0.73 & 0.55 \\
\hline & & Plan 5 & 0.52 & 0.61 & 0.78 & 0.61 & 0.85 & 0.33 & 0.68 & 0.80 & 0.34 & 0.53 \\
\hline & & Plan 6 & 0.52 & 0.63 & 0.61 & 0.42 & 0.65 & 0.37 & 0.46 & 0.57 & 0.39 & 0.44 \\
\hline & & Plan 7 & 0.54 & 0.52 & 0.62 & 0.82 & 0.35 & 0.51 & 0.72 & 0.66 & 0.48 & 0.43 \\
\hline & & Plan 8 & 0.50 & 0.64 & 0.65 & 0.46 & 0.89 & 0.30 & 0.49 & 0.83 & 0.33 & 0.48 \\
\hline
\end{tabular}




\begin{tabular}{|c|c|c|c|c|c|c|c|c|c|c|c|c|}
\hline \multicolumn{2}{|c|}{$\begin{array}{l}\text { Experimental } \\
\text { Wave }\end{array}$} & \multicolumn{11}{|c|}{ Wave Height $(\mathrm{m})$ at Indicated Gauge Location; swl $=+0.9 \mathrm{~m}$} \\
\hline $\begin{array}{l}\text { Period } \\
\text { (sec) }\end{array}$ & $\begin{array}{l}\text { Height } \\
(\mathrm{m})\end{array}$ & Plan & $\begin{array}{l}\text { Gauge } \\
1\end{array}$ & $\begin{array}{l}\text { Gauge } \\
2\end{array}$ & $\begin{array}{l}\text { Gauge } \\
3\end{array}$ & $\begin{array}{l}\text { Gauge } \\
4\end{array}$ & $\begin{array}{l}\text { Gauge } \\
5\end{array}$ & $\begin{array}{l}\text { Gauge } \\
6\end{array}$ & $\begin{array}{l}\text { Gauge } \\
7\end{array}$ & $\begin{array}{l}\text { Gauge } \\
8\end{array}$ & $\begin{array}{l}\text { Gauge } \\
9\end{array}$ & $\begin{array}{l}\text { Gauge } \\
10\end{array}$ \\
\hline \multirow[t]{27}{*}{6} & \multirow[t]{9}{*}{1} & EC & 0.93 & 0.86 & 0.57 & 0.59 & 0.94 & 0.39 & 0.84 & 0.71 & 0.92 & 0.49 \\
\hline & & Plan 1 & 0.92 & 0.90 & 0.59 & 0.63 & 0.86 & 0.41 & 0.73 & 0.73 & 0.89 & 0.64 \\
\hline & & Plan 2 & 0.93 & 1.01 & 0.64 & 0.67 & 0.98 & 0.44 & 0.82 & 0.80 & 1.00 & 0.60 \\
\hline & & Plan 3 & 0.97 & 0.97 & 0.73 & 0.67 & 1.09 & 0.54 & 0.97 & 0.81 & 1.01 & 0.59 \\
\hline & & Plan 4 & 0.95 & 1.05 & 0.62 & 0.65 & 0.95 & 0.46 & 0.86 & 0.80 & 1.07 & 0.28 \\
\hline & & Plan 5 & 0.97 & 0.95 & 0.71 & 0.67 & 1.02 & 0.49 & 0.99 & 0.79 & 1.04 & 0.47 \\
\hline & & Plan 6 & 0.95 & 0.97 & 0.72 & 0.71 & 1.12 & 0.52 & 1.00 & 0.83 & 1.08 & 0.24 \\
\hline & & Plan 7 & 0.96 & 0.90 & 0.67 & 0.65 & 1.02 & 0.48 & 0.96 & 0.78 & 1.00 & 0.25 \\
\hline & & Plan 8 & 0.97 & 0.94 & 0.68 & 0.65 & 1.07 & 0.50 & 0.97 & 0.80 & 1.03 & 0.41 \\
\hline & \multirow[t]{9}{*}{2} & EC & 1.77 & 1.54 & 1.18 & 1.24 & 1.66 & 0.62 & 1.44 & 1.23 & 1.61 & 0.78 \\
\hline & & Plan 1 & 1.73 & 1.48 & 1.11 & 1.18 & 1.38 & 0.59 & 1.24 & 1.21 & 1.50 & 1.17 \\
\hline & & Plan 2 & 1.79 & 1.53 & 1.10 & 1.18 & 1.46 & 0.62 & 1.28 & 1.25 & 1.56 & 1.00 \\
\hline & & Plan 3 & 1.81 & 1.50 & 1.21 & 1.21 & 1.60 & 0.74 & 1.42 & 1.27 & 1.59 & 0.83 \\
\hline & & Plan 4 & 1.80 & 1.69 & 1.14 & 1.29 & 1.54 & 0.69 & 1.42 & 1.32 & 1.74 & 0.50 \\
\hline & & Plan 5 & 1.77 & 1.46 & 1.22 & 1.23 & 1.57 & 0.69 & 1.47 & 1.25 & 1.63 & 0.80 \\
\hline & & Plan 6 & 1.74 & 1.45 & 1.20 & 1.23 & 1.61 & 0.71 & 1.46 & 1.27 & 1.64 & 0.35 \\
\hline & & Plan 7 & 1.78 & 1.44 & 1.24 & 1.27 & 1.65 & 0.70 & 1.50 & 1.27 & 1.65 & 0.38 \\
\hline & & Plan 8 & 1.80 & 1.53 & 1.22 & 1.24 & 1.69 & 0.75 & 1.55 & 1.32 & 1.66 & 0.67 \\
\hline & \multirow[t]{9}{*}{2.5} & EC & 2.30 & 1.61 & 1.28 & 1.36 & 1.66 & 0.69 & 1.46 & 1.41 & 1.84 & 0.89 \\
\hline & & Plan 1 & 2.35 & 1.59 & 1.41 & 1.41 & 1.56 & 0.84 & 1.37 & 1.50 & 2.00 & 1.44 \\
\hline & & Plan 2 & 2.34 & 1.71 & 1.28 & 1.36 & 1.61 & 0.74 & 1.37 & 1.47 & 1.87 & 1.14 \\
\hline & & Plan 3 & 2.39 & 1.58 & 1.38 & 1.40 & 1.65 & 0.81 & 1.49 & 1.45 & 1.83 & 1.01 \\
\hline & & Plan 4 & 2.33 & 1.71 & 1.20 & 1.36 & 1.55 & 0.76 & 1.39 & 1.45 & 1.96 & 0.55 \\
\hline & & Plan 5 & 2.29 & 1.61 & 1.43 & 1.46 & 1.74 & 0.82 & 1.56 & 1.50 & 1.97 & 0.96 \\
\hline & & Plan 6 & 2.33 & 1.62 & 1.43 & 1.47 & 1.80 & 0.83 & 1.56 & 1.50 & 1.98 & 0.41 \\
\hline & & Plan 7 & 2.36 & 1.58 & 1.41 & 1.44 & 1.75 & 0.81 & 1.55 & 1.49 & 1.97 & 0.44 \\
\hline & & Plan 8 & 2.34 & 1.60 & 1.39 & 1.44 & 1.77 & 0.84 & 1.57 & 1.47 & 1.93 & 0.75 \\
\hline
\end{tabular}




\begin{tabular}{|c|c|c|c|c|c|c|c|c|c|c|c|c|}
\hline \multicolumn{2}{|c|}{$\begin{array}{l}\text { Experimental } \\
\text { Wave }\end{array}$} & \multicolumn{11}{|c|}{ Wave Height $(\mathrm{m})$ at Indicated Gauge Location; $\mathrm{swl}=+0.9 \mathrm{~m}$} \\
\hline $\begin{array}{l}\text { Period } \\
\text { (sec) }\end{array}$ & $\begin{array}{l}\text { Height } \\
(\mathrm{m})\end{array}$ & Plan & $\begin{array}{l}\text { Gauge } \\
11\end{array}$ & $\begin{array}{l}\text { Gauge } \\
12\end{array}$ & $\begin{array}{l}\text { Gauge } \\
13\end{array}$ & $\begin{array}{l}\text { Gauge } \\
14\end{array}$ & $\begin{array}{l}\text { Gauge } \\
15\end{array}$ & $\begin{array}{l}\text { Gauge } \\
16\end{array}$ & $\begin{array}{l}\text { Gauge } \\
17\end{array}$ & $\begin{array}{l}\text { Gauge } \\
18\end{array}$ & $\begin{array}{l}\text { Gauge } \\
19\end{array}$ & $\begin{array}{l}\text { Gauge } \\
20\end{array}$ \\
\hline \multirow[t]{27}{*}{6} & \multirow[t]{9}{*}{1} & EC & 0.27 & 0.29 & 0.34 & 0.47 & 0.40 & 0.35 & 0.42 & 0.45 & 0.30 & 0.31 \\
\hline & & Plan 1 & 0.36 & 0.60 & 0.66 & 0.83 & 0.76 & 0.55 & 0.90 & 0.85 & 0.49 & 0.59 \\
\hline & & Plan 2 & 0.33 & 0.51 & 0.68 & 0.77 & 0.74 & 0.44 & 0.81 & 0.87 & 0.41 & 0.50 \\
\hline & & Plan 3 & 0.38 & 0.40 & 0.43 & 0.63 & 0.55 & 0.44 & 0.62 & 0.58 & 0.40 & 0.56 \\
\hline & & Plan 4 & 0.34 & 0.52 & 0.69 & 0.76 & 0.57 & 0.42 & 0.63 & 0.71 & 0.40 & 0.31 \\
\hline & & Plan 5 & 0.37 & 0.32 & 0.38 & 0.29 & 0.46 & 0.23 & 0.31 & 0.37 & 0.21 & 0.38 \\
\hline & & Plan 6 & 0.32 & 0.37 & 0.34 & 0.23 & 0.37 & 0.18 & 0.29 & 0.32 & 0.20 & 0.25 \\
\hline & & Plan 7 & 0.27 & 0.26 & 0.34 & 0.43 & 0.16 & 0.26 & 0.41 & 0.37 & 0.25 & 0.22 \\
\hline & & Plan 8 & 0.30 & 0.32 & 0.35 & 0.25 & 0.47 & 0.19 & 0.22 & 0.38 & 0.19 & 0.30 \\
\hline & \multirow[t]{9}{*}{2} & EC & 0.42 & 0.44 & 0.51 & 0.69 & 0.61 & 0.53 & 0.65 & 0.67 & 0.47 & 0.49 \\
\hline & & Plan 1 & 0.64 & 0.96 & 1.00 & 1.33 & 1.30 & 0.89 & 1.34 & 1.34 & 0.77 & 0.99 \\
\hline & & Plan 2 & 0.53 & 0.80 & 1.01 & 1.15 & 1.14 & 0.65 & 1.22 & 1.26 & 0.65 & 0.81 \\
\hline & & Plan 3 & 0.54 & 0.57 & 0.63 & 0.95 & 0.78 & 0.64 & 0.89 & 0.84 & 0.57 & 0.79 \\
\hline & & Plan 4 & 0.63 & 0.87 & 1.05 & 1.14 & 0.90 & 0.66 & 0.95 & 1.10 & 0.63 & 0.50 \\
\hline & & Plan 5 & 0.54 & 0.46 & 0.54 & 0.41 & 0.66 & 0.32 & 0.53 & 0.54 & 0.30 & 0.56 \\
\hline & & Plan 6 & 0.45 & 0.51 & 0.47 & 0.32 & 0.51 & 0.26 & 0.39 & 0.44 & 0.29 & 0.35 \\
\hline & & Plan 7 & 0.40 & 0.41 & 0.50 & 0.63 & 0.29 & 0.37 & 0.59 & 0.57 & 0.35 & 0.32 \\
\hline & & Plan 8 & 0.46 & 0.50 & 0.53 & 0.38 & 0.71 & 0.30 & 0.36 & 0.60 & 0.30 & 0.48 \\
\hline & \multirow[t]{9}{*}{2.5} & EC & 0.46 & 0.49 & 0.56 & 0.77 & 0.71 & 0.59 & 0.72 & 0.72 & 0.54 & 0.54 \\
\hline & & Plan 1 & 0.88 & 1.08 & 1.23 & 1.54 & 1.62 & 0.98 & 1.49 & 1.59 & 0.93 & 1.22 \\
\hline & & Plan 2 & 0.62 & 0.91 & 1.15 & 1.30 & 1.32 & 0.77 & 1.33 & 1.44 & 0.76 & 0.91 \\
\hline & & Plan 3 & 0.64 & 0.61 & 0.68 & 1.02 & 0.92 & 0.68 & 0.95 & 0.88 & 0.66 & 0.89 \\
\hline & & Plan 4 & 0.70 & 0.94 & 1.12 & 1.23 & 0.98 & 0.71 & 1.06 & 1.16 & 0.71 & 0.55 \\
\hline & & Plan 5 & 0.62 & 0.54 & 0.63 & 0.50 & 0.76 & 0.40 & 0.65 & 0.66 & 0.37 & 0.66 \\
\hline & & Plan 6 & 0.52 & 0.59 & 0.54 & 0.38 & 0.57 & 0.30 & 0.45 & 0.49 & 0.32 & 0.40 \\
\hline & & Plan 7 & 0.49 & 0.48 & 0.58 & 0.74 & 0.38 & 0.44 & 0.69 & 0.66 & 0.42 & 0.38 \\
\hline & & Plan 8 & 0.50 & 0.54 & 0.57 & 0.41 & 0.77 & 0.36 & 0.41 & 0.64 & 0.34 & 0.54 \\
\hline
\end{tabular}




\begin{tabular}{|c|c|c|c|c|c|c|c|c|c|c|c|c|}
\hline \multicolumn{2}{|c|}{$\begin{array}{l}\text { Experimental } \\
\text { Wave }\end{array}$} & \multicolumn{11}{|c|}{ Wave Height $(\mathrm{m})$ at Indicated Gauge Location; swl $=+0.9 \mathrm{~m}$} \\
\hline $\begin{array}{l}\text { Period } \\
\text { (sec) }\end{array}$ & $\begin{array}{l}\text { Height } \\
(\mathrm{m})\end{array}$ & Plan & $\begin{array}{l}\text { Gauge } \\
1\end{array}$ & $\begin{array}{l}\text { Gauge } \\
2\end{array}$ & $\begin{array}{l}\text { Gauge } \\
3\end{array}$ & $\begin{array}{l}\text { Gauge } \\
4\end{array}$ & $\begin{array}{l}\text { Gauge } \\
5\end{array}$ & $\begin{array}{l}\text { Gauge } \\
6\end{array}$ & $\begin{array}{l}\text { Gauge } \\
7 \\
\end{array}$ & $\begin{array}{l}\text { Gauge } \\
8\end{array}$ & $\begin{array}{l}\text { Gauge } \\
9\end{array}$ & $\begin{array}{l}\text { Gauge } \\
10\end{array}$ \\
\hline \multirow[t]{27}{*}{7} & \multirow[t]{9}{*}{1} & EC & 0.90 & 0.94 & 0.70 & 0.62 & 0.90 & 0.39 & 0.71 & 0.79 & 1.07 & 0.51 \\
\hline & & Plan 1 & 0.88 & 0.93 & 0.68 & 0.63 & 0.79 & 0.38 & 0.63 & 0.80 & 1.02 & 0.74 \\
\hline & & Plan 2 & 0.90 & 1.01 & 0.71 & 0.64 & 0.87 & 0.39 & 0.69 & 0.85 & 1.09 & 0.61 \\
\hline & & Plan 3 & 0.93 & 0.93 & 0.77 & 0.64 & 0.92 & 0.48 & 0.74 & 0.82 & 1.09 & 0.60 \\
\hline & & Plan 4 & 0.95 & 1.05 & 0.70 & 0.66 & 0.87 & 0.41 & 0.72 & 0.88 & 1.19 & 0.30 \\
\hline & & Plan 5 & 0.93 & 0.96 & 0.81 & 0.68 & 0.91 & 0.45 & 0.79 & 0.84 & 1.17 & 0.57 \\
\hline & & Plan 6 & 0.93 & 0.97 & 0.83 & 0.71 & 0.97 & 0.47 & 0.79 & 0.87 & 1.19 & 0.25 \\
\hline & & Plan 7 & 0.94 & 0.90 & 0.75 & 0.65 & 0.88 & 0.43 & 0.73 & 0.82 & 1.10 & 0.25 \\
\hline & & Plan 8 & 0.95 & 1.00 & 0.81 & 0.70 & 0.97 & 0.47 & 0.79 & 0.86 & 1.17 & 0.44 \\
\hline & \multirow[t]{9}{*}{2} & EC & 1.76 & 1.71 & 1.43 & 1.29 & 1.48 & 0.65 & 1.22 & 1.47 & 1.89 & 0.83 \\
\hline & & Plan 1 & 1.78 & 1.64 & 1.58 & 1.29 & 1.39 & 0.75 & 1.20 & 1.54 & 2.03 & 1.55 \\
\hline & & Plan 2 & 1.77 & 1.74 & 1.39 & 1.25 & 1.41 & 0.66 & 1.19 & 1.51 & 1.88 & 1.08 \\
\hline & & Plan 3 & 1.80 & 1.67 & 1.53 & 1.31 & 1.47 & 0.75 & 1.25 & 1.51 & 1.91 & 1.05 \\
\hline & & Plan 4 & 1.84 & 1.82 & 1.39 & 1.33 & 1.45 & 0.71 & 1.24 & 1.56 & 2.04 & 0.58 \\
\hline & & Plan 5 & 1.80 & 1.66 & 1.57 & 1.36 & 1.48 & 0.73 & 1.29 & 1.50 & 1.95 & 0.97 \\
\hline & & Plan 6 & 1.80 & 1.70 & 1.63 & 1.43 & 1.58 & 0.77 & 1.33 & 1.56 & 2.02 & 0.41 \\
\hline & & Plan 7 & 1.81 & 1.63 & 1.55 & 1.36 & 1.53 & 0.76 & 1.29 & 1.53 & 1.97 & 0.42 \\
\hline & & Plan 8 & 1.84 & 1.69 & 1.55 & 1.38 & 1.57 & 0.78 & 1.31 & 1.56 & 1.99 & 0.74 \\
\hline & \multirow[t]{9}{*}{2.5} & EC & 2.34 & 1.69 & 1.44 & 1.34 & 1.43 & 0.74 & 1.22 & 1.54 & 1.97 & 0.83 \\
\hline & & Plan 1 & 2.40 & 1.59 & 1.55 & 1.35 & 1.31 & 0.82 & 1.19 & 1.60 & 2.09 & 1.61 \\
\hline & & Plan 2 & 2.35 & 1.70 & 1.35 & 1.26 & 1.34 & 0.73 & 1.17 & 1.59 & 1.96 & 1.11 \\
\hline & & Plan 3 & 2.41 & 1.70 & 1.58 & 1.37 & 1.40 & 0.83 & 1.28 & 1.62 & 2.01 & 1.14 \\
\hline & & Plan 4 & 2.42 & 1.77 & 1.37 & 1.34 & 1.39 & 0.78 & 1.22 & 1.60 & 2.10 & 0.59 \\
\hline & & Plan 5 & 2.35 & 1.61 & 1.50 & 1.32 & 1.38 & 0.82 & 1.26 & 1.58 & 2.02 & 1.06 \\
\hline & & Plan 6 & 2.37 & 1.64 & 1.55 & 1.38 & 1.48 & 0.88 & 1.28 & 1.61 & 2.08 & 0.42 \\
\hline & & Plan 7 & 2.38 & 1.67 & 1.53 & 1.37 & 1.48 & 0.86 & 1.28 & 1.61 & 2.05 & 0.43 \\
\hline & & Plan 8 & 2.40 & 1.65 & 1.53 & 1.38 & 1.53 & 0.88 & 1.29 & 1.61 & 2.05 & 0.76 \\
\hline
\end{tabular}




\begin{tabular}{|c|c|c|c|c|c|c|c|c|c|c|c|c|}
\hline \multicolumn{2}{|c|}{$\begin{array}{l}\text { Experimental } \\
\text { Wave }\end{array}$} & \multicolumn{11}{|c|}{ Wave Height $(\mathrm{m})$ at Indicated Gauge Location; swl $=+0.9 \mathrm{~m}$} \\
\hline $\begin{array}{l}\text { Period } \\
\text { (sec) }\end{array}$ & $\begin{array}{l}\text { Height } \\
(\mathrm{m})\end{array}$ & Plan & $\begin{array}{l}\text { Gauge } \\
11\end{array}$ & $\begin{array}{l}\text { Gauge } \\
12\end{array}$ & $\begin{array}{l}\text { Gauge } \\
13\end{array}$ & $\begin{array}{l}\text { Gauge } \\
14\end{array}$ & $\begin{array}{l}\text { Gauge } \\
15\end{array}$ & $\begin{array}{l}\text { Gauge } \\
16\end{array}$ & $\begin{array}{l}\text { Gauge } \\
17\end{array}$ & $\begin{array}{l}\text { Gauge } \\
18\end{array}$ & $\begin{array}{l}\text { Gauge } \\
19\end{array}$ & $\begin{array}{l}\text { Gauge } \\
20\end{array}$ \\
\hline \multirow[t]{27}{*}{7} & \multirow[t]{9}{*}{1} & EC & 0.29 & 0.29 & 0.34 & 0.48 & 0.41 & 0.33 & 0.43 & 0.41 & 0.31 & 0.34 \\
\hline & & Plan 1 & 0.50 & 0.56 & 0.62 & 0.78 & 0.83 & 0.50 & 0.80 & 0.75 & 0.47 & 0.67 \\
\hline & & Plan 2 & 0.38 & 0.48 & 0.66 & 0.80 & 0.80 & 0.43 & 0.68 & 0.77 & 0.42 & 0.55 \\
\hline & & Plan 3 & 0.44 & 0.40 & 0.38 & 0.57 & 0.52 & 0.39 & 0.61 & 0.50 & 0.38 & 0.57 \\
\hline & & Plan 4 & 0.40 & 0.57 & 0.68 & 0.74 & 0.53 & 0.40 & 0.66 & 0.68 & 0.40 & 0.33 \\
\hline & & Plan 5 & 0.41 & 0.28 & 0.35 & 0.28 & 0.46 & 0.24 & 0.33 & 0.32 & 0.23 & 0.42 \\
\hline & & Plan 6 & 0.31 & 0.36 & 0.33 & 0.22 & 0.33 & 0.17 & 0.26 & 0.28 & 0.19 & 0.24 \\
\hline & & Plan 7 & 0.27 & 0.27 & 0.34 & 0.42 & 0.17 & 0.24 & 0.40 & 0.37 & 0.24 & 0.21 \\
\hline & & Plan 8 & 0.32 & 0.32 & 0.33 & 0.24 & 0.46 & 0.20 & 0.22 & 0.34 & 0.20 & 0.35 \\
\hline & \multirow[t]{9}{*}{2} & EC & 0.45 & 0.45 & 0.50 & 0.70 & 0.66 & 0.52 & 0.61 & 0.63 & 0.46 & 0.55 \\
\hline & & Plan 1 & 1.09 & 0.97 & 1.10 & 1.36 & 1.66 & 0.90 & 1.31 & 1.39 & 0.83 & 1.39 \\
\hline & & Plan 2 & 0.64 & 0.83 & 1.09 & 1.26 & 1.38 & 0.72 & 1.11 & 1.27 & 0.70 & 1.01 \\
\hline & & Plan 3 & 0.73 & 0.64 & 0.64 & 0.95 & 0.84 & 0.66 & 1.00 & 0.89 & 0.60 & 0.89 \\
\hline & & Plan 4 & 0.72 & 0.96 & 1.11 & 1.19 & 0.92 & 0.66 & 1.05 & 1.11 & 0.65 & 0.57 \\
\hline & & Plan 5 & 0.67 & 0.52 & 0.53 & 0.43 & 0.71 & 0.41 & 0.61 & 0.55 & 0.38 & 0.68 \\
\hline & & Plan 6 & 0.49 & 0.54 & 0.49 & 0.36 & 0.50 & 0.26 & 0.39 & 0.41 & 0.30 & 0.35 \\
\hline & & Plan 7 & 0.42 & 0.44 & 0.55 & 0.70 & 0.35 & 0.38 & 0.63 & 0.61 & 0.37 & 0.36 \\
\hline & & Plan 8 & 0.49 & 0.49 & 0.52 & 0.39 & 0.70 & 0.34 & 0.37 & 0.55 & 0.33 & 0.56 \\
\hline & \multirow[t]{9}{*}{2.5} & EC & 0.46 & 0.47 & 0.51 & 0.71 & 0.67 & 0.53 & 0.63 & 0.64 & 0.49 & 0.58 \\
\hline & & Plan 1 & 1.17 & 0.99 & 1.08 & 1.33 & 1.65 & 0.93 & 1.29 & 1.38 & 0.86 & 1.41 \\
\hline & & Plan 2 & 0.70 & 0.81 & 1.09 & 1.29 & 1.40 & 0.73 & 1.08 & 1.26 & 0.72 & 1.03 \\
\hline & & Plan 3 & 0.84 & 0.71 & 0.69 & 0.97 & 0.93 & 0.71 & 1.06 & 0.93 & 0.67 & 0.97 \\
\hline & & Plan 4 & 0.72 & 0.96 & 1.09 & 1.17 & 0.91 & 0.66 & 1.07 & 1.09 & 0.66 & 0.61 \\
\hline & & Plan 5 & 0.74 & 0.57 & 0.56 & 0.46 & 0.78 & 0.46 & 0.63 & 0.61 & 0.44 & 0.74 \\
\hline & & Plan 6 & 0.50 & 0.57 & 0.51 & 0.38 & 0.51 & 0.29 & 0.42 & 0.43 & 0.32 & 0.39 \\
\hline & & Plan 7 & 0.46 & 0.47 & 0.57 & 0.71 & 0.39 & 0.39 & 0.66 & 0.63 & 0.38 & 0.40 \\
\hline & & Plan 8 & 0.50 & 0.49 & 0.51 & 0.38 & 0.69 & 0.37 & 0.39 & 0.55 & 0.34 & 0.56 \\
\hline
\end{tabular}




\begin{tabular}{|c|c|c|c|c|c|c|c|c|c|c|c|c|}
\hline \multicolumn{2}{|c|}{$\begin{array}{l}\text { Experimental } \\
\text { Wave }\end{array}$} & \multicolumn{11}{|c|}{ Wave Height $(\mathrm{m})$ at Indicated Gauge Location; $\mathrm{swl}=+0.9 \mathrm{~m}$} \\
\hline $\begin{array}{l}\text { Period } \\
\text { (sec) }\end{array}$ & $\begin{array}{l}\text { Height } \\
(\mathrm{m})\end{array}$ & Plan & $\begin{array}{l}\text { Gauge } \\
1\end{array}$ & $\begin{array}{l}\text { Gauge } \\
2\end{array}$ & $\begin{array}{l}\text { Gauge } \\
3\end{array}$ & $\begin{array}{l}\text { Gauge } \\
4\end{array}$ & $\begin{array}{l}\text { Gauge } \\
5\end{array}$ & $\begin{array}{l}\text { Gauge } \\
6\end{array}$ & $\begin{array}{l}\text { Gauge } \\
7\end{array}$ & $\begin{array}{l}\text { Gauge } \\
8\end{array}$ & $\begin{array}{l}\text { Gauge } \\
9\end{array}$ & $\begin{array}{l}\text { Gauge } \\
10\end{array}$ \\
\hline \multirow[t]{27}{*}{8} & \multirow[t]{9}{*}{1} & EC & 0.93 & 1.11 & 0.80 & 0.67 & 0.91 & 0.45 & 0.75 & 1.03 & 1.25 & 0.48 \\
\hline & & Plan 1 & 0.91 & 1.11 & 0.78 & 0.66 & 0.82 & 0.43 & 0.69 & 0.99 & 1.18 & 1.00 \\
\hline & & Plan 2 & 0.93 & 1.17 & 0.80 & 0.67 & 0.89 & 0.45 & 0.72 & 1.05 & 1.26 & 0.66 \\
\hline & & Plan 3 & 0.96 & 1.11 & 0.88 & 0.67 & 0.89 & 0.50 & 0.77 & 1.05 & 1.24 & 0.73 \\
\hline & & Plan 4 & 0.98 & 1.24 & 0.81 & 0.71 & 0.91 & 0.50 & 0.76 & 1.10 & 1.37 & 0.34 \\
\hline & & Plan 5 & 0.95 & 1.10 & 0.90 & 0.69 & 0.88 & 0.49 & 0.77 & 1.04 & 1.28 & 0.62 \\
\hline & & Plan 6 & 0.95 & 1.10 & 0.91 & 0.72 & 0.94 & 0.54 & 0.78 & 1.08 & 1.33 & 0.24 \\
\hline & & Plan 7 & 0.96 & 1.11 & 0.92 & 0.73 & 0.95 & 0.54 & 0.81 & 1.10 & 1.34 & 0.26 \\
\hline & & Plan 8 & 0.98 & 1.11 & 0.89 & 0.71 & 0.96 & 0.53 & 0.78 & 1.08 & 1.32 & 0.44 \\
\hline & \multirow[t]{9}{*}{2} & EC & 1.89 & 1.80 & 1.41 & 1.29 & 1.58 & 0.86 & 1.19 & 1.64 & 2.03 & 0.74 \\
\hline & & Plan 1 & 1.94 & 1.71 & 1.51 & 1.25 & 1.40 & 0.90 & 1.15 & 1.65 & 2.09 & 1.72 \\
\hline & & Plan 2 & 1.93 & 1.82 & 1.35 & 1.23 & 1.51 & 0.86 & 1.12 & 1.63 & 2.00 & 1.13 \\
\hline & & Plan 3 & 1.96 & 1.81 & 1.54 & 1.29 & 1.47 & 0.91 & 1.22 & 1.70 & 2.02 & 1.20 \\
\hline & & Plan 4 & 1.97 & 1.93 & 1.39 & 1.32 & 1.60 & 0.95 & 1.19 & 1.72 & 2.18 & 0.60 \\
\hline & & Plan 5 & 1.94 & 1.78 & 1.57 & 1.34 & 1.53 & 0.95 & 1.24 & 1.68 & 2.10 & 1.07 \\
\hline & & Plan 6 & 1.94 & 1.74 & 1.54 & 1.33 & 1.65 & 1.04 & 1.22 & 1.71 & 2.14 & 0.39 \\
\hline & & Plan 7 & 1.95 & 1.72 & 1.56 & 1.36 & 1.65 & 1.04 & 1.22 & 1.71 & 2.15 & 0.40 \\
\hline & & Plan 8 & 1.99 & 1.84 & 1.59 & 1.39 & 1.72 & 1.08 & 1.28 & 1.80 & 2.21 & 0.74 \\
\hline & \multirow[t]{9}{*}{2.5} & EC & 2.36 & 1.87 & 1.40 & 1.29 & 1.63 & 0.93 & 1.22 & 1.71 & 2.12 & 0.79 \\
\hline & & Plan 1 & 2.40 & 1.78 & 1.53 & 1.32 & 1.47 & 1.01 & 1.21 & 1.76 & 2.24 & 1.86 \\
\hline & & Plan 2 & 2.37 & 1.88 & 1.33 & 1.25 & 1.57 & 0.92 & 1.14 & 1.68 & 2.06 & 1.22 \\
\hline & & Plan 3 & 2.42 & 1.87 & 1.52 & 1.31 & 1.46 & 0.96 & 1.28 & 1.78 & 2.12 & 1.31 \\
\hline & & Plan 4 & 2.42 & 1.95 & 1.34 & 1.28 & 1.63 & 1.02 & 1.18 & 1.73 & 2.20 & 0.63 \\
\hline & & Plan 5 & 2.38 & 1.81 & 1.54 & 1.32 & 1.55 & 1.02 & 1.25 & 1.76 & 2.18 & 1.15 \\
\hline & & Plan 6 & 2.39 & 1.80 & 1.54 & 1.34 & 1.68 & 1.11 & 1.24 & 1.79 & 2.22 & 0.43 \\
\hline & & Plan 7 & 2.42 & 1.80 & 1.50 & 1.32 & 1.66 & 1.10 & 1.23 & 1.75 & 2.17 & 0.42 \\
\hline & & Plan 8 & 2.42 & 1.80 & 1.49 & 1.32 & 1.70 & 1.13 & 1.23 & 1.76 & 2.18 & 0.73 \\
\hline
\end{tabular}




\begin{tabular}{|c|c|c|c|c|c|c|c|c|c|c|c|c|}
\hline \multicolumn{2}{|c|}{$\begin{array}{l}\text { Experimental } \\
\text { Wave }\end{array}$} & \multicolumn{11}{|c|}{ Wave Height $(\mathrm{m})$ at Indicated Gauge Location; $\mathrm{swl}=+0.9 \mathrm{~m}$} \\
\hline $\begin{array}{l}\text { Period } \\
\text { (sec) }\end{array}$ & $\begin{array}{l}\text { Height } \\
(\mathrm{m})\end{array}$ & Plan & $\begin{array}{l}\text { Gauge } \\
11\end{array}$ & $\begin{array}{l}\text { Gauge } \\
12\end{array}$ & $\begin{array}{l}\text { Gauge } \\
13\end{array}$ & $\begin{array}{l}\text { Gauge } \\
14\end{array}$ & $\begin{array}{l}\text { Gauge } \\
15\end{array}$ & $\begin{array}{l}\text { Gauge } \\
16\end{array}$ & $\begin{array}{l}\text { Gauge } \\
17\end{array}$ & $\begin{array}{l}\text { Gauge } \\
18\end{array}$ & $\begin{array}{l}\text { Gauge } \\
19\end{array}$ & $\begin{array}{l}\text { Gauge } \\
20\end{array}$ \\
\hline \multirow[t]{27}{*}{8} & \multirow[t]{9}{*}{1} & EC & 0.28 & 0.28 & 0.32 & 0.43 & 0.40 & 0.32 & 0.38 & 0.39 & 0.29 & 0.33 \\
\hline & & Plan 1 & 0.72 & 0.62 & 0.63 & 0.77 & 0.98 & 0.56 & 0.86 & 0.80 & 0.52 & 0.86 \\
\hline & & Plan 2 & 0.44 & 0.52 & 0.72 & 0.85 & 0.93 & 0.45 & 0.69 & 0.77 & 0.45 & 0.72 \\
\hline & & Plan 3 & 0.56 & 0.45 & 0.44 & 0.58 & 0.52 & 0.46 & 0.72 & 0.61 & 0.43 & 0.59 \\
\hline & & Plan 4 & 0.43 & 0.62 & 0.75 & 0.80 & 0.56 & 0.44 & 0.72 & 0.74 & 0.43 & 0.38 \\
\hline & & Plan 5 & 0.47 & 0.35 & 0.34 & 0.25 & 0.48 & 0.26 & 0.35 & 0.36 & 0.25 & 0.45 \\
\hline & & Plan 6 & 0.30 & 0.34 & 0.30 & 0.21 & 0.30 & 0.16 & 0.24 & 0.24 & 0.17 & 0.23 \\
\hline & & Plan 7 & 0.28 & 0.28 & 0.37 & 0.46 & 0.21 & 0.25 & 0.42 & 0.39 & 0.25 & 0.23 \\
\hline & & Plan 8 & 0.30 & 0.29 & 0.30 & 0.21 & 0.43 & 0.19 & 0.22 & 0.34 & 0.19 & 0.34 \\
\hline & \multirow[t]{9}{*}{2} & EC & 0.44 & 0.43 & 0.47 & 0.63 & 0.61 & 0.48 & 0.59 & 0.58 & 0.43 & 0.53 \\
\hline & & Plan 1 & 1.31 & 1.00 & 1.00 & 1.21 & 1.62 & 0.92 & 1.40 & 1.37 & 0.88 & 1.48 \\
\hline & & Plan 2 & 0.71 & 0.75 & 0.99 & 1.19 & 1.37 & 0.68 & 1.03 & 1.11 & 0.66 & 1.07 \\
\hline & & Plan 3 & 0.92 & 0.75 & 0.77 & 0.98 & 0.86 & 0.76 & 1.17 & 1.02 & 0.72 & 0.97 \\
\hline & & Plan 4 & 0.66 & 0.88 & 1.03 & 1.12 & 0.83 & 0.61 & 1.02 & 1.00 & 0.60 & 0.63 \\
\hline & & Plan 5 & 0.81 & 0.64 & 0.55 & 0.46 & 0.81 & 0.47 & 0.69 & 0.65 & 0.46 & 0.74 \\
\hline & & Plan 6 & 0.45 & 0.48 & 0.44 & 0.35 & 0.44 & 0.25 & 0.36 & 0.37 & 0.27 & 0.34 \\
\hline & & Plan 7 & 0.41 & 0.42 & 0.52 & 0.65 & 0.39 & 0.35 & 0.59 & 0.56 & 0.34 & 0.38 \\
\hline & & Plan 8 & 0.49 & 0.47 & 0.48 & 0.36 & 0.66 & 0.33 & 0.40 & 0.54 & 0.33 & 0.53 \\
\hline & \multirow[t]{9}{*}{2.5} & EC & 0.48 & 0.49 & 0.49 & 0.66 & 0.65 & 0.52 & 0.64 & 0.61 & 0.47 & 0.57 \\
\hline & & Plan 1 & 1.43 & 1.09 & 1.07 & 1.28 & 1.70 & 1.00 & 1.47 & 1.42 & 0.96 & 1.52 \\
\hline & & Plan 2 & 0.74 & 0.80 & 1.00 & 1.20 & 1.40 & 0.72 & 1.04 & 1.15 & 0.68 & 1.09 \\
\hline & & Plan 3 & 1.01 & 0.82 & 0.83 & 1.03 & 0.93 & 0.83 & 1.26 & 1.11 & 0.77 & 1.02 \\
\hline & & Plan 4 & 0.69 & 0.91 & 1.05 & 1.15 & 0.87 & 0.62 & 1.04 & 1.00 & 0.61 & 0.68 \\
\hline & & Plan 5 & 0.87 & 0.68 & 0.58 & 0.50 & 0.88 & 0.51 & 0.74 & 0.73 & 0.48 & 0.80 \\
\hline & & Plan 6 & 0.49 & 0.53 & 0.48 & 0.38 & 0.48 & 0.30 & 0.39 & 0.41 & 0.31 & 0.37 \\
\hline & & Plan 7 & 0.45 & 0.48 & 0.55 & 0.68 & 0.42 & 0.37 & 0.62 & 0.57 & 0.36 & 0.42 \\
\hline & & Plan 8 & 0.51 & 0.49 & 0.47 & 0.37 & 0.65 & 0.34 & 0.42 & 0.54 & 0.33 & 0.52 \\
\hline
\end{tabular}


Table D2. Wave heights for waves from 45 degrees North; $+0.9 \mathrm{~m}$ swl.

\begin{tabular}{|c|c|c|c|c|c|c|c|c|c|c|c|c|}
\hline \multicolumn{2}{|c|}{$\begin{array}{l}\text { Experimental } \\
\text { Wave }\end{array}$} & \multicolumn{11}{|c|}{ Wave Height $(\mathrm{m})$ at Indicated Gauge Location; swl = +0.9 m } \\
\hline $\begin{array}{l}\text { Period } \\
\text { (sec) }\end{array}$ & $\begin{array}{l}\text { Height } \\
(\mathrm{m})\end{array}$ & Plan & $\begin{array}{l}\text { Gauge } \\
1\end{array}$ & $\begin{array}{l}\text { Gauge } \\
2\end{array}$ & $\begin{array}{l}\text { Gauge } \\
3\end{array}$ & $\begin{array}{l}\text { Gauge } \\
4\end{array}$ & $\begin{array}{l}\text { Gauge } \\
5\end{array}$ & $\begin{array}{l}\text { Gauge } \\
6\end{array}$ & \begin{tabular}{|l} 
Gauge \\
7
\end{tabular} & $\begin{array}{l}\text { Gauge } \\
8\end{array}$ & $\begin{array}{l}\text { Gauge } \\
9\end{array}$ & $\begin{array}{l}\text { Gauge } \\
10\end{array}$ \\
\hline \multirow[t]{27}{*}{5} & \multirow[t]{9}{*}{1} & EC & 0.91 & 0.89 & 0.83 & 0.85 & 1.06 & 0.85 & 0.68 & 0.49 & 1.04 & 0.47 \\
\hline & & Plan 1 & 0.87 & 0.75 & 0.88 & 0.80 & 1.05 & 0.83 & 0.60 & 0.43 & 0.98 & 1.18 \\
\hline & & Plan 2 & 0.90 & 0.83 & 0.97 & 0.89 & 1.10 & 0.94 & 0.73 & 0.48 & 1.04 & 0.86 \\
\hline & & Plan 3 & 0.88 & 0.76 & 0.90 & 0.82 & 1.04 & 0.89 & 0.69 & 0.46 & 0.95 & 0.81 \\
\hline & & Plan 4 & 0.99 & 0.87 & 0.84 & 0.88 & 1.04 & 0.78 & 0.72 & 0.54 & 1.19 & 0.56 \\
\hline & & Plan 5 & 0.97 & 0.92 & 0.89 & 0.93 & 1.16 & 0.86 & 0.75 & 0.57 & 1.23 & 1.02 \\
\hline & & Plan 6 & 0.95 & 0.92 & 0.88 & 0.89 & 1.09 & 0.83 & 0.76 & 0.56 & 1.24 & 0.30 \\
\hline & & Plan 7 & 0.95 & 0.91 & 0.91 & 0.93 & 1.13 & 0.89 & 0.76 & 0.56 & 1.22 & 0.33 \\
\hline & & Plan 8 & 0.93 & 1.00 & 0.97 & 0.98 & 1.19 & 0.93 & 0.83 & 0.62 & 1.27 & 0.56 \\
\hline & \multirow[t]{9}{*}{2} & EC & 1.74 & 1.34 & 1.30 & 1.37 & 1.67 & 1.28 & 1.04 & 0.75 & 1.55 & 0.82 \\
\hline & & Plan 1 & 1.77 & 1.24 & 1.45 & 1.39 & 1.77 & 1.39 & 0.96 & 0.76 & 1.45 & 1.97 \\
\hline & & Plan 2 & 1.76 & 1.23 & 1.47 & 1.40 & 1.71 & 1.43 & 1.04 & 0.74 & 1.49 & 1.37 \\
\hline & & Plan 3 & 1.79 & 1.14 & 1.42 & 1.33 & 1.62 & 1.38 & 1.04 & 0.70 & 1.41 & 1.39 \\
\hline & & Plan 4 & 1.91 & 1.23 & 1.25 & 1.36 & 1.61 & 1.14 & 0.97 & 0.84 & 1.73 & 0.83 \\
\hline & & Plan 5 & 1.85 & 1.31 & 1.33 & 1.45 & 1.74 & 1.21 & 1.00 & 0.91 & 1.86 & 1.47 \\
\hline & & Plan 6 & 1.85 & 1.30 & 1.33 & 1.47 & 1.71 & 1.19 & 1.01 & 0.93 & 1.90 & 0.49 \\
\hline & & Plan 7 & 1.80 & 1.25 & 1.29 & 1.39 & 1.59 & 1.16 & 0.98 & 0.90 & 1.83 & 0.45 \\
\hline & & Plan 8 & 1.84 & 1.28 & 1.30 & 1.42 & 1.64 & 1.17 & 1.02 & 0.91 & 1.80 & 0.82 \\
\hline & \multirow[t]{9}{*}{2.5} & EC & 2.24 & 1.43 & 1.68 & 1.59 & 1.97 & 1.63 & 1.19 & 0.91 & 1.69 & 1.02 \\
\hline & & Plan 1 & 2.26 & 1.38 & 1.63 & 1.55 & 1.97 & 1.55 & 1.11 & 0.82 & 1.51 & 2.06 \\
\hline & & Plan 2 & 2.19 & 1.48 & 1.82 & 1.69 & 2.04 & 1.78 & 1.31 & 0.91 & 1.51 & 1.61 \\
\hline & & Plan 3 & 2.24 & 1.34 & 1.72 & 1.59 & 1.95 & 1.66 & 1.22 & 0.85 & 1.50 & 1.64 \\
\hline & & Plan 4 & 2.37 & 1.43 & 1.43 & 1.55 & 1.94 & 1.37 & 1.12 & 0.95 & 1.78 & 0.96 \\
\hline & & Plan 5 & 2.40 & 1.50 & 1.50 & 1.58 & 2.03 & 1.42 & 1.10 & 0.92 & 1.79 & 1.71 \\
\hline & & Plan 6 & 2.45 & 1.48 & 1.49 & 1.63 & 2.05 & 1.39 & 1.15 & 1.01 & 1.91 & 0.60 \\
\hline & & Plan 7 & 2.34 & 1.40 & 1.48 & 1.59 & 2.02 & 1.43 & 1.11 & 0.96 & 1.75 & 0.60 \\
\hline & & Plan 8 & 2.39 & 1.47 & 1.52 & 1.67 & 2.09 & 1.44 & 1.16 & 1.01 & 1.79 & 1.03 \\
\hline
\end{tabular}




\begin{tabular}{|c|c|c|c|c|c|c|c|c|c|c|c|c|}
\hline \multicolumn{2}{|c|}{$\begin{array}{l}\text { Experimental } \\
\text { Wave }\end{array}$} & \multicolumn{11}{|c|}{ Wave Height $(\mathrm{m})$ at Indicated Gauge Location; swl $=+0.9 \mathrm{~m}$} \\
\hline $\begin{array}{l}\text { Period } \\
\text { (sec) }\end{array}$ & $\begin{array}{l}\text { Height } \\
(\mathrm{m})\end{array}$ & Plan & $\begin{array}{l}\text { Gauge } \\
11\end{array}$ & $\begin{array}{l}\text { Gauge } \\
12\end{array}$ & $\begin{array}{l}\text { Gauge } \\
13\end{array}$ & $\begin{array}{l}\text { Gauge } \\
14\end{array}$ & $\begin{array}{l}\text { Gauge } \\
15\end{array}$ & $\begin{array}{l}\text { Gauge } \\
16\end{array}$ & $\begin{array}{l}\text { Gauge } \\
17\end{array}$ & $\begin{array}{l}\text { Gauge } \\
18\end{array}$ & $\begin{array}{l}\text { Gauge } \\
19\end{array}$ & $\begin{array}{l}\text { Gauge } \\
20\end{array}$ \\
\hline \multirow[t]{27}{*}{5} & \multirow[t]{9}{*}{1} & EC & 0.32 & 0.17 & 0.22 & 0.48 & 0.38 & 0.37 & 0.34 & 0.28 & 0.31 & 0.45 \\
\hline & & Plan 1 & 0.72 & 0.54 & 0.39 & 0.65 & 0.88 & 0.55 & 0.96 & 0.63 & 0.48 & 1.07 \\
\hline & & Plan 2 & 0.50 & 0.42 & 0.30 & 0.60 & 0.77 & 0.55 & 0.47 & 0.62 & 0.44 & 0.66 \\
\hline & & Plan 3 & 0.72 & 0.56 & 0.32 & 0.55 & 0.75 & 0.48 & 0.73 & 0.39 & 0.46 & 0.90 \\
\hline & & Plan 4 & 0.55 & 0.31 & 0.34 & 0.51 & 0.48 & 0.20 & 0.39 & 0.32 & 0.21 & 0.46 \\
\hline & & Plan 5 & 0.77 & 0.60 & 0.45 & 0.36 & 0.61 & 0.55 & 0.66 & 0.38 & 0.48 & 0.82 \\
\hline & & Plan 6 & 0.29 & 0.29 & 0.30 & 0.22 & 0.24 & 0.17 & 0.33 & 0.22 & 0.18 & 0.26 \\
\hline & & Plan 7 & 0.36 & 0.29 & 0.28 & 0.44 & 0.22 & 0.19 & 0.54 & 0.26 & 0.19 & 0.41 \\
\hline & & Plan 8 & 0.37 & 0.27 & 0.30 & 0.22 & 0.36 & 0.33 & 0.29 & 0.26 & 0.28 & 0.41 \\
\hline & \multirow[t]{9}{*}{2} & EC & 0.64 & 0.49 & 0.40 & 0.80 & 0.74 & 0.66 & 0.54 & 0.54 & 0.57 & 0.74 \\
\hline & & Plan 1 & 1.52 & 0.90 & 0.57 & 0.84 & 1.44 & 0.89 & 1.38 & 1.00 & 0.80 & 1.60 \\
\hline & & Plan 2 & 0.78 & 0.73 & 0.45 & 0.97 & 1.22 & 0.88 & 0.68 & 0.97 & 0.74 & 0.98 \\
\hline & & Plan 3 & 1.21 & 0.89 & 0.49 & 0.77 & 1.24 & 0.72 & 1.14 & 0.60 & 0.71 & 1.43 \\
\hline & & Plan 4 & 0.85 & 0.53 & 0.51 & 0.78 & 0.74 & 0.33 & 0.62 & 0.49 & 0.32 & 0.70 \\
\hline & & Plan 5 & 1.10 & 0.83 & 0.66 & 0.52 & 0.85 & 0.78 & 0.96 & 0.50 & 0.68 & 1.15 \\
\hline & & Plan 6 & 0.48 & 0.43 & 0.44 & 0.34 & 0.36 & 0.27 & 0.51 & 0.32 & 0.28 & 0.40 \\
\hline & & Plan 7 & 0.48 & 0.38 & 0.35 & 0.58 & 0.34 & 0.25 & 0.69 & 0.33 & 0.25 & 0.55 \\
\hline & & Plan 8 & 0.53 & 0.37 & 0.39 & 0.34 & 0.52 & 0.45 & 0.38 & 0.36 & 0.38 & 0.56 \\
\hline & \multirow[t]{9}{*}{2.5} & EC & 0.71 & 0.65 & 0.56 & 0.98 & 0.90 & 0.81 & 0.69 & 0.72 & 0.71 & 0.93 \\
\hline & & Plan 1 & 1.70 & 1.05 & 0.70 & 0.97 & 1.50 & 1.06 & 1.51 & 1.14 & 0.94 & 1.68 \\
\hline & & Plan 2 & 0.99 & 0.90 & 0.69 & 1.24 & 1.41 & 1.09 & 0.95 & 1.19 & 0.93 & 1.19 \\
\hline & & Plan 3 & 1.34 & 1.05 & 0.65 & 0.89 & 1.43 & 0.95 & 1.27 & 0.77 & 0.91 & 1.57 \\
\hline & & Plan 4 & 1.01 & 0.68 & 0.57 & 0.86 & 0.86 & 0.38 & 0.84 & 0.55 & 0.41 & 0.81 \\
\hline & & Plan 5 & 1.32 & 0.97 & 0.71 & 0.53 & 1.06 & 0.92 & 1.06 & 0.65 & 0.79 & 1.34 \\
\hline & & Plan 6 & 0.62 & 0.60 & 0.56 & 0.41 & 0.49 & 0.39 & 0.63 & 0.44 & 0.38 & 0.50 \\
\hline & & Plan 7 & 0.68 & 0.58 & 0.51 & 0.76 & 0.46 & 0.36 & 0.94 & 0.48 & 0.40 & 0.70 \\
\hline & & Plan 8 & 0.69 & 0.55 & 0.55 & 0.46 & 0.75 & 0.55 & 0.45 & 0.55 & 0.46 & 0.71 \\
\hline
\end{tabular}




\begin{tabular}{|c|c|c|c|c|c|c|c|c|c|c|c|c|}
\hline \multicolumn{2}{|c|}{$\begin{array}{l}\text { Experimental } \\
\text { Wave }\end{array}$} & \multicolumn{11}{|c|}{ Wave Height $(\mathrm{m})$ at Indicated Gauge Location; swl $=+0.9 \mathrm{~m}$} \\
\hline $\begin{array}{l}\text { Period } \\
\text { (sec) }\end{array}$ & $\begin{array}{l}\text { Height } \\
(\mathrm{m})\end{array}$ & Plan & $\begin{array}{l}\text { Gauge } \\
1\end{array}$ & $\begin{array}{l}\text { Gauge } \\
2\end{array}$ & $\begin{array}{l}\text { Gauge } \\
3\end{array}$ & $\begin{array}{l}\text { Gauge } \\
4\end{array}$ & $\begin{array}{l}\text { Gauge } \\
5\end{array}$ & $\begin{array}{l}\text { Gauge } \\
6\end{array}$ & $\begin{array}{l}\text { Gauge } \\
7\end{array}$ & $\begin{array}{l}\text { Gauge } \\
8\end{array}$ & $\begin{array}{l}\text { Gauge } \\
9\end{array}$ & $\begin{array}{l}\text { Gauge } \\
10\end{array}$ \\
\hline \multirow[t]{27}{*}{6} & \multirow[t]{9}{*}{1} & EC & 0.92 & 0.92 & 1.03 & 0.95 & 1.52 & 1.01 & 0.78 & 0.43 & 0.84 & 0.56 \\
\hline & & Plan 1 & 0.91 & 0.81 & 1.09 & 0.92 & 1.56 & 1.09 & 0.66 & 0.41 & 0.81 & 1.33 \\
\hline & & Plan 2 & 0.95 & 0.86 & 1.16 & 0.98 & 1.53 & 1.13 & 0.80 & 0.45 & 0.85 & 0.87 \\
\hline & & Plan 3 & 0.95 & 0.82 & 1.16 & 0.97 & 1.60 & 1.16 & 0.78 & 0.44 & 0.80 & 1.01 \\
\hline & & Plan 4 & 0.95 & 0.97 & 1.08 & 1.02 & 1.55 & 1.04 & 0.86 & 0.49 & 0.98 & 0.53 \\
\hline & & Plan 5 & 1.00 & 0.99 & 1.09 & 1.05 & 1.72 & 1.11 & 0.85 & 0.52 & 1.02 & 1.19 \\
\hline & & Plan 6 & 0.97 & 1.00 & 1.08 & 1.02 & 1.61 & 1.05 & 0.87 & 0.51 & 1.04 & 0.30 \\
\hline & & Plan 7 & 0.97 & 0.96 & 1.09 & 1.03 & 1.61 & 1.08 & 0.86 & 0.50 & 0.99 & 0.33 \\
\hline & & Plan 8 & 0.96 & 1.01 & 1.12 & 1.06 & 1.65 & 1.09 & 0.90 & 0.53 & 1.01 & 0.54 \\
\hline & \multirow[t]{9}{*}{2} & EC & 1.73 & 1.26 & 1.38 & 1.38 & 2.03 & 1.36 & 1.04 & 0.71 & 1.21 & 0.80 \\
\hline & & Plan 1 & 1.73 & 1.16 & 1.55 & 1.45 & 2.16 & 1.54 & 0.95 & 0.75 & 1.20 & 1.93 \\
\hline & & Plan 2 & 1.71 & 1.27 & 1.72 & 1.56 & 2.17 & 1.65 & 1.16 & 0.77 & 1.33 & 1.34 \\
\hline & & Plan 3 & 1.73 & 1.09 & 1.58 & 1.44 & 2.12 & 1.60 & 1.05 & 0.73 & 1.13 & 1.43 \\
\hline & & Plan 4 & 1.77 & 1.33 & 1.45 & 1.41 & 2.05 & 1.37 & 1.10 & 0.79 & 1.48 & 0.70 \\
\hline & & Plan 5 & 1.78 & 1.42 & 1.55 & 1.55 & 2.29 & 1.51 & 1.16 & 0.87 & 1.58 & 1.56 \\
\hline & & Plan 6 & 1.75 & 1.49 & 1.62 & 1.61 & 2.25 & 1.47 & 1.23 & 0.88 & 1.66 & 0.46 \\
\hline & & Plan 7 & 1.70 & 1.38 & 1.56 & 1.52 & 2.17 & 1.46 & 1.17 & 0.84 & 1.55 & 0.44 \\
\hline & & Plan 8 & 1.78 & 1.49 & 1.63 & 1.61 & 2.26 & 1.49 & 1.25 & 0.88 & 1.60 & 0.81 \\
\hline & \multirow[t]{9}{*}{2.5} & EC & 2.22 & 1.38 & 1.79 & 1.72 & 2.38 & 1.77 & 1.21 & 0.94 & 1.51 & 0.97 \\
\hline & & Plan 1 & 2.23 & 1.35 & 1.75 & 1.69 & 2.43 & 1.76 & 1.10 & 0.87 & 1.38 & 2.10 \\
\hline & & Plan 2 & 2.24 & 1.53 & 1.98 & 1.84 & 2.42 & 1.91 & 1.39 & 1.00 & 1.56 & 1.61 \\
\hline & & Plan 3 & 2.21 & 1.28 & 1.81 & 1.72 & 2.41 & 1.83 & 1.17 & 0.88 & 1.31 & 1.62 \\
\hline & & Plan 4 & 2.37 & 1.53 & 1.62 & 1.73 & 2.35 & 1.59 & 1.26 & 1.02 & 1.76 & 0.85 \\
\hline & & Plan 5 & 2.33 & 1.58 & 1.69 & 1.79 & 2.47 & 1.65 & 1.19 & 1.05 & 1.81 & 1.68 \\
\hline & & Plan 6 & 2.38 & 1.71 & 1.83 & 1.88 & 2.44 & 1.64 & 1.33 & 1.11 & 1.97 & 0.52 \\
\hline & & Plan 7 & 2.33 & 1.57 & 1.74 & 1.82 & 2.37 & 1.66 & 1.27 & 1.07 & 1.82 & 0.51 \\
\hline & & Plan 8 & 2.38 & 1.66 & 1.80 & 1.87 & 2.42 & 1.64 & 1.30 & 1.12 & 1.86 & 0.89 \\
\hline
\end{tabular}




\begin{tabular}{|c|c|c|c|c|c|c|c|c|c|c|c|c|}
\hline \multicolumn{2}{|c|}{$\begin{array}{l}\text { Experimental } \\
\text { Wave }\end{array}$} & \multicolumn{11}{|c|}{ Wave Height $(\mathrm{m})$ at Indicated Gauge Location; swl $=+0.9 \mathrm{~m}$} \\
\hline $\begin{array}{l}\text { Period } \\
\text { (sec) }\end{array}$ & $\begin{array}{l}\text { Height } \\
(\mathrm{m})\end{array}$ & Plan & $\begin{array}{l}\text { Gauge } \\
11\end{array}$ & $\begin{array}{l}\text { Gauge } \\
12\end{array}$ & $\begin{array}{l}\text { Gauge } \\
13\end{array}$ & $\begin{array}{l}\text { Gauge } \\
14\end{array}$ & $\begin{array}{l}\text { Gauge } \\
15\end{array}$ & $\begin{array}{l}\text { Gauge } \\
16\end{array}$ & $\begin{array}{l}\text { Gauge } \\
17\end{array}$ & $\begin{array}{l}\text { Gauge } \\
18\end{array}$ & $\begin{array}{l}\text { Gauge } \\
19\end{array}$ & $\begin{array}{l}\text { Gauge } \\
20\end{array}$ \\
\hline \multirow[t]{27}{*}{6} & \multirow[t]{9}{*}{1} & EC & 0.34 & 0.23 & 0.34 & 0.63 & 0.51 & 0.42 & 0.47 & 0.44 & 0.38 & 0.45 \\
\hline & & Plan 1 & 0.84 & 0.66 & 0.60 & 0.86 & 0.84 & 0.73 & 1.22 & 0.78 & 0.66 & 1.14 \\
\hline & & Plan 2 & 0.45 & 0.49 & 0.46 & 0.74 & 0.69 & 0.55 & 0.78 & 0.66 & 0.52 & 0.66 \\
\hline & & Plan 3 & 0.93 & 0.70 & 0.53 & 0.74 & 0.74 & 0.75 & 0.93 & 0.59 & 0.65 & 1.02 \\
\hline & & Plan 4 & 0.52 & 0.35 & 0.49 & 0.70 & 0.48 & 0.29 & 0.55 & 0.50 & 0.26 & 0.40 \\
\hline & & Plan 5 & 0.96 & 0.81 & 0.63 & 0.45 & 0.96 & 0.61 & 0.79 & 0.50 & 0.64 & 0.97 \\
\hline & & Plan 6 & 0.35 & 0.42 & 0.39 & 0.28 & 0.37 & 0.20 & 0.42 & 0.28 & 0.26 & 0.28 \\
\hline & & Plan 7 & 0.40 & 0.36 & 0.40 & 0.55 & 0.24 & 0.30 & 0.62 & 0.46 & 0.28 & 0.36 \\
\hline & & Plan 8 & 0.40 & 0.37 & 0.39 & 0.28 & 0.50 & 0.32 & 0.29 & 0.32 & 0.30 & 0.44 \\
\hline & \multirow[t]{9}{*}{2} & EC & 0.51 & 0.42 & 0.48 & 0.84 & 0.73 & 0.61 & 0.63 & 0.62 & 0.52 & 0.64 \\
\hline & & Plan 1 & 1.62 & 0.94 & 0.85 & 1.12 & 1.31 & 0.98 & 1.64 & 1.11 & 0.91 & 1.60 \\
\hline & & Plan 2 & 0.66 & 0.77 & 0.67 & 1.02 & 1.04 & 0.84 & 1.09 & 0.98 & 0.74 & 1.02 \\
\hline & & Plan 3 & 1.30 & 0.97 & 0.73 & 1.02 & 1.11 & 0.99 & 1.29 & 0.84 & 0.92 & 1.38 \\
\hline & & Plan 4 & 0.72 & 0.51 & 0.60 & 0.86 & 0.68 & 0.38 & 0.65 & 0.62 & 0.35 & 0.54 \\
\hline & & Plan 5 & 1.26 & 1.07 & 0.86 & 0.62 & 1.22 & 0.81 & 1.07 & 0.66 & 0.81 & 1.32 \\
\hline & & Plan 6 & 0.52 & 0.59 & 0.53 & 0.39 & 0.49 & 0.31 & 0.57 & 0.41 & 0.33 & 0.43 \\
\hline & & Plan 7 & 0.54 & 0.49 & 0.51 & 0.71 & 0.38 & 0.39 & 0.78 & 0.57 & 0.36 & 0.49 \\
\hline & & Plan 8 & 0.58 & 0.53 & 0.51 & 0.40 & 0.69 & 0.44 & 0.41 & 0.46 & 0.39 & 0.63 \\
\hline & \multirow[t]{9}{*}{2.5} & EC & 0.64 & 0.56 & 0.59 & 1.02 & 0.84 & 0.76 & 0.73 & 0.76 & 0.71 & 0.79 \\
\hline & & Plan 1 & 1.92 & 1.10 & 1.04 & 1.30 & 1.41 & 1.09 & 1.90 & 1.33 & 1.02 & 1.76 \\
\hline & & Plan 2 & 0.95 & 0.88 & 0.77 & 1.20 & 1.17 & 0.99 & 1.23 & 1.17 & 0.90 & 1.17 \\
\hline & & Plan 3 & 1.37 & 1.13 & 0.85 & 1.14 & 1.26 & 1.10 & 1.49 & 0.98 & 1.05 & 1.56 \\
\hline & & Plan 4 & 0.87 & 0.63 & 0.68 & 0.99 & 0.75 & 0.45 & 0.81 & 0.72 & 0.44 & 0.68 \\
\hline & & Plan 5 & 1.35 & 1.15 & 0.93 & 0.66 & 1.28 & 0.86 & 1.16 & 0.70 & 0.87 & 1.39 \\
\hline & & Plan 6 & 0.58 & 0.63 & 0.56 & 0.44 & 0.54 & 0.35 & 0.60 & 0.47 & 0.36 & 0.47 \\
\hline & & Plan 7 & 0.63 & 0.55 & 0.54 & 0.80 & 0.40 & 0.44 & 0.85 & 0.63 & 0.41 & 0.55 \\
\hline & & Plan 8 & 0.62 & 0.55 & 0.52 & 0.44 & 0.74 & 0.46 & 0.45 & 0.50 & 0.42 & 0.68 \\
\hline
\end{tabular}




\begin{tabular}{|c|c|c|c|c|c|c|c|c|c|c|c|c|}
\hline \multicolumn{2}{|c|}{$\begin{array}{l}\text { Experimental } \\
\text { Wave }\end{array}$} & \multicolumn{11}{|c|}{ Wave Height $(\mathrm{m})$ at Indicated Gauge Location; swl $=+0.9 \mathrm{~m}$} \\
\hline $\begin{array}{l}\text { Period } \\
\text { (sec) }\end{array}$ & $\begin{array}{l}\text { Height } \\
(\mathrm{m})\end{array}$ & Plan & $\begin{array}{l}\text { Gauge } \\
1\end{array}$ & $\begin{array}{l}\text { Gauge } \\
2\end{array}$ & $\begin{array}{l}\text { Gauge } \\
3\end{array}$ & $\begin{array}{l}\text { Gauge } \\
4\end{array}$ & $\begin{array}{l}\text { Gauge } \\
5\end{array}$ & $\begin{array}{l}\text { Gauge } \\
6\end{array}$ & $\begin{array}{l}\text { Gauge } \\
7\end{array}$ & $\begin{array}{l}\text { Gauge } \\
8\end{array}$ & $\begin{array}{l}\text { Gauge } \\
9\end{array}$ & $\begin{array}{l}\text { Gauge } \\
10\end{array}$ \\
\hline \multirow[t]{27}{*}{7} & \multirow[t]{9}{*}{1} & EC & 0.88 & 0.88 & 1.13 & 1.09 & 1.65 & 1.20 & 0.77 & 0.48 & 0.86 & 0.63 \\
\hline & & Plan 1 & 0.89 & 0.84 & 1.11 & 1.03 & 1.65 & 1.21 & 0.73 & 0.44 & 0.78 & 1.25 \\
\hline & & Plan 2 & 0.92 & 0.87 & 1.14 & 1.08 & 1.64 & 1.21 & 0.75 & 0.44 & 0.77 & 0.86 \\
\hline & & Plan 3 & 0.90 & 0.82 & 1.16 & 1.08 & 1.67 & 1.29 & 0.82 & 0.46 & 0.78 & 1.13 \\
\hline & & Plan 4 & 0.93 & 1.00 & 1.07 & 1.14 & 1.71 & 1.15 & 0.81 & 0.48 & 0.89 & 0.50 \\
\hline & & Plan 5 & 0.95 & 1.00 & 1.07 & 1.15 & 1.79 & 1.22 & 0.89 & 0.51 & 0.96 & 1.21 \\
\hline & & Plan 6 & 0.93 & 1.01 & 1.06 & 1.12 & 1.71 & 1.15 & 0.82 & 0.52 & 0.95 & 0.33 \\
\hline & & Plan 7 & 0.92 & 0.98 & 1.07 & 1.14 & 1.70 & 1.17 & 0.81 & 0.51 & 0.92 & 0.33 \\
\hline & & Plan 8 & 0.93 & 1.02 & 1.08 & 1.15 & 1.72 & 1.17 & 0.85 & 0.53 & 0.93 & 0.61 \\
\hline & \multirow[t]{9}{*}{2} & EC & 1.70 & 1.42 & 1.42 & 1.61 & 2.32 & 1.57 & 1.08 & 0.84 & 1.35 & 0.79 \\
\hline & & Plan 1 & 1.74 & 1.25 & 1.55 & 1.60 & 2.36 & 1.70 & 1.05 & 0.86 & 1.44 & 1.89 \\
\hline & & Plan 2 & 1.72 & 1.39 & 1.73 & 1.74 & 2.47 & 1.84 & 1.19 & 0.89 & 1.45 & 1.42 \\
\hline & & Plan 3 & 1.73 & 1.20 & 1.63 & 1.64 & 2.40 & 1.85 & 1.16 & 0.88 & 1.30 & 1.52 \\
\hline & & Plan 4 & 1.80 & 1.59 & 1.56 & 1.72 & 2.45 & 1.65 & 1.22 & 0.92 & 1.64 & 0.76 \\
\hline & & Plan 5 & 1.78 & 1.62 & 1.60 & 1.76 & 2.58 & 1.73 & 1.26 & 0.99 & 1.72 & 1.60 \\
\hline & & Plan 6 & 1.78 & 1.68 & 1.63 & 1.80 & 2.55 & 1.71 & 1.26 & 1.00 & 1.75 & 0.50 \\
\hline & & Plan 7 & 1.76 & 1.57 & 1.60 & 1.74 & 2.48 & 1.73 & 1.19 & 0.97 & 1.64 & 0.47 \\
\hline & & Plan 8 & 1.77 & 1.61 & 1.57 & 1.74 & 2.48 & 1.68 & 1.21 & 0.96 & 1.59 & 0.83 \\
\hline & \multirow[t]{9}{*}{2.5} & EC & 2.26 & 1.35 & 1.57 & 1.67 & 2.38 & 1.75 & 1.14 & 0.94 & 1.36 & 0.92 \\
\hline & & Plan 1 & 2.23 & 1.33 & 1.58 & 1.68 & 2.43 & 1.78 & 1.19 & 0.90 & 1.29 & 1.89 \\
\hline & & Plan 2 & 2.28 & 1.38 & 1.63 & 1.75 & 2.49 & 1.90 & 1.21 & 0.96 & 1.25 & 1.43 \\
\hline & & Plan 3 & 2.25 & 1.26 & 1.61 & 1.68 & 2.41 & 1.87 & 1.22 & 0.92 & 1.18 & 1.65 \\
\hline & & Plan 4 & 2.39 & 1.62 & 1.56 & 1.84 & 2.57 & 1.75 & 1.25 & 1.00 & 1.67 & 0.84 \\
\hline & & Plan 5 & 2.34 & 1.66 & 1.62 & 1.88 & 2.65 & 1.81 & 1.26 & 1.06 & 1.75 & 1.68 \\
\hline & & Plan 6 & 2.41 & 1.64 & 1.54 & 1.85 & 2.60 & 1.76 & 1.21 & 1.04 & 1.68 & 0.55 \\
\hline & & Plan 7 & 2.34 & 1.56 & 1.53 & 1.81 & 2.55 & 1.77 & 1.17 & 1.03 & 1.59 & 0.52 \\
\hline & & Plan 8 & 2.39 & 1.67 & 1.60 & 1.90 & 2.64 & 1.80 & 1.23 & 1.08 & 1.67 & 0.93 \\
\hline
\end{tabular}




\begin{tabular}{|c|c|c|c|c|c|c|c|c|c|c|c|c|}
\hline \multicolumn{2}{|c|}{$\begin{array}{l}\text { Experimental } \\
\text { Wave }\end{array}$} & \multicolumn{11}{|c|}{ Wave Height $(\mathrm{m})$ at Indicated Gauge Location; swl $=+0.9 \mathrm{~m}$} \\
\hline $\begin{array}{l}\text { Period } \\
\text { (sec) }\end{array}$ & $\begin{array}{l}\text { Height } \\
(\mathrm{m})\end{array}$ & Plan & $\begin{array}{l}\text { Gauge } \\
11\end{array}$ & $\begin{array}{l}\text { Gauge } \\
12\end{array}$ & $\begin{array}{l}\text { Gauge } \\
13\end{array}$ & $\begin{array}{l}\text { Gauge } \\
14\end{array}$ & $\begin{array}{l}\text { Gauge } \\
15\end{array}$ & $\begin{array}{l}\text { Gauge } \\
16\end{array}$ & $\begin{array}{l}\text { Gauge } \\
17\end{array}$ & $\begin{array}{l}\text { Gauge } \\
18\end{array}$ & $\begin{array}{l}\text { Gauge } \\
19\end{array}$ & $\begin{array}{l}\text { Gauge } \\
20\end{array}$ \\
\hline \multirow[t]{27}{*}{7} & \multirow[t]{9}{*}{1} & EC & 0.39 & 0.30 & 0.39 & 0.64 & 0.55 & 0.44 & 0.48 & 0.48 & 0.41 & 0.52 \\
\hline & & Plan 1 & 0.82 & 0.74 & 0.82 & 1.03 & 0.78 & 0.78 & 1.32 & 1.03 & 0.70 & 1.03 \\
\hline & & Plan 2 & 0.44 & 0.59 & 0.61 & 0.75 & 0.79 & 0.54 & 0.74 & 0.75 & 0.49 & 0.67 \\
\hline & & Plan 3 & 0.97 & 0.70 & 0.59 & 0.77 & 0.76 & 0.74 & 1.01 & 0.72 & 0.68 & 0.99 \\
\hline & & Plan 4 & 0.49 & 0.47 & 0.62 & 0.78 & 0.54 & 0.34 & 0.64 & 0.59 & 0.33 & 0.40 \\
\hline & & Plan 5 & 0.99 & 0.85 & 0.65 & 0.44 & 1.02 & 0.62 & 0.72 & 0.47 & 0.63 & 1.03 \\
\hline & & Plan 6 & 0.39 & 0.46 & 0.40 & 0.28 & 0.35 & 0.22 & 0.38 & 0.29 & 0.25 & 0.29 \\
\hline & & Plan 7 & 0.40 & 0.39 & 0.42 & 0.56 & 0.28 & 0.30 & 0.62 & 0.49 & 0.28 & 0.32 \\
\hline & & Plan 8 & 0.44 & 0.41 & 0.38 & 0.29 & 0.54 & 0.33 & 0.28 & 0.31 & 0.30 & 0.49 \\
\hline & \multirow[t]{9}{*}{2} & EC & 0.54 & 0.43 & 0.45 & 0.75 & 0.66 & 0.52 & 0.60 & 0.59 & 0.48 & 0.60 \\
\hline & & Plan 1 & 1.51 & 0.98 & 1.25 & 1.56 & 1.32 & 1.04 & 1.92 & 1.58 & 0.92 & 1.53 \\
\hline & & Plan 2 & 0.69 & 0.86 & 0.81 & 1.03 & 1.18 & 0.83 & 1.02 & 1.07 & 0.71 & 1.05 \\
\hline & & Plan 3 & 1.31 & 0.96 & 0.84 & 1.11 & 1.07 & 1.01 & 1.40 & 1.07 & 0.92 & 1.28 \\
\hline & & Plan 4 & 0.75 & 0.73 & 0.80 & 1.02 & 0.79 & 0.49 & 0.80 & 0.79 & 0.45 & 0.62 \\
\hline & & Plan 5 & 1.29 & 1.10 & 0.89 & 0.64 & 1.30 & 0.82 & 1.00 & 0.70 & 0.81 & 1.31 \\
\hline & & Plan 6 & 0.55 & 0.57 & 0.49 & 0.40 & 0.47 & 0.31 & 0.49 & 0.40 & 0.33 & 0.37 \\
\hline & & Plan 7 & 0.55 & 0.47 & 0.50 & 0.74 & 0.42 & 0.40 & 0.72 & 0.61 & 0.35 & 0.43 \\
\hline & & Plan 8 & 0.58 & 0.50 & 0.45 & 0.39 & 0.68 & 0.39 & 0.39 & 0.45 & 0.37 & 0.59 \\
\hline & \multirow[t]{9}{*}{2.5} & EC & 0.62 & 0.54 & 0.55 & 0.94 & 0.80 & 0.67 & 0.69 & 0.72 & 0.60 & 0.72 \\
\hline & & Plan 1 & 1.69 & 1.14 & 1.30 & 1.53 & 1.34 & 1.17 & 1.92 & 1.55 & 1.08 & 1.50 \\
\hline & & Plan 2 & 0.89 & 0.93 & 0.92 & 1.22 & 1.29 & 0.94 & 1.13 & 1.18 & 0.82 & 1.10 \\
\hline & & Plan 3 & 1.33 & 1.02 & 0.88 & 1.12 & 1.13 & 1.08 & 1.46 & 1.09 & 0.99 & 1.38 \\
\hline & & Plan 4 & 0.85 & 0.81 & 0.90 & 1.15 & 0.87 & 0.53 & 0.95 & 0.87 & 0.53 & 0.73 \\
\hline & & Plan 5 & 1.36 & 1.17 & 0.94 & 0.68 & 1.38 & 0.84 & 1.09 & 0.75 & 0.84 & 1.38 \\
\hline & & Plan 6 & 0.58 & 0.62 & 0.56 & 0.47 & 0.52 & 0.33 & 0.56 & 0.44 & 0.36 & 0.42 \\
\hline & & Plan 7 & 0.59 & 0.53 & 0.57 & 0.83 & 0.46 & 0.42 & 0.83 & 0.65 & 0.40 & 0.52 \\
\hline & & Plan 8 & 0.63 & 0.55 & 0.53 & 0.47 & 0.75 & 0.43 & 0.48 & 0.51 & 0.41 & 0.67 \\
\hline
\end{tabular}




\begin{tabular}{|c|c|c|c|c|c|c|c|c|c|c|c|c|}
\hline \multicolumn{2}{|c|}{$\begin{array}{l}\text { Experimental } \\
\text { Wave }\end{array}$} & \multicolumn{11}{|c|}{ Wave Height $(\mathrm{m})$ at Indicated Gauge Location; swl $=+0.9 \mathrm{~m}$} \\
\hline $\begin{array}{l}\text { Period } \\
\text { (sec) }\end{array}$ & $\begin{array}{l}\text { Height } \\
(\mathrm{m})\end{array}$ & Plan & $\begin{array}{l}\text { Gauge } \\
1\end{array}$ & $\begin{array}{l}\text { Gauge } \\
2\end{array}$ & $\begin{array}{l}\text { Gauge } \\
3\end{array}$ & $\begin{array}{l}\text { Gauge } \\
4\end{array}$ & $\begin{array}{l}\text { Gauge } \\
5\end{array}$ & $\begin{array}{l}\text { Gauge } \\
6\end{array}$ & $\begin{array}{l}\text { Gauge } \\
7\end{array}$ & $\begin{array}{l}\text { Gauge } \\
8\end{array}$ & $\begin{array}{l}\text { Gauge } \\
9\end{array}$ & $\begin{array}{l}\text { Gauge } \\
10\end{array}$ \\
\hline \multirow[t]{27}{*}{8} & \multirow[t]{9}{*}{1} & EC & 0.93 & 0.96 & 1.06 & 1.19 & 1.86 & 1.42 & 0.89 & 0.62 & 0.93 & 0.61 \\
\hline & & Plan 1 & 0.93 & 0.90 & 1.04 & 1.14 & 1.82 & 1.36 & 0.84 & 0.57 & 0.83 & 1.19 \\
\hline & & Plan 2 & 0.95 & 0.92 & 1.06 & 1.17 & 1.75 & 1.40 & 0.88 & 0.56 & 0.82 & 0.91 \\
\hline & & Plan 3 & 0.95 & 0.87 & 1.08 & 1.17 & 1.85 & 1.45 & 0.89 & 0.61 & 0.82 & 1.16 \\
\hline & & Plan 4 & 0.95 & 1.08 & 1.01 & 1.27 & 1.86 & 1.33 & 0.95 & 0.62 & 0.98 & 0.54 \\
\hline & & Plan 5 & 0.97 & 1.07 & 0.99 & 1.25 & 1.97 & 1.35 & 0.94 & 0.67 & 1.03 & 1.27 \\
\hline & & Plan 6 & 0.94 & 1.09 & 0.99 & 1.25 & 1.92 & 1.34 & 0.92 & 0.68 & 1.06 & 0.33 \\
\hline & & Plan 7 & 0.94 & 1.06 & 1.02 & 1.26 & 1.93 & 1.38 & 0.91 & 0.66 & 1.02 & 0.32 \\
\hline & & Plan 8 & 0.96 & 1.10 & 1.01 & 1.27 & 1.94 & 1.36 & 0.95 & 0.69 & 1.03 & 0.62 \\
\hline & \multirow[t]{9}{*}{2} & EC & 1.86 & 1.37 & 1.24 & 1.61 & 2.42 & 1.66 & 1.10 & 1.03 & 1.38 & 1.40 \\
\hline & & Plan 1 & 1.87 & 1.22 & 1.35 & 1.64 & 2.49 & 1.79 & 1.11 & 1.01 & 1.36 & 1.74 \\
\hline & & Plan 2 & 1.85 & 1.29 & 1.44 & 1.70 & 2.51 & 1.93 & 1.18 & 1.05 & 1.34 & 1.40 \\
\hline & & Plan 3 & 1.87 & 1.24 & 1.47 & 1.69 & 2.58 & 1.94 & 1.20 & 1.11 & 1.41 & 1.56 \\
\hline & & Plan 4 & 1.87 & 1.55 & 1.36 & 1.81 & 2.57 & 1.78 & 1.30 & 1.11 & 1.72 & 0.80 \\
\hline & & Plan 5 & 1.89 & 1.58 & 1.40 & 1.84 & 2.72 & 1.81 & 1.30 & 1.23 & 1.86 & 1.59 \\
\hline & & Plan 6 & 1.87 & 1.61 & 1.40 & 1.84 & 2.69 & 1.81 & 1.28 & 1.23 & 1.86 & 0.50 \\
\hline & & Plan 7 & 1.85 & 1.53 & 1.39 & 1.80 & 2.66 & 1.84 & 1.25 & 1.20 & 1.77 & 0.47 \\
\hline & & Plan 8 & 1.91 & 1.61 & 1.40 & 1.83 & 2.71 & 1.84 & 1.30 & 1.21 & 1.76 & 0.86 \\
\hline & \multirow[t]{9}{*}{2.5} & EC & 2.24 & 1.45 & 1.29 & 1.68 & 2.48 & 1.73 & 1.20 & 1.15 & 1.49 & 0.83 \\
\hline & & Plan 1 & 2.27 & 1.43 & 1.52 & 1.74 & 2.56 & 1.91 & 1.29 & 1.09 & 1.46 & 1.81 \\
\hline & & Plan 2 & 2.30 & 1.42 & 1.53 & 1.76 & 2.55 & 2.03 & 1.35 & 1.12 & 1.33 & 1.48 \\
\hline & & Plan 3 & 2.27 & 1.34 & 1.54 & 1.73 & 2.55 & 1.99 & 1.30 & 1.17 & 1.43 & 1.59 \\
\hline & & Plan 4 & 2.38 & 1.71 & 1.50 & 1.95 & 2.71 & 1.92 & 1.45 & 1.14 & 1.71 & 0.90 \\
\hline & & Plan 5 & 2.35 & 1.76 & 1.52 & 1.94 & 2.79 & 1.90 & 1.41 & 1.24 & 1.88 & 1.72 \\
\hline & & Plan 6 & 2.41 & 1.77 & 1.48 & 1.94 & 2.79 & 1.94 & 1.43 & 1.24 & 1.85 & 0.57 \\
\hline & & Plan 7 & 2.35 & 1.69 & 1.49 & 1.93 & 2.76 & 1.96 & 1.37 & 1.25 & 1.80 & 0.54 \\
\hline & & Plan 8 & 2.38 & 1.74 & 1.50 & 1.97 & 2.83 & 1.97 & 1.44 & 1.23 & 1.75 & 0.97 \\
\hline
\end{tabular}




\begin{tabular}{|c|c|c|c|c|c|c|c|c|c|c|c|c|}
\hline \multicolumn{2}{|c|}{$\begin{array}{l}\text { Experimental } \\
\text { Wave }\end{array}$} & \multicolumn{11}{|c|}{ Wave Height $(\mathrm{m})$ at Indicated Gauge Location; swl $=+0.9 \mathrm{~m}$} \\
\hline $\begin{array}{l}\text { Period } \\
\text { (sec) }\end{array}$ & $\begin{array}{l}\text { Height } \\
(\mathrm{m})\end{array}$ & Plan & $\begin{array}{l}\text { Gauge } \\
11\end{array}$ & $\begin{array}{l}\text { Gauge } \\
12\end{array}$ & $\begin{array}{l}\text { Gauge } \\
13\end{array}$ & $\begin{array}{l}\text { Gauge } \\
14\end{array}$ & $\begin{array}{l}\text { Gauge } \\
15\end{array}$ & $\begin{array}{l}\text { Gauge } \\
16\end{array}$ & $\begin{array}{l}\text { Gauge } \\
17\end{array}$ & $\begin{array}{l}\text { Gauge } \\
18\end{array}$ & $\begin{array}{l}\text { Gauge } \\
19\end{array}$ & $\begin{array}{l}\text { Gauge } \\
20\end{array}$ \\
\hline \multirow[t]{27}{*}{8} & \multirow[t]{9}{*}{1} & EC & 0.41 & 0.31 & 0.37 & 0.59 & 0.56 & 0.43 & 0.47 & 0.45 & 0.40 & 0.51 \\
\hline & & Plan 1 & 0.87 & 0.84 & 1.07 & 1.29 & 1.07 & 0.85 & 1.38 & 1.21 & 0.75 & 1.14 \\
\hline & & Plan 2 & 0.59 & 0.65 & 0.74 & 0.88 & 1.03 & 0.62 & 0.69 & 0.75 & 0.57 & 0.90 \\
\hline & & Plan 3 & 1.01 & 0.73 & 0.62 & 0.77 & 0.75 & 0.76 & 1.07 & 0.82 & 0.70 & 0.94 \\
\hline & & Plan 4 & 0.56 & 0.66 & 0.77 & 0.89 & 0.65 & 0.44 & 0.78 & 0.68 & 0.42 & 0.57 \\
\hline & & Plan 5 & 1.02 & 0.83 & 0.62 & 0.46 & 1.05 & 0.62 & 0.75 & 0.52 & 0.62 & 1.03 \\
\hline & & Plan 6 & 0.37 & 0.42 & 0.38 & 0.29 & 0.34 & 0.21 & 0.36 & 0.28 & 0.22 & 0.28 \\
\hline & & Plan 7 & 0.37 & 0.35 & 0.41 & 0.58 & 0.30 & 0.30 & 0.58 & 0.47 & 0.27 & 0.33 \\
\hline & & Plan 8 & 0.43 & 0.38 & 0.36 & 0.29 & 0.53 & 0.30 & 0.32 & 0.32 & 0.28 & 0.47 \\
\hline & \multirow[t]{9}{*}{2} & EC & 0.94 & 0.86 & 1.15 & 1.34 & 1.21 & 0.93 & 1.48 & 1.29 & 0.84 & 1.22 \\
\hline & & Plan 1 & 1.52 & 1.11 & 1.44 & 1.74 & 1.59 & 1.09 & 1.88 & 1.67 & 0.99 & 1.58 \\
\hline & & Plan 2 & 0.85 & 0.89 & 1.02 & 1.26 & 1.44 & 0.92 & 1.03 & 1.16 & 0.81 & 1.25 \\
\hline & & Plan 3 & 1.27 & 0.97 & 0.92 & 1.16 & 1.11 & 1.01 & 1.47 & 1.18 & 0.94 & 1.29 \\
\hline & & Plan 4 & 0.82 & 0.95 & 1.07 & 1.24 & 0.97 & 0.61 & 1.11 & 0.98 & 0.61 & 0.89 \\
\hline & & Plan 5 & 1.26 & 1.06 & 0.86 & 0.68 & 1.27 & 0.78 & 1.06 & 0.81 & 0.75 & 1.27 \\
\hline & & Plan 6 & 0.52 & 0.57 & 0.53 & 0.45 & 0.48 & 0.32 & 0.50 & 0.41 & 0.34 & 0.39 \\
\hline & & Plan 7 & 0.53 & 0.51 & 0.55 & 0.79 & 0.46 & 0.40 & 0.76 & 0.60 & 0.38 & 0.52 \\
\hline & & Plan 8 & 0.59 & 0.53 & 0.51 & 0.45 & 0.71 & 0.39 & 0.51 & 0.51 & 0.39 & 0.59 \\
\hline & \multirow[t]{9}{*}{2.5} & EC & 0.61 & 0.56 & 0.54 & 0.81 & 0.75 & 0.60 & 0.72 & 0.68 & 0.55 & 0.68 \\
\hline & & Plan 1 & 1.65 & 1.24 & 1.55 & 1.84 & 1.67 & 1.23 & 1.90 & 1.72 & 1.10 & 1.64 \\
\hline & & Plan 2 & 1.21 & 1.01 & 1.13 & 1.39 & 1.60 & 1.01 & 1.09 & 1.23 & 0.89 & 1.38 \\
\hline & & Plan 3 & 1.26 & 1.01 & 0.95 & 1.23 & 1.12 & 1.05 & 1.48 & 1.24 & 0.95 & 1.30 \\
\hline & & Plan 4 & 0.92 & 1.06 & 1.18 & 1.37 & 1.09 & 0.68 & 1.25 & 1.07 & 0.68 & 1.00 \\
\hline & & Plan 5 & 1.36 & 1.11 & 0.88 & 0.73 & 1.33 & 0.82 & 1.10 & 0.86 & 0.78 & 1.30 \\
\hline & & Plan 6 & 0.59 & 0.65 & 0.60 & 0.51 & 0.54 & 0.39 & 0.57 & 0.47 & 0.41 & 0.45 \\
\hline & & Plan 7 & 0.61 & 0.60 & 0.63 & 0.88 & 0.54 & 0.45 & 0.87 & 0.65 & 0.44 & 0.59 \\
\hline & & Plan 8 & 0.67 & 0.63 & 0.60 & 0.52 & 0.80 & 0.45 & 0.58 & 0.59 & 0.45 & 0.66 \\
\hline
\end{tabular}


Table D3. Wave heights for waves from 0 degrees; $+0.9 \mathrm{~m}$ swl.

\begin{tabular}{|c|c|c|c|c|c|c|c|c|c|c|c|c|}
\hline \multicolumn{2}{|c|}{$\begin{array}{l}\text { Experimental } \\
\text { Wave }\end{array}$} & \multicolumn{11}{|c|}{ Wave Height $(\mathrm{m})$ at Indicated Gauge Location; swl $=+0.9 \mathrm{~m}$} \\
\hline $\begin{array}{l}\text { Period } \\
\text { (sec) }\end{array}$ & $\begin{array}{l}\text { Height } \\
(\mathrm{m})\end{array}$ & Plan & $\begin{array}{l}\text { Gauge } \\
1\end{array}$ & $\begin{array}{l}\text { Gauge } \\
2\end{array}$ & $\begin{array}{l}\text { Gauge } \\
3\end{array}$ & $\begin{array}{l}\text { Gauge } \\
4\end{array}$ & $\begin{array}{l}\text { Gauge } \\
5\end{array}$ & $\begin{array}{l}\text { Gauge } \\
6\end{array}$ & $\begin{array}{l}\text { Gauge } \\
7\end{array}$ & $\begin{array}{l}\text { Gauge } \\
8\end{array}$ & $\begin{array}{l}\text { Gauge } \\
9\end{array}$ & $\begin{array}{l}\text { Gauge } \\
10 \\
\end{array}$ \\
\hline \multirow[t]{27}{*}{5} & \multirow[t]{9}{*}{1} & EC & 0.99 & 0.70 & 0.87 & 0.93 & 0.69 & 0.76 & 0.88 & 0.80 & 0.76 & 0.59 \\
\hline & & Plan 1 & 0.94 & 0.72 & 0.74 & 0.85 & 0.70 & 0.66 & 0.82 & 0.71 & 0.67 & 0.60 \\
\hline & & Plan 2 & 0.99 & 0.76 & 0.78 & 0.93 & 0.69 & 0.69 & 0.87 & 0.79 & 0.76 & 0.39 \\
\hline & & Plan 3 & 0.98 & 0.71 & 0.87 & 0.88 & 0.71 & 0.77 & 0.86 & 0.76 & 0.70 & 0.88 \\
\hline & & Plan 4 & 0.93 & 0.72 & 0.71 & 0.89 & 0.64 & 0.64 & 0.83 & 0.73 & 0.74 & 0.26 \\
\hline & & Plan 5 & 0.92 & 0.68 & 0.73 & 0.84 & 0.60 & 0.60 & 0.82 & 0.75 & 0.76 & 0.86 \\
\hline & & Plan 6 & 0.92 & 0.64 & 0.65 & 0.82 & 0.63 & 0.58 & 0.75 & 0.68 & 0.66 & 0.30 \\
\hline & & Plan 7 & 0.93 & 0.77 & 0.78 & 0.94 & 0.73 & 0.69 & 0.87 & 0.78 & 0.77 & 0.41 \\
\hline & & Plan 8 & 0.93 & 0.82 & 0.81 & 0.98 & 0.75 & 0.74 & 0.93 & 0.84 & 0.80 & 0.68 \\
\hline & \multirow[t]{9}{*}{2} & EC & 1.91 & 1.37 & 1.56 & 1.52 & 1.25 & 1.31 & 1.53 & 1.42 & 1.37 & 1.05 \\
\hline & & Plan 1 & 1.87 & 1.40 & 1.37 & 1.51 & 1.21 & 1.18 & 1.49 & 1.32 & 1.30 & 1.11 \\
\hline & & Plan 2 & 1.87 & 1.41 & 1.37 & 1.52 & 1.21 & 1.21 & 1.50 & 1.37 & 1.33 & 0.78 \\
\hline & & Plan 3 & 1.89 & 1.39 & 1.55 & 1.48 & 1.25 & 1.32 & 1.50 & 1.37 & 1.32 & 1.48 \\
\hline & & Plan 4 & 1.90 & 1.47 & 1.37 & 1.58 & 1.22 & 1.21 & 1.55 & 1.41 & 1.42 & 0.57 \\
\hline & & Plan 5 & 1.85 & 1.43 & 1.43 & 1.56 & 1.25 & 1.21 & 1.53 & 1.46 & 1.47 & 1.66 \\
\hline & & Plan 6 & 1.86 & 1.48 & 1.39 & 1.55 & 1.27 & 1.19 & 1.50 & 1.44 & 1.39 & 0.64 \\
\hline & & Plan 7 & 1.86 & 1.49 & 1.40 & 1.56 & 1.31 & 1.23 & 1.53 & 1.45 & 1.39 & 0.74 \\
\hline & & Plan 8 & 1.84 & 1.46 & 1.40 & 1.54 & 1.24 & 1.20 & 1.51 & 1.40 & 1.33 & 1.07 \\
\hline & \multirow[t]{9}{*}{2.5} & EC & 2.44 & 1.58 & 1.80 & 1.76 & 1.42 & 1.46 & 1.77 & 1.69 & 1.71 & 1.22 \\
\hline & & Plan 1 & 2.46 & 1.70 & 1.63 & 1.73 & 1.42 & 1.31 & 1.71 & 1.66 & 1.73 & 1.33 \\
\hline & & Plan 2 & 2.44 & 1.64 & 1.60 & 1.76 & 1.41 & 1.33 & 1.72 & 1.63 & 1.66 & 1.00 \\
\hline & & Plan 3 & 2.51 & 1.61 & 1.81 & 1.72 & 1.40 & 1.45 & 1.71 & 1.66 & 1.69 & 1.62 \\
\hline & & Plan 4 & 2.38 & 1.71 & 1.57 & 1.75 & 1.37 & 1.31 & 1.71 & 1.64 & 1.79 & 0.64 \\
\hline & & Plan 5 & 2.36 & 1.70 & 1.71 & 1.82 & 1.44 & 1.35 & 1.75 & 1.75 & 1.86 & 1.86 \\
\hline & & Plan 6 & 2.38 & 1.68 & 1.58 & 1.73 & 1.40 & 1.33 & 1.72 & 1.63 & 1.67 & 0.70 \\
\hline & & Plan 7 & 2.38 & 1.67 & 1.59 & 1.76 & 1.41 & 1.33 & 1.72 & 1.66 & 1.69 & 0.79 \\
\hline & & Plan 8 & 2.37 & 1.73 & 1.65 & 1.79 & 1.42 & 1.35 & 1.77 & 1.69 & 1.70 & 1.24 \\
\hline
\end{tabular}




\begin{tabular}{|c|c|c|c|c|c|c|c|c|c|c|c|c|}
\hline \multicolumn{2}{|c|}{$\begin{array}{l}\text { Experimental } \\
\text { Wave }\end{array}$} & \multicolumn{11}{|c|}{ Wave Height $(\mathrm{m})$ at Indicated Gauge Location; swl $=+0.9 \mathrm{~m}$} \\
\hline $\begin{array}{l}\text { Period } \\
\text { (sec) }\end{array}$ & $\begin{array}{l}\text { Height } \\
(\mathrm{m})\end{array}$ & Plan & $\begin{array}{l}\text { Gauge } \\
11\end{array}$ & $\begin{array}{l}\text { Gauge } \\
12\end{array}$ & $\begin{array}{l}\text { Gauge } \\
13\end{array}$ & $\begin{array}{l}\text { Gauge } \\
14\end{array}$ & $\begin{array}{l}\text { Gauge } \\
15\end{array}$ & $\begin{array}{l}\text { Gauge } \\
16\end{array}$ & $\begin{array}{l}\text { Gauge } \\
17\end{array}$ & $\begin{array}{l}\text { Gauge } \\
18\end{array}$ & $\begin{array}{l}\text { Gauge } \\
19\end{array}$ & $\begin{array}{l}\text { Gauge } \\
20\end{array}$ \\
\hline \multirow[t]{27}{*}{5} & \multirow[t]{9}{*}{1} & EC & 0.47 & 0.55 & 0.55 & 0.62 & 0.53 & 0.55 & 0.67 & 0.68 & 0.53 & 0.44 \\
\hline & & Plan 1 & 0.54 & 0.70 & 0.68 & 0.73 & 0.77 & 0.58 & 0.83 & 0.83 & 0.58 & 0.57 \\
\hline & & Plan 2 & 0.34 & 0.54 & 0.78 & 0.93 & 0.59 & 0.56 & 0.91 & 0.85 & 0.55 & 0.43 \\
\hline & & Plan 3 & 0.71 & 0.51 & 0.45 & 0.48 & 0.76 & 0.57 & 0.46 & 0.67 & 0.52 & 0.64 \\
\hline & & Plan 4 & 0.39 & 0.56 & 0.70 & 0.78 & 0.34 & 0.45 & 0.79 & 0.62 & 0.47 & 0.43 \\
\hline & & Plan 5 & 0.62 & 0.45 & 0.39 & 0.21 & 0.78 & 0.39 & 0.30 & 0.58 & 0.36 & 0.59 \\
\hline & & Plan 6 & 0.42 & 0.51 & 0.42 & 0.25 & 0.40 & 0.31 & 0.36 & 0.36 & 0.36 & 0.31 \\
\hline & & Plan 7 & 0.55 & 0.55 & 0.49 & 0.59 & 0.26 & 0.40 & 0.68 & 0.46 & 0.42 & 0.45 \\
\hline & & Plan 8 & 0.54 & 0.63 & 0.58 & 0.35 & 0.76 & 0.36 & 0.42 & 0.64 & 0.37 & 0.45 \\
\hline & \multirow[t]{9}{*}{2} & EC & 0.81 & 0.98 & 0.98 & 1.10 & 0.91 & 0.98 & 1.13 & 1.17 & 0.90 & 0.76 \\
\hline & & Plan 1 & 1.04 & 1.33 & 1.21 & 1.22 & 1.45 & 1.05 & 1.41 & 1.41 & 1.06 & 1.03 \\
\hline & & Plan 2 & 0.66 & 0.99 & 1.33 & 1.52 & 1.15 & 0.92 & 1.50 & 1.45 & 0.96 & 0.63 \\
\hline & & Plan 3 & 1.07 & 0.93 & 0.79 & 0.86 & 1.25 & 1.03 & 0.84 & 1.08 & 0.89 & 1.14 \\
\hline & & Plan 4 & 0.81 & 1.11 & 1.31 & 1.43 & 0.78 & 0.93 & 1.36 & 1.21 & 0.92 & 0.70 \\
\hline & & Plan 5 & 1.25 & 0.95 & 0.77 & 0.47 & 1.44 & 0.86 & 0.57 & 1.05 & 0.69 & 1.21 \\
\hline & & Plan 6 & 0.88 & 1.07 & 0.91 & 0.59 & 0.88 & 0.71 & 0.75 & 0.71 & 0.76 & 0.64 \\
\hline & & Plan 7 & 0.97 & 0.97 & 0.88 & 1.06 & 0.53 & 0.74 & 1.17 & 0.88 & 0.73 & 0.73 \\
\hline & & Plan 8 & 0.86 & 1.03 & 0.95 & 0.59 & 1.18 & 0.61 & 0.68 & 0.99 & 0.59 & 0.78 \\
\hline & \multirow[t]{9}{*}{2.5} & EC & 0.88 & 1.08 & 1.09 & 1.25 & 1.04 & 1.10 & 1.25 & 1.29 & 1.00 & 0.90 \\
\hline & & Plan 1 & 1.12 & 1.57 & 1.47 & 1.50 & 1.78 & 1.22 & 1.69 & 1.71 & 1.21 & 1.25 \\
\hline & & Plan 2 & 0.79 & 1.17 & 1.52 & 1.69 & 1.42 & 1.02 & 1.70 & 1.65 & 1.10 & 0.79 \\
\hline & & Plan 3 & 1.17 & 1.08 & 0.93 & 1.04 & 1.37 & 1.19 & 1.01 & 1.18 & 1.04 & 1.31 \\
\hline & & Plan 4 & 0.90 & 1.25 & 1.47 & 1.63 & 0.97 & 1.00 & 1.53 & 1.40 & 1.00 & 0.77 \\
\hline & & Plan 5 & 1.39 & 1.10 & 0.91 & 0.57 & 1.63 & 1.01 & 0.76 & 1.16 & 0.81 & 1.41 \\
\hline & & Plan 6 & 0.96 & 1.18 & 1.00 & 0.64 & 1.02 & 0.76 & 0.84 & 0.82 & 0.79 & 0.71 \\
\hline & & Plan 7 & 1.04 & 1.05 & 0.96 & 1.17 & 0.60 & 0.80 & 1.29 & 1.00 & 0.79 & 0.78 \\
\hline & & Plan 8 & 0.96 & 1.15 & 1.07 & 0.67 & 1.32 & 0.69 & 0.78 & 1.09 & 0.65 & 0.94 \\
\hline
\end{tabular}




\begin{tabular}{|c|c|c|c|c|c|c|c|c|c|c|c|c|}
\hline \multicolumn{2}{|c|}{$\begin{array}{l}\text { Experimental } \\
\text { Wave }\end{array}$} & \multicolumn{11}{|c|}{ Wave Height $(\mathrm{m})$ at Indicated Gauge Location; swl $=+0.9 \mathrm{~m}$} \\
\hline $\begin{array}{l}\text { Period } \\
\text { (sec) }\end{array}$ & $\begin{array}{l}\text { Height } \\
\text { (m) }\end{array}$ & Plan & $\begin{array}{l}\text { Gauge } \\
1\end{array}$ & $\begin{array}{l}\text { Gauge } \\
2\end{array}$ & $\begin{array}{l}\text { Gauge } \\
3\end{array}$ & $\begin{array}{l}\text { Gauge } \\
4\end{array}$ & $\begin{array}{l}\text { Gauge } \\
5\end{array}$ & $\begin{array}{l}\text { Gauge } \\
6\end{array}$ & $\begin{array}{l}\text { Gauge } \\
7\end{array}$ & $\begin{array}{l}\text { Gauge } \\
8\end{array}$ & $\begin{array}{l}\text { Gauge } \\
9\end{array}$ & $\begin{array}{l}\text { Gauge } \\
10\end{array}$ \\
\hline \multirow[t]{27}{*}{6} & \multirow[t]{9}{*}{1} & EC & 1.00 & 0.77 & 0.89 & 0.98 & 0.75 & 0.73 & 0.92 & 0.86 & 0.98 & 0.71 \\
\hline & & Plan 1 & 0.99 & 0.80 & 0.80 & 0.95 & 0.80 & 0.67 & 0.83 & 0.83 & 0.97 & 0.77 \\
\hline & & Plan 2 & 0.99 & 0.85 & 0.84 & 1.01 & 0.79 & 0.68 & 0.89 & 0.90 & 1.06 & 0.53 \\
\hline & & Plan 3 & 1.04 & 0.75 & 0.88 & 0.96 & 0.76 & 0.75 & 0.86 & 0.84 & 0.94 & 0.94 \\
\hline & & Plan 4 & 0.98 & 0.76 & 0.72 & 0.91 & 0.70 & 0.61 & 0.80 & 0.80 & 1.01 & 0.30 \\
\hline & & Plan 5 & 0.96 & 0.73 & 0.74 & 0.89 & 0.69 & 0.61 & 0.78 & 0.80 & 0.95 & 0.93 \\
\hline & & Plan 6 & 0.96 & 0.73 & 0.72 & 0.89 & 0.71 & 0.60 & 0.80 & 0.77 & 0.91 & 0.33 \\
\hline & & Plan 7 & 0.97 & 0.79 & 0.78 & 0.95 & 0.76 & 0.66 & 0.86 & 0.82 & 0.97 & 0.40 \\
\hline & & Plan 8 & 0.97 & 0.81 & 0.79 & 0.98 & 0.77 & 0.65 & 0.88 & 0.86 & 1.01 & 0.66 \\
\hline & \multirow[t]{9}{*}{2} & EC & 1.88 & 1.31 & 1.42 & 1.49 & 1.23 & 1.15 & 1.35 & 1.40 & 1.61 & 1.10 \\
\hline & & Plan 1 & 1.85 & 1.35 & 1.27 & 1.46 & 1.25 & 1.05 & 1.31 & 1.37 & 1.57 & 1.27 \\
\hline & & Plan 2 & 1.86 & 1.42 & 1.34 & 1.53 & 1.29 & 1.10 & 1.37 & 1.44 & 1.67 & 0.89 \\
\hline & & Plan 3 & 1.91 & 1.35 & 1.44 & 1.49 & 1.27 & 1.21 & 1.33 & 1.40 & 1.57 & 1.52 \\
\hline & & Plan 4 & 1.87 & 1.37 & 1.24 & 1.51 & 1.25 & 1.06 & 1.32 & 1.39 & 1.72 & 0.56 \\
\hline & & Plan 5 & 1.82 & 1.40 & 1.33 & 1.49 & 1.32 & 1.12 & 1.34 & 1.41 & 1.66 & 1.63 \\
\hline & & Plan 6 & 1.84 & 1.35 & 1.23 & 1.48 & 1.29 & 1.07 & 1.32 & 1.34 & 1.55 & 0.59 \\
\hline & & Plan 7 & 1.84 & 1.35 & 1.25 & 1.51 & 1.28 & 1.07 & 1.34 & 1.37 & 1.56 & 0.64 \\
\hline & & Plan 8 & 1.84 & 1.40 & 1.28 & 1.50 & 1.28 & 1.06 & 1.33 & 1.40 & 1.64 & 1.06 \\
\hline & \multirow[t]{9}{*}{2.5} & EC & 2.43 & 1.67 & 1.70 & 1.73 & 1.48 & 1.40 & 1.61 & 1.72 & 1.97 & 1.31 \\
\hline & & Plan 1 & 2.37 & 1.72 & 1.52 & 1.71 & 1.58 & 1.35 & 1.58 & 1.67 & 1.88 & 1.63 \\
\hline & & Plan 2 & 2.38 & 1.75 & 1.52 & 1.70 & 1.54 & 1.33 & 1.59 & 1.70 & 1.92 & 1.15 \\
\hline & & Plan 3 & 2.45 & 1.67 & 1.67 & 1.70 & 1.55 & 1.47 & 1.56 & 1.70 & 1.93 & 1.83 \\
\hline & & Plan 4 & 2.37 & 1.60 & 1.35 & 1.64 & 1.50 & 1.25 & 1.49 & 1.57 & 1.86 & 0.68 \\
\hline & & Plan 5 & 2.37 & 1.60 & 1.45 & 1.66 & 1.56 & 1.31 & 1.52 & 1.59 & 1.83 & 1.88 \\
\hline & & Plan 6 & 2.37 & 1.62 & 1.40 & 1.59 & 1.52 & 1.27 & 1.51 & 1.51 & 1.70 & 0.65 \\
\hline & & Plan 7 & 2.37 & 1.56 & 1.35 & 1.60 & 1.53 & 1.26 & 1.46 & 1.48 & 1.65 & 0.70 \\
\hline & & Plan 8 & 2.38 & 1.63 & 1.40 & 1.56 & 1.53 & 1.27 & 1.49 & 1.49 & 1.69 & 1.17 \\
\hline
\end{tabular}




\begin{tabular}{|c|c|c|c|c|c|c|c|c|c|c|c|c|}
\hline \multicolumn{2}{|c|}{$\begin{array}{l}\text { Experimental } \\
\text { Wave }\end{array}$} & \multicolumn{11}{|c|}{ Wave Height $(\mathrm{m})$ at Indicated Gauge Location; $\mathrm{swl}=+0.9 \mathrm{~m}$} \\
\hline $\begin{array}{l}\text { Period } \\
\text { (sec) }\end{array}$ & $\begin{array}{l}\text { Height } \\
(\mathrm{m})\end{array}$ & Plan & $\begin{array}{l}\text { Gauge } \\
11\end{array}$ & $\begin{array}{l}\text { Gauge } \\
12\end{array}$ & $\begin{array}{l}\text { Gauge } \\
13\end{array}$ & $\begin{array}{l}\text { Gauge } \\
14\end{array}$ & $\begin{array}{l}\text { Gauge } \\
15\end{array}$ & $\begin{array}{l}\text { Gauge } \\
16\end{array}$ & $\begin{array}{l}\text { Gauge } \\
17\end{array}$ & $\begin{array}{l}\text { Gauge } \\
18\end{array}$ & $\begin{array}{l}\text { Gauge } \\
19\end{array}$ & $\begin{array}{l}\text { Gauge } \\
20\end{array}$ \\
\hline \multirow[t]{27}{*}{6} & \multirow[t]{9}{*}{1} & EC & 0.48 & 0.51 & 0.53 & 0.70 & 0.62 & 0.58 & 0.61 & 0.69 & 0.52 & 0.53 \\
\hline & & Plan 1 & 0.65 & 0.75 & 0.75 & 0.84 & 0.92 & 0.70 & 0.78 & 0.91 & 0.64 & 0.68 \\
\hline & & Plan 2 & 0.43 & 0.58 & 0.85 & 1.00 & 0.80 & 0.60 & 0.89 & 0.99 & 0.55 & 0.50 \\
\hline & & Plan 3 & 0.75 & 0.51 & 0.44 & 0.50 & 0.79 & 0.56 & 0.52 & 0.63 & 0.52 & 0.72 \\
\hline & & Plan 4 & 0.43 & 0.59 & 0.72 & 0.79 & 0.41 & 0.45 & 0.81 & 0.69 & 0.46 & 0.42 \\
\hline & & Plan 5 & 0.69 & 0.48 & 0.37 & 0.23 & 0.79 & 0.42 & 0.38 & 0.51 & 0.41 & 0.66 \\
\hline & & Plan 6 & 0.46 & 0.53 & 0.44 & 0.28 & 0.45 & 0.30 & 0.42 & 0.35 & 0.36 & 0.31 \\
\hline & & Plan 7 & 0.53 & 0.51 & 0.48 & 0.57 & 0.28 & 0.37 & 0.67 & 0.49 & 0.39 & 0.41 \\
\hline & & Plan 8 & 0.51 & 0.55 & 0.52 & 0.33 & 0.68 & 0.35 & 0.37 & 0.52 & 0.35 & 0.48 \\
\hline & \multirow[t]{9}{*}{2} & EC & 0.77 & 0.84 & 0.85 & 1.09 & 0.97 & 0.93 & 0.96 & 1.05 & 0.83 & 0.83 \\
\hline & & Plan 1 & 1.06 & 1.19 & 1.17 & 1.27 & 1.47 & 1.11 & 1.24 & 1.31 & 1.04 & 1.19 \\
\hline & & Plan 2 & 0.74 & 0.96 & 1.32 & 1.55 & 1.33 & 0.95 & 1.37 & 1.48 & 0.90 & 0.83 \\
\hline & & Plan 3 & 1.09 & 0.87 & 0.74 & 0.84 & 1.25 & 0.98 & 0.93 & 0.98 & 0.88 & 1.24 \\
\hline & & Plan 4 & 0.78 & 1.04 & 1.22 & 1.36 & 0.76 & 0.79 & 1.38 & 1.18 & 0.78 & 0.70 \\
\hline & & Plan 5 & 1.23 & 0.91 & 0.69 & 0.43 & 1.40 & 0.81 & 0.72 & 0.89 & 0.73 & 1.26 \\
\hline & & Plan 6 & 0.81 & 0.96 & 0.78 & 0.50 & 0.81 & 0.56 & 0.73 & 0.63 & 0.62 & 0.58 \\
\hline & & Plan 7 & 0.84 & 0.84 & 0.79 & 0.95 & 0.51 & 0.62 & 1.09 & 0.85 & 0.61 & 0.63 \\
\hline & & Plan 8 & 0.81 & 0.89 & 0.83 & 0.54 & 1.07 & 0.58 & 0.59 & 0.82 & 0.54 & 0.82 \\
\hline & \multirow[t]{9}{*}{2.5} & EC & 0.88 & 0.98 & 0.99 & 1.25 & 1.14 & 1.08 & 1.11 & 1.19 & 0.97 & 0.97 \\
\hline & & Plan 1 & 1.23 & 1.48 & 1.39 & 1.46 & 1.75 & 1.35 & 1.53 & 1.55 & 1.23 & 1.46 \\
\hline & & Plan 2 & 0.90 & 1.14 & 1.51 & 1.74 & 1.61 & 1.05 & 1.59 & 1.67 & 1.04 & 1.03 \\
\hline & & Plan 3 & 1.34 & 1.07 & 0.91 & 1.03 & 1.45 & 1.16 & 1.19 & 1.15 & 1.05 & 1.47 \\
\hline & & Plan 4 & 0.88 & 1.14 & 1.32 & 1.49 & 0.85 & 0.86 & 1.48 & 1.27 & 0.85 & 0.77 \\
\hline & & Plan 5 & 1.43 & 1.06 & 0.77 & 0.51 & 1.57 & 0.96 & 0.90 & 1.00 & 0.86 & 1.42 \\
\hline & & Plan 6 & 0.88 & 1.05 & 0.85 & 0.56 & 0.88 & 0.62 & 0.79 & 0.72 & 0.64 & 0.64 \\
\hline & & Plan 7 & 0.92 & 0.91 & 0.84 & 1.03 & 0.58 & 0.65 & 1.16 & 0.89 & 0.65 & 0.69 \\
\hline & & Plan 8 & 0.88 & 0.95 & 0.88 & 0.58 & 1.09 & 0.65 & 0.65 & 0.86 & 0.57 & 0.89 \\
\hline
\end{tabular}




\begin{tabular}{|c|c|c|c|c|c|c|c|c|c|c|c|c|}
\hline \multicolumn{2}{|c|}{$\begin{array}{l}\text { Experimental } \\
\text { Wave }\end{array}$} & \multicolumn{11}{|c|}{ Wave Height $(\mathrm{m})$ at Indicated Gauge Location; swl $=+0.9 \mathrm{~m}$} \\
\hline $\begin{array}{l}\text { Period } \\
\text { (sec) }\end{array}$ & $\begin{array}{l}\text { Height } \\
(\mathrm{m})\end{array}$ & Plan & $\begin{array}{l}\text { Gauge } \\
1\end{array}$ & $\begin{array}{l}\text { Gauge } \\
2\end{array}$ & $\begin{array}{l}\text { Gauge } \\
3\end{array}$ & $\begin{array}{l}\text { Gauge } \\
4\end{array}$ & $\begin{array}{l}\text { Gauge } \\
5\end{array}$ & $\begin{array}{l}\text { Gauge } \\
6\end{array}$ & $\begin{array}{l}\text { Gauge } \\
7\end{array}$ & $\begin{array}{l}\text { Gauge } \\
8\end{array}$ & $\begin{array}{l}\text { Gauge } \\
9\end{array}$ & $\begin{array}{l}\text { Gauge } \\
10\end{array}$ \\
\hline \multirow[t]{27}{*}{7} & \multirow[t]{9}{*}{1} & EC & 0.99 & 0.81 & 0.89 & 0.94 & 0.76 & 0.69 & 0.81 & 0.88 & 1.05 & 0.67 \\
\hline & & Plan 1 & 0.97 & 0.82 & 0.78 & 0.89 & 0.74 & 0.63 & 0.80 & 0.86 & 0.99 & 0.81 \\
\hline & & Plan 2 & 0.96 & 0.86 & 0.82 & 0.94 & 0.75 & 0.62 & 0.81 & 0.92 & 1.09 & 0.54 \\
\hline & & Plan 3 & 0.99 & 0.82 & 0.88 & 0.92 & 0.74 & 0.71 & 0.78 & 0.86 & 0.99 & 0.94 \\
\hline & & Plan 4 & 0.95 & 0.82 & 0.72 & 0.85 & 0.67 & 0.58 & 0.75 & 0.86 & 1.08 & 0.31 \\
\hline & & Plan 5 & 0.92 & 0.80 & 0.76 & 0.85 & 0.69 & 0.59 & 0.73 & 0.84 & 1.03 & 0.95 \\
\hline & & Plan 6 & 0.93 & 0.80 & 0.72 & 0.84 & 0.70 & 0.57 & 0.72 & 0.82 & 1.00 & 0.32 \\
\hline & & Plan 7 & 0.94 & 0.86 & 0.78 & 0.89 & 0.75 & 0.64 & 0.77 & 0.85 & 1.04 & 0.37 \\
\hline & & Plan 8 & 0.93 & 0.83 & 0.75 & 0.89 & 0.70 & 0.59 & 0.75 & 0.86 & 1.04 & 0.62 \\
\hline & \multirow[t]{9}{*}{2} & EC & 1.88 & 1.38 & 1.41 & 1.53 & 1.28 & 1.23 & 1.37 & 1.48 & 1.66 & 1.10 \\
\hline & & Plan 1 & 1.83 & 1.42 & 1.25 & 1.49 & 1.29 & 1.15 & 1.37 & 1.46 & 1.61 & 1.46 \\
\hline & & Plan 2 & 1.86 & 1.52 & 1.32 & 1.53 & 1.38 & 1.22 & 1.41 & 1.52 & 1.70 & 1.05 \\
\hline & & Plan 3 & 1.87 & 1.38 & 1.40 & 1.50 & 1.32 & 1.28 & 1.36 & 1.46 & 1.59 & 1.60 \\
\hline & & Plan 4 & 1.86 & 1.59 & 1.29 & 1.54 & 1.34 & 1.18 & 1.41 & 1.58 & 1.87 & 0.64 \\
\hline & & Plan 5 & 1.81 & 1.56 & 1.33 & 1.47 & 1.33 & 1.16 & 1.40 & 1.53 & 1.76 & 1.71 \\
\hline & & Plan 6 & 1.84 & 1.56 & 1.33 & 1.61 & 1.43 & 1.22 & 1.42 & 1.54 & 1.72 & 0.63 \\
\hline & & Plan 7 & 1.84 & 1.59 & 1.31 & 1.55 & 1.42 & 1.22 & 1.41 & 1.53 & 1.71 & 0.66 \\
\hline & & Plan 8 & 1.84 & 1.57 & 1.28 & 1.51 & 1.36 & 1.18 & 1.38 & 1.50 & 1.70 & 1.11 \\
\hline & \multirow[t]{9}{*}{2.5} & EC & 2.48 & 1.68 & 1.68 & 1.84 & 1.78 & 1.63 & 1.66 & 1.70 & 1.86 & 1.28 \\
\hline & & Plan 1 & 2.41 & 1.77 & 1.52 & 1.76 & 1.77 & 1.50 & 1.65 & 1.66 & 1.80 & 1.80 \\
\hline & & Plan 2 & 2.42 & 1.75 & 1.49 & 1.75 & 1.76 & 1.49 & 1.62 & 1.67 & 1.83 & 1.32 \\
\hline & & Plan 3 & 2.47 & 1.68 & 1.66 & 1.80 & 1.76 & 1.64 & 1.63 & 1.67 & 1.82 & 1.94 \\
\hline & & Plan 4 & 2.42 & 1.88 & 1.49 & 1.79 & 1.76 & 1.49 & 1.67 & 1.76 & 2.06 & 0.83 \\
\hline & & Plan 5 & 2.39 & 1.92 & 1.61 & 1.85 & 1.88 & 1.59 & 1.72 & 1.76 & 1.98 & 2.07 \\
\hline & & Plan 6 & 2.38 & 1.89 & 1.53 & 1.80 & 1.76 & 1.49 & 1.67 & 1.77 & 1.95 & 0.74 \\
\hline & & Plan 7 & 2.40 & 1.89 & 1.52 & 1.79 & 1.82 & 1.54 & 1.67 & 1.72 & 1.88 & 0.76 \\
\hline & & Plan 8 & 2.39 & 1.86 & 1.49 & 1.74 & 1.76 & 1.49 & 1.64 & 1.70 & 1.88 & 1.31 \\
\hline
\end{tabular}




\begin{tabular}{|c|c|c|c|c|c|c|c|c|c|c|c|c|}
\hline \multicolumn{2}{|c|}{$\begin{array}{l}\text { Experimental } \\
\text { Wave }\end{array}$} & \multicolumn{11}{|c|}{ Wave Height $(\mathrm{m})$ at Indicated Gauge Location; swl $=+0.9 \mathrm{~m}$} \\
\hline $\begin{array}{l}\text { Period } \\
\text { (sec) }\end{array}$ & $\begin{array}{l}\text { Height } \\
(\mathrm{m})\end{array}$ & Plan & $\begin{array}{l}\text { Gauge } \\
11\end{array}$ & $\begin{array}{l}\text { Gauge } \\
12\end{array}$ & $\begin{array}{l}\text { Gauge } \\
13\end{array}$ & $\begin{array}{l}\text { Gauge } \\
14\end{array}$ & $\begin{array}{l}\text { Gauge } \\
15\end{array}$ & $\begin{array}{l}\text { Gauge } \\
16\end{array}$ & $\begin{array}{l}\text { Gauge } \\
17\end{array}$ & $\begin{array}{l}\text { Gauge } \\
18\end{array}$ & $\begin{array}{l}\text { Gauge } \\
19\end{array}$ & $\begin{array}{l}\text { Gauge } \\
20\end{array}$ \\
\hline \multirow[t]{27}{*}{7} & \multirow[t]{9}{*}{1} & EC & 0.46 & 0.49 & 0.51 & 0.68 & 0.60 & 0.51 & 0.61 & 0.63 & 0.48 & 0.51 \\
\hline & & Plan 1 & 0.71 & 0.72 & 0.70 & 0.75 & 0.93 & 0.66 & 0.72 & 0.78 & 0.64 & 0.74 \\
\hline & & Plan 2 & 0.44 & 0.56 & 0.82 & 0.98 & 0.83 & 0.56 & 0.83 & 0.91 & 0.53 & 0.58 \\
\hline & & Plan 3 & 0.77 & 0.53 & 0.42 & 0.47 & 0.76 & 0.54 & 0.61 & 0.61 & 0.51 & 0.75 \\
\hline & & Plan 4 & 0.44 & 0.62 & 0.72 & 0.78 & 0.41 & 0.44 & 0.82 & 0.69 & 0.45 & 0.40 \\
\hline & & Plan 5 & 0.71 & 0.51 & 0.37 & 0.24 & 0.80 & 0.43 & 0.44 & 0.45 & 0.43 & 0.71 \\
\hline & & Plan 6 & 0.44 & 0.52 & 0.43 & 0.28 & 0.41 & 0.28 & 0.39 & 0.32 & 0.33 & 0.30 \\
\hline & & Plan 7 & 0.49 & 0.50 & 0.48 & 0.57 & 0.28 & 0.36 & 0.66 & 0.50 & 0.36 & 0.38 \\
\hline & & Plan 8 & 0.47 & 0.49 & 0.45 & 0.30 & 0.62 & 0.32 & 0.33 & 0.43 & 0.32 & 0.47 \\
\hline & \multirow[t]{9}{*}{2} & EC & 0.76 & 0.81 & 0.79 & 1.03 & 0.99 & 0.85 & 0.92 & 0.98 & 0.76 & 0.84 \\
\hline & & Plan 1 & 1.18 & 1.25 & 1.16 & 1.17 & 1.48 & 1.17 & 1.27 & 1.24 & 1.09 & 1.30 \\
\hline & & Plan 2 & 0.87 & 0.98 & 1.28 & 1.51 & 1.50 & 0.92 & 1.26 & 1.42 & 0.89 & 1.05 \\
\hline & & Plan 3 & 1.20 & 0.95 & 0.78 & 0.86 & 1.20 & 0.99 & 1.19 & 1.09 & 0.92 & 1.27 \\
\hline & & Plan 4 & 0.83 & 1.11 & 1.27 & 1.38 & 0.85 & 0.80 & 1.39 & 1.21 & 0.79 & 0.75 \\
\hline & & Plan 5 & 1.32 & 1.02 & 0.74 & 0.51 & 1.41 & 0.85 & 0.90 & 0.90 & 0.80 & 1.31 \\
\hline & & Plan 6 & 0.84 & 0.98 & 0.77 & 0.52 & 0.81 & 0.55 & 0.73 & 0.63 & 0.59 & 0.58 \\
\hline & & Plan 7 & 0.84 & 0.85 & 0.81 & 0.99 & 0.60 & 0.61 & 1.09 & 0.87 & 0.61 & 0.65 \\
\hline & & Plan 8 & 0.84 & 0.87 & 0.78 & 0.52 & 1.03 & 0.59 & 0.61 & 0.74 & 0.55 & 0.86 \\
\hline & \multirow[t]{9}{*}{2.5} & EC & 0.87 & 0.95 & 0.90 & 1.20 & 1.14 & 1.01 & 1.01 & 1.07 & 0.93 & 0.99 \\
\hline & & Plan 1 & 1.40 & 1.52 & 1.40 & 1.41 & 1.71 & 1.43 & 1.62 & 1.44 & 1.33 & 1.59 \\
\hline & & Plan 2 & 1.02 & 1.12 & 1.40 & 1.68 & 1.73 & 1.06 & 1.40 & 1.54 & 1.00 & 1.26 \\
\hline & & Plan 3 & 1.56 & 1.19 & 0.99 & 1.10 & 1.42 & 1.19 & 1.57 & 1.26 & 1.12 & 1.61 \\
\hline & & Plan 4 & 1.00 & 1.26 & 1.41 & 1.56 & 1.02 & 0.88 & 1.57 & 1.36 & 0.89 & 0.88 \\
\hline & & Plan 5 & 1.65 & 1.33 & 0.95 & 0.68 & 1.68 & 1.09 & 1.27 & 1.04 & 1.04 & 1.66 \\
\hline & & Plan 6 & 0.95 & 1.10 & 0.88 & 0.62 & 0.92 & 0.62 & 0.84 & 0.73 & 0.68 & 0.66 \\
\hline & & Plan 7 & 0.95 & 0.97 & 0.93 & 1.16 & 0.72 & 0.69 & 1.25 & 0.98 & 0.71 & 0.76 \\
\hline & & Plan 8 & 0.97 & 0.98 & 0.88 & 0.62 & 1.12 & 0.69 & 0.71 & 0.81 & 0.63 & 0.98 \\
\hline
\end{tabular}




\begin{tabular}{|c|c|c|c|c|c|c|c|c|c|c|c|c|}
\hline \multicolumn{2}{|c|}{$\begin{array}{l}\text { Experimental } \\
\text { Wave }\end{array}$} & \multicolumn{11}{|c|}{ Wave Height $(\mathrm{m})$ at Indicated Gauge Location; swl $=+0.9 \mathrm{~m}$} \\
\hline $\begin{array}{l}\text { Period } \\
\text { (sec) }\end{array}$ & $\begin{array}{l}\text { Height } \\
(\mathrm{m})\end{array}$ & Plan & $\begin{array}{l}\text { Gauge } \\
1\end{array}$ & $\begin{array}{l}\text { Gauge } \\
2\end{array}$ & $\begin{array}{l}\text { Gauge } \\
3\end{array}$ & $\begin{array}{l}\text { Gauge } \\
4\end{array}$ & $\begin{array}{l}\text { Gauge } \\
5\end{array}$ & $\begin{array}{l}\text { Gauge } \\
6\end{array}$ & $\begin{array}{l}\text { Gauge } \\
7\end{array}$ & $\begin{array}{l}\text { Gauge } \\
8\end{array}$ & $\begin{array}{l}\text { Gauge } \\
9\end{array}$ & $\begin{array}{l}\text { Gauge } \\
10\end{array}$ \\
\hline \multirow[t]{27}{*}{8} & \multirow[t]{9}{*}{1} & EC & 0.97 & 0.87 & 0.82 & 0.87 & 0.74 & 0.72 & 0.84 & 0.97 & 1.10 & 0.57 \\
\hline & & Plan 1 & 0.96 & 0.95 & 0.77 & 0.88 & 0.81 & 0.72 & 0.87 & 0.98 & 1.08 & 0.97 \\
\hline & & Plan 2 & 0.95 & 0.95 & 0.76 & 0.88 & 0.81 & 0.70 & 0.84 & 0.99 & 1.14 & 0.64 \\
\hline & & Plan 3 & 0.99 & 0.93 & 0.86 & 0.89 & 0.78 & 0.78 & 0.86 & 0.97 & 1.06 & 1.04 \\
\hline & & Plan 4 & 0.98 & 0.94 & 0.71 & 0.83 & 0.78 & 0.69 & 0.81 & 0.96 & 1.16 & 0.34 \\
\hline & & Plan 5 & 0.96 & 0.92 & 0.74 & 0.84 & 0.73 & 0.67 & 0.81 & 0.93 & 1.08 & 1.03 \\
\hline & & Plan 6 & 0.96 & 0.93 & 0.72 & 0.85 & 0.75 & 0.65 & 0.80 & 0.95 & 1.11 & 0.31 \\
\hline & & Plan 7 & 0.97 & 0.95 & 0.74 & 0.86 & 0.77 & 0.69 & 0.82 & 0.95 & 1.11 & 0.33 \\
\hline & & Plan 8 & 0.97 & 0.92 & 0.72 & 0.84 & 0.73 & 0.65 & 0.79 & 0.94 & 1.11 & 0.58 \\
\hline & \multirow[t]{9}{*}{2} & EC & 1.99 & 1.69 & 1.53 & 1.62 & 1.65 & 1.55 & 1.64 & 1.69 & 1.85 & 1.13 \\
\hline & & Plan 1 & 1.94 & 1.75 & 1.39 & 1.60 & 1.74 & 1.48 & 1.62 & 1.63 & 1.74 & 1.71 \\
\hline & & Plan 2 & 1.96 & 1.78 & 1.38 & 1.59 & 1.78 & 1.51 & 1.62 & 1.65 & 1.80 & 1.41 \\
\hline & & Plan 3 & 1.97 & 1.70 & 1.54 & 1.64 & 1.68 & 1.59 & 1.63 & 1.68 & 1.79 & 1.87 \\
\hline & & Plan 4 & 2.01 & 1.78 & 1.35 & 1.66 & 1.79 & 1.53 & 1.62 & 1.64 & 1.86 & 0.80 \\
\hline & & Plan 5 & 1.98 & 1.70 & 1.35 & 1.57 & 1.72 & 1.49 & 1.59 & 1.55 & 1.70 & 1.89 \\
\hline & & Plan 6 & 1.99 & 1.69 & 1.31 & 1.64 & 1.67 & 1.43 & 1.56 & 1.60 & 1.72 & 0.65 \\
\hline & & Plan 7 & 2.00 & 1.70 & 1.31 & 1.61 & 1.68 & 1.45 & 1.57 & 1.58 & 1.69 & 0.67 \\
\hline & & Plan 8 & 1.98 & 1.71 & 1.30 & 1.54 & 1.69 & 1.45 & 1.54 & 1.53 & 1.66 & 1.13 \\
\hline & \multirow[t]{9}{*}{2.5} & EC & 2.44 & 1.92 & 1.72 & 1.87 & 1.98 & 1.85 & 1.88 & 1.80 & 1.88 & 1.31 \\
\hline & & Plan 1 & 2.42 & 2.00 & 1.57 & 1.85 & 2.07 & 1.72 & 1.84 & 1.78 & 1.86 & 1.94 \\
\hline & & Plan 2 & 2.41 & 2.02 & 1.56 & 1.83 & 2.07 & 1.74 & 1.83 & 1.81 & 1.91 & 1.68 \\
\hline & & Plan 3 & 2.47 & 1.92 & 1.71 & 1.84 & 1.98 & 1.83 & 1.84 & 1.82 & 1.91 & 2.07 \\
\hline & & Plan 4 & 2.50 & 2.00 & 1.50 & 1.84 & 2.06 & 1.72 & 1.78 & 1.77 & 2.00 & 0.92 \\
\hline & & Plan 5 & 2.45 & 1.96 & 1.59 & 1.85 & 2.01 & 1.68 & 1.80 & 1.81 & 2.00 & 2.13 \\
\hline & & Plan 6 & 2.45 & 1.97 & 1.51 & 1.82 & 1.97 & 1.66 & 1.77 & 1.76 & 1.88 & 0.76 \\
\hline & & Plan 7 & 2.45 & 1.97 & 1.52 & 1.84 & 2.01 & 1.69 & 1.78 & 1.75 & 1.86 & 0.79 \\
\hline & & Plan 8 & 2.45 & 1.97 & 1.51 & 1.81 & 1.98 & 1.67 & 1.76 & 1.74 & 1.88 & 1.33 \\
\hline
\end{tabular}




\begin{tabular}{|c|c|c|c|c|c|c|c|c|c|c|c|c|}
\hline \multicolumn{2}{|c|}{$\begin{array}{l}\text { Experimental } \\
\text { Wave }\end{array}$} & \multicolumn{11}{|c|}{ Wave Height $(\mathrm{m})$ at Indicated Gauge Location; $\mathrm{swl}=+0.9 \mathrm{~m}$} \\
\hline $\begin{array}{l}\text { Period } \\
\text { (sec) }\end{array}$ & $\begin{array}{l}\text { Height } \\
(\mathrm{m})\end{array}$ & Plan & $\begin{array}{l}\text { Gauge } \\
11\end{array}$ & $\begin{array}{l}\text { Gauge } \\
12\end{array}$ & $\begin{array}{l}\text { Gauge } \\
13\end{array}$ & $\begin{array}{l}\text { Gauge } \\
14\end{array}$ & $\begin{array}{l}\text { Gauge } \\
15\end{array}$ & $\begin{array}{l}\text { Gauge } \\
16\end{array}$ & $\begin{array}{l}\text { Gauge } \\
17\end{array}$ & $\begin{array}{l}\text { Gauge } \\
18\end{array}$ & $\begin{array}{l}\text { Gauge } \\
19\end{array}$ & $\begin{array}{l}\text { Gauge } \\
20\end{array}$ \\
\hline \multirow[t]{27}{*}{8} & \multirow[t]{9}{*}{1} & EC & 0.42 & 0.43 & 0.43 & 0.55 & 0.54 & 0.46 & 0.49 & 0.52 & 0.42 & 0.45 \\
\hline & & Plan 1 & 0.86 & 0.79 & 0.74 & 0.76 & 0.97 & 0.75 & 0.85 & 0.83 & 0.70 & 0.88 \\
\hline & & Plan 2 & 0.53 & 0.58 & 0.80 & 0.95 & 0.97 & 0.55 & 0.75 & 0.84 & 0.52 & 0.74 \\
\hline & & Plan 3 & 0.87 & 0.60 & 0.52 & 0.56 & 0.71 & 0.63 & 0.85 & 0.79 & 0.59 & 0.75 \\
\hline & & Plan 4 & 0.43 & 0.62 & 0.74 & 0.80 & 0.45 & 0.44 & 0.82 & 0.69 & 0.45 & 0.42 \\
\hline & & Plan 5 & 0.81 & 0.62 & 0.43 & 0.29 & 0.87 & 0.48 & 0.53 & 0.52 & 0.48 & 0.79 \\
\hline & & Plan 6 & 0.41 & 0.49 & 0.40 & 0.28 & 0.39 & 0.26 & 0.36 & 0.29 & 0.31 & 0.28 \\
\hline & & Plan 7 & 0.42 & 0.43 & 0.45 & 0.55 & 0.29 & 0.32 & 0.61 & 0.46 & 0.33 & 0.35 \\
\hline & & Plan 8 & 0.44 & 0.43 & 0.40 & 0.27 & 0.56 & 0.29 & 0.32 & 0.39 & 0.29 & 0.44 \\
\hline & \multirow[t]{9}{*}{2} & EC & 0.83 & 0.89 & 0.84 & 1.05 & 1.05 & 0.93 & 0.97 & 1.01 & 0.84 & 0.92 \\
\hline & & Plan 1 & 1.36 & 1.49 & 1.40 & 1.42 & 1.65 & 1.42 & 1.60 & 1.41 & 1.32 & 1.50 \\
\hline & & Plan 2 & 1.07 & 1.10 & 1.34 & 1.57 & 1.76 & 1.05 & 1.33 & 1.46 & 0.98 & 1.30 \\
\hline & & Plan 3 & 1.52 & 1.19 & 1.08 & 1.20 & 1.34 & 1.21 & 1.61 & 1.37 & 1.12 & 1.51 \\
\hline & & Plan 4 & 0.90 & 1.16 & 1.32 & 1.45 & 0.96 & 0.81 & 1.45 & 1.21 & 0.80 & 0.89 \\
\hline & & Plan 5 & 1.51 & 1.20 & 0.86 & 0.66 & 1.54 & 0.97 & 1.20 & 1.04 & 0.90 & 1.47 \\
\hline & & Plan 6 & 0.81 & 0.94 & 0.74 & 0.53 & 0.77 & 0.54 & 0.70 & 0.60 & 0.58 & 0.56 \\
\hline & & Plan 7 & 0.83 & 0.85 & 0.83 & 1.00 & 0.66 & 0.60 & 1.08 & 0.83 & 0.61 & 0.68 \\
\hline & & Plan 8 & 0.86 & 0.85 & 0.75 & 0.54 & 0.99 & 0.59 & 0.67 & 0.73 & 0.55 & 0.84 \\
\hline & \multirow[t]{9}{*}{2.5} & EC & 0.92 & 0.99 & 0.92 & 1.18 & 1.19 & 1.04 & 1.07 & 1.10 & 0.96 & 1.04 \\
\hline & & Plan 1 & 1.55 & 1.71 & 1.60 & 1.62 & 1.84 & 1.64 & 1.80 & 1.62 & 1.49 & 1.73 \\
\hline & & Plan 2 & 1.18 & 1.27 & 1.48 & 1.76 & 1.99 & 1.19 & 1.49 & 1.59 & 1.13 & 1.52 \\
\hline & & Plan 3 & 1.72 & 1.32 & 1.23 & 1.39 & 1.44 & 1.34 & 1.84 & 1.54 & 1.24 & 1.67 \\
\hline & & Plan 4 & 1.00 & 1.25 & 1.41 & 1.58 & 1.06 & 0.86 & 1.57 & 1.30 & 0.86 & 1.00 \\
\hline & & Plan 5 & 1.70 & 1.37 & 0.99 & 0.80 & 1.68 & 1.11 & 1.42 & 1.21 & 1.02 & 1.65 \\
\hline & & Plan 6 & 0.92 & 1.07 & 0.84 & 0.62 & 0.88 & 0.61 & 0.82 & 0.70 & 0.64 & 0.65 \\
\hline & & Plan 7 & 0.95 & 0.97 & 0.91 & 1.12 & 0.76 & 0.68 & 1.20 & 0.93 & 0.69 & 0.79 \\
\hline & & Plan 8 & 0.98 & 0.97 & 0.85 & 0.63 & 1.10 & 0.68 & 0.75 & 0.82 & 0.62 & 0.98 \\
\hline
\end{tabular}


Table D4. Wave heights for waves from 45 degrees South; $0.0 \mathrm{~m}$ swl.

\begin{tabular}{|c|c|c|c|c|c|c|c|c|c|c|c|c|}
\hline \multicolumn{2}{|c|}{$\begin{array}{l}\text { Experimental } \\
\text { Wave }\end{array}$} & \multicolumn{11}{|c|}{ Wave Height $(\mathrm{m})$ at Indicated Gauge Location; swl $=+0.0 \mathrm{~m}$} \\
\hline $\begin{array}{l}\text { Period } \\
\text { (sec) }\end{array}$ & $\begin{array}{l}\text { Height } \\
(\mathrm{m})\end{array}$ & Plan & $\begin{array}{l}\text { Gauge } \\
1\end{array}$ & $\begin{array}{l}\text { Gauge } \\
2\end{array}$ & $\begin{array}{l}\text { Gauge } \\
3\end{array}$ & $\begin{array}{l}\text { Gauge } \\
4\end{array}$ & $\begin{array}{l}\text { Gauge } \\
5\end{array}$ & $\begin{array}{l}\text { Gauge } \\
6\end{array}$ & $\begin{array}{l}\text { Gauge } \\
7\end{array}$ & $\begin{array}{l}\text { Gauge } \\
8\end{array}$ & $\begin{array}{l}\text { Gauge } \\
9\end{array}$ & \begin{tabular}{|l} 
Gauge \\
10 \\
\end{tabular} \\
\hline \multirow[t]{27}{*}{5} & \multirow[t]{9}{*}{1} & EC & 0.99 & 0.64 & 0.58 & 0.71 & 1.09 & 0.49 & 0.50 & 0.60 & 0.76 & 0.39 \\
\hline & & Plan 1 & 1.00 & 0.65 & 0.60 & 0.73 & 1.07 & 0.48 & 0.48 & 0.58 & 0.76 & 0.49 \\
\hline & & Plan 2 & 0.96 & 0.41 & 0.52 & 0.61 & 0.74 & 0.38 & 0.36 & 0.42 & 0.55 & 0.35 \\
\hline & & Plan 3 & 1.00 & 0.43 & 0.61 & 0.62 & 0.83 & 0.48 & 0.39 & 0.49 & 0.61 & 0.35 \\
\hline & & Plan 4 & 1.01 & 0.60 & 0.58 & 0.72 & 1.02 & 0.51 & 0.47 & 0.57 & 0.72 & 0.19 \\
\hline & & Plan 5 & 1.03 & 0.60 & 0.59 & 0.73 & 1.06 & 0.53 & 0.48 & 0.59 & 0.76 & 0.33 \\
\hline & & Plan 6 & 1.00 & 0.58 & 0.65 & 0.75 & 1.13 & 0.61 & 0.52 & 0.64 & 0.77 & 0.14 \\
\hline & & Plan 7 & 1.01 & 0.55 & 0.65 & 0.74 & 1.09 & 0.59 & 0.50 & 0.62 & 0.75 & 0.17 \\
\hline & & Plan 8 & 1.04 & 0.60 & 0.66 & 0.75 & 1.11 & 0.61 & 0.55 & 0.66 & 0.77 & 0.29 \\
\hline & \multirow[t]{9}{*}{2} & EC & 1.99 & 0.99 & 1.00 & 1.21 & 1.53 & 0.75 & 0.90 & 0.92 & 1.20 & 0.64 \\
\hline & & Plan 1 & 2.02 & 0.97 & 0.93 & 1.14 & 1.36 & 0.69 & 0.80 & 0.84 & 1.08 & 0.67 \\
\hline & & Plan 2 & 1.99 & 0.93 & 0.96 & 1.16 & 1.42 & 0.68 & 0.82 & 0.85 & 1.11 & 0.64 \\
\hline & & Plan 3 & 2.04 & 1.01 & 1.12 & 1.26 & 1.61 & 0.91 & 0.96 & 0.99 & 1.26 & 0.73 \\
\hline & & Plan 4 & 2.02 & 0.96 & 0.95 & 1.15 & 1.41 & 0.75 & 0.86 & 0.87 & 1.11 & 0.28 \\
\hline & & Plan 5 & 2.00 & 0.94 & 0.96 & 1.17 & 1.45 & 0.75 & 0.88 & 0.90 & 1.11 & 0.63 \\
\hline & & Plan 6 & 2.03 & 0.90 & 1.11 & 1.24 & 1.58 & 0.90 & 0.95 & 0.97 & 1.16 & 0.24 \\
\hline & & Plan 7 & 2.01 & 0.89 & 1.10 & 1.24 & 1.57 & 0.89 & 0.94 & 0.97 & 1.17 & 0.28 \\
\hline & & Plan 8 & 2.06 & 0.87 & 1.07 & 1.21 & 1.49 & 0.87 & 0.92 & 0.94 & 1.12 & 0.48 \\
\hline & \multirow[t]{9}{*}{2.5} & EC & 2.37 & 1.03 & 1.07 & 1.29 & 1.56 & 0.76 & 0.99 & 1.01 & 1.32 & 0.71 \\
\hline & & Plan 1 & 2.40 & 1.09 & 1.07 & 1.29 & 1.54 & 0.79 & 0.96 & 0.97 & 1.31 & 0.80 \\
\hline & & Plan 2 & 2.43 & 1.12 & 1.10 & 1.32 & 1.59 & 0.79 & 1.00 & 1.03 & 1.37 & 0.75 \\
\hline & & Plan 3 & 2.49 & 1.06 & 1.23 & 1.38 & 1.61 & 0.93 & 1.07 & 1.09 & 1.38 & 0.86 \\
\hline & & Plan 4 & 2.44 & 1.07 & 1.07 & 1.31 & 1.56 & 0.82 & 1.01 & 1.00 & 1.28 & 0.33 \\
\hline & & Plan 5 & 2.41 & 1.15 & 1.12 & 1.33 & 1.65 & 0.86 & 1.06 & 1.07 & 1.37 & 0.82 \\
\hline & & Plan 6 & 2.42 & 1.00 & 1.22 & 1.35 & 1.56 & 0.93 & 1.07 & 1.09 & 1.33 & 0.29 \\
\hline & & Plan 7 & 2.41 & 0.97 & 1.22 & 1.37 & 1.64 & 0.95 & 1.07 & 1.09 & 1.33 & 0.33 \\
\hline & & Plan 8 & 2.47 & 0.95 & 1.17 & 1.34 & 1.60 & 0.95 & 1.04 & 1.05 & 1.27 & 0.55 \\
\hline
\end{tabular}




\begin{tabular}{|c|c|c|c|c|c|c|c|c|c|c|c|c|}
\hline \multicolumn{2}{|c|}{$\begin{array}{l}\text { Experimental } \\
\text { Wave }\end{array}$} & \multicolumn{11}{|c|}{ Wave Height $(\mathrm{m})$ at Indicated Gauge Location; swl $=0.0 \mathrm{~m}$} \\
\hline $\begin{array}{l}\text { Period } \\
\text { (sec) }\end{array}$ & $\begin{array}{l}\text { Height } \\
(\mathrm{m})\end{array}$ & Plan & $\begin{array}{l}\text { Gauge } \\
11\end{array}$ & $\begin{array}{l}\text { Gauge } \\
12\end{array}$ & $\begin{array}{l}\text { Gauge } \\
13\end{array}$ & $\begin{array}{l}\text { Gauge } \\
14\end{array}$ & $\begin{array}{l}\text { Gauge } \\
15\end{array}$ & $\begin{array}{l}\text { Gauge } \\
16\end{array}$ & $\begin{array}{l}\text { Gauge } \\
17\end{array}$ & $\begin{array}{l}\text { Gauge } \\
18\end{array}$ & $\begin{array}{l}\text { Gauge } \\
19\end{array}$ & $\begin{array}{l}\text { Gauge } \\
20\end{array}$ \\
\hline \multirow[t]{27}{*}{5} & \multirow[t]{9}{*}{1} & EC & 0.22 & 0.34 & 0.34 & 0.45 & 0.32 & 0.30 & 0.49 & 0.49 & 0.29 & 0.29 \\
\hline & & Plan 1 & 0.28 & 0.48 & 0.60 & 0.83 & 0.46 & 0.53 & 0.80 & 0.64 & 0.49 & 0.62 \\
\hline & & Plan 2 & 0.12 & 0.22 & 0.39 & 0.54 & 0.29 & 0.33 & 0.46 & 0.42 & 0.29 & 0.34 \\
\hline & & Plan 3 & 0.26 & 0.39 & 0.34 & 0.46 & 0.35 & 0.30 & 0.52 & 0.47 & 0.32 & 0.39 \\
\hline & & Plan 4 & 0.18 & 0.29 & 0.56 & 0.68 & 0.37 & 0.39 & 0.46 & 0.48 & 0.37 & 0.36 \\
\hline & & Plan 5 & 0.31 & 0.45 & 0.50 & 0.32 & 0.51 & 0.25 & 0.40 & 0.43 & 0.30 & 0.33 \\
\hline & & Plan 6 & 0.29 & 0.35 & 0.37 & 0.21 & 0.35 & 0.25 & 0.20 & 0.28 & 0.27 & 0.26 \\
\hline & & Plan 7 & 0.31 & 0.28 & 0.32 & 0.44 & 0.15 & 0.27 & 0.35 & 0.33 & 0.26 & 0.30 \\
\hline & & Plan 8 & 0.27 & 0.36 & 0.37 & 0.21 & 0.52 & 0.12 & 0.25 & 0.47 & 0.20 & 0.26 \\
\hline & \multirow[t]{9}{*}{2} & EC & 0.39 & 0.52 & 0.50 & 0.66 & 0.52 & 0.47 & 0.71 & 0.69 & 0.43 & 0.45 \\
\hline & & Plan 1 & 0.44 & 0.68 & 0.85 & 1.03 & 0.80 & 0.69 & 0.96 & 0.91 & 0.67 & 0.71 \\
\hline & & Plan 2 & 0.35 & 0.52 & 0.81 & 1.02 & 0.74 & 0.59 & 0.88 & 0.88 & 0.56 & 0.64 \\
\hline & & Plan 3 & 0.50 & 0.65 & 0.65 & 0.93 & 0.59 & 0.61 & 0.94 & 0.83 & 0.58 & 0.77 \\
\hline & & Plan 4 & 0.35 & 0.54 & 0.85 & 0.96 & 0.58 & 0.60 & 0.69 & 0.74 & 0.55 & 0.52 \\
\hline & & Plan 5 & 0.52 & 0.59 & 0.66 & 0.41 & 0.77 & 0.34 & 0.51 & 0.59 & 0.39 & 0.49 \\
\hline & & Plan 6 & 0.46 & 0.54 & 0.54 & 0.31 & 0.52 & 0.39 & 0.32 & 0.39 & 0.41 & 0.35 \\
\hline & & Plan 7 & 0.51 & 0.45 & 0.49 & 0.67 & 0.27 & 0.40 & 0.55 & 0.50 & 0.39 & 0.46 \\
\hline & & Plan 8 & 0.43 & 0.54 & 0.55 & 0.32 & 0.76 & 0.22 & 0.37 & 0.65 & 0.32 & 0.38 \\
\hline & \multirow[t]{9}{*}{2.5} & EC & 0.44 & 0.57 & 0.53 & 0.72 & 0.58 & 0.52 & 0.78 & 0.77 & 0.47 & 0.49 \\
\hline & & Plan 1 & 0.52 & 0.82 & 0.95 & 1.17 & 0.94 & 0.79 & 1.12 & 1.06 & 0.77 & 0.84 \\
\hline & & Plan 2 & 0.43 & 0.62 & 0.95 & 1.17 & 0.90 & 0.68 & 1.03 & 1.03 & 0.65 & 0.74 \\
\hline & & Plan 3 & 0.61 & 0.70 & 0.68 & 0.98 & 0.69 & 0.66 & 0.99 & 0.90 & 0.64 & 0.79 \\
\hline & & Plan 4 & 0.42 & 0.62 & 0.93 & 1.08 & 0.67 & 0.66 & 0.76 & 0.83 & 0.59 & 0.60 \\
\hline & & Plan 5 & 0.66 & 0.71 & 0.74 & 0.44 & 0.94 & 0.43 & 0.60 & 0.72 & 0.46 & 0.63 \\
\hline & & Plan 6 & 0.54 & 0.62 & 0.60 & 0.36 & 0.59 & 0.43 & 0.36 & 0.46 & 0.46 & 0.41 \\
\hline & & Plan 7 & 0.59 & 0.53 & 0.55 & 0.75 & 0.34 & 0.45 & 0.62 & 0.57 & 0.43 & 0.51 \\
\hline & & Plan 8 & 0.45 & 0.58 & 0.60 & 0.35 & 0.81 & 0.27 & 0.41 & 0.70 & 0.35 & 0.42 \\
\hline
\end{tabular}




\begin{tabular}{|c|c|c|c|c|c|c|c|c|c|c|c|c|}
\hline \multicolumn{2}{|c|}{$\begin{array}{l}\text { Experimental } \\
\text { Wave }\end{array}$} & \multicolumn{11}{|c|}{ Wave Height $(\mathrm{m})$ at Indicated Gauge Location; swl $=0.0 \mathrm{~m}$} \\
\hline $\begin{array}{l}\text { Period } \\
\text { (sec) }\end{array}$ & $\begin{array}{l}\text { Height } \\
(\mathrm{m})\end{array}$ & Plan & $\begin{array}{l}\text { Gauge } \\
1\end{array}$ & $\begin{array}{l}\text { Gauge } \\
2\end{array}$ & $\begin{array}{l}\text { Gauge } \\
3\end{array}$ & $\begin{array}{l}\text { Gauge } \\
4\end{array}$ & $\begin{array}{l}\text { Gauge } \\
5\end{array}$ & $\begin{array}{l}\text { Gauge } \\
6\end{array}$ & $\begin{array}{l}\text { Gauge } \\
7\end{array}$ & $\begin{array}{l}\text { Gauge } \\
8\end{array}$ & $\begin{array}{l}\text { Gauge } \\
9\end{array}$ & $\begin{array}{l}\text { Gauge } \\
10\end{array}$ \\
\hline \multirow[t]{27}{*}{6} & \multirow[t]{9}{*}{1} & EC & 1.06 & 0.77 & 0.67 & 0.72 & 1.03 & 0.51 & 0.81 & 0.70 & 0.88 & 0.49 \\
\hline & & Plan 1 & 1.06 & 0.85 & 0.72 & 0.76 & 0.99 & 0.58 & 0.75 & 0.72 & 0.92 & 0.59 \\
\hline & & Plan 2 & 1.08 & 0.74 & 0.66 & 0.73 & 0.93 & 0.51 & 0.74 & 0.70 & 0.87 & 0.52 \\
\hline & & Plan 3 & 1.10 & 0.71 & 0.73 & 0.69 & 0.99 & 0.61 & 0.79 & 0.71 & 0.88 & 0.55 \\
\hline & & Plan 4 & 1.08 & 0.85 & 0.72 & 0.78 & 1.00 & 0.56 & 0.86 & 0.76 & 0.95 & 0.24 \\
\hline & & Plan 5 & 1.12 & 0.81 & 0.70 & 0.77 & 1.05 & 0.57 & 0.83 & 0.75 & 0.92 & 0.50 \\
\hline & & Plan 6 & 1.08 & 0.73 & 0.78 & 0.79 & 1.09 & 0.63 & 0.87 & 0.76 & 0.91 & 0.18 \\
\hline & & Plan 7 & 1.08 & 0.73 & 0.77 & 0.76 & 1.08 & 0.62 & 0.88 & 0.76 & 0.92 & 0.20 \\
\hline & & Plan 8 & 1.10 & 0.76 & 0.77 & 0.77 & 1.09 & 0.63 & 0.91 & 0.77 & 0.91 & 0.38 \\
\hline & \multirow[t]{9}{*}{2} & EC & 1.98 & 1.09 & 1.06 & 1.06 & 1.32 & 0.71 & 1.16 & 1.05 & 1.36 & 0.67 \\
\hline & & Plan 1 & 1.97 & 1.14 & 1.05 & 1.06 & 1.17 & 0.74 & 1.04 & 1.06 & 1.34 & 0.93 \\
\hline & & Plan 2 & 1.99 & 1.11 & 1.05 & 1.07 & 1.21 & 0.69 & 1.08 & 1.08 & 1.38 & 0.81 \\
\hline & & Plan 3 & 2.03 & 1.08 & 1.18 & 1.08 & 1.33 & 0.85 & 1.20 & 1.11 & 1.39 & 0.79 \\
\hline & & Plan 4 & 1.98 & 1.20 & 1.10 & 1.11 & 1.28 & 0.77 & 1.18 & 1.13 & 1.48 & 0.39 \\
\hline & & Plan 5 & 1.95 & 1.13 & 1.08 & 1.09 & 1.28 & 0.78 & 1.16 & 1.07 & 1.36 & 0.78 \\
\hline & & Plan 6 & 1.97 & 1.05 & 1.23 & 1.15 & 1.39 & 0.88 & 1.26 & 1.12 & 1.40 & 0.28 \\
\hline & & Plan 7 & 1.96 & 1.06 & 1.24 & 1.14 & 1.40 & 0.86 & 1.26 & 1.13 & 1.43 & 0.30 \\
\hline & & Plan 8 & 1.98 & 1.05 & 1.21 & 1.14 & 1.36 & 0.89 & 1.23 & 1.12 & 1.39 & 0.53 \\
\hline & \multirow[t]{9}{*}{2.5} & EC & 2.34 & 1.12 & 1.12 & 1.19 & 1.35 & 0.77 & 1.21 & 1.09 & 1.38 & 0.75 \\
\hline & & Plan 1 & 2.39 & 1.22 & 1.14 & 1.21 & 1.31 & 0.86 & 1.14 & 1.14 & 1.42 & 1.06 \\
\hline & & Plan 2 & 2.36 & 1.20 & 1.14 & 1.20 & 1.35 & 0.79 & 1.19 & 1.15 & 1.43 & 0.89 \\
\hline & & Plan 3 & 2.43 & 1.17 & 1.28 & 1.25 & 1.44 & 0.95 & 1.30 & 1.21 & 1.46 & 0.93 \\
\hline & & Plan 4 & 2.36 & 1.21 & 1.14 & 1.20 & 1.35 & 0.84 & 1.19 & 1.16 & 1.48 & 0.43 \\
\hline & & Plan 5 & 2.36 & 1.23 & 1.17 & 1.24 & 1.40 & 0.85 & 1.26 & 1.17 & 1.44 & 0.89 \\
\hline & & Plan 6 & 2.36 & 1.11 & 1.31 & 1.27 & 1.38 & 0.94 & 1.31 & 1.19 & 1.44 & 0.32 \\
\hline & & Plan 7 & 2.34 & 1.11 & 1.31 & 1.28 & 1.49 & 0.96 & 1.35 & 1.20 & 1.45 & 0.33 \\
\hline & & Plan 8 & 2.41 & 1.10 & 1.26 & 1.24 & 1.46 & 0.97 & 1.28 & 1.19 & 1.41 & 0.59 \\
\hline
\end{tabular}




\begin{tabular}{|c|c|c|c|c|c|c|c|c|c|c|c|c|}
\hline \multicolumn{2}{|c|}{$\begin{array}{l}\text { Experimental } \\
\text { Wave }\end{array}$} & \multicolumn{11}{|c|}{ Wave Height $(\mathrm{m})$ at Indicated Gauge Location; swl $=0.0 \mathrm{~m}$} \\
\hline $\begin{array}{l}\text { Period } \\
\text { (sec) }\end{array}$ & $\begin{array}{l}\text { Height } \\
(\mathrm{m})\end{array}$ & Plan & $\begin{array}{l}\text { Gauge } \\
11\end{array}$ & $\begin{array}{l}\text { Gauge } \\
12\end{array}$ & $\begin{array}{l}\text { Gauge } \\
13\end{array}$ & $\begin{array}{l}\text { Gauge } \\
14\end{array}$ & $\begin{array}{l}\text { Gauge } \\
15\end{array}$ & $\begin{array}{l}\text { Gauge } \\
16\end{array}$ & $\begin{array}{l}\text { Gauge } \\
17\end{array}$ & $\begin{array}{l}\text { Gauge } \\
18\end{array}$ & $\begin{array}{l}\text { Gauge } \\
19\end{array}$ & $\begin{array}{l}\text { Gauge } \\
20\end{array}$ \\
\hline \multirow[t]{27}{*}{6} & \multirow[t]{9}{*}{1} & EC & 0.26 & 0.34 & 0.33 & 0.48 & 0.38 & 0.38 & 0.44 & 0.44 & 0.33 & 0.35 \\
\hline & & Plan 1 & 0.40 & 0.64 & 0.69 & 0.77 & 0.74 & 0.53 & 0.84 & 0.82 & 0.53 & 0.60 \\
\hline & & Plan 2 & 0.31 & 0.46 & 0.64 & 0.76 & 0.70 & 0.42 & 0.69 & 0.77 & 0.39 & 0.50 \\
\hline & & Plan 3 & 0.37 & 0.41 & 0.39 & 0.52 & 0.45 & 0.42 & 0.53 & 0.51 & 0.37 & 0.52 \\
\hline & & Plan 4 & 0.33 & 0.48 & 0.70 & 0.79 & 0.55 & 0.47 & 0.55 & 0.70 & 0.41 & 0.37 \\
\hline & & Plan 5 & 0.39 & 0.39 & 0.43 & 0.28 & 0.52 & 0.26 & 0.36 & 0.39 & 0.27 & 0.40 \\
\hline & & Plan 6 & 0.31 & 0.35 & 0.33 & 0.22 & 0.33 & 0.23 & 0.22 & 0.28 & 0.21 & 0.26 \\
\hline & & Plan 7 & 0.33 & 0.29 & 0.34 & 0.46 & 0.20 & 0.25 & 0.38 & 0.35 & 0.24 & 0.30 \\
\hline & & Plan 8 & 0.29 & 0.34 & 0.36 & 0.23 & 0.50 & 0.17 & 0.22 & 0.42 & 0.19 & 0.30 \\
\hline & \multirow[t]{9}{*}{2} & EC & 0.37 & 0.47 & 0.43 & 0.62 & 0.54 & 0.47 & 0.56 & 0.58 & 0.45 & 0.46 \\
\hline & & Plan 1 & 0.68 & 0.86 & 0.87 & 1.01 & 1.12 & 0.73 & 0.98 & 1.07 & 0.71 & 0.87 \\
\hline & & Plan 2 & 0.52 & 0.64 & 0.87 & 1.02 & 1.01 & 0.57 & 0.90 & 1.06 & 0.56 & 0.71 \\
\hline & & Plan 3 & 0.57 & 0.56 & 0.52 & 0.71 & 0.68 & 0.57 & 0.69 & 0.68 & 0.54 & 0.71 \\
\hline & & Plan 4 & 0.51 & 0.71 & 0.92 & 1.00 & 0.73 & 0.60 & 0.76 & 0.92 & 0.55 & 0.51 \\
\hline & & Plan 5 & 0.62 & 0.54 & 0.52 & 0.35 & 0.73 & 0.41 & 0.49 & 0.54 & 0.40 & 0.61 \\
\hline & & Plan 6 & 0.42 & 0.49 & 0.46 & 0.31 & 0.44 & 0.32 & 0.30 & 0.37 & 0.31 & 0.34 \\
\hline & & Plan 7 & 0.45 & 0.41 & 0.48 & 0.63 & 0.35 & 0.34 & 0.51 & 0.52 & 0.32 & 0.41 \\
\hline & & Plan 8 & 0.41 & 0.46 & 0.47 & 0.32 & 0.63 & 0.27 & 0.31 & 0.52 & 0.30 & 0.43 \\
\hline & \multirow[t]{9}{*}{2.5} & EC & 0.42 & 0.52 & 0.48 & 0.68 & 0.61 & 0.54 & 0.66 & 0.64 & 0.49 & 0.51 \\
\hline & & Plan 1 & 0.71 & 0.91 & 0.97 & 1.16 & 1.20 & 0.83 & 1.11 & 1.21 & 0.77 & 0.96 \\
\hline & & Plan 2 & 0.57 & 0.74 & 0.99 & 1.13 & 1.08 & 0.65 & 1.01 & 1.17 & 0.64 & 0.81 \\
\hline & & Plan 3 & 0.65 & 0.65 & 0.61 & 0.82 & 0.77 & 0.66 & 0.81 & 0.78 & 0.61 & 0.82 \\
\hline & & Plan 4 & 0.55 & 0.75 & 0.97 & 1.07 & 0.77 & 0.64 & 0.80 & 0.97 & 0.59 & 0.56 \\
\hline & & Plan 5 & 0.69 & 0.63 & 0.60 & 0.40 & 0.82 & 0.46 & 0.56 & 0.63 & 0.45 & 0.69 \\
\hline & & Plan 6 & 0.48 & 0.55 & 0.52 & 0.34 & 0.49 & 0.36 & 0.35 & 0.43 & 0.37 & 0.39 \\
\hline & & Plan 7 & 0.51 & 0.47 & 0.54 & 0.70 & 0.37 & 0.38 & 0.57 & 0.56 & 0.38 & 0.46 \\
\hline & & Plan 8 & 0.45 & 0.51 & 0.53 & 0.36 & 0.71 & 0.30 & 0.36 & 0.60 & 0.33 & 0.47 \\
\hline
\end{tabular}




\begin{tabular}{|c|c|c|c|c|c|c|c|c|c|c|c|c|}
\hline \multicolumn{2}{|c|}{$\begin{array}{l}\text { Experimental } \\
\text { Wave }\end{array}$} & \multicolumn{11}{|c|}{ Wave Height $(\mathrm{m})$ at Indicated Gauge Location; swl $=0.0 \mathrm{~m}$} \\
\hline $\begin{array}{l}\text { Period } \\
\text { (sec) }\end{array}$ & \begin{tabular}{|l} 
Height \\
$(\mathrm{m})$
\end{tabular} & Plan & $\begin{array}{l}\text { Gauge } \\
1\end{array}$ & $\begin{array}{l}\text { Gauge } \\
2\end{array}$ & $\begin{array}{l}\text { Gauge } \\
3\end{array}$ & $\begin{array}{l}\text { Gauge } \\
4\end{array}$ & $\begin{array}{l}\text { Gauge } \\
5\end{array}$ & $\begin{array}{l}\text { Gauge } \\
6\end{array}$ & $\begin{array}{l}\text { Gauge } \\
7\end{array}$ & $\begin{array}{l}\text { Gauge } \\
8\end{array}$ & $\begin{array}{l}\text { Gauge } \\
9\end{array}$ & $\begin{array}{l}\text { Gauge } \\
10\end{array}$ \\
\hline \multirow[t]{27}{*}{7} & \multirow[t]{9}{*}{1} & EC & 0.99 & 0.72 & 0.65 & 0.62 & 0.86 & 0.45 & 0.69 & 0.68 & 0.92 & 0.44 \\
\hline & & Plan 1 & 0.99 & 0.83 & 0.71 & 0.68 & 0.86 & 0.53 & 0.67 & 0.76 & 1.02 & 0.65 \\
\hline & & Plan 2 & 1.00 & 0.74 & 0.65 & 0.61 & 0.81 & 0.46 & 0.67 & 0.73 & 0.95 & 0.54 \\
\hline & & Plan 3 & 1.03 & 0.75 & 0.75 & 0.63 & 0.92 & 0.58 & 0.76 & 0.75 & 0.99 & 0.54 \\
\hline & & Plan 4 & 1.01 & 0.79 & 0.69 & 0.66 & 0.86 & 0.50 & 0.72 & 0.76 & 1.01 & 0.27 \\
\hline & & Plan 5 & 1.04 & 0.82 & 0.71 & 0.69 & 0.94 & 0.53 & 0.77 & 0.76 & 1.01 & 0.49 \\
\hline & & Plan 6 & 1.01 & 0.72 & 0.80 & 0.71 & 0.98 & 0.59 & 0.78 & 0.76 & 1.00 & 0.18 \\
\hline & & Plan 7 & 1.01 & 0.70 & 0.77 & 0.68 & 0.94 & 0.57 & 0.76 & 0.75 & 0.98 & 0.19 \\
\hline & & Plan 8 & 1.03 & 0.75 & 0.79 & 0.70 & 0.99 & 0.60 & 0.81 & 0.79 & 1.02 & 0.35 \\
\hline & \multirow[t]{9}{*}{2} & EC & 1.99 & 1.18 & 1.15 & 1.06 & 1.35 & 0.72 & 1.10 & 1.17 & 1.60 & 0.68 \\
\hline & & Plan 1 & 1.99 & 1.26 & 1.15 & 1.05 & 1.20 & 0.75 & 1.01 & 1.19 & 1.57 & 1.12 \\
\hline & & Plan 2 & 1.98 & 1.22 & 1.14 & 1.04 & 1.26 & 0.73 & 1.05 & 1.20 & 1.61 & 0.90 \\
\hline & & Plan 3 & 2.05 & 1.22 & 1.29 & 1.09 & 1.37 & 0.88 & 1.15 & 1.27 & 1.67 & 0.90 \\
\hline & & Plan 4 & 2.01 & 1.27 & 1.17 & 1.08 & 1.30 & 0.80 & 1.09 & 1.23 & 1.67 & 0.45 \\
\hline & & Plan 5 & 1.99 & 1.23 & 1.17 & 1.06 & 1.32 & 0.80 & 1.12 & 1.18 & 1.56 & 0.84 \\
\hline & & Plan 6 & 1.99 & 1.12 & 1.31 & 1.13 & 1.41 & 0.90 & 1.17 & 1.22 & 1.60 & 0.30 \\
\hline & & Plan 7 & 1.99 & 1.12 & 1.31 & 1.13 & 1.43 & 0.88 & 1.18 & 1.23 & 1.60 & 0.31 \\
\hline & & Plan 8 & 2.03 & 1.12 & 1.29 & 1.12 & 1.42 & 0.91 & 1.17 & 1.22 & 1.58 & 0.54 \\
\hline & \multirow[t]{9}{*}{2.5} & EC & 2.46 & 1.29 & 1.25 & 1.17 & 1.42 & 0.81 & 1.19 & 1.28 & 1.72 & 0.80 \\
\hline & & Plan 1 & 2.49 & 1.36 & 1.25 & 1.18 & 1.32 & 0.86 & 1.11 & 1.32 & 1.75 & 1.27 \\
\hline & & Plan 2 & 2.06 & 1.25 & 1.16 & 1.08 & 1.28 & 0.75 & 1.07 & 1.23 & 1.63 & 0.91 \\
\hline & & Plan 3 & 2.56 & 1.23 & 1.32 & 1.17 & 1.36 & 0.92 & 1.19 & 1.30 & 1.69 & 0.96 \\
\hline & & Plan 4 & 2.49 & 1.25 & 1.20 & 1.15 & 1.31 & 0.86 & 1.11 & 1.27 & 1.69 & 0.49 \\
\hline & & Plan 5 & 2.54 & 1.33 & 1.23 & 1.17 & 1.38 & 0.87 & 1.17 & 1.28 & 1.70 & 1.00 \\
\hline & & Plan 6 & 2.50 & 1.21 & 1.41 & 1.23 & 1.39 & 1.00 & 1.23 & 1.32 & 1.72 & 0.35 \\
\hline & & Plan 7 & 2.47 & 1.20 & 1.41 & 1.23 & 1.50 & 1.01 & 1.25 & 1.32 & 1.73 & 0.36 \\
\hline & & Plan 8 & 2.53 & 1.23 & 1.40 & 1.23 & 1.51 & 1.02 & 1.26 & 1.34 & 1.72 & 0.63 \\
\hline
\end{tabular}




\begin{tabular}{|c|c|c|c|c|c|c|c|c|c|c|c|c|}
\hline \multicolumn{2}{|c|}{$\begin{array}{l}\text { Experimental } \\
\text { Wave }\end{array}$} & \multicolumn{11}{|c|}{ Wave Height $(\mathrm{m})$ at Indicated Gauge Location; swl $=0.0 \mathrm{~m}$} \\
\hline $\begin{array}{l}\text { Period } \\
\text { (sec) }\end{array}$ & $\begin{array}{l}\text { Height } \\
(\mathrm{m})\end{array}$ & Plan & $\begin{array}{l}\text { Gauge } \\
11\end{array}$ & $\begin{array}{l}\text { Gauge } \\
12\end{array}$ & $\begin{array}{l}\text { Gauge } \\
13\end{array}$ & $\begin{array}{l}\text { Gauge } \\
14\end{array}$ & $\begin{array}{l}\text { Gauge } \\
15\end{array}$ & $\begin{array}{l}\text { Gauge } \\
16\end{array}$ & $\begin{array}{l}\text { Gauge } \\
17\end{array}$ & $\begin{array}{l}\text { Gauge } \\
18\end{array}$ & $\begin{array}{l}\text { Gauge } \\
19\end{array}$ & $\begin{array}{l}\text { Gauge } \\
20\end{array}$ \\
\hline \multirow[t]{27}{*}{7} & \multirow[t]{9}{*}{1} & EC & 0.24 & 0.29 & 0.28 & 0.43 & 0.37 & 0.31 & 0.39 & 0.39 & 0.28 & 0.31 \\
\hline & & Plan 1 & 0.47 & 0.57 & 0.65 & 0.76 & 0.80 & 0.51 & 0.72 & 0.75 & 0.48 & 0.64 \\
\hline & & Plan 2 & 0.36 & 0.44 & 0.60 & 0.71 & 0.71 & 0.41 & 0.58 & 0.72 & 0.37 & 0.52 \\
\hline & & Plan 3 & 0.39 & 0.41 & 0.37 & 0.50 & 0.48 & 0.40 & 0.51 & 0.48 & 0.37 & 0.51 \\
\hline & & Plan 4 & 0.33 & 0.47 & 0.64 & 0.69 & 0.48 & 0.39 & 0.55 & 0.62 & 0.36 & 0.33 \\
\hline & & Plan 5 & 0.41 & 0.38 & 0.39 & 0.27 & 0.50 & 0.27 & 0.36 & 0.36 & 0.28 & 0.42 \\
\hline & & Plan 6 & 0.26 & 0.30 & 0.30 & 0.22 & 0.28 & 0.20 & 0.19 & 0.23 & 0.19 & 0.22 \\
\hline & & Plan 7 & 0.27 & 0.24 & 0.32 & 0.44 & 0.22 & 0.23 & 0.32 & 0.34 & 0.22 & 0.26 \\
\hline & & Plan 8 & 0.27 & 0.29 & 0.32 & 0.23 & 0.43 & 0.17 & 0.21 & 0.36 & 0.19 & 0.30 \\
\hline & \multirow[t]{9}{*}{2} & EC & 0.40 & 0.47 & 0.45 & 0.61 & 0.57 & 0.48 & 0.56 & 0.57 & 0.43 & 0.50 \\
\hline & & Plan 1 & 0.84 & 0.87 & 0.89 & 1.01 & 1.24 & 0.78 & 0.97 & 1.10 & 0.70 & 1.02 \\
\hline & & Plan 2 & 0.63 & 0.69 & 0.93 & 1.08 & 1.14 & 0.59 & 0.90 & 1.10 & 0.56 & 0.88 \\
\hline & & Plan 3 & 0.66 & 0.62 & 0.58 & 0.77 & 0.73 & 0.65 & 0.77 & 0.72 & 0.57 & 0.80 \\
\hline & & Plan 4 & 0.55 & 0.75 & 0.95 & 1.02 & 0.75 & 0.58 & 0.79 & 0.92 & 0.51 & 0.56 \\
\hline & & Plan 5 & 0.67 & 0.58 & 0.53 & 0.38 & 0.74 & 0.45 & 0.54 & 0.56 & 0.42 & 0.67 \\
\hline & & Plan 6 & 0.42 & 0.46 & 0.45 & 0.33 & 0.42 & 0.31 & 0.30 & 0.36 & 0.28 & 0.33 \\
\hline & & Plan 7 & 0.44 & 0.40 & 0.49 & 0.63 & 0.38 & 0.32 & 0.50 & 0.51 & 0.31 & 0.42 \\
\hline & & Plan 8 & 0.41 & 0.43 & 0.45 & 0.33 & 0.60 & 0.28 & 0.33 & 0.51 & 0.29 & 0.43 \\
\hline & \multirow[t]{9}{*}{2.5} & EC & 0.48 & 0.57 & 0.52 & 0.72 & 0.70 & 0.57 & 0.68 & 0.68 & 0.52 & 0.58 \\
\hline & & Plan 1 & 0.94 & 0.95 & 0.97 & 1.12 & 1.43 & 0.90 & 1.05 & 1.20 & 0.82 & 1.14 \\
\hline & & Plan 2 & 0.64 & 0.70 & 0.95 & 1.10 & 1.15 & 0.60 & 0.92 & 1.13 & 0.57 & 0.90 \\
\hline & & Plan 3 & 0.75 & 0.68 & 0.62 & 0.79 & 0.81 & 0.71 & 0.81 & 0.78 & 0.63 & 0.87 \\
\hline & & Plan 4 & 0.58 & 0.77 & 0.98 & 1.06 & 0.79 & 0.61 & 0.85 & 0.96 & 0.55 & 0.59 \\
\hline & & Plan 5 & 0.80 & 0.68 & 0.60 & 0.44 & 0.88 & 0.54 & 0.63 & 0.65 & 0.50 & 0.78 \\
\hline & & Plan 6 & 0.48 & 0.54 & 0.51 & 0.37 & 0.48 & 0.36 & 0.35 & 0.40 & 0.37 & 0.38 \\
\hline & & Plan 7 & 0.50 & 0.48 & 0.56 & 0.71 & 0.46 & 0.38 & 0.58 & 0.57 & 0.38 & 0.49 \\
\hline & & Plan 8 & 0.49 & 0.52 & 0.54 & 0.40 & 0.71 & 0.35 & 0.40 & 0.61 & 0.38 & 0.51 \\
\hline
\end{tabular}




\begin{tabular}{|c|c|c|c|c|c|c|c|c|c|c|c|c|}
\hline \multicolumn{2}{|c|}{$\begin{array}{l}\text { Experimental } \\
\text { Wave }\end{array}$} & \multicolumn{11}{|c|}{ Wave Height $(\mathrm{m})$ at Indicated Gauge Location; swl $=0.0 \mathrm{~m}$} \\
\hline $\begin{array}{l}\text { Period } \\
(\mathrm{sec})\end{array}$ & $\begin{array}{l}\text { Height } \\
(\mathrm{m})\end{array}$ & Plan & $\begin{array}{l}\text { Gauge } \\
1\end{array}$ & $\begin{array}{l}\text { Gauge } \\
2\end{array}$ & $\begin{array}{l}\text { Gauge } \\
3\end{array}$ & $\begin{array}{l}\text { Gauge } \\
4\end{array}$ & $\begin{array}{l}\text { Gauge } \\
5\end{array}$ & $\begin{array}{l}\text { Gauge } \\
6\end{array}$ & $\begin{array}{l}\text { Gauge } \\
7\end{array}$ & $\begin{array}{l}\text { Gauge } \\
8\end{array}$ & $\begin{array}{l}\text { Gauge } \\
9\end{array}$ & $\begin{array}{l}\text { Gauge } \\
10\end{array}$ \\
\hline \multirow[t]{27}{*}{8} & \multirow[t]{9}{*}{1} & EC & 0.91 & 0.73 & 0.66 & 0.57 & 0.77 & 0.42 & 0.55 & 0.75 & 0.92 & 0.37 \\
\hline & & Plan 1 & 0.93 & 0.84 & 0.72 & 0.62 & 0.77 & 0.48 & 0.59 & 0.82 & 1.03 & 0.77 \\
\hline & & Plan 2 & 0.93 & 0.76 & 0.67 & 0.58 & 0.71 & 0.42 & 0.57 & 0.79 & 0.96 & 0.58 \\
\hline & & Plan 3 & 0.97 & 0.77 & 0.78 & 0.60 & 0.78 & 0.52 & 0.63 & 0.83 & 1.01 & 0.55 \\
\hline & & Plan 4 & 0.96 & 0.79 & 0.70 & 0.61 & 0.76 & 0.47 & 0.59 & 0.82 & 0.99 & 0.29 \\
\hline & & Plan 5 & 0.96 & 0.89 & 0.80 & 0.71 & 0.92 & 0.53 & 0.69 & 0.87 & 1.09 & 0.57 \\
\hline & & Plan 6 & 0.97 & 0.74 & 0.82 & 0.67 & 0.87 & 0.57 & 0.63 & 0.84 & 1.01 & 0.19 \\
\hline & & Plan 7 & 0.96 & 0.71 & 0.79 & 0.64 & 0.83 & 0.54 & 0.61 & 0.82 & 0.99 & 0.18 \\
\hline & & Plan 8 & 0.99 & 0.75 & 0.81 & 0.66 & 0.85 & 0.56 & 0.63 & 0.86 & 1.01 & 0.32 \\
\hline & \multirow[t]{9}{*}{2} & EC & 1.90 & 1.32 & 1.23 & 1.06 & 1.31 & 0.80 & 0.99 & 1.31 & 1.66 & 0.66 \\
\hline & & Plan 1 & 1.94 & 1.46 & 1.29 & 1.13 & 1.26 & 0.83 & 1.00 & 1.39 & 1.76 & 1.40 \\
\hline & & Plan 2 & 1.92 & 1.41 & 1.26 & 1.08 & 1.33 & 0.83 & 1.02 & 1.38 & 1.73 & 1.02 \\
\hline & & Plan 3 & 1.98 & 1.38 & 1.42 & 1.13 & 1.33 & 0.93 & 1.10 & 1.44 & 1.76 & 0.98 \\
\hline & & Plan 4 & 1.94 & 1.38 & 1.24 & 1.08 & 1.30 & 0.85 & 0.99 & 1.38 & 1.72 & 0.52 \\
\hline & & Plan 5 & 1.94 & 1.32 & 1.23 & 1.07 & 1.21 & 0.79 & 1.01 & 1.31 & 1.64 & 0.95 \\
\hline & & Plan 6 & 1.94 & 1.29 & 1.44 & 1.16 & 1.32 & 0.97 & 1.04 & 1.40 & 1.73 & 0.32 \\
\hline & & Plan 7 & 1.96 & 1.23 & 1.38 & 1.12 & 1.38 & 0.97 & 1.03 & 1.36 & 1.66 & 0.32 \\
\hline & & Plan 8 & 1.96 & 1.22 & 1.36 & 1.10 & 1.33 & 0.96 & 1.01 & 1.36 & 1.64 & 0.53 \\
\hline & \multirow[t]{9}{*}{2.5} & EC & 2.38 & 1.34 & 1.23 & 1.09 & 1.37 & 0.84 & 1.05 & 1.38 & 1.74 & 0.73 \\
\hline & & Plan 1 & 2.47 & 1.43 & 1.25 & 1.14 & 1.26 & 0.87 & 1.02 & 1.40 & 1.75 & 1.45 \\
\hline & & Plan 2 & 2.41 & 1.41 & 1.26 & 1.11 & 1.36 & 0.86 & 1.05 & 1.43 & 1.79 & 1.09 \\
\hline & & Plan 3 & 2.44 & 1.38 & 1.42 & 1.17 & 1.38 & 0.99 & 1.13 & 1.48 & 1.80 & 1.07 \\
\hline & & Plan 4 & 2.42 & 1.38 & 1.29 & 1.17 & 1.37 & 0.93 & 1.05 & 1.43 & 1.79 & 0.56 \\
\hline & & Plan 5 & 2.46 & 1.42 & 1.28 & 1.16 & 1.33 & 0.88 & 1.09 & 1.39 & 1.75 & 1.09 \\
\hline & & Plan 6 & 2.45 & 1.31 & 1.45 & 1.21 & 1.38 & 1.06 & 1.11 & 1.48 & 1.80 & 0.37 \\
\hline & & Plan 7 & 2.44 & 1.28 & 1.44 & 1.19 & 1.47 & 1.06 & 1.11 & 1.46 & 1.78 & 0.36 \\
\hline & & Plan 8 & 2.44 & 1.28 & 1.42 & 1.20 & 1.47 & 1.06 & 1.10 & 1.46 & 1.75 & 0.62 \\
\hline
\end{tabular}




\begin{tabular}{|c|c|c|c|c|c|c|c|c|c|c|c|c|}
\hline \multicolumn{2}{|c|}{$\begin{array}{l}\text { Experimental } \\
\text { Wave }\end{array}$} & \multicolumn{11}{|c|}{ Wave Height $(\mathrm{m})$ at Indicated Gauge Location; swl $=0.0 \mathrm{~m}$} \\
\hline $\begin{array}{l}\text { Period } \\
\text { (sec) }\end{array}$ & $\begin{array}{l}\text { Height } \\
(\mathrm{m})\end{array}$ & Plan & $\begin{array}{l}\text { Gauge } \\
11\end{array}$ & $\begin{array}{l}\text { Gauge } \\
12\end{array}$ & $\begin{array}{l}\text { Gauge } \\
13\end{array}$ & $\begin{array}{l}\text { Gauge } \\
14\end{array}$ & $\begin{array}{l}\text { Gauge } \\
15\end{array}$ & $\begin{array}{l}\text { Gauge } \\
16\end{array}$ & $\begin{array}{l}\text { Gauge } \\
17\end{array}$ & $\begin{array}{l}\text { Gauge } \\
18\end{array}$ & $\begin{array}{l}\text { Gauge } \\
19\end{array}$ & $\begin{array}{l}\text { Gauge } \\
20\end{array}$ \\
\hline \multirow[t]{27}{*}{8} & \multirow[t]{9}{*}{1} & EC & 0.24 & 0.28 & 0.26 & 0.36 & 0.33 & 0.26 & 0.33 & 0.34 & 0.25 & 0.29 \\
\hline & & Plan 1 & 0.60 & 0.53 & 0.58 & 0.64 & 0.80 & 0.50 & 0.63 & 0.67 & 0.46 & 0.72 \\
\hline & & Plan 2 & 0.41 & 0.41 & 0.58 & 0.69 & 0.76 & 0.38 & 0.52 & 0.66 & 0.35 & 0.61 \\
\hline & & Plan 3 & 0.45 & 0.41 & 0.37 & 0.45 & 0.44 & 0.40 & 0.51 & 0.48 & 0.38 & 0.49 \\
\hline & & Plan 4 & 0.33 & 0.45 & 0.60 & 0.64 & 0.44 & 0.34 & 0.52 & 0.57 & 0.32 & 0.35 \\
\hline & & Plan 5 & 0.49 & 0.42 & 0.39 & 0.28 & 0.54 & 0.31 & 0.39 & 0.41 & 0.31 & 0.46 \\
\hline & & Plan 6 & 0.25 & 0.28 & 0.28 & 0.21 & 0.26 & 0.19 & 0.18 & 0.21 & 0.18 & 0.20 \\
\hline & & Plan 7 & 0.26 & 0.24 & 0.30 & 0.39 & 0.23 & 0.21 & 0.30 & 0.31 & 0.20 & 0.25 \\
\hline & & Plan 8 & 0.27 & 0.27 & 0.28 & 0.21 & 0.39 & 0.17 & 0.21 & 0.33 & 0.19 & 0.27 \\
\hline & \multirow[t]{9}{*}{2} & EC & 0.43 & 0.48 & 0.44 & 0.57 & 0.60 & 0.47 & 0.54 & 0.56 & 0.43 & 0.50 \\
\hline & & Plan 1 & 1.07 & 0.85 & 0.89 & 1.05 & 1.41 & 0.84 & 1.03 & 1.13 & 0.77 & 1.22 \\
\hline & & Plan 2 & 0.75 & 0.71 & 0.94 & 1.11 & 1.28 & 0.66 & 0.89 & 1.10 & 0.61 & 0.99 \\
\hline & & Plan 3 & 0.80 & 0.70 & 0.65 & 0.78 & 0.77 & 0.69 & 0.88 & 0.82 & 0.65 & 0.83 \\
\hline & & Plan 4 & 0.57 & 0.74 & 0.91 & 0.97 & 0.72 & 0.52 & 0.79 & 0.87 & 0.48 & 0.56 \\
\hline & & Plan 5 & 0.80 & 0.65 & 0.54 & 0.42 & 0.83 & 0.49 & 0.62 & 0.62 & 0.47 & 0.74 \\
\hline & & Plan 6 & 0.42 & 0.45 & 0.42 & 0.33 & 0.41 & 0.30 & 0.29 & 0.35 & 0.29 & 0.32 \\
\hline & & Plan 7 & 0.43 & 0.42 & 0.48 & 0.61 & 0.43 & 0.32 & 0.47 & 0.49 & 0.31 & 0.41 \\
\hline & & Plan 8 & 0.43 & 0.43 & 0.42 & 0.33 & 0.58 & 0.29 & 0.34 & 0.49 & 0.30 & 0.42 \\
\hline & \multirow[t]{9}{*}{2.5} & EC & 0.49 & 0.55 & 0.49 & 0.63 & 0.66 & 0.52 & 0.60 & 0.63 & 0.48 & 0.57 \\
\hline & & Plan 1 & 1.12 & 0.92 & 0.90 & 1.03 & 1.43 & 0.88 & 1.07 & 1.16 & 0.82 & 1.27 \\
\hline & & Plan 2 & 0.81 & 0.75 & 0.96 & 1.11 & 1.32 & 0.68 & 0.92 & 1.13 & 0.63 & 1.08 \\
\hline & & Plan 3 & 0.87 & 0.75 & 0.70 & 0.82 & 0.84 & 0.74 & 0.91 & 0.89 & 0.69 & 0.94 \\
\hline & & Plan 4 & 0.62 & 0.79 & 0.96 & 1.03 & 0.79 & 0.56 & 0.85 & 0.92 & 0.51 & 0.64 \\
\hline & & Plan 5 & 0.91 & 0.73 & 0.60 & 0.48 & 0.94 & 0.55 & 0.70 & 0.74 & 0.54 & 0.85 \\
\hline & & Plan 6 & 0.48 & 0.52 & 0.49 & 0.38 & 0.46 & 0.35 & 0.34 & 0.40 & 0.34 & 0.38 \\
\hline & & Plan 7 & 0.50 & 0.49 & 0.55 & 0.69 & 0.49 & 0.35 & 0.54 & 0.54 & 0.36 & 0.50 \\
\hline & & Plan 8 & 0.50 & 0.50 & 0.49 & 0.37 & 0.67 & 0.34 & 0.40 & 0.58 & 0.36 & 0.48 \\
\hline
\end{tabular}


Table D5. Wave heights for waves from 45 degrees North; $0.0 \mathrm{~m}$ swl.

\begin{tabular}{|c|c|c|c|c|c|c|c|c|c|c|c|c|}
\hline \multicolumn{2}{|c|}{$\begin{array}{l}\text { Experimental } \\
\text { Wave }\end{array}$} & \multicolumn{11}{|c|}{ Wave Height $(\mathrm{m})$ at Indicated Gauge Location; swl $=0.0 \mathrm{~m}$} \\
\hline $\begin{array}{l}\text { Period } \\
(\mathrm{sec})\end{array}$ & $\begin{array}{l}\text { Height } \\
(\mathrm{m})\end{array}$ & Plan & $\begin{array}{l}\text { Gauge } \\
1\end{array}$ & $\begin{array}{l}\text { Gauge } \\
2\end{array}$ & $\begin{array}{l}\text { Gauge } \\
3\end{array}$ & $\begin{array}{l}\text { Gauge } \\
4\end{array}$ & $\begin{array}{l}\text { Gauge } \\
5\end{array}$ & $\begin{array}{l}\text { Gauge } \\
6\end{array}$ & \begin{tabular}{|l} 
Gauge \\
7 \\
\end{tabular} & $\begin{array}{l}\text { Gauge } \\
8\end{array}$ & $\begin{array}{l}\text { Gauge } \\
9\end{array}$ & $\begin{array}{l}\text { Gauge } \\
10\end{array}$ \\
\hline \multirow[t]{27}{*}{5} & \multirow[t]{9}{*}{1} & EC & 1.00 & 0.78 & 0.84 & 0.81 & 1.08 & 0.93 & 0.66 & 0.52 & 1.03 & 0.52 \\
\hline & & Plan 1 & 1.01 & 0.77 & 0.86 & 0.81 & 1.10 & 0.89 & 0.66 & 0.51 & 1.02 & 1.22 \\
\hline & & Plan 2 & 0.95 & 0.75 & 0.83 & 0.77 & 1.08 & 0.89 & 0.62 & 0.51 & 1.00 & 0.77 \\
\hline & & Plan 3 & 1.08 & 0.75 & 0.98 & 0.83 & 1.11 & 1.05 & 0.75 & 0.55 & 1.03 & 0.98 \\
\hline & & Plan 4 & 1.10 & 0.88 & 1.00 & 0.97 & 1.22 & 1.02 & 0.84 & 0.60 & 1.24 & 0.43 \\
\hline & & Plan 5 & 1.05 & 0.82 & 0.96 & 0.92 & 1.17 & 1.00 & 0.80 & 0.62 & 1.24 & 1.06 \\
\hline & & Plan 6 & 1.06 & 0.85 & 0.98 & 0.96 & 1.22 & 1.06 & 0.85 & 0.64 & 1.30 & 0.24 \\
\hline & & Plan 7 & 1.03 & 0.81 & 0.97 & 0.92 & 1.20 & 1.04 & 0.79 & 0.63 & 1.26 & 0.24 \\
\hline & & Plan 8 & 1.04 & 0.80 & 0.93 & 0.85 & 1.09 & 1.00 & 0.79 & 0.58 & 1.17 & 0.45 \\
\hline & \multirow[t]{9}{*}{2} & EC & 1.93 & 1.14 & 1.25 & 1.17 & 1.41 & 1.29 & 1.04 & 0.76 & 1.31 & 0.81 \\
\hline & & Plan 1 & 1.93 & 1.18 & 1.30 & 1.19 & 1.41 & 1.28 & 1.08 & 0.77 & 1.32 & 1.55 \\
\hline & & Plan 2 & 1.93 & 1.17 & 1.29 & 1.15 & 1.43 & 1.28 & 1.04 & 0.74 & 1.32 & 1.10 \\
\hline & & Plan 3 & 2.02 & 1.14 & 1.47 & 1.21 & 1.45 & 1.48 & 1.16 & 0.81 & 1.32 & 1.39 \\
\hline & & Plan 4 & 2.09 & 1.06 & 1.17 & 1.18 & 1.56 & 1.25 & 1.01 & 0.83 & 1.41 & 0.52 \\
\hline & & Plan 5 & 2.05 & 1.07 & 1.23 & 1.19 & 1.53 & 1.22 & 1.03 & 0.85 & 1.46 & 1.40 \\
\hline & & Plan 6 & 2.08 & 1.09 & 1.19 & 1.21 & 1.59 & 1.30 & 1.04 & 0.89 & 1.52 & 0.35 \\
\hline & & Plan 7 & 2.04 & 1.05 & 1.19 & 1.17 & 1.53 & 1.27 & 1.00 & 0.84 & 1.40 & 0.34 \\
\hline & & Plan 8 & 2.06 & 1.06 & 1.19 & 1.13 & 1.44 & 1.26 & 1.02 & 0.78 & 1.30 & 0.70 \\
\hline & \multirow[t]{9}{*}{2.5} & EC & 2.27 & 1.28 & 1.43 & 1.32 & 1.62 & 1.42 & 1.17 & 0.85 & 1.48 & 0.89 \\
\hline & & Plan 1 & 2.25 & 1.09 & 1.33 & 1.27 & 1.51 & 1.29 & 1.01 & 0.82 & 1.39 & 1.55 \\
\hline & & Plan 2 & 2.24 & 1.26 & 1.47 & 1.31 & 1.59 & 1.41 & 1.13 & 0.85 & 1.53 & 1.25 \\
\hline & & Plan 3 & 2.36 & 1.24 & 1.65 & 1.40 & 1.68 & 1.62 & 1.25 & 0.92 & 1.46 & 1.48 \\
\hline & & Plan 4 & 2.52 & 1.26 & 1.37 & 1.26 & 1.59 & 1.33 & 1.15 & 0.87 & 1.47 & 0.55 \\
\hline & & Plan 5 & 2.54 & 1.34 & 1.42 & 1.27 & 1.59 & 1.37 & 1.25 & 0.92 & 1.45 & 1.51 \\
\hline & & Plan 6 & 2.52 & 1.28 & 1.39 & 1.27 & 1.62 & 1.37 & 1.23 & 0.90 & 1.49 & 0.41 \\
\hline & & Plan 7 & 2.49 & 1.26 & 1.43 & 1.27 & 1.59 & 1.39 & 1.19 & 0.89 & 1.44 & 0.40 \\
\hline & & Plan 8 & 2.51 & 1.27 & 1.41 & 1.30 & 1.62 & 1.40 & 1.23 & 0.91 & 1.47 & 0.81 \\
\hline
\end{tabular}




\begin{tabular}{|c|c|c|c|c|c|c|c|c|c|c|c|c|}
\hline \multicolumn{2}{|c|}{$\begin{array}{l}\text { Experimental } \\
\text { Wave }\end{array}$} & \multicolumn{11}{|c|}{ Wave Height $(\mathrm{m})$ at Indicated Gauge Location; swl $=0.0 \mathrm{~m}$} \\
\hline $\begin{array}{l}\text { Period } \\
\text { (sec) }\end{array}$ & $\begin{array}{l}\text { Height } \\
(\mathrm{m})\end{array}$ & Plan & $\begin{array}{l}\text { Gauge } \\
11\end{array}$ & $\begin{array}{l}\text { Gauge } \\
12\end{array}$ & $\begin{array}{l}\text { Gauge } \\
13\end{array}$ & $\begin{array}{l}\text { Gauge } \\
14\end{array}$ & $\begin{array}{l}\text { Gauge } \\
15\end{array}$ & $\begin{array}{l}\text { Gauge } \\
16\end{array}$ & $\begin{array}{l}\text { Gauge } \\
17\end{array}$ & $\begin{array}{l}\text { Gauge } \\
18\end{array}$ & $\begin{array}{l}\text { Gauge } \\
19\end{array}$ & $\begin{array}{l}\text { Gauge } \\
20\end{array}$ \\
\hline \multirow[t]{27}{*}{5} & \multirow[t]{9}{*}{1} & EC & 0.33 & 0.36 & 0.32 & 0.60 & 0.51 & 0.46 & 0.39 & 0.42 & 0.36 & 0.54 \\
\hline & & Plan 1 & 0.89 & 0.54 & 0.35 & 0.54 & 1.03 & 0.61 & 0.70 & 0.70 & 0.49 & 1.07 \\
\hline & & Plan 2 & 0.46 & 0.53 & 0.32 & 0.60 & 0.80 & 0.59 & 0.40 & 0.64 & 0.47 & 0.66 \\
\hline & & Plan 3 & 0.87 & 0.61 & 0.34 & 0.54 & 0.91 & 0.54 & 0.67 & 0.47 & 0.50 & 1.08 \\
\hline & & Plan 4 & 0.73 & 0.52 & 0.38 & 0.53 & 0.56 & 0.24 & 0.63 & 0.33 & 0.29 & 0.65 \\
\hline & & Plan 5 & 0.87 & 0.56 & 0.40 & 0.30 & 0.74 & 0.64 & 0.51 & 0.50 & 0.51 & 0.91 \\
\hline & & Plan 6 & 0.40 & 0.44 & 0.43 & 0.27 & 0.32 & 0.33 & 0.37 & 0.32 & 0.33 & 0.33 \\
\hline & & Plan 7 & 0.42 & 0.44 & 0.37 & 0.50 & 0.32 & 0.21 & 0.61 & 0.32 & 0.25 & 0.55 \\
\hline & & Plan 8 & 0.38 & 0.35 & 0.40 & 0.27 & 0.46 & 0.32 & 0.19 & 0.39 & 0.27 & 0.37 \\
\hline & \multirow[t]{9}{*}{2} & EC & 0.58 & 0.66 & 0.55 & 0.82 & 0.83 & 0.69 & 0.67 & 0.77 & 0.57 & 0.76 \\
\hline & & Plan 1 & 1.10 & 0.93 & 0.65 & 0.76 & 1.26 & 0.94 & 1.06 & 0.92 & 0.79 & 1.36 \\
\hline & & Plan 2 & 0.66 & 0.78 & 0.63 & 1.04 & 1.10 & 0.90 & 0.74 & 0.97 & 0.74 & 0.86 \\
\hline & & Plan 3 & 1.16 & 0.87 & 0.51 & 0.72 & 1.30 & 0.83 & 0.84 & 0.78 & 0.71 & 1.44 \\
\hline & & Plan 4 & 0.86 & 0.68 & 0.57 & 0.72 & 0.69 & 0.40 & 0.78 & 0.51 & 0.43 & 0.74 \\
\hline & & Plan 5 & 1.12 & 0.72 & 0.50 & 0.38 & 1.02 & 0.79 & 0.60 & 0.71 & 0.62 & 1.10 \\
\hline & & Plan 6 & 0.58 & 0.63 & 0.56 & 0.35 & 0.48 & 0.45 & 0.48 & 0.41 & 0.47 & 0.41 \\
\hline & & Plan 7 & 0.61 & 0.60 & 0.48 & 0.66 & 0.46 & 0.33 & 0.77 & 0.44 & 0.37 & 0.66 \\
\hline & & Plan 8 & 0.59 & 0.58 & 0.58 & 0.36 & 0.77 & 0.42 & 0.33 & 0.65 & 0.39 & 0.50 \\
\hline & \multirow[t]{9}{*}{2.5} & EC & 0.70 & 0.78 & 0.68 & 0.97 & 0.96 & 0.79 & 0.81 & 0.91 & 0.67 & 0.87 \\
\hline & & Plan 1 & 0.66 & 0.75 & 0.64 & 0.94 & 0.93 & 0.75 & 0.77 & 0.88 & 0.64 & 0.84 \\
\hline & & Plan 2 & 1.08 & 0.96 & 0.62 & 0.73 & 1.40 & 0.91 & 1.00 & 1.01 & 0.76 & 1.44 \\
\hline & & Plan 3 & 0.74 & 0.90 & 0.74 & 1.17 & 1.21 & 0.98 & 0.93 & 1.09 & 0.82 & 0.96 \\
\hline & & Plan 4 & 0.91 & 0.77 & 0.71 & 0.92 & 0.72 & 0.50 & 0.90 & 0.66 & 0.53 & 0.81 \\
\hline & & Plan 5 & 1.25 & 0.86 & 0.61 & 0.45 & 1.21 & 0.88 & 0.65 & 0.86 & 0.68 & 1.20 \\
\hline & & Plan 6 & 0.68 & 0.75 & 0.65 & 0.41 & 0.58 & 0.53 & 0.55 & 0.50 & 0.55 & 0.48 \\
\hline & & Plan 7 & 0.72 & 0.73 & 0.59 & 0.80 & 0.52 & 0.42 & 0.89 & 0.56 & 0.47 & 0.74 \\
\hline & & Plan 8 & 0.66 & 0.70 & 0.70 & 0.44 & 0.90 & 0.48 & 0.42 & 0.76 & 0.46 & 0.60 \\
\hline
\end{tabular}




\begin{tabular}{|c|c|c|c|c|c|c|c|c|c|c|c|c|}
\hline \multicolumn{2}{|c|}{$\begin{array}{l}\text { Experimental } \\
\text { Wave }\end{array}$} & \multicolumn{11}{|c|}{ Wave Height $(\mathrm{m})$ at Indicated Gauge Location; swl $=0.0 \mathrm{~m}$} \\
\hline $\begin{array}{l}\text { Period } \\
\text { (sec) }\end{array}$ & $\begin{array}{l}\text { Height } \\
(\mathrm{m})\end{array}$ & Plan & $\begin{array}{l}\text { Gauge } \\
1\end{array}$ & $\begin{array}{l}\text { Gauge } \\
2\end{array}$ & $\begin{array}{l}\text { Gauge } \\
3\end{array}$ & $\begin{array}{l}\text { Gauge } \\
4\end{array}$ & $\begin{array}{l}\text { Gauge } \\
5\end{array}$ & $\begin{array}{l}\text { Gauge } \\
6\end{array}$ & $\begin{array}{l}\text { Gauge } \\
7\end{array}$ & $\begin{array}{l}\text { Gauge } \\
8\end{array}$ & $\begin{array}{l}\text { Gauge } \\
9\end{array}$ & $\begin{array}{l}\text { Gauge } \\
10\end{array}$ \\
\hline \multirow[t]{27}{*}{6} & \multirow[t]{9}{*}{1} & EC & 1.07 & 0.78 & 1.01 & 0.95 & 1.39 & 1.04 & 0.78 & 0.59 & 0.92 & 0.63 \\
\hline & & Plan 1 & 1.08 & 0.82 & 1.04 & 1.00 & 1.43 & 1.07 & 0.78 & 0.61 & 0.96 & 1.32 \\
\hline & & Plan 2 & 1.04 & 0.75 & 0.97 & 0.90 & 1.29 & 0.99 & 0.75 & 0.57 & 0.89 & 0.76 \\
\hline & & Plan 3 & 1.13 & 0.77 & 1.16 & 0.99 & 1.48 & 1.20 & 0.83 & 0.62 & 0.92 & 1.04 \\
\hline & & Plan 4 & 1.14 & 0.94 & 1.19 & 1.13 & 1.50 & 1.18 & 1.05 & 0.73 & 1.20 & 0.41 \\
\hline & & Plan 5 & 1.10 & 0.88 & 1.15 & 1.08 & 1.54 & 1.17 & 0.96 & 0.71 & 1.10 & 1.17 \\
\hline & & Plan 6 & 1.12 & 0.89 & 1.14 & 1.07 & 1.47 & 1.15 & 1.03 & 0.71 & 1.15 & 0.30 \\
\hline & & Plan 7 & 1.10 & 0.87 & 1.16 & 1.09 & 1.51 & 1.18 & 0.98 & 0.71 & 1.17 & 0.30 \\
\hline & & Plan 8 & 1.09 & 0.86 & 1.11 & 0.99 & 1.43 & 1.11 & 0.94 & 0.65 & 1.06 & 0.47 \\
\hline & \multirow[t]{9}{*}{2} & EC & 1.92 & 0.98 & 1.23 & 1.21 & 1.64 & 1.24 & 0.98 & 0.78 & 1.08 & 0.78 \\
\hline & & Plan 1 & 1.94 & 0.91 & 1.12 & 1.32 & 1.76 & 1.32 & 0.89 & 0.84 & 1.16 & 1.41 \\
\hline & & Plan 2 & 1.89 & 0.98 & 1.21 & 1.20 & 1.59 & 1.23 & 0.97 & 0.78 & 1.11 & 0.96 \\
\hline & & Plan 3 & 1.99 & 0.95 & 1.40 & 1.34 & 1.86 & 1.51 & 1.04 & 0.86 & 1.12 & 1.27 \\
\hline & & Plan 4 & 1.98 & 1.02 & 1.31 & 1.30 & 1.71 & 1.28 & 1.09 & 0.90 & 1.23 & 0.46 \\
\hline & & Plan 5 & 2.00 & 1.04 & 1.35 & 1.35 & 1.87 & 1.38 & 1.13 & 0.95 & 1.32 & 1.30 \\
\hline & & Plan 6 & 2.00 & 1.10 & 1.41 & 1.45 & 1.94 & 1.43 & 1.25 & 1.02 & 1.53 & 0.39 \\
\hline & & Plan 7 & 1.98 & 1.04 & 1.40 & 1.40 & 1.89 & 1.40 & 1.20 & 0.99 & 1.42 & 0.38 \\
\hline & & Plan 8 & 2.02 & 1.07 & 1.38 & 1.40 & 1.85 & 1.39 & 1.17 & 0.93 & 1.36 & 0.66 \\
\hline & \multirow[t]{9}{*}{2.5} & EC & 2.29 & 1.17 & 1.43 & 1.35 & 1.78 & 1.39 & 1.15 & 0.88 & 1.19 & 0.91 \\
\hline & & Plan 1 & 2.24 & 1.13 & 1.38 & 1.37 & 1.84 & 1.42 & 1.06 & 0.86 & 1.21 & 1.54 \\
\hline & & Plan 2 & 2.22 & 1.18 & 1.41 & 1.34 & 1.79 & 1.41 & 1.11 & 0.87 & 1.21 & 1.08 \\
\hline & & Plan 3 & 2.36 & 1.20 & 1.66 & 1.47 & 1.97 & 1.70 & 1.27 & 0.96 & 1.21 & 1.41 \\
\hline & & Plan 4 & 2.44 & 1.11 & 1.34 & 1.43 & 1.78 & 1.38 & 1.16 & 0.93 & 1.32 & 0.51 \\
\hline & & Plan 5 & 2.45 & 1.19 & 1.38 & 1.42 & 1.83 & 1.43 & 1.19 & 0.95 & 1.24 & 1.41 \\
\hline & & Plan 6 & 2.48 & 1.15 & 1.34 & 1.44 & 1.84 & 1.42 & 1.19 & 0.98 & 1.33 & 0.40 \\
\hline & & Plan 7 & 2.44 & 1.13 & 1.35 & 1.38 & 1.75 & 1.39 & 1.13 & 0.95 & 1.24 & 0.40 \\
\hline & & Plan 8 & 2.46 & 1.15 & 1.39 & 1.47 & 1.83 & 1.45 & 1.21 & 0.97 & 1.33 & 0.74 \\
\hline
\end{tabular}




\begin{tabular}{|c|c|c|c|c|c|c|c|c|c|c|c|c|}
\hline \multicolumn{2}{|c|}{$\begin{array}{l}\text { Experimental } \\
\text { Wave }\end{array}$} & \multicolumn{11}{|c|}{ Wave Height $(\mathrm{m})$ at Indicated Gauge Location; swl $=0.0 \mathrm{~m}$} \\
\hline $\begin{array}{l}\text { Period } \\
\text { (sec) }\end{array}$ & $\begin{array}{l}\text { Height } \\
(\mathrm{m})\end{array}$ & Plan & $\begin{array}{l}\text { Gauge } \\
11\end{array}$ & $\begin{array}{l}\text { Gauge } \\
12\end{array}$ & $\begin{array}{l}\text { Gauge } \\
13\end{array}$ & $\begin{array}{l}\text { Gauge } \\
14\end{array}$ & $\begin{array}{l}\text { Gauge } \\
15\end{array}$ & $\begin{array}{l}\text { Gauge } \\
16\end{array}$ & $\begin{array}{l}\text { Gauge } \\
17\end{array}$ & $\begin{array}{l}\text { Gauge } \\
18\end{array}$ & $\begin{array}{l}\text { Gauge } \\
19\end{array}$ & $\begin{array}{l}\text { Gauge } \\
20\end{array}$ \\
\hline \multirow[t]{27}{*}{6} & \multirow[t]{9}{*}{1} & EC & 0.32 & 0.34 & 0.34 & 0.62 & 0.54 & 0.48 & 0.39 & 0.49 & 0.39 & 0.52 \\
\hline & & Plan 1 & 1.01 & 0.70 & 0.56 & 0.72 & 1.06 & 0.78 & 0.93 & 0.77 & 0.67 & 1.15 \\
\hline & & Plan 2 & 0.41 & 0.51 & 0.39 & 0.66 & 0.70 & 0.59 & 0.54 & 0.63 & 0.49 & 0.60 \\
\hline & & Plan 3 & 1.00 & 0.74 & 0.52 & 0.70 & 0.92 & 0.73 & 0.81 & 0.59 & 0.66 & 1.09 \\
\hline & & Plan 4 & 0.59 & 0.47 & 0.51 & 0.65 & 0.52 & 0.33 & 0.57 & 0.47 & 0.34 & 0.50 \\
\hline & & Plan 5 & 1.01 & 0.73 & 0.57 & 0.38 & 1.03 & 0.66 & 0.62 & 0.63 & 0.56 & 1.04 \\
\hline & & Plan 6 & 0.38 & 0.45 & 0.42 & 0.27 & 0.36 & 0.28 & 0.34 & 0.32 & 0.28 & 0.31 \\
\hline & & Plan 7 & 0.42 & 0.40 & 0.39 & 0.55 & 0.31 & 0.27 & 0.57 & 0.40 & 0.27 & 0.46 \\
\hline & & Plan 8 & 0.38 & 0.34 & 0.38 & 0.26 & 0.50 & 0.27 & 0.23 & 0.38 & 0.24 & 0.40 \\
\hline & \multirow[t]{9}{*}{2} & EC & 0.50 & 0.52 & 0.46 & 0.74 & 0.73 & 0.59 & 0.55 & 0.67 & 0.54 & 0.64 \\
\hline & & Plan 1 & 1.02 & 0.86 & 0.87 & 1.02 & 1.16 & 0.89 & 1.22 & 1.08 & 0.76 & 1.24 \\
\hline & & Plan 2 & 0.57 & 0.69 & 0.61 & 0.92 & 0.93 & 0.73 & 0.74 & 0.86 & 0.62 & 0.77 \\
\hline & & Plan 3 & 1.10 & 0.88 & 0.67 & 0.88 & 1.10 & 0.89 & 1.00 & 0.77 & 0.80 & 1.32 \\
\hline & & Plan 4 & 0.63 & 0.59 & 0.64 & 0.79 & 0.62 & 0.44 & 0.67 & 0.63 & 0.41 & 0.60 \\
\hline & & Plan 5 & 1.12 & 0.87 & 0.64 & 0.47 & 1.16 & 0.73 & 0.69 & 0.70 & 0.66 & 1.16 \\
\hline & & Plan 6 & 0.52 & 0.57 & 0.50 & 0.35 & 0.47 & 0.39 & 0.40 & 0.43 & 0.36 & 0.40 \\
\hline & & Plan 7 & 0.54 & 0.52 & 0.47 & 0.66 & 0.44 & 0.36 & 0.65 & 0.51 & 0.34 & 0.54 \\
\hline & & Plan 8 & 0.54 & 0.50 & 0.49 & 0.35 & 0.70 & 0.37 & 0.34 & 0.52 & 0.34 & 0.54 \\
\hline & \multirow[t]{9}{*}{2.5} & EC & 0.60 & 0.66 & 0.59 & 0.91 & 0.86 & 0.73 & 0.72 & 0.80 & 0.66 & 0.77 \\
\hline & & Plan 1 & 1.10 & 1.00 & 0.88 & 1.05 & 1.25 & 1.02 & 1.34 & 1.00 & 0.91 & 1.37 \\
\hline & & Plan 2 & 0.66 & 0.78 & 0.78 & 1.15 & 1.08 & 0.86 & 0.94 & 1.05 & 0.76 & 0.87 \\
\hline & & Plan 3 & 1.18 & 1.01 & 0.75 & 0.96 & 1.24 & 1.01 & 1.09 & 0.85 & 0.90 & 1.47 \\
\hline & & Plan 4 & 0.72 & 0.67 & 0.75 & 0.94 & 0.68 & 0.50 & 0.80 & 0.73 & 0.47 & 0.68 \\
\hline & & Plan 5 & 1.20 & 0.91 & 0.69 & 0.50 & 1.23 & 0.80 & 0.75 & 0.78 & 0.71 & 1.23 \\
\hline & & Plan 6 & 0.56 & 0.63 & 0.57 & 0.40 & 0.52 & 0.42 & 0.46 & 0.48 & 0.42 & 0.43 \\
\hline & & Plan 7 & 0.59 & 0.58 & 0.54 & 0.78 & 0.48 & 0.40 & 0.74 & 0.56 & 0.39 & 0.60 \\
\hline & & Plan 8 & 0.60 & 0.58 & 0.57 & 0.40 & 0.81 & 0.40 & 0.39 & 0.63 & 0.39 & 0.57 \\
\hline
\end{tabular}




\begin{tabular}{|c|c|c|c|c|c|c|c|c|c|c|c|c|}
\hline \multicolumn{2}{|c|}{$\begin{array}{l}\text { Experimental } \\
\text { Wave }\end{array}$} & \multicolumn{11}{|c|}{ Wave Height $(\mathrm{m})$ at Indicated Gauge Location; swl $=0.0 \mathrm{~m}$} \\
\hline $\begin{array}{l}\text { Period } \\
\text { (sec) }\end{array}$ & $\begin{array}{l}\text { Height } \\
(\mathrm{m})\end{array}$ & Plan & $\begin{array}{l}\text { Gauge } \\
1\end{array}$ & $\begin{array}{l}\text { Gauge } \\
2\end{array}$ & $\begin{array}{l}\text { Gauge } \\
3\end{array}$ & $\begin{array}{l}\text { Gauge } \\
4\end{array}$ & $\begin{array}{l}\text { Gauge } \\
5\end{array}$ & $\begin{array}{l}\text { Gauge } \\
6\end{array}$ & $\begin{array}{l}\text { Gauge } \\
7\end{array}$ & $\begin{array}{l}\text { Gauge } \\
8\end{array}$ & $\begin{array}{l}\text { Gauge } \\
9\end{array}$ & $\begin{array}{l}\text { Gauge } \\
10\end{array}$ \\
\hline \multirow[t]{27}{*}{7} & \multirow[t]{9}{*}{1} & EC & 0.99 & 0.82 & 1.06 & 1.07 & 1.55 & 1.12 & 0.78 & 0.65 & 0.88 & 0.66 \\
\hline & & Plan 1 & 0.99 & 0.80 & 1.05 & 1.09 & 1.57 & 1.14 & 0.76 & 0.63 & 0.87 & 1.31 \\
\hline & & Plan 2 & 0.97 & 0.76 & 1.05 & 1.03 & 1.47 & 1.06 & 0.75 & 0.65 & 0.88 & 0.82 \\
\hline & & Plan 3 & 1.04 & 0.79 & 1.23 & 1.14 & 1.70 & 1.32 & 0.85 & 0.68 & 0.89 & 1.16 \\
\hline & & Plan 4 & 1.05 & 0.97 & 1.25 & 1.25 & 1.73 & 1.27 & 1.00 & 0.80 & 1.12 & 0.44 \\
\hline & & Plan 5 & 1.02 & 0.95 & 1.25 & 1.22 & 1.78 & 1.31 & 0.98 & 0.77 & 1.08 & 1.18 \\
\hline & & Plan 6 & 1.04 & 0.98 & 1.25 & 1.24 & 1.74 & 1.28 & 1.01 & 0.81 & 1.16 & 0.35 \\
\hline & & Plan 7 & 1.02 & 0.92 & 1.24 & 1.21 & 1.72 & 1.27 & 0.95 & 0.79 & 1.10 & 0.34 \\
\hline & & Plan 8 & 1.02 & 0.92 & 1.21 & 1.16 & 1.66 & 1.23 & 0.93 & 0.73 & 1.04 & 0.55 \\
\hline & \multirow[t]{9}{*}{2} & EC & 1.91 & 0.95 & 1.14 & 1.28 & 1.78 & 1.31 & 0.92 & 0.82 & 1.14 & 0.72 \\
\hline & & Plan 1 & 1.94 & 0.91 & 1.12 & 1.32 & 1.76 & 1.32 & 0.89 & 0.84 & 1.16 & 1.41 \\
\hline & & Plan 2 & 1.89 & 0.96 & 1.15 & 1.28 & 1.77 & 1.31 & 0.92 & 0.84 & 1.21 & 0.99 \\
\hline & & Plan 3 & 1.96 & 0.95 & 1.38 & 1.43 & 1.92 & 1.59 & 1.05 & 0.94 & 1.23 & 1.31 \\
\hline & & Plan 4 & 2.00 & 1.09 & 1.40 & 1.50 & 2.01 & 1.49 & 1.19 & 0.98 & 1.47 & 0.52 \\
\hline & & Plan 5 & 2.01 & 1.11 & 1.39 & 1.51 & 2.11 & 1.54 & 1.16 & 1.02 & 1.46 & 1.36 \\
\hline & & Plan 6 & 2.04 & 1.27 & 1.54 & 1.57 & 2.21 & 1.63 & 1.36 & 1.10 & 1.61 & 0.43 \\
\hline & & Plan 7 & 2.00 & 1.11 & 1.44 & 1.49 & 2.08 & 1.55 & 1.21 & 1.04 & 1.51 & 0.40 \\
\hline & & Plan 8 & 2.00 & 1.13 & 1.44 & 1.52 & 2.10 & 1.55 & 1.20 & 1.03 & 1.51 & 0.70 \\
\hline & \multirow[t]{9}{*}{2.5} & EC & 2.29 & 1.21 & 1.40 & 1.38 & 1.86 & 1.42 & 1.14 & 0.95 & 1.24 & 0.87 \\
\hline & & Plan 1 & 2.31 & 1.17 & 1.35 & 1.36 & 1.85 & 1.43 & 1.08 & 0.87 & 1.16 & 1.41 \\
\hline & & Plan 2 & 2.32 & 1.23 & 1.40 & 1.39 & 1.88 & 1.46 & 1.12 & 0.91 & 1.22 & 1.12 \\
\hline & & Plan 3 & 2.45 & 1.20 & 1.62 & 1.48 & 2.01 & 1.70 & 1.25 & 0.99 & 1.21 & 1.40 \\
\hline & & Plan 4 & 2.50 & 1.25 & 1.44 & 1.54 & 1.99 & 1.54 & 1.21 & 1.02 & 1.43 & 0.59 \\
\hline & & Plan 5 & 2.50 & 1.26 & 1.44 & 1.53 & 2.07 & 1.58 & 1.23 & 1.02 & 1.36 & 1.39 \\
\hline & & Plan 6 & 2.58 & 1.29 & 1.45 & 1.55 & 2.03 & 1.55 & 1.24 & 1.05 & 1.46 & 0.46 \\
\hline & & Plan 7 & 2.49 & 1.25 & 1.44 & 1.51 & 2.00 & 1.57 & 1.18 & 1.01 & 1.40 & 0.45 \\
\hline & & Plan 8 & 2.49 & 1.26 & 1.45 & 1.55 & 2.04 & 1.57 & 1.21 & 1.03 & 1.41 & 0.76 \\
\hline
\end{tabular}




\begin{tabular}{|c|c|c|c|c|c|c|c|c|c|c|c|c|}
\hline \multicolumn{2}{|c|}{$\begin{array}{l}\text { Experimental } \\
\text { Wave }\end{array}$} & \multicolumn{11}{|c|}{ Wave Height $(\mathrm{m})$ at Indicated Gauge Location; swl $=0.0 \mathrm{~m}$} \\
\hline $\begin{array}{l}\text { Period } \\
\text { (sec) }\end{array}$ & $\begin{array}{l}\text { Height } \\
(\mathrm{m})\end{array}$ & Plan & $\begin{array}{l}\text { Gauge } \\
11\end{array}$ & $\begin{array}{l}\text { Gauge } \\
12\end{array}$ & $\begin{array}{l}\text { Gauge } \\
13\end{array}$ & $\begin{array}{l}\text { Gauge } \\
14\end{array}$ & $\begin{array}{l}\text { Gauge } \\
15\end{array}$ & $\begin{array}{l}\text { Gauge } \\
16\end{array}$ & $\begin{array}{l}\text { Gauge } \\
17\end{array}$ & $\begin{array}{l}\text { Gauge } \\
18\end{array}$ & $\begin{array}{l}\text { Gauge } \\
19\end{array}$ & $\begin{array}{l}\text { Gauge } \\
20\end{array}$ \\
\hline \multirow[t]{27}{*}{7} & \multirow[t]{9}{*}{1} & EC & 0.39 & 0.36 & 0.35 & 0.64 & 0.60 & 0.46 & 0.42 & 0.49 & 0.41 & 0.52 \\
\hline & & Plan 1 & 0.97 & 0.71 & 0.71 & 0.82 & 0.94 & 0.79 & 1.14 & 0.91 & 0.69 & 1.08 \\
\hline & & Plan 2 & 0.44 & 0.59 & 0.46 & 0.74 & 0.76 & 0.59 & 0.65 & 0.68 & 0.50 & 0.62 \\
\hline & & Plan 3 & 1.04 & 0.73 & 0.60 & 0.79 & 0.87 & 0.79 & 0.92 & 0.69 & 0.71 & 1.11 \\
\hline & & Plan 4 & 0.57 & 0.53 & 0.61 & 0.75 & 0.60 & 0.40 & 0.60 & 0.59 & 0.34 & 0.53 \\
\hline & & Plan 5 & 1.05 & 0.80 & 0.62 & 0.44 & 1.10 & 0.64 & 0.64 & 0.58 & 0.61 & 1.07 \\
\hline & & Plan 6 & 0.41 & 0.45 & 0.41 & 0.30 & 0.37 & 0.29 & 0.34 & 0.32 & 0.28 & 0.29 \\
\hline & & Plan 7 & 0.41 & 0.39 & 0.41 & 0.57 & 0.34 & 0.30 & 0.53 & 0.46 & 0.25 & 0.41 \\
\hline & & Plan 8 & 0.44 & 0.37 & 0.38 & 0.29 & 0.54 & 0.30 & 0.28 & 0.38 & 0.27 & 0.46 \\
\hline & \multirow[t]{9}{*}{2} & EC & 0.50 & 0.51 & 0.44 & 0.73 & 0.69 & 0.57 & 0.53 & 0.63 & 0.49 & 0.63 \\
\hline & & Plan 1 & 1.02 & 0.86 & 0.87 & 1.02 & 1.16 & 0.89 & 1.22 & 1.08 & 0.76 & 1.24 \\
\hline & & Plan 2 & 0.64 & 0.73 & 0.64 & 0.91 & 1.00 & 0.72 & 0.76 & 0.85 & 0.63 & 0.83 \\
\hline & & Plan 3 & 1.08 & 0.86 & 0.71 & 0.92 & 1.07 & 0.88 & 1.07 & 0.89 & 0.79 & 1.27 \\
\hline & & Plan 4 & 0.71 & 0.69 & 0.72 & 0.88 & 0.72 & 0.48 & 0.72 & 0.70 & 0.44 & 0.69 \\
\hline & & Plan 5 & 1.18 & 0.90 & 0.67 & 0.52 & 1.20 & 0.75 & 0.78 & 0.73 & 0.68 & 1.22 \\
\hline & & Plan 6 & 0.55 & 0.59 & 0.53 & 0.39 & 0.52 & 0.41 & 0.42 & 0.45 & 0.38 & 0.39 \\
\hline & & Plan 7 & 0.55 & 0.53 & 0.50 & 0.70 & 0.48 & 0.38 & 0.64 & 0.52 & 0.35 & 0.55 \\
\hline & & Plan 8 & 0.56 & 0.50 & 0.49 & 0.37 & 0.72 & 0.36 & 0.37 & 0.54 & 0.36 & 0.53 \\
\hline & \multirow[t]{9}{*}{2.5} & EC & 0.59 & 0.62 & 0.57 & 0.86 & 0.82 & 0.67 & 0.69 & 0.73 & 0.61 & 0.74 \\
\hline & & Plan 1 & 1.03 & 1.01 & 1.05 & 1.21 & 1.21 & 1.05 & 1.41 & 1.19 & 0.93 & 1.25 \\
\hline & & Plan 2 & 0.75 & 0.86 & 0.85 & 1.14 & 1.18 & 0.89 & 0.95 & 1.07 & 0.76 & 0.98 \\
\hline & & Plan 3 & 1.15 & 0.95 & 0.79 & 1.01 & 1.13 & 0.98 & 1.16 & 0.97 & 0.88 & 1.32 \\
\hline & & Plan 4 & 0.76 & 0.78 & 0.88 & 1.06 & 0.83 & 0.55 & 0.89 & 0.84 & 0.53 & 0.80 \\
\hline & & Plan 5 & 1.22 & 0.97 & 0.77 & 0.59 & 1.26 & 0.78 & 0.82 & 0.78 & 0.72 & 1.24 \\
\hline & & Plan 6 & 0.57 & 0.64 & 0.60 & 0.45 & 0.53 & 0.44 & 0.48 & 0.47 & 0.43 & 0.44 \\
\hline & & Plan 7 & 0.59 & 0.59 & 0.58 & 0.82 & 0.56 & 0.42 & 0.74 & 0.59 & 0.42 & 0.62 \\
\hline & & Plan 8 & 0.62 & 0.60 & 0.59 & 0.44 & 0.79 & 0.41 & 0.46 & 0.61 & 0.42 & 0.59 \\
\hline
\end{tabular}




\begin{tabular}{|c|c|c|c|c|c|c|c|c|c|c|c|c|}
\hline \multicolumn{2}{|c|}{$\begin{array}{l}\text { Experimental } \\
\text { Wave }\end{array}$} & \multicolumn{11}{|c|}{ Wave Height $(\mathrm{m})$ at Indicated Gauge Location; swl $=0.0 \mathrm{~m}$} \\
\hline $\begin{array}{l}\text { Period } \\
\text { (sec) }\end{array}$ & $\begin{array}{l}\text { Height } \\
(\mathrm{m})\end{array}$ & Plan & $\begin{array}{l}\text { Gauge } \\
1\end{array}$ & $\begin{array}{l}\text { Gauge } \\
2\end{array}$ & $\begin{array}{l}\text { Gauge } \\
3\end{array}$ & $\begin{array}{l}\text { Gauge } \\
4\end{array}$ & $\begin{array}{l}\text { Gauge } \\
5\end{array}$ & $\begin{array}{l}\text { Gauge } \\
6\end{array}$ & $\begin{array}{l}\text { Gauge } \\
7\end{array}$ & $\begin{array}{l}\text { Gauge } \\
8\end{array}$ & $\begin{array}{l}\text { Gauge } \\
9\end{array}$ & $\begin{array}{l}\text { Gauge } \\
10\end{array}$ \\
\hline \multirow[t]{27}{*}{8} & \multirow[t]{9}{*}{1} & EC & 0.94 & 0.79 & 0.93 & 1.05 & 1.55 & 1.16 & 0.74 & 0.63 & 0.87 & 0.56 \\
\hline & & Plan 1 & 0.94 & 0.78 & 0.92 & 1.05 & 1.52 & 1.14 & 0.74 & 0.60 & 0.82 & 1.11 \\
\hline & & Plan 2 & 0.92 & 0.75 & 0.93 & 1.02 & 1.45 & 1.09 & 0.71 & 0.62 & 0.88 & 0.76 \\
\hline & & Plan 3 & 0.99 & 0.77 & 1.07 & 1.11 & 1.65 & 1.35 & 0.82 & 0.67 & 0.85 & 1.06 \\
\hline & & Plan 4 & 0.98 & 0.91 & 1.07 & 1.21 & 1.66 & 1.28 & 0.90 & 0.75 & 1.07 & 0.43 \\
\hline & & Plan 5 & 0.97 & 0.93 & 1.11 & 1.21 & 1.76 & 1.33 & 0.92 & 0.77 & 1.08 & 1.09 \\
\hline & & Plan 6 & 0.98 & 0.92 & 1.07 & 1.22 & 1.71 & 1.30 & 0.89 & 0.79 & 1.13 & 0.34 \\
\hline & & Plan 7 & 0.96 & 0.88 & 1.07 & 1.19 & 1.68 & 1.29 & 0.85 & 0.76 & 1.07 & 0.31 \\
\hline & & Plan 8 & 0.96 & 0.88 & 1.04 & 1.13 & 1.64 & 1.27 & 0.83 & 0.71 & 1.01 & 0.48 \\
\hline & \multirow[t]{9}{*}{2} & EC & 1.83 & 1.06 & 1.16 & 1.38 & 1.96 & 1.49 & 1.00 & 0.96 & 1.22 & 0.73 \\
\hline & & Plan 1 & 1.86 & 0.98 & 1.12 & 1.34 & 1.88 & 1.44 & 0.94 & 0.87 & 1.11 & 1.35 \\
\hline & & Plan 2 & 1.86 & 1.05 & 1.16 & 1.33 & 1.88 & 1.45 & 0.97 & 0.91 & 1.20 & 1.07 \\
\hline & & Plan 3 & 1.95 & 1.05 & 1.37 & 1.51 & 2.17 & 1.76 & 1.07 & 1.04 & 1.28 & 1.31 \\
\hline & & Plan 4 & 1.92 & 1.21 & 1.37 & 1.57 & 2.18 & 1.65 & 1.16 & 1.06 & 1.44 & 0.61 \\
\hline & & Plan 5 & 1.95 & 1.21 & 1.35 & 1.55 & 2.26 & 1.67 & 1.15 & 1.10 & 1.43 & 1.35 \\
\hline & & Plan 6 & 1.96 & 1.26 & 1.37 & 1.59 & 2.27 & 1.71 & 1.18 & 1.19 & 1.58 & 0.45 \\
\hline & & Plan 7 & 1.92 & 1.20 & 1.36 & 1.55 & 2.23 & 1.69 & 1.12 & 1.14 & 1.49 & 0.43 \\
\hline & & Plan 8 & 1.94 & 1.24 & 1.38 & 1.58 & 2.26 & 1.72 & 1.17 & 1.14 & 1.49 & 0.73 \\
\hline & \multirow[t]{9}{*}{2.5} & EC & 2.30 & 1.20 & 1.28 & 1.36 & 1.88 & 1.47 & 1.12 & 1.03 & 1.27 & 0.79 \\
\hline & & Plan 1 & 2.35 & 1.16 & 1.21 & 1.31 & 1.76 & 1.42 & 1.06 & 0.93 & 1.17 & 1.29 \\
\hline & & Plan 2 & 2.28 & 1.21 & 1.28 & 1.37 & 1.88 & 1.49 & 1.11 & 1.00 & 1.27 & 1.14 \\
\hline & & Plan 3 & 2.45 & 1.17 & 1.46 & 1.45 & 2.00 & 1.71 & 1.20 & 1.08 & 1.28 & 1.33 \\
\hline & & Plan 4 & 2.47 & 1.34 & 1.44 & 1.56 & 2.13 & 1.65 & 1.30 & 1.14 & 1.53 & 0.65 \\
\hline & & Plan 5 & 2.47 & 1.34 & 1.42 & 1.57 & 2.20 & 1.67 & 1.29 & 1.17 & 1.50 & 1.33 \\
\hline & & Plan 6 & 2.50 & 1.39 & 1.43 & 1.59 & 2.23 & 1.72 & 1.31 & 1.19 & 1.60 & 0.48 \\
\hline & & Plan 7 & 2.42 & 1.30 & 1.41 & 1.52 & 2.15 & 1.66 & 1.25 & 1.14 & 1.52 & 0.45 \\
\hline & & Plan 8 & 2.46 & 1.35 & 1.43 & 1.58 & 2.21 & 1.70 & 1.28 & 1.17 & 1.54 & 0.76 \\
\hline
\end{tabular}




\begin{tabular}{|c|c|c|c|c|c|c|c|c|c|c|c|c|}
\hline \multicolumn{2}{|c|}{$\begin{array}{l}\text { Experimental } \\
\text { Wave }\end{array}$} & \multicolumn{11}{|c|}{ Wave Height $(\mathrm{m})$ at Indicated Gauge Location; $\mathrm{swl}=0.0 \mathrm{~m}$} \\
\hline $\begin{array}{l}\text { Period } \\
\text { (sec) }\end{array}$ & $\begin{array}{l}\text { Height } \\
\text { (m) }\end{array}$ & Plan & $\begin{array}{l}\text { Gauge } \\
11\end{array}$ & $\begin{array}{l}\text { Gauge } \\
12\end{array}$ & $\begin{array}{l}\text { Gauge } \\
13\end{array}$ & $\begin{array}{l}\text { Gauge } \\
14\end{array}$ & $\begin{array}{l}\text { Gauge } \\
15\end{array}$ & $\begin{array}{l}\text { Gauge } \\
16\end{array}$ & $\begin{array}{l}\text { Gauge } \\
17\end{array}$ & $\begin{array}{l}\text { Gauge } \\
18\end{array}$ & $\begin{array}{l}\text { Gauge } \\
19\end{array}$ & $\begin{array}{l}\text { Gauge } \\
20\end{array}$ \\
\hline \multirow[t]{27}{*}{8} & \multirow[t]{9}{*}{1} & EC & 0.37 & 0.34 & 0.32 & 0.57 & 0.49 & 0.40 & 0.42 & 0.44 & 0.35 & 0.49 \\
\hline & & Plan 1 & 0.84 & 0.71 & 0.84 & 0.96 & 0.97 & 0.75 & 1.07 & 0.96 & 0.68 & 1.00 \\
\hline & & Plan 2 & 0.50 & 0.59 & 0.54 & 0.75 & 0.82 & 0.55 & 0.59 & 0.63 & 0.48 & 0.71 \\
\hline & & Plan 3 & 0.94 & 0.68 & 0.61 & 0.76 & 0.78 & 0.72 & 0.90 & 0.75 & 0.67 & 0.98 \\
\hline & & Plan 4 & 0.57 & 0.58 & 0.68 & 0.79 & 0.64 & 0.41 & 0.65 & 0.62 & 0.36 & 0.61 \\
\hline & & Plan 5 & 0.96 & 0.73 & 0.58 & 0.45 & 0.98 & 0.58 & 0.63 & 0.58 & 0.55 & 0.99 \\
\hline & & Plan 6 & 0.37 & 0.38 & 0.39 & 0.30 & 0.33 & 0.26 & 0.30 & 0.29 & 0.25 & 0.28 \\
\hline & & Plan 7 & 0.36 & 0.35 & 0.38 & 0.54 & 0.33 & 0.27 & 0.48 & 0.40 & 0.24 & 0.42 \\
\hline & & Plan 8 & 0.39 & 0.32 & 0.35 & 0.28 & 0.46 & 0.26 & 0.29 & 0.34 & 0.26 & 0.40 \\
\hline & \multirow[t]{9}{*}{2} & EC & 0.54 & 0.55 & 0.48 & 0.76 & 0.71 & 0.56 & 0.63 & 0.64 & 0.53 & 0.66 \\
\hline & & Plan 1 & 1.00 & 0.90 & 1.09 & 1.26 & 1.27 & 0.92 & 1.35 & 1.27 & 0.82 & 1.22 \\
\hline & & Plan 2 & 0.76 & 0.79 & 0.77 & 1.02 & 1.15 & 0.77 & 0.83 & 0.92 & 0.69 & 0.97 \\
\hline & & Plan 3 & 1.05 & 0.85 & 0.80 & 1.02 & 1.04 & 0.89 & 1.13 & 1.02 & 0.79 & 1.19 \\
\hline & & Plan 4 & 0.77 & 0.83 & 0.95 & 1.10 & 0.91 & 0.57 & 0.92 & 0.89 & 0.54 & 0.85 \\
\hline & & Plan 5 & 1.16 & 0.91 & 0.74 & 0.61 & 1.19 & 0.72 & 0.81 & 0.76 & 0.67 & 1.15 \\
\hline & & Plan 6 & 0.53 & 0.56 & 0.56 & 0.44 & 0.50 & 0.40 & 0.41 & 0.44 & 0.38 & 0.41 \\
\hline & & Plan 7 & 0.55 & 0.55 & 0.56 & 0.78 & 0.53 & 0.41 & 0.68 & 0.57 & 0.38 & 0.61 \\
\hline & & Plan 8 & 0.59 & 0.55 & 0.55 & 0.43 & 0.74 & 0.39 & 0.45 & 0.57 & 0.39 & 0.56 \\
\hline & \multirow[t]{9}{*}{2.5} & EC & 0.57 & 0.63 & 0.56 & 0.83 & 0.77 & 0.62 & 0.71 & 0.69 & 0.58 & 0.71 \\
\hline & & Plan 1 & 0.99 & 1.04 & 1.14 & 1.27 & 1.26 & 1.01 & 1.37 & 1.23 & 0.92 & 1.27 \\
\hline & & Plan 2 & 0.82 & 0.85 & 0.89 & 1.15 & 1.24 & 0.86 & 0.96 & 1.02 & 0.79 & 1.07 \\
\hline & & Plan 3 & 1.11 & 0.92 & 0.86 & 1.07 & 1.10 & 0.90 & 1.19 & 1.01 & 0.84 & 1.26 \\
\hline & & Plan 4 & 0.79 & 0.89 & 1.03 & 1.21 & 0.97 & 0.63 & 1.02 & 0.96 & 0.60 & 0.92 \\
\hline & & Plan 5 & 1.16 & 0.97 & 0.80 & 0.67 & 1.18 & 0.73 & 0.87 & 0.78 & 0.68 & 1.17 \\
\hline & & Plan 6 & 0.57 & 0.63 & 0.64 & 0.49 & 0.55 & 0.44 & 0.49 & 0.47 & 0.43 & 0.46 \\
\hline & & Plan 7 & 0.59 & 0.61 & 0.62 & 0.86 & 0.60 & 0.43 & 0.76 & 0.60 & 0.42 & 0.67 \\
\hline & & Plan 8 & 0.62 & 0.61 & 0.62 & 0.47 & 0.79 & 0.41 & 0.52 & 0.62 & 0.43 & 0.60 \\
\hline
\end{tabular}


Table D6. Wave heights for waves from 0 degrees; $0.0 \mathrm{~m}$ swl.

\begin{tabular}{|c|c|c|c|c|c|c|c|c|c|c|c|c|}
\hline \multicolumn{2}{|c|}{$\begin{array}{l}\text { Experimental } \\
\text { Wave }\end{array}$} & \multicolumn{11}{|c|}{ Wave Height $(\mathrm{m})$ at Indicated Gauge Location; swl $=0.0 \mathrm{~m}$} \\
\hline $\begin{array}{l}\text { Period } \\
(\mathrm{sec})\end{array}$ & $\begin{array}{l}\text { Height } \\
(\mathrm{m})\end{array}$ & Plan & $\begin{array}{l}\text { Gauge } \\
1\end{array}$ & $\begin{array}{l}\text { Gauge } \\
2\end{array}$ & $\begin{array}{l}\text { Gauge } \\
3\end{array}$ & $\begin{array}{l}\text { Gauge } \\
4\end{array}$ & $\begin{array}{l}\text { Gauge } \\
5\end{array}$ & $\begin{array}{l}\text { Gauge } \\
6\end{array}$ & $\begin{array}{l}\text { Gauge } \\
7\end{array}$ & $\begin{array}{l}\text { Gauge } \\
8\end{array}$ & $\begin{array}{l}\text { Gauge } \\
9\end{array}$ & $\begin{array}{l}\text { Gauge } \\
10\end{array}$ \\
\hline \multirow[t]{27}{*}{5} & \multirow[t]{9}{*}{1} & EC & 0.99 & 0.68 & 0.99 & 0.88 & 0.88 & 0.82 & 0.84 & 0.73 & 0.75 & 0.50 \\
\hline & & Plan 1 & 0.99 & 0.74 & 0.91 & 0.87 & 0.90 & 0.73 & 0.85 & 0.70 & 0.72 & 0.61 \\
\hline & & Plan 2 & 0.99 & 0.73 & 0.90 & 0.88 & 0.87 & 0.78 & 0.83 & 0.71 & 0.75 & 0.42 \\
\hline & & Plan 3 & 1.03 & 0.63 & 0.95 & 0.85 & 0.80 & 0.74 & 0.82 & 0.71 & 0.69 & 0.74 \\
\hline & & Plan 4 & 1.01 & 0.75 & 0.93 & 0.90 & 0.86 & 0.78 & 0.87 & 0.75 & 0.79 & 0.21 \\
\hline & & Plan 5 & 1.01 & 0.52 & 0.73 & 0.81 & 0.75 & 0.54 & 0.73 & 0.72 & 0.74 & 0.68 \\
\hline & & Plan 6 & 0.99 & 0.74 & 0.93 & 0.89 & 0.92 & 0.76 & 0.85 & 0.77 & 0.75 & 0.22 \\
\hline & & Plan 7 & 1.00 & 0.74 & 0.92 & 0.90 & 0.89 & 0.75 & 0.84 & 0.77 & 0.75 & 0.25 \\
\hline & & Plan 8 & 1.02 & 0.76 & 0.97 & 0.96 & 0.98 & 0.77 & 0.87 & 0.83 & 0.82 & 0.50 \\
\hline & \multirow[t]{9}{*}{2} & EC & 2.10 & 1.27 & 1.71 & 1.38 & 1.34 & 1.36 & 1.43 & 1.31 & 1.41 & 0.86 \\
\hline & & Plan 1 & 2.06 & 1.31 & 1.47 & 1.35 & 1.34 & 1.20 & 1.40 & 1.25 & 1.36 & 1.03 \\
\hline & & Plan 2 & 2.02 & 1.34 & 1.54 & 1.38 & 1.38 & 1.31 & 1.41 & 1.27 & 1.39 & 0.78 \\
\hline & & Plan 3 & 2.08 & 1.26 & 1.68 & 1.37 & 1.32 & 1.32 & 1.41 & 1.31 & 1.40 & 1.14 \\
\hline & & Plan 4 & 2.05 & 1.36 & 1.48 & 1.32 & 1.32 & 1.21 & 1.38 & 1.30 & 1.35 & 0.37 \\
\hline & & Plan 5 & 2.04 & 1.27 & 1.46 & 1.24 & 1.28 & 1.13 & 1.27 & 1.24 & 1.36 & 1.14 \\
\hline & & Plan 6 & 2.06 & 1.32 & 1.50 & 1.31 & 1.32 & 1.19 & 1.32 & 1.26 & 1.33 & 0.33 \\
\hline & & Plan 7 & 2.03 & 1.34 & 1.51 & 1.30 & 1.31 & 1.21 & 1.34 & 1.24 & 1.28 & 0.37 \\
\hline & & Plan 8 & 2.04 & 1.34 & 1.55 & 1.36 & 1.36 & 1.22 & 1.36 & 1.30 & 1.34 & 0.72 \\
\hline & \multirow[t]{9}{*}{2.5} & EC & 2.49 & 1.42 & 1.87 & 1.52 & 1.36 & 1.50 & 1.62 & 1.42 & 1.50 & 0.91 \\
\hline & & Plan 1 & 2.43 & 1.47 & 1.64 & 1.49 & 1.36 & 1.32 & 1.59 & 1.37 & 1.50 & 1.24 \\
\hline & & Plan 2 & 2.43 & 1.53 & 1.69 & 1.52 & 1.34 & 1.40 & 1.60 & 1.46 & 1.53 & 1.00 \\
\hline & & Plan 3 & 2.50 & 1.44 & 1.92 & 1.57 & 1.38 & 1.47 & 1.64 & 1.51 & 1.60 & 1.27 \\
\hline & & Plan 4 & 2.47 & 1.55 & 1.71 & 1.51 & 1.41 & 1.34 & 1.55 & 1.50 & 1.59 & 0.44 \\
\hline & & Plan 5 & 2.42 & 1.49 & 1.75 & 1.43 & 1.43 & 1.23 & 1.38 & 1.53 & 1.73 & 1.12 \\
\hline & & Plan 6 & 2.45 & 1.51 & 1.66 & 1.47 & 1.37 & 1.32 & 1.51 & 1.48 & 1.52 & 0.39 \\
\hline & & Plan 7 & 2.43 & 1.48 & 1.69 & 1.52 & 1.37 & 1.31 & 1.52 & 1.48 & 1.50 & 0.42 \\
\hline & & Plan 8 & 2.46 & 1.54 & 1.73 & 1.52 & 1.40 & 1.35 & 1.54 & 1.51 & 1.52 & 0.79 \\
\hline
\end{tabular}




\begin{tabular}{|c|c|c|c|c|c|c|c|c|c|c|c|c|}
\hline \multicolumn{2}{|c|}{$\begin{array}{l}\text { Experimental } \\
\text { Wave }\end{array}$} & \multicolumn{11}{|c|}{ Wave Height $(\mathrm{m})$ at Indicated Gauge Location; swl $=0.0 \mathrm{~m}$} \\
\hline $\begin{array}{l}\text { Period } \\
\text { (sec) }\end{array}$ & $\begin{array}{l}\text { Height } \\
(\mathrm{m})\end{array}$ & Plan & $\begin{array}{l}\text { Gauge } \\
11\end{array}$ & $\begin{array}{l}\text { Gauge } \\
12\end{array}$ & $\begin{array}{l}\text { Gauge } \\
13\end{array}$ & $\begin{array}{l}\text { Gauge } \\
14\end{array}$ & $\begin{array}{l}\text { Gauge } \\
15\end{array}$ & $\begin{array}{l}\text { Gauge } \\
16\end{array}$ & $\begin{array}{l}\text { Gauge } \\
17\end{array}$ & $\begin{array}{l}\text { Gauge } \\
18\end{array}$ & $\begin{array}{l}\text { Gauge } \\
19\end{array}$ & $\begin{array}{l}\text { Gauge } \\
20\end{array}$ \\
\hline \multirow[t]{27}{*}{5} & \multirow[t]{9}{*}{1} & EC & 0.43 & 0.60 & 0.52 & 0.59 & 0.56 & 0.46 & 0.68 & 0.73 & 0.46 & 0.43 \\
\hline & & Plan 1 & 0.59 & 0.73 & 0.67 & 0.76 & 0.81 & 0.62 & 0.75 & 0.81 & 0.65 & 0.57 \\
\hline & & Plan 2 & 0.33 & 0.48 & 0.73 & 0.92 & 0.56 & 0.54 & 0.81 & 0.78 & 0.53 & 0.49 \\
\hline & & Plan 3 & 0.64 & 0.46 & 0.41 & 0.47 & 0.71 & 0.47 & 0.47 & 0.66 & 0.45 & 0.57 \\
\hline & & Plan 4 & 0.41 & 0.55 & 0.75 & 0.84 & 0.36 & 0.51 & 0.72 & 0.63 & 0.50 & 0.51 \\
\hline & & Plan 5 & 0.51 & 0.37 & 0.40 & 0.21 & 0.70 & 0.29 & 0.33 & 0.52 & 0.28 & 0.50 \\
\hline & & Plan 6 & 0.49 & 0.61 & 0.54 & 0.24 & 0.50 & 0.44 & 0.35 & 0.37 & 0.47 & 0.33 \\
\hline & & Plan 7 & 0.55 & 0.56 & 0.47 & 0.58 & 0.31 & 0.39 & 0.60 & 0.44 & 0.41 & 0.49 \\
\hline & & Plan 8 & 0.47 & 0.61 & 0.60 & 0.30 & 0.76 & 0.27 & 0.44 & 0.63 & 0.39 & 0.37 \\
\hline & \multirow[t]{9}{*}{2} & EC & 0.67 & 0.92 & 0.84 & 1.03 & 0.83 & 0.73 & 1.11 & 1.15 & 0.70 & 0.71 \\
\hline & & Plan 1 & 0.92 & 1.20 & 1.21 & 1.24 & 1.35 & 1.04 & 1.32 & 1.36 & 1.04 & 0.91 \\
\hline & & Plan 2 & 0.58 & 0.86 & 1.27 & 1.47 & 1.21 & 0.91 & 1.27 & 1.30 & 0.85 & 0.92 \\
\hline & & Plan 3 & 1.08 & 0.92 & 0.76 & 0.91 & 1.12 & 0.86 & 0.91 & 1.09 & 0.77 & 1.00 \\
\hline & & Plan 4 & 0.65 & 0.91 & 1.21 & 1.35 & 0.78 & 0.83 & 1.08 & 1.03 & 0.78 & 0.77 \\
\hline & & Plan 5 & 0.96 & 0.84 & 0.72 & 0.40 & 1.17 & 0.62 & 0.56 & 0.87 & 0.58 & 0.91 \\
\hline & & Plan 6 & 0.65 & 0.86 & 0.83 & 0.46 & 0.72 & 0.64 & 0.54 & 0.52 & 0.65 & 0.46 \\
\hline & & Plan 7 & 0.73 & 0.80 & 0.73 & 0.98 & 0.47 & 0.59 & 0.90 & 0.72 & 0.55 & 0.68 \\
\hline & & Plan 8 & 0.66 & 0.90 & 0.88 & 0.49 & 0.99 & 0.43 & 0.66 & 0.81 & 0.59 & 0.57 \\
\hline & \multirow[t]{9}{*}{2.5} & EC & 0.71 & 0.96 & 0.88 & 1.09 & 0.89 & 0.81 & 1.12 & 1.16 & 0.75 & 0.80 \\
\hline & & Plan 1 & 1.01 & 1.29 & 1.29 & 1.41 & 1.40 & 1.22 & 1.42 & 1.44 & 1.15 & 1.07 \\
\hline & & Plan 2 & 0.69 & 0.94 & 1.37 & 1.52 & 1.38 & 1.00 & 1.36 & 1.41 & 0.91 & 1.09 \\
\hline & & Plan 3 & 1.14 & 0.97 & 0.84 & 1.01 & 1.17 & 0.94 & 1.02 & 1.13 & 0.84 & 1.11 \\
\hline & & Plan 4 & 0.72 & 1.01 & 1.33 & 1.47 & 0.93 & 0.91 & 1.19 & 1.15 & 0.82 & 0.86 \\
\hline & & Plan 5 & 0.93 & 0.95 & 0.83 & 0.49 & 1.20 & 0.63 & 0.72 & 0.90 & 0.64 & 0.89 \\
\hline & & Plan 6 & 0.71 & 0.94 & 0.90 & 0.53 & 0.79 & 0.67 & 0.59 & 0.57 & 0.66 & 0.53 \\
\hline & & Plan 7 & 0.79 & 0.85 & 0.81 & 1.09 & 0.53 & 0.63 & 0.99 & 0.80 & 0.57 & 0.76 \\
\hline & & Plan 8 & 0.69 & 0.94 & 0.95 & 0.54 & 1.04 & 0.48 & 0.71 & 0.86 & 0.59 & 0.59 \\
\hline
\end{tabular}




\begin{tabular}{|c|c|c|c|c|c|c|c|c|c|c|c|c|}
\hline \multicolumn{2}{|c|}{$\begin{array}{l}\text { Experimental } \\
\text { Wave }\end{array}$} & \multicolumn{11}{|c|}{ Wave Height $(\mathrm{m})$ at Indicated Gauge Location; swl $=0.0 \mathrm{~m}$} \\
\hline $\begin{array}{l}\text { Period } \\
\text { (sec) }\end{array}$ & $\begin{array}{l}\text { Height } \\
(\mathrm{m})\end{array}$ & Plan & $\begin{array}{l}\text { Gauge } \\
1\end{array}$ & $\begin{array}{l}\text { Gauge } \\
2\end{array}$ & $\begin{array}{l}\text { Gauge } \\
3\end{array}$ & $\begin{array}{l}\text { Gauge } \\
4\end{array}$ & $\begin{array}{l}\text { Gauge } \\
5\end{array}$ & $\begin{array}{l}\text { Gauge } \\
6\end{array}$ & $\begin{array}{l}\text { Gauge } \\
7\end{array}$ & $\begin{array}{l}\text { Gauge } \\
8\end{array}$ & $\begin{array}{l}\text { Gauge } \\
9\end{array}$ & $\begin{array}{l}\text { Gauge } \\
10\end{array}$ \\
\hline \multirow[t]{27}{*}{6} & \multirow[t]{9}{*}{1} & EC & 0.98 & 0.66 & 0.97 & 0.88 & 0.79 & 0.76 & 0.86 & 0.75 & 0.87 & 0.55 \\
\hline & & Plan 1 & 1.08 & 0.77 & 0.92 & 0.94 & 0.89 & 0.74 & 0.87 & 0.82 & 0.98 & 0.73 \\
\hline & & Plan 2 & 1.08 & 0.77 & 0.93 & 0.94 & 0.86 & 0.76 & 0.87 & 0.82 & 0.98 & 0.52 \\
\hline & & Plan 3 & 1.11 & 0.71 & 1.00 & 0.92 & 0.84 & 0.79 & 0.87 & 0.81 & 0.93 & 0.81 \\
\hline & & Plan 4 & 1.11 & 0.71 & 0.86 & 0.91 & 0.77 & 0.69 & 0.82 & 0.78 & 0.95 & 0.25 \\
\hline & & Plan 5 & 1.09 & 0.74 & 0.94 & 0.88 & 0.88 & 0.73 & 0.87 & 0.82 & 0.97 & 0.85 \\
\hline & & Plan 6 & 1.09 & 0.71 & 0.91 & 0.92 & 0.82 & 0.70 & 0.86 & 0.80 & 0.92 & 0.24 \\
\hline & & Plan 7 & 1.10 & 0.76 & 0.94 & 0.95 & 0.85 & 0.73 & 0.89 & 0.83 & 0.94 & 0.25 \\
\hline & & Plan 8 & 1.10 & 0.74 & 0.92 & 0.92 & 0.87 & 0.70 & 0.85 & 0.81 & 0.95 & 0.45 \\
\hline & \multirow[t]{9}{*}{2} & EC & 2.04 & 1.12 & 1.34 & 1.22 & 1.34 & 1.21 & 1.15 & 1.20 & 1.46 & 0.84 \\
\hline & & Plan 1 & 1.99 & 1.15 & 1.16 & 1.18 & 1.29 & 1.07 & 1.11 & 1.16 & 1.39 & 1.12 \\
\hline & & Plan 2 & 2.00 & 1.24 & 1.28 & 1.18 & 1.32 & 1.18 & 1.19 & 1.20 & 1.44 & 0.89 \\
\hline & & Plan 3 & 2.04 & 1.06 & 1.29 & 1.19 & 1.31 & 1.17 & 1.09 & 1.14 & 1.38 & 1.18 \\
\hline & & Plan 4 & 2.07 & 1.18 & 1.23 & 1.30 & 1.33 & 1.14 & 1.18 & 1.23 & 1.44 & 0.47 \\
\hline & & Plan 5 & 2.02 & 1.13 & 1.29 & 1.26 & 1.32 & 1.09 & 1.13 & 1.21 & 1.44 & 1.25 \\
\hline & & Plan 6 & 2.04 & 1.19 & 1.25 & 1.26 & 1.35 & 1.10 & 1.17 & 1.23 & 1.41 & 0.40 \\
\hline & & Plan 7 & 2.02 & 1.16 & 1.23 & 1.25 & 1.34 & 1.10 & 1.13 & 1.19 & 1.37 & 0.39 \\
\hline & & Plan 8 & 2.05 & 1.28 & 1.35 & 1.34 & 1.43 & 1.18 & 1.22 & 1.31 & 1.53 & 0.79 \\
\hline & \multirow[t]{9}{*}{2.5} & EC & 2.45 & 1.39 & 1.66 & 1.41 & 1.42 & 1.40 & 1.41 & 1.51 & 1.77 & 0.96 \\
\hline & & Plan 1 & 2.40 & 1.37 & 1.36 & 1.28 & 1.40 & 1.18 & 1.31 & 1.35 & 1.59 & 1.23 \\
\hline & & Plan 2 & 2.37 & 1.40 & 1.36 & 1.33 & 1.42 & 1.30 & 1.34 & 1.38 & 1.61 & 1.07 \\
\hline & & Plan 3 & 2.45 & 1.34 & 1.56 & 1.34 & 1.39 & 1.35 & 1.35 & 1.42 & 1.68 & 1.26 \\
\hline & & Plan 4 & 2.40 & 1.35 & 1.35 & 1.25 & 1.39 & 1.21 & 1.30 & 1.27 & 1.54 & 0.51 \\
\hline & & Plan 5 & 2.38 & 1.28 & 1.37 & 1.22 & 1.32 & 1.14 & 1.19 & 1.25 & 1.54 & 1.15 \\
\hline & & Plan 6 & 2.41 & 1.29 & 1.31 & 1.22 & 1.35 & 1.19 & 1.21 & 1.21 & 1.42 & 0.40 \\
\hline & & Plan 7 & 2.39 & 1.32 & 1.36 & 1.26 & 1.34 & 1.21 & 1.24 & 1.25 & 1.46 & 0.41 \\
\hline & & Plan 8 & 2.40 & 1.40 & 1.44 & 1.33 & 1.39 & 1.26 & 1.32 & 1.34 & 1.54 & 0.79 \\
\hline
\end{tabular}




\begin{tabular}{|c|c|c|c|c|c|c|c|c|c|c|c|c|}
\hline \multicolumn{2}{|c|}{$\begin{array}{l}\text { Experimental } \\
\text { Wave }\end{array}$} & \multicolumn{11}{|c|}{ Wave Height $(\mathrm{m})$ at Indicated Gauge Location; $\mathrm{swl}=0.0 \mathrm{~m}$} \\
\hline $\begin{array}{l}\text { Period } \\
\text { (sec) }\end{array}$ & $\begin{array}{l}\text { Height } \\
(\mathrm{m})\end{array}$ & Plan & $\begin{array}{l}\text { Gauge } \\
11\end{array}$ & $\begin{array}{l}\text { Gauge } \\
12\end{array}$ & $\begin{array}{l}\text { Gauge } \\
13\end{array}$ & $\begin{array}{l}\text { Gauge } \\
14\end{array}$ & $\begin{array}{l}\text { Gauge } \\
15\end{array}$ & $\begin{array}{l}\text { Gauge } \\
16\end{array}$ & \begin{tabular}{|l} 
Gauge \\
17
\end{tabular} & $\begin{array}{l}\text { Gauge } \\
18\end{array}$ & $\begin{array}{l}\text { Gauge } \\
19\end{array}$ & $\begin{array}{l}\text { Gauge } \\
20\end{array}$ \\
\hline \multirow[t]{27}{*}{6} & \multirow[t]{9}{*}{1} & EC & 0.37 & 0.49 & 0.43 & 0.59 & 0.54 & 0.46 & 0.54 & 0.61 & 0.43 & 0.47 \\
\hline & & Plan 1 & 0.66 & 0.78 & 0.75 & 0.83 & 0.89 & 0.71 & 0.77 & 0.89 & 0.68 & 0.70 \\
\hline & & Plan 2 & 0.43 & 0.53 & 0.78 & 0.93 & 0.79 & 0.51 & 0.79 & 0.92 & 0.50 & 0.54 \\
\hline & & Plan 3 & 0.71 & 0.51 & 0.41 & 0.48 & 0.73 & 0.52 & 0.50 & 0.62 & 0.49 & 0.70 \\
\hline & & Plan 4 & 0.41 & 0.54 & 0.70 & 0.77 & 0.41 & 0.43 & 0.68 & 0.63 & 0.44 & 0.43 \\
\hline & & Plan 5 & 0.69 & 0.50 & 0.43 & 0.25 & 0.82 & 0.40 & 0.38 & 0.57 & 0.41 & 0.66 \\
\hline & & Plan 6 & 0.40 & 0.51 & 0.45 & 0.25 & 0.41 & 0.35 & 0.31 & 0.32 & 0.37 & 0.28 \\
\hline & & Plan 7 & 0.47 & 0.49 & 0.45 & 0.57 & 0.31 & 0.34 & 0.55 & 0.44 & 0.36 & 0.42 \\
\hline & & Plan 8 & 0.41 & 0.49 & 0.48 & 0.28 & 0.58 & 0.26 & 0.35 & 0.47 & 0.32 & 0.36 \\
\hline & \multirow[t]{9}{*}{2} & EC & 0.60 & 0.76 & 0.66 & 0.85 & 0.84 & 0.68 & 0.80 & 0.86 & 0.66 & 0.71 \\
\hline & & Plan 1 & 1.02 & 1.06 & 1.00 & 1.06 & 1.26 & 0.98 & 1.01 & 1.13 & 0.91 & 1.09 \\
\hline & & Plan 2 & 0.70 & 0.79 & 1.08 & 1.26 & 1.21 & 0.77 & 1.08 & 1.22 & 0.74 & 0.87 \\
\hline & & Plan 3 & 1.04 & 0.78 & 0.65 & 0.75 & 1.01 & 0.80 & 0.82 & 0.88 & 0.72 & 1.01 \\
\hline & & Plan 4 & 0.69 & 0.84 & 0.98 & 1.11 & 0.73 & 0.65 & 0.98 & 0.94 & 0.62 & 0.64 \\
\hline & & Plan 5 & 1.03 & 0.79 & 0.63 & 0.44 & 1.11 & 0.67 & 0.65 & 0.77 & 0.59 & 1.02 \\
\hline & & Plan 6 & 0.59 & 0.74 & 0.65 & 0.42 & 0.60 & 0.52 & 0.48 & 0.48 & 0.50 & 0.44 \\
\hline & & Plan 7 & 0.63 & 0.67 & 0.62 & 0.80 & 0.52 & 0.46 & 0.76 & 0.61 & 0.47 & 0.59 \\
\hline & & Plan 8 & 0.67 & 0.77 & 0.72 & 0.45 & 0.87 & 0.46 & 0.56 & 0.70 & 0.51 & 0.62 \\
\hline & \multirow[t]{9}{*}{2.5} & EC & 0.67 & 0.87 & 0.78 & 1.03 & 0.93 & 0.80 & 0.98 & 1.00 & 0.75 & 0.80 \\
\hline & & Plan 1 & 1.06 & 1.20 & 1.19 & 1.25 & 1.37 & 1.09 & 1.28 & 1.33 & 1.03 & 1.13 \\
\hline & & Plan 2 & 0.82 & 0.93 & 1.18 & 1.37 & 1.37 & 0.84 & 1.22 & 1.35 & 0.82 & 0.95 \\
\hline & & Plan 3 & 1.12 & 0.92 & 0.78 & 0.91 & 1.13 & 0.90 & 0.97 & 0.99 & 0.83 & 1.13 \\
\hline & & Plan 4 & 0.69 & 0.85 & 1.02 & 1.21 & 0.77 & 0.66 & 1.01 & 0.95 & 0.63 & 0.72 \\
\hline & & Plan 5 & 0.96 & 0.81 & 0.68 & 0.49 & 1.07 & 0.63 & 0.67 & 0.78 & 0.59 & 0.95 \\
\hline & & Plan 6 & 0.59 & 0.74 & 0.67 & 0.43 & 0.61 & 0.52 & 0.49 & 0.49 & 0.50 & 0.45 \\
\hline & & Plan 7 & 0.65 & 0.71 & 0.66 & 0.85 & 0.55 & 0.49 & 0.79 & 0.63 & 0.48 & 0.63 \\
\hline & & Plan 8 & 0.66 & 0.79 & 0.75 & 0.47 & 0.86 & 0.46 & 0.61 & 0.72 & 0.52 & 0.60 \\
\hline
\end{tabular}




\begin{tabular}{|c|c|c|c|c|c|c|c|c|c|c|c|c|}
\hline \multicolumn{2}{|c|}{$\begin{array}{l}\text { Experimental } \\
\text { Wave }\end{array}$} & \multicolumn{11}{|c|}{ Wave Height $(\mathrm{m})$ at Indicated Gauge Location; swl $=0.0 \mathrm{~m}$} \\
\hline $\begin{array}{l}\text { Period } \\
\text { (sec) }\end{array}$ & $\begin{array}{l}\text { Height } \\
(\mathrm{m})\end{array}$ & Plan & $\begin{array}{l}\text { Gauge } \\
1\end{array}$ & $\begin{array}{l}\text { Gauge } \\
2\end{array}$ & $\begin{array}{l}\text { Gauge } \\
3\end{array}$ & $\begin{array}{l}\text { Gauge } \\
4\end{array}$ & $\begin{array}{l}\text { Gauge } \\
5\end{array}$ & $\begin{array}{l}\text { Gauge } \\
6\end{array}$ & $\begin{array}{l}\text { Gauge } \\
7\end{array}$ & $\begin{array}{l}\text { Gauge } \\
8\end{array}$ & $\begin{array}{l}\text { Gauge } \\
9\end{array}$ & $\begin{array}{l}\text { Gauge } \\
10\end{array}$ \\
\hline \multirow[t]{27}{*}{7} & \multirow[t]{9}{*}{1} & EC & 1.04 & 0.75 & 1.02 & 0.91 & 0.89 & 0.78 & 0.83 & 0.86 & 1.07 & 0.62 \\
\hline & & Plan 1 & 1.03 & 0.81 & 0.90 & 0.90 & 0.90 & 0.70 & 0.82 & 0.88 & 1.07 & 0.76 \\
\hline & & Plan 2 & 1.02 & 0.83 & 0.94 & 0.93 & 0.92 & 0.74 & 0.84 & 0.90 & 1.12 & 0.57 \\
\hline & & Plan 3 & 1.03 & 0.71 & 0.97 & 0.89 & 0.86 & 0.75 & 0.79 & 0.83 & 1.02 & 0.85 \\
\hline & & Plan 4 & 1.02 & 0.79 & 0.87 & 0.89 & 0.82 & 0.69 & 0.78 & 0.89 & 1.12 & 0.30 \\
\hline & & Plan 5 & 1.01 & 0.77 & 0.94 & 0.85 & 0.90 & 0.71 & 0.78 & 0.85 & 1.07 & 0.85 \\
\hline & & Plan 6 & 1.02 & 0.77 & 0.90 & 0.88 & 0.87 & 0.68 & 0.78 & 0.84 & 1.05 & 0.27 \\
\hline & & Plan 7 & 1.02 & 0.77 & 0.89 & 0.89 & 0.86 & 0.69 & 0.77 & 0.84 & 1.04 & 0.26 \\
\hline & & Plan 8 & 1.01 & 0.78 & 0.92 & 0.90 & 0.91 & 0.69 & 0.77 & 0.85 & 1.06 & 0.47 \\
\hline & \multirow[t]{9}{*}{2} & EC & 2.08 & 1.14 & 1.36 & 1.36 & 1.44 & 1.32 & 1.20 & 1.28 & 1.53 & 0.88 \\
\hline & & Plan 1 & 2.02 & 1.14 & 1.20 & 1.36 & 1.38 & 1.15 & 1.15 & 1.26 & 1.45 & 1.25 \\
\hline & & Plan 2 & 2.01 & 1.19 & 1.20 & 1.33 & 1.43 & 1.27 & 1.17 & 1.25 & 1.47 & 0.98 \\
\hline & & Plan 3 & 2.07 & 1.07 & 1.32 & 1.35 & 1.40 & 1.28 & 1.16 & 1.26 & 1.48 & 1.32 \\
\hline & & Plan 4 & 2.04 & 1.29 & 1.25 & 1.43 & 1.47 & 1.29 & 1.25 & 1.34 & 1.55 & 0.56 \\
\hline & & Plan 5 & 1.99 & 1.20 & 1.30 & 1.30 & 1.41 & 1.19 & 1.19 & 1.26 & 1.46 & 1.32 \\
\hline & & Plan 6 & 2.04 & 1.29 & 1.30 & 1.38 & 1.48 & 1.25 & 1.25 & 1.31 & 1.50 & 0.47 \\
\hline & & Plan 7 & 2.01 & 1.25 & 1.25 & 1.34 & 1.44 & 1.21 & 1.19 & 1.30 & 1.50 & 0.43 \\
\hline & & Plan 8 & 2.02 & 1.31 & 1.30 & 1.37 & 1.49 & 1.25 & 1.25 & 1.34 & 1.56 & 0.83 \\
\hline & \multirow[t]{9}{*}{2.5} & EC & 2.55 & 1.42 & 1.64 & 1.57 & 1.74 & 1.62 & 1.48 & 1.50 & 1.75 & 1.05 \\
\hline & & Plan 1 & 2.47 & 1.39 & 1.39 & 1.49 & 1.67 & 1.40 & 1.37 & 1.38 & 1.59 & 1.45 \\
\hline & & Plan 2 & 2.46 & 1.53 & 1.47 & 1.55 & 1.79 & 1.58 & 1.44 & 1.43 & 1.63 & 1.29 \\
\hline & & Plan 3 & 2.57 & 1.45 & 1.69 & 1.64 & 1.76 & 1.63 & 1.50 & 1.51 & 1.73 & 1.52 \\
\hline & & Plan 4 & 2.50 & 1.57 & 1.50 & 1.57 & 1.71 & 1.50 & 1.46 & 1.54 & 1.81 & 0.68 \\
\hline & & Plan 5 & 2.48 & 1.43 & 1.49 & 1.46 & 1.60 & 1.38 & 1.37 & 1.44 & 1.68 & 1.42 \\
\hline & & Plan 6 & 2.48 & 1.49 & 1.47 & 1.51 & 1.63 & 1.42 & 1.41 & 1.48 & 1.69 & 0.53 \\
\hline & & Plan 7 & 2.49 & 1.47 & 1.46 & 1.48 & 1.63 & 1.41 & 1.38 & 1.47 & 1.69 & 0.52 \\
\hline & & Plan 8 & 2.51 & 1.52 & 1.48 & 1.54 & 1.67 & 1.45 & 1.42 & 1.51 & 1.74 & 0.98 \\
\hline
\end{tabular}




\begin{tabular}{|c|c|c|c|c|c|c|c|c|c|c|c|c|}
\hline \multicolumn{2}{|c|}{$\begin{array}{l}\text { Experimental } \\
\text { Wave }\end{array}$} & \multicolumn{11}{|c|}{ Wave Height $(\mathrm{m})$ at Indicated Gauge Location; swl $=0.0 \mathrm{~m}$} \\
\hline $\begin{array}{l}\text { Period } \\
\text { (sec) }\end{array}$ & $\begin{array}{l}\text { Height } \\
(\mathrm{m})\end{array}$ & Plan & $\begin{array}{l}\text { Gauge } \\
11\end{array}$ & $\begin{array}{l}\text { Gauge } \\
12\end{array}$ & $\begin{array}{l}\text { Gauge } \\
13\end{array}$ & $\begin{array}{l}\text { Gauge } \\
14\end{array}$ & $\begin{array}{l}\text { Gauge } \\
15\end{array}$ & $\begin{array}{l}\text { Gauge } \\
16\end{array}$ & $\begin{array}{l}\text { Gauge } \\
17\end{array}$ & $\begin{array}{l}\text { Gauge } \\
18\end{array}$ & $\begin{array}{l}\text { Gauge } \\
19\end{array}$ & $\begin{array}{l}\text { Gauge } \\
20\end{array}$ \\
\hline \multirow[t]{27}{*}{7} & \multirow[t]{9}{*}{1} & EC & 0.41 & 0.53 & 0.46 & 0.65 & 0.63 & 0.48 & 0.58 & 0.64 & 0.47 & 0.50 \\
\hline & & Plan 1 & 0.71 & 0.76 & 0.76 & 0.83 & 0.97 & 0.68 & 0.74 & 0.86 & 0.64 & 0.75 \\
\hline & & Plan 2 & 0.47 & 0.54 & 0.81 & 0.98 & 0.87 & 0.53 & 0.80 & 0.93 & 0.51 & 0.62 \\
\hline & & Plan 3 & 0.73 & 0.52 & 0.43 & 0.48 & 0.73 & 0.53 & 0.53 & 0.60 & 0.49 & 0.70 \\
\hline & & Plan 4 & 0.42 & 0.56 & 0.73 & 0.79 & 0.44 & 0.43 & 0.72 & 0.68 & 0.43 & 0.42 \\
\hline & & Plan 5 & 0.70 & 0.53 & 0.44 & 0.28 & 0.81 & 0.41 & 0.43 & 0.52 & 0.42 & 0.68 \\
\hline & & Plan 6 & 0.39 & 0.49 & 0.44 & 0.27 & 0.40 & 0.33 & 0.31 & 0.30 & 0.34 & 0.27 \\
\hline & & Plan 7 & 0.42 & 0.44 & 0.45 & 0.57 & 0.33 & 0.32 & 0.53 & 0.45 & 0.32 & 0.39 \\
\hline & & Plan 8 & 0.40 & 0.47 & 0.46 & 0.30 & 0.56 & 0.27 & 0.34 & 0.43 & 0.30 & 0.38 \\
\hline & \multirow[t]{9}{*}{2} & EC & 0.63 & 0.76 & 0.65 & 0.86 & 0.84 & 0.73 & 0.75 & 0.83 & 0.68 & 0.74 \\
\hline & & Plan 1 & 1.14 & 1.13 & 1.00 & 1.00 & 1.32 & 1.03 & 1.04 & 1.09 & 0.94 & 1.20 \\
\hline & & Plan 2 & 0.82 & 0.84 & 1.01 & 1.19 & 1.26 & 0.77 & 0.99 & 1.16 & 0.73 & 0.91 \\
\hline & & Plan 3 & 1.14 & 0.86 & 0.74 & 0.81 & 1.06 & 0.85 & 0.97 & 0.93 & 0.78 & 1.16 \\
\hline & & Plan 4 & 0.76 & 0.89 & 1.02 & 1.13 & 0.78 & 0.64 & 1.02 & 0.95 & 0.61 & 0.71 \\
\hline & & Plan 5 & 1.11 & 0.85 & 0.66 & 0.52 & 1.13 & 0.72 & 0.78 & 0.81 & 0.62 & 1.11 \\
\hline & & Plan 6 & 0.63 & 0.76 & 0.65 & 0.46 & 0.63 & 0.51 & 0.51 & 0.50 & 0.49 & 0.47 \\
\hline & & Plan 7 & 0.64 & 0.69 & 0.65 & 0.82 & 0.57 & 0.47 & 0.77 & 0.62 & 0.46 & 0.62 \\
\hline & & Plan 8 & 0.68 & 0.74 & 0.67 & 0.46 & 0.84 & 0.46 & 0.55 & 0.67 & 0.48 & 0.62 \\
\hline & \multirow[t]{9}{*}{2.5} & EC & 0.78 & 0.91 & 0.80 & 1.03 & 1.06 & 0.84 & 0.92 & 0.97 & 0.81 & 0.90 \\
\hline & & Plan 1 & 1.28 & 1.28 & 1.21 & 1.26 & 1.49 & 1.21 & 1.25 & 1.27 & 1.10 & 1.39 \\
\hline & & Plan 2 & 1.03 & 1.04 & 1.20 & 1.40 & 1.56 & 0.95 & 1.20 & 1.36 & 0.91 & 1.20 \\
\hline & & Plan 3 & 1.33 & 1.09 & 1.00 & 1.12 & 1.27 & 1.06 & 1.27 & 1.14 & 1.00 & 1.42 \\
\hline & & Plan 4 & 0.89 & 1.05 & 1.16 & 1.29 & 0.99 & 0.75 & 1.12 & 1.14 & 0.72 & 0.79 \\
\hline & & Plan 5 & 1.21 & 0.98 & 0.78 & 0.62 & 1.25 & 0.80 & 0.89 & 0.89 & 0.71 & 1.26 \\
\hline & & Plan 6 & 0.72 & 0.86 & 0.74 & 0.53 & 0.71 & 0.58 & 0.57 & 0.58 & 0.56 & 0.54 \\
\hline & & Plan 7 & 0.75 & 0.80 & 0.76 & 0.95 & 0.67 & 0.54 & 0.88 & 0.74 & 0.54 & 0.70 \\
\hline & & Plan 8 & 0.80 & 0.84 & 0.77 & 0.54 & 0.95 & 0.53 & 0.66 & 0.76 & 0.56 & 0.74 \\
\hline
\end{tabular}




\begin{tabular}{|c|c|c|c|c|c|c|c|c|c|c|c|c|}
\hline \multicolumn{2}{|c|}{$\begin{array}{l}\text { Experimental } \\
\text { Wave }\end{array}$} & \multicolumn{11}{|c|}{ Wave Height $(\mathrm{m})$ at Indicated Gauge Location; swl $=0.0 \mathrm{~m}$} \\
\hline $\begin{array}{l}\text { Period } \\
\text { (sec) }\end{array}$ & $\begin{array}{l}\text { Height } \\
(\mathrm{m})\end{array}$ & Plan & $\begin{array}{l}\text { Gauge } \\
1\end{array}$ & $\begin{array}{l}\text { Gauge } \\
2\end{array}$ & $\begin{array}{l}\text { Gauge } \\
3\end{array}$ & $\begin{array}{l}\text { Gauge } \\
4\end{array}$ & $\begin{array}{l}\text { Gauge } \\
5\end{array}$ & $\begin{array}{l}\text { Gauge } \\
6\end{array}$ & $\begin{array}{l}\text { Gauge } \\
7\end{array}$ & $\begin{array}{l}\text { Gauge } \\
8\end{array}$ & $\begin{array}{l}\text { Gauge } \\
9\end{array}$ & $\begin{array}{l}\text { Gauge } \\
10\end{array}$ \\
\hline \multirow[t]{27}{*}{8} & \multirow[t]{9}{*}{1} & EC & 0.97 & 0.73 & 0.90 & 0.83 & 0.80 & 0.76 & 0.79 & 0.86 & 1.01 & 0.50 \\
\hline & & Plan 1 & 0.96 & 0.78 & 0.80 & 0.81 & 0.83 & 0.70 & 0.80 & 0.87 & 0.99 & 0.84 \\
\hline & & Plan 2 & 0.96 & 0.77 & 0.79 & 0.81 & 0.81 & 0.70 & 0.77 & 0.87 & 1.02 & 0.62 \\
\hline & & Plan 3 & 0.98 & 0.72 & 0.88 & 0.82 & 0.80 & 0.75 & 0.78 & 0.86 & 0.97 & 0.82 \\
\hline & & Plan 4 & 0.97 & 0.81 & 0.81 & 0.85 & 0.81 & 0.71 & 0.79 & 0.92 & 1.08 & 0.34 \\
\hline & & Plan 5 & 0.96 & 0.75 & 0.83 & 0.81 & 0.80 & 0.67 & 0.74 & 0.83 & 0.99 & 0.82 \\
\hline & & Plan 6 & 0.96 & 0.77 & 0.83 & 0.83 & 0.82 & 0.68 & 0.75 & 0.86 & 1.01 & 0.27 \\
\hline & & Plan 7 & 0.97 & 0.81 & 0.84 & 0.85 & 0.82 & 0.70 & 0.77 & 0.89 & 1.03 & 0.25 \\
\hline & & Plan 8 & 0.98 & 0.78 & 0.83 & 0.83 & 0.84 & 0.68 & 0.75 & 0.85 & 1.01 & 0.44 \\
\hline & \multirow[t]{9}{*}{2} & EC & 1.97 & 1.35 & 1.49 & 1.50 & 1.68 & 1.62 & 1.44 & 1.42 & 1.55 & 0.95 \\
\hline & & Plan 1 & 1.92 & 1.38 & 1.32 & 1.49 & 1.68 & 1.46 & 1.38 & 1.37 & 1.48 & 1.34 \\
\hline & & Plan 2 & 1.90 & 1.41 & 1.30 & 1.45 & 1.67 & 1.53 & 1.40 & 1.41 & 1.55 & 1.23 \\
\hline & & Plan 3 & 1.97 & 1.28 & 1.43 & 1.45 & 1.63 & 1.56 & 1.37 & 1.36 & 1.49 & 1.45 \\
\hline & & Plan 4 & 2.01 & 1.45 & 1.31 & 1.51 & 1.66 & 1.47 & 1.41 & 1.48 & 1.66 & 0.68 \\
\hline & & Plan 5 & 1.99 & 1.41 & 1.44 & 1.50 & 1.66 & 1.46 & 1.44 & 1.42 & 1.58 & 1.46 \\
\hline & & Plan 6 & 2.00 & 1.40 & 1.32 & 1.47 & 1.64 & 1.43 & 1.39 & 1.39 & 1.52 & 0.53 \\
\hline & & Plan 7 & 1.97 & 1.39 & 1.32 & 1.46 & 1.64 & 1.43 & 1.37 & 1.39 & 1.53 & 0.50 \\
\hline & & Plan 8 & 1.98 & 1.38 & 1.31 & 1.46 & 1.64 & 1.42 & 1.37 & 1.39 & 1.52 & 0.87 \\
\hline & \multirow[t]{9}{*}{2.5} & EC & 2.45 & 1.48 & 1.65 & 1.59 & 1.78 & 1.72 & 1.56 & 1.56 & 1.73 & 1.09 \\
\hline & & Plan 1 & 2.38 & 1.52 & 1.43 & 1.53 & 1.77 & 1.54 & 1.47 & 1.46 & 1.60 & 1.50 \\
\hline & & Plan 2 & 2.40 & 1.59 & 1.44 & 1.55 & 1.85 & 1.69 & 1.51 & 1.47 & 1.62 & 1.40 \\
\hline & & Plan 3 & 2.45 & 1.52 & 1.65 & 1.61 & 1.82 & 1.76 & 1.58 & 1.56 & 1.69 & 1.60 \\
\hline & & Plan 4 & 2.49 & 1.56 & 1.45 & 1.60 & 1.80 & 1.60 & 1.52 & 1.55 & 1.74 & 0.74 \\
\hline & & Plan 5 & 2.43 & 1.49 & 1.54 & 1.55 & 1.74 & 1.53 & 1.50 & 1.50 & 1.69 & 1.52 \\
\hline & & Plan 6 & 2.46 & 1.54 & 1.47 & 1.58 & 1.78 & 1.58 & 1.52 & 1.53 & 1.66 & 0.59 \\
\hline & & Plan 7 & 2.41 & 1.50 & 1.45 & 1.55 & 1.76 & 1.56 & 1.48 & 1.49 & 1.65 & 0.56 \\
\hline & & Plan 8 & 2.47 & 1.55 & 1.49 & 1.59 & 1.80 & 1.60 & 1.53 & 1.53 & 1.67 & 1.01 \\
\hline
\end{tabular}




\begin{tabular}{|c|c|c|c|c|c|c|c|c|c|c|c|c|}
\hline \multicolumn{2}{|c|}{$\begin{array}{l}\text { Experimental } \\
\text { Wave }\end{array}$} & \multicolumn{11}{|c|}{ Wave Height $(\mathrm{m})$ at Indicated Gauge Location; swl $=0.0 \mathrm{~m}$} \\
\hline $\begin{array}{l}\text { Period } \\
\text { (sec) }\end{array}$ & $\begin{array}{l}\text { Height } \\
(\mathrm{m})\end{array}$ & Plan & $\begin{array}{l}\text { Gauge } \\
11\end{array}$ & $\begin{array}{l}\text { Gauge } \\
12\end{array}$ & $\begin{array}{l}\text { Gauge } \\
13\end{array}$ & $\begin{array}{l}\text { Gauge } \\
14\end{array}$ & $\begin{array}{l}\text { Gauge } \\
15\end{array}$ & $\begin{array}{l}\text { Gauge } \\
16\end{array}$ & $\begin{array}{l}\text { Gauge } \\
17\end{array}$ & $\begin{array}{l}\text { Gauge } \\
18\end{array}$ & $\begin{array}{l}\text { Gauge } \\
19\end{array}$ & $\begin{array}{l}\text { Gauge } \\
20\end{array}$ \\
\hline \multirow[t]{27}{*}{8} & \multirow[t]{9}{*}{1} & EC & 0.39 & 0.48 & 0.41 & 0.53 & 0.52 & 0.42 & 0.49 & 0.56 & 0.39 & 0.43 \\
\hline & & Plan 1 & 0.76 & 0.72 & 0.69 & 0.73 & 0.91 & 0.67 & 0.68 & 0.78 & 0.63 & 0.78 \\
\hline & & Plan 2 & 0.52 & 0.51 & 0.70 & 0.85 & 0.85 & 0.49 & 0.66 & 0.80 & 0.47 & 0.65 \\
\hline & & Plan 3 & 0.73 & 0.54 & 0.47 & 0.51 & 0.64 & 0.55 & 0.61 & 0.65 & 0.51 & 0.67 \\
\hline & & Plan 4 & 0.43 & 0.56 & 0.70 & 0.75 & 0.45 & 0.40 & 0.67 & 0.63 & 0.41 & 0.44 \\
\hline & & Plan 5 & 0.71 & 0.53 & 0.41 & 0.29 & 0.77 & 0.39 & 0.45 & 0.51 & 0.41 & 0.67 \\
\hline & & Plan 6 & 0.36 & 0.45 & 0.40 & 0.26 & 0.36 & 0.31 & 0.27 & 0.28 & 0.31 & 0.25 \\
\hline & & Plan 7 & 0.41 & 0.43 & 0.43 & 0.54 & 0.34 & 0.30 & 0.50 & 0.42 & 0.31 & 0.39 \\
\hline & & Plan 8 & 0.39 & 0.43 & 0.42 & 0.27 & 0.53 & 0.25 & 0.33 & 0.41 & 0.29 & 0.35 \\
\hline & \multirow[t]{9}{*}{2} & EC & 0.74 & 0.84 & 0.73 & 0.93 & 0.96 & 0.81 & 0.83 & 0.90 & 0.77 & 0.84 \\
\hline & & Plan 1 & 1.26 & 1.32 & 1.26 & 1.24 & 1.46 & 1.24 & 1.27 & 1.19 & 1.16 & 1.41 \\
\hline & & Plan 2 & 1.04 & 0.99 & 1.15 & 1.33 & 1.59 & 0.91 & 1.05 & 1.24 & 0.87 & 1.24 \\
\hline & & Plan 3 & 1.27 & 1.01 & 0.93 & 1.02 & 1.13 & 1.02 & 1.23 & 1.17 & 0.93 & 1.26 \\
\hline & & Plan 4 & 0.83 & 0.94 & 1.07 & 1.19 & 0.87 & 0.66 & 1.07 & 0.98 & 0.66 & 0.76 \\
\hline & & Plan 5 & 1.28 & 1.05 & 0.82 & 0.67 & 1.22 & 0.86 & 1.02 & 0.94 & 0.77 & 1.27 \\
\hline & & Plan 6 & 0.67 & 0.78 & 0.65 & 0.49 & 0.64 & 0.53 & 0.51 & 0.51 & 0.52 & 0.47 \\
\hline & & Plan 7 & 0.70 & 0.74 & 0.70 & 0.87 & 0.66 & 0.50 & 0.79 & 0.68 & 0.51 & 0.64 \\
\hline & & Plan 8 & 0.74 & 0.74 & 0.67 & 0.48 & 0.84 & 0.48 & 0.58 & 0.66 & 0.50 & 0.67 \\
\hline & \multirow[t]{9}{*}{2.5} & EC & 0.81 & 0.92 & 0.80 & 1.05 & 1.04 & 0.91 & 0.91 & 1.03 & 0.85 & 0.96 \\
\hline & & Plan 1 & 1.33 & 1.40 & 1.33 & 1.36 & 1.52 & 1.34 & 1.40 & 1.31 & 1.21 & 1.47 \\
\hline & & Plan 2 & 1.11 & 1.07 & 1.22 & 1.45 & 1.71 & 1.01 & 1.18 & 1.39 & 0.94 & 1.33 \\
\hline & & Plan 3 & 1.35 & 1.14 & 1.07 & 1.23 & 1.22 & 1.17 & 1.44 & 1.26 & 1.05 & 1.45 \\
\hline & & Plan 4 & 0.91 & 1.04 & 1.13 & 1.26 & 1.00 & 0.72 & 1.11 & 1.11 & 0.72 & 0.85 \\
\hline & & Plan 5 & 1.33 & 1.11 & 0.88 & 0.73 & 1.27 & 0.89 & 1.08 & 0.99 & 0.78 & 1.35 \\
\hline & & Plan 6 & 0.75 & 0.87 & 0.74 & 0.55 & 0.73 & 0.60 & 0.60 & 0.60 & 0.58 & 0.57 \\
\hline & & Plan 7 & 0.77 & 0.80 & 0.77 & 0.95 & 0.73 & 0.55 & 0.89 & 0.77 & 0.56 & 0.74 \\
\hline & & Plan 8 & 0.82 & 0.84 & 0.79 & 0.56 & 0.95 & 0.56 & 0.69 & 0.79 & 0.57 & 0.78 \\
\hline
\end{tabular}




\section{Appendix E: Cross-Channel Root-Mean-Square $H_{s}$ from Physical Model Experiments}

Table E1. RMS $H_{s}$ across channel transect lines for waves from 45 degrees South; $+0.9 \mathrm{~m} \mathrm{swl}$.

\begin{tabular}{|c|c|c|c|c|c|c|c|c|c|}
\hline \multicolumn{2}{|c|}{$\begin{array}{l}\text { Experimental } \\
\text { Wave }\end{array}$} & \multirow[b]{2}{*}{ Plan } & \multicolumn{5}{|c|}{$H_{s}(\mathrm{~m})$ at Indicated Lines; swl $=+0.9 \mathrm{~m}$} & \multirow[b]{2}{*}{$\begin{array}{l}H_{s, \text { Line2/ }} / \\
H_{s, \text { Line1 }}\end{array}$} & \multirow[b]{2}{*}{$\begin{array}{l}H_{s, \text { Line3 }} / \\
H_{s, \text { Line1 }}\end{array}$} \\
\hline $\begin{array}{l}T_{p} \\
\text { (sec) }\end{array}$ & \begin{tabular}{|l}
$H_{s, i n c}$ \\
$(\mathrm{~m})$
\end{tabular} & & Line 0 & Line 1 & Line 2 & Line 3 & Line 4 & & \\
\hline \multirow[t]{27}{*}{5} & \multirow[t]{9}{*}{1} & EC & 0.458 & 0.491 & 0.272 & 0.293 & 0.264 & 0.554 & 0.596 \\
\hline & & Plan 1 & 0.541 & 0.570 & 0.473 & 0.561 & 0.489 & 0.831 & 0.984 \\
\hline & & Plan 2 & 0.762 & 0.802 & 0.528 & 0.616 & 0.539 & 0.658 & 0.768 \\
\hline & & Plan 3 & 0.696 & 0.790 & 0.487 & 0.540 & 0.513 & 0.617 & 0.683 \\
\hline & & Plan 4 & 0.641 & 0.692 & 0.447 & 0.442 & 0.401 & 0.646 & 0.640 \\
\hline & & Plan 5 & 0.671 & 0.749 & 0.370 & 0.344 & 0.318 & 0.494 & 0.459 \\
\hline & & Plan 6 & 0.637 & 0.749 & 0.294 & 0.281 & 0.273 & 0.393 & 0.376 \\
\hline & & Plan 7 & 0.618 & 0.715 & 0.299 & 0.271 & 0.264 & 0.418 & 0.380 \\
\hline & & Plan 8 & 0.587 & 0.694 & 0.292 & 0.304 & 0.286 & 0.421 & 0.439 \\
\hline & \multirow[t]{9}{*}{2} & EC & 1.169 & 1.209 & 0.580 & 0.603 & 0.550 & 0.480 & 0.499 \\
\hline & & Plan 1 & 1.181 & 1.148 & 0.940 & 1.095 & 0.975 & 0.819 & 0.954 \\
\hline & & Plan 2 & 1.152 & 1.146 & 0.773 & 0.885 & 0.782 & 0.675 & 0.772 \\
\hline & & Plan 3 & 1.252 & 1.286 & 0.795 & 0.850 & 0.811 & 0.618 & 0.661 \\
\hline & & Plan 4 & 1.189 & 1.227 & 0.786 & 0.775 & 0.723 & 0.640 & 0.631 \\
\hline & & Plan 5 & 1.111 & 1.183 & 0.560 & 0.531 & 0.471 & 0.474 & 0.449 \\
\hline & & Plan 6 & 1.171 & 1.268 & 0.486 & 0.461 & 0.441 & 0.383 & 0.364 \\
\hline & & Plan 7 & 1.141 & 1.247 & 0.525 & 0.466 & 0.467 & 0.421 & 0.374 \\
\hline & & Plan 8 & 1.169 & 1.281 & 0.530 & 0.537 & 0.505 & 0.414 & 0.419 \\
\hline & \multirow[t]{9}{*}{2.5} & EC & 1.324 & 1.357 & 0.671 & 0.691 & 0.622 & 0.495 & 0.509 \\
\hline & & Plan 1 & 1.318 & 1.337 & 1.083 & 1.242 & 1.148 & 0.810 & 0.929 \\
\hline & & Plan 2 & 1.299 & 1.293 & 0.898 & 1.027 & 0.909 & 0.695 & 0.794 \\
\hline & & Plan 3 & 1.329 & 1.352 & 0.831 & 0.886 & 0.850 & 0.615 & 0.656 \\
\hline & & Plan 4 & 1.341 & 1.352 & 0.879 & 0.870 & 0.812 & 0.650 & 0.644 \\
\hline & & Plan 5 & 1.309 & 1.370 & 0.678 & 0.657 & 0.588 & 0.495 & 0.479 \\
\hline & & Plan 6 & 1.278 & 1.347 & 0.527 & 0.506 & 0.472 & 0.391 & 0.376 \\
\hline & & Plan 7 & 1.305 & 1.378 & 0.610 & 0.549 & 0.535 & 0.443 & 0.399 \\
\hline & & Plan 8 & 1.348 & 1.420 & 0.603 & 0.611 & 0.584 & 0.424 & 0.430 \\
\hline
\end{tabular}




\begin{tabular}{|c|c|c|c|c|c|c|c|c|c|}
\hline \multicolumn{2}{|c|}{$\begin{array}{l}\text { Experimental } \\
\text { Wave }\end{array}$} & \multirow[b]{2}{*}{ Plan } & \multicolumn{5}{|c|}{$H_{s}(\mathrm{~m})$ at Indicated Lines; $\mathrm{swl}=+0.9 \mathrm{~m}$} & \multirow[b]{2}{*}{$\begin{array}{l}H_{s, \text { Line2/ }} \\
H_{s, \text { Line1 }}\end{array}$} & \multirow[b]{2}{*}{$\begin{array}{l}H_{s, \text { Line3 }} / \\
H_{s, \text { Line1 }}\end{array}$} \\
\hline $\begin{array}{l}T_{p} \\
\text { (sec) }\end{array}$ & $\begin{array}{l}H_{s, i n c} \\
(\mathrm{~m})\end{array}$ & & Line 0 & Line 1 & Line 2 & Line 3 & Line 4 & & \\
\hline \multirow[t]{27}{*}{6} & \multirow[t]{9}{*}{1} & EC & 0.689 & 0.787 & 0.380 & 0.393 & 0.360 & 0.482 & 0.500 \\
\hline & & Plan 1 & 0.717 & 0.746 & 0.636 & 0.747 & 0.658 & 0.853 & 1.002 \\
\hline & & Plan 2 & 0.787 & 0.832 & 0.598 & 0.682 & 0.627 & 0.719 & 0.820 \\
\hline & & Plan 3 & 0.798 & 0.907 & 0.498 & 0.539 & 0.518 & 0.549 & 0.594 \\
\hline & & Plan 4 & 0.798 & 0.852 & 0.551 & 0.548 & 0.503 & 0.646 & 0.643 \\
\hline & & Plan 5 & 0.786 & 0.891 & 0.373 & 0.344 & 0.328 & 0.418 & 0.386 \\
\hline & & Plan 6 & 0.806 & 0.936 & 0.306 & 0.291 & 0.260 & 0.326 & 0.311 \\
\hline & & Plan 7 & 0.746 & 0.871 & 0.320 & 0.296 & 0.290 & 0.367 & 0.340 \\
\hline & & Plan 8 & 0.768 & 0.898 & 0.330 & 0.320 & 0.304 & 0.368 & 0.356 \\
\hline & \multirow[t]{9}{*}{2} & EC & 1.330 & 1.367 & 0.585 & 0.597 & 0.551 & 0.428 & 0.437 \\
\hline & & Plan 1 & 1.267 & 1.223 & 1.048 & 1.193 & 1.060 & 0.857 & 0.975 \\
\hline & & Plan 2 & 1.285 & 1.277 & 0.923 & 1.034 & 0.947 & 0.723 & 0.809 \\
\hline & & Plan 3 & 1.315 & 1.361 & 0.723 & 0.776 & 0.744 & 0.531 & 0.570 \\
\hline & & Plan 4 & 1.392 & 1.389 & 0.873 & 0.847 & 0.785 & 0.628 & 0.610 \\
\hline & & Plan 5 & 1.309 & 1.366 & 0.565 & 0.522 & 0.480 & 0.413 & 0.382 \\
\hline & & Plan 6 & 1.299 & 1.379 & 0.425 & 0.399 & 0.364 & 0.308 & 0.289 \\
\hline & & Plan 7 & 1.318 & 1.399 & 0.473 & 0.437 & 0.430 & 0.338 & 0.312 \\
\hline & & Plan 8 & 1.336 & 1.433 & 0.516 & 0.491 & 0.476 & 0.360 & 0.342 \\
\hline & \multirow[t]{9}{*}{2.5} & EC & 1.426 & 1.465 & 0.658 & 0.677 & 0.608 & 0.449 & 0.462 \\
\hline & & Plan 1 & 1.473 & 1.501 & 1.255 & 1.392 & 1.278 & 0.836 & 0.927 \\
\hline & & Plan 2 & 1.462 & 1.459 & 1.051 & 1.171 & 1.074 & 0.720 & 0.802 \\
\hline & & Plan 3 & 1.455 & 1.486 & 0.810 & 0.861 & 0.814 & 0.546 & 0.579 \\
\hline & & Plan 4 & 1.440 & 1.475 & 0.939 & 0.927 & 0.847 & 0.637 & 0.628 \\
\hline & & Plan 5 & 1.504 & 1.569 & 0.671 & 0.621 & 0.576 & 0.427 & 0.396 \\
\hline & & Plan 6 & 1.510 & 1.583 & 0.494 & 0.454 & 0.411 & 0.312 & 0.287 \\
\hline & & Plan 7 & 1.478 & 1.563 & 0.556 & 0.521 & 0.502 & 0.356 & 0.333 \\
\hline & & Plan 8 & 1.478 & 1.563 & 0.567 & 0.545 & 0.520 & 0.363 & 0.349 \\
\hline & & & & & & & & & heet 20 \\
\hline
\end{tabular}




\begin{tabular}{|c|c|c|c|c|c|c|c|c|c|}
\hline \multicolumn{2}{|c|}{$\begin{array}{l}\text { Experimental } \\
\text { Wave }\end{array}$} & \multirow[b]{2}{*}{ Plan } & \multicolumn{5}{|c|}{$H_{s}(\mathrm{~m})$ at Indicated Lines; $\mathrm{swl}=+0.9 \mathrm{~m}$} & \multirow[b]{2}{*}{$\begin{array}{l}H_{s, \text { Line2/ }} / \\
H_{s, \text { Line1 }}\end{array}$} & \multirow[b]{2}{*}{$\begin{array}{l}H_{s, \text { Line }} / \\
H_{s, \text { Line1 }}\end{array}$} \\
\hline $\begin{array}{l}T_{p} \\
\text { (sec) }\end{array}$ & $\begin{array}{l}H_{s, i n c} \\
(\mathrm{~m})\end{array}$ & & Line 0 & Line 1 & Line 2 & Line 3 & Line 4 & & \\
\hline \multirow[t]{27}{*}{7} & \multirow[t]{9}{*}{1} & EC & 0.766 & 0.802 & 0.394 & 0.394 & 0.356 & 0.491 & 0.491 \\
\hline & & Plan 1 & 0.760 & 0.756 & 0.649 & 0.723 & 0.640 & 0.858 & 0.957 \\
\hline & & Plan 2 & 0.801 & 0.814 & 0.603 & 0.656 & 0.599 & 0.740 & 0.806 \\
\hline & & Plan 3 & 0.787 & 0.834 & 0.486 & 0.516 & 0.489 & 0.584 & 0.619 \\
\hline & & Plan 4 & 0.825 & 0.853 & 0.562 & 0.545 & 0.494 & 0.659 & 0.638 \\
\hline & & Plan 5 & 0.827 & 0.865 & 0.393 & 0.356 & 0.332 & 0.455 & 0.412 \\
\hline & & Plan 6 & 0.843 & 0.888 & 0.299 & 0.263 & 0.242 & 0.337 & 0.296 \\
\hline & & Plan 7 & 0.771 & 0.821 & 0.317 & 0.288 & 0.281 & 0.386 & 0.351 \\
\hline & & Plan 8 & 0.843 & 0.884 & 0.336 & 0.316 & 0.307 & 0.380 & 0.357 \\
\hline & \multirow[t]{9}{*}{2} & EC & 1.484 & 1.403 & 0.603 & 0.597 & 0.548 & 0.430 & 0.426 \\
\hline & & Plan 1 & 1.510 & 1.443 & 1.232 & 1.328 & 1.230 & 0.853 & 0.920 \\
\hline & & Plan 2 & 1.475 & 1.391 & 1.004 & 1.103 & 1.020 & 0.722 & 0.793 \\
\hline & & Plan 3 & 1.512 & 1.431 & 0.820 & 0.847 & 0.805 & 0.573 & 0.592 \\
\hline & & Plan 4 & 1.530 & 1.466 & 0.940 & 0.891 & 0.814 & 0.641 & 0.608 \\
\hline & & Plan 5 & 1.535 & 1.445 & 0.653 & 0.589 & 0.551 & 0.452 & 0.408 \\
\hline & & Plan 6 & 1.590 & 1.508 & 0.462 & 0.395 & 0.354 & 0.306 & 0.262 \\
\hline & & Plan 7 & 1.516 & 1.469 & 0.515 & 0.470 & 0.462 & 0.350 & 0.320 \\
\hline & & Plan 8 & 1.545 & 1.496 & 0.540 & 0.495 & 0.491 & 0.361 & 0.331 \\
\hline & \multirow[t]{9}{*}{2.5} & EC & 1.495 & 1.438 & 0.613 & 0.615 & 0.575 & 0.426 & 0.428 \\
\hline & & Plan 1 & 1.498 & 1.467 & 1.254 & 1.325 & 1.244 & 0.855 & 0.903 \\
\hline & & Plan 2 & 1.451 & 1.419 & 1.022 & 1.104 & 1.027 & 0.720 & 0.778 \\
\hline & & Plan 3 & 1.557 & 1.482 & 0.885 & 0.910 & 0.866 & 0.597 & 0.614 \\
\hline & & Plan 4 & 1.508 & 1.483 & 0.932 & 0.895 & 0.814 & 0.629 & 0.604 \\
\hline & & Plan 5 & 1.480 & 1.466 & 0.710 & 0.638 & 0.611 & 0.484 & 0.435 \\
\hline & & Plan 6 & 1.529 & 1.518 & 0.481 & 0.416 & 0.382 & 0.317 & 0.274 \\
\hline & & Plan 7 & 1.527 & 1.507 & 0.538 & 0.498 & 0.484 & 0.357 & 0.331 \\
\hline & & Plan 8 & 1.524 & 1.521 & 0.544 & 0.504 & 0.496 & 0.357 & 0.331 \\
\hline & & & & & & & & & heet 3 o \\
\hline
\end{tabular}




\begin{tabular}{|c|c|c|c|c|c|c|c|c|c|}
\hline \multicolumn{2}{|c|}{$\begin{array}{l}\text { Experimental } \\
\text { Wave }\end{array}$} & \multirow[b]{2}{*}{ Plan } & \multicolumn{5}{|c|}{$H_{s}(\mathrm{~m})$ at Indicated Lines; $\mathrm{swl}=+0.9 \mathrm{~m}$} & \multirow[b]{2}{*}{$\begin{array}{l}H_{s, \text { Line2/ }} \\
H_{s, \text { Line1 }}\end{array}$} & \multirow[b]{2}{*}{$\begin{array}{l}H_{s, \text { Line3/ }} \\
H_{s, \text { Line1 }}\end{array}$} \\
\hline $\begin{array}{l}T_{p} \\
\text { (sec) }\end{array}$ & $\begin{array}{l}H_{s, i n c} \\
(\mathrm{~m})\end{array}$ & & Line 0 & Line 1 & Line 2 & Line 3 & Line 4 & & \\
\hline \multirow[t]{27}{*}{8} & \multirow[t]{9}{*}{1} & EC & 0.879 & 0.919 & 0.366 & 0.370 & 0.338 & 0.398 & 0.403 \\
\hline & & Plan 1 & 0.869 & 0.861 & 0.760 & 0.818 & 0.743 & 0.883 & 0.950 \\
\hline & & Plan 2 & 0.906 & 0.916 & 0.654 & 0.719 & 0.663 & 0.714 & 0.785 \\
\hline & & Plan 3 & 0.904 & 0.924 & 0.560 & 0.578 & 0.549 & 0.606 & 0.626 \\
\hline & & Plan 4 & 0.949 & 0.971 & 0.616 & 0.583 & 0.538 & 0.634 & 0.601 \\
\hline & & Plan 5 & 0.910 & 0.930 & 0.427 & 0.375 & 0.362 & 0.458 & 0.403 \\
\hline & & Plan 6 & 0.925 & 0.973 & 0.283 & 0.243 & 0.213 & 0.290 & 0.249 \\
\hline & & Plan 7 & 0.933 & 0.987 & 0.337 & 0.305 & 0.297 & 0.341 & 0.309 \\
\hline & & Plan 8 & 0.919 & 0.970 & 0.318 & 0.300 & 0.298 & 0.328 & 0.310 \\
\hline & \multirow[t]{9}{*}{2} & EC & 1.517 & 1.515 & 0.556 & 0.564 & 0.514 & 0.367 & 0.372 \\
\hline & & Plan 1 & 1.504 & 1.496 & 1.275 & 1.344 & 1.269 & 0.852 & 0.898 \\
\hline & & Plan 2 & 1.488 & 1.480 & 0.974 & 1.066 & 0.967 & 0.658 & 0.721 \\
\hline & & Plan 3 & 1.561 & 1.513 & 0.935 & 0.947 & 0.913 & 0.618 & 0.626 \\
\hline & & Plan 4 & 1.571 & 1.585 & 0.885 & 0.837 & 0.766 & 0.558 & 0.528 \\
\hline & & Plan 5 & 1.571 & 1.550 & 0.739 & 0.671 & 0.629 & 0.477 & 0.433 \\
\hline & & Plan 6 & 1.543 & 1.600 & 0.424 & 0.358 & 0.328 & 0.265 & 0.224 \\
\hline & & Plan 7 & 1.554 & 1.603 & 0.490 & 0.456 & 0.436 & 0.305 & 0.284 \\
\hline & & Plan 8 & 1.619 & 1.665 & 0.521 & 0.486 & 0.477 & 0.313 & 0.292 \\
\hline & \multirow[t]{9}{*}{2.5} & EC & 1.542 & 1.577 & 0.595 & 0.606 & 0.553 & 0.378 & 0.384 \\
\hline & & Plan 1 & 1.557 & 1.598 & 1.377 & 1.420 & 1.324 & 0.862 & 0.889 \\
\hline & & Plan 2 & 1.511 & 1.530 & 1.013 & 1.088 & 0.995 & 0.662 & 0.711 \\
\hline & & Plan 3 & 1.584 & 1.574 & 1.015 & 1.022 & 0.977 & 0.645 & 0.649 \\
\hline & & Plan 4 & 1.555 & 1.607 & 0.908 & 0.865 & 0.779 & 0.565 & 0.538 \\
\hline & & Plan 5 & 1.567 & 1.605 & 0.792 & 0.728 & 0.686 & 0.494 & 0.453 \\
\hline & & Plan 6 & 1.569 & 1.656 & 0.465 & 0.396 & 0.365 & 0.281 & 0.239 \\
\hline & & Plan 7 & 1.557 & 1.627 & 0.526 & 0.482 & 0.460 & 0.324 & 0.296 \\
\hline & & Plan 8 & 1.547 & 1.646 & 0.527 & 0.487 & 0.473 & 0.320 & 0.296 \\
\hline & & & & & & & & & heet 4 of \\
\hline
\end{tabular}


Table E2. RMS $H_{s}$ across channel transect lines for waves from 45 degrees North; $+0.9 \mathrm{~m} \mathrm{swl}$.

\begin{tabular}{|c|c|c|c|c|c|c|c|c|c|}
\hline \multicolumn{2}{|c|}{$\begin{array}{l}\text { Experimental } \\
\text { Wave }\end{array}$} & \multirow[b]{2}{*}{ Plan } & \multicolumn{5}{|c|}{$H_{s}(\mathrm{~m})$ at Indicated Lines; $\mathrm{swl}=+0.9 \mathrm{~m}$} & \multirow[b]{2}{*}{$\begin{array}{l}H_{s, \text { Line2/ }} \\
H_{s, \text { Line1 }}\end{array}$} & \multirow[b]{2}{*}{$\begin{array}{l}H_{s, \text { Line } 3 /} \\
H_{s, \text { Line } 1}\end{array}$} \\
\hline $\begin{array}{l}T_{p} \\
\text { (sec) }\end{array}$ & $\begin{array}{l}H_{s, i n c} \\
(\mathrm{~m})\end{array}$ & & Line 0 & Line 1 & Line 2 & Line 3 & Line 4 & & \\
\hline \multirow[t]{27}{*}{5} & \multirow[t]{9}{*}{1} & EC & 0.859 & 0.851 & 0.353 & 0.364 & 0.355 & 0.415 & 0.427 \\
\hline & & Plan 1 & 0.811 & 0.814 & 0.746 & 0.814 & 0.768 & 0.917 & 1.001 \\
\hline & & Plan 2 & 0.898 & 0.889 & 0.570 & 0.610 & 0.580 & 0.642 & 0.686 \\
\hline & & Plan 3 & 0.828 & 0.832 & 0.614 & 0.661 & 0.627 & 0.738 & 0.795 \\
\hline & & Plan 4 & 0.866 & 0.883 & 0.466 & 0.376 & 0.343 & 0.527 & 0.426 \\
\hline & & Plan 5 & 0.911 & 0.948 & 0.682 & 0.609 & 0.593 & 0.719 & 0.642 \\
\hline & & Plan 6 & 0.897 & 0.928 & 0.282 & 0.255 & 0.223 & 0.304 & 0.275 \\
\hline & & Plan 7 & 0.920 & 0.944 & 0.345 & 0.352 & 0.302 & 0.366 & 0.373 \\
\hline & & Plan 8 & 0.985 & 0.996 & 0.364 & 0.327 & 0.321 & 0.365 & 0.328 \\
\hline & \multirow[t]{9}{*}{2} & EC & 1.339 & 1.302 & 0.651 & 0.652 & 0.622 & 0.500 & 0.500 \\
\hline & & Plan 1 & 1.366 & 1.315 & 1.266 & 1.263 & 1.184 & 0.963 & 0.961 \\
\hline & & Plan 2 & 1.373 & 1.329 & 0.912 & 0.951 & 0.904 & 0.687 & 0.716 \\
\hline & & Plan 3 & 1.302 & 1.272 & 1.004 & 1.058 & 0.983 & 0.789 & 0.832 \\
\hline & & Plan 4 & 1.283 & 1.305 & 0.716 & 0.590 & 0.530 & 0.549 & 0.452 \\
\hline & & Plan 5 & 1.361 & 1.398 & 0.976 & 0.864 & 0.825 & 0.698 & 0.618 \\
\hline & & Plan 6 & 1.367 & 1.400 & 0.438 & 0.390 & 0.338 & 0.313 & 0.279 \\
\hline & & Plan 7 & 1.311 & 1.339 & 0.455 & 0.468 & 0.397 & 0.340 & 0.350 \\
\hline & & Plan 8 & 1.336 & 1.353 & 0.521 & 0.452 & 0.443 & 0.385 & 0.334 \\
\hline & \multirow[t]{9}{*}{2.5} & EC & 1.568 & 1.525 & 0.804 & 0.805 & 0.790 & 0.527 & 0.528 \\
\hline & & Plan 1 & 1.525 & 1.448 & 1.391 & 1.371 & 1.292 & 0.961 & 0.947 \\
\hline & & Plan 2 & 1.667 & 1.560 & 1.133 & 1.165 & 1.110 & 0.726 & 0.747 \\
\hline & & Plan 3 & 1.559 & 1.485 & 1.169 & 1.232 & 1.139 & 0.787 & 0.830 \\
\hline & & Plan 4 & 1.473 & 1.480 & 0.831 & 0.730 & 0.613 & 0.561 & 0.493 \\
\hline & & Plan 5 & 1.527 & 1.509 & 1.133 & 1.014 & 0.973 & 0.750 & 0.672 \\
\hline & & Plan 6 & 1.533 & 1.555 & 0.563 & 0.515 & 0.446 & 0.362 & 0.331 \\
\hline & & Plan 7 & 1.491 & 1.506 & 0.632 & 0.640 & 0.539 & 0.419 & 0.425 \\
\hline & & Plan 8 & 1.554 & 1.548 & 0.686 & 0.600 & 0.586 & 0.443 & 0.387 \\
\hline
\end{tabular}




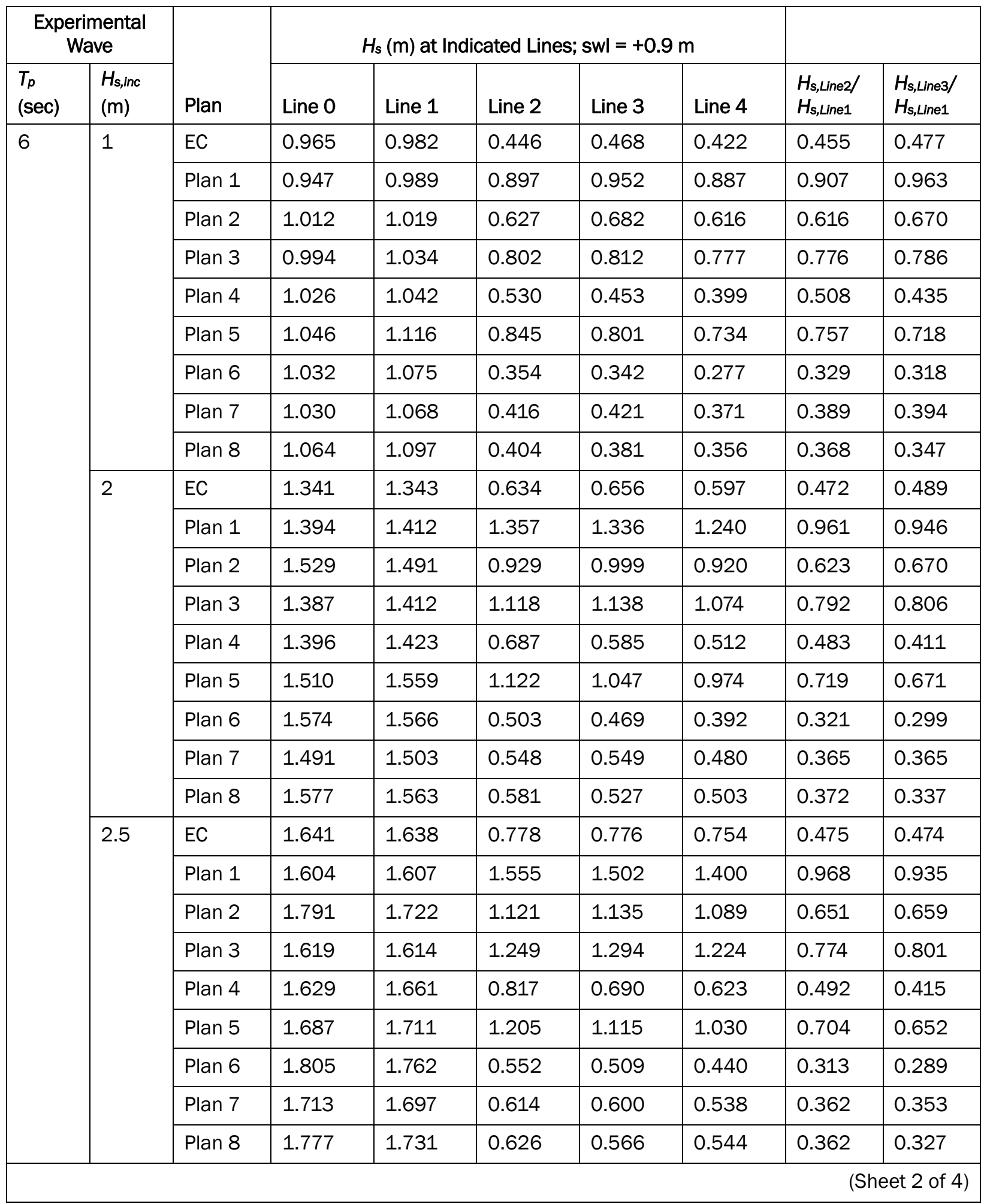




\begin{tabular}{|c|c|c|c|c|c|c|c|c|c|}
\hline \multicolumn{2}{|c|}{$\begin{array}{l}\text { Experimental } \\
\text { Wave }\end{array}$} & \multirow[b]{2}{*}{ Plan } & \multicolumn{5}{|c|}{$H_{s}(\mathrm{~m})$ at Indicated Lines; swl $=+0.9 \mathrm{~m}$} & \multirow[b]{2}{*}{$\begin{array}{l}H_{s, \text { Line } 2 /} \\
H_{s, \text { Line1 }}\end{array}$} & \multirow[b]{2}{*}{$\begin{array}{l}H_{s, \text { Line3 } /} \\
H_{s, \text { Line1 }}\end{array}$} \\
\hline $\begin{array}{l}T_{p} \\
\text { (sec) }\end{array}$ & $\begin{array}{l}H_{s, i n c} \\
(\mathrm{~m})\end{array}$ & & Line 0 & Line 1 & Line 2 & Line 3 & Line 4 & & \\
\hline \multirow[t]{27}{*}{7} & \multirow[t]{9}{*}{1} & $\mathrm{EC}$ & 1.042 & 1.070 & 0.489 & 0.492 & 0.474 & 0.457 & 0.460 \\
\hline & & Plan 1 & 0.996 & 1.054 & 0.949 & 0.993 & 0.933 & 0.901 & 0.942 \\
\hline & & Plan 2 & 1.036 & 1.050 & 0.663 & 0.697 & 0.645 & 0.631 & 0.663 \\
\hline & & Plan 3 & 1.030 & 1.088 & 0.853 & 0.845 & 0.804 & 0.784 & 0.776 \\
\hline & & Plan 4 & 1.073 & 1.091 & 0.583 & 0.519 & 0.450 & 0.534 & 0.475 \\
\hline & & Plan 5 & 1.074 & 1.154 & 0.870 & 0.804 & 0.750 & 0.754 & 0.697 \\
\hline & & Plan 6 & 1.064 & 1.102 & 0.376 & 0.326 & 0.276 & 0.342 & 0.296 \\
\hline & & Plan 7 & 1.065 & 1.099 & 0.426 & 0.432 & 0.375 & 0.387 & 0.393 \\
\hline & & Plan 8 & 1.084 & 1.114 & 0.441 & 0.401 & 0.376 & 0.396 & 0.359 \\
\hline & \multirow[t]{9}{*}{2} & EC & 1.487 & 1.519 & 0.610 & 0.598 & 0.558 & 0.401 & 0.394 \\
\hline & & Plan 1 & 1.476 & 1.575 & 1.472 & 1.473 & 1.375 & 0.935 & 0.936 \\
\hline & & Plan 2 & 1.627 & 1.662 & 0.995 & 1.020 & 0.959 & 0.599 & 0.614 \\
\hline & & Plan 3 & 1.502 & 1.610 & 1.175 & 1.172 & 1.101 & 0.729 & 0.728 \\
\hline & & Plan 4 & 1.629 & 1.658 & 0.819 & 0.710 & 0.637 & 0.494 & 0.428 \\
\hline & & Plan 5 & 1.659 & 1.742 & 1.155 & 1.058 & 0.979 & 0.663 & 0.607 \\
\hline & & Plan 6 & 1.704 & 1.736 & 0.506 & 0.431 & 0.367 & 0.292 & 0.248 \\
\hline & & Plan 7 & 1.637 & 1.684 & 0.555 & 0.535 & 0.474 & 0.330 & 0.317 \\
\hline & & Plan 8 & 1.639 & 1.668 & 0.569 & 0.509 & 0.477 & 0.341 & 0.305 \\
\hline & \multirow[t]{9}{*}{2.5} & EC & 1.534 & 1.597 & 0.737 & 0.721 & 0.681 & 0.461 & 0.452 \\
\hline & & Plan 1 & 1.536 & 1.607 & 1.535 & 1.513 & 1.394 & 0.955 & 0.942 \\
\hline & & Plan 2 & 1.593 & 1.657 & 1.100 & 1.127 & 1.044 & 0.664 & 0.680 \\
\hline & & Plan 3 & 1.526 & 1.615 & 1.230 & 1.234 & 1.162 & 0.761 & 0.764 \\
\hline & & Plan 4 & 1.678 & 1.733 & 0.919 & 0.803 & 0.722 & 0.530 & 0.464 \\
\hline & & Plan 5 & 1.720 & 1.792 & 1.214 & 1.124 & 1.028 & 0.677 & 0.627 \\
\hline & & Plan 6 & 1.680 & 1.746 & 0.557 & 0.481 & 0.409 & 0.319 & 0.275 \\
\hline & & Plan 7 & 1.639 & 1.710 & 0.619 & 0.601 & 0.531 & 0.362 & 0.352 \\
\hline & & Plan 8 & 1.727 & 1.770 & 0.643 & 0.575 & 0.541 & 0.363 & 0.325 \\
\hline
\end{tabular}




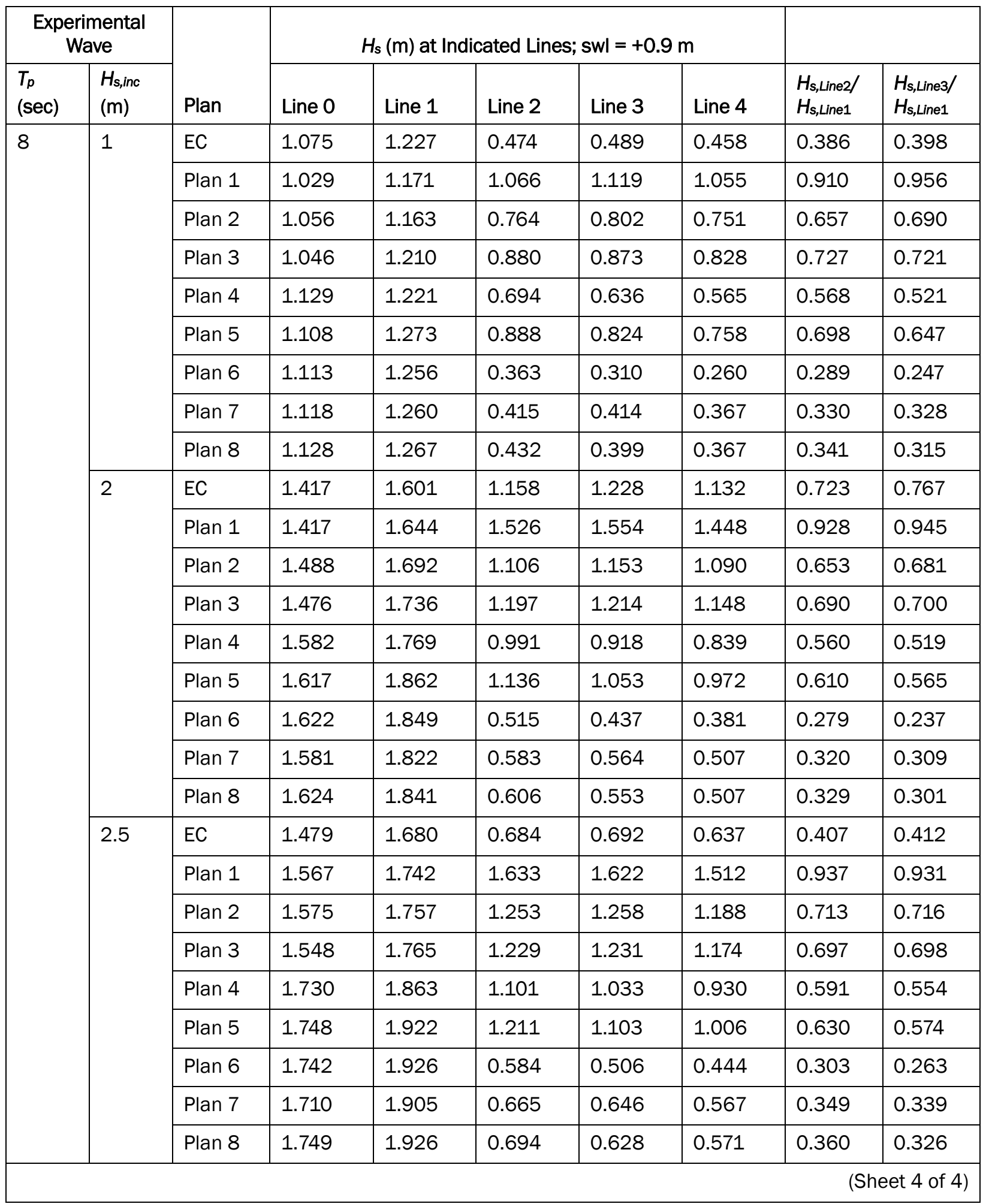


Table E3. RMS $H_{s}$ across channel transect lines for waves from 0 degrees; $+0.9 \mathrm{~m}$ swl.

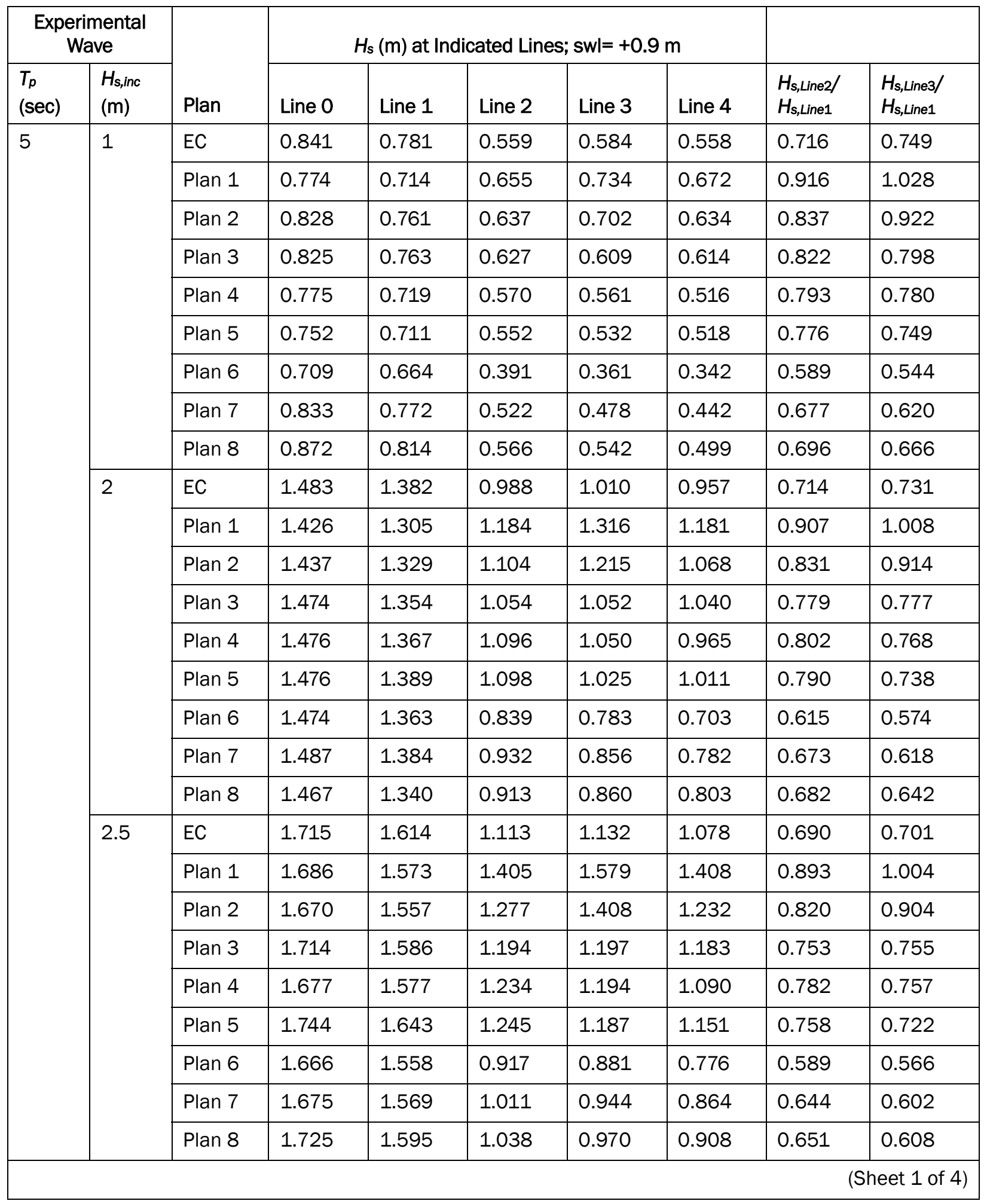




\begin{tabular}{|c|c|c|c|c|c|c|c|c|c|}
\hline \multicolumn{2}{|c|}{$\begin{array}{l}\text { Experimental } \\
\text { Wave }\end{array}$} & \multirow[b]{2}{*}{ Plan } & \multicolumn{5}{|c|}{$H_{s}(\mathrm{~m})$ at Indicated Lines; swl $=+0.9 \mathrm{~m}$} & \multirow[b]{2}{*}{$\begin{array}{l}H_{s, \text { Line2 }} / \\
H_{s, \text { Line1 }}\end{array}$} & \multirow[b]{2}{*}{$\begin{array}{l}H_{s, \text { Line } 3 /} \\
H_{s, \text { Line1 }}\end{array}$} \\
\hline $\begin{array}{l}T_{p} \\
\text { (sec) }\end{array}$ & $\begin{array}{l}H_{s, i n c} \\
(\mathrm{~m})\end{array}$ & & Line 0 & Line 1 & Line 2 & Line 3 & Line 4 & & \\
\hline \multirow[t]{27}{*}{6} & \multirow[t]{9}{*}{1} & EC & 0.886 & 0.852 & 0.594 & 0.606 & 0.582 & 0.697 & 0.712 \\
\hline & & Plan 1 & 0.855 & 0.828 & 0.755 & 0.807 & 0.752 & 0.912 & 0.974 \\
\hline & & Plan 2 & 0.828 & 0.761 & 0.637 & 0.702 & 0.634 & 0.837 & 0.922 \\
\hline & & Plan 3 & 0.868 & 0.830 & 0.655 & 0.636 & 0.628 & 0.789 & 0.766 \\
\hline & & Plan 4 & 0.798 & 0.795 & 0.595 & 0.587 & 0.534 & 0.749 & 0.739 \\
\hline & & Plan 5 & 0.788 & 0.776 & 0.593 & 0.563 & 0.537 & 0.765 & 0.725 \\
\hline & & Plan 6 & 0.782 & 0.765 & 0.417 & 0.394 & 0.343 & 0.545 & 0.515 \\
\hline & & Plan 7 & 0.843 & 0.820 & 0.502 & 0.472 & 0.431 & 0.612 & 0.576 \\
\hline & & Plan 8 & 0.864 & 0.841 & 0.525 & 0.490 & 0.456 & 0.625 & 0.583 \\
\hline & \multirow[t]{9}{*}{2} & EC & 1.409 & 1.357 & 0.939 & 0.953 & 0.910 & 0.692 & 0.702 \\
\hline & & Plan 1 & 1.364 & 1.320 & 1.196 & 1.280 & 1.184 & 0.906 & 0.970 \\
\hline & & Plan 2 & 1.431 & 1.386 & 1.131 & 1.229 & 1.111 & 0.816 & 0.887 \\
\hline & & Plan 3 & 1.427 & 1.362 & 1.052 & 1.064 & 1.047 & 0.772 & 0.781 \\
\hline & & Plan 4 & 1.379 & 1.364 & 1.032 & 1.017 & 0.913 & 0.756 & 0.746 \\
\hline & & Plan 5 & 1.407 & 1.380 & 1.065 & 1.021 & 0.984 & 0.772 & 0.740 \\
\hline & & Plan 6 & 1.360 & 1.323 & 0.746 & 0.709 & 0.611 & 0.564 & 0.536 \\
\hline & & Plan 7 & 1.374 & 1.332 & 0.817 & 0.779 & 0.704 & 0.614 & 0.585 \\
\hline & & Plan 8 & 1.395 & 1.352 & 0.845 & 0.781 & 0.738 & 0.625 & 0.577 \\
\hline & \multirow[t]{9}{*}{2.5} & EC & 1.698 & 1.649 & 1.095 & 1.108 & 1.046 & 0.664 & 0.672 \\
\hline & & Plan 1 & 1.649 & 1.619 & 1.446 & 1.551 & 1.422 & 0.893 & 0.958 \\
\hline & & Plan 2 & 1.658 & 1.627 & 1.322 & 1.441 & 1.281 & 0.812 & 0.886 \\
\hline & & Plan 3 & 1.680 & 1.653 & 1.278 & 1.273 & 1.237 & 0.773 & 0.770 \\
\hline & & Plan 4 & 1.536 & 1.547 & 1.139 & 1.102 & 0.988 & 0.736 & 0.713 \\
\hline & & Plan 5 & 1.575 & 1.570 & 1.228 & 1.182 & 1.120 & 0.782 & 0.753 \\
\hline & & Plan 6 & 1.539 & 1.508 & 0.817 & 0.771 & 0.671 & 0.542 & 0.511 \\
\hline & & Plan 7 & 1.505 & 1.479 & 0.884 & 0.841 & 0.748 & 0.597 & 0.568 \\
\hline & & Plan 8 & 1.530 & 1.501 & 0.911 & 0.824 & 0.785 & 0.607 & 0.549 \\
\hline
\end{tabular}




\begin{tabular}{|c|c|c|c|c|c|c|c|c|c|}
\hline \multicolumn{2}{|c|}{$\begin{array}{l}\text { Experimental } \\
\text { Wave }\end{array}$} & \multirow[b]{2}{*}{ Plan } & \multicolumn{5}{|c|}{$H_{s}(\mathrm{~m})$ at Indicated Lines; swl $=+0.9 \mathrm{~m}$} & \multirow[b]{2}{*}{$\begin{array}{l}H_{s, \text { Line2 }} / \\
H_{s, \text { Line1 }}\end{array}$} & \multirow[b]{2}{*}{$\begin{array}{l}H_{s, \text { Line } 3 /} \\
H_{s, \text { Line1 }}\end{array}$} \\
\hline $\begin{array}{l}T_{p} \\
\text { (sec) }\end{array}$ & $\begin{array}{l}H_{s, i n c} \\
(\mathrm{~m})\end{array}$ & & Line 0 & Line 1 & Line 2 & Line 3 & Line 4 & & \\
\hline \multirow[t]{27}{*}{7} & \multirow[t]{9}{*}{1} & EC & 0.881 & 0.846 & 0.570 & 0.574 & 0.548 & 0.674 & 0.679 \\
\hline & & Plan 1 & 0.831 & 0.812 & 0.740 & 0.779 & 0.721 & 0.911 & 0.959 \\
\hline & & Plan 2 & 0.873 & 0.854 & 0.698 & 0.752 & 0.693 & 0.818 & 0.881 \\
\hline & & Plan 3 & 0.876 & 0.822 & 0.656 & 0.643 & 0.628 & 0.798 & 0.783 \\
\hline & & Plan 4 & 0.801 & 0.806 & 0.599 & 0.587 & 0.529 & 0.744 & 0.729 \\
\hline & & Plan 5 & 0.805 & 0.791 & 0.610 & 0.579 & 0.543 & 0.772 & 0.732 \\
\hline & & Plan 6 & 0.792 & 0.774 & 0.406 & 0.364 & 0.319 & 0.525 & 0.470 \\
\hline & & Plan 7 & 0.844 & 0.819 & 0.485 & 0.465 & 0.419 & 0.592 & 0.567 \\
\hline & & Plan 8 & 0.823 & 0.802 & 0.477 & 0.445 & 0.414 & 0.595 & 0.555 \\
\hline & \multirow[t]{9}{*}{2} & EC & 1.444 & 1.415 & 0.909 & 0.921 & 0.865 & 0.643 & 0.651 \\
\hline & & Plan 1 & 1.390 & 1.385 & 1.250 & 1.314 & 1.213 & 0.903 & 0.949 \\
\hline & & Plan 2 & 1.462 & 1.452 & 1.163 & 1.248 & 1.141 & 0.801 & 0.860 \\
\hline & & Plan 3 & 1.428 & 1.406 & 1.118 & 1.131 & 1.102 & 0.795 & 0.805 \\
\hline & & Plan 4 & 1.478 & 1.495 & 1.082 & 1.047 & 0.938 & 0.724 & 0.700 \\
\hline & & Plan 5 & 1.458 & 1.452 & 1.142 & 1.084 & 1.027 & 0.787 & 0.747 \\
\hline & & Plan 6 & 1.505 & 1.474 & 0.765 & 0.706 & 0.602 & 0.519 & 0.479 \\
\hline & & Plan 7 & 1.490 & 1.469 & 0.838 & 0.801 & 0.717 & 0.570 & 0.545 \\
\hline & & Plan 8 & 1.457 & 1.433 & 0.845 & 0.767 & 0.728 & 0.589 & 0.535 \\
\hline & \multirow[t]{9}{*}{2.5} & EC & 1.735 & 1.727 & 1.053 & 1.058 & 1.002 & 0.610 & 0.612 \\
\hline & & Plan 1 & 1.686 & 1.678 & 1.514 & 1.590 & 1.453 & 0.902 & 0.947 \\
\hline & & Plan 2 & 1.663 & 1.678 & 1.330 & 1.421 & 1.287 & 0.793 & 0.847 \\
\hline & & Plan 3 & 1.715 & 1.707 & 1.400 & 1.403 & 1.346 & 0.820 & 0.822 \\
\hline & & Plan 4 & 1.729 & 1.755 & 1.238 & 1.192 & 1.066 & 0.705 & 0.679 \\
\hline & & Plan 5 & 1.797 & 1.792 & 1.423 & 1.367 & 1.280 & 0.794 & 0.763 \\
\hline & & Plan 6 & 1.745 & 1.736 & 0.872 & 0.800 & 0.694 & 0.502 & 0.461 \\
\hline & & Plan 7 & 1.738 & 1.730 & 0.962 & 0.921 & 0.823 & 0.556 & 0.532 \\
\hline & & Plan 8 & 1.703 & 1.698 & 0.976 & 0.862 & 0.819 & 0.575 & 0.508 \\
\hline
\end{tabular}




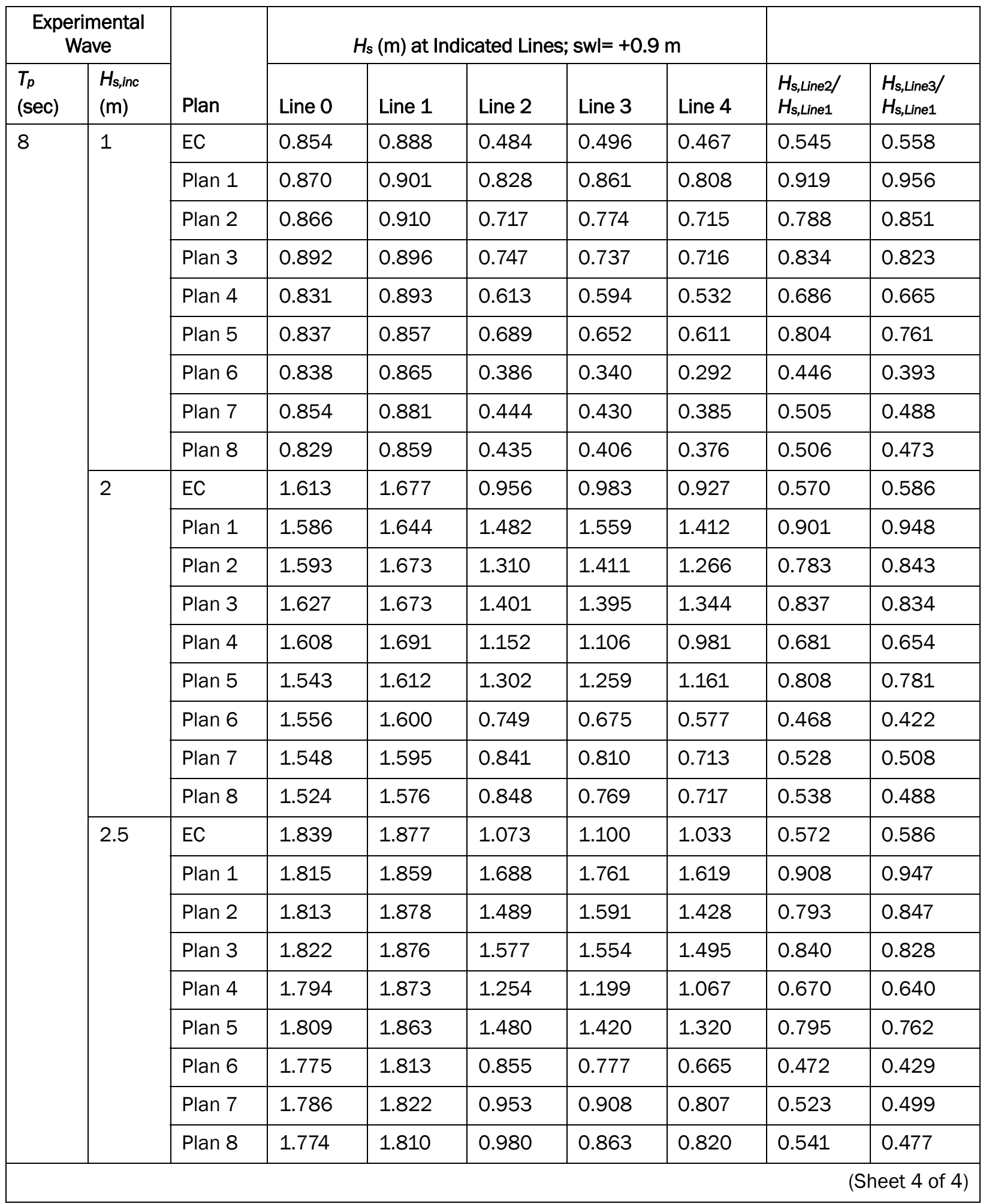


Table E4. RMS $H_{s}$ across channel transect lines for waves from 45 degrees South; $+0.0 \mathrm{~m} \mathrm{swl}$.

\begin{tabular}{|c|c|c|c|c|c|c|c|c|c|}
\hline \multicolumn{2}{|c|}{$\begin{array}{l}\text { Experimental } \\
\text { Wave }\end{array}$} & \multirow[b]{2}{*}{ Plan } & \multicolumn{5}{|c|}{$H_{s}(\mathrm{~m})$ at Indicated Lines; $\mathrm{swl}=+0.9 \mathrm{~m}$} & \multirow[b]{2}{*}{$\begin{array}{l}H_{s, \text { Line } 2 /} \\
H_{s, \text { Line } 1}\end{array}$} & \multirow[b]{2}{*}{$\begin{array}{l}H_{s, \text { Line } 3 /} \\
H_{s, \text { Line1 }}\end{array}$} \\
\hline $\begin{array}{l}T_{p} \\
\text { (sec) }\end{array}$ & $\begin{array}{l}H_{s, i n c} \\
(m)\end{array}$ & & Line 0 & Line 1 & Line 2 & Line 3 & Line 4 & & \\
\hline \multirow[t]{27}{*}{5} & \multirow[t]{9}{*}{1} & EC & 0.644 & 0.723 & 0.354 & 0.379 & 0.368 & 0.490 & 0.525 \\
\hline & & Plan 1 & 0.663 & 0.712 & 0.563 & 0.615 & 0.590 & 0.791 & 0.863 \\
\hline & & Plan 2 & 0.520 & 0.510 & 0.355 & 0.366 & 0.353 & 0.696 & 0.717 \\
\hline & & Plan 3 & 0.560 & 0.581 & 0.363 & 0.400 & 0.398 & 0.626 & 0.689 \\
\hline & & Plan 4 & 0.637 & 0.687 & 0.432 & 0.410 & 0.408 & 0.629 & 0.597 \\
\hline & & Plan 5 & 0.646 & 0.717 & 0.392 & 0.404 & 0.354 & 0.547 & 0.563 \\
\hline & & Plan 6 & 0.663 & 0.764 & 0.286 & 0.276 & 0.269 & 0.374 & 0.361 \\
\hline & & Plan 7 & 0.649 & 0.740 & 0.319 & 0.271 & 0.298 & 0.431 & 0.366 \\
\hline & & Plan 8 & 0.676 & 0.766 & 0.307 & 0.340 & 0.331 & 0.401 & 0.444 \\
\hline & \multirow[t]{9}{*}{2} & EC & 1.070 & 1.097 & 0.550 & 0.576 & 0.538 & 0.501 & 0.525 \\
\hline & & Plan 1 & 1.018 & 0.982 & 0.760 & 0.824 & 0.770 & 0.774 & 0.839 \\
\hline & & Plan 2 & 1.025 & 1.011 & 0.706 & 0.746 & 0.707 & 0.698 & 0.738 \\
\hline & & Plan 3 & 1.137 & 1.174 & 0.707 & 0.732 & 0.737 & 0.602 & 0.623 \\
\hline & & Plan 4 & 1.020 & 1.028 & 0.656 & 0.627 & 0.613 & 0.638 & 0.609 \\
\hline & & Plan 5 & 1.026 & 1.050 & 0.568 & 0.571 & 0.497 & 0.541 & 0.544 \\
\hline & & Plan 6 & 1.091 & 1.140 & 0.434 & 0.416 & 0.384 & 0.381 & 0.365 \\
\hline & & Plan 7 & 1.088 & 1.136 & 0.496 & 0.423 & 0.450 & 0.437 & 0.372 \\
\hline & & Plan 8 & 1.059 & 1.091 & 0.472 & 0.503 & 0.469 & 0.432 & 0.461 \\
\hline & \multirow[t]{9}{*}{2.5} & $\mathrm{EC}$ & 1.137 & 1.159 & 0.604 & 0.637 & 0.591 & 0.521 & 0.549 \\
\hline & & Plan 1 & 1.154 & 1.148 & 0.880 & 0.962 & 0.899 & 0.766 & 0.838 \\
\hline & & Plan 2 & 1.184 & 1.191 & 0.824 & 0.881 & 0.820 & 0.692 & 0.740 \\
\hline & & Plan 3 & 1.231 & 1.240 & 0.775 & 0.796 & 0.785 & 0.625 & 0.642 \\
\hline & & Plan 4 & 1.155 & 1.161 & 0.735 & 0.699 & 0.683 & 0.634 & 0.602 \\
\hline & & Plan 5 & 1.199 & 1.234 & 0.687 & 0.690 & 0.615 & 0.557 & 0.559 \\
\hline & & Plan 6 & 1.199 & 1.218 & 0.500 & 0.470 & 0.444 & 0.410 & 0.386 \\
\hline & & Plan 7 & 1.199 & 1.237 & 0.563 & 0.484 & 0.505 & 0.455 & 0.391 \\
\hline & & Plan 8 & 1.162 & 1.205 & 0.514 & 0.546 & 0.512 & 0.426 & 0.453 \\
\hline
\end{tabular}




\begin{tabular}{|c|c|c|c|c|c|c|c|c|c|}
\hline \multicolumn{2}{|c|}{$\begin{array}{l}\text { Experimental } \\
\text { Wave }\end{array}$} & \multirow[b]{2}{*}{ Plan } & \multicolumn{5}{|c|}{$H_{s}(\mathrm{~m})$ at Indicated Lines; $\mathrm{swl}=+0.9 \mathrm{~m}$} & \multirow[b]{2}{*}{$\begin{array}{l}H_{s, \text { Line2 }} / \\
H_{s, \text { Line1 }}\end{array}$} & \multirow[b]{2}{*}{$\begin{array}{l}H_{s, \text { Line } 3 /} \\
H_{s, \text { Line1 }}\end{array}$} \\
\hline $\begin{array}{l}T_{p} \\
\text { (sec) }\end{array}$ & $\begin{array}{l}H_{s, i n c} \\
(\mathrm{~m})\end{array}$ & & Line 0 & Line 1 & Line 2 & Line 3 & Line 4 & & \\
\hline \multirow[t]{27}{*}{6} & \multirow[t]{9}{*}{1} & EC & 0.722 & 0.807 & 0.389 & 0.401 & 0.378 & 0.482 & 0.497 \\
\hline & & Plan 1 & 0.774 & 0.807 & 0.628 & 0.717 & 0.663 & 0.778 & 0.888 \\
\hline & & Plan 2 & 0.713 & 0.763 & 0.559 & 0.616 & 0.576 & 0.733 & 0.807 \\
\hline & & Plan 3 & 0.712 & 0.808 & 0.452 & 0.468 & 0.473 & 0.560 & 0.579 \\
\hline & & Plan 4 & 0.783 & 0.842 & 0.551 & 0.527 & 0.514 & 0.655 & 0.625 \\
\hline & & Plan 5 & 0.760 & 0.839 & 0.406 & 0.394 & 0.360 & 0.484 & 0.470 \\
\hline & & Plan 6 & 0.767 & 0.865 & 0.286 & 0.266 & 0.253 & 0.331 & 0.308 \\
\hline & & Plan 7 & 0.754 & 0.864 & 0.334 & 0.287 & 0.300 & 0.386 & 0.332 \\
\hline & & Plan 8 & 0.763 & 0.876 & 0.323 & 0.330 & 0.318 & 0.369 & 0.376 \\
\hline & \multirow[t]{9}{*}{2} & EC & 1.070 & 1.141 & 0.524 & 0.527 & 0.502 & 0.459 & 0.462 \\
\hline & & Plan 1 & 1.086 & 1.089 & 0.875 & 0.960 & 0.896 & 0.803 & 0.881 \\
\hline & & Plan 2 & 1.079 & 1.111 & 0.794 & 0.848 & 0.805 & 0.715 & 0.763 \\
\hline & & Plan 3 & 1.117 & 1.192 & 0.640 & 0.651 & 0.649 & 0.536 & 0.546 \\
\hline & & Plan 4 & 1.139 & 1.191 & 0.744 & 0.699 & 0.684 & 0.624 & 0.587 \\
\hline & & Plan 5 & 1.099 & 1.145 & 0.581 & 0.560 & 0.523 & 0.507 & 0.489 \\
\hline & & Plan 6 & 1.146 & 1.225 & 0.402 & 0.358 & 0.340 & 0.328 & 0.292 \\
\hline & & Plan 7 & 1.150 & 1.234 & 0.467 & 0.406 & 0.426 & 0.379 & 0.329 \\
\hline & & Plan 8 & 1.134 & 1.212 & 0.444 & 0.436 & 0.426 & 0.367 & 0.359 \\
\hline & \multirow[t]{9}{*}{2.5} & EC & 1.146 & 1.181 & 0.585 & 0.603 & 0.553 & 0.495 & 0.511 \\
\hline & & Plan 1 & 1.189 & 1.190 & 0.974 & 1.063 & 0.995 & 0.818 & 0.893 \\
\hline & & Plan 2 & 1.178 & 1.205 & 0.884 & 0.933 & 0.902 & 0.734 & 0.774 \\
\hline & & Plan 3 & 1.236 & 1.287 & 0.741 & 0.747 & 0.744 & 0.576 & 0.580 \\
\hline & & Plan 4 & 1.186 & 1.224 & 0.794 & 0.741 & 0.729 & 0.648 & 0.606 \\
\hline & & Plan 5 & 1.214 & 1.241 & 0.661 & 0.633 & 0.599 & 0.532 & 0.510 \\
\hline & & Plan 6 & 1.236 & 1.264 & 0.452 & 0.406 & 0.395 & 0.357 & 0.321 \\
\hline & & Plan 7 & 1.237 & 1.304 & 0.524 & 0.450 & 0.472 & 0.402 & 0.345 \\
\hline & & Plan 8 & 1.203 & 1.274 & 0.495 & 0.489 & 0.482 & 0.388 & 0.384 \\
\hline
\end{tabular}




\begin{tabular}{|c|c|c|c|c|c|c|c|c|c|}
\hline \multicolumn{2}{|c|}{$\begin{array}{l}\text { Experimental } \\
\text { Wave }\end{array}$} & \multirow[b]{2}{*}{ Plan } & \multicolumn{5}{|c|}{$H_{s}(\mathrm{~m})$ at Indicated Lines; $\mathrm{swl}=+0.9 \mathrm{~m}$} & \multirow[b]{2}{*}{$\begin{array}{l}H_{s, \text { Line2/ }} \\
H_{s, \text { Line1 }}\end{array}$} & \multirow[b]{2}{*}{$\begin{array}{l}H_{s, \text { Line3 }} / \\
H_{s, \text { Line1 }}\end{array}$} \\
\hline $\begin{array}{l}T_{p} \\
\text { (sec) }\end{array}$ & $\begin{array}{l}H_{s, i n c} \\
(\mathrm{~m})\end{array}$ & & Line 0 & Line 1 & Line 2 & Line 3 & Line 4 & & \\
\hline \multirow[t]{27}{*}{7} & \multirow[t]{9}{*}{1} & EC & 0.664 & 0.741 & 0.349 & 0.358 & 0.331 & 0.471 & 0.483 \\
\hline & & Plan 1 & 0.740 & 0.788 & 0.629 & 0.687 & 0.633 & 0.798 & 0.872 \\
\hline & & Plan 2 & 0.668 & 0.742 & 0.546 & 0.582 & 0.555 & 0.736 & 0.785 \\
\hline & & Plan 3 & 0.711 & 0.812 & 0.447 & 0.464 & 0.460 & 0.550 & 0.571 \\
\hline & & Plan 4 & 0.714 & 0.788 & 0.505 & 0.478 & 0.456 & 0.641 & 0.606 \\
\hline & & Plan 5 & 0.743 & 0.820 & 0.395 & 0.389 & 0.357 & 0.482 & 0.474 \\
\hline & & Plan 6 & 0.742 & 0.836 & 0.258 & 0.228 & 0.215 & 0.309 & 0.273 \\
\hline & & Plan 7 & 0.715 & 0.815 & 0.304 & 0.263 & 0.277 & 0.373 & 0.323 \\
\hline & & Plan 8 & 0.747 & 0.855 & 0.295 & 0.295 & 0.291 & 0.346 & 0.346 \\
\hline & \multirow[t]{9}{*}{2} & EC & 1.131 & 1.223 & 0.532 & 0.539 & 0.504 & 0.435 & 0.441 \\
\hline & & Plan 1 & 1.155 & 1.173 & 0.951 & 1.015 & 0.954 & 0.810 & 0.865 \\
\hline & & Plan 2 & 1.136 & 1.203 & 0.863 & 0.906 & 0.876 & 0.717 & 0.753 \\
\hline & & Plan 3 & 1.202 & 1.294 & 0.715 & 0.719 & 0.706 & 0.552 & 0.556 \\
\hline & & Plan 4 & 1.177 & 1.250 & 0.774 & 0.712 & 0.689 & 0.619 & 0.570 \\
\hline & & Plan 5 & 1.154 & 1.222 & 0.622 & 0.592 & 0.557 & 0.509 & 0.484 \\
\hline & & Plan 6 & 1.187 & 1.282 & 0.397 & 0.349 & 0.323 & 0.310 & 0.273 \\
\hline & & Plan 7 & 1.190 & 1.288 & 0.465 & 0.407 & 0.419 & 0.361 & 0.316 \\
\hline & & Plan 8 & 1.180 & 1.278 & 0.440 & 0.428 & 0.421 & 0.345 & 0.335 \\
\hline & \multirow[t]{9}{*}{2.5} & EC & 1.238 & 1.321 & 0.631 & 0.653 & 0.595 & 0.478 & 0.494 \\
\hline & & Plan 1 & 1.266 & 1.303 & 1.057 & 1.147 & 1.064 & 0.811 & 0.881 \\
\hline & & Plan 2 & 1.167 & 1.228 & 0.877 & 0.920 & 0.897 & 0.714 & 0.749 \\
\hline & & Plan 3 & 1.242 & 1.315 & 0.768 & 0.776 & 0.767 & 0.584 & 0.590 \\
\hline & & Plan 4 & 1.200 & 1.277 & 0.807 & 0.757 & 0.728 & 0.632 & 0.593 \\
\hline & & Plan 5 & 1.247 & 1.307 & 0.728 & 0.696 & 0.656 & 0.557 & 0.533 \\
\hline & & Plan 6 & 1.284 & 1.353 & 0.457 & 0.402 & 0.384 & 0.338 & 0.297 \\
\hline & & Plan 7 & 1.283 & 1.384 & 0.534 & 0.477 & 0.485 & 0.386 & 0.345 \\
\hline & & Plan 8 & 1.289 & 1.393 & 0.519 & 0.512 & 0.507 & 0.373 & 0.367 \\
\hline
\end{tabular}




\begin{tabular}{|c|c|c|c|c|c|c|c|c|c|}
\hline \multicolumn{2}{|c|}{$\begin{array}{l}\text { Experimental } \\
\text { Wave }\end{array}$} & \multirow[b]{2}{*}{ Plan } & \multicolumn{5}{|c|}{$H_{s}(\mathrm{~m})$ at Indicated Lines; $\mathrm{swl}=+0.9 \mathrm{~m}$} & \multirow[b]{2}{*}{$\begin{array}{l}H_{s, \text { Line2/ }} \\
H_{s, \text { Line1 }}\end{array}$} & \multirow[b]{2}{*}{$\begin{array}{l}H_{s, \text { Line3 }} / \\
H_{s, \text { Line1 }}\end{array}$} \\
\hline $\begin{array}{l}T_{p} \\
\text { (sec) }\end{array}$ & $\begin{array}{l}H_{s, i n c} \\
(\mathrm{~m})\end{array}$ & & Line 0 & Line 1 & Line 2 & Line 3 & Line 4 & & \\
\hline \multirow[t]{27}{*}{8} & \multirow[t]{9}{*}{1} & $\mathrm{EC}$ & 0.659 & 0.702 & 0.307 & 0.312 & 0.296 & 0.438 & 0.445 \\
\hline & & Plan 1 & 0.733 & 0.761 & 0.631 & 0.656 & 0.625 & 0.828 & 0.861 \\
\hline & & Plan 2 & 0.674 & 0.717 & 0.543 & 0.572 & 0.556 & 0.758 & 0.798 \\
\hline & & Plan 3 & 0.721 & 0.773 & 0.448 & 0.451 & 0.451 & 0.580 & 0.583 \\
\hline & & Plan 4 & 0.705 & 0.749 & 0.484 & 0.439 & 0.426 & 0.646 & 0.586 \\
\hline & & Plan 5 & 0.801 & 0.839 & 0.439 & 0.428 & 0.397 & 0.523 & 0.510 \\
\hline & & Plan 6 & 0.743 & 0.800 & 0.244 & 0.214 & 0.199 & 0.305 & 0.267 \\
\hline & & Plan 7 & 0.717 & 0.775 & 0.283 & 0.249 & 0.259 & 0.365 & 0.322 \\
\hline & & Plan 8 & 0.743 & 0.801 & 0.271 & 0.274 & 0.271 & 0.339 & 0.342 \\
\hline & \multirow[t]{9}{*}{2} & EC & 1.206 & 1.249 & 0.524 & 0.537 & 0.495 & 0.420 & 0.430 \\
\hline & & Plan 1 & 1.300 & 1.287 & 1.072 & 1.119 & 1.060 & 0.833 & 0.869 \\
\hline & & Plan 2 & 1.257 & 1.293 & 0.918 & 0.975 & 0.926 & 0.710 & 0.754 \\
\hline & & Plan 3 & 1.314 & 1.342 & 0.790 & 0.787 & 0.771 & 0.589 & 0.586 \\
\hline & & Plan 4 & 1.240 & 1.284 & 0.761 & 0.687 & 0.657 & 0.593 & 0.535 \\
\hline & & Plan 5 & 1.214 & 1.226 & 0.696 & 0.663 & 0.620 & 0.568 & 0.540 \\
\hline & & Plan 6 & 1.301 & 1.324 & 0.392 & 0.336 & 0.320 & 0.296 & 0.254 \\
\hline & & Plan 7 & 1.247 & 1.306 & 0.463 & 0.410 & 0.409 & 0.354 & 0.314 \\
\hline & & Plan 8 & 1.230 & 1.283 & 0.432 & 0.422 & 0.412 & 0.337 & 0.329 \\
\hline & \multirow[t]{9}{*}{2.5} & EC & 1.226 & 1.313 & 0.586 & 0.599 & 0.564 & 0.446 & 0.456 \\
\hline & & Plan 1 & 1.279 & 1.299 & 1.102 & 1.147 & 1.098 & 0.848 & 0.883 \\
\hline & & Plan 2 & 1.268 & 1.338 & 0.957 & 1.009 & 0.972 & 0.715 & 0.754 \\
\hline & & Plan 3 & 1.327 & 1.386 & 0.849 & 0.832 & 0.844 & 0.613 & 0.600 \\
\hline & & Plan 4 & 1.280 & 1.345 & 0.814 & 0.744 & 0.712 & 0.605 & 0.553 \\
\hline & & Plan 5 & 1.290 & 1.325 & 0.793 & 0.751 & 0.722 & 0.599 & 0.567 \\
\hline & & Plan 6 & 1.327 & 1.393 & 0.451 & 0.386 & 0.373 & 0.324 & 0.277 \\
\hline & & Plan 7 & 1.310 & 1.402 & 0.528 & 0.469 & 0.471 & 0.377 & 0.334 \\
\hline & & Plan 8 & 1.301 & 1.393 & 0.502 & 0.490 & 0.481 & 0.360 & 0.352 \\
\hline
\end{tabular}


Table E5. RMS $H_{s}$ across channel transect lines for waves from 45 degrees North; $+0.0 \mathrm{~m} \mathrm{swl}$.

\begin{tabular}{|c|c|c|c|c|c|c|c|c|c|}
\hline \multicolumn{2}{|c|}{$\begin{array}{l}\text { Experimental } \\
\text { Wave }\end{array}$} & \multirow[b]{2}{*}{ Plan } & \multicolumn{5}{|c|}{$H_{s}(\mathrm{~m})$ at Indicated Lines; $\mathrm{swl}=+0.9 \mathrm{~m}$} & \multirow[b]{2}{*}{$\begin{array}{l}H_{s, \text { Line2 }} / \\
H_{s, \text { Line1 }}\end{array}$} & \multirow[b]{2}{*}{$\begin{array}{l}H_{s, \text { Line3 }} / \\
H_{s, \text { Line1 }}\end{array}$} \\
\hline $\begin{array}{l}T_{p} \\
\text { (sec) }\end{array}$ & $\begin{array}{l}H_{s, i n c} \\
(\mathrm{~m})\end{array}$ & & Line 0 & Line 1 & Line 2 & Line 3 & Line 4 & & \\
\hline \multirow[t]{27}{*}{5} & \multirow[t]{9}{*}{1} & EC & 0.811 & 0.871 & 0.439 & 0.455 & 0.447 & 0.504 & 0.522 \\
\hline & & Plan 1 & 0.817 & 0.865 & 0.770 & 0.800 & 0.790 & 0.891 & 0.926 \\
\hline & & Plan 2 & 0.783 & 0.849 & 0.556 & 0.616 & 0.599 & 0.655 & 0.726 \\
\hline & & Plan 3 & 0.860 & 0.923 & 0.706 & 0.724 & 0.740 & 0.765 & 0.784 \\
\hline & & Plan 4 & 0.954 & 1.014 & 0.531 & 0.504 & 0.452 & 0.524 & 0.497 \\
\hline & & Plan 5 & 0.900 & 0.996 & 0.698 & 0.637 & 0.668 & 0.701 & 0.640 \\
\hline & & Plan 6 & 0.932 & 1.043 & 0.367 & 0.343 & 0.330 & 0.352 & 0.328 \\
\hline & & Plan 7 & 0.900 & 1.011 & 0.404 & 0.414 & 0.396 & 0.400 & 0.410 \\
\hline & & Plan 8 & 0.862 & 0.950 & 0.374 & 0.342 & 0.346 & 0.393 & 0.360 \\
\hline & \multirow[t]{9}{*}{2} & EC & 1.191 & 1.186 & 0.695 & 0.735 & 0.706 & 0.586 & 0.620 \\
\hline & & Plan 1 & 1.223 & 1.191 & 1.048 & 1.098 & 1.052 & 0.879 & 0.922 \\
\hline & & Plan 2 & 1.203 & 1.188 & 0.865 & 0.924 & 0.861 & 0.729 & 0.778 \\
\hline & & Plan 3 & 1.283 & 1.268 & 0.982 & 1.016 & 1.033 & 0.774 & 0.801 \\
\hline & & Plan 4 & 1.138 & 1.240 & 0.680 & 0.645 & 0.572 & 0.548 & 0.520 \\
\hline & & Plan 5 & 1.165 & 1.246 & 0.910 & 0.825 & 0.837 & 0.730 & 0.662 \\
\hline & & Plan 6 & 1.165 & 1.296 & 0.506 & 0.468 & 0.430 & 0.391 & 0.362 \\
\hline & & Plan 7 & 1.139 & 1.236 & 0.554 & 0.550 & 0.506 & 0.448 & 0.445 \\
\hline & & Plan 8 & 1.127 & 1.185 & 0.574 & 0.544 & 0.526 & 0.484 & 0.459 \\
\hline & \multirow[t]{9}{*}{2.5} & EC & 1.346 & 1.335 & 0.785 & 0.825 & 0.792 & 0.588 & 0.618 \\
\hline & & Plan 1 & 1.234 & 1.231 & 1.040 & 1.123 & 1.107 & 0.845 & 0.912 \\
\hline & & Plan 2 & 1.353 & 1.331 & 0.983 & 1.043 & 0.961 & 0.738 & 0.784 \\
\hline & & Plan 3 & 1.440 & 1.414 & 1.065 & 1.109 & 1.119 & 0.753 & 0.785 \\
\hline & & Plan 4 & 1.300 & 1.307 & 0.783 & 0.727 & 0.674 & 0.599 & 0.556 \\
\hline & & Plan 5 & 1.345 & 1.334 & 1.013 & 0.941 & 0.940 & 0.759 & 0.705 \\
\hline & & Plan 6 & 1.317 & 1.344 & 0.596 & 0.552 & 0.508 & 0.443 & 0.410 \\
\hline & & Plan 7 & 1.322 & 1.323 & 0.665 & 0.642 & 0.602 & 0.503 & 0.485 \\
\hline & & Plan 8 & 1.330 & 1.347 & 0.671 & 0.638 & 0.618 & 0.499 & 0.474 \\
\hline
\end{tabular}




\begin{tabular}{|c|c|c|c|c|c|c|c|c|c|}
\hline \multicolumn{2}{|c|}{$\begin{array}{l}\text { Experimental } \\
\text { Wave }\end{array}$} & \multirow[b]{2}{*}{ Plan } & \multicolumn{5}{|c|}{$H_{s}(\mathrm{~m})$ at Indicated Lines; $\mathrm{swl}=+0.9 \mathrm{~m}$} & \multirow[b]{2}{*}{$\begin{array}{l}H_{s, \text { Line2 }} / \\
H_{s, \text { Line1 }}\end{array}$} & \multirow[b]{2}{*}{$\begin{array}{l}H_{s, \text { Line } 3 /} \\
H_{s, \text { Line1 }}\end{array}$} \\
\hline $\begin{array}{l}T_{p} \\
\text { (sec) }\end{array}$ & $\begin{array}{l}H_{s, i n c} \\
(\mathrm{~m})\end{array}$ & & Line 0 & Line 1 & Line 2 & Line 3 & Line 4 & & \\
\hline \multirow[t]{27}{*}{6} & \multirow[t]{9}{*}{1} & EC & 0.921 & 0.983 & 0.471 & 0.475 & 0.469 & 0.479 & 0.483 \\
\hline & & Plan 1 & 0.960 & 1.011 & 0.903 & 0.932 & 0.888 & 0.893 & 0.921 \\
\hline & & Plan 2 & 0.876 & 0.930 & 0.564 & 0.614 & 0.579 & 0.606 & 0.660 \\
\hline & & Plan 3 & 0.984 & 1.053 & 0.823 & 0.826 & 0.812 & 0.781 & 0.785 \\
\hline & & Plan 4 & 1.092 & 1.158 & 0.535 & 0.485 & 0.443 & 0.461 & 0.419 \\
\hline & & Plan 5 & 1.040 & 1.130 & 0.822 & 0.790 & 0.776 & 0.728 & 0.699 \\
\hline & & Plan 6 & 1.040 & 1.129 & 0.368 & 0.331 & 0.303 & 0.326 & 0.293 \\
\hline & & Plan 7 & 1.050 & 1.142 & 0.419 & 0.404 & 0.386 & 0.367 & 0.354 \\
\hline & & Plan 8 & 0.990 & 1.068 & 0.373 & 0.353 & 0.346 & 0.350 & 0.330 \\
\hline & \multirow[t]{9}{*}{2} & EC & 1.147 & 1.182 & 0.613 & 0.627 & 0.616 & 0.519 & 0.530 \\
\hline & & Plan 1 & 1.130 & 1.238 & 1.057 & 1.098 & 1.044 & 0.854 & 0.887 \\
\hline & & Plan 2 & 1.133 & 1.169 & 0.766 & 0.805 & 0.756 & 0.655 & 0.689 \\
\hline & & Plan 3 & 1.245 & 1.328 & 0.981 & 1.000 & 0.999 & 0.738 & 0.753 \\
\hline & & Plan 4 & 1.217 & 1.267 & 0.634 & 0.585 & 0.556 & 0.500 & 0.462 \\
\hline & & Plan 5 & 1.257 & 1.365 & 0.931 & 0.884 & 0.872 & 0.682 & 0.647 \\
\hline & & Plan 6 & 1.330 & 1.468 & 0.473 & 0.422 & 0.398 & 0.322 & 0.288 \\
\hline & & Plan 7 & 1.291 & 1.413 & 0.522 & 0.496 & 0.473 & 0.369 & 0.351 \\
\hline & & Plan 8 & 1.290 & 1.373 & 0.517 & 0.499 & 0.476 & 0.377 & 0.363 \\
\hline & \multirow[t]{9}{*}{2.5} & EC & 1.318 & 1.312 & 0.749 & 0.774 & 0.744 & 0.571 & 0.590 \\
\hline & & Plan 1 & 1.301 & 1.323 & 1.137 & 1.212 & 1.112 & 0.860 & 0.916 \\
\hline & & Plan 2 & 1.313 & 1.316 & 0.910 & 0.965 & 0.900 & 0.692 & 0.733 \\
\hline & & Plan 3 & 1.456 & 1.466 & 1.086 & 1.117 & 1.106 & 0.741 & 0.762 \\
\hline & & Plan 4 & 1.298 & 1.343 & 0.730 & 0.672 & 0.636 & 0.544 & 0.500 \\
\hline & & Plan 5 & 1.332 & 1.362 & 0.996 & 0.950 & 0.935 & 0.731 & 0.697 \\
\hline & & Plan 6 & 1.316 & 1.380 & 0.520 & 0.471 & 0.443 & 0.377 & 0.341 \\
\hline & & Plan 7 & 1.292 & 1.320 & 0.590 & 0.557 & 0.528 & 0.447 & 0.422 \\
\hline & & Plan 8 & 1.345 & 1.389 & 0.588 & 0.569 & 0.538 & 0.423 & 0.410 \\
\hline
\end{tabular}




\begin{tabular}{|c|c|c|c|c|c|c|c|c|c|}
\hline \multicolumn{2}{|c|}{$\begin{array}{l}\text { Experimental } \\
\text { Wave }\end{array}$} & \multirow[b]{2}{*}{ Plan } & \multicolumn{5}{|c|}{$H_{s}(\mathrm{~m})$ at Indicated Lines; $\mathrm{swl}=+0.9 \mathrm{~m}$} & \multirow[b]{2}{*}{$\begin{array}{l}H_{s, \text { Line2/ }} \\
H_{s, \text { Line1 }}\end{array}$} & \multirow[b]{2}{*}{$\begin{array}{l}H_{s, \text { Line3 }} / \\
H_{s, \text { Line1 }}\end{array}$} \\
\hline $\begin{array}{l}T_{p} \\
\text { (sec) }\end{array}$ & $\begin{array}{l}H_{s, i n c} \\
(\mathrm{~m})\end{array}$ & & Line 0 & Line 1 & Line 2 & Line 3 & Line 4 & & \\
\hline \multirow[t]{27}{*}{7} & \multirow[t]{9}{*}{1} & EC & 0.989 & 1.044 & 0.500 & 0.500 & 0.475 & 0.479 & 0.479 \\
\hline & & Plan 1 & 0.988 & 1.047 & 0.931 & 0.967 & 0.908 & 0.890 & 0.924 \\
\hline & & Plan 2 & 0.955 & 1.006 & 0.628 & 0.669 & 0.607 & 0.625 & 0.666 \\
\hline & & Plan 3 & 1.069 & 1.148 & 0.889 & 0.859 & 0.859 & 0.774 & 0.749 \\
\hline & & Plan 4 & 1.164 & 1.225 & 0.590 & 0.543 & 0.499 & 0.482 & 0.443 \\
\hline & & Plan 5 & 1.146 & 1.233 & 0.862 & 0.822 & 0.786 & 0.699 & 0.667 \\
\hline & & Plan 6 & 1.165 & 1.238 & 0.387 & 0.334 & 0.300 & 0.313 & 0.270 \\
\hline & & Plan 7 & 1.133 & 1.208 & 0.430 & 0.403 & 0.384 & 0.356 & 0.333 \\
\hline & & Plan 8 & 1.103 & 1.163 & 0.415 & 0.390 & 0.378 & 0.357 & 0.335 \\
\hline & \multirow[t]{9}{*}{2} & EC & 1.131 & 1.242 & 0.592 & 0.601 & 0.583 & 0.476 & 0.484 \\
\hline & & Plan 1 & 1.130 & 1.238 & 1.057 & 1.098 & 1.044 & 0.854 & 0.887 \\
\hline & & Plan 2 & 1.135 & 1.256 & 0.795 & 0.834 & 0.779 & 0.633 & 0.664 \\
\hline & & Plan 3 & 1.275 & 1.395 & 0.996 & 1.008 & 1.006 & 0.714 & 0.722 \\
\hline & & Plan 4 & 1.342 & 1.468 & 0.710 & 0.649 & 0.621 & 0.483 & 0.442 \\
\hline & & Plan 5 & 1.347 & 1.507 & 0.978 & 0.932 & 0.907 & 0.649 & 0.619 \\
\hline & & Plan 6 & 1.463 & 1.624 & 0.506 & 0.451 & 0.406 & 0.312 & 0.278 \\
\hline & & Plan 7 & 1.358 & 1.519 & 0.543 & 0.512 & 0.482 & 0.358 & 0.337 \\
\hline & & Plan 8 & 1.376 & 1.525 & 0.534 & 0.511 & 0.483 & 0.350 & 0.335 \\
\hline & \multirow[t]{9}{*}{2.5} & EC & 1.330 & 1.358 & 0.714 & 0.730 & 0.695 & 0.526 & 0.537 \\
\hline & & Plan 1 & 1.297 & 1.323 & 1.151 & 1.231 & 1.131 & 0.870 & 0.930 \\
\hline & & Plan 2 & 1.341 & 1.359 & 0.957 & 1.014 & 0.944 & 0.704 & 0.746 \\
\hline & & Plan 3 & 1.441 & 1.480 & 1.080 & 1.090 & 1.073 & 0.730 & 0.737 \\
\hline & & Plan 4 & 1.415 & 1.477 & 0.828 & 0.772 & 0.735 & 0.561 & 0.523 \\
\hline & & Plan 5 & 1.415 & 1.494 & 1.028 & 0.980 & 0.940 & 0.688 & 0.656 \\
\hline & & Plan 6 & 1.432 & 1.503 & 0.550 & 0.485 & 0.448 & 0.366 & 0.323 \\
\hline & & Plan 7 & 1.404 & 1.472 & 0.618 & 0.586 & 0.551 & 0.420 & 0.398 \\
\hline & & Plan 8 & 1.423 & 1.492 & 0.608 & 0.579 & 0.545 & 0.408 & 0.388 \\
\hline
\end{tabular}




\begin{tabular}{|c|c|c|c|c|c|c|c|c|c|}
\hline \multicolumn{2}{|c|}{$\begin{array}{l}\text { Experimental } \\
\text { Wave }\end{array}$} & \multirow[b]{2}{*}{ Plan } & \multicolumn{5}{|c|}{$H_{s}(\mathrm{~m})$ at Indicated Lines; $\mathrm{swl}=+0.9 \mathrm{~m}$} & \multirow[b]{2}{*}{$\begin{array}{l}H_{s, \text { Line2/ }} \\
H_{s, \text { Line1 }}\end{array}$} & \multirow[b]{2}{*}{$\begin{array}{l}H_{s, \text { Line3 }} / \\
H_{s, \text { Line1 }}\end{array}$} \\
\hline $\begin{array}{l}T_{p} \\
\text { (sec) }\end{array}$ & $\begin{array}{l}H_{s, i n c} \\
(\mathrm{~m})\end{array}$ & & Line 0 & Line 1 & Line 2 & Line 3 & Line 4 & & \\
\hline \multirow[t]{27}{*}{8} & \multirow[t]{9}{*}{1} & $\mathrm{EC}$ & 0.933 & 1.045 & 0.445 & 0.439 & 0.429 & 0.425 & 0.420 \\
\hline & & Plan 1 & 0.922 & 1.018 & 0.901 & 0.939 & 0.894 & 0.885 & 0.922 \\
\hline & & Plan 2 & 0.906 & 0.997 & 0.634 & 0.665 & 0.617 & 0.636 & 0.667 \\
\hline & & Plan 3 & 0.995 & 1.131 & 0.828 & 0.803 & 0.807 & 0.732 & 0.711 \\
\hline & & Plan 4 & 1.069 & 1.175 & 0.621 & 0.579 & 0.544 & 0.528 & 0.493 \\
\hline & & Plan 5 & 1.092 & 1.223 & 0.798 & 0.751 & 0.734 & 0.653 & 0.614 \\
\hline & & Plan 6 & 1.076 & 1.211 & 0.357 & 0.300 & 0.275 & 0.295 & 0.248 \\
\hline & & Plan 7 & 1.054 & 1.179 & 0.397 & 0.371 & 0.363 & 0.337 & 0.315 \\
\hline & & Plan 8 & 1.022 & 1.141 & 0.372 & 0.350 & 0.338 & 0.326 & 0.306 \\
\hline & \multirow[t]{9}{*}{2} & EC & 1.208 & 1.378 & 0.623 & 0.634 & 0.612 & 0.452 & 0.460 \\
\hline & & Plan 1 & 1.155 & 1.302 & 1.132 & 1.195 & 1.123 & 0.869 & 0.917 \\
\hline & & Plan 2 & 1.185 & 1.330 & 0.890 & 0.934 & 0.867 & 0.669 & 0.702 \\
\hline & & Plan 3 & 1.322 & 1.529 & 1.023 & 1.024 & 1.012 & 0.669 & 0.670 \\
\hline & & Plan 4 & 1.391 & 1.550 & 0.867 & 0.818 & 0.775 & 0.559 & 0.528 \\
\hline & & Plan 5 & 1.378 & 1.582 & 0.993 & 0.928 & 0.883 & 0.628 & 0.586 \\
\hline & & Plan 6 & 1.413 & 1.636 & 0.512 & 0.440 & 0.409 & 0.313 & 0.269 \\
\hline & & Plan 7 & 1.377 & 1.588 & 0.585 & 0.550 & 0.527 & 0.368 & 0.346 \\
\hline & & Plan 8 & 1.407 & 1.609 & 0.578 & 0.550 & 0.513 & 0.359 & 0.342 \\
\hline & \multirow[t]{9}{*}{2.5} & EC & 1.282 & 1.389 & 0.686 & 0.703 & 0.662 & 0.494 & 0.506 \\
\hline & & Plan 1 & 1.229 & 1.302 & 1.153 & 1.224 & 1.149 & 0.886 & 0.941 \\
\hline & & Plan 2 & 1.287 & 1.386 & 0.982 & 1.032 & 0.967 & 0.709 & 0.745 \\
\hline & & Plan 3 & 1.364 & 1.494 & 1.070 & 1.072 & 1.050 & 0.716 & 0.718 \\
\hline & & Plan 4 & 1.453 & 1.587 & 0.934 & 0.891 & 0.843 & 0.588 & 0.561 \\
\hline & & Plan 5 & 1.449 & 1.605 & 1.014 & 0.947 & 0.904 & 0.632 & 0.590 \\
\hline & & Plan 6 & 1.473 & 1.650 & 0.565 & 0.493 & 0.451 & 0.342 & 0.299 \\
\hline & & Plan 7 & 1.413 & 1.585 & 0.640 & 0.610 & 0.575 & 0.404 & 0.385 \\
\hline & & Plan 8 & 1.456 & 1.623 & 0.624 & 0.595 & 0.556 & 0.384 & 0.367 \\
\hline
\end{tabular}


Table E6. RMS $H_{s}$ across channel transect lines for waves from 0 degrees; $+0.0 \mathrm{~m} \mathrm{swl}$.

\begin{tabular}{|c|c|c|c|c|c|c|c|c|c|}
\hline \multicolumn{2}{|c|}{$\begin{array}{l}\text { Experimental } \\
\text { Wave }\end{array}$} & \multirow[b]{2}{*}{ Plan } & \multicolumn{5}{|c|}{$H_{s}(\mathrm{~m})$ at Indicated Lines; swl $=+0.9 \mathrm{~m}$} & \multirow[b]{2}{*}{$\begin{array}{l}H_{s, \text { Line } 2 /} \\
H_{s, \text { Line1 }}\end{array}$} & \multirow[b]{2}{*}{$\begin{array}{l}H_{s, \text { Line }} / \\
H_{s, \text { Line1 }}\end{array}$} \\
\hline $\begin{array}{l}T_{p} \\
\text { (sec) }\end{array}$ & $\begin{array}{l}H_{s, i n c} \\
(\mathrm{~m})\end{array}$ & & Line 0 & Line 1 & Line 2 & Line 3 & Line 4 & & \\
\hline \multirow[t]{27}{*}{5} & \multirow[t]{9}{*}{1} & EC & 0.858 & 0.805 & 0.531 & 0.572 & 0.558 & 0.660 & 0.710 \\
\hline & & Plan 1 & 0.842 & 0.786 & 0.676 & 0.734 & 0.686 & 0.859 & 0.933 \\
\hline & & Plan 2 & 0.838 & 0.790 & 0.615 & 0.651 & 0.614 & 0.778 & 0.824 \\
\hline & & Plan 3 & 0.819 & 0.754 & 0.559 & 0.558 & 0.567 & 0.741 & 0.740 \\
\hline & & Plan 4 & 0.861 & 0.810 & 0.596 & 0.552 & 0.549 & 0.736 & 0.681 \\
\hline & & Plan 5 & 0.697 & 0.700 & 0.460 & 0.479 & 0.448 & 0.658 & 0.684 \\
\hline & & Plan 6 & 0.859 & 0.813 & 0.450 & 0.435 & 0.394 & 0.553 & 0.535 \\
\hline & & Plan 7 & 0.855 & 0.804 & 0.495 & 0.452 & 0.450 & 0.616 & 0.562 \\
\hline & & Plan 8 & 0.900 & 0.856 & 0.508 & 0.531 & 0.478 & 0.593 & 0.621 \\
\hline & \multirow[t]{9}{*}{2} & EC & 1.469 & 1.371 & 0.872 & 0.905 & 0.879 & 0.636 & 0.660 \\
\hline & & Plan 1 & 1.376 & 1.312 & 1.127 & 1.245 & 1.118 & 0.859 & 0.949 \\
\hline & & Plan 2 & 1.423 & 1.353 & 1.044 & 1.140 & 1.043 & 0.772 & 0.843 \\
\hline & & Plan 3 & 1.452 & 1.352 & 0.970 & 0.972 & 0.960 & 0.717 & 0.719 \\
\hline & & Plan 4 & 1.391 & 1.315 & 0.966 & 0.906 & 0.866 & 0.735 & 0.689 \\
\hline & & Plan 5 & 1.327 & 1.258 & 0.850 & 0.832 & 0.800 & 0.675 & 0.661 \\
\hline & & Plan 6 & 1.381 & 1.284 & 0.659 & 0.637 & 0.549 & 0.513 & 0.496 \\
\hline & & Plan 7 & 1.383 & 1.280 & 0.750 & 0.675 & 0.656 & 0.586 & 0.527 \\
\hline & & Plan 8 & 1.418 & 1.318 & 0.743 & 0.733 & 0.665 & 0.564 & 0.556 \\
\hline & \multirow[t]{9}{*}{2.5} & EC & 1.616 & 1.482 & 0.917 & 0.948 & 0.924 & 0.619 & 0.640 \\
\hline & & Plan 1 & 1.537 & 1.432 & 1.256 & 1.348 & 1.232 & 0.877 & 0.941 \\
\hline & & Plan 2 & 1.581 & 1.470 & 1.145 & 1.259 & 1.155 & 0.779 & 0.856 \\
\hline & & Plan 3 & 1.657 & 1.524 & 1.057 & 1.050 & 1.038 & 0.694 & 0.689 \\
\hline & & Plan 4 & 1.591 & 1.482 & 1.062 & 1.021 & 0.954 & 0.717 & 0.689 \\
\hline & & Plan 5 & 1.563 & 1.469 & 0.889 & 0.884 & 0.818 & 0.606 & 0.602 \\
\hline & & Plan 6 & 1.550 & 1.443 & 0.723 & 0.690 & 0.592 & 0.501 & 0.478 \\
\hline & & Plan 7 & 1.566 & 1.436 & 0.821 & 0.743 & 0.715 & 0.572 & 0.517 \\
\hline & & Plan 8 & 1.599 & 1.468 & 0.796 & 0.778 & 0.691 & 0.543 & 0.530 \\
\hline & & & & & & & & & leet 1 of \\
\hline
\end{tabular}




\begin{tabular}{|c|c|c|c|c|c|c|c|c|c|}
\hline \multicolumn{2}{|c|}{$\begin{array}{l}\text { Experimental } \\
\text { Wave }\end{array}$} & \multirow[b]{2}{*}{ Plan } & \multicolumn{5}{|c|}{$H_{s}(\mathrm{~m})$ at Indicated Lines; $\mathrm{swl}=+0.9 \mathrm{~m}$} & \multirow[b]{2}{*}{$\begin{array}{l}H_{s, \text { Line2 }} / \\
H_{s, \text { Line1 }}\end{array}$} & \multirow[b]{2}{*}{$\begin{array}{l}H_{s, \text { Line } 3 /} \\
H_{s, \text { Line1 }}\end{array}$} \\
\hline $\begin{array}{l}T_{p} \\
\text { (sec) }\end{array}$ & $\begin{array}{l}H_{s, i n c} \\
(\mathrm{~m})\end{array}$ & & Line 0 & Line 1 & Line 2 & Line 3 & Line 4 & & \\
\hline \multirow[t]{27}{*}{6} & \multirow[t]{9}{*}{1} & EC & 0.846 & 0.806 & 0.495 & 0.514 & 0.510 & 0.613 & 0.637 \\
\hline & & Plan 1 & 0.879 & 0.860 & 0.752 & 0.795 & 0.760 & 0.874 & 0.925 \\
\hline & & Plan 2 & 0.881 & 0.860 & 0.662 & 0.706 & 0.682 & 0.770 & 0.822 \\
\hline & & Plan 3 & 0.885 & 0.851 & 0.604 & 0.592 & 0.608 & 0.710 & 0.695 \\
\hline & & Plan 4 & 0.830 & 0.809 & 0.565 & 0.518 & 0.508 & 0.699 & 0.641 \\
\hline & & Plan 5 & 0.859 & 0.856 & 0.583 & 0.569 & 0.557 & 0.681 & 0.665 \\
\hline & & Plan 6 & 0.854 & 0.823 & 0.386 & 0.362 & 0.326 & 0.468 & 0.440 \\
\hline & & Plan 7 & 0.886 & 0.850 & 0.459 & 0.416 & 0.410 & 0.540 & 0.489 \\
\hline & & Plan 8 & 0.861 & 0.838 & 0.429 & 0.418 & 0.392 & 0.512 & 0.499 \\
\hline & \multirow[t]{9}{*}{2} & EC & 1.230 & 1.279 & 0.749 & 0.776 & 0.746 & 0.586 & 0.607 \\
\hline & & Plan 1 & 1.161 & 1.207 & 1.050 & 1.091 & 1.045 & 0.870 & 0.904 \\
\hline & & Plan 2 & 1.234 & 1.272 & 0.965 & 1.038 & 0.968 & 0.759 & 0.816 \\
\hline & & Plan 3 & 1.184 & 1.222 & 0.903 & 0.878 & 0.878 & 0.739 & 0.719 \\
\hline & & Plan 4 & 1.238 & 1.267 & 0.851 & 0.798 & 0.747 & 0.671 & 0.630 \\
\hline & & Plan 5 & 1.229 & 1.246 & 0.877 & 0.838 & 0.814 & 0.704 & 0.673 \\
\hline & & Plan 6 & 1.238 & 1.257 & 0.575 & 0.536 & 0.473 & 0.457 & 0.427 \\
\hline & & Plan 7 & 1.215 & 1.229 & 0.635 & 0.595 & 0.559 & 0.517 & 0.484 \\
\hline & & Plan 8 & 1.321 & 1.340 & 0.691 & 0.652 & 0.614 & 0.515 & 0.487 \\
\hline & \multirow[t]{9}{*}{2.5} & EC & 1.491 & 1.508 & 0.872 & 0.904 & 0.858 & 0.578 & 0.599 \\
\hline & & Plan 1 & 1.335 & 1.373 & 1.189 & 1.251 & 1.170 & 0.866 & 0.911 \\
\hline & & Plan 2 & 1.362 & 1.415 & 1.089 & 1.166 & 1.067 & 0.770 & 0.824 \\
\hline & & Plan 3 & 1.417 & 1.445 & 1.015 & 1.005 & 0.989 & 0.702 & 0.695 \\
\hline & & Plan 4 & 1.317 & 1.347 & 0.890 & 0.828 & 0.776 & 0.661 & 0.615 \\
\hline & & Plan 5 & 1.288 & 1.297 & 0.849 & 0.817 & 0.788 & 0.655 & 0.630 \\
\hline & & Plan 6 & 1.274 & 1.278 & 0.580 & 0.542 & 0.482 & 0.454 & 0.424 \\
\hline & & Plan 7 & 1.312 & 1.305 & 0.673 & 0.624 & 0.583 & 0.515 & 0.478 \\
\hline & & Plan 8 & 1.392 & 1.374 & 0.703 & 0.665 & 0.618 & 0.512 & 0.484 \\
\hline
\end{tabular}




\begin{tabular}{|c|c|c|c|c|c|c|c|c|c|}
\hline \multicolumn{2}{|c|}{$\begin{array}{l}\text { Experimental } \\
\text { Wave }\end{array}$} & \multirow[b]{2}{*}{ Plan } & \multicolumn{5}{|c|}{$H_{s}(\mathrm{~m})$ at Indicated Lines; $\mathrm{swl}=+0.9 \mathrm{~m}$} & \multirow[b]{2}{*}{$\begin{array}{l}H_{s, \text { Line2/ }} \\
H_{s, \text { Line1 }}\end{array}$} & \multirow[b]{2}{*}{$\begin{array}{l}H_{s, \text { Line3 }} / \\
H_{s, \text { Line1 }}\end{array}$} \\
\hline $\begin{array}{l}T_{p} \\
\text { (sec) }\end{array}$ & $\begin{array}{l}H_{s, i n c} \\
(\mathrm{~m})\end{array}$ & & Line 0 & Line 1 & Line 2 & Line 3 & Line 4 & & \\
\hline \multirow[t]{27}{*}{7} & \multirow[t]{9}{*}{1} & EC & 0.900 & 0.893 & 0.541 & 0.566 & 0.540 & 0.606 & 0.633 \\
\hline & & Plan 1 & 0.873 & 0.883 & 0.765 & 0.806 & 0.757 & 0.867 & 0.913 \\
\hline & & Plan 2 & 0.900 & 0.913 & 0.699 & 0.746 & 0.707 & 0.766 & 0.817 \\
\hline & & Plan 3 & 0.865 & 0.856 & 0.621 & 0.602 & 0.600 & 0.726 & 0.703 \\
\hline & & Plan 4 & 0.854 & 0.872 & 0.591 & 0.546 & 0.526 & 0.677 & 0.626 \\
\hline & & Plan 5 & 0.858 & 0.870 & 0.591 & 0.580 & 0.553 & 0.680 & 0.666 \\
\hline & & Plan 6 & 0.852 & 0.854 & 0.383 & 0.348 & 0.306 & 0.449 & 0.407 \\
\hline & & Plan 7 & 0.851 & 0.849 & 0.440 & 0.405 & 0.390 & 0.518 & 0.476 \\
\hline & & Plan 8 & 0.868 & 0.865 & 0.425 & 0.407 & 0.377 & 0.491 & 0.470 \\
\hline & \multirow[t]{9}{*}{2} & EC & 1.293 & 1.358 & 0.762 & 0.774 & 0.751 & 0.561 & 0.570 \\
\hline & & Plan 1 & 1.237 & 1.284 & 1.108 & 1.139 & 1.080 & 0.863 & 0.887 \\
\hline & & Plan 2 & 1.241 & 1.324 & 0.978 & 1.028 & 0.951 & 0.739 & 0.777 \\
\hline & & Plan 3 & 1.254 & 1.319 & 0.999 & 0.967 & 0.972 & 0.758 & 0.733 \\
\hline & & Plan 4 & 1.326 & 1.384 & 0.894 & 0.828 & 0.770 & 0.646 & 0.598 \\
\hline & & Plan 5 & 1.265 & 1.306 & 0.939 & 0.891 & 0.872 & 0.719 & 0.682 \\
\hline & & Plan 6 & 1.324 & 1.363 & 0.605 & 0.552 & 0.486 & 0.444 & 0.405 \\
\hline & & Plan 7 & 1.281 & 1.333 & 0.659 & 0.615 & 0.574 & 0.494 & 0.462 \\
\hline & & Plan 8 & 1.329 & 1.383 & 0.687 & 0.637 & 0.596 & 0.496 & 0.461 \\
\hline & \multirow[t]{9}{*}{2.5} & EC & 1.545 & 1.620 & 0.921 & 0.946 & 0.893 & 0.568 & 0.584 \\
\hline & & Plan 1 & 1.424 & 1.487 & 1.296 & 1.321 & 1.260 & 0.872 & 0.889 \\
\hline & & Plan 2 & 1.513 & 1.582 & 1.202 & 1.263 & 1.174 & 0.760 & 0.798 \\
\hline & & Plan 3 & 1.594 & 1.627 & 1.225 & 1.204 & 1.201 & 0.753 & 0.740 \\
\hline & & Plan 4 & 1.547 & 1.610 & 1.039 & 0.967 & 0.902 & 0.645 & 0.600 \\
\hline & & Plan 5 & 1.461 & 1.499 & 1.043 & 1.001 & 0.980 & 0.696 & 0.668 \\
\hline & & Plan 6 & 1.487 & 1.529 & 0.689 & 0.626 & 0.560 & 0.451 & 0.410 \\
\hline & & Plan 7 & 1.472 & 1.521 & 0.767 & 0.715 & 0.666 & 0.504 & 0.470 \\
\hline & & Plan 8 & 1.514 & 1.563 & 0.797 & 0.735 & 0.692 & 0.510 & 0.470 \\
\hline
\end{tabular}




\begin{tabular}{|c|c|c|c|c|c|c|c|c|c|}
\hline \multicolumn{2}{|c|}{$\begin{array}{l}\text { Experimental } \\
\text { Wave }\end{array}$} & \multirow[b]{2}{*}{ Plan } & \multicolumn{5}{|c|}{$H_{s}(\mathrm{~m})$ at Indicated Lines; $\mathrm{swl}=+0.9 \mathrm{~m}$} & \multirow[b]{2}{*}{$\begin{array}{l}H_{s, \text { Line2 }} / \\
H_{s, \text { Line1 }}\end{array}$} & \multirow[b]{2}{*}{$\begin{array}{l}H_{s, \text { Line } 3 /} \\
H_{s, \text { Line1 }}\end{array}$} \\
\hline $\begin{array}{l}T_{p} \\
\text { (sec) }\end{array}$ & $\begin{array}{l}H_{s, i n c} \\
(\mathrm{~m})\end{array}$ & & Line 0 & Line 1 & Line 2 & Line 3 & Line 4 & & \\
\hline \multirow[t]{27}{*}{8} & \multirow[t]{9}{*}{1} & EC & 0.824 & 0.849 & 0.465 & 0.482 & 0.467 & 0.548 & 0.567 \\
\hline & & Plan 1 & 0.800 & 0.844 & 0.747 & 0.764 & 0.736 & 0.885 & 0.906 \\
\hline & & Plan 2 & 0.900 & 0.913 & 0.699 & 0.746 & 0.707 & 0.766 & 0.817 \\
\hline & & Plan 3 & 0.811 & 0.835 & 0.632 & 0.600 & 0.613 & 0.756 & 0.718 \\
\hline & & Plan 4 & 0.827 & 0.869 & 0.576 & 0.523 & 0.505 & 0.662 & 0.602 \\
\hline & & Plan 5 & 0.795 & 0.813 & 0.585 & 0.563 & 0.539 & 0.720 & 0.692 \\
\hline & & Plan 6 & 0.810 & 0.832 & 0.355 & 0.318 & 0.282 & 0.427 & 0.382 \\
\hline & & Plan 7 & 0.833 & 0.850 & 0.422 & 0.391 & 0.375 & 0.496 & 0.460 \\
\hline & & Plan 8 & 0.815 & 0.832 & 0.394 & 0.386 & 0.353 & 0.474 & 0.465 \\
\hline & \multirow[t]{9}{*}{2} & EC & 1.448 & 1.546 & 0.843 & 0.868 & 0.842 & 0.545 & 0.561 \\
\hline & & Plan 1 & 1.398 & 1.480 & 1.286 & 1.328 & 1.259 & 0.869 & 0.897 \\
\hline & & Plan 2 & 1.389 & 1.514 & 1.154 & 1.216 & 1.132 & 0.762 & 0.803 \\
\hline & & Plan 3 & 1.388 & 1.483 & 1.152 & 1.130 & 1.130 & 0.777 & 0.762 \\
\hline & & Plan 4 & 1.427 & 1.539 & 0.962 & 0.880 & 0.810 & 0.625 & 0.572 \\
\hline & & Plan 5 & 1.451 & 1.515 & 1.096 & 1.042 & 1.014 & 0.724 & 0.688 \\
\hline & & Plan 6 & 1.397 & 1.475 & 0.633 & 0.563 & 0.501 & 0.429 & 0.381 \\
\hline & & Plan 7 & 1.392 & 1.477 & 0.710 & 0.663 & 0.611 & 0.481 & 0.449 \\
\hline & & Plan 8 & 1.387 & 1.474 & 0.711 & 0.651 & 0.615 & 0.482 & 0.442 \\
\hline & \multirow[t]{9}{*}{2.5} & EC & 1.574 & 1.673 & 0.942 & 0.956 & 0.949 & 0.563 & 0.572 \\
\hline & & Plan 1 & 1.494 & 1.572 & 1.384 & 1.422 & 1.337 & 0.880 & 0.904 \\
\hline & & Plan 2 & 1.528 & 1.635 & 1.260 & 1.331 & 1.236 & 0.771 & 0.814 \\
\hline & & Plan 3 & 1.592 & 1.684 & 1.291 & 1.280 & 1.264 & 0.767 & 0.760 \\
\hline & & Plan 4 & 1.538 & 1.645 & 1.031 & 0.957 & 0.904 & 0.626 & 0.582 \\
\hline & & Plan 5 & 1.526 & 1.593 & 1.150 & 1.091 & 1.069 & 0.722 & 0.685 \\
\hline & & Plan 6 & 1.533 & 1.619 & 0.710 & 0.645 & 0.583 & 0.439 & 0.398 \\
\hline & & Plan 7 & 1.501 & 1.589 & 0.780 & 0.735 & 0.697 & 0.491 & 0.463 \\
\hline & & Plan 8 & 1.547 & 1.630 & 0.819 & 0.753 & 0.722 & 0.503 & 0.462 \\
\hline
\end{tabular}




\section{Appendix F: Numerical Model Configurations}

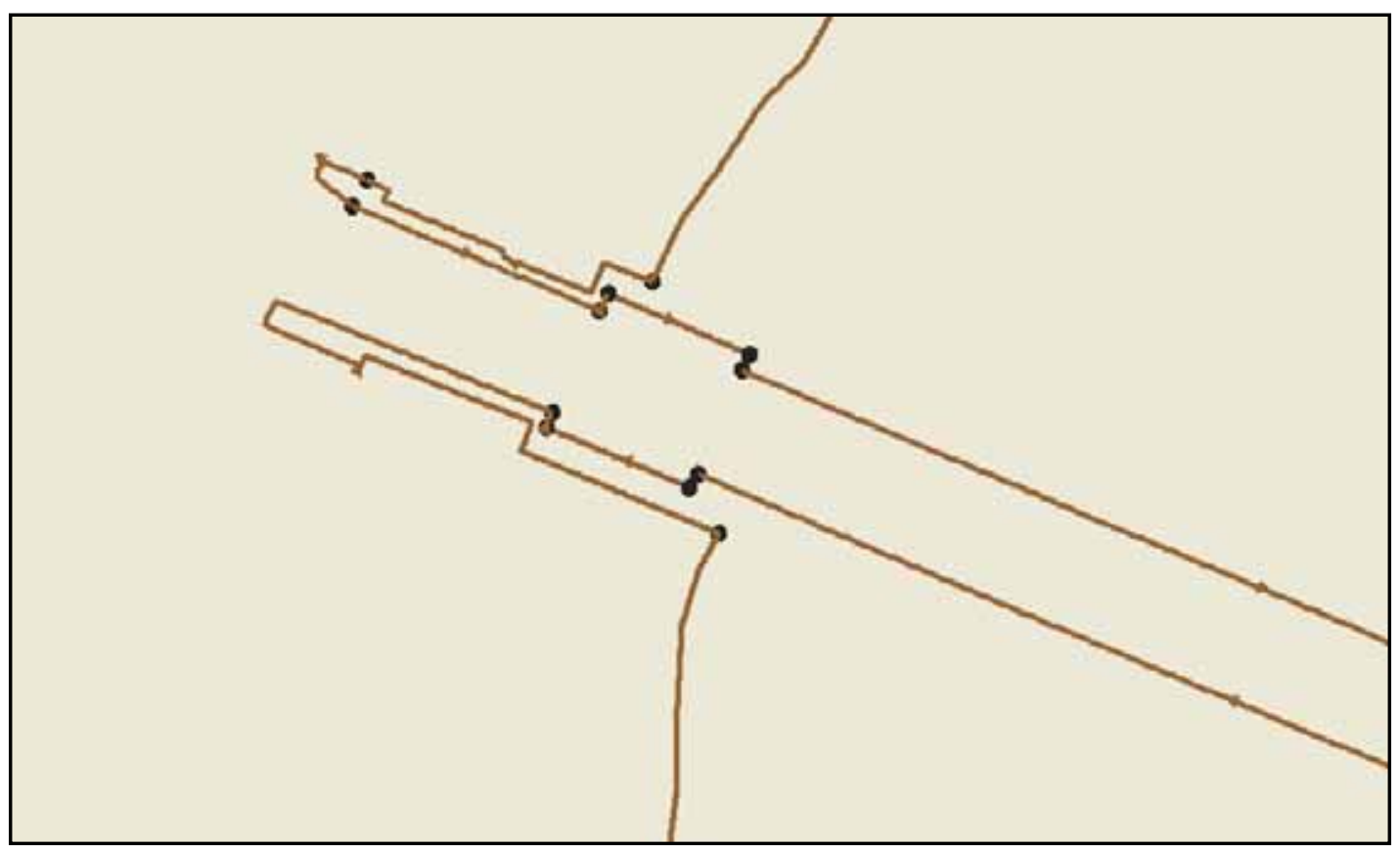

Figure F1. Existing A.

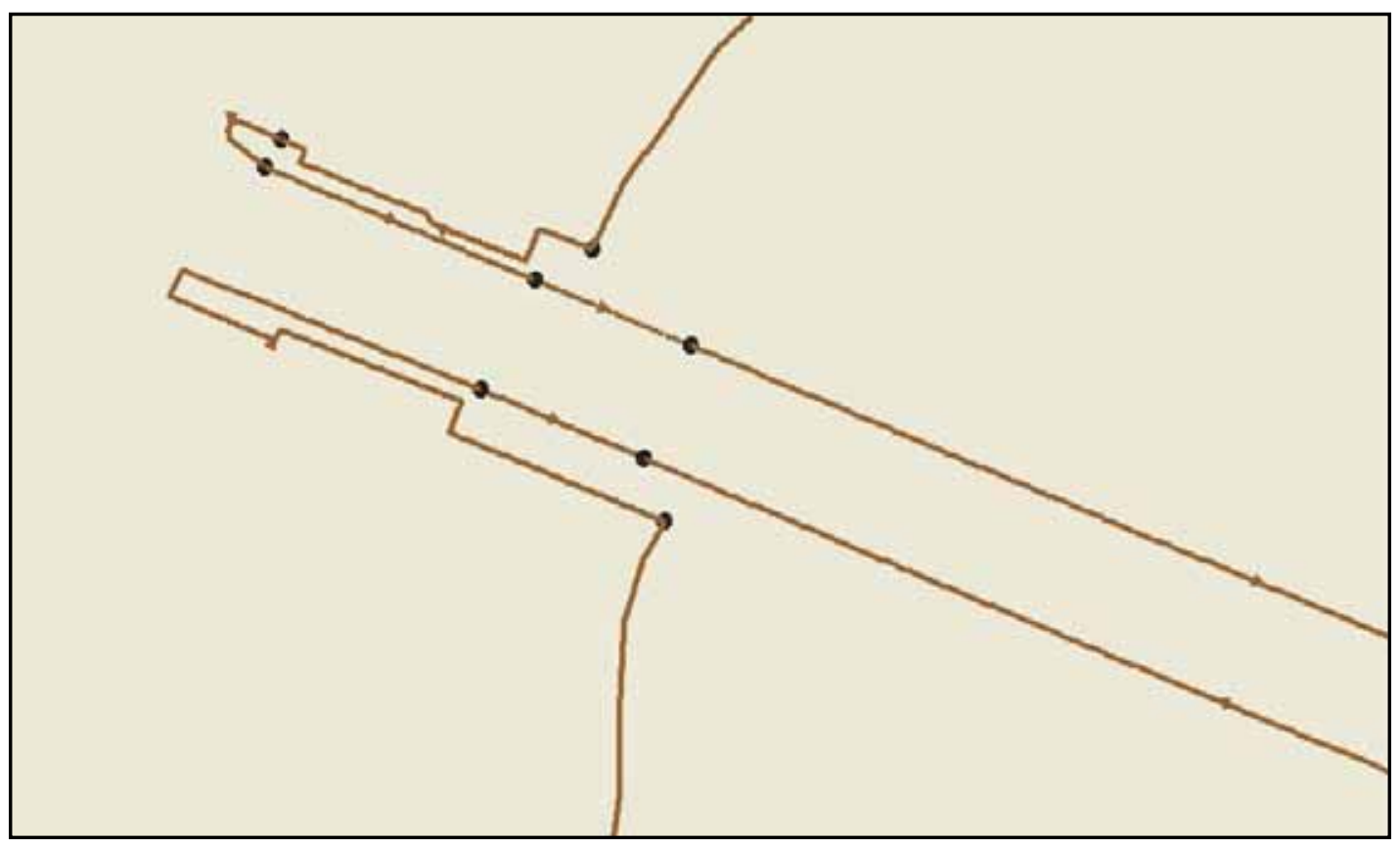

Figure F2. Plan 1. 


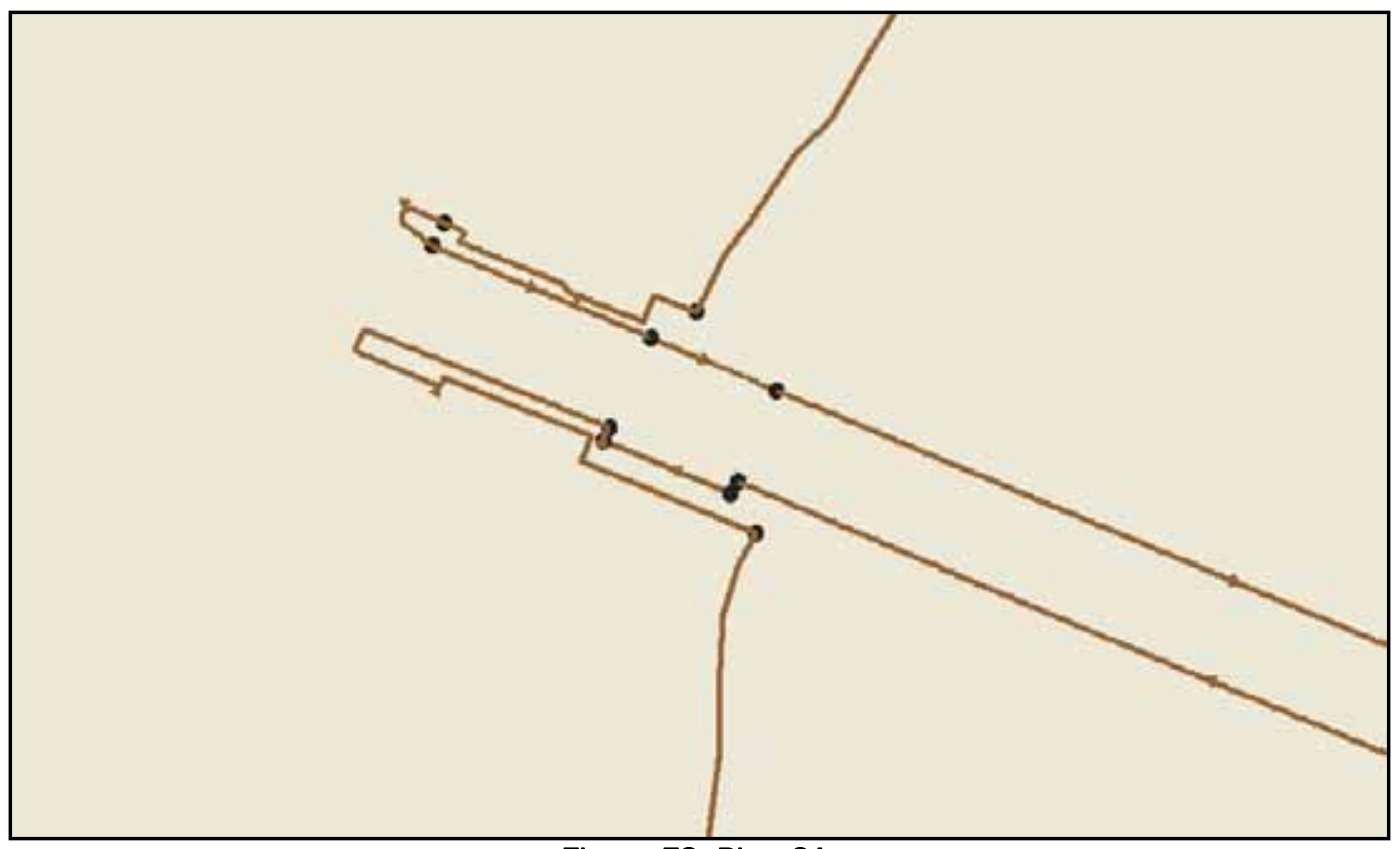

Figure F3. Plan 2A.

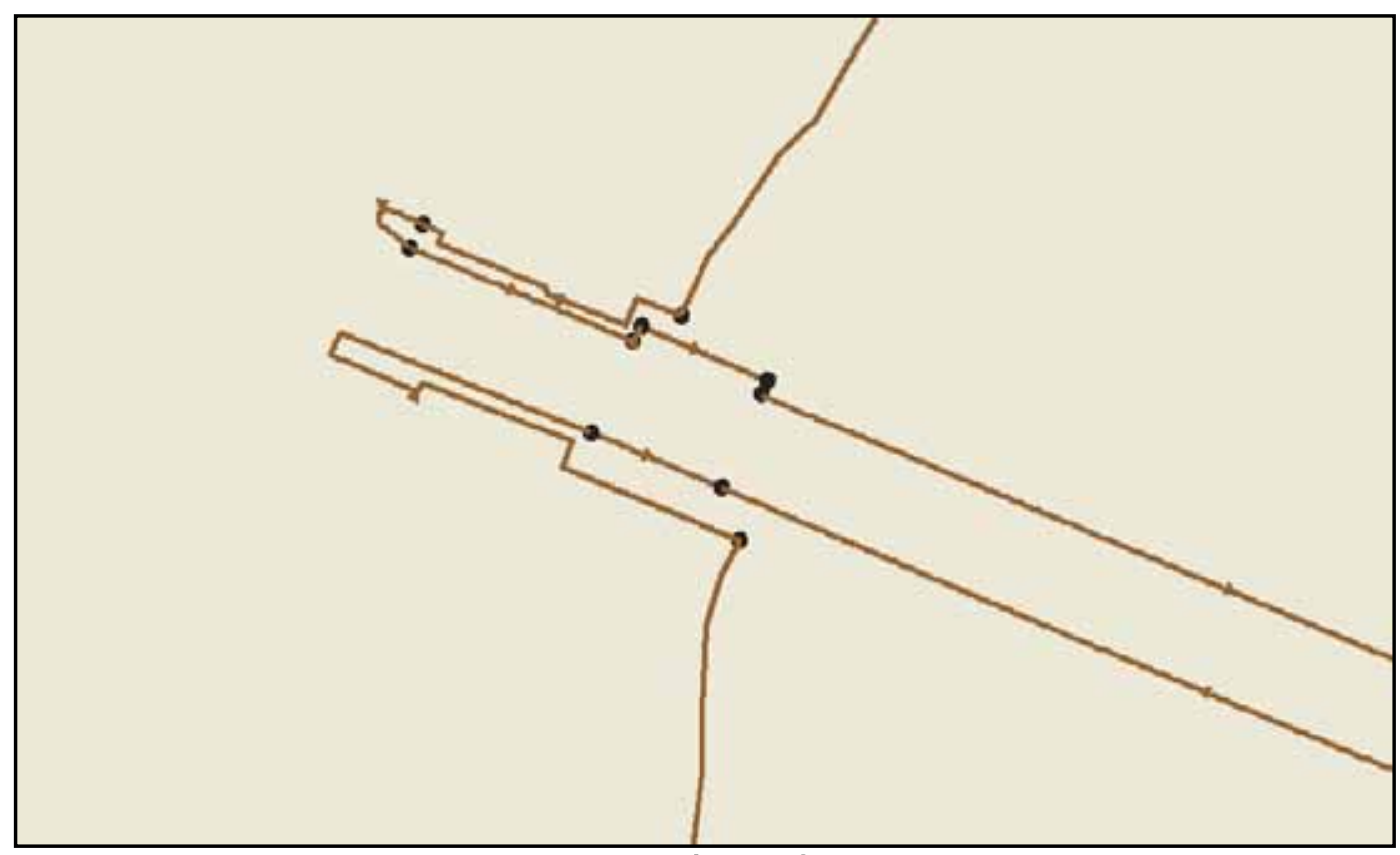

Figure F4. Plan 3A. 


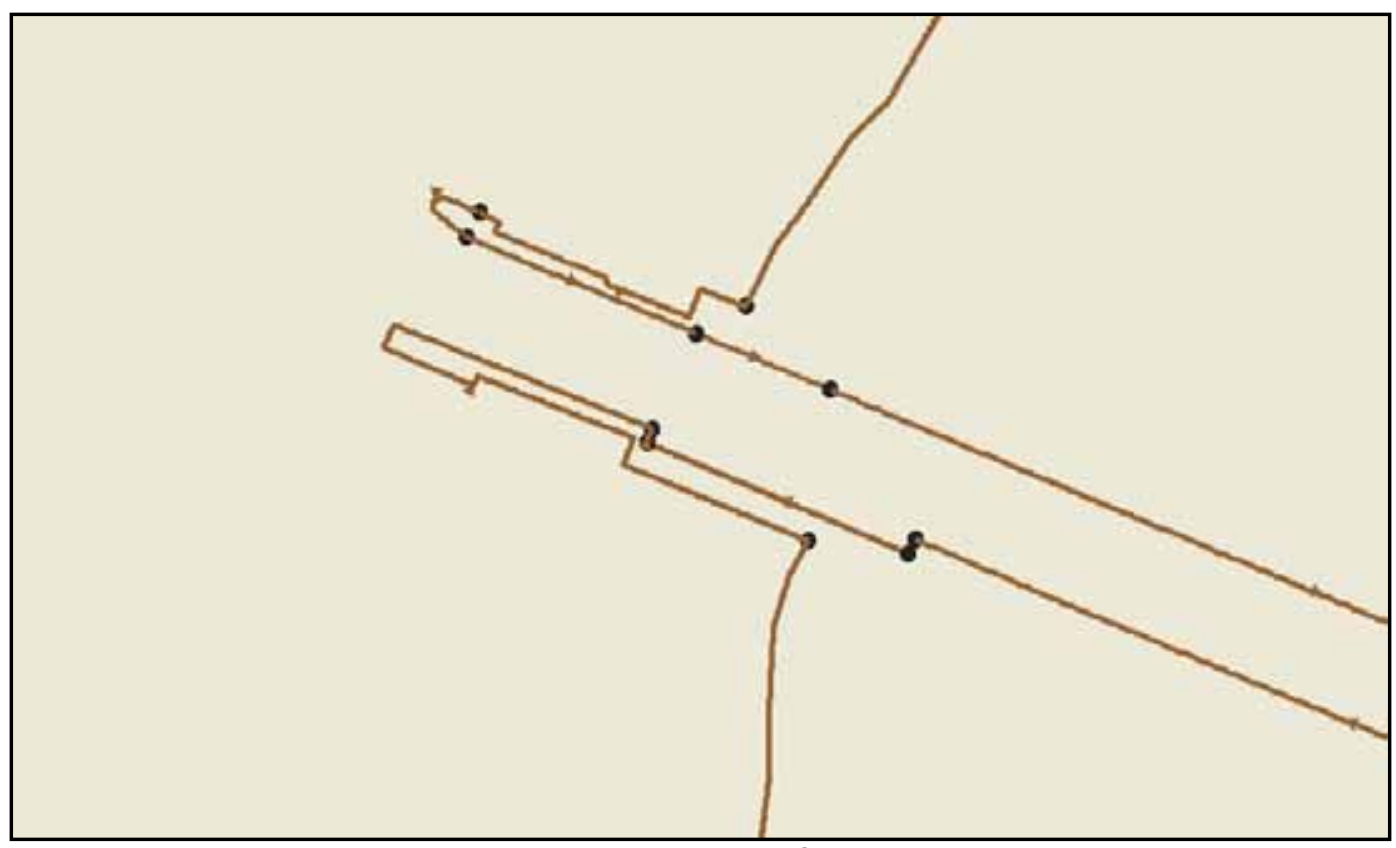

Figure F5. Plan 4A.

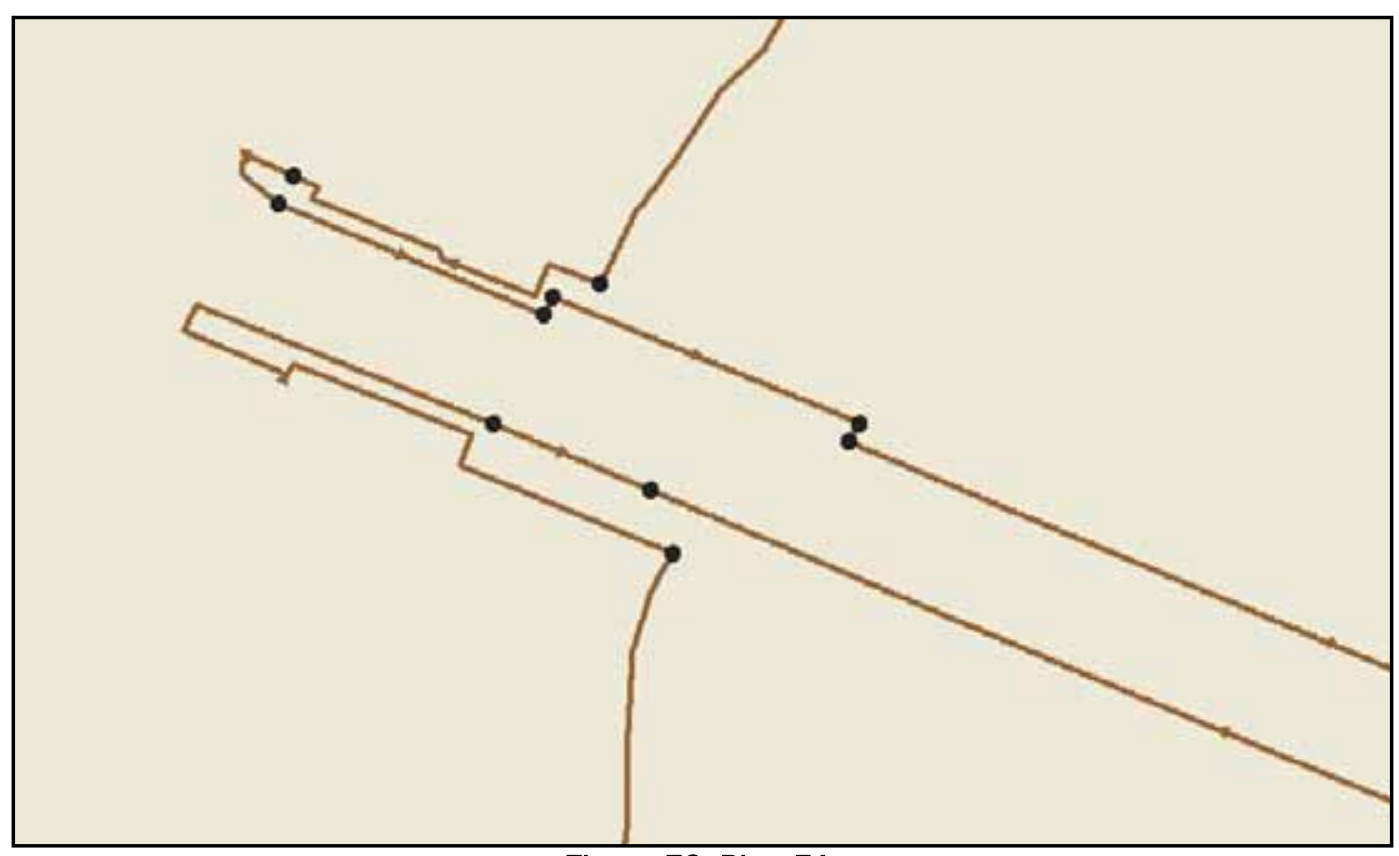

Figure F6. Plan 5A. 


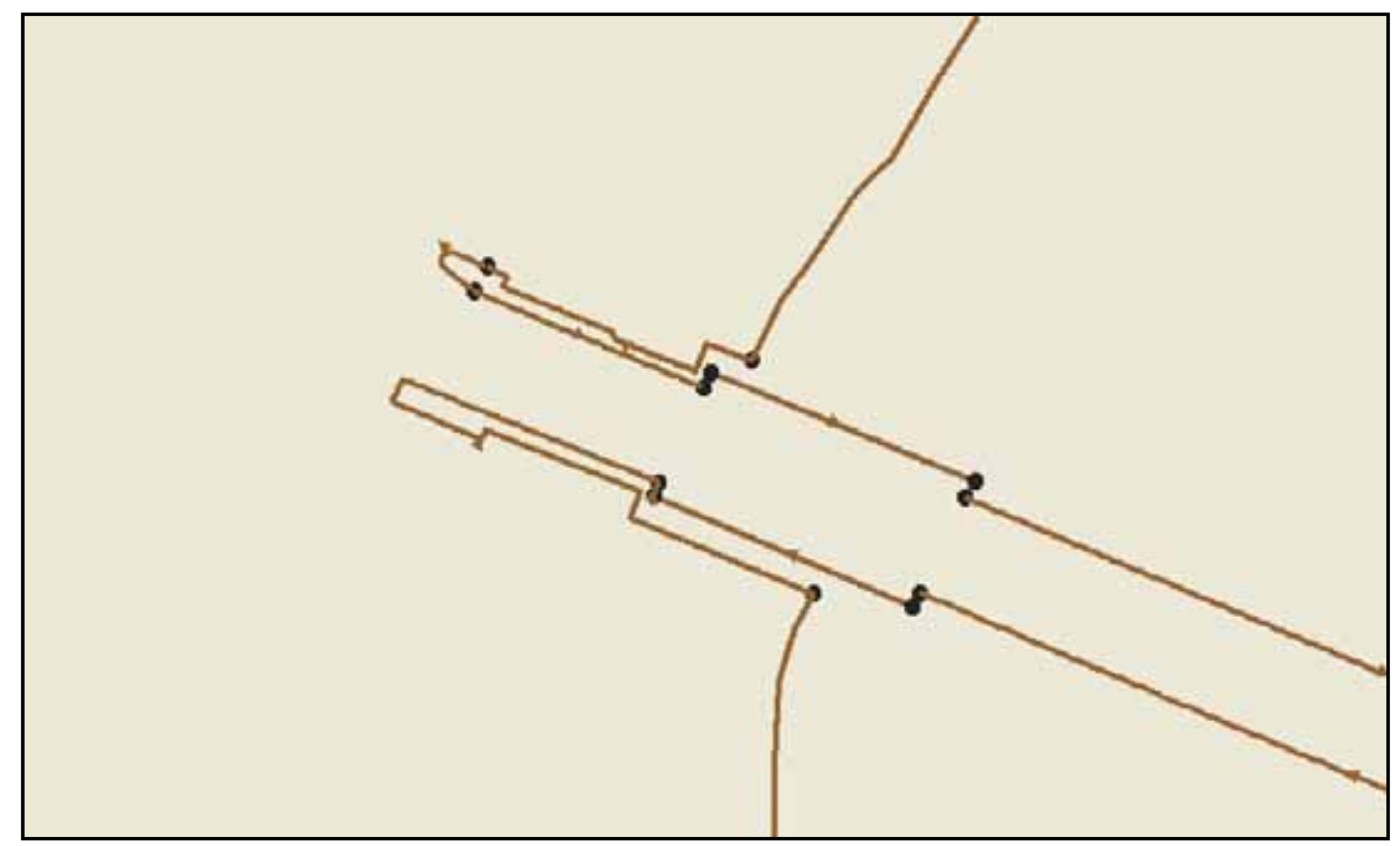

Figure F7. Plan 6A.

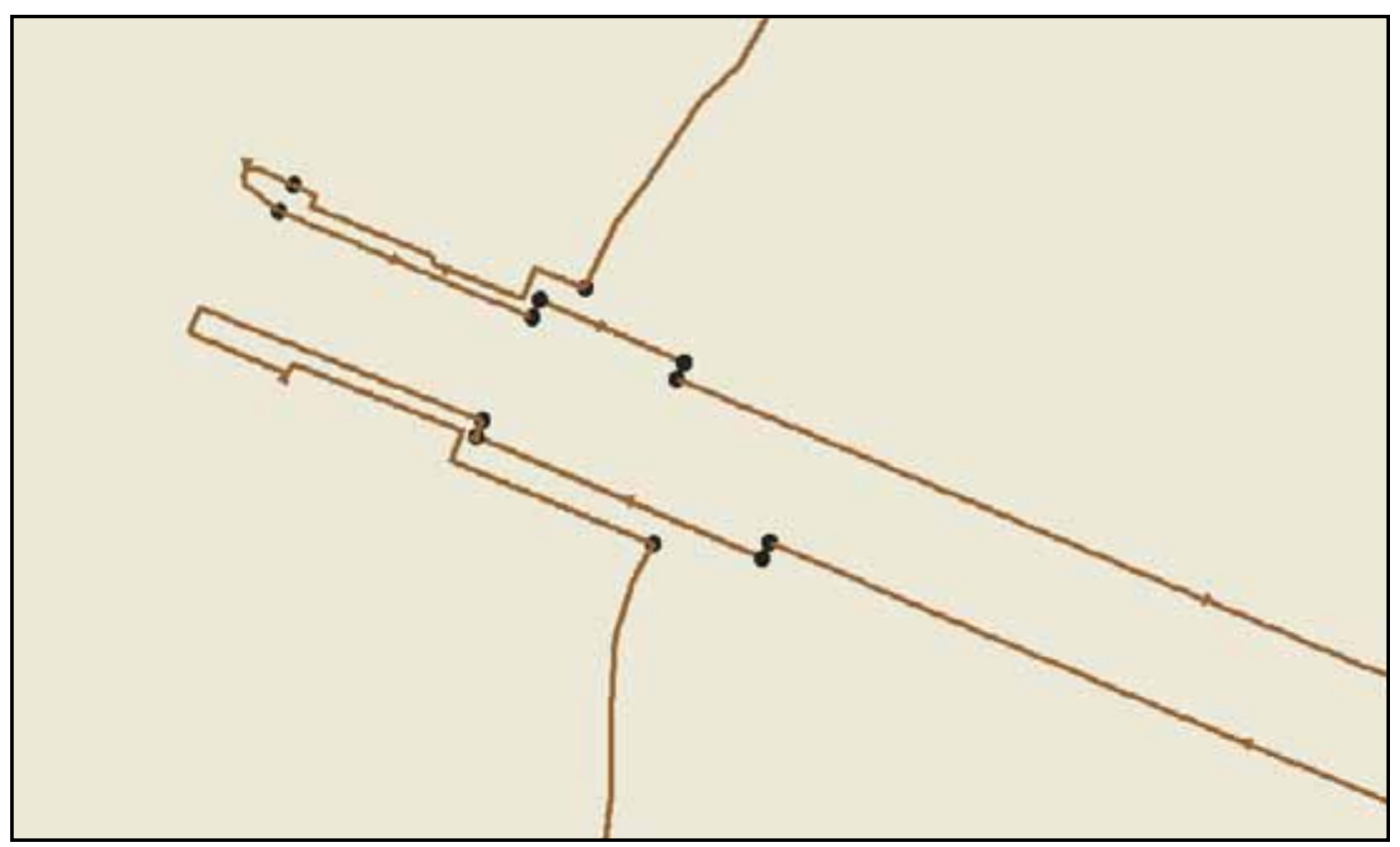

Figure F8. Plan 7A. 


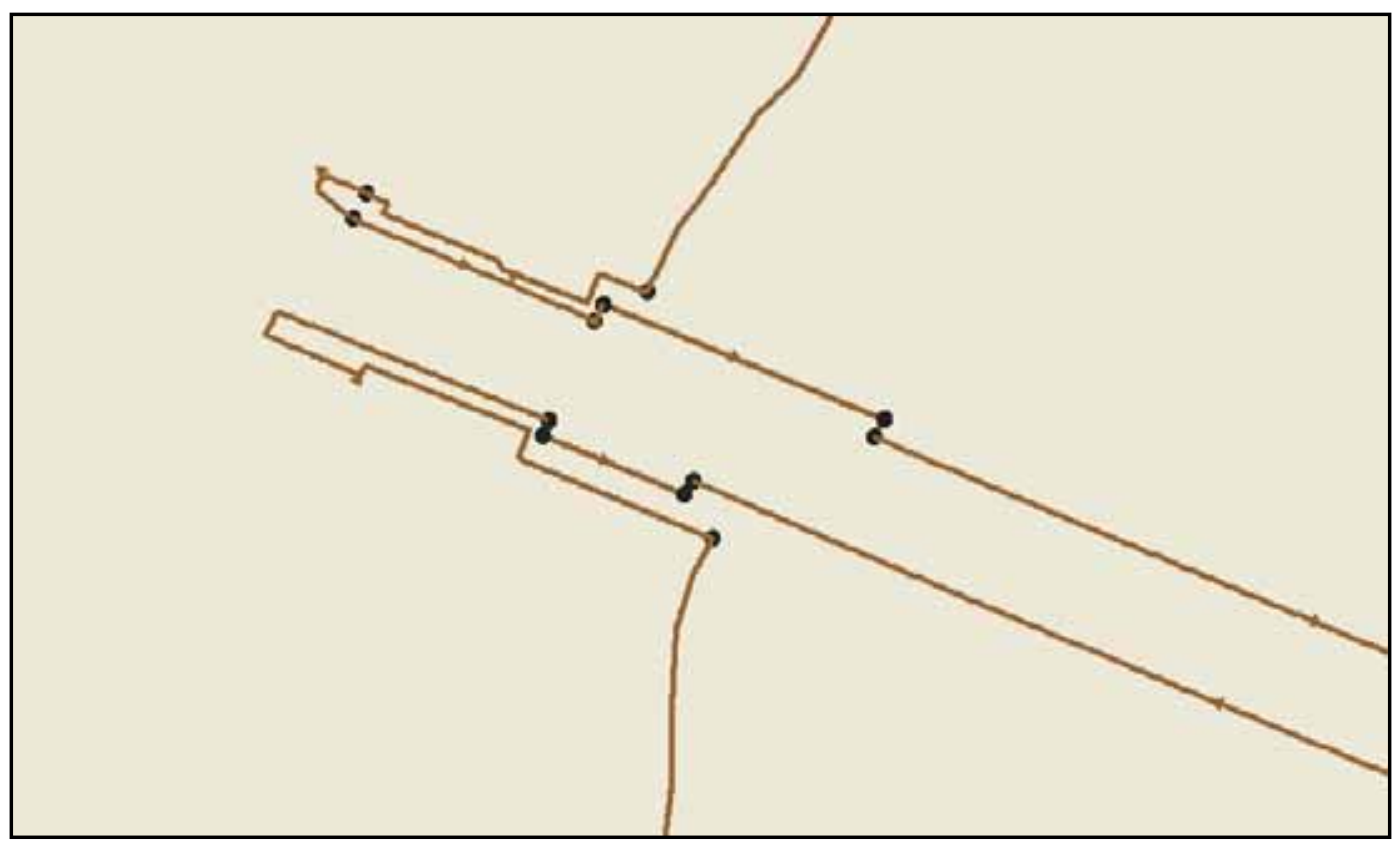

Figure F9. Plan 8A. 


\section{Appendix G: Cross-Channel Average $H_{s}$ from Numerical Model}

Table G1. RMS $H_{s}$ across channel transect lines for waves from 45 degrees South.

\begin{tabular}{|c|c|c|c|c|c|c|c|}
\hline \multicolumn{2}{|c|}{$\begin{array}{l}\text { Experimental } \\
\text { Wave }\end{array}$} & \multirow[b]{2}{*}{ Plan } & \multicolumn{5}{|c|}{$H_{s}(\mathrm{~m})$ at Indicated Lines } \\
\hline $\begin{array}{l}T_{p} \\
\text { (sec) }\end{array}$ & $\begin{array}{l}H_{s, i n c} \\
(\mathrm{~m})\end{array}$ & & Line 1 & Line 2 & Line 3 & $\begin{array}{l}H_{s, \text { Line2 } /} / \\
H_{s, \text { Line1 }}\end{array}$ & $\begin{array}{l}H_{s, \text { Line3 }} / \\
H_{s, \text { Line } 1}\end{array}$ \\
\hline \multirow[t]{9}{*}{5} & \multirow[t]{9}{*}{1} & EC & 0.491 & 0.288 & 0.299 & 0.587 & 0.609 \\
\hline & & Plan 1 & 0.583 & 0.475 & 0.450 & 0.814 & 0.771 \\
\hline & & Plan 2 & 0.572 & 0.435 & 0.360 & 0.761 & 0.629 \\
\hline & & Plan 3 & 0.592 & 0.416 & 0.396 & 0.703 & 0.669 \\
\hline & & Plan 4 & 0.577 & 0.389 & 0.342 & 0.674 & 0.593 \\
\hline & & Plan 5 & 0.524 & 0.347 & 0.366 & 0.662 & 0.698 \\
\hline & & Plan 6 & 0.579 & 0.289 & 0.289 & 0.499 & 0.499 \\
\hline & & Plan 7 & 0.583 & 0.307 & 0.318 & 0.526 & 0.545 \\
\hline & & Plan 8 & 0.580 & 0.301 & 0.355 & 0.520 & 0.611 \\
\hline \multirow[t]{9}{*}{7} & \multirow[t]{9}{*}{2} & EC & 0.870 & 0.445 & 0.483 & 0.512 & 0.555 \\
\hline & & Plan 1 & 1.012 & 0.866 & 0.833 & 0.856 & 0.823 \\
\hline & & Plan 2 & 1.004 & 0.811 & 0.755 & 0.808 & 0.753 \\
\hline & & Plan 3 & 0.952 & 0.633 & 0.590 & 0.665 & 0.619 \\
\hline & & Plan 4 & 1.014 & 0.752 & 0.716 & 0.741 & 0.706 \\
\hline & & Plan 5 & 0.930 & 0.569 & 0.553 & 0.612 & 0.595 \\
\hline & & Plan 6 & 0.975 & 0.373 & 0.376 & 0.383 & 0.385 \\
\hline & & Plan 7 & 0.991 & 0.432 & 0.415 & 0.436 & 0.419 \\
\hline & & Plan 8 & 0.984 & 0.422 & 0.451 & 0.428 & 0.458 \\
\hline \multirow[t]{9}{*}{8} & \multirow[t]{9}{*}{2.5} & EC & 1.003 & 0.428 & 0.461 & 0.426 & 0.459 \\
\hline & & Plan 1 & 1.191 & 1.035 & 0.974 & 0.869 & 0.818 \\
\hline & & Plan 2 & 1.179 & 0.950 & 0.885 & 0.806 & 0.751 \\
\hline & & Plan 3 & 1.141 & 0.715 & 0.662 & 0.626 & 0.581 \\
\hline & & Plan 4 & 1.192 & 0.895 & 0.808 & 0.751 & 0.678 \\
\hline & & Plan 5 & 1.080 & 0.652 & 0.598 & 0.603 & 0.554 \\
\hline & & Plan 6 & 1.132 & 0.369 & 0.373 & 0.326 & 0.329 \\
\hline & & Plan 7 & 1.141 & 0.457 & 0.405 & 0.401 & 0.355 \\
\hline & & Plan 8 & 1.135 & 0.421 & 0.443 & 0.371 & 0.390 \\
\hline
\end{tabular}


Table G2. RMS $H_{s}$ across channel transect lines for waves from 0 degrees.

\begin{tabular}{|c|c|c|c|c|c|c|c|}
\hline \multicolumn{2}{|c|}{$\begin{array}{l}\text { Experimental } \\
\text { Wave }\end{array}$} & \multirow[b]{2}{*}{ Plan } & \multicolumn{5}{|c|}{$H_{s}(\mathrm{~m})$ at Indicated Lines } \\
\hline $\begin{array}{l}T_{p} \\
\text { (sec) }\end{array}$ & $\begin{array}{l}H_{s, i n c} \\
(\mathrm{~m})\end{array}$ & & Line 1 & Line 2 & Line 3 & $\begin{array}{l}H_{s, \text { Line2/ }} / \\
H_{s, \text { Line1 }}\end{array}$ & $\begin{array}{l}H_{s, \text { Line } 3 /} \\
H_{s, \text { Line } 1}\end{array}$ \\
\hline \multirow[t]{9}{*}{5} & \multirow[t]{9}{*}{1} & EC & 0.512 & 0.333 & 0.340 & 0.651 & 0.665 \\
\hline & & Plan 1 & 0.615 & 0.534 & 0.565 & 0.868 & 0.918 \\
\hline & & Plan 2 & 0.624 & 0.468 & 0.423 & 0.750 & 0.678 \\
\hline & & Plan 3 & 0.619 & 0.468 & 0.429 & 0.757 & 0.694 \\
\hline & & Plan 4 & 0.626 & 0.467 & 0.451 & 0.747 & 0.721 \\
\hline & & Plan 5 & 0.575 & 0.429 & 0.413 & 0.747 & 0.719 \\
\hline & & Plan 6 & 0.622 & 0.366 & 0.361 & 0.589 & 0.580 \\
\hline & & Plan 7 & 0.623 & 0.382 & 0.418 & 0.612 & 0.671 \\
\hline & & Plan 8 & 0.623 & 0.382 & 0.420 & 0.613 & 0.675 \\
\hline \multirow[t]{9}{*}{7} & \multirow[t]{9}{*}{2} & EC & 0.975 & 0.516 & 0.542 & 0.530 & 0.556 \\
\hline & & Plan 1 & 1.115 & 1.002 & 0.992 & 0.899 & 0.890 \\
\hline & & Plan 2 & 1.132 & 0.850 & 0.808 & 0.751 & 0.714 \\
\hline & & Plan 3 & 1.112 & 0.793 & 0.729 & 0.713 & 0.656 \\
\hline & & Plan 4 & 1.137 & 0.833 & 0.815 & 0.732 & 0.716 \\
\hline & & Plan 5 & 1.067 & 0.762 & 0.698 & 0.714 & 0.654 \\
\hline & & Plan 6 & 1.111 & 0.471 & 0.461 & 0.424 & 0.415 \\
\hline & & Plan 7 & 1.128 & 0.527 & 0.534 & 0.468 & 0.474 \\
\hline & & Plan 8 & 1.125 & 0.534 & 0.540 & 0.475 & 0.480 \\
\hline \multirow[t]{9}{*}{8} & \multirow[t]{9}{*}{2.5} & EC & 1.122 & 0.497 & 0.522 & 0.443 & 0.465 \\
\hline & & Plan 1 & 1.319 & 1.188 & 1.139 & 0.901 & 0.864 \\
\hline & & Plan 2 & 1.311 & 1.003 & 0.944 & 0.765 & 0.720 \\
\hline & & Plan 3 & 1.293 & 0.923 & 0.843 & 0.714 & 0.652 \\
\hline & & Plan 4 & 1.326 & 0.976 & 0.896 & 0.736 & 0.676 \\
\hline & & Plan 5 & 1.252 & 0.885 & 0.773 & 0.707 & 0.618 \\
\hline & & Plan 6 & 1.286 & 0.466 & 0.456 & 0.362 & 0.354 \\
\hline & & Plan 7 & 1.294 & 0.545 & 0.522 & 0.421 & 0.404 \\
\hline & & Plan 8 & 1.289 & 0.541 & 0.534 & 0.419 & 0.414 \\
\hline
\end{tabular}


Table G3. RMS $H_{s}$ across channel transect lines for waves from 45 degrees North.

\begin{tabular}{|c|c|c|c|c|c|c|c|}
\hline \multicolumn{2}{|c|}{$\begin{array}{c}\text { Experimental } \\
\text { Wave }\end{array}$} & \multirow{2}{*}{ Plan } & \multicolumn{5}{|c|}{$H_{s}(\mathrm{~m})$ at Indicated Lines } \\
\hline $\begin{array}{l}T_{p} \\
\text { (sec) }\end{array}$ & $\begin{array}{l}H_{s, i n c} \\
(\mathrm{~m})\end{array}$ & & Line 1 & Line 2 & Line 3 & $\begin{array}{l}H_{s, \text { Line } 2 /} \\
H_{s, \text { Line1 }}\end{array}$ & $\begin{array}{l}H_{s, \text { Line3 } /} \\
H_{s, \text { Line1 }}\end{array}$ \\
\hline \multirow[t]{9}{*}{5} & \multirow[t]{9}{*}{1} & EC & 0.475 & 0.292 & 0.289 & 0.616 & 0.609 \\
\hline & & Plan 1 & 0.547 & 0.466 & 0.502 & 0.852 & 0.918 \\
\hline & & Plan 2 & 0.574 & 0.385 & 0.377 & 0.671 & 0.657 \\
\hline & & Plan 3 & 0.563 & 0.425 & 0.407 & 0.754 & 0.722 \\
\hline & & Plan 4 & 0.575 & 0.383 & 0.418 & 0.667 & 0.728 \\
\hline & & Plan 5 & 0.500 & 0.388 & 0.354 & 0.777 & 0.708 \\
\hline & & Plan 6 & 0.570 & 0.309 & 0.308 & 0.541 & 0.540 \\
\hline & & Plan 7 & 0.568 & 0.311 & 0.366 & 0.548 & 0.644 \\
\hline & & Plan 8 & 0.575 & 0.332 & 0.350 & 0.578 & 0.608 \\
\hline \multirow[t]{9}{*}{7} & \multirow[t]{9}{*}{2} & EC & 0.902 & 0.465 & 0.490 & 0.515 & 0.542 \\
\hline & & Plan 1 & 1.005 & 0.902 & 0.897 & 0.898 & 0.892 \\
\hline & & Plan 2 & 1.036 & 0.695 & 0.681 & 0.671 & 0.657 \\
\hline & & Plan 3 & 1.019 & 0.786 & 0.743 & 0.772 & 0.730 \\
\hline & & Plan 4 & 1.040 & 0.693 & 0.725 & 0.667 & 0.697 \\
\hline & & Plan 5 & 0.964 & 0.748 & 0.669 & 0.777 & 0.694 \\
\hline & & Plan 6 & 1.025 & 0.402 & 0.401 & 0.392 & 0.391 \\
\hline & & Plan 7 & 1.039 & 0.443 & 0.471 & 0.426 & 0.454 \\
\hline & & Plan 8 & 1.044 & 0.476 & 0.463 & 0.456 & 0.443 \\
\hline \multirow[t]{9}{*}{8} & \multirow[t]{9}{*}{2.5} & EC & 1.039 & 0.447 & 0.469 & 0.431 & 0.452 \\
\hline & & Plan 1 & 1.205 & 1.082 & 1.041 & 0.898 & 0.864 \\
\hline & & Plan 2 & 1.195 & 0.843 & 0.811 & 0.706 & 0.679 \\
\hline & & Plan 3 & 1.205 & 0.925 & 0.860 & 0.768 & 0.714 \\
\hline & & Plan 4 & 1.209 & 0.827 & 0.795 & 0.684 & 0.658 \\
\hline & & Plan 5 & 1.154 & 0.879 & 0.754 & 0.761 & 0.653 \\
\hline & & Plan 6 & 1.189 & 0.400 & 0.398 & 0.336 & 0.335 \\
\hline & & Plan 7 & 1.194 & 0.458 & 0.459 & 0.383 & 0.384 \\
\hline & & Plan 8 & 1.193 & 0.491 & 0.460 & 0.411 & 0.385 \\
\hline
\end{tabular}




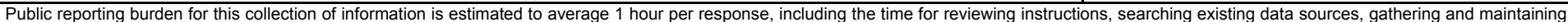

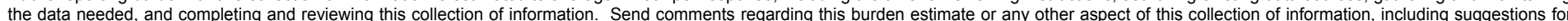

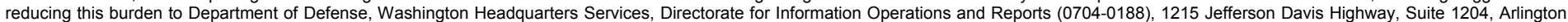

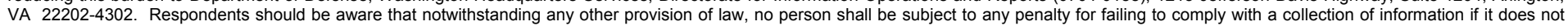
display a currently valid OMB control number. PLEASE DO NOT RETURN YOUR FORM TO THE ABOVE ADDRESS.

\begin{tabular}{l|l}
$\begin{array}{l}\text { 1. REPORT DATE (DD-MM-YYYY) } \\
\text { June } 2006\end{array}$ & $\begin{array}{c}\text { 2. REPORT TYPE } \\
\text { Final report }\end{array}$ \\
\hline
\end{tabular}

\section{TITLE AND SUBTITLE}

Monitoring of Entrance Channel Navigation Improvements at Pentwater, Michigan, and Design Guidance for Pocket Wave Absorbers

3. DATES COVERED (From - To)

5a. CONTRACT NUMBER

5b. GRANT NUMBER

5c. PROGRAM ELEMENT NUMBER

5d. PROJECT NUMBER

5e. TASK NUMBER

5f. WORK UNIT NUMBER A1050

8. PERFORMING ORGANIZATION REPORT NUMBER

ERDC/CHL TR-06-3

U.S. Army Engineer Research and Development Center

Coastal and Hydraulics Laboratory

3909 Halls Ferry Road, Vicksburg, MS 39180-6199;

U.S. Army Engineer District, Detroit

477 Michigan Avenue, Detroit, MI 48226

\section{SPONSORING / MONITORING AGENCY NAME(S) AND ADDRESS(ES)}

Headquarters, U.S. Army Corps of Engineers

Washington, DC 20314-1000

10. SPONSOR/MONITOR'S ACRONYM(S)

11. SPONSOR/MONITOR'S REPORT NUMBER(S)

\section{DISTRIBUTION / AVAILABILITY STATEMENT}

Approved for public release; distribution is unlimited.

\section{SUPPLEMENTARY NOTES}

\section{ABSTRACT}

In 2002, Pentwater, MI, was accepted for inclusion in the Monitoring Completed Navigation Projects Program. The objectives of the monitoring effort at Pentwater Harbor were to evaluate the design of existing pocket wave absorbers and to develop better design guidance for future pocket wave absorber projects. The study included collection of field wave data at Pentwater, physical modeling, and numerical modeling. Monitoring of the prototype harbor entrance was conducted during spring of 2003 and 2004. The field data provided a basis for validating the physical model. The physical model provided extensive data for the Pentwater configuration and eight other plans, as well as data for calibrating and validating the CGWAVE numerical model. It was concluded that the wave absorber design at Pentwater is very effective, maximizing energy dissipation per unit length of constructed absorber. In addition, guidelines are provided to aid in evaluation of other pocket wave absorber designs and to assist in future projects. Numerical modeling is an effective tool to aid in future evaluations and design.

\begin{tabular}{|c|c|c|c|c|c|}
\hline \multicolumn{2}{|c|}{$\begin{array}{l}\text { 15. SUBJECT TERMS } \\
\text { Design guidance } \\
\text { Entrance channels } \\
\text { Great Lakes }\end{array}$} & \multicolumn{3}{|c|}{$\begin{array}{l}\text { Monitoring Completed Navigation Projects } \\
\text { Pentwater, MI } \\
\text { Physical and numerical models } \\
\text { Prototype wave data }\end{array}$} & $\begin{array}{l}\text { Wave absorbers } \\
\text { Wave heights }\end{array}$ \\
\hline \multicolumn{3}{|c|}{ 16. SECURITY CLASSIFICATION OF: } & $\begin{array}{l}\text { 17. LIMITATION } \\
\text { OF ABSTRACT }\end{array}$ & $\begin{array}{l}\text { 18. NUMBER } \\
\text { OF PAGES }\end{array}$ & $\begin{array}{l}\text { 19a. NAME OF RESPONSIBLE } \\
\text { PERSON }\end{array}$ \\
\hline $\begin{array}{l}\text { a. REPORT } \\
\text { UNCLASSIFIED }\end{array}$ & $\begin{array}{l}\text { b. ABSTRACT } \\
\text { UNCLASSIFIED }\end{array}$ & $\begin{array}{l}\text { c. THIS PAGE } \\
\text { UNCLASSIFIED }\end{array}$ & & 250 & $\begin{array}{l}\text { 19b. TELEPHONE NUMBER (include } \\
\text { area code) }\end{array}$ \\
\hline
\end{tabular}

